\title{
Fresh-Core Reload of the Neutron Radiography (NRAD) Reactor with Uranium(20)-Erbium- Zirconium-Hydride Fuel
}

John D. Bess

Thomas L. Maddock

Margaret A. Marshall

Leland M. Montierth

Ann Marie Phillips

Kenneth A. Schreck

J. Blair Briggs

Eric C. Woolstenhulme

John M. Bolin

Anthony Veca

Richard D. McKnight

Richard M. Lell

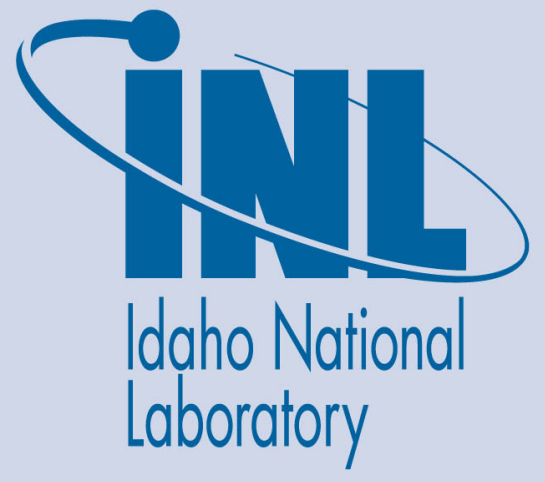

\section{March 2011}

The INL is a U.S. Department of Energy National Laboratory operated by Battelle Energy Alliance 
INL/EXT-10-19486

\title{
Fresh-Core Reload of the Neutron Radiography (NRAD) Reactor with Uranium(20)-Erbium-Zirconium- Hydride Fuel
}

\author{
John D. Bess \\ Thomas L. Maddock \\ Margaret A. Marshall ${ }^{1}$ \\ Leland M. Montierth \\ Ann Marie Phillips \\ Kenneth A. Schreck \\ J. Blair Briggs \\ Eric C. Woolstenhulme \\ John M. Bolin ${ }^{2}$ \\ Anthony $\mathrm{Veca}^{2}$ \\ Richard D. McKnight ${ }^{3}$ \\ Richard M. Lell ${ }^{3}$
}

${ }^{1}$ University of Idaho/ldaho National Laboratory

${ }^{2}$ General Atomics

${ }^{3}$ Argonne National Laboratory

March 2011

Idaho National Laboratory
Idaho Falls, Idaho 83415

http://www.inl.gov

Prepared for the

U.S. Department of Energy

Office of Nuclear Energy

Under DOE Idaho Operations Office

Contract DE-AC07-05ID14517 
NEA/NSC/DOC(2006)1

Fundamental - FUND

NRAD-FUND-RESR-001

CRIT

\title{
FRESH-CORE RELOAD OF THE NEUTRON RADIOGRAPHY (NRAD) REACTOR WITH URANIUM(20)-ERBIUM- ZIRCONIUM-HYDRIDE FUEL
}

\author{
Evaluators \\ John D. Bess \\ Thomas L. Maddock \\ Idaho National Laboratory \\ Margaret A. Marshall \\ University of Idaho/Idaho National Laboratory \\ Internal Reviewers \\ Leland M. Montierth \\ Ann Marie Phillips \\ Kenneth A. Schreck \\ J. Blair Briggs \\ Eric C. Woolstenhulme \\ Idaho National Laboratory \\ John M. Bolin \\ Anthony Veca \\ General Atomics \\ Independent Reviewers \\ Richard D. McKnight \\ Richard M. Lell \\ Argonne National Laboratory
}


NEA/NSC/DOC(2006)1

Fundamental - FUND

NRAD-FUND-RESR-001

CRIT

Status of Compilation / Evaluation / Peer Review

\begin{tabular}{|c|c|c|c|c|c|}
\hline & Section 1 & Compiled & $\begin{array}{l}\text { Independent } \\
\text { Review }\end{array}$ & $\begin{array}{l}\text { Working Group } \\
\text { Review }\end{array}$ & Approved \\
\hline 1.0 & DETAILED DESCRIPTION & YES & YES & YES & YES \\
\hline 1.1 & $\begin{array}{l}\text { Description of the Critical and / or } \\
\text { Subcritical Configuration }\end{array}$ & YES & YES & YES & YES \\
\hline 1.2 & $\begin{array}{l}\text { Description of Buckling and } \\
\text { Extrapolation Length Measurements }\end{array}$ & NA & NA & NA & NA \\
\hline 1.3 & $\begin{array}{l}\text { Description of Spectral Characteristics } \\
\text { Measurements }\end{array}$ & NA & NA & NA & NA \\
\hline 1.4 & $\begin{array}{l}\text { Description of Reactivity Effects } \\
\text { Measurements }\end{array}$ & NA & NA & NA & NA \\
\hline 1.5 & $\begin{array}{l}\text { Description of Reactivity Coefficient } \\
\text { Measurements }\end{array}$ & NA & NA & NA & NA \\
\hline 1.6 & Description of Kinetics Measurements & NA & NA & NA & NA \\
\hline 1.7 & $\begin{array}{l}\text { Description of Reaction-Rate } \\
\text { Distribution Measurements }\end{array}$ & NA & NA & NA & NA \\
\hline 1.8 & $\begin{array}{l}\text { Description of Power Distribution } \\
\text { Measurements }\end{array}$ & NA & NA & NA & NA \\
\hline 1.9 & Description of Isotopic Measurements & NA & NA & NA & NA \\
\hline 1.10 & $\begin{array}{l}\text { Description of Other Miscellaneous } \\
\text { Types of Measurements }\end{array}$ & NA & NA & NA & NA \\
\hline & Section 2 & Evaluated & $\begin{array}{l}\text { Independent } \\
\text { Review }\end{array}$ & $\begin{array}{l}\text { Working Group } \\
\text { Review }\end{array}$ & Approved \\
\hline 2.0 & $\begin{array}{l}\text { EVALUATION OF EXPERIMENTAL } \\
\text { DATA }\end{array}$ & YES & YES & YES & YES \\
\hline 2.1 & $\begin{array}{l}\text { Evaluation of Critical and / or Subcritical } \\
\text { Configuration Data }\end{array}$ & YES & YES & YES & YES \\
\hline 2.2 & $\begin{array}{l}\text { Evaluation of Buckling and Extrapolation } \\
\text { Length Data }\end{array}$ & NA & NA & NA & NA \\
\hline 2.3 & $\begin{array}{l}\text { Evaluation of Spectral Characteristics } \\
\text { Data }\end{array}$ & NA & NA & NA & NA \\
\hline 2.4 & Evaluation of Reactivity Effects Data & NA & NA & NA & NA \\
\hline 2.5 & Evaluation of Reactivity Coefficient Data & NA & NA & NA & NA \\
\hline 2.6 & $\begin{array}{l}\text { Evaluation of Kinetics Measurements } \\
\text { Data }\end{array}$ & NA & NA & NA & NA \\
\hline 2.7 & $\begin{array}{l}\text { Evaluation of Reaction Rate } \\
\text { Distributions }\end{array}$ & NA & NA & NA & NA \\
\hline 2.8 & Evaluation of Power Distribution Data & NA & NA & NA & NA \\
\hline 2.9 & Evaluation of Isotopic Measurements & NA & NA & NA & NA \\
\hline 2.10 & $\begin{array}{l}\text { Evaluation of Other Miscellaneous Types } \\
\text { of Measurements }\end{array}$ & NA & NA & NA & NA \\
\hline
\end{tabular}


NEA/NSC/DOC(2006)1

Fundamental - FUND

NRAD-FUND-RESR-001

CRIT

\begin{tabular}{|c|c|c|c|c|}
\hline Section 3 & Compiled & $\begin{array}{c}\text { Independent } \\
\text { Review }\end{array}$ & $\begin{array}{c}\text { Working } \\
\text { Group Review }\end{array}$ & Approved \\
\hline $3.0 \quad$ BENCHMARK SPECIFICATIONS & YES & YES & YES & YES \\
\hline $\begin{array}{ll}\text { 3.1 } & \text { Benchmark-Model Specifications for } \\
\text { Critical and / or Subcritical } \\
\text { Measurements }\end{array}$ & YES & YES & YES & YES \\
\hline $\begin{array}{ll}\text { 3.2 } & \text { Benchmark-Model Specifications for } \\
\text { Buckling and Extrapolation Length } \\
\text { Measurements }\end{array}$ & NA & NA & NA & NA \\
\hline $\begin{array}{ll}3.3 & \text { Benchmark-Model Specifications for } \\
& \text { Spectral Characteristics Measurements }\end{array}$ & NA & NA & NA & NA \\
\hline $\begin{array}{ll}\text { 3.4 } & \text { Benchmark-Model Specifications for } \\
& \text { Reactivity Effects Measurements }\end{array}$ & NA & NA & NA & NA \\
\hline $\begin{array}{ll}\text { 3.5 } & \text { Benchmark-Model Specifications for } \\
& \text { Reactivity Coefficient Measurements }\end{array}$ & NA & NA & NA & NA \\
\hline $\begin{array}{ll}\text { 3.6 } & \text { Benchmark-Model Specifications for } \\
\text { Kinetics Measurements }\end{array}$ & NA & NA & NA & NA \\
\hline $\begin{array}{ll}\text { 3.7 } & \text { Benchmark-Model Specifications for } \\
& \text { Reaction-Rate Distribution } \\
& \text { Measurements } \\
\end{array}$ & NA & NA & NA & NA \\
\hline $\begin{array}{ll}\text { 3.8 } & \text { Benchmark-Model Specifications for } \\
& \text { Power Distribution Measurements }\end{array}$ & NA & NA & NA & NA \\
\hline $\begin{array}{ll}3.9 & \text { Benchmark-Model Specifications for } \\
& \text { Isotopic Measurements }\end{array}$ & NA & NA & NA & NA \\
\hline $\begin{array}{l}\text { 3.10 Benchmark-Model Specifications of } \\
\text { Other Miscellaneous Types of } \\
\text { Measurements }\end{array}$ & NA & NA & NA & NA \\
\hline Section 4 & Compiled & $\begin{array}{c}\text { Independent } \\
\text { Review }\end{array}$ & $\begin{array}{c}\text { Working } \\
\text { Group Review }\end{array}$ & Approved \\
\hline $\begin{array}{ll}4.0 & \text { RESULTS OF SAMPLE } \\
& \text { CALCULATIONS }\end{array}$ & YES & YES & YES & YES \\
\hline $\begin{array}{ll}4.1 & \text { Results of Calculations of the Critical or } \\
\text { Subcritical Configurations }\end{array}$ & YES & YES & YES & YES \\
\hline $\begin{array}{ll}4.2 & \text { Results of Buckling and Extrapolation } \\
\text { Length Calculations }\end{array}$ & NA & NA & NA & NA \\
\hline $\begin{array}{ll}4.3 & \text { Results of Spectral Characteristics } \\
\text { Calculations }\end{array}$ & NA & NA & NA & NA \\
\hline $4.4 \quad$ Results of Reactivity Effect Calculations & NA & NA & NA & NA \\
\hline $\begin{array}{ll}4.5 & \text { Results of Reactivity Coefficient } \\
\text { Calculations }\end{array}$ & NA & NA & NA & NA \\
\hline $\begin{array}{ll}4.6 & \text { Results of Kinetics Parameter } \\
& \text { Calculations }\end{array}$ & NA & NA & NA & NA \\
\hline $\begin{array}{ll}4.7 & \text { Results of Reaction-Rate Distribution } \\
& \text { Calculations }\end{array}$ & NA & NA & NA & NA \\
\hline $\begin{array}{ll}4.8 & \text { Results of Power Distribution } \\
\text { Calculations }\end{array}$ & NA & NA & NA & NA \\
\hline 4.9 Results of Isotopic Calculations & NA & NA & NA & NA \\
\hline $\begin{array}{l}\text { 4.10 Results of Calculations of Other } \\
\text { Miscellaneous Types of Measurements }\end{array}$ & NA & NA & NA & NA \\
\hline Section 5 & Compiled & $\begin{array}{l}\text { Independent } \\
\text { Review }\end{array}$ & $\begin{array}{c}\text { Working Group } \\
\text { Review }\end{array}$ & Approved \\
\hline 5.0 REFERENCES & YES & YES & YES & YES \\
\hline $\begin{array}{l}\text { Appendix A: Computer Codes, Cross Sections, and } \\
\text { Typical Input Listings }\end{array}$ & YES & YES & YES & YES \\
\hline
\end{tabular}


NEA/NSC/DOC(2006)1

Fundamental - FUND

NRAD-FUND-RESR-001

CRIT

\title{
FRESH-CORE RELOAD OF THE NEUTRON RADIOGRAPHY (NRAD) REACTOR WITH URANIUM(20)-ERBIUM-ZIRCONIUM-HYDRIDE FUEL
}

\author{
IDENTIFICATION NUMBER: NRAD-FUND-RESR-001 \\ CRIT
}

KEY WORDS: acceptable, criticality, enriched uranium, erbium, graphite, graphite-reflected, light water, neutron radiography, NRAD, research reactor, startup measurements, thermal, TRIGA, uranium, uranium-erbium-zirconium-hydride fuel, water-reflected, zirconium-hydride, zirconium-hydride-moderated

\section{SUMMARY INFORMATION}

\subsection{DETAILED DESCRIPTION}

The neutron radiography (NRAD) reactor is a $250 \mathrm{~kW}$ TRIGA ${ }^{\circledR}$ (Training, Research, Isotopes, General Atomics) Mark II ${ }^{\mathrm{a}, \mathrm{b}}$ tank-type research reactor located in the basement, below the main hot cell, of the Hot Fuel Examination Facility (HFEF) at the Idaho National Laboratory (INL). It is equipped with two beam tubes with separate radiography stations for the performance of neutron radiography irradiation on small test components. ${ }^{\mathrm{c}}$

The NRAD reactor is currently under the direction of the Battelle Energy Alliance (BEA) and is operated and maintained by the INL and Hot Cell Services Division. It is primarily used for neutron radiography analysis of both irradiated and unirradiated fuels and materials. Typical applications for examining the internal features of fuel elements and assemblies include fuel pellet separations, fuel central-void formation, pellet cracking, evidence of fuel melting, and material integrity under normal and extreme conditions. Examination of the behavior of large test loops and assemblies can also be performed. Due to the intense gamma activity of most irradiated specimens, the HFEF uses an indirect radiography, where a beam of neutrons passes through a specimen, strikes a gamma-insensitive metal foil (typically indium or dysprosium, for epithermal or thermal neutron spectra, respectively), and activates the foil. The foil can then be placed against a sheet of x-ray photographic film. X-rays from the metal film then render an image on the film, which is then developed. While this method takes longer than the conventional direct method, the results eliminate gamma interference and are more detailed. Neutron tomography capabilities are being developed, where radiographs are obtained from different rotational angles and digitized to reconstruct cross-sections of a specimen. Direct radiography, such as Polaroid or track-etch radiography, and in-tank irradiations and/or experiments with small in-core samples can also be performed in the NRAD reactor.

The NRAD core is designed for steady-state operation with or without in-core and/or in-tank experiments. The combined reactivity worth of all removable experiments within the reactor tank is limited to less than $\$ 0.50$.

The NRAD reactor is a TRIGA-conversion-type reactor originally located at the Puerto Rico Nuclear Center (PRNC). It was converted to a TRIGA-FLIP-(Fuel Life Improvement Program)-fueled system

\footnotetext{
${ }^{\text {a }}$ TRIGA ${ }^{\circledR}$ Nuclear Reactors, General Atomics, http://triga.ga.com/ (Accessed October 15, 2009).

b D. M. Fouquet, J. Razvi, W. L. Whittemore, "TRIGA Research Reactors: A Pathway to the Peaceful Applications of Nuclear Energy," Nuclear News, 46(12), 46-56 (2003).

c "NRAD Safety Analysis Report,” DSA-005-NRAD rev. 5, Idaho National Laboratory (April 2, 2009). [This reference is not available for public release.]
} 
NEA/NSC/DOC(2006)1

\author{
Fundamental - FUND \\ NRAD-FUND-RESR-001 \\ CRIT
}

$\left(70 \%{ }^{235} \mathrm{U}\right)$ in 1971 . The 2-MW research reactor was closed in 1976 and then a portion of the TRIGA reactor fuel elements and other components (with a single radiography beam line) were moved in 1977 by the US Department of Energy (DOE) to Argonne National Laboratory (West) in Idaho Falls, Idaho. The NRAD reactor was first brought to critical in October 1977, and then became operational in 1978. A second beam line was added in $1982{ }^{\mathrm{b}}$

The Reduced Enrichment for Research and Test Reactors (RERTR) Program, in support of the Global Threat Reduction Initiative (GTRI), required conversion of all civilian reactor facilities from highly enriched uranium (HEU) to low enriched uranium (LEU) fuel $\left(<20 \%{ }^{235} \mathrm{U}\right)$. Therefore, the original FLIP-fueled core was completely defueled by August 26, 2009. Refueling with LEU began on September 17, 2009 and initial approach to critical began on March 9, 2010. The freshly fueled LEU core achieved criticality with 56 fuel elements on March 19, 2010 at 14:22:58. Key management, staff, and operators present during the initial critical included Ken Schreck (Facility Manager), Ryan Archibald (Reactor Operator), Tom Maddock (System Engineer), Randy Damiana (LEU Conversion Project Manager), Rick Cain (HFEF Staff serving as Auditor), Ann Marie Phillips (LEU Conversion Project Manager), Steve Sorrell (DOE-ID Regulator), Scott Ferrara (DOE-ID Regulator), Gary Engelstad (Refueling Operator), Jarod Littell (Reactor Operator), and Orin Harman (Reactor Operator in Training).

Start-up testing for the HEU/LEU fuel conversion of the NRAD TRIGA reactor began on March 9, 2010 and was completed on June 7, 2010. Measurements included the neutron multiplication in the approach to initial criticality, and the determination of control rod worths, excess reactivity, and shutdown margin for the initial core configuration (56 fuel elements). An additional cluster containing four fuel elements was loaded into the NRAD core, and the operational core was then brought to cold critical with 60 fuel elements on March 31, 2010. Control rod worths, excess reactivity, and shutdown margin were also measured for the operational core configuration. Calorimetric power calibrations were performed up to $250 \mathrm{~kW}$, and excess reactivity was determined at full power $(250 \mathrm{~kW})$. Additional measurements were performed to evaluate the worth of some of the graphite reflector blocks used in the core.

Available data regarding the materials and configuration of the NRAD reactor is limited to the start-up test plan, ${ }^{\mathrm{c}}$ measurement results from the start-up tests, ${ }^{\mathrm{d}}$ safety analysis reports, ${ }^{\mathrm{e}, \mathrm{f}}$ a system design description, ${ }^{\mathrm{g}}$ and various component design drawings (Appendix F). Significant information and clarification were provided by Tom Maddock, a former staff member at the HFEF facility, and Ken Schreck, the NRAD Reactor Manager throughout the conversion process.

\footnotetext{
${ }^{a}$ A. A. Weeks, D. P. Pruett, and C. C. Heidel, "Modifications to the NRAD Reactor (1997 to Present)," CONF8604117-1, Proc. 10 $0^{\text {th }}$ U.S. TRIGA User's Conference, College Station, Texas (April 7-9, 1986).

${ }^{\text {b }}$ G. R. Imel, G. C. McClellan, and D. P. Pruett, “The Neutron Radiography Reactor (NRAD),” CONF-900873--2, Proc. $1^{\text {st }}$ Int. Top. Mtg. Neutron Radiography System Design and Characterization, Pembroke, Canada (August 2830, 1990).
}

c “Startup Plan for the NRAD Reactor Final Report,” PLN-3285 rev. 3, Idaho National Laboratory (August 2010). [This reference is not available for public release.]

d "Startup Report for the NRAD Reactor," 911195 rev. 0, GA Project 39296, TRIGA Reactor Division of General Atomics (November 4, 2010). [This reference is not available for public release.]

e "NRAD Safety Analysis Report," DSA-005-NRAD rev. 5, Idaho National Laboratory (April 2, 2009). [This reference is not available for public release.]

f "NRAD Reactor Fuel Core Conversion,” DSA-005-NRAD-ADD-3 rev. 0, Idaho National Laboratory (April 2 , 2009). [This reference is not available for public release.]

g “HFEF/N Neutron Radiography Facility System Design Description,” W0170-0004-SA rev. 2, Idaho National Laboratory (June 1, 1978). [This reference is not available for public release.] 
NEA/NSC/DOC(2006)1

Fundamental - FUND

NRAD-FUND-RESR-001

CRIT

General Atomics provided some information regarding TRIGA reactor fuel and control rods and developed the start-up plan for the LEU conversion of the NRAD., ${ }^{\mathrm{a}, \mathrm{b}}$ Additional material data were obtained from samples analyzed at independent laboratories.

A benchmark of an annular TRIGA Mark II reactor containing U(20)-Zr-H fuel (no erbium content) has already been evaluated. ${ }^{c}$

\subsection{Description of the Critical and / or Subcritical Configuration}

\subsubsection{Overview of Experiment}

The 60-fuel-element operational core configuration of the NRAD LEU TRIGA reactor has been evaluated as an acceptable benchmark experiment. The initial critical configuration developed during the fuel loading process, which contains only 56 fuel elements, has not been evaluated as a benchmark as it is very similar to the evaluated core configuration.

\subsubsection{Geometry of the Experiment Configuration and Measurement Procedure}

The NRAD reactor (Figure 1.1) is a $250 \mathrm{~kW}$ TRIGA LEU conversion reactor that is a water-moderated, heterogeneous, solid-fuel, tank-type research reactor. The reactor is composed of fuel in three- and fourelement clusters that can be arranged in a variety of lattice patterns, depending on reactivity requirements. The grid plate consists of 36 holes, on a 6-by-6 rectangular pattern, that mate with the end fittings of the fuel cluster assemblies. ${ }^{\mathrm{d}}$

The dimensions obtained from most of the references were reported in feet and inches. Where referenced in this report, the original dimensions are then followed by their converted values in units of meters or centimeters, in parenthesis. The number of decimal places in the converted units does not imply additional precision, but preservation of the original measurement.

\footnotetext{
a "Neutron Radiography Reactor Analysis and Support: HEU to LEU Conversion of the NRAD Reactor, Final Report," 911124 rev. 2, GA Project 39296, TRIGA Reactor Division of General Atomics (February 12, 2010). [This reference is not available for public release.]

b "Neutron Radiography Reactor Analysis and Support: Startup Plan for the NRAD Reactor, Final Report," 911183 rev. 1, GA Project 39296, TRIGA Reactor Division of General Atomics (January 13, 2010). [This reference is not available for public release.]

${ }^{c}$ R. Jeraj and M. Ravnik, "TRIGA Mark II Reactor: U(20) - Zirconium Hydride Fuel Rods in Water with Graphite Reflector," Rev. 0 (September 30, 1999), IEU-COMP-THERM-003, International Handbook of Evaluated Criticality Safety Benchmark Experiments, NEA/NSC/DOC(95)03, OECD-NEA (2010).

d "NRAD Reactor Fuel Core Conversion," DSA-005-NRAD-ADD-3 rev. 0, Idaho National Laboratory (April 2, 2009). [This reference is not available for public release.]
} 
NEA/NSC/DOC(2006)1

Fundamental - FUND

NRAD-FUND-RESR-001

CRIT

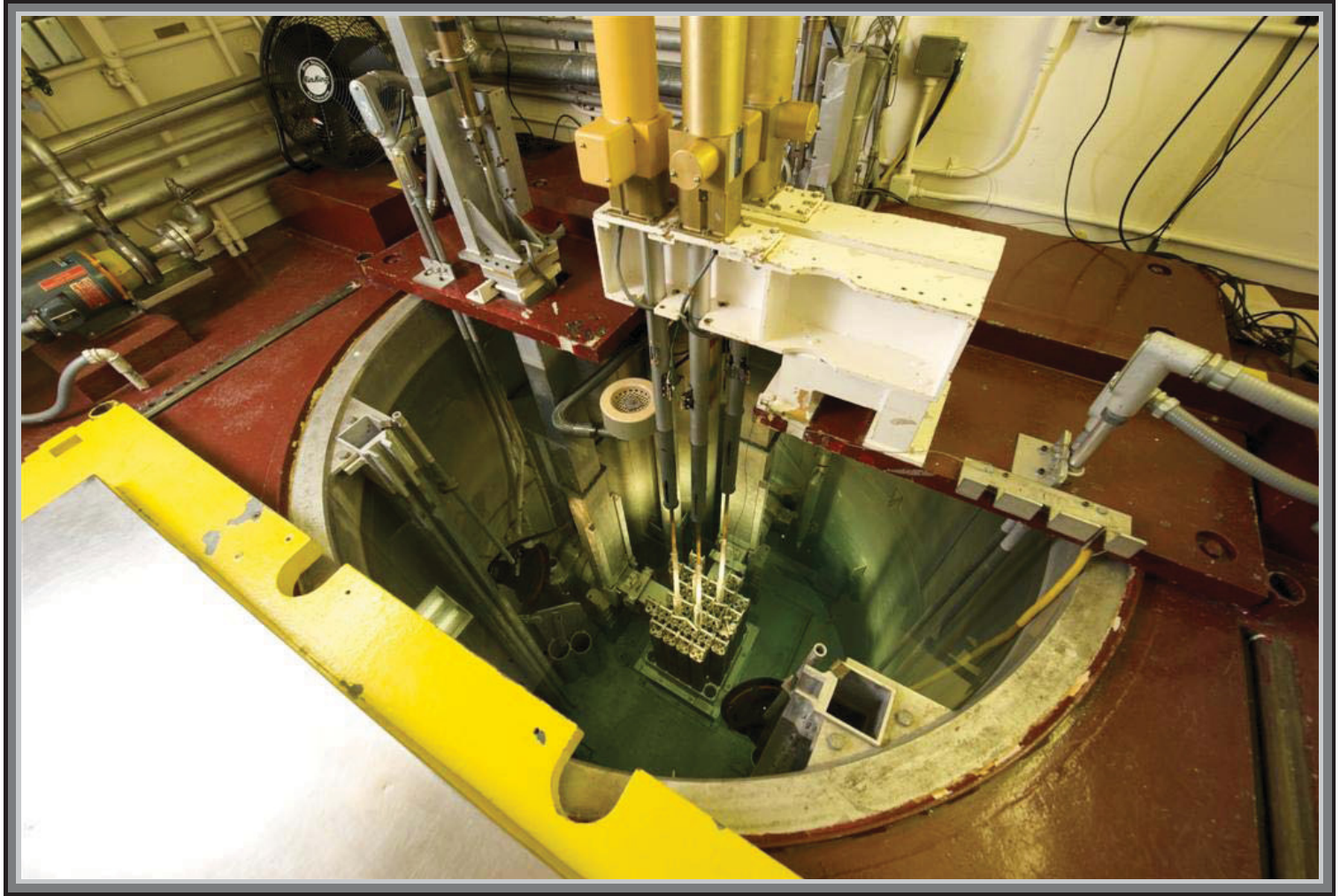

Figure 1.1a. Top-Down View of the NRAD Reactor.

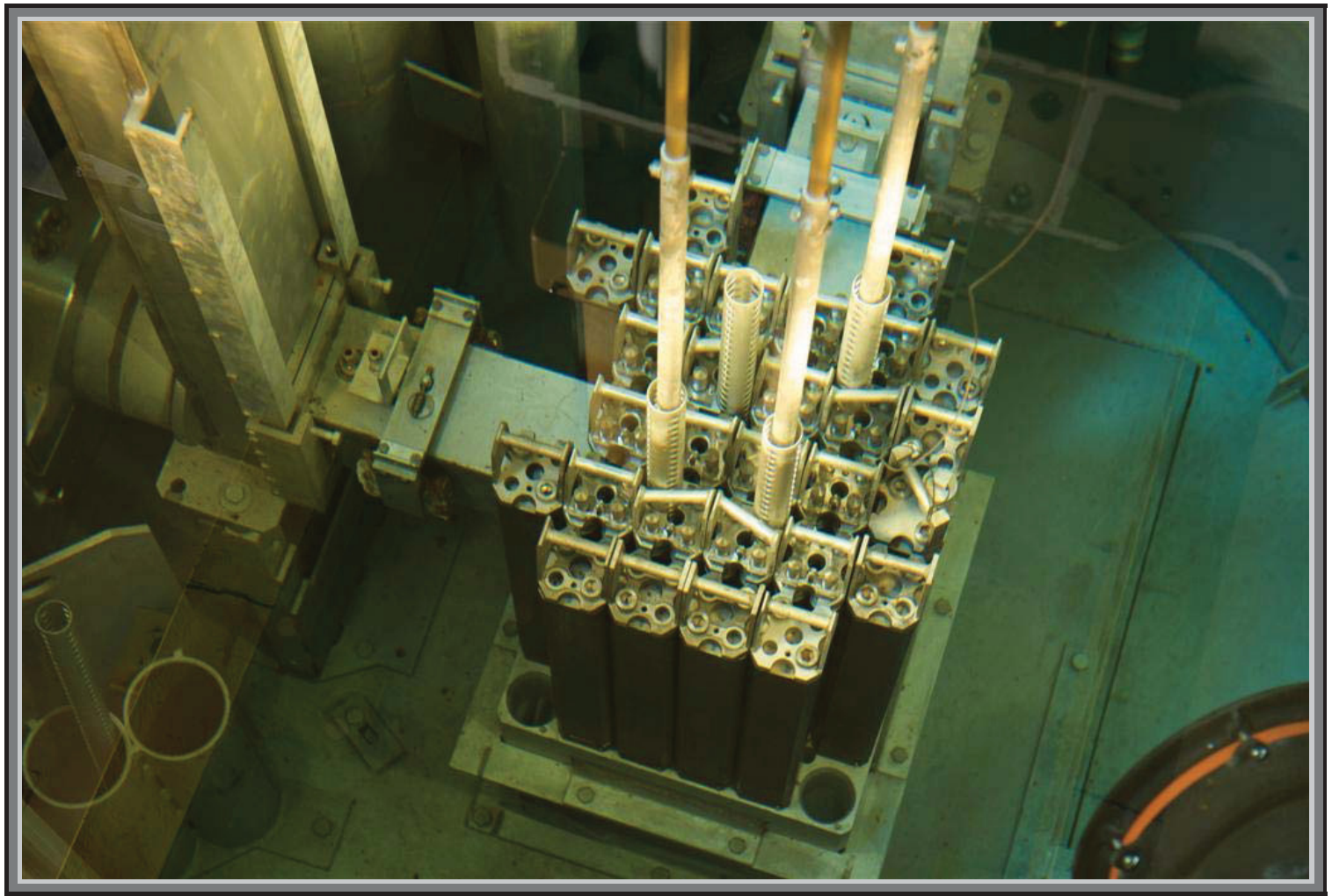

Figure 1.1b. In-Tank View of the NRAD Reactor Core. 
NEA/NSC/DOC(2006)1

Fundamental - FUND

NRAD-FUND-RESR-001

CRIT

\subsubsection{Facility Description}

\section{Site and Facility}

The NRAD reactor is located in the basement, below the main hot cell, of the Hot Fuels Examination Facility (HFEF), shown in Figure 1.2, at the Materials and Fuels Complex (MFC) of the Idaho National Laboratory (INL), formerly known as Argonne-West.

The floor area in the reactor room is $11 \mathrm{ft} 6 \mathrm{in} .(3.5052 \mathrm{~m})$ by $12 \mathrm{ft}(3.6576 \mathrm{~m})$ with a height of $16 \mathrm{ft} 9 \mathrm{in}$. $(5.1054 \mathrm{~m})$, and is located at the east end of the HFEF cask tunnel. Prior to placement of the reactor tank, the original floor and soil were excavated down to the rock level and then backfilled with concrete to the depth of the original floor. ${ }^{\mathrm{a}}$

The excavation is approximately $10 \mathrm{ft}(3.048 \mathrm{~m})$ deep.

The reactor tank fills most of the room in which it is placed. It is embedded in a massive, reinforcedconcrete block that is surrounded on three sides by reinforced-concrete walls. The concrete serves both as a working platform at the top level of the reactor tank and as a biological shield. ${ }^{\mathrm{b}}$

The reactor tank is surrounded by concrete except around the beam tubes, where additional shielding is required. The concrete around the tank is filled up to the tank top, about $5 \mathrm{ft} 6 \mathrm{in}$. $(1.6764 \mathrm{~m})$ from the ceiling. The North, East, and South walls have a concrete thickness of 2.5, 4, and $5 \mathrm{ft}(76.2,121.92$, and $152.4 \mathrm{~cm})$, respectively. The West wall, to a height of $11.5 \mathrm{ft}(3.5052 \mathrm{~m})$ was formed by the concrete surrounding the tank. The remaining height of the West wall consists of 2 in. $(5.08 \mathrm{~cm})$ thick lead bricks sandwiched between steel plates. Two sections of this shielding wall are fixed at either side with two other sections capable of sliding open to provide access to the reactor room. This opening is $5 \mathrm{ft} 3 \mathrm{in}$. $(1.6002 \mathrm{~m})$ wide and $5 \mathrm{ft} 6 \mathrm{in}$. $(1.6764 \mathrm{~m})$ high. A fixed ladder provides entry for personnel from the cask tunnel. ${ }^{\mathrm{a}}$

The ceiling is made of 42 in. (106.68 cm) thick reinforced high-density concrete. ${ }^{b}$

Additional shielding was provided by embedding steel plates, borated polyethylene, and lead bricks within the concrete shielding. The maximum thickness of the West shield is $12 \mathrm{in} .(30.48 \mathrm{~cm})$ steel plus 1 in. $(2.54 \mathrm{~cm})$ polyethylene. A 6 in. $(15.24 \mathrm{~cm})$ thick steel slab with 1 in. $(2.54 \mathrm{~cm})$ thick borated polyethylene slab is placed to the north of the reactor around the north beam tube penetration. A 4 in. $(10.16 \mathrm{~cm})$ thick layer of lead bricks is embedded in a rectangular box to the West side of the top of the reactor tank. ${ }^{\mathrm{a}}$

A plan and elevation view of the NRAD is shown in Figures 1.3 and 1.4, respectively. The placement of the fuel handling cask is shown in these two figures; however, the cask is not placed in the tank, except when fuel loading and unloading tasks are being performed.

\footnotetext{
a "HFEF/N Neutron Radiography Facility System Design Description,” W0170-0004-SA rev. 2, Idaho National Laboratory (June 1, 1978). [This reference is not available for public release.]

b “NRAD Safety Analysis Report,” DSA-005-NRAD rev. 5, Idaho National Laboratory (April 2, 2009). [This reference is not available for public release.]
} 
NEA/NSC/DOC(2006)1

Fundamental - FUND

NRAD-FUND-RESR-001

CRIT

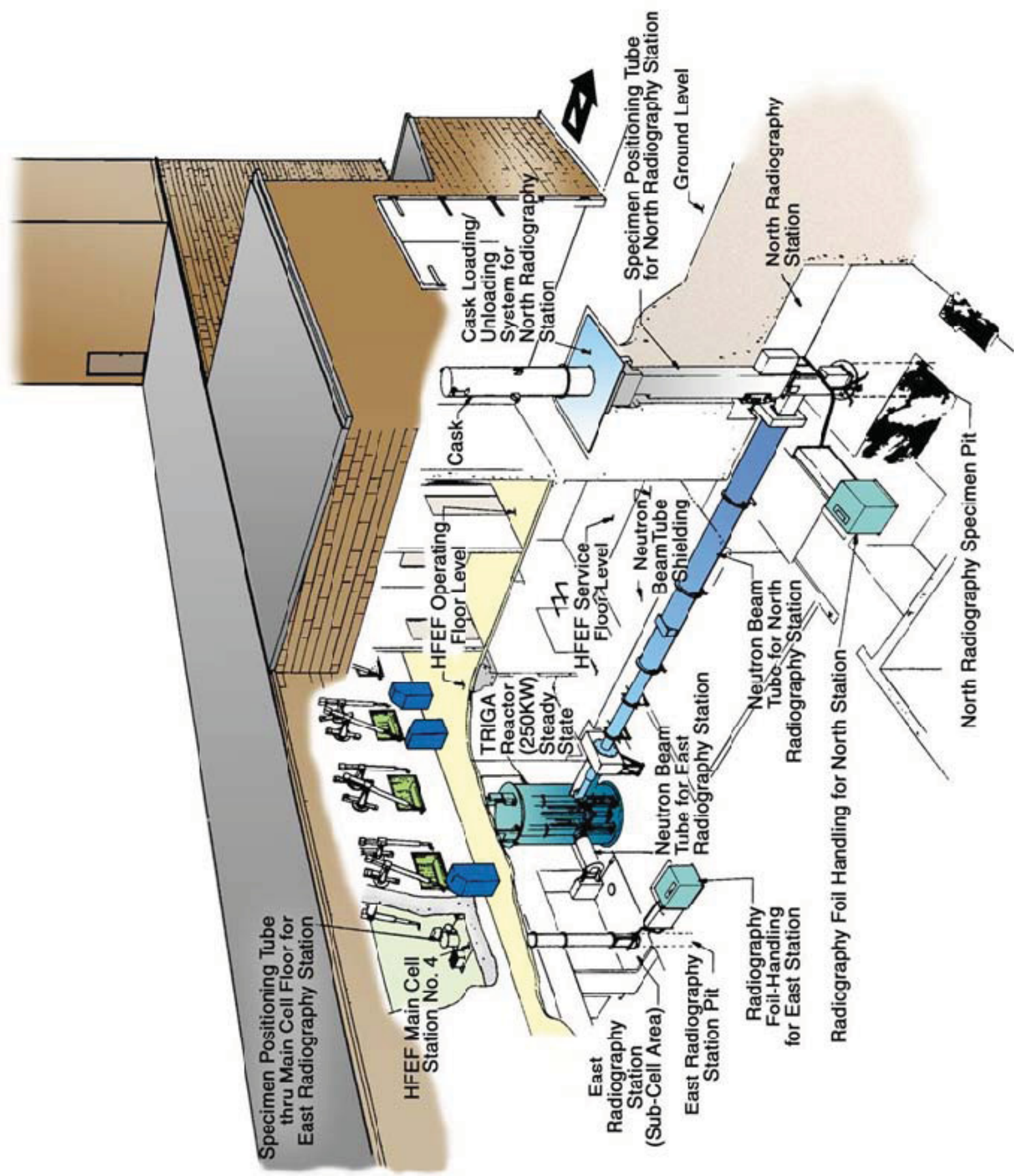

Figure 1.2. Hot Fuels Examination Facility. 
NEA/NSC/DOC(2006)1

Fundamental - FUND

NRAD-FUND-RESR-001 CRIT

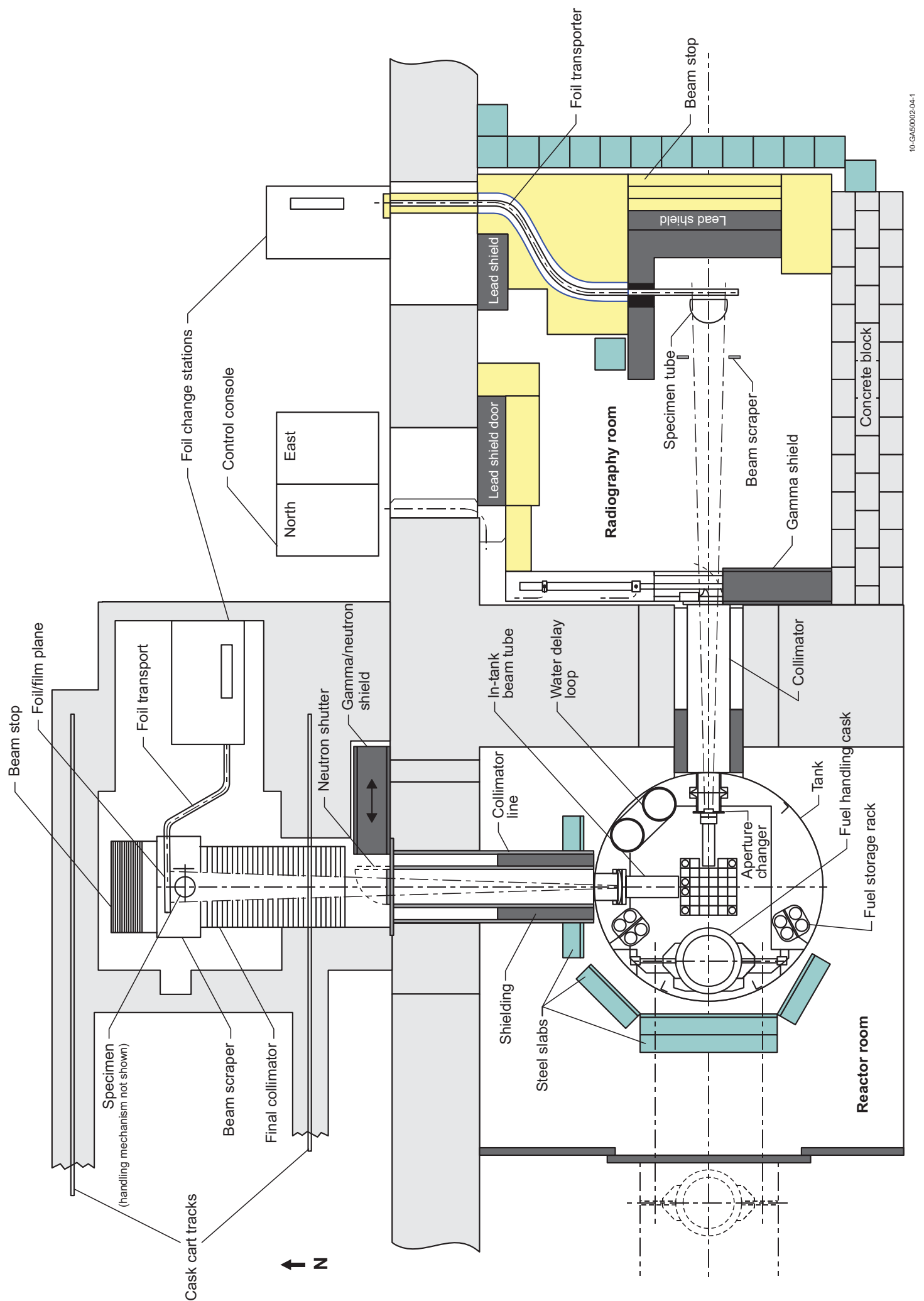

Figure 1.3. Plan View of the NRAD Facility. ${ }^{\mathrm{a}}$

a "NRAD Safety Analysis Report," DSA-005-NRAD rev. 5, Idaho National Laboratory (April 2, 2009). [This reference is not available for public release.] 
NEA/NSC/DOC(2006)1

Fundamental - FUND

NRAD-FUND-RESR-001

CRIT

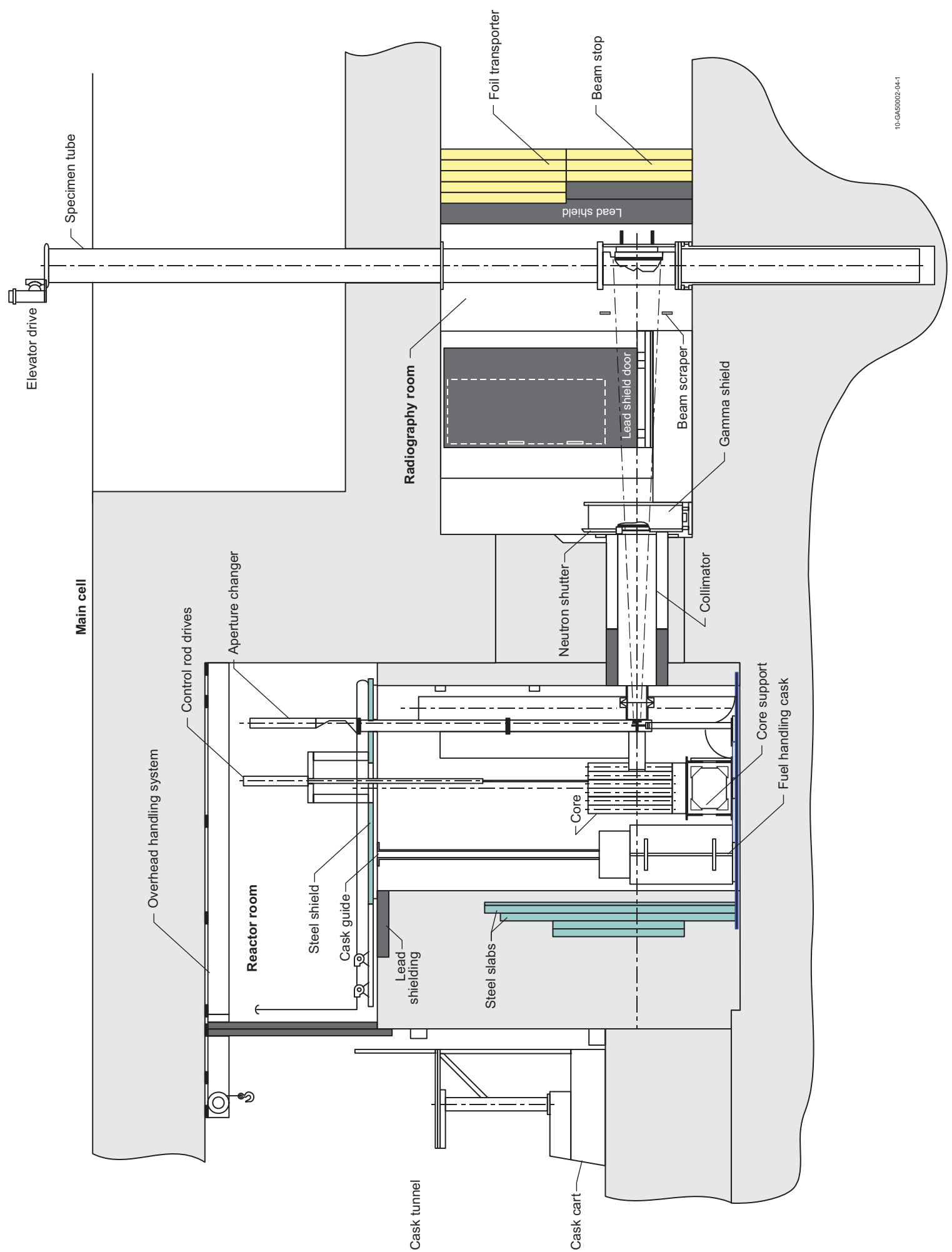

Figure 1.4. Elevation View of the NRAD Facility. ${ }^{a}$

a "NRAD Safety Analysis Report," DSA-005-NRAD rev. 5, Idaho National Laboratory (April 2, 2009). [This reference is not available for public release.] 


\section{Reactor Containment}

A reactor tank houses the reactor core and contains the primary coolant. The tank is a welded construction of aluminum 6061-T6 that is $6.5 \mathrm{ft}(1.9812 \mathrm{~m})$ in diameter, $11.5 \mathrm{ft}(3.5052 \mathrm{~m})$ high, has 0.25 in. $(0.635 \mathrm{~cm})$ thick walls, and has a bottom that is $0.5 \mathrm{in} .(1.27 \mathrm{~cm})$ thick. It is open at the top. ${ }^{\text {a }}$

Two collars are butted to the outside surface of the tank to mate with beam-tube liners and two pipe stubs are welded to the inside surface to mate with nozzles. The only penetration in the tank wall is located near the top of the tank for the water-overflow pipe. Delay loops are provided inside the tank to allow ${ }^{16} \mathrm{~N}$ contained in the water to decay prior to entering the primary coolant system. ${ }^{\mathrm{b}}$

A diagram of the NRAD cross-section in the reactor tank is shown in Figure 1.5.

A reactor top shield also serves as a working platform and is made of 2 in. $(5.08 \mathrm{~cm})$ thick steel. It is comprised of three sections: one that is fixed and supports the control-rod drives, one that is mounted on rollers and can be moved to access the reactor tank, and one that can be moved, if required, by an overhead handling system. These slabs are large enough that they cannot be dropped into the reactor core during handling. ${ }^{\mathrm{c}}$

a "NRAD Reactor Fuel Core Conversion," DSA-005-NRAD-ADD-3 rev. 0, Idaho National Laboratory (April 2 , 2009). [This reference is not available for public release.]

b “HFEF/N Neutron Radiography Facility System Design Description,” W0170-0004-SA rev. 2, Idaho National Laboratory (June 1, 1978). [This reference is not available for public release.]

c “NRAD Safety Analysis Report,” DSA-005-NRAD rev. 5, Idaho National Laboratory (April 2, 2009). [This reference is not available for public release.] 
NEA/NSC/DOC(2006)1

Fundamental - FUND

NRAD-FUND-RESR-001

CRIT

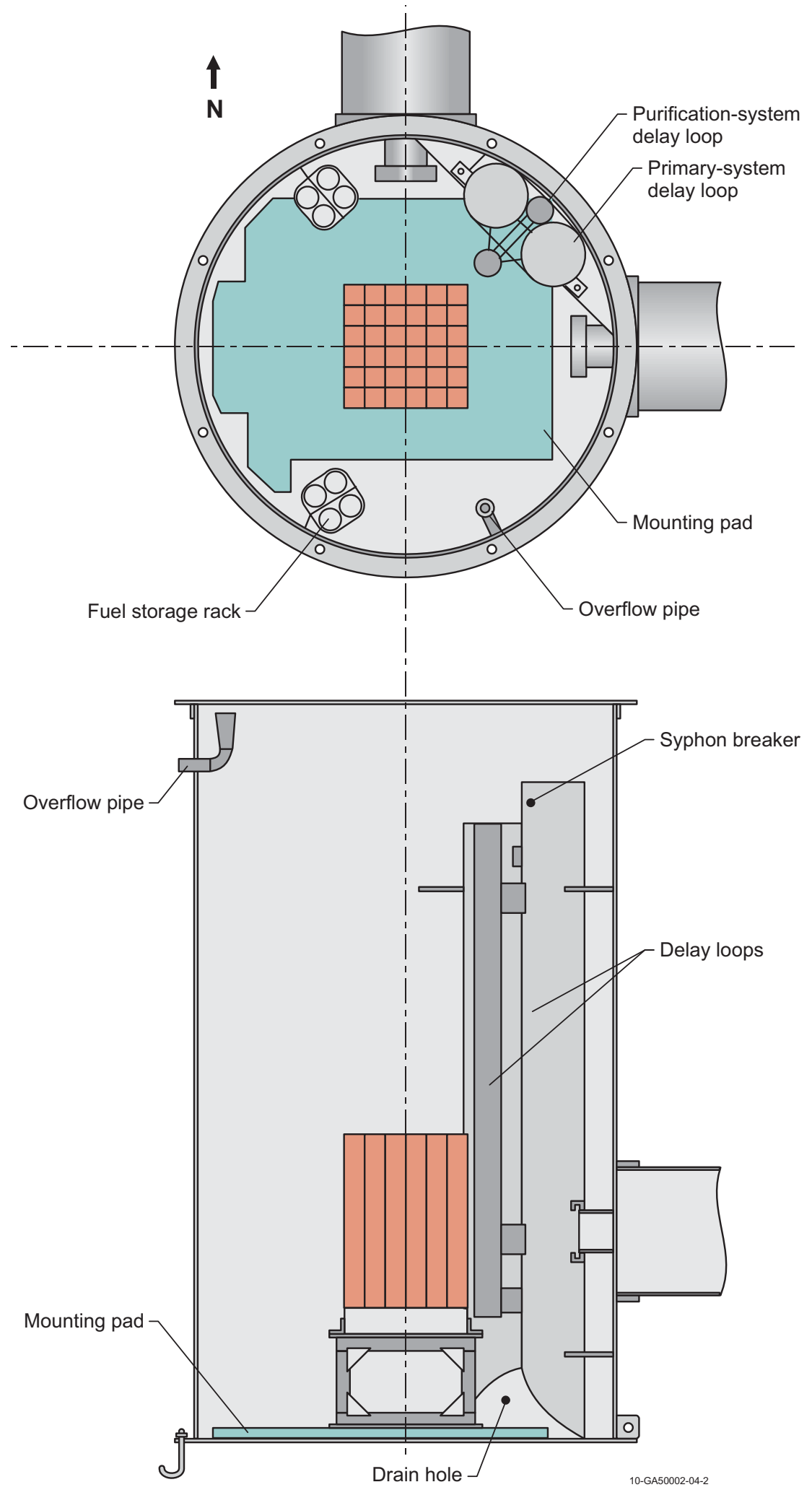

Figure 1.5. NRAD Tank. 
NEA/NSC/DOC(2006)1

Fundamental - FUND

NRAD-FUND-RESR-001

CRIT

\section{Non-Nuclear Components}

A 2 in. $(5.08 \mathrm{~cm})$ diameter overflow pipe maintains the maximum water level 2 in. $(5.08 \mathrm{~cm})$ below the top of the tank. The two 24 in. $(60.96 \mathrm{~cm})$ diameter collars butted to the outside of the tank surface are designed to provide support and a seal for the beam-tube liners. The two 9 in. $(22.86 \mathrm{~cm})$ diameter pipe stubs, which are aligned with the collars, are welded inside the tank for mating with nozzles. The nozzles extend between the reactor tank wall and the core skirt to exclude water from the path of the beam line. ${ }^{\text {a }}$

Attached to the inner tank wall is a primary coolant system water delay loop. The holdup tank is shaped like an upright " $U$ " and is made of 12 in. $(30.48 \mathrm{~cm})$ diameter aluminum pipe with a total length of $20 \mathrm{ft}$ $(6.096 \mathrm{~m})$ and a holding capacity of 120 gal. ( 454.25 L).

\section{Moderator/Coolant}

The reactor core is cooled via natural circulation of water within the open reactor tank. Heat is removed from the reactor tank by forced circulation induced by a primary water system through a water-to-water heat exchanger. The secondary side of the heat exchanger is then cooled by the HFEF cooling water system, which is cooled by the HFEF cooling tower. ${ }^{b}$

The tank water also serves as a biological shield for the reactor and is approximately $10 \mathrm{ft}(3.048 \mathrm{~m})$ deep.

\subsubsection{Reactor Core}

The NRAD LEU core configuration contains 60 fuel elements, two water-followed shim control rods, and one water-followed regulating rod (Figure 1.6). A water hole is provided as an experimental irradiation position. The NRAD reactor uses graphite neutron reflector assemblies located along the periphery grid plate locations. The number and position of fuel-element and reflector assemblies can be varied to adjust core reactivity.

Core positions are designated by a grid reference system, as labeled in Figure 1.6. The location of individual elements within a grid position is defined in Figure 1.7. Positions in the grid are identified with a letter-number pair. For example, the location of the in-core irradiation assembly is identified as $\mathrm{C}$ 4. The location of a specific position within an assembly is further designated by its location with respect to the center of the assembly. The location of the in-core irradiation position is identified as C-4 SW.

The circular items labeled "G" through "N", in Figure 1.6, are in-pool storage locations.

\footnotetext{
a "HFEF/N Neutron Radiography Facility System Design Description,” W0170-0004-SA rev. 2, Idaho National Laboratory (June 1, 1978). [This reference is not available for public release.]

b "NRAD Reactor Fuel Core Conversion," DSA-005-NRAD-ADD-3 rev. 0, Idaho National Laboratory (April 2, 2009). [This reference is not available for public release.]
} 
NEA/NSC/DOC(2006)1

Fundamental - FUND

NRAD-FUND-RESR-001

CRIT

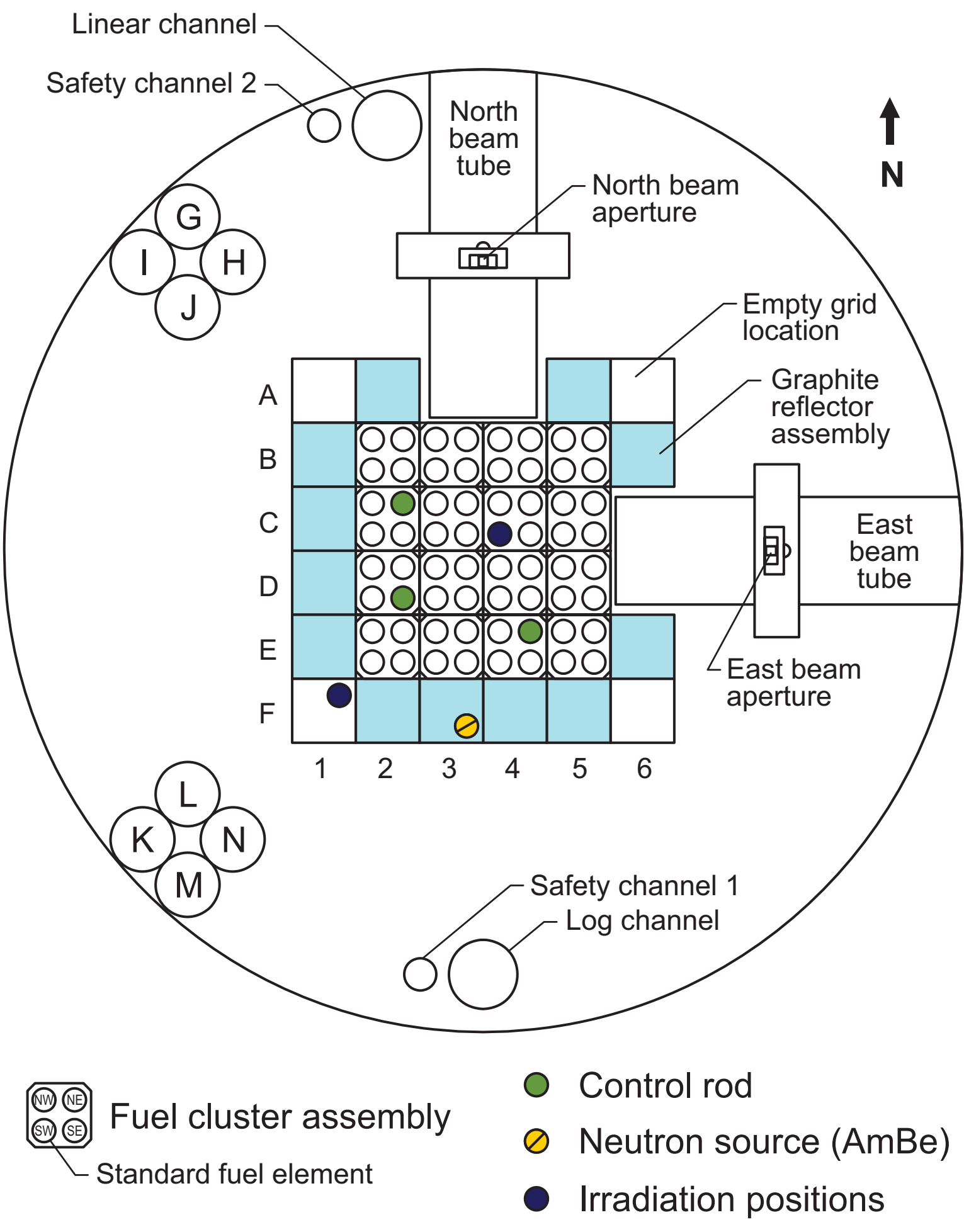

10-GA50002-04-3

Figure 1.6. NRAD LEU Core Configuration. ${ }^{a}$

\footnotetext{
a "NRAD Reactor Fuel Core Conversion," DSA-005-NRAD-ADD-3 rev. 0, Idaho National Laboratory (April 2, 2009). [This reference is not available for public release.]
} 
NEA/NSC/DOC(2006)1

Fundamental - FUND

NRAD-FUND-RESR-001

CRIT

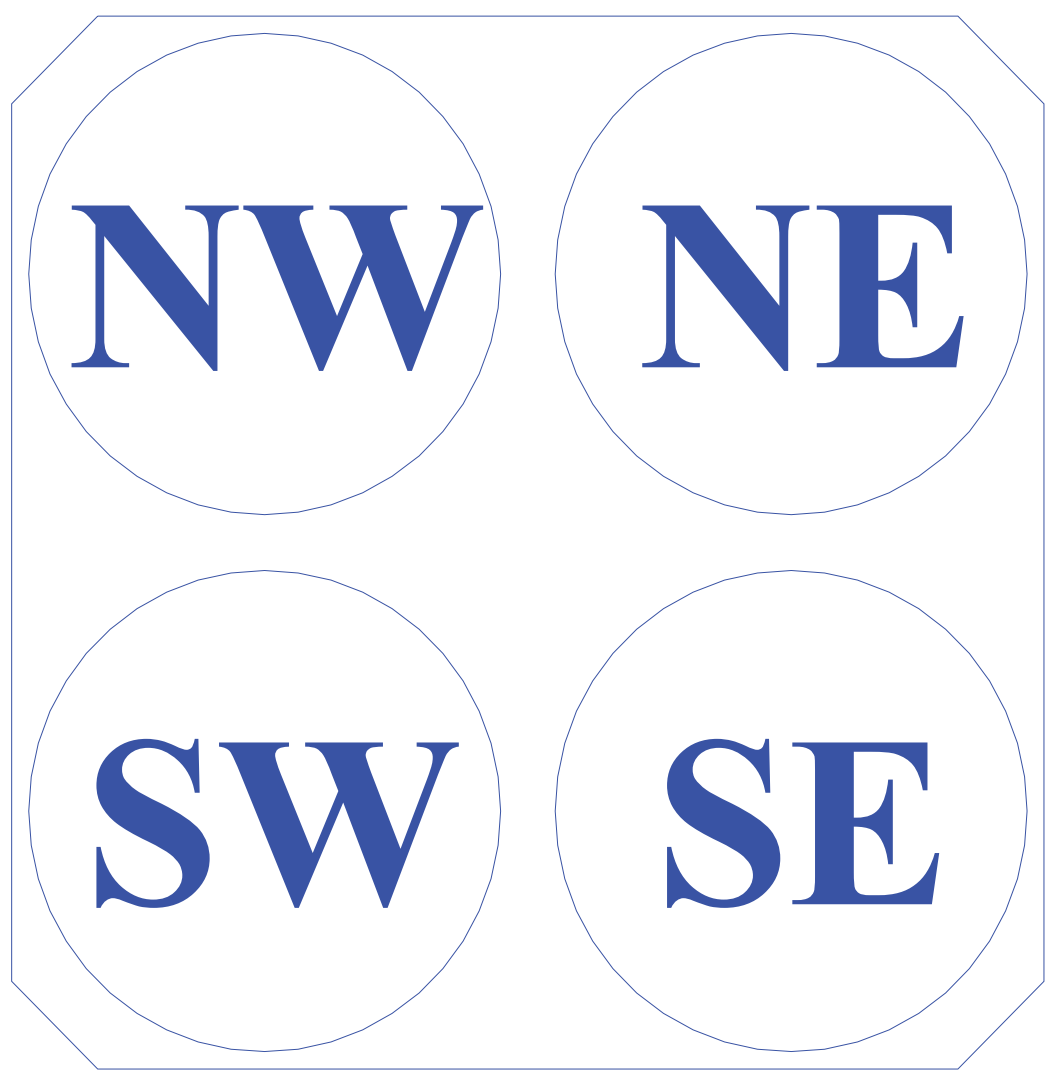

Figure 1.7. Notation for Fuel Element Cluster Position. ${ }^{\mathrm{a}}$

a "NRAD Reactor Fuel Core Conversion," DSA-005-NRAD-ADD-3 rev. 0, Idaho National Laboratory (April 2, 2009). [This reference is not available for public release.] 
NEA/NSC/DOC(2006)1

Fundamental - FUND

NRAD-FUND-RESR-001

CRIT

\section{Core Support Structure}

A welded aluminum core support structure (Figure 1.8), below the grid plate, supports the reactor core approximately $16.5 \mathrm{in} .(41.91 \mathrm{~cm})$ above the bottom of the reactor tank (Figure 1.9). It is bolted to the reactor tank in eight places. ${ }^{\mathrm{a}}$

A 1 in. $(2.54 \mathrm{~cm})$ thick aluminum mounting pad (Figures 1.5 and 1.9) is welded to the inside surface of the tank bottom. ${ }^{\text {b }}$

\section{Grid Plate Assembly}

The fuel clusters are supported by a 5 in. $(12.7 \mathrm{~cm})$ thick grid plate composed of aluminum 1100 forgings (Figure 1.10). The grid plate has 36 holes placed in a $6 \times 6$ rectangular pitch lattice for holding the fuel cluster and reflector assemblies. ${ }^{\mathrm{a}}$

The grid plate assembly is bolted to the support structure (Figure 1.9).

The nominal spacing between cluster assemblies in the grid plate is shown in Figure 1.11. There is more space between the rods in the East-West direction than in the North-South direction. ${ }^{a}$ The original PRNC grid plate was designed to use Materials Testing Reactor (MTR)-type uranium-aluminum plate fuel. The NRAD reactor is a conversion reactor, where the original plate-type fuel bundles were replaced by TRIGA fuel cluster assemblies designed by General Atomics while still at PRNC. The NRAD reactor is one of thirteen conversion reactors. ${ }^{\mathrm{c}}$

Core positions are designated by a grid reference system, as labeled in Figure 1.6. The location of individual elements within a grid position is defined in Figure 1.7.

Each cluster location utilizes a dowel pin to insure proper cluster orientation. Each dowel pin is approximately $0.250 \mathrm{in} .(0.635 \mathrm{~cm})$ in diameter and $1.000 \mathrm{in} .(2.54 \mathrm{~cm})$ in length. There are additional holes in the grid plate that allow for water flow and grid-plate cooling. ${ }^{b}$

\footnotetext{
a "NRAD Reactor Fuel Core Conversion," DSA-005-NRAD-ADD-3 rev. 0, Idaho National Laboratory (April 2 , 2009). [This reference is not available for public release.]

b "HFEF/N Neutron Radiography Facility System Design Description,” W0170-0004-SA rev. 2, Idaho National Laboratory (June 1, 1978). [This reference is not available for public release.]

c R. E. Smith, “TRIGA Fuel Summary Report,” ICP/INT-05-817, Idaho Cleanup Project, Idaho National Laboratory (March 2005). [This reference is not available for public release.]
} 


\section{NEA/NSC/DOC(2006)1}

Fundamental - FUND

NRAD-FUND-RESR-001

CRIT
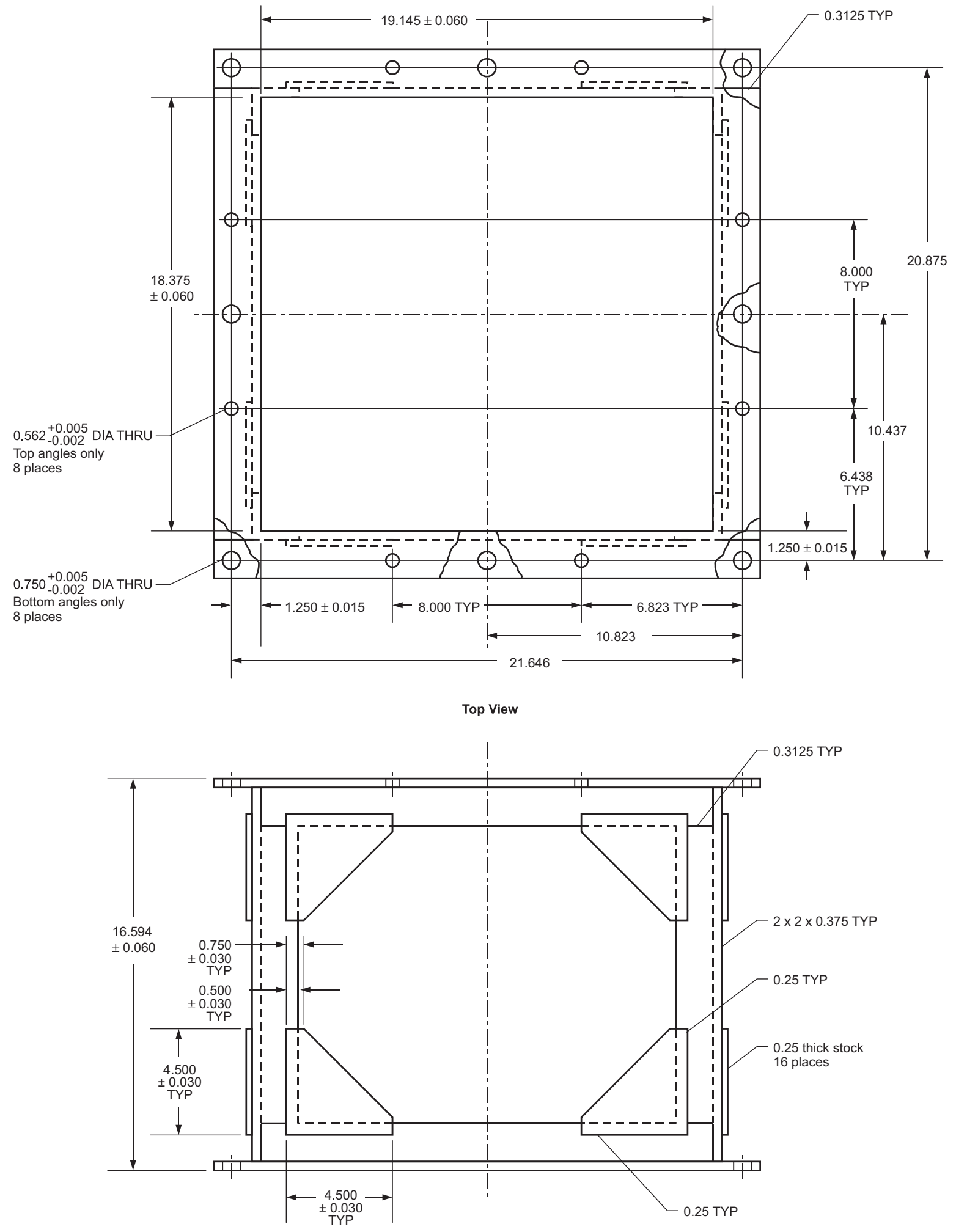

Dimensions in inches

Side View

09-GA50001-152-3

Figure 1.8. Aluminum Core Support Structure. 
Fundamental - FUND

NRAD-FUND-RESR-001 CRIT

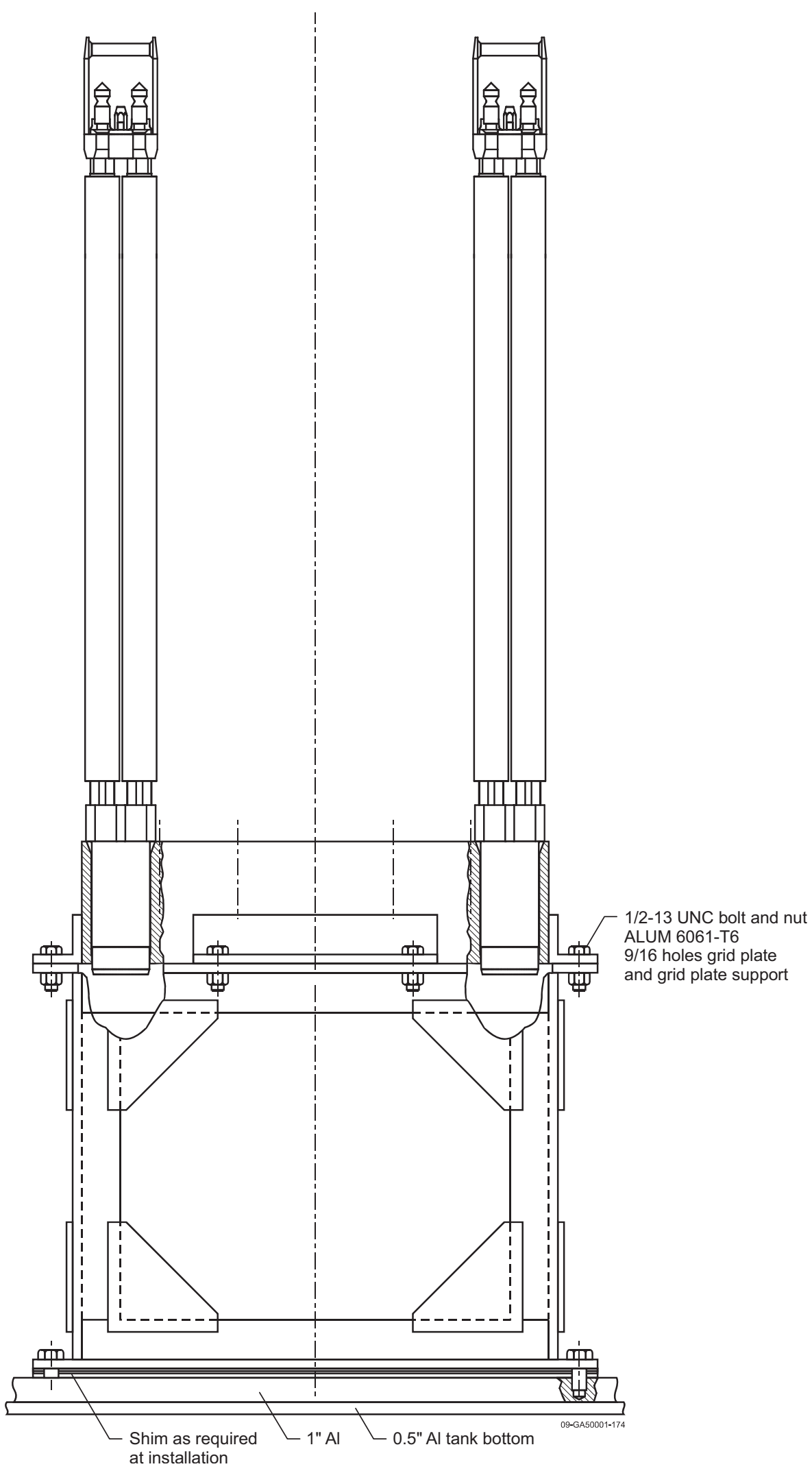

Figure 1.9. Schematic of Core Support Assembly. 
NEA/NSC/DOC(2006)1

Fundamental - FUND

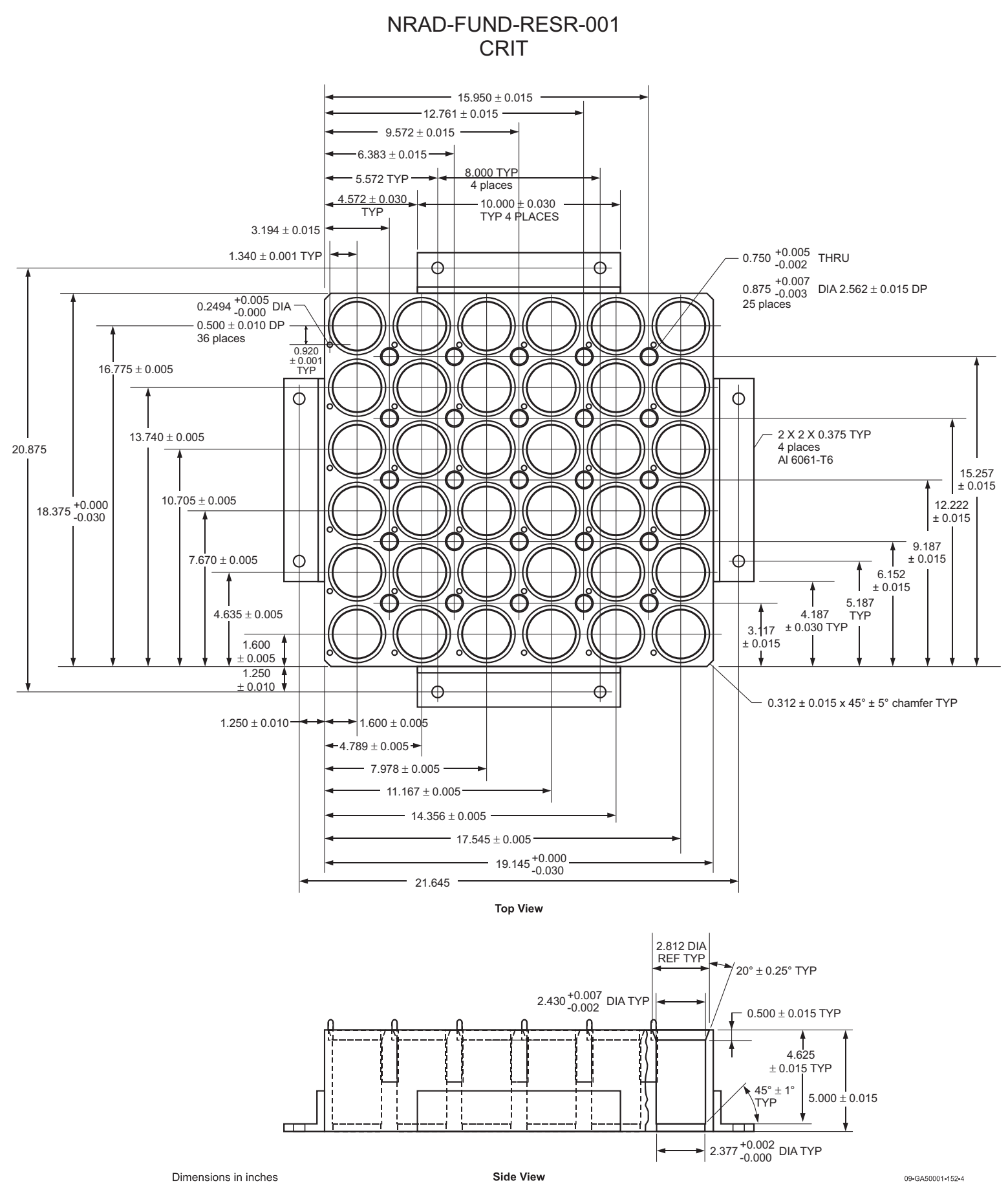

Figure 1.10. Grid Plate Assembly. 
NEA/NSC/DOC(2006)1

Fundamental - FUND

NRAD-FUND-RESR-001

CRIT

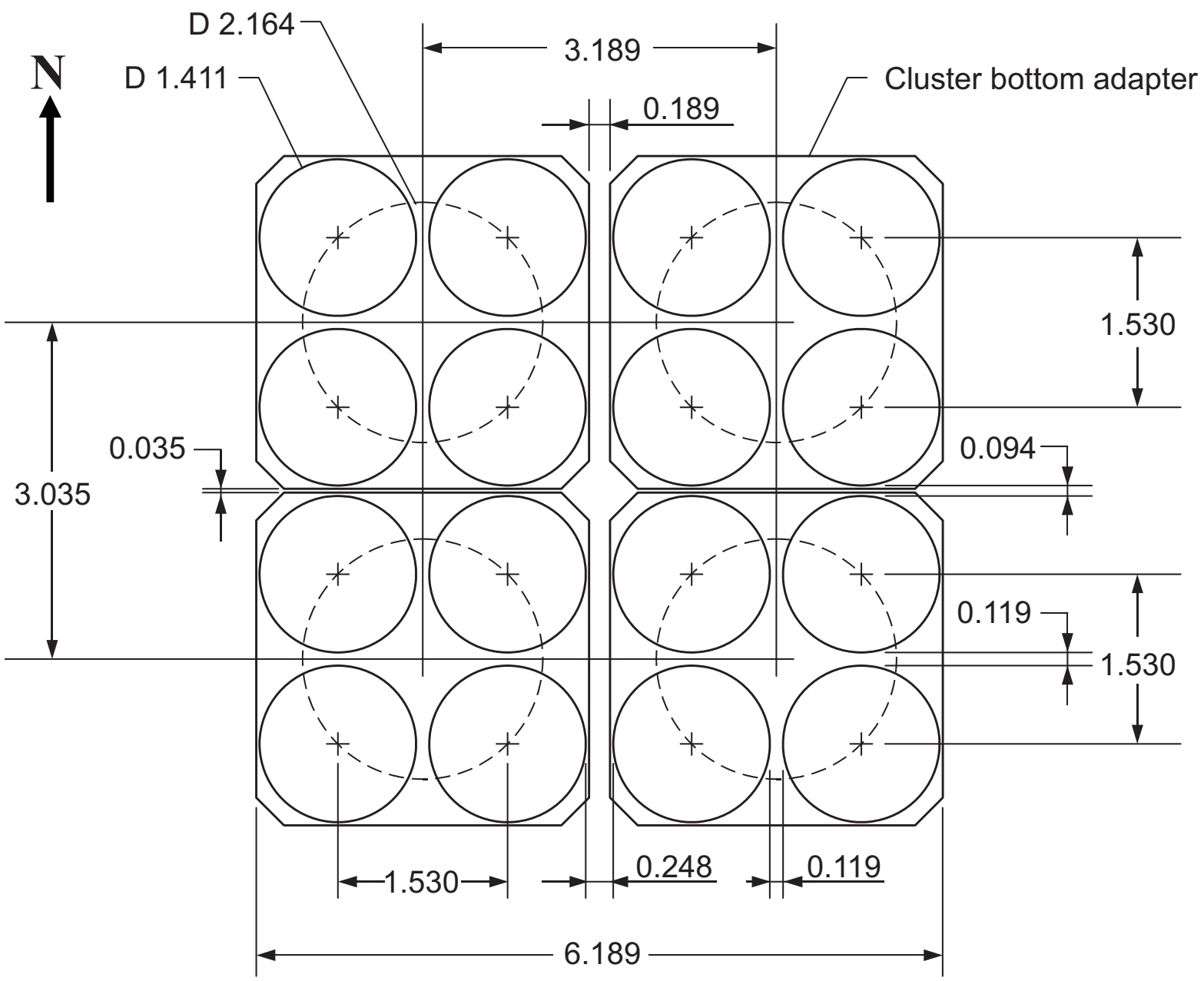

Dimensions in inches

09-GA50001-182

Figure 1.11. Nominal Cluster and Fuel Element Spacing. ${ }^{\text {a }}$

a "NRAD Reactor Fuel Core Conversion," DSA-005-NRAD-ADD-3 rev. 0, Idaho National Laboratory (April 2, 2009). [This reference is not available for public release.] 
NRAD-FUND-RESR-001 CRIT

\section{Fuel Cluster Assembly}

Conversion cluster assemblies contain three or four TRIGA fuel elements. The three-element variation uses the fourth position to accommodate a control rod or a sample irradiation tube. ${ }^{\text {a }}$

Fuel elements are contained within a four-element fuel cluster assembly (Figures 1.12 and 1.13). As depicted in Figure 1.13, the assembly consists of four fuel elements contained within a bottom cluster fitting assembly (Figure 1.14) and a top handle assembly (Figure 1.15). The assembly was designed to fit TRIGA fuel into the conversion reactor grid format. The top handle assembly is comprised of a locking bolt (Figure 1.16), handle with support plate (Figure 1.17), and locking plate (Figure 1.18). The top and bottom end adapters are attached to the fuel elements to hold the clusters together.

A three-element cluster assembly with a guide tube (Figure 1.35) is shown in Figures 1.19 and 1.20. These cluster assemblies (located in grid positions C-2, C-4, D-2, and E-4) allow for the placement and use of either control rods or water-filled sample irradiation positions within the core. The three fuel element top handle assemblies (Figure 1.21) are comprised of special top fittings (Figure 1.22) and locking plates (Figure 1.23) that were designed to accommodate the guide tube. The same bottom adapter (Figure 1.14) and locking bolt (Figure 1.16) used in the four element cluster assembly are used to complete the three-element cluster assemblies.

A threaded insert (Figure 1.15) is also used in the top assembly. It has a diameter of 0.25 in. $(0.635 \mathrm{~cm})$ and a length of $1.0 \mathrm{in} .(2.54 \mathrm{~cm})$.

\footnotetext{
${ }^{a}$ R. E. Smith, “TRIGA Fuel Summary Report,” ICP/INT-05-817, Idaho Cleanup Project, Idaho National Laboratory (March 2005). [This reference is not available for public release.]
} 
NEA/NSC/DOC(2006)1

Fundamental - FUND

NRAD-FUND-RESR-001 CRIT

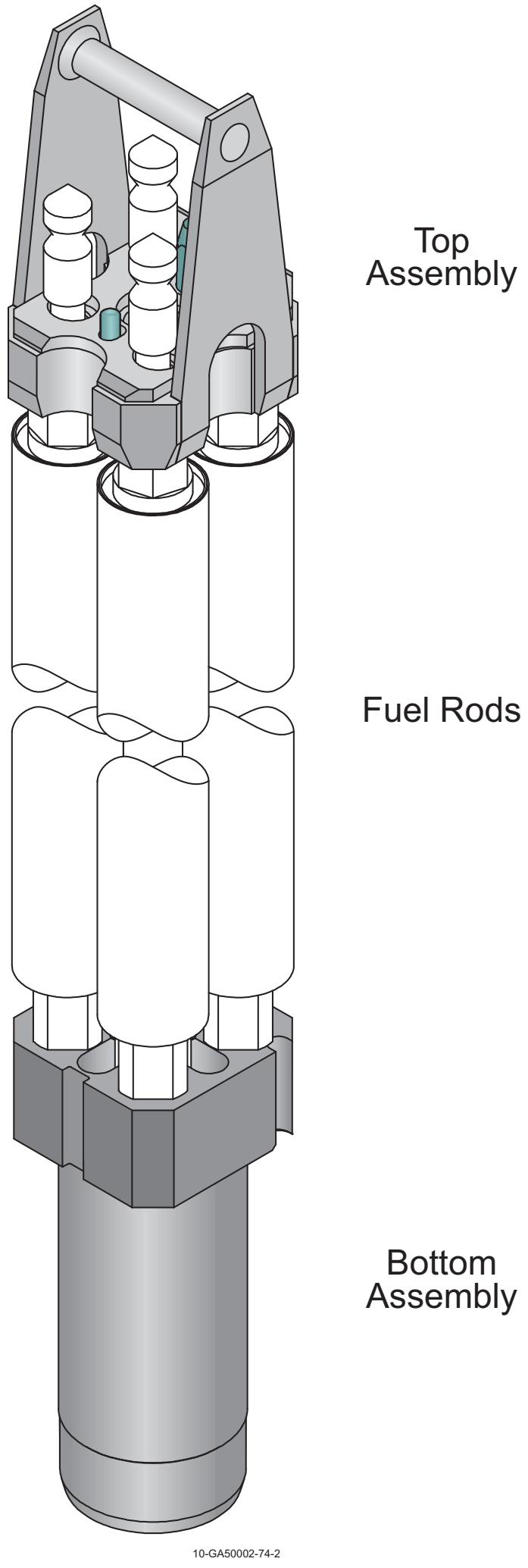

Figure 1.12. Four Fuel Element Cluster Assembly. 
NEA/NSC/DOC(2006)1

Fundamental - FUND

NRAD-FUND-RESR-001 CRIT
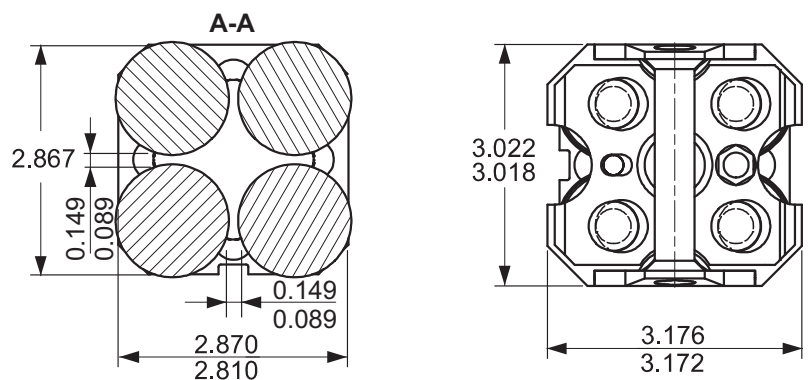

Top

Assembly

Fuel Rods
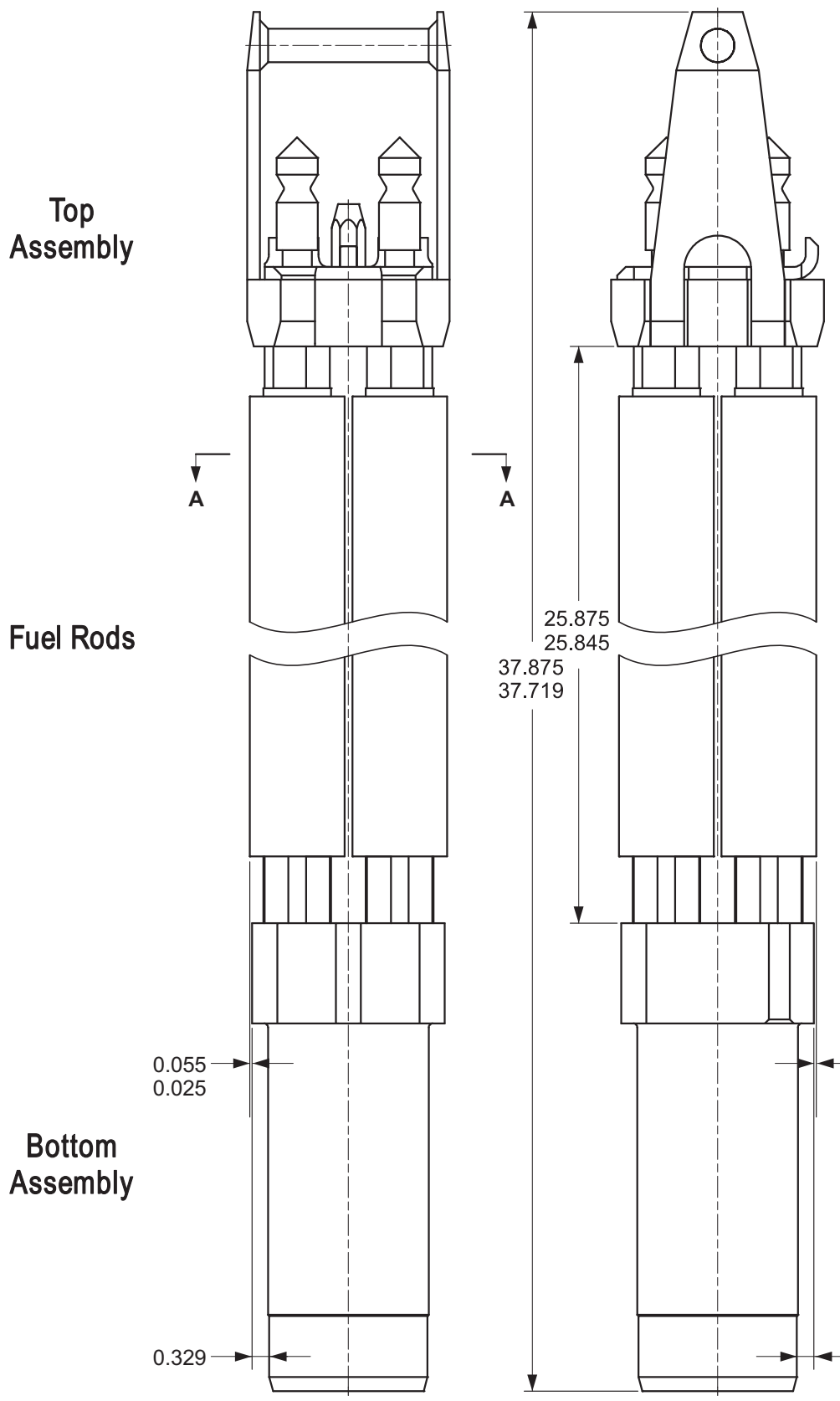

Dimensions in inches

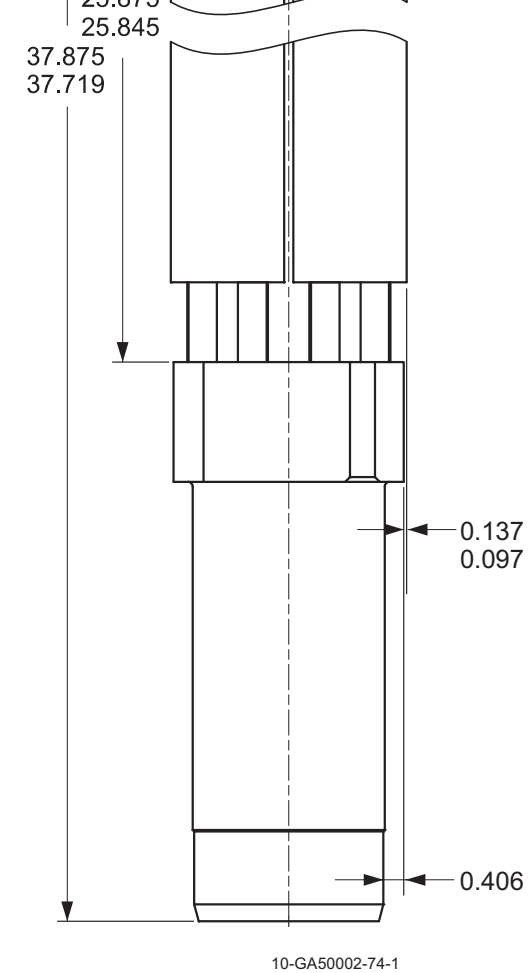

Figure 1.13. Four Fuel Element Cluster Assembly. 
NEA/NSC/DOC(2006)1

Fundamental - FUND

NRAD-FUND-RESR-001 CRIT
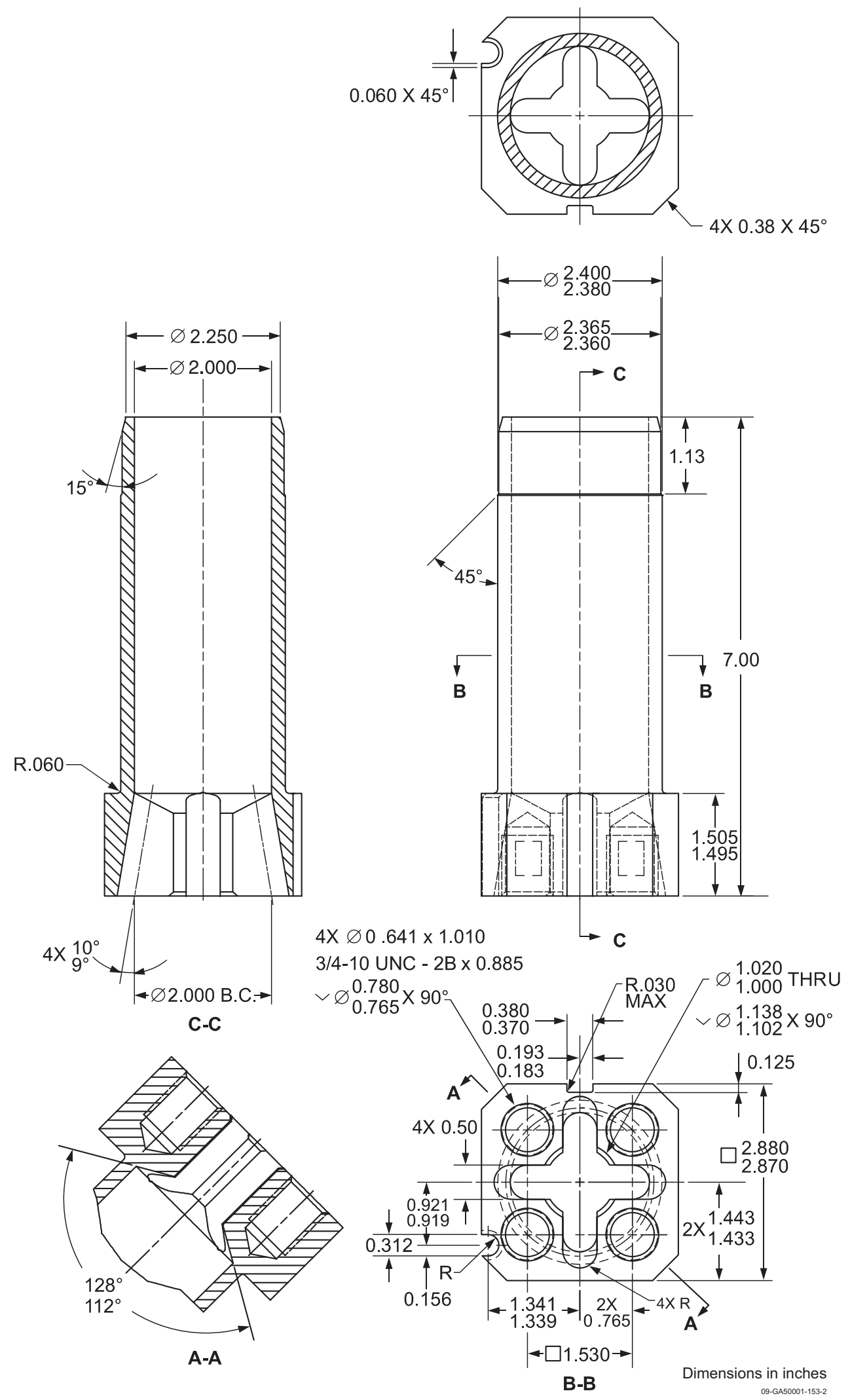

Figure 1.14. Bottom Cluster Fitting Assembly. 
NEA/NSC/DOC(2006)1

Fundamental - FUND

NRAD-FUND-RESR-001 CRIT

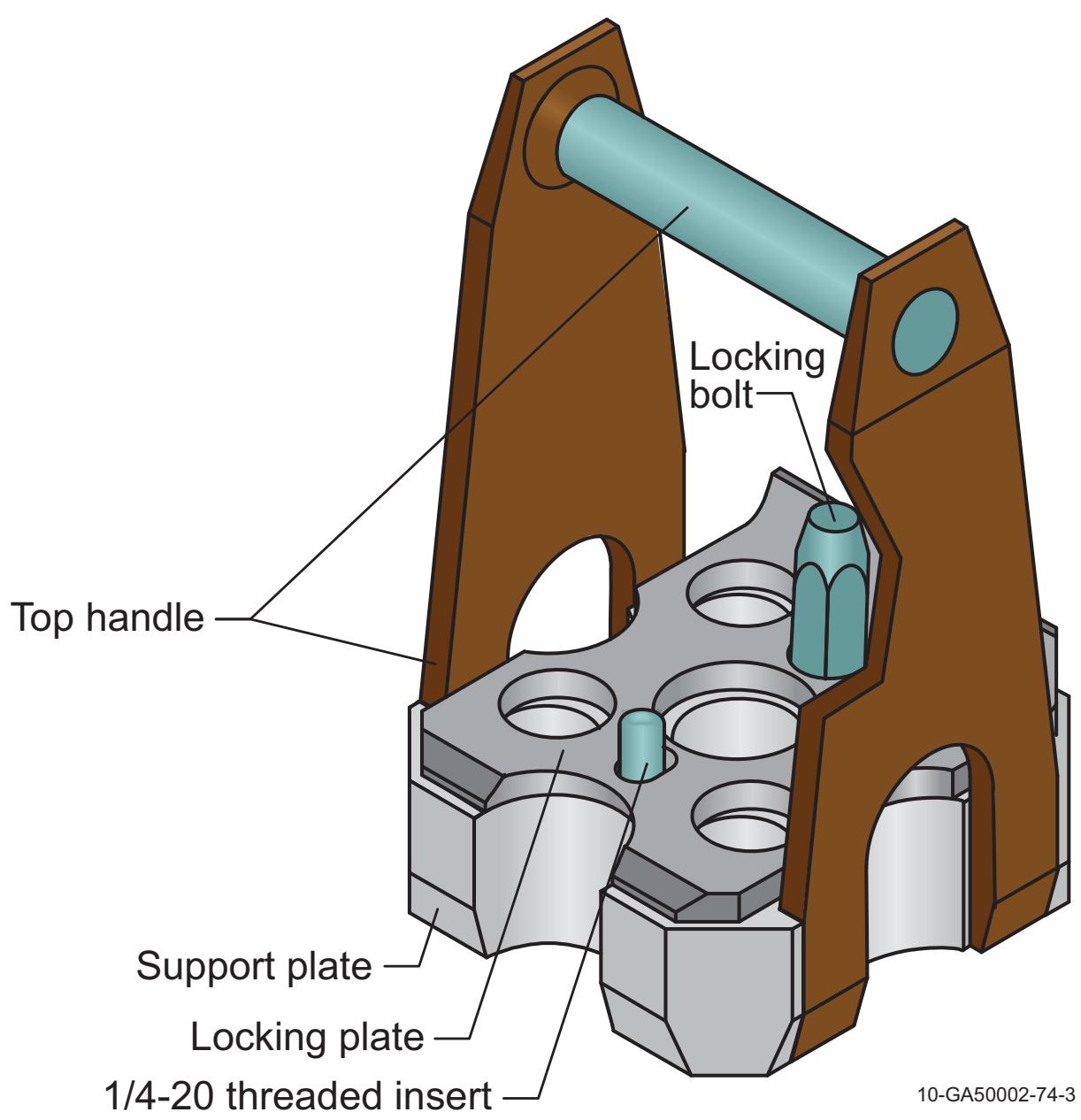

Figure 1.15. Top Handle Assembly for Four Element Cluster Assembly.
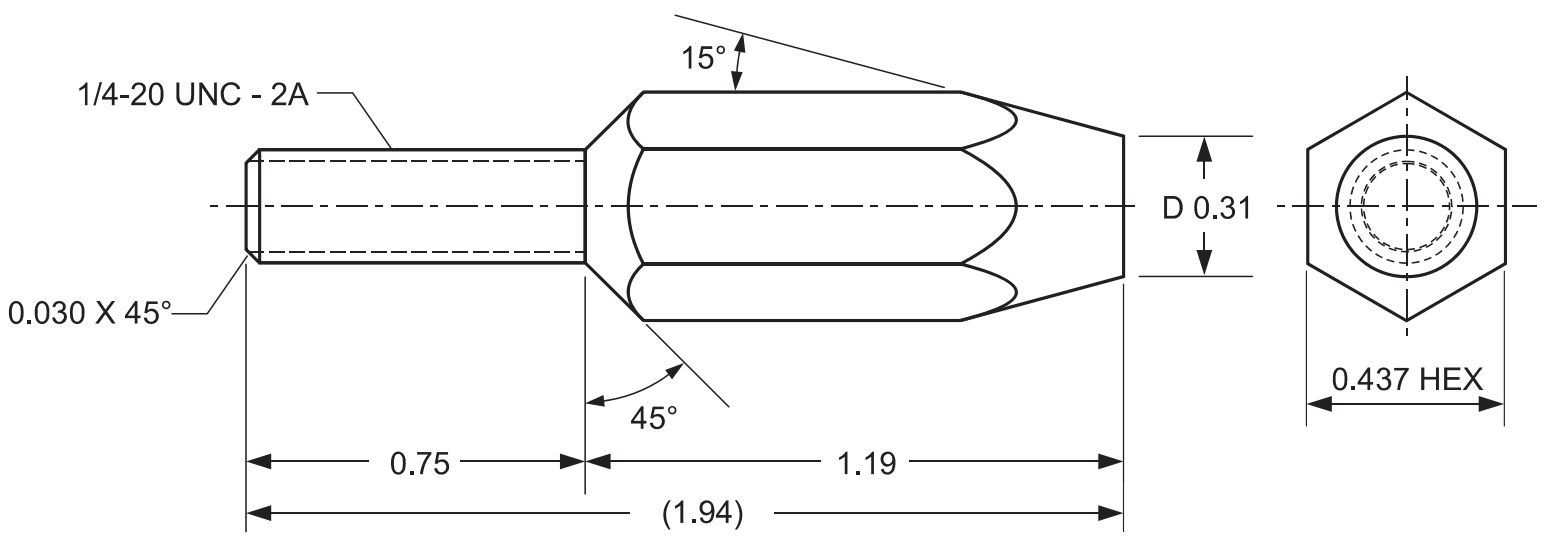

Dimensions in inches

09-GA50001-152-1

Figure 1.16. Locking Bolt for Top Handle Assembly. 
NEA/NSC/DOC(2006)1

Fundamental - FUND

NRAD-FUND-RESR-001

CRIT
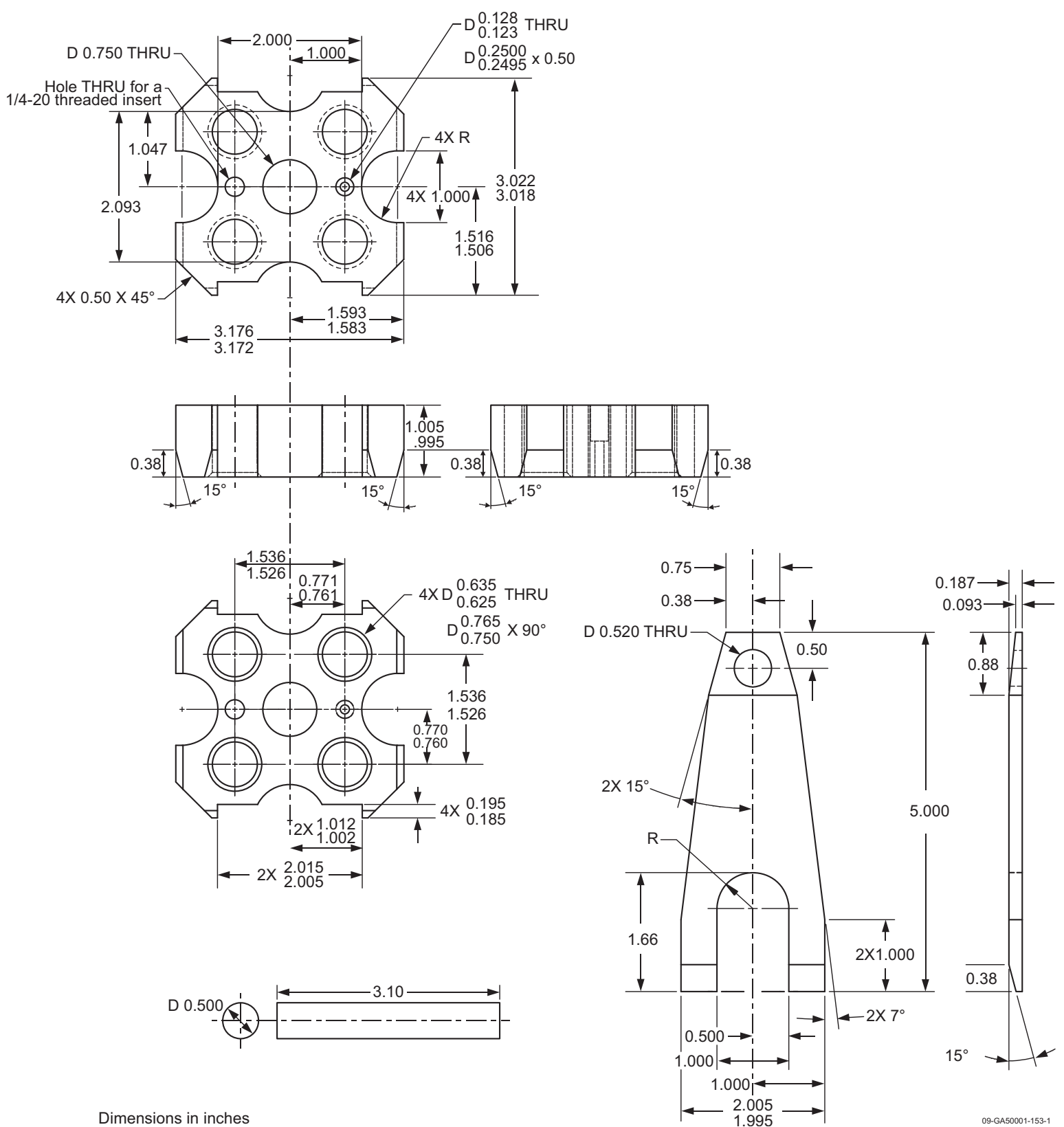

Dimensions in inches

Figure 1.17. Top Handle with Support Plate for Four Element Cluster Assembly. 
NEA/NSC/DOC(2006)1

Fundamental - FUND

NRAD-FUND-RESR-001 CRIT

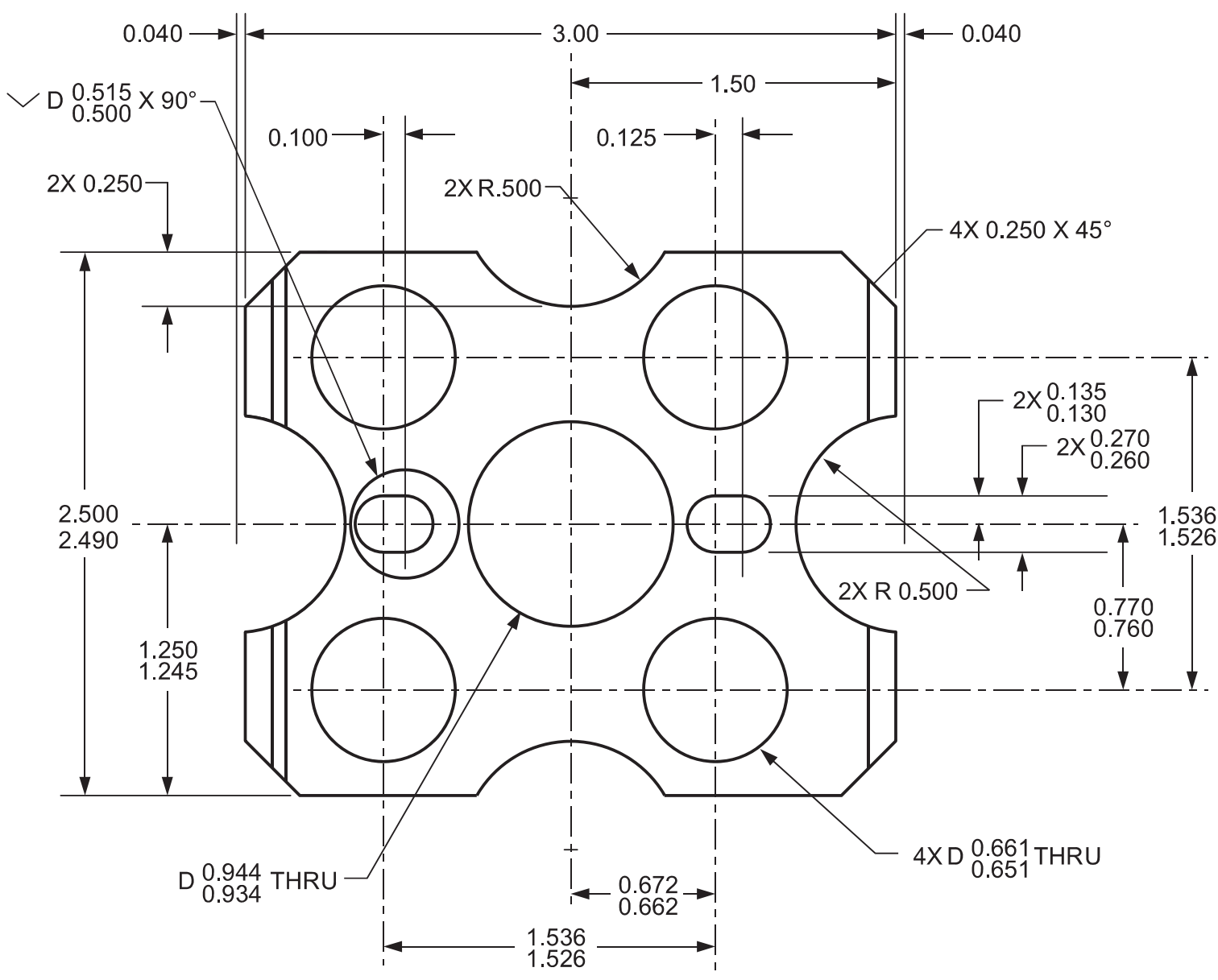

Top View

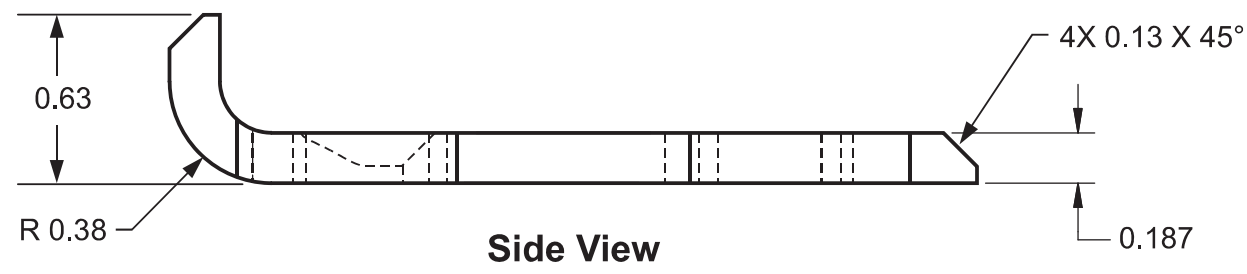

Dimensions in inches

09-GA50001-152-2

Figure 1.18. Locking Plate for Four Element Cluster Assembly. 
NEA/NSC/DOC(2006)1

Fundamental - FUND

NRAD-FUND-RESR-001

CRIT

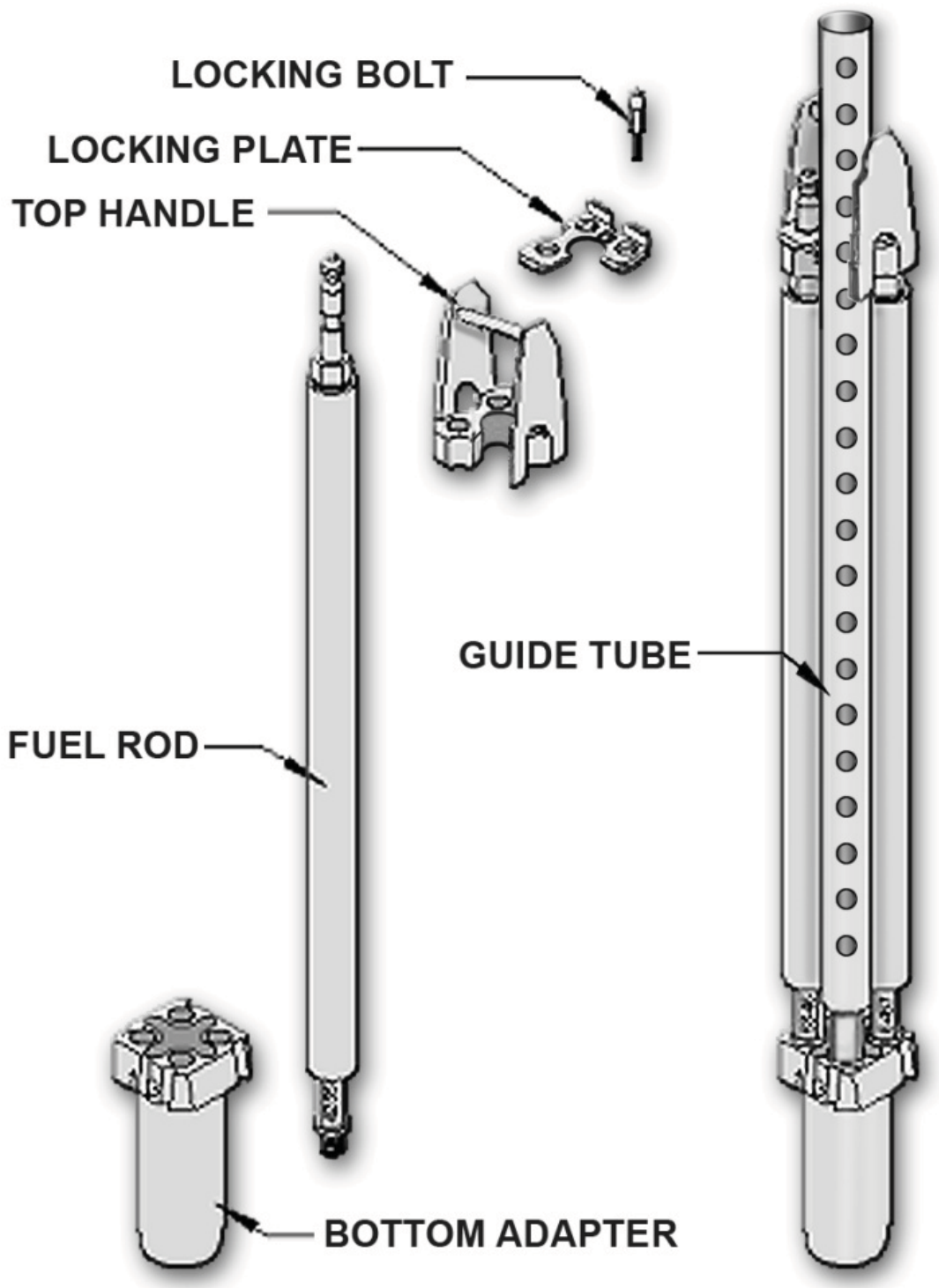

Figure 1.19. Three Fuel Element Cluster Assembly. ${ }^{\mathrm{a}}$

a "NRAD Reactor Fuel Core Conversion," DSA-005-NRAD-ADD-3 rev. 0, Idaho National Laboratory (April 2, 2009). [This reference is not available for public release.] 
NEA/NSC/DOC(2006)1

Fundamental - FUND

NRAD-FUND-RESR-001

CRIT

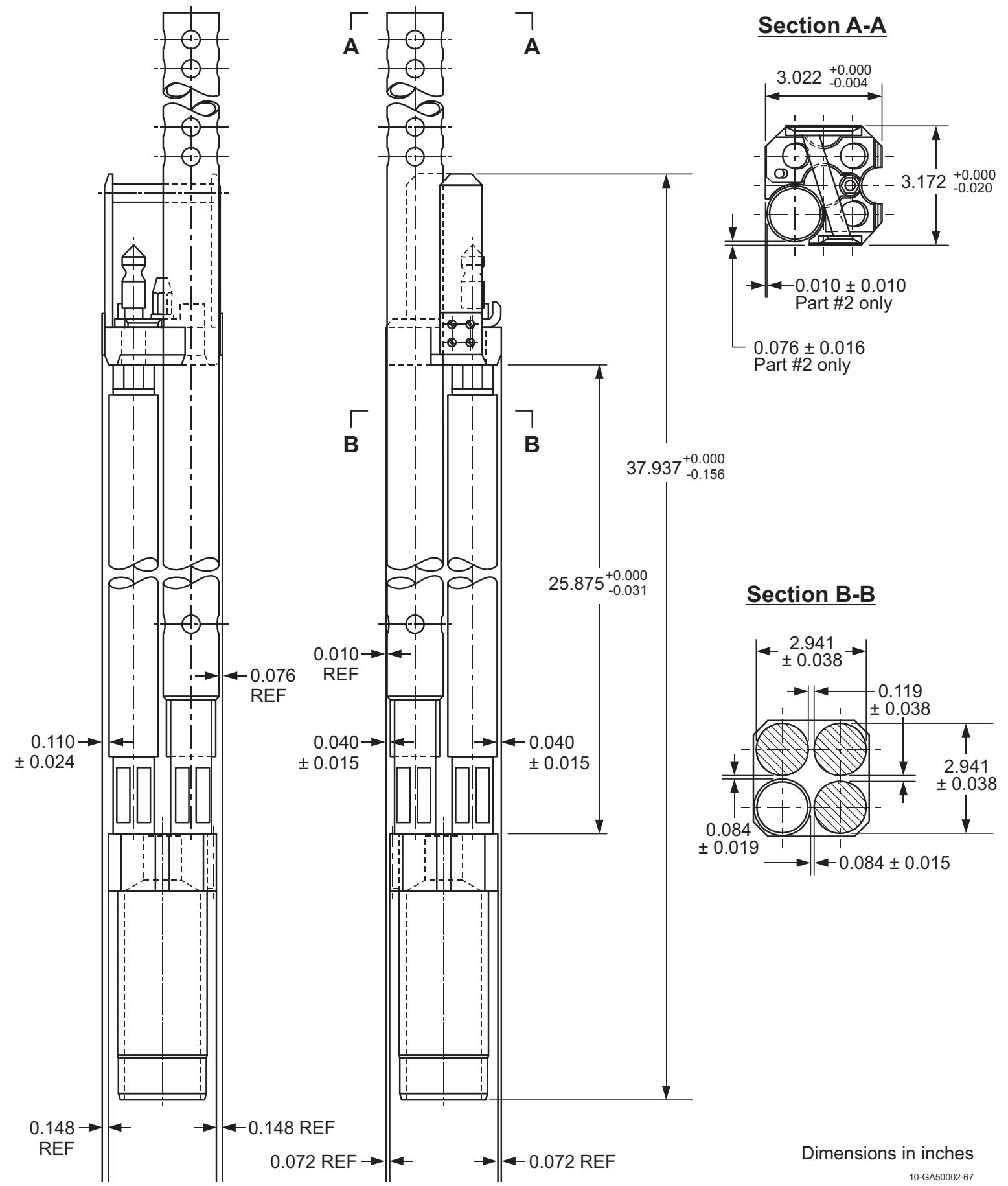

Figure 1.20. Three Fuel Element Cluster Assembly. 
NEA/NSC/DOC(2006)1

Fundamental - FUND

NRAD-FUND-RESR-001

CRIT

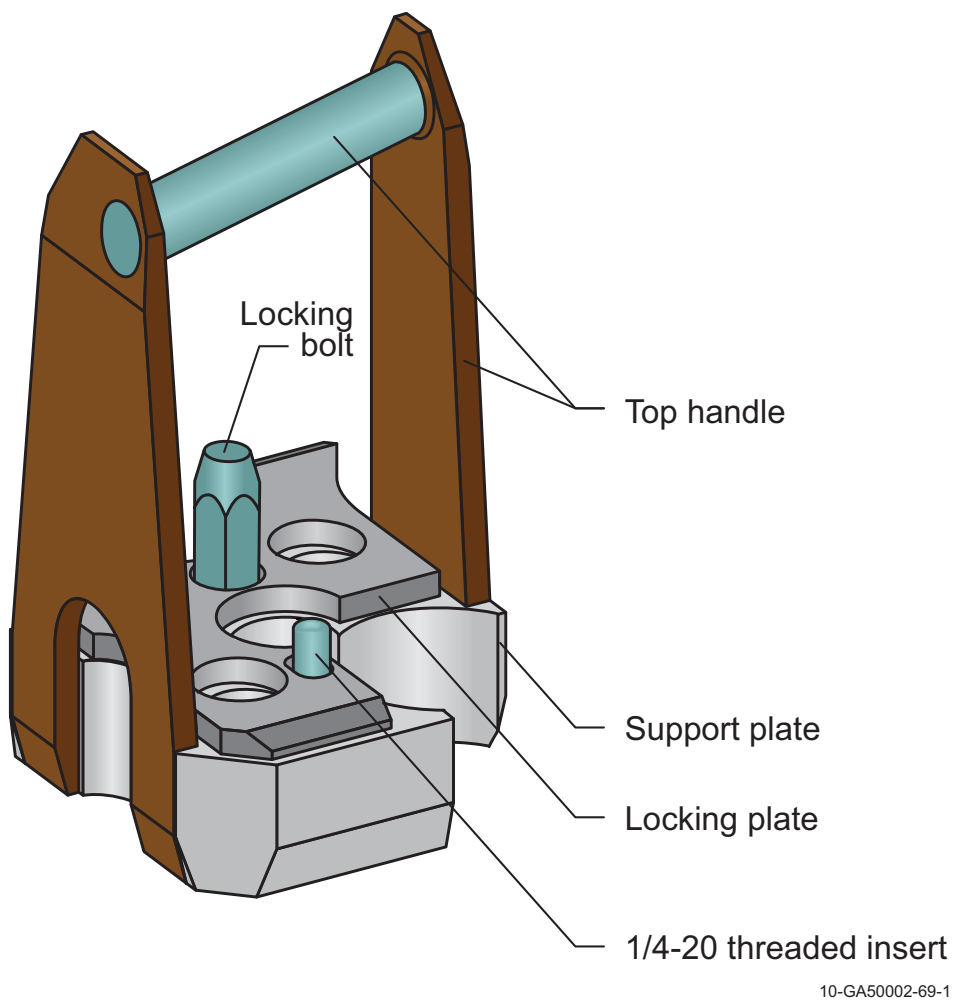

Figure 1.21a. Top Handle Assembly for C2, C4, and E4 Three Element Cluster Assembly.

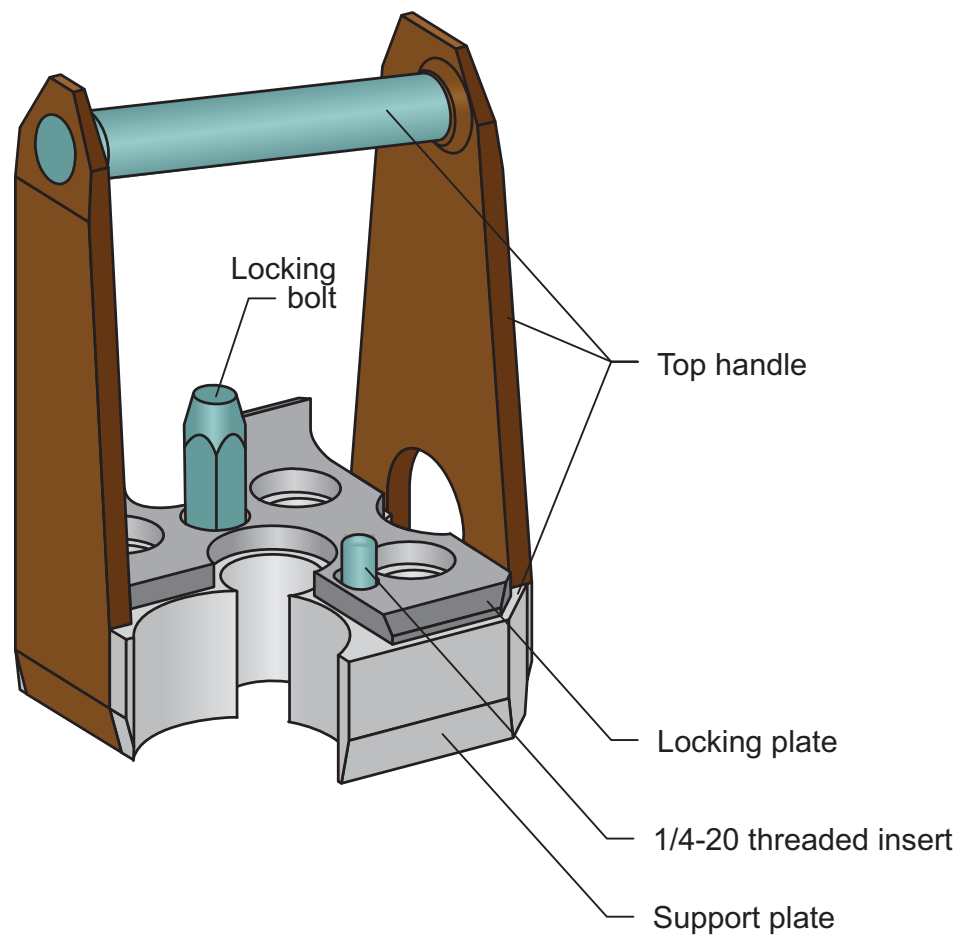

10-GA50002-69-2

Figure 1.21b. Top Handle Assembly for D2 Three Element Cluster Assembly. 
NEA/NSC/DOC(2006)1

Fundamental - FUND

NRAD-FUND-RESR-001

CRIT
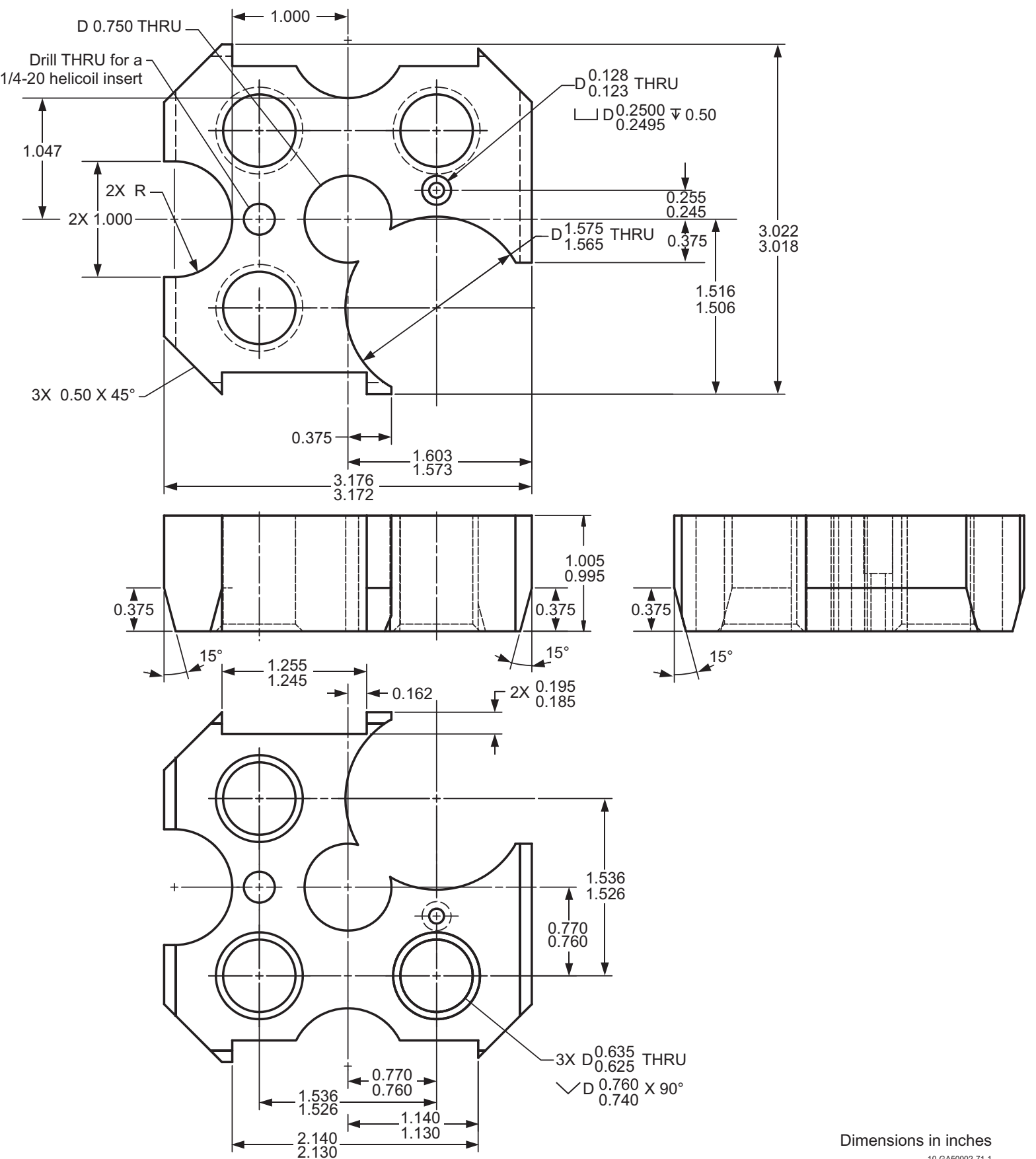

Dimensions in inches 10-GA50002-71-1

Figure 1.22a. Support Plate for C2, C4, and E4 Three Element Cluster Assembly. 
NEA/NSC/DOC(2006)1

Fundamental - FUND

NRAD-FUND-RESR-001

CRIT
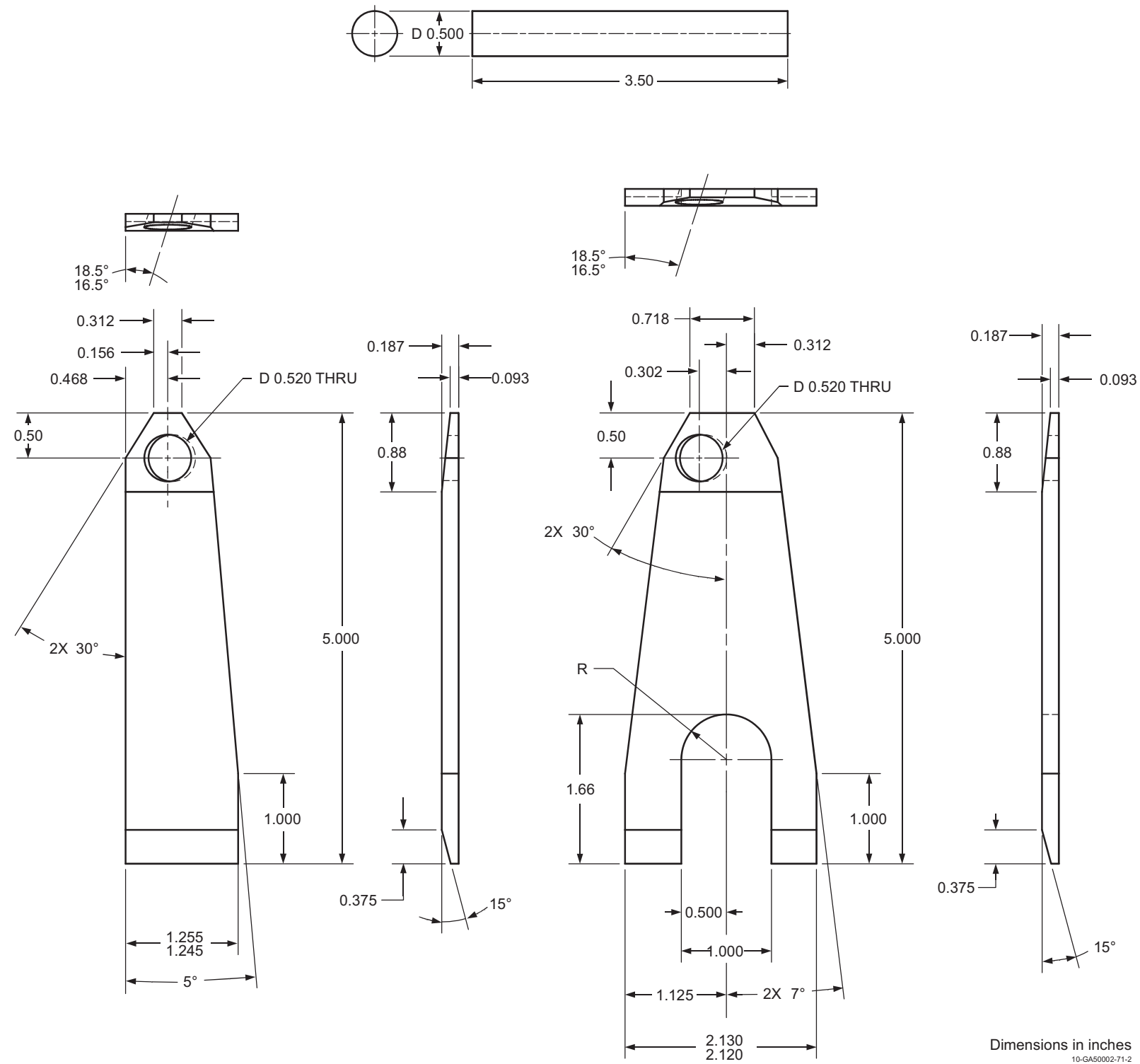

Figure 1.22b. Top Handle for C2, C4, and E4 Three Element Cluster Assembly. 


\section{NEA/NSC/DOC(2006)1}

Fundamental - FUND

NRAD-FUND-RESR-001 CRIT
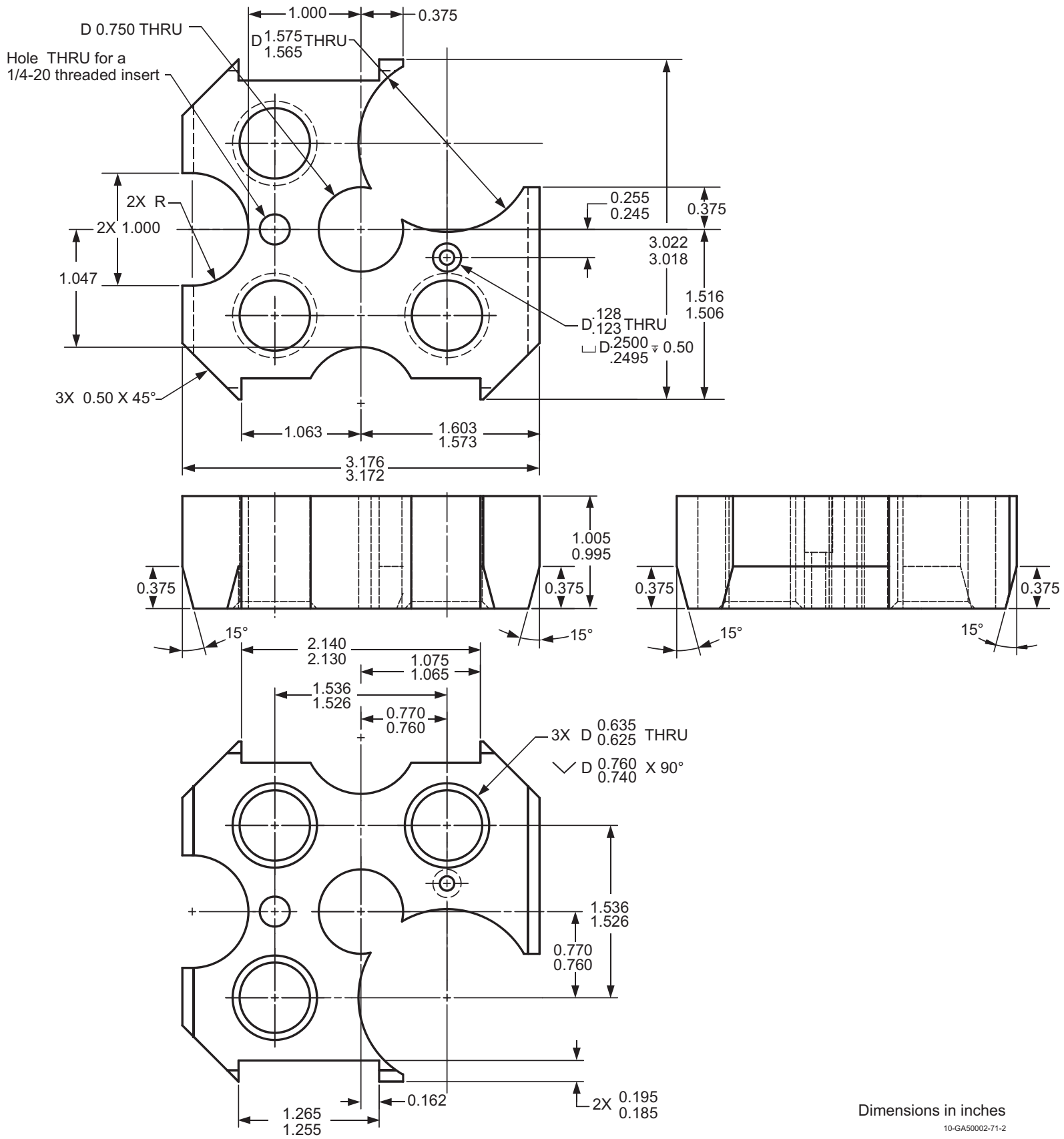

Figure 1.22c. Support Plate for D2 Three Element Cluster Assembly. 
NEA/NSC/DOC(2006)1

Fundamental - FUND

NRAD-FUND-RESR-001

CRIT
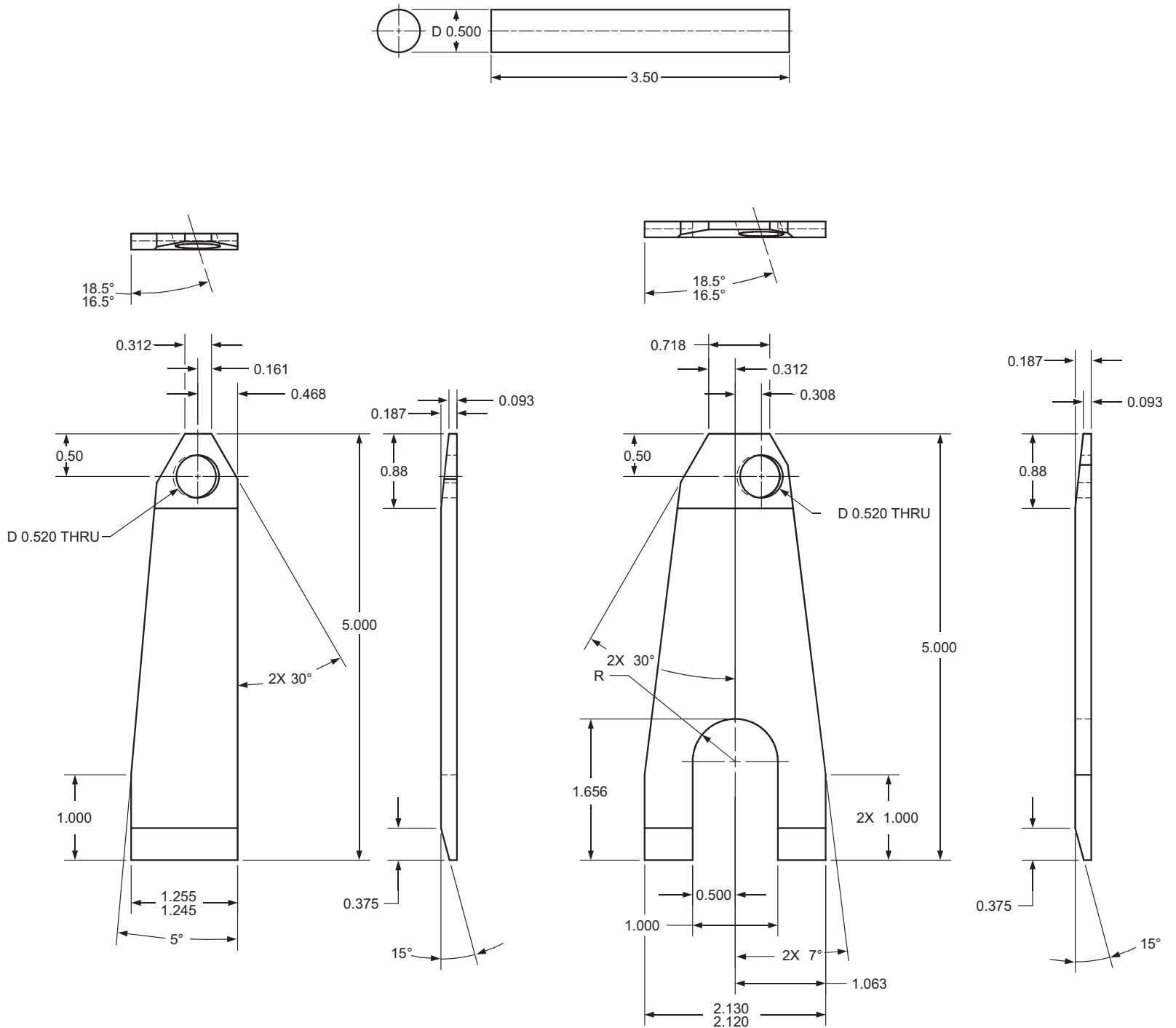

Dimensions in inches

Figure 1.22d. Top Handle for D2 Three Element Cluster Assembly. 
NEA/NSC/DOC(2006)1

Fundamental - FUND

NRAD-FUND-RESR-001

CRIT
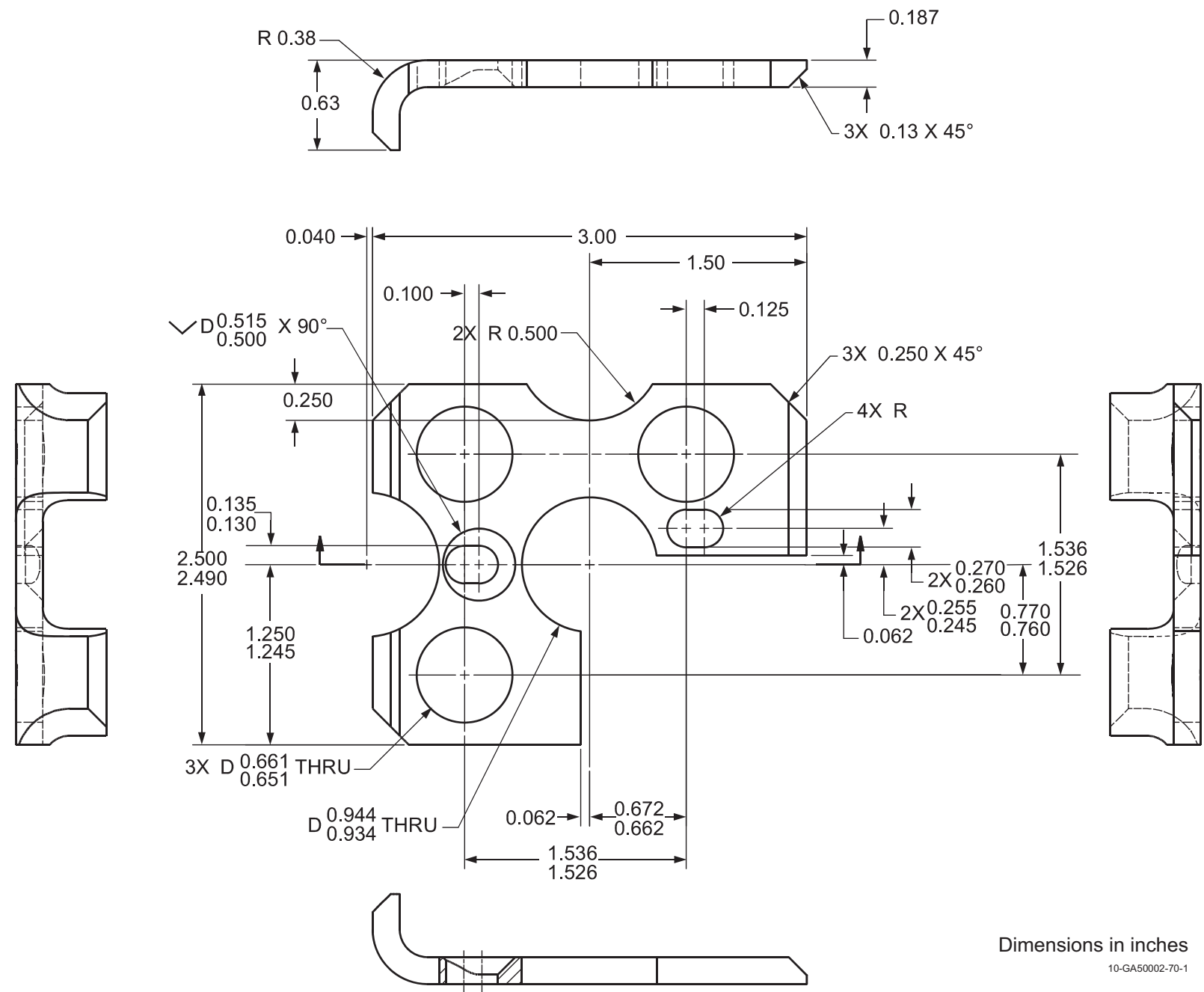

Figure 1.23a. Locking Plate for C2, C4, and E4 Three Element Cluster Assembly. 
NEA/NSC/DOC(2006)1

Fundamental - FUND

NRAD-FUND-RESR-001

CRIT
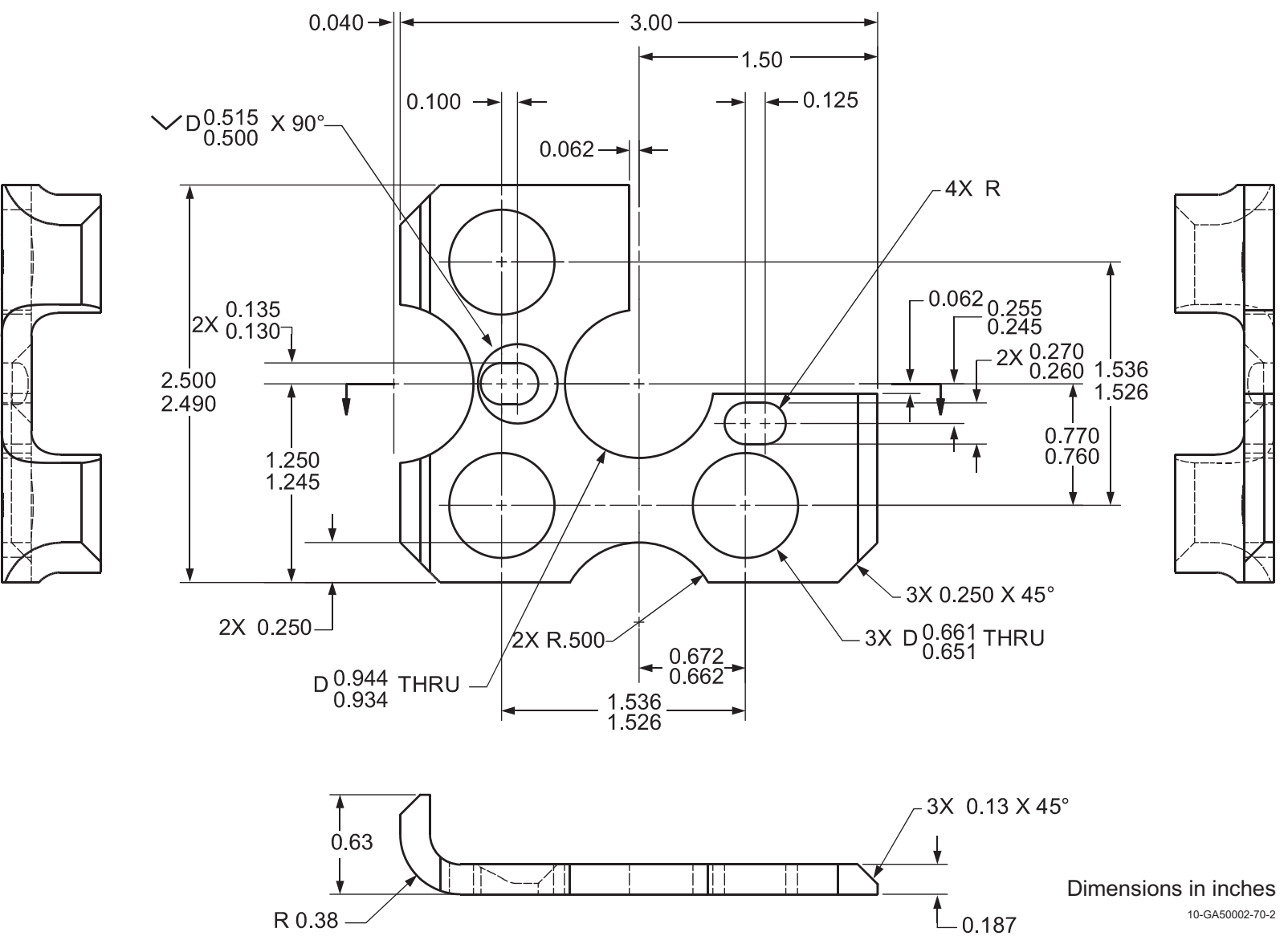

Figure 1.23b. Locking Plate for D2 Three Element Cluster Assembly. 


\section{Fuel Elements}

The fuel is a mixture of uranium, erbium, and zirconium hydride. The uranium is enriched to approximately $19.75 \%$ in ${ }^{235} \mathrm{U}$ and is approximately $30 \mathrm{wt} . \%$ of the fuel, thus the nomenclature TRIGA LEU (30/20). The elements contain a uniform dispersion of $0.9 \mathrm{wt} \%$ natural erbium that is used as a burnable poison to offset initial reactivity of the fresh fuel and contribute to the prompt negative temperature coefficient. A hole is drilled through the center of the active fuel section to facilitate hydriding of the fuel, and later filled with a zirconium rod. The zirconium rod provides structural support and prevents fuel damage during reactor operations due to fuel expansion. Finally they are clad with stainless steel. ${ }^{\mathrm{a}}$

A typical fuel element design is shown in Figure 1.24. The fuel element (sometimes referred to as rod) is comprised of three fuel pellets (Figure 1.25), with a zirconium rod in each (Figure 1.26), a molybdenum poison disc (Figure 1.27), and two graphite axial reflectors (Figure 1.28). These components are contained within stainless steel 304 cladding with welded top (Figure 1.29) and bottom (Figure 1.30) end fittings.

Typical design parameters for the LEU fuel to be used in the NRAD reactor are found in Tables 1.1 through 1.4. There are some discrepancies and duplication of data in these four tables. It should be noted that these parameters are typical for the TRIGA fuel used in the NRAD reactor and are reported in various documentation utilized with NRAD operations and analyses.

The gap between the fuel and cladding initially results in higher fuel temperatures for LEU TRIGA fuel. It closes over time due to burnup and fuel swelling due to fission product accumulation. ${ }^{\mathrm{b}}$

\footnotetext{
a "NRAD Reactor Fuel Core Conversion," DSA-005-NRAD-ADD-3 rev. 0, Idaho National Laboratory (April 2 , 2009). [This reference is not available for public release.]

${ }^{\mathrm{b}}$ Personal communication with John M. Bolin at General Atomics (April 22, 2010). 


\section{NEA/NSC/DOC(2006)1}

Fundamental - FUND

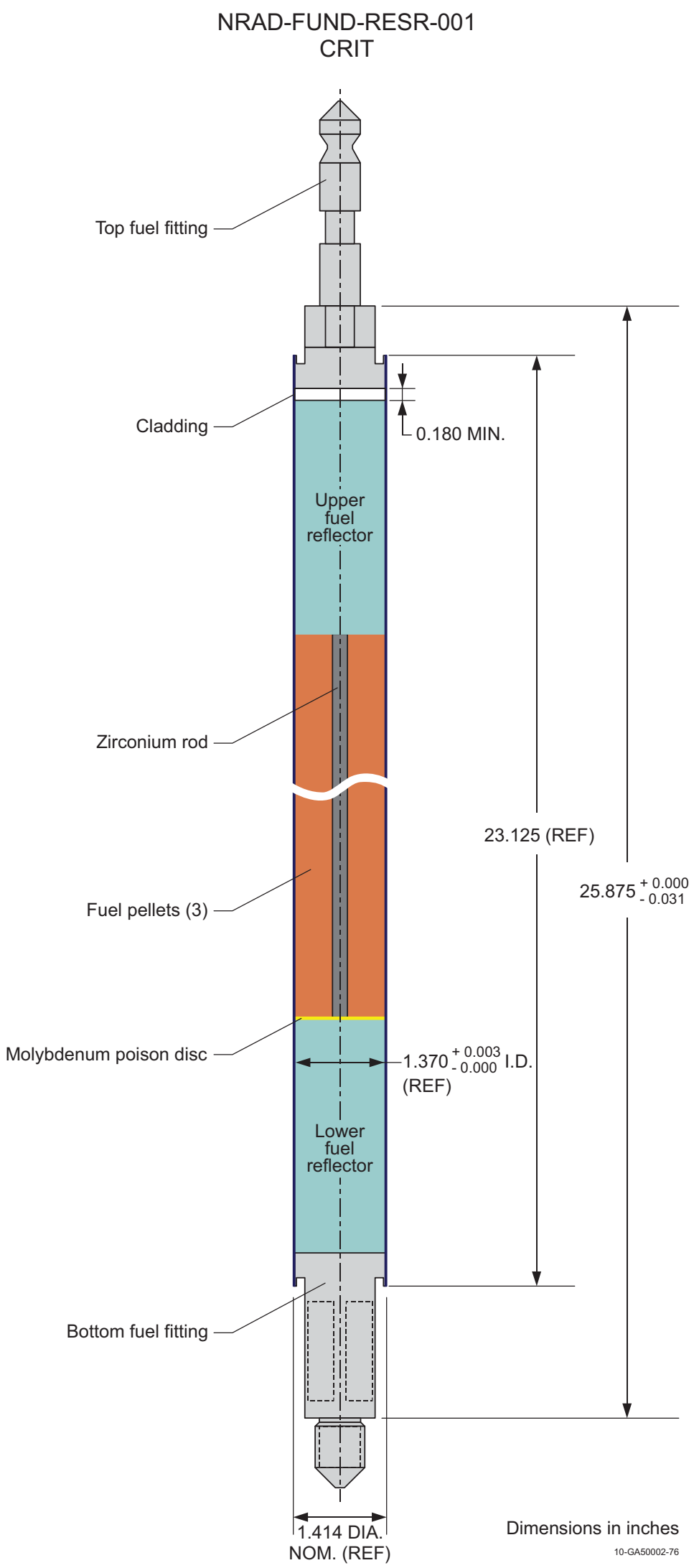

Figure 1.24. Typical TRIGA Fuel Element. 


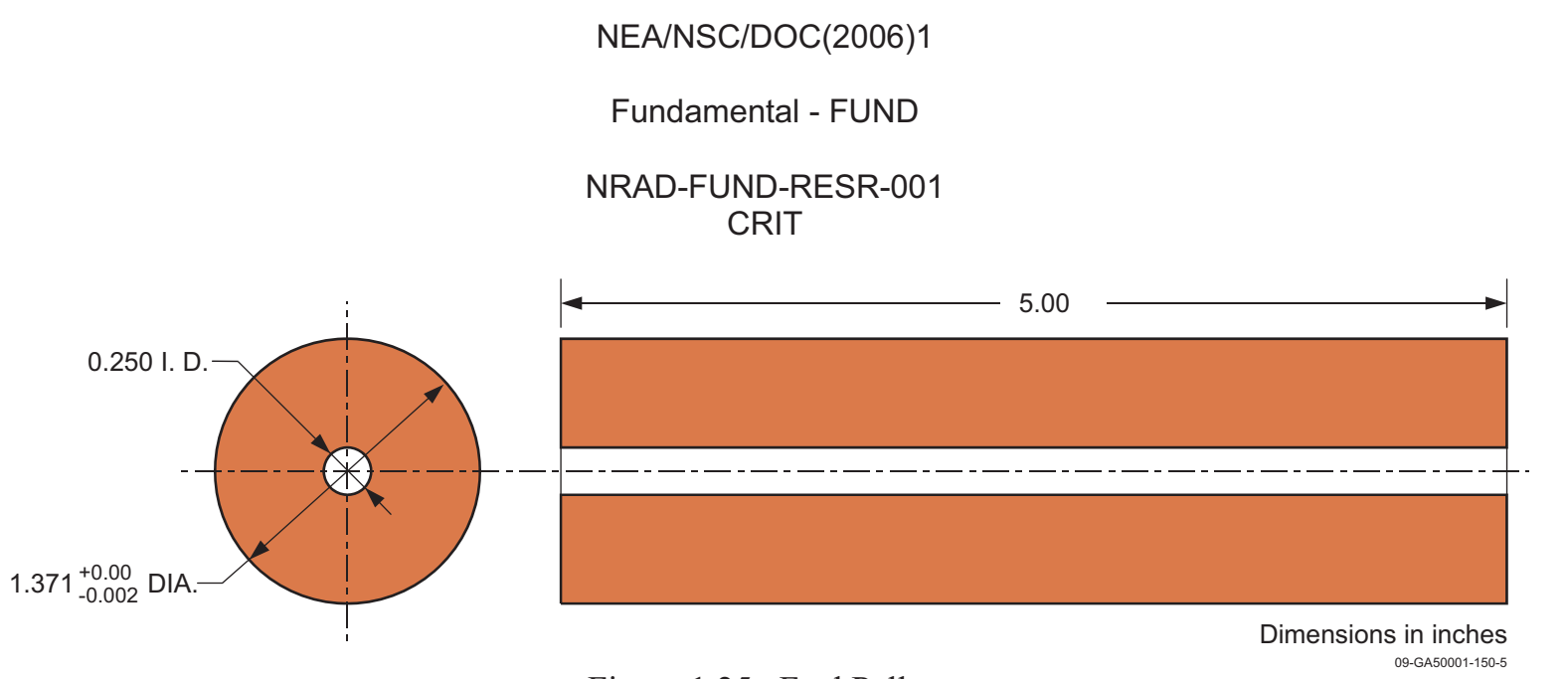

Figure 1.25. Fuel Pellet.

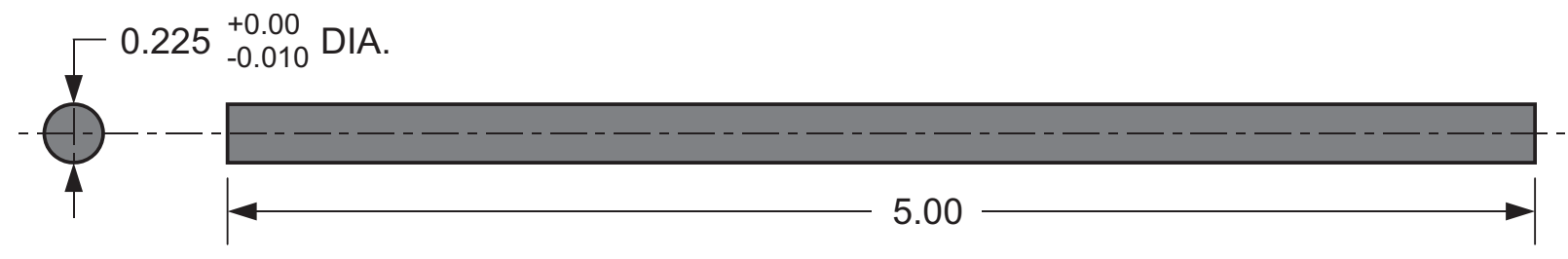

Dimensions in inches

Figure 1.26. Zirconium Rod.

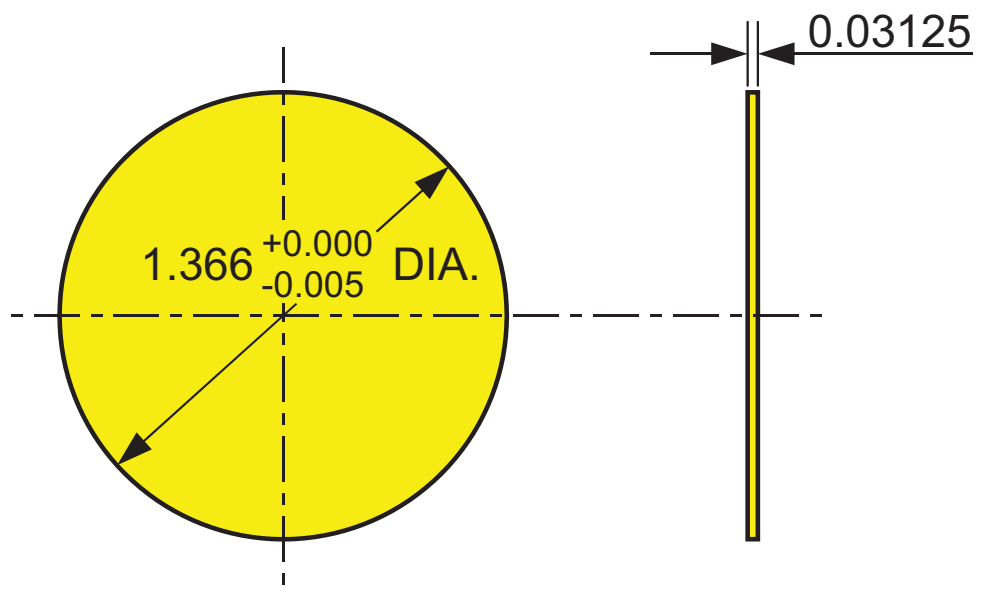

Dimensions in inches

09-GA50001-150-3

Figure 1.27. Molybdenum Poison Disc. 


\section{NEA/NSC/DOC(2006)1}

Fundamental - FUND

\section{NRAD-FUND-RESR-001}

CRIT

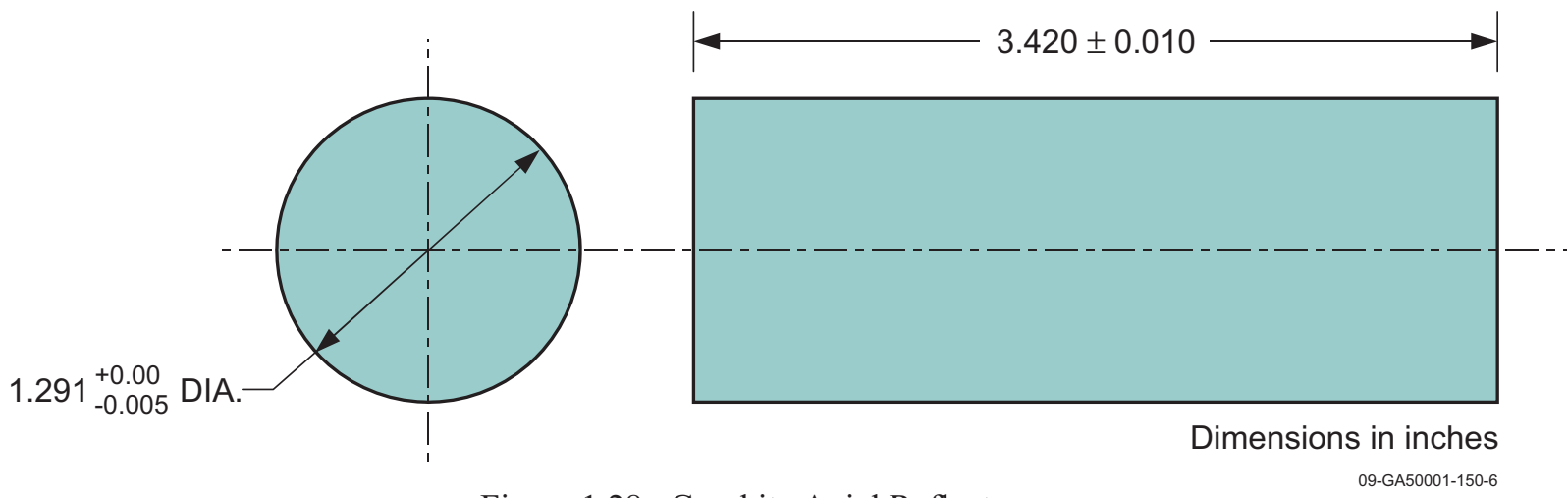

Figure 1.28. Graphite Axial Reflector.

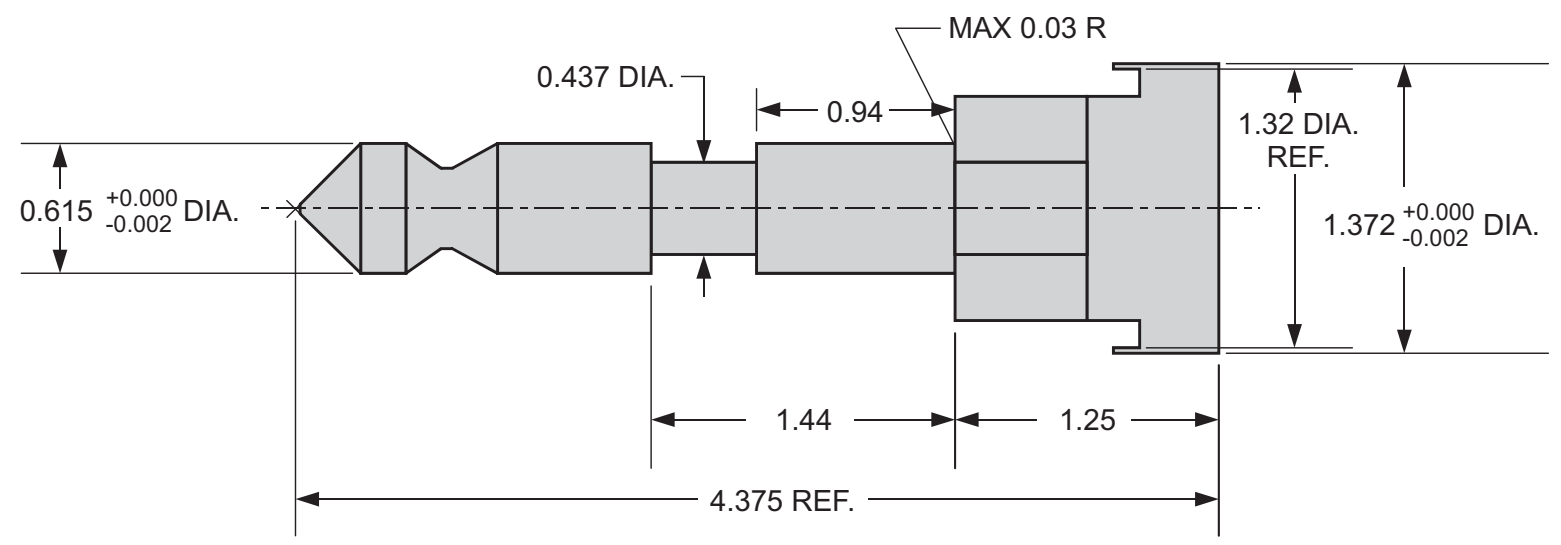

Dimensions in inches

Figure 1.29. Top Fuel Fitting.

09-GA50001-150-1

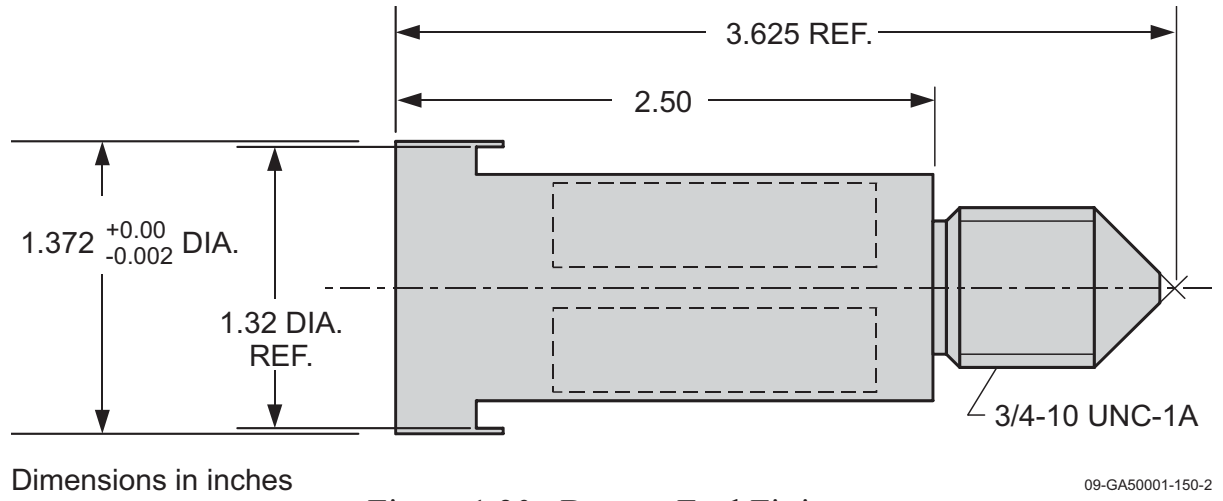

Figure 1.30. Bottom Fuel Fitting. 
NRAD-FUND-RESR-001

CRIT

Table 1.1. Typical Fuel (30/20) Element Specifications. ${ }^{(a)}$

\begin{tabular}{|c|c|}
\hline Uranium Content (wt.\%) & 30 \\
${ }^{235}$ U Enrichment (wt.\%) & 20 \\
Fuel Meat Length & 15 in. $(38.1 \mathrm{~cm})$ \\
Fuel Meat Outer Diameter & 1.371 in. $(3.48234 \mathrm{~cm})$ \\
Uranium Mass (g) & 750.16 \\
${ }^{235}$ U Mass (g) & 149 \\
Hydrogen to Zirconium Ratio & 1.6 \\
Erbium Content (wt.\%) & 0.8916 \\
Zirconium Rod Length & 15 in. $(38.1 \mathrm{~cm})$ \\
Zirconium Rod Diameter & 0.225 in. $(0.5715 \mathrm{~cm})$ \\
Overall Element Length & 30.13 in. $(76.5302 \mathrm{~cm})$ \\
Overall Element Outer Diameter & 1.48 in. $(3.7592 \mathrm{~cm})$ \\
Cladding Thickness & 0.02 in. $(0.0508 \mathrm{~cm})$ \\
Graphite Reflector Length (Top/Bottom) & 3.42 in. $(8.6868 \mathrm{~cm}) / 3.42 \mathrm{in} .(8.6868 \mathrm{~cm})$ \\
Graphite Reflector Outer Diameter & 1.291 in. $(3.27914 \mathrm{~cm})$ \\
Molybdenum Disc? & Yes \\
Number of U-Zr-H and Zr-Rod Sections & 3 \\
\hline \hline
\end{tabular}

(a) L. M. Montierth, "Criticality Safety Evaluation for the NRAD Core Conversion," INL/INT-07-13231 rev. 1, Idaho National Laboratory (September 2008). [This reference is not available for public release.] 
NEA/NSC/DOC(2006)1

Fundamental - FUND

NRAD-FUND-RESR-001

CRIT

Table 1.2. Typical NRAD LEU (30/20) Fuel Design Parameters. ${ }^{(a)}$

\begin{tabular}{|c|c||}
\hline Number of Fuel Elements & 60 \\
Fuel Type & UZrH-Er \\
Zirconium Rod Diameter & $5.715 \mathrm{~mm}$ \\
Fuel Meat Outer Diameter & $34.823 \mathrm{~mm}$ \\
Fuel Meat Length & $381 \mathrm{~mm}$ \\
Clad Thickness & $0.508 \mathrm{~mm}$ \\
Clad Material & $304 \mathrm{SS}$ \\
Total Uranium, wt.\% & 30.0 \\
Uranium Density, g/cm ${ }^{\mathbf{3}}$ & 2.14 \\
Weight of ${ }^{235} \mathbf{U}, \mathbf{g}$ & 149.32 \\
Weight of ${ }^{238} \mathbf{U}, \mathbf{g}$ & 599.33 \\
Uranium Enrichment, \% & 19.75 \\
Total Fuel Weight, $\mathbf{g}$ & 2519 \\
Erbium, wt.\% & 0.90 \\
\hline \hline
\end{tabular}

(a) "NRAD Reactor Fuel Core Conversion," DSA-005-NRAD-ADD-3 rev. 0, Idaho National Laboratory (April 2, 2009). [This reference is not available for public release.] 
NRAD-FUND-RESR-001

\section{CRIT}

Table 1.3. Additional NRAD LEU (30/20) Fuel Design Data. ${ }^{(a)}$

\begin{tabular}{|c|c||}
\hline Number of Fuel Elements - Critical Test & $53^{(\mathrm{b})}$ \\
Number of Fuel Elements - Full Load & 60 \\
Fuel Type & UZrH-Er (30/20) \\
Enrichment (\%) & 19.75 \\
Uranium Density (g/cm ${ }^{3}$ ) & 2.14 \\
Number of Fuel Elements per Cluster & 30 \\
${ }^{235}$ U per Fuel Cluster (g) & 4 \\
${ }^{235}$ U per Fuel Element (g) & 592.43 \\
${ }^{166}$ Er per Fuel Element (g) & 148.11 \\
${ }^{167}$ Er per Fuel Element (g) & 7.46 \\
Erbium Density (wt.\%) & 5.15 \\
Zirconium Rod Outer Diameter (in.) & 0.90 \\
Fuel Meat Inner Diameter (in.) & 0.225 \\
Fuel Meat Outer Diameter (in.) & 0.250 \\
Fuel Meat Length (in.) & 1.371 \\
Cladding Thickness (in.) & 15.0 \\
Cladding Material & 0.020 \\
\hline \hline
\end{tabular}

(a) "Neutron Radiography Reactor Analysis and Support: HEU to LEU Conversion of the NRAD Reactor, Final Report," 911124 rev. 2, GA Project 39296, TRIGA Reactor Division of General Atomics (February 12, 2010). [This reference is not available for public release.]

(b) This number is inconsistent with actual critical test results. 
NEA/NSC/DOC(2006)1

Fundamental - FUND

NRAD-FUND-RESR-001

CRIT

Table 1.4. Typical ${ }^{(\mathrm{a})}$ TRIGA (30/20) Fuel Design Parameters for Cluster Assemblies . ${ }^{(b)}$

\begin{tabular}{|c|c|}
\hline Catalog Number & 419 \\
\hline Drawing Number & T4S210D105 \\
\hline Fuel Length & 15 in. $(38.1 \mathrm{~cm})$ \\
\hline Fuel Outer Diameter & 1.37 in. $(3.4798 \mathrm{~cm})$ \\
\hline Uranium Content (wt.\%) & $30^{(\mathrm{c})}$ \\
\hline Uranium mass (g) & 710 \\
\hline${ }^{235}$ U Enrichment (wt.\%) & $20^{(\mathrm{d})}$ \\
\hline${ }^{235} \mathrm{U}$ mass $(\mathrm{g})$ & 141 \\
\hline Hydrogen to Zirconium Ratio & $1.6^{(\mathrm{e})}$ \\
\hline Erbium Content (wt.\%) & $0.9^{(\mathrm{f})}$ \\
\hline Zirconium Rod Length & 15 in. $(38.1 \mathrm{~cm})^{(\mathrm{g})}$ \\
\hline Fuel Element Overall Length & 30.13 in. $(76.5302 \mathrm{~cm})$ \\
\hline Fuel Element Overall Outer Diameter & 1.41 in. $(3.5814 \mathrm{~cm})$ \\
\hline Cladding Thickness & 0.02 in. $(0.0508 \mathrm{~cm})$ \\
\hline End Fitting Type & Threaded \\
\hline Graphite Reflector Length (Top/Bottom) & 2.6 in. $(6.604 \mathrm{~cm}) / 3.4$ in. $(8.636 \mathrm{~cm})$ \\
\hline Graphite Reflector Outer Diameter & 1.3 in. $(3.302 \mathrm{~cm})$ \\
\hline Molybdenum Disc & Yes \\
\hline Samarium Trioxide Disc & No \\
\hline Number of U-Zr-H and Zr-Rod Sections & 3 \\
\hline Molybdenum Disc Thickness & 0.031 in. $(0.07874 \mathrm{~cm})$ \\
\hline
\end{tabular}

(a) Variations from these typical listings do exist.

(b) R. E. Smith, "TRIGA Fuel Summary Report," ICP/INT-05-817, Idaho Cleanup Project, Idaho National Laboratory (March 2005). [This reference is not available for public release.]

(c) The nominal value of uranium content is 28.5 to $31.5 \mathrm{wt} . \%$ for a single fuel meat and 29.65 to $30.35 \mathrm{wt} . \%$ for a fuel rod assembly.

(d) The ${ }^{235} \mathrm{U}$ enrichment is between 19.5 and $19.99 \mathrm{wt} . \%$ for all fuel meat.

(e) The fuel element average range of acceptance for the $\mathrm{H} / \mathrm{Z}$ atom ratio is 1.57 to 1.65 . Meats in the range of 1.66 to 1.70 may be used if installed as the top or bottom meat in a fuel rod assembly. The average $\mathrm{H} / \mathrm{Zr}$ ratio for a fuel rod shall not exceed 1.65.

(f) Fuel erbium content is specified on a per-order basis, which is considered the nominal value. The content in an individual fuel meat is restricted to within $+10 \%$ and $-15 \%$ of the nominal value. A single element is restricted to between $+5 \%$ and $-10 \%$. A cluster of fuel elements (containing either 3 or 4 rods) is restricted between $+3 \%$ and $-6 \%$. Finally, the core content is to remain between $+0 \%$ and $-3 \%$ of the nominal erbium content.

(g) The length of the zirconium rod is always the same length as the fuel segments. 
NEA/NSC/DOC(2006)1

Fundamental - FUND

NRAD-FUND-RESR-001

CRIT

\section{Control Rods}

The NRAD reactor uses PRNC-type control rods, control-rod drives, and instrument console. It is controlled by three boron-carbide cylindrical control rods (two shim rods and one regulating rod). All three control rods are supported from the bridge structure located at the top of the reactor tank and are water-followed when withdrawn from the core. ${ }^{\text {a }}$

Positions of the control rods are shown in Figure 1.6. The shim control rods are in positions D-2 SE and C-2 NE. The regulating control rod is located in position E-4 NE. Any one control rod can shut down the reactor.

The control elements for the NRAD reactor can be either the original PRNC control rods with $0.5 \mathrm{MW}-$ year of operation or new ones purchased from General Atomics with the same part number as those used

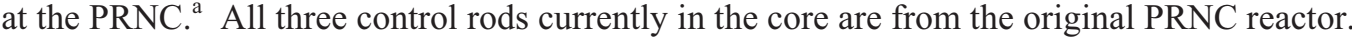

Each control rod consists of a boron carbide $\left(\mathrm{B}_{4} \mathrm{C}\right)$ poison section that is $15 \mathrm{in} .(38.1 \mathrm{~cm})$ long and 1.19 in. $(3.0226 \mathrm{~cm})$ in diameter contained within an aluminum 6061-T6 tube 24 in. $(60.96 \mathrm{~cm})$ long with an outer diameter of $1.25 \mathrm{in} .(3.175 \mathrm{~cm})$ and a wall thickness of $0.028 \mathrm{in} .(0.07112 \mathrm{~cm})$. The container has a $1 / 2 \times 13$ threaded connection on the upper end for attachment to an extension rod. A diagram of the control rod is shown in Figure 1.31. ${ }^{\mathrm{a}}$

Full travel of an NRAD control rod is 15 in. $(38.1 \mathrm{~cm})$. The rod position indication displays 0-1000 units of travel from a down limit switch to the up limit switch, respectively. Each unit of display is equal to 0.015 in. $(0.0381 \mathrm{~cm})$ of rod travel. A good confidence band $(3 \sigma)$ for knowing the location of the control rod is \pm 4 units $(0.06$ in., $0.1524 \mathrm{~cm})$. The drive travel in the reactor room was physically measured and validated that the full travel length is 15 in. The digital position indication is adjusted at the zero, down limit, and again at 1000 units, or the upper limit, using potentiometers on the back of the reactor console. As much as -3 units to zero units at the lower limit and 999 or 1000 units at the upper limit is allowed.

Control rod position data are obtained from a potentiometer connected to the drive pinion. Limit switches are provided to indicate the up and down positions of the magnet, and magnet contact with the control rod..$^{\mathrm{c}}$

The bottom of the control rod is $0.75 \mathrm{in} .(1.905 \mathrm{~cm})$ above the inside bottom of the control rod guide tube when the control rod is completely inserted. The bottom end of a control rod is shown in Figure 1.32.

\footnotetext{
a "NRAD Reactor Fuel Core Conversion," DSA-005-NRAD-ADD-3 rev. 0, Idaho National Laboratory (April 2, 2009). [This reference is not available for public release.]

${ }^{b}$ Personal communication with Ken Schreck at HFEF (April 5-6, 2010).

c "HFEF/N Neutron Radiography Facility System Design Description,” W0170-0004-SA rev. 2, Idaho National Laboratory (June 1, 1978). [This reference is not available for public release.]
} 


\section{NEA/NSC/DOC(2006)1}

Fundamental - FUND

NRAD-FUND-RESR-001 CRIT

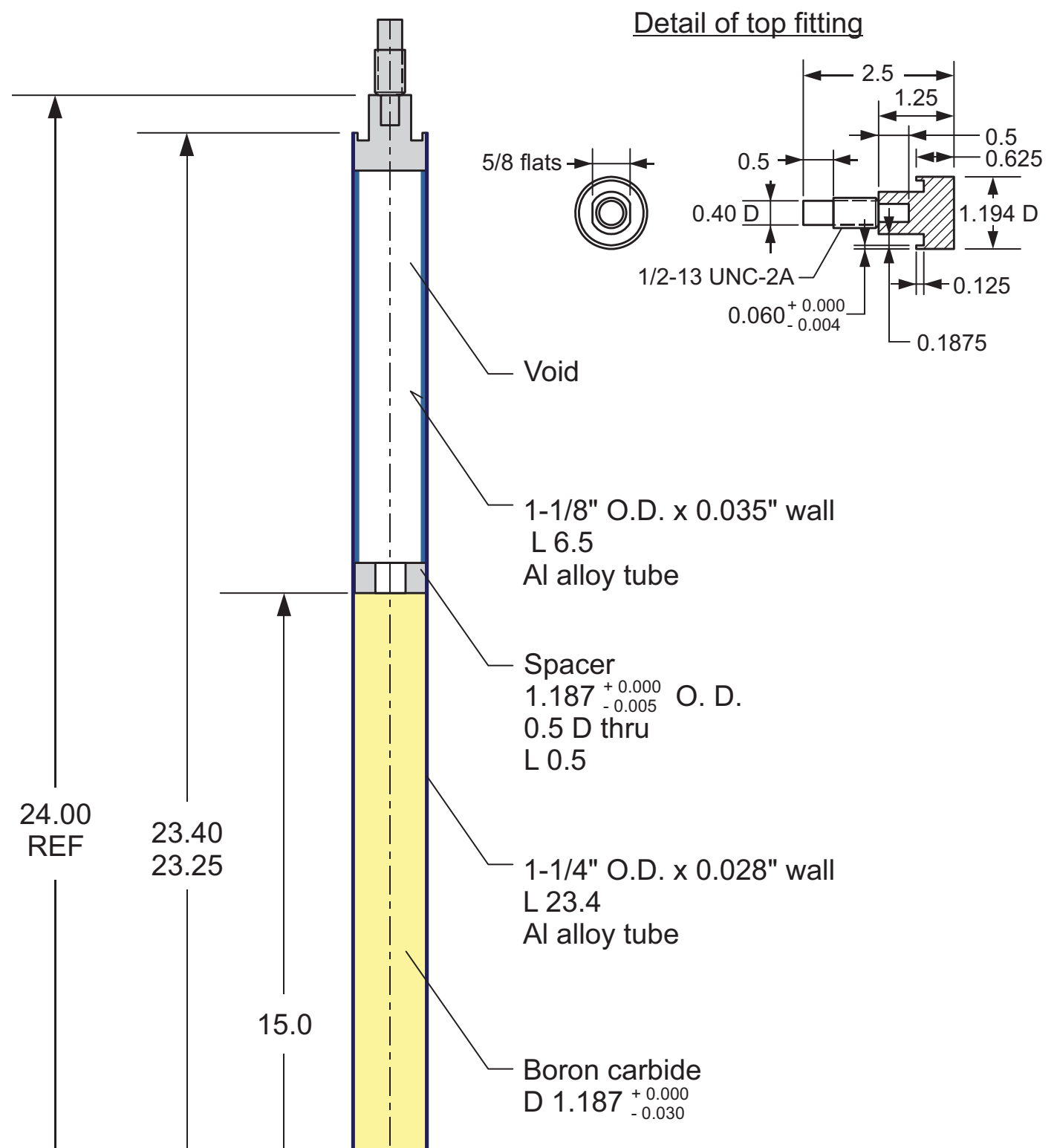

\section{Detail of bottom fitting}

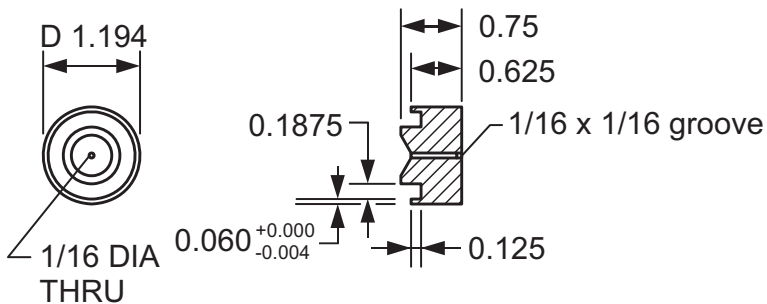

Dimensions in inches

Figure 1.31. NRAD Control Rod. 


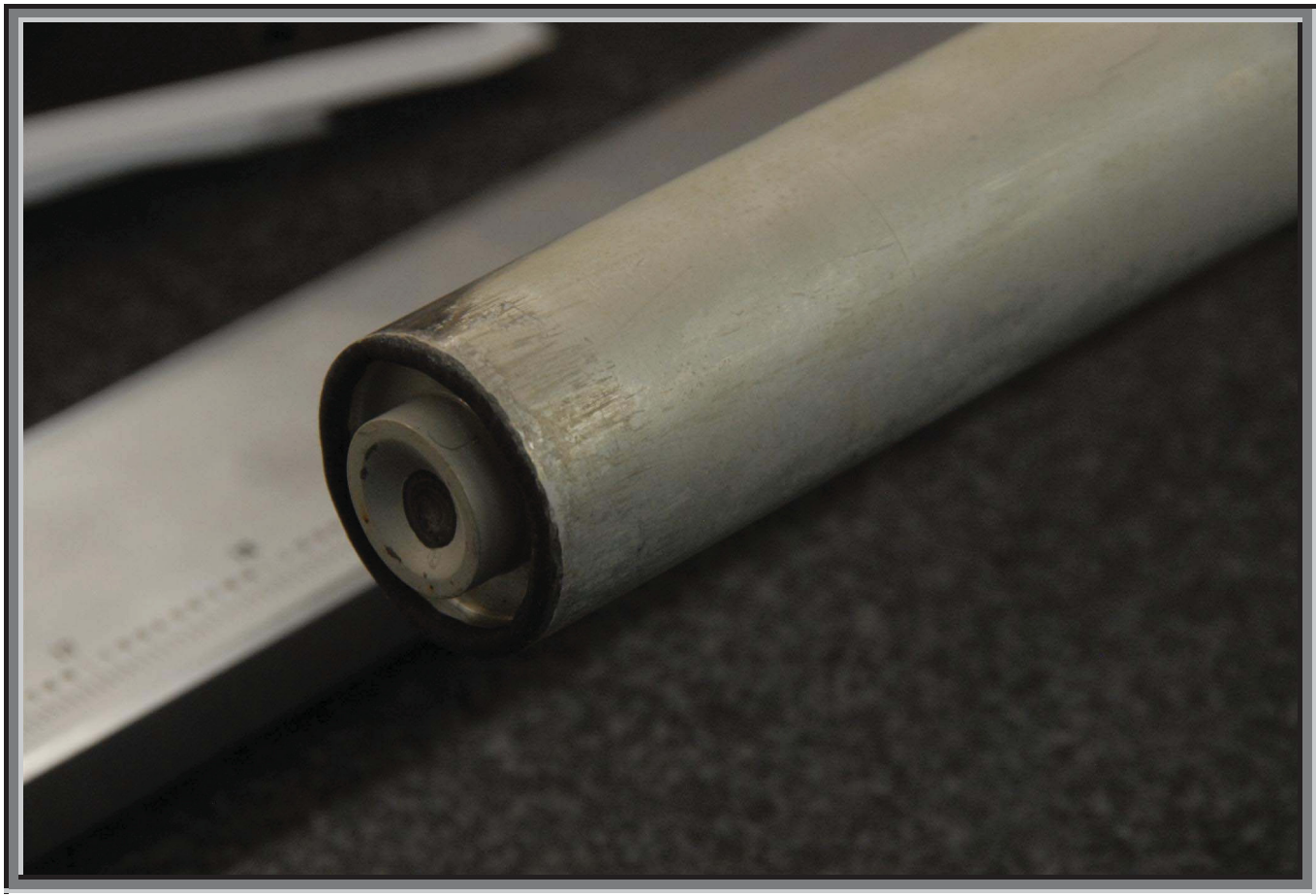

Figure 1.32. Bottom of Control Rod.

An aluminum extension, or connection, rod is attached to the control rod, connecting it to the driveline, control rod drive, instrumentation, and support structure located above the reactor core and tank. The extension rod is 33.750 in. $(85.725 \mathrm{~cm})$ long and is a tube with an outer diameter of $0.875 \mathrm{in} .(2.2225 \mathrm{~cm})$ and an inner diameter of $0.635 \mathrm{in} .(1.6129 \mathrm{~cm})$. The assembly interface of the extension rod to the control rod is depicted in Figure 1.33 and a photograph of the interface is shown in Figure 1.34.

A guide tube placed into the three fuel element cluster assemblies is used to direct the vertical movement of the control rod. Figure 1.35 shows the guide tube and Figures 1.19 and 1.20 demonstrate how the guide tube is placed into the three fuel element cluster assembly. New guide tubes were fabricated in 2009.

Assembly 2 in Figure 1.35 shows how the weldment goes together, representing an intermediate step in the construction process of the guide tube. Once the tube is connected to the fitting, it is turned and pulled. A 0.1875 in. $(0.47625 \mathrm{~cm})$ diameter, 1.5 in. $(3.81 \mathrm{~cm})$ long, $18-8$ stainless steel dowel pin holds the guide tube base and bottom adapter together.

An empty guide tube is used to guide experiments into an irradiation position in the core. 


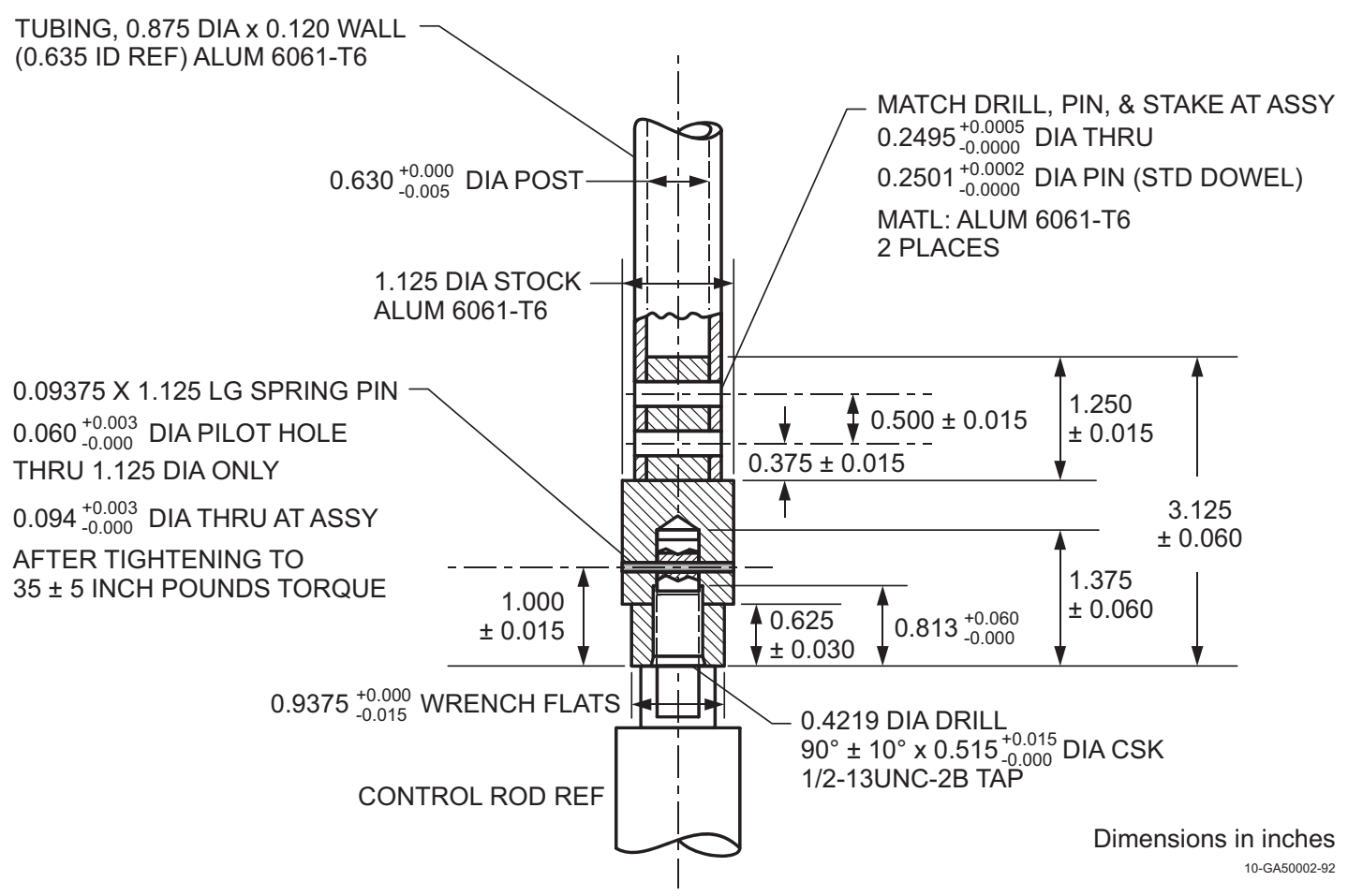

Figure 1.33. Interface between Control Rod and Extension Rod.

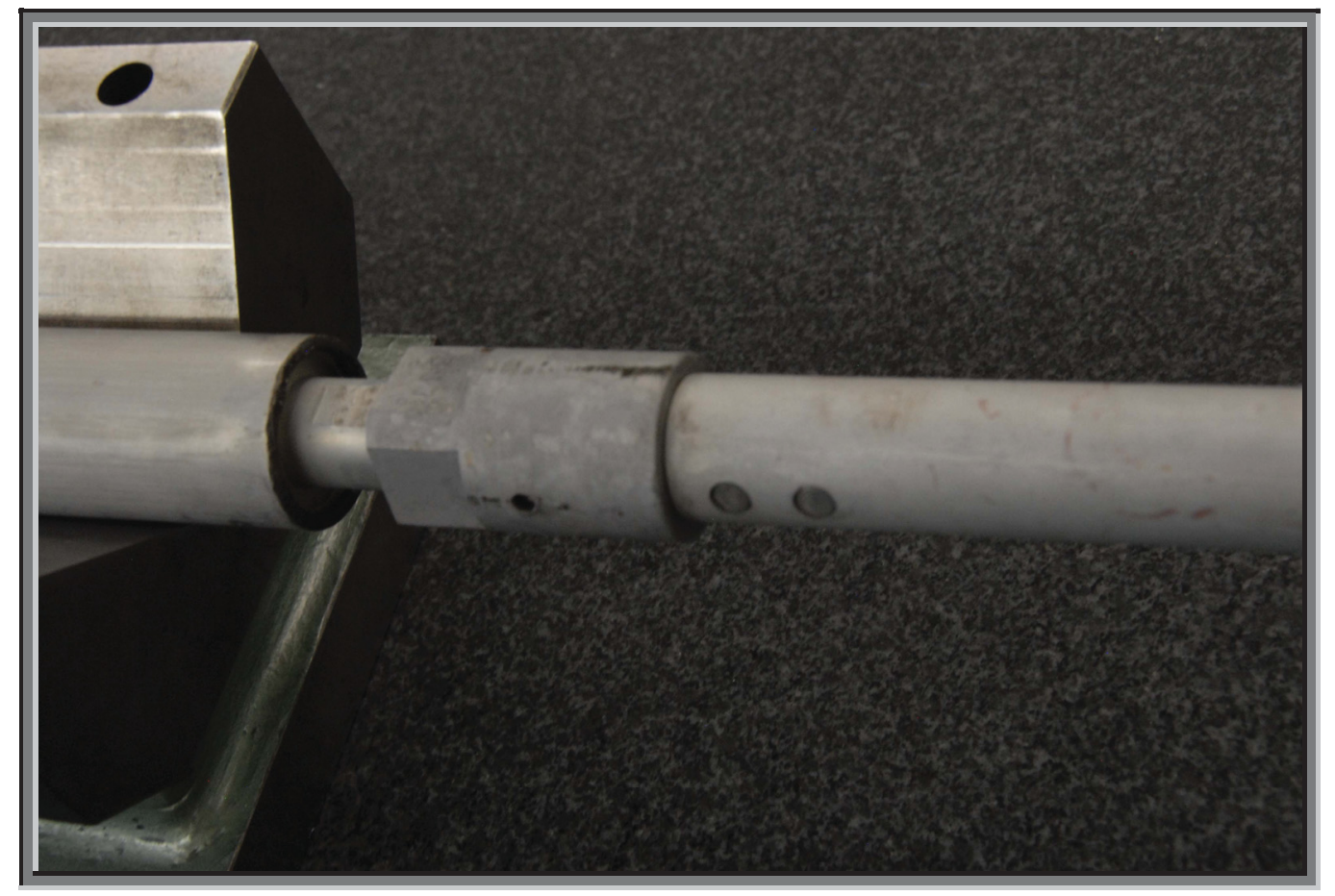

Figure 1.34. Interface between Control Rod and Extension Rod. 


\section{NEA/NSC/DOC(2006)1}

Fundamental - FUND

\section{NRAD-FUND-RESR-001 \\ CRIT}
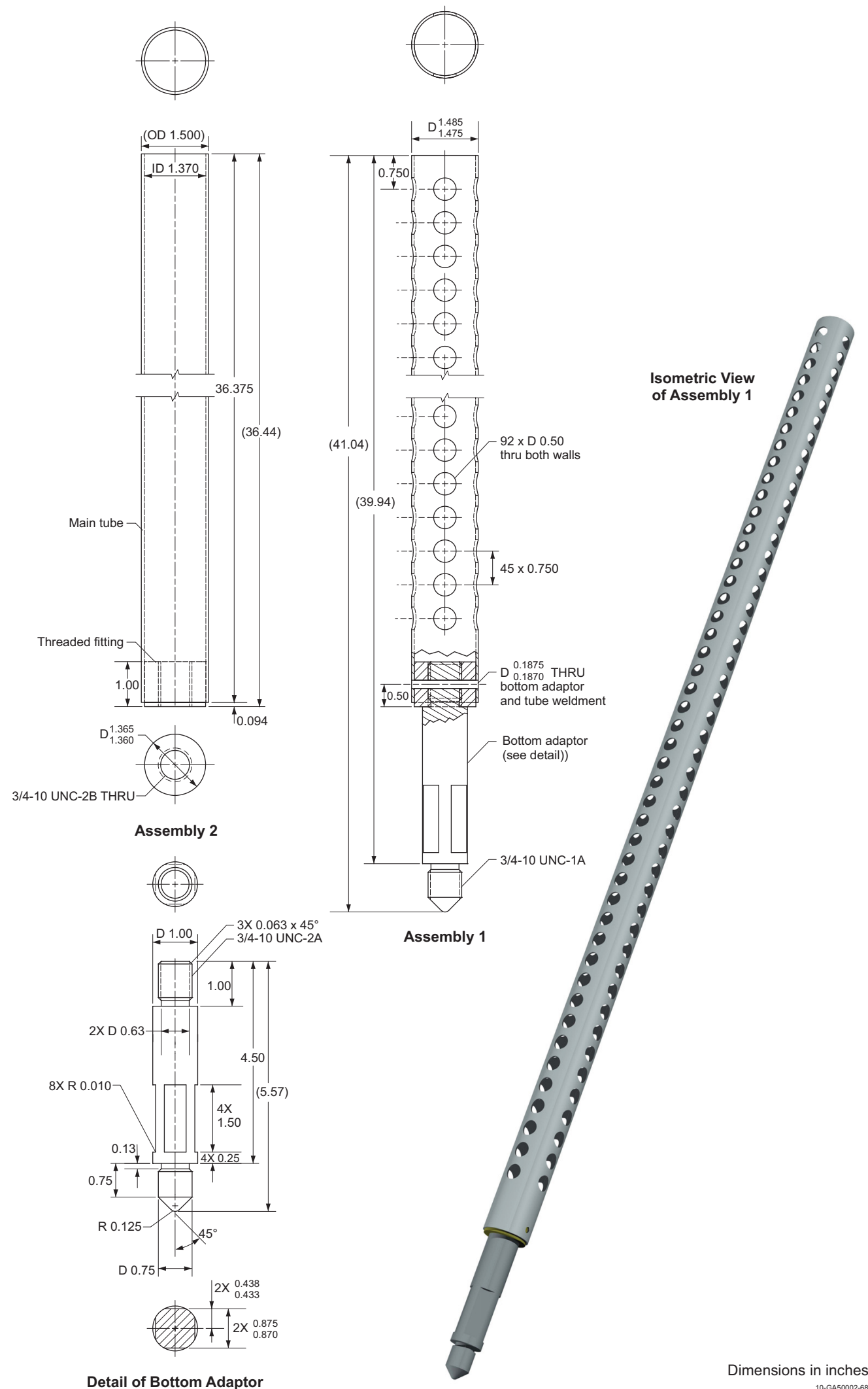

Detail of Bottom Adaptor

Figure 1.35. Control Rod Guide Tube. 


\section{Graphite Reflector Assembly}

Graphite reflector assemblies are located in the periphery grid plate locations. The top and bottom of each reflector assembly have adapters for handling and insertion into the core grid plate. The assemblies, as shown in Figure 1.36, are 25.9 in. $(65.786 \mathrm{~cm})$ long and have a horizontal cross section in a square shape, with each side of the square 2.9 in. $(7.366 \mathrm{~cm})$ in length. ${ }^{\mathrm{a}}$

Dimensions of the graphite block are shown in Figure 1.37. The top cast assembly fitting is shown in Figure 1.38. The bottom fitting was actually replaced with those used for the fuel assemblies, shown in Figure 1.14. The assembly fittings are attached to the graphite blocks using aluminum 2011-T3 socket head cap screws, tie rod, and stud, as shown in Figure 1.36.

Photographs of unmachined graphite identical to that used in the NRAD graphite assemblies are shown in Figure 1.39.

\footnotetext{
a “HFEF/N Neutron Radiography Facility System Design Description,” W0170-0004-SA rev. 2, Idaho National Laboratory (June 1, 1978). [This reference is not available for public release.]
} 
NEA/NSC/DOC(2006)1

Fundamental - FUND

NRAD-FUND-RESR-001

CRIT

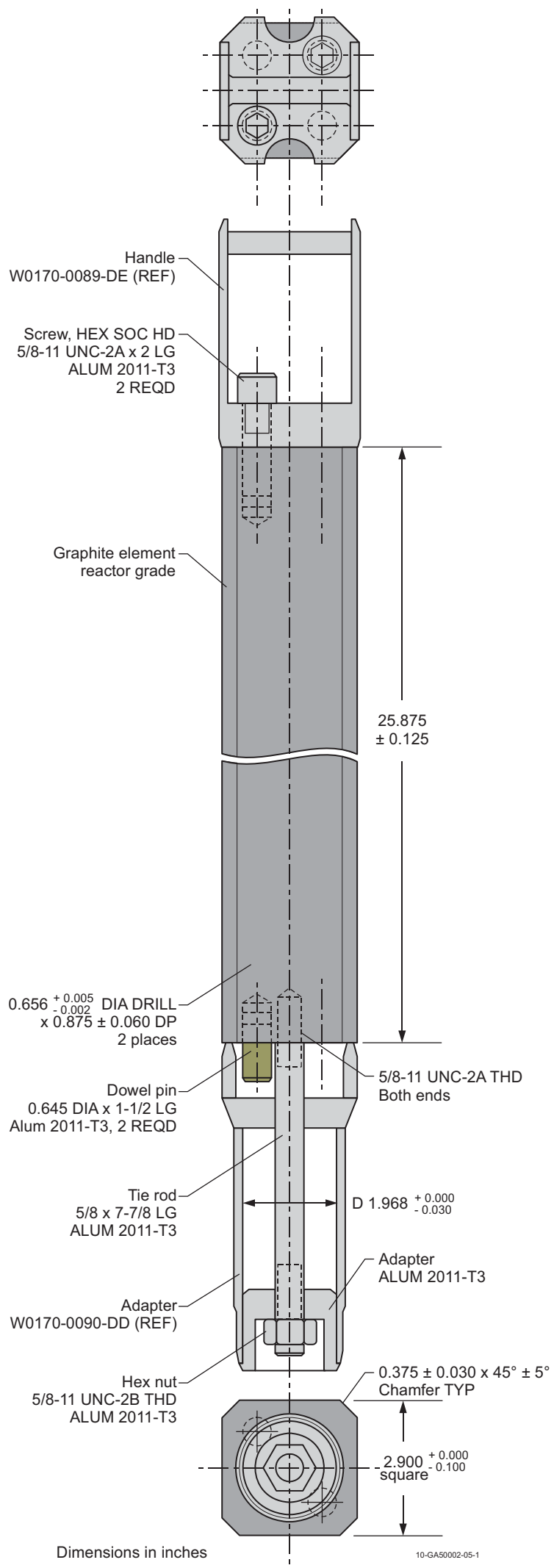

Figure 1.36. NRAD Graphite Reflector Assembly. 


\section{NEA/NSC/DOC(2006)1}

Fundamental - FUND

\section{NRAD-FUND-RESR-001} CRIT

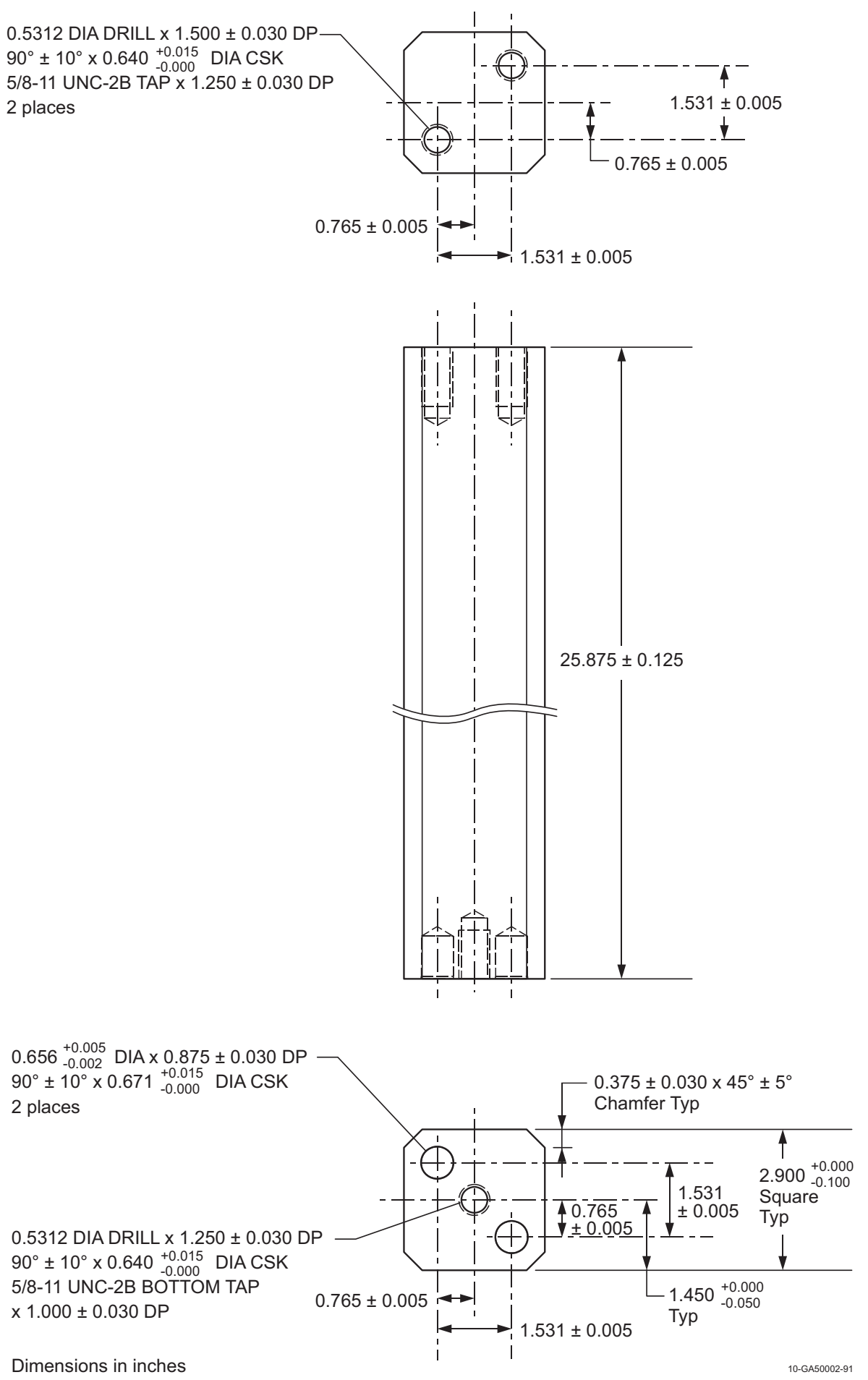

Figure 1.37. Graphite Reflector Block. 
NEA/NSC/DOC(2006)1

Fundamental - FUND

NRAD-FUND-RESR-001

CRIT
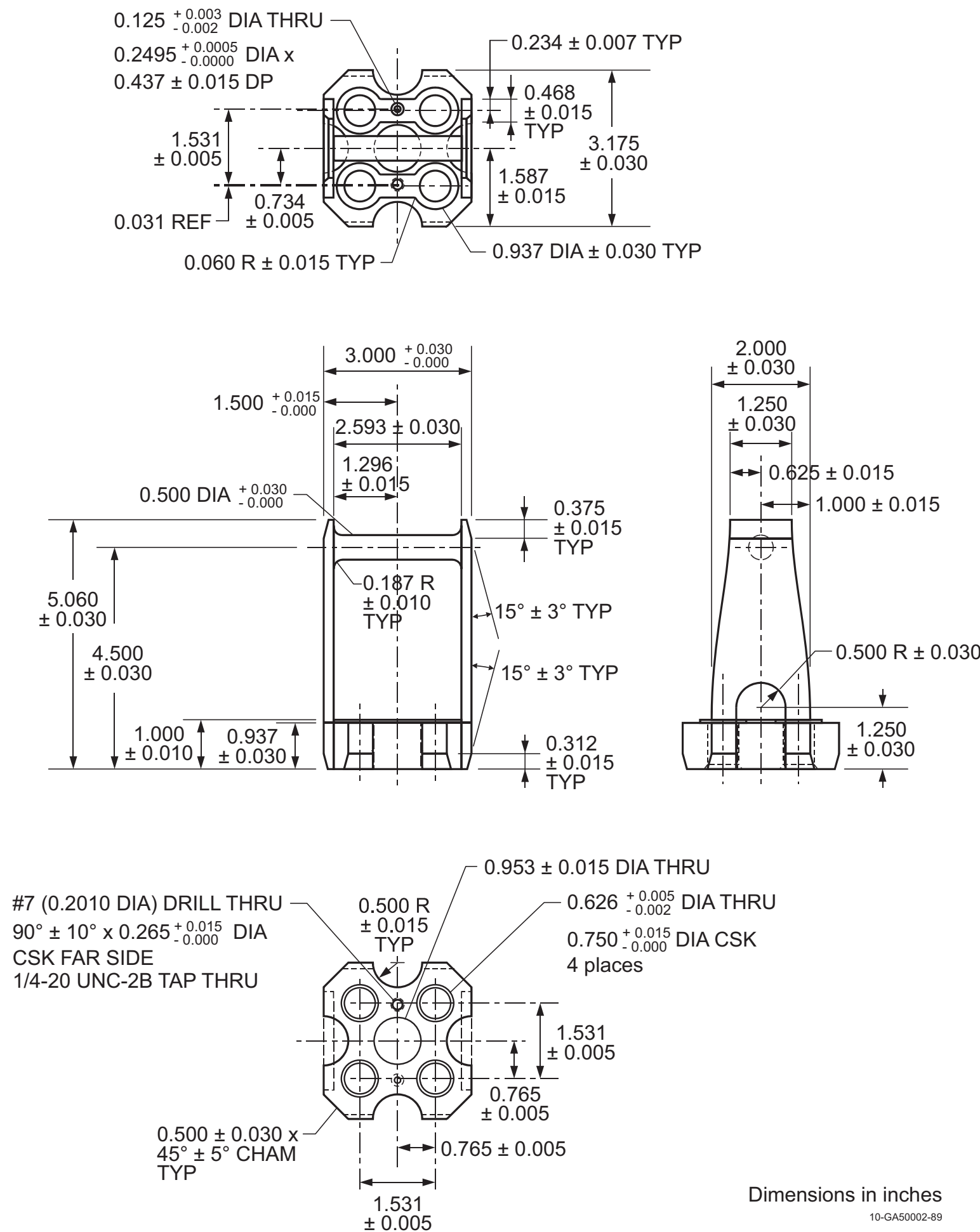

Figure 1.38. Graphite Reflector Top Assembly. 
NEA/NSC/DOC(2006)1

Fundamental - FUND

NRAD-FUND-RESR-001

CRIT
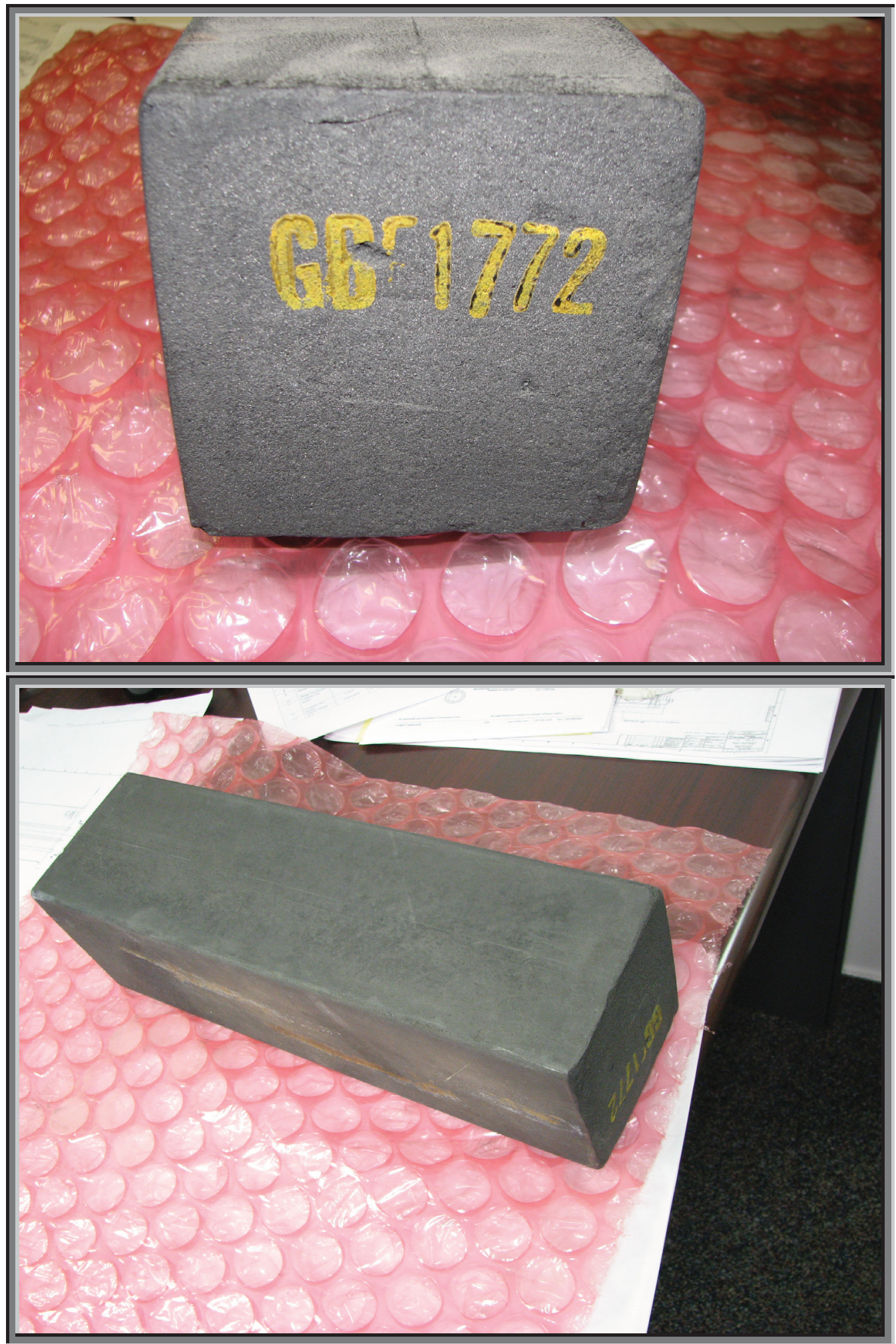

Figure 1.39. Unfinished Graphite Reflector Block. 
NEA/NSC/DOC(2006)1

Fundamental - FUND

NRAD-FUND-RESR-001

CRIT

\section{Beam Ports}

The NRAD reactor services two radiography stations, as shown in Figures 1.2 through 1.4. The main radiography station is used to neutron-radiograph highly irradiated fuel elements, fuel assemblies, and loop experiments, which might chemically react with air. This station is located within HFEF's main cell, which contains argon atmosphere. The second neutron radiography station is located outside of the main cell, allowing for the irradiation of either irradiated or unirradiated specimens.

The two beam tubes are positioned to the North (to secondary station) and East (to main station) sides of the reactor core. The in-tank portion of the beam lines includes a beam-filter tube and an aperture mechanism that excludes water from the neutron path. A through-the-wall collimator encased in the concrete of the reactor-room shielding and walls then extends from the reactor tank to the radiography station. $^{\text {a }}$

The in-tank portion of the East beam line (Figure 1.40) is an air-filled aluminum tube extending from the reactor core to the reactor tank wall. The aperture mechanism (Figure 1.41) is placed approximately midway and is housed in a water-tight aluminum box, sealed at the top, and extends upward to the top shield. This housing contains the aperture elements and remotely operated mechanism for changing the size of the aperture. The beam filter tube that extends from the core to the aperture mechanism is removable, to allow for loading of additional filter material when required. It is usually filled with helium. The inner end of the tube extends to about $0.8 \mathrm{in} .(2.032 \mathrm{~cm})$ from the outermost fuel elements. ${ }^{\text {a }}$

The beam-filter tube (Figure 1.42) is rectangular in cross section. Clamp rails force the beam-filter tube into intimate contact with the window of the aperture housing, leaving just a thin film of water along the interface. A bolted flange at the top of the tube allows access for loading. The bottom of the aperture housing extends to the tank floor to provide additional support. The source tube then extends from the aperture mechanism to the tank wall, where the flange on the source tube is sealed to the flange of the nozzle welded to the tank wall. The nozzle is equipped with gas-purge fittings to remove water from the tube after any operations requiring the removal and reinstallation of the aperture housing. The fittings also allow for maintenance of a helium-filled atmosphere. A Boral lining, 0.265-inch-(.6731-cm)-thick, is provided to minimize neutron scatter and monitor seal leakage. ${ }^{\mathrm{b}}$

The beam-filter tubes are also referred to as "wet packages" when referenced in reactor operations.

Figure 1.3 provides the general layout of a beam line in the NRAD reactor facility.

A $55 \mathrm{ft}(16.764 \mathrm{~m})$ helium-filled beam tube extends from the north face of the reactor to the secondary radiography station. The aperture mechanism is identical to that of the east beam tube with different neutron beam length/diameter $(\mathrm{L} / \mathrm{D})$ ratios because of the difference in beam tube length. ${ }^{\mathrm{a}}$

The aperture mechanism provides control of some neutron beam properties. The smaller the aperture, the sharper the definition of the neutron radiograph (with longer exposure time required). There are three apertures: 3.5 in. $(8.89 \mathrm{~cm})$ with an $\mathrm{L} / \mathrm{D}$ of $50,1.39$ in. $(3.5306 \mathrm{~cm})$ with an $\mathrm{L} / \mathrm{D}$ of 125 , and 0.59 in. $(1.4986 \mathrm{~cm})$ with an $\mathrm{L} / \mathrm{D}$ of 300 . The two smaller apertures are located in a movable aperture block (Figure 1.43) while the largest aperture is in a fixed block (Figure 1.44) that is uncovered when the movable block is driven up out of the way. Both movable and fixed blocks are made from boron nitride. ${ }^{b}$

\footnotetext{
a “NRAD Safety Analysis Report,” DSA-005-NRAD rev. 5, Idaho National Laboratory (April 2, 2009). [This reference is not available for public release.]

b "HFEF/N Neutron Radiography Facility System Design Description,” W0170-0004-SA rev. 2, Idaho National Laboratory (June 1, 1978). [This reference is not available for public release.]
} 
The movable aperture block is held within an aperture assembly (Figure 1.45) and is vertically supported by an aperture block guide (Figure 1.46) and aligned with an aperture block adjusting screw (Figure 1.47). A lower tube seal plate (Figure 1.48) is used for the fixed block disc aperture.

The L/D ratios for the North beam tube are 185, 300, and 700 for the same aperture dimensions as the East beam tube. ${ }^{a}$

Graphite reflector assemblies are not used in the center East and North sides of the core to allow closer access to the fuel, as shown in Figure 1.6. These positions (A-3, A-4, C-6, and D-6) instead contain an in-core beam tube support structure comprised of aluminum 6061 (Figure 1.49). A hex head cap screw can be adjusted to the desired height to provide support for the beam filter tubes extending into the core from the beam apertures. The centerline of the beam tube is located at core midplane.

The aperture setting of the East beam tube at the time of the experiments was at its typical L/D setting of 125. The aperture setting of the North beam tube was also at its typical L/D setting of 300 . Both of these settings indicate that the moveable aperture block (Figure 1.43) was raised such that the lower hole was aligned with the path of the beam tube. The East beam filter tube was filled with air and the North with helium. However, the tubes may be filled with either gas, or evacuated to contain void space.

The original drawings for the beam assemblies are different in regards to beam filter tube length (due to the difference in the length and width of the core grid plate) and the depicted layout of the aperture assembly mechanism. However, the current positioning motors in the reactor room conflict with the description of the North beam tube aperture assembly and match that of the East beam line. Therefore, based on the configuration of the motors, the staff believes that the North beam arrangement is identical to the East beam arrangement, except for the length of the "wet package".

${ }^{a}$ G. R. Imel, G. C. McClellan, and D. P. Pruett, “The Neutron Radiography Reactor (NRAD),” CONF-900873--2, Proc. $1^{\text {st }}$ Int. Top. Mtg. Neutron Radiography System Design and Characterization, Pembroke, Canada (August 2830, 1990).

${ }^{\mathrm{b}}$ Personal communication with Ken Schreck at HFEF (April 29, 2010). 
NEA/NSC/DOC(2006)1

Fundamental - FUND

NRAD-FUND-RESR-001

CRIT

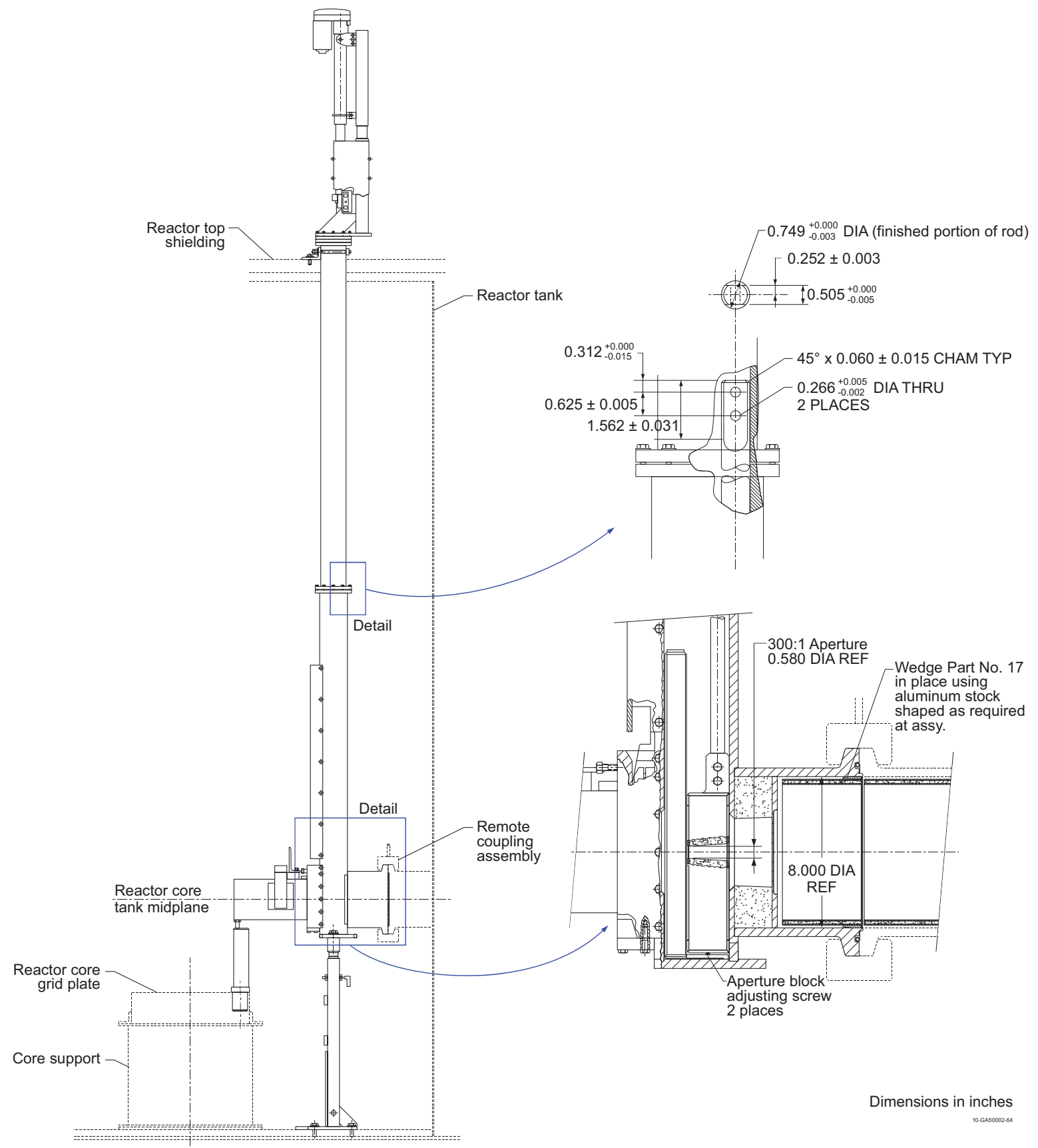

Figure 1.40. In-Tank Portion of the Beam Line. 
NEA/NSC/DOC(2006)1

Fundamental - FUND

NRAD-FUND-RESR-001
CRIT
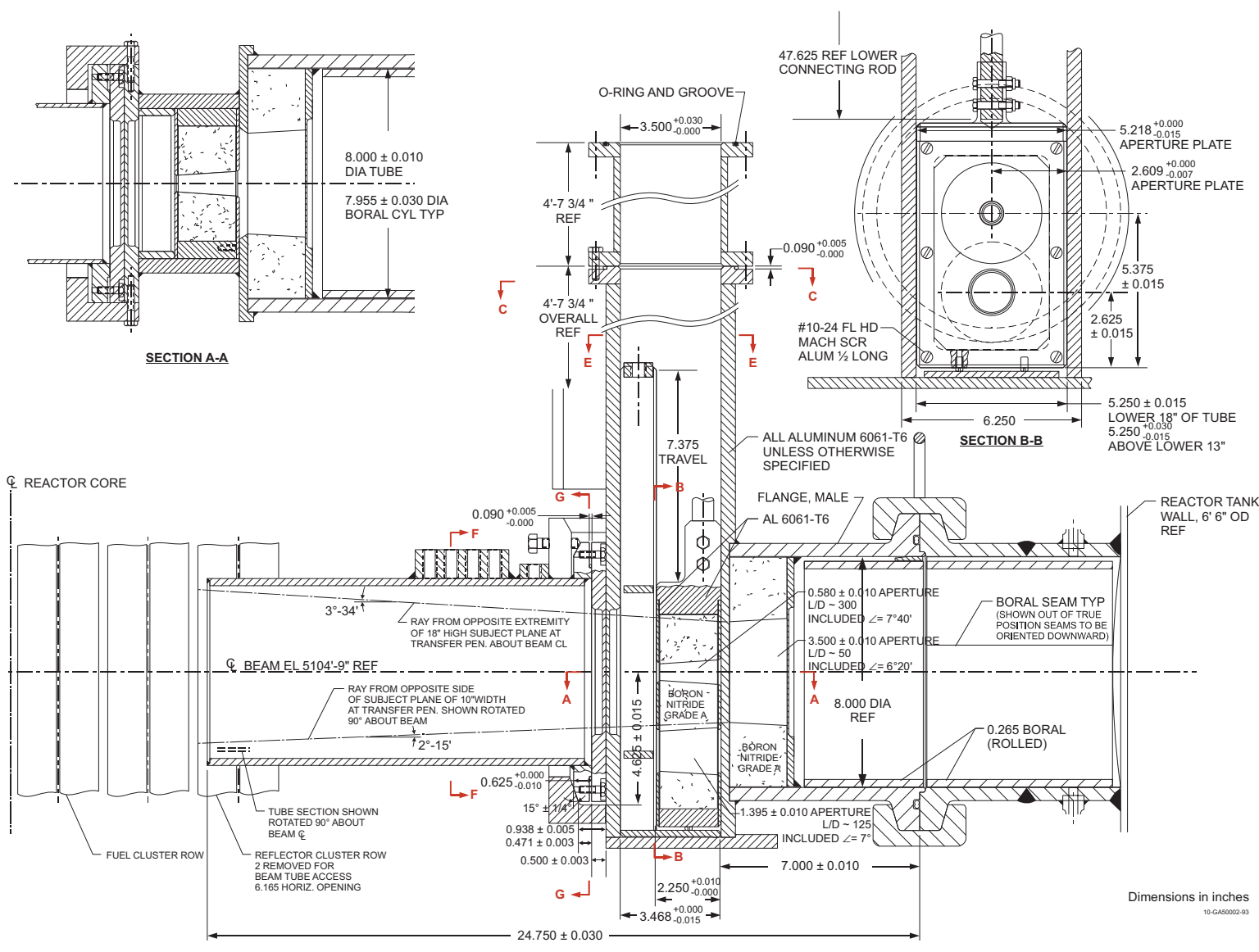

Figure 1.41a. East Beam Line Aperture Mechanism. 
NEA/NSC/DOC(2006)1

Fundamental - FUND

NRAD-FUND-RESR-001

CRIT
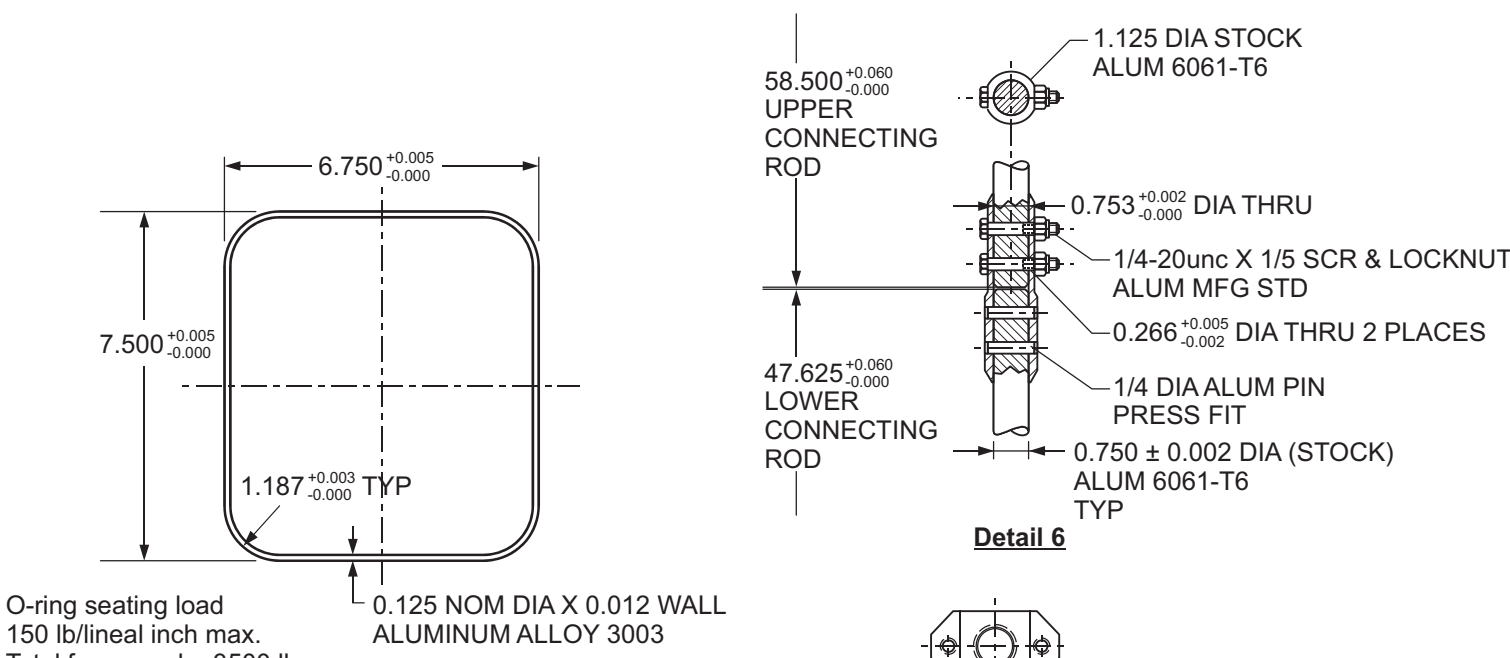

$50 \mathrm{lb} /$ lineal inch max.

Detail O-Ring
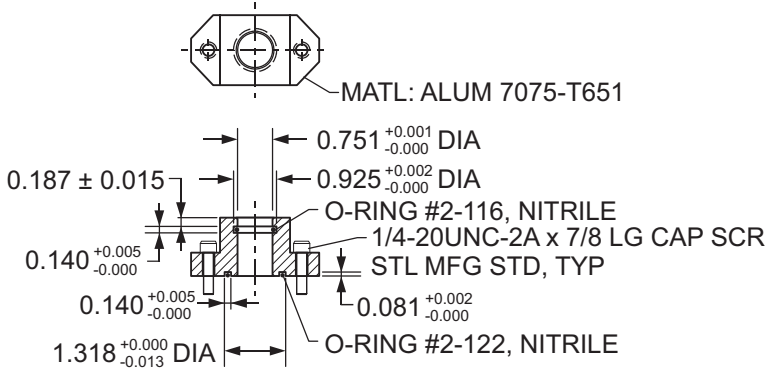

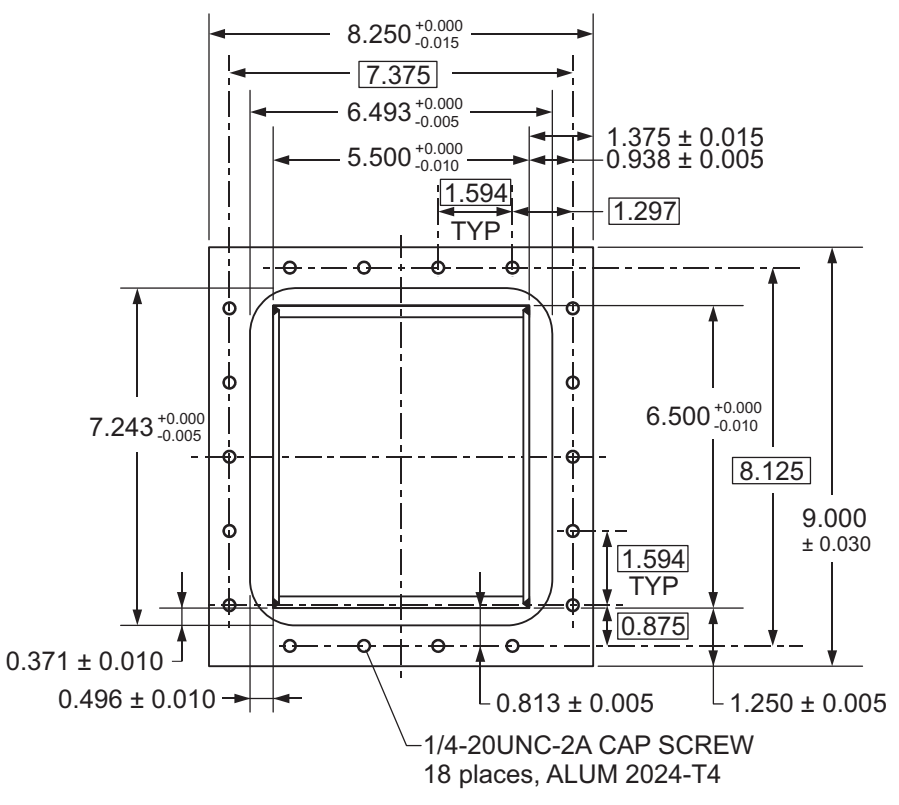

Section G-G
Detail 7

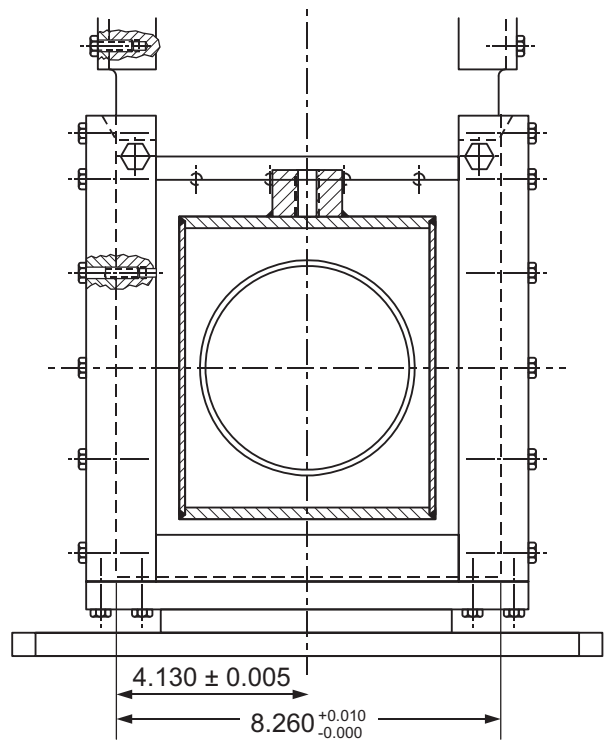

Section F-F

Dimensions in inches 10-GA50002-94

Figure 1.41b. East Beam Line Aperture Mechanism. 
NEA/NSC/DOC(2006)1

Fundamental - FUND

NRAD-FUND-RESR-001

CRIT
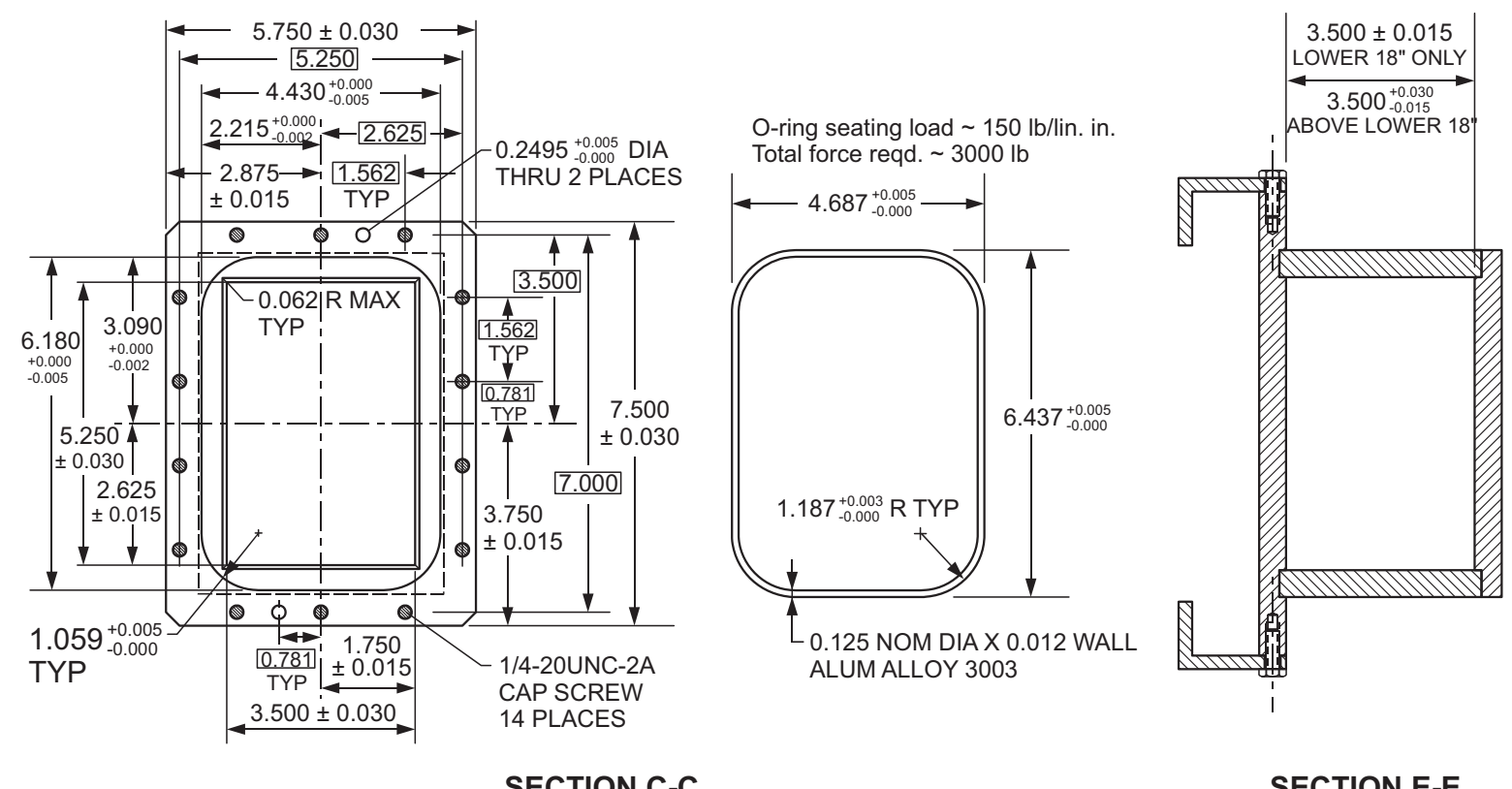

SECTION C-C

SECTION E-E

Dimensions in inches

10-GA50002-95

Figure 1.41c. East Beam Line Aperture Mechanism. 
NEA/NSC/DOC(2006)1

Fundamental - FUND

NRAD-FUND-RESR-001

CRIT

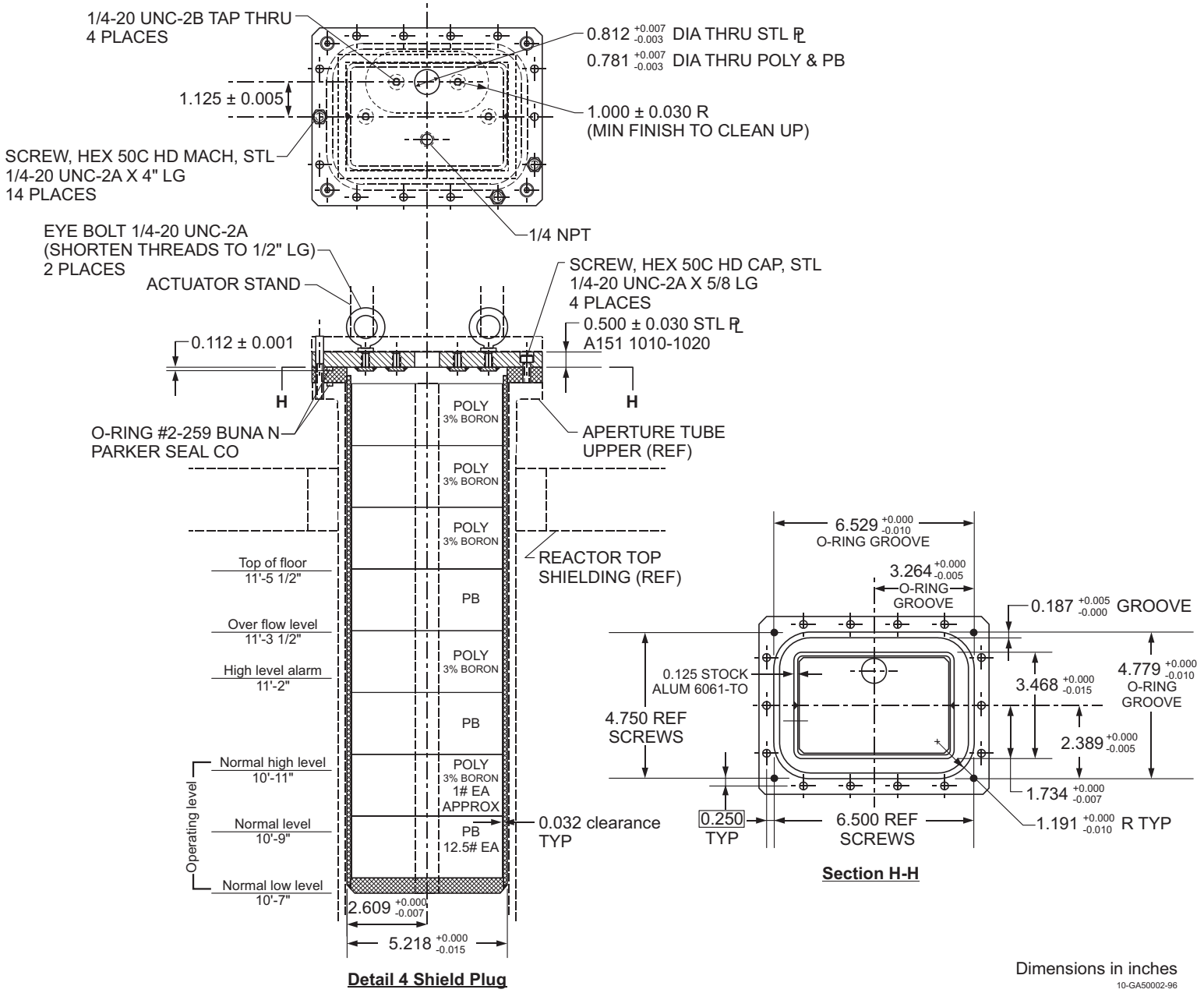

Figure 1.41d. East Beam Line Aperture Mechanism. 
NEA/NSC/DOC(2006)1

Fundamental - FUND

NRAD-FUND-RESR-001

CRIT

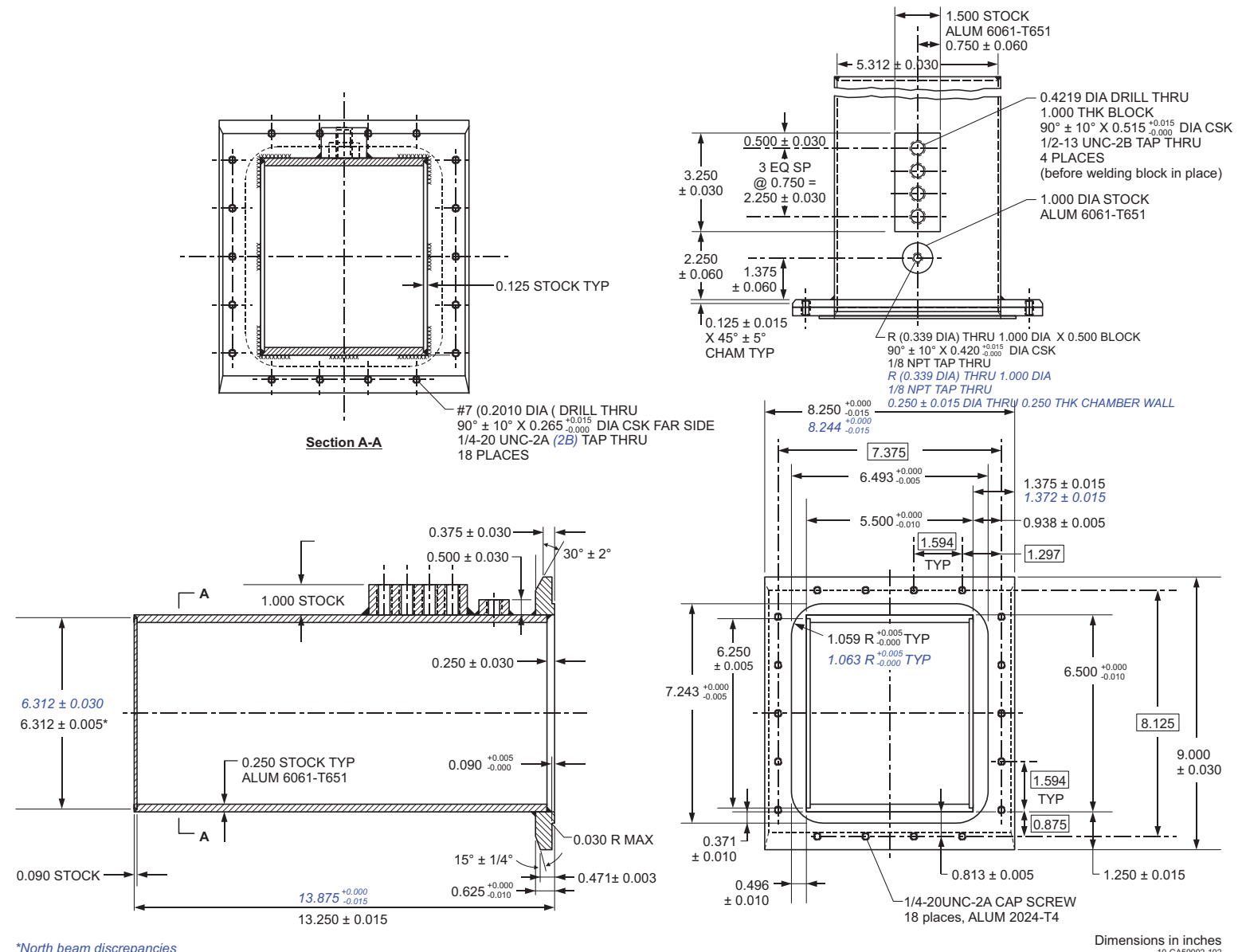

Figure 1.42. East and North Beam Filter Tubes. 
NEA/NSC/DOC(2006)1

Fundamental - FUND

NRAD-FUND-RESR-001

CRIT
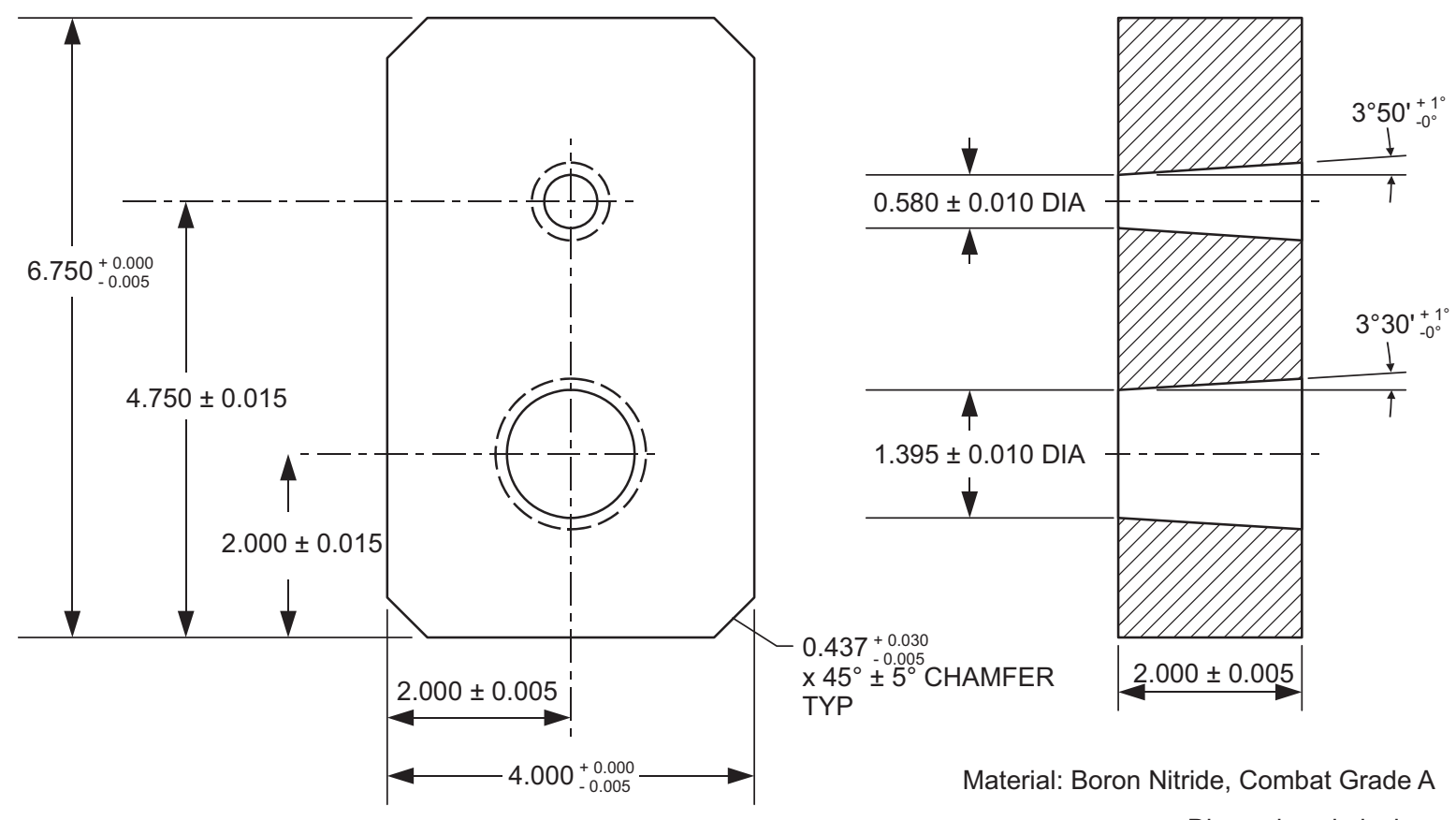

Material: Boron Nitride, Combat Grade A

Dimensions in inches 10-GA50002-101-1

Figure 1.43. Moveable Aperture Block.

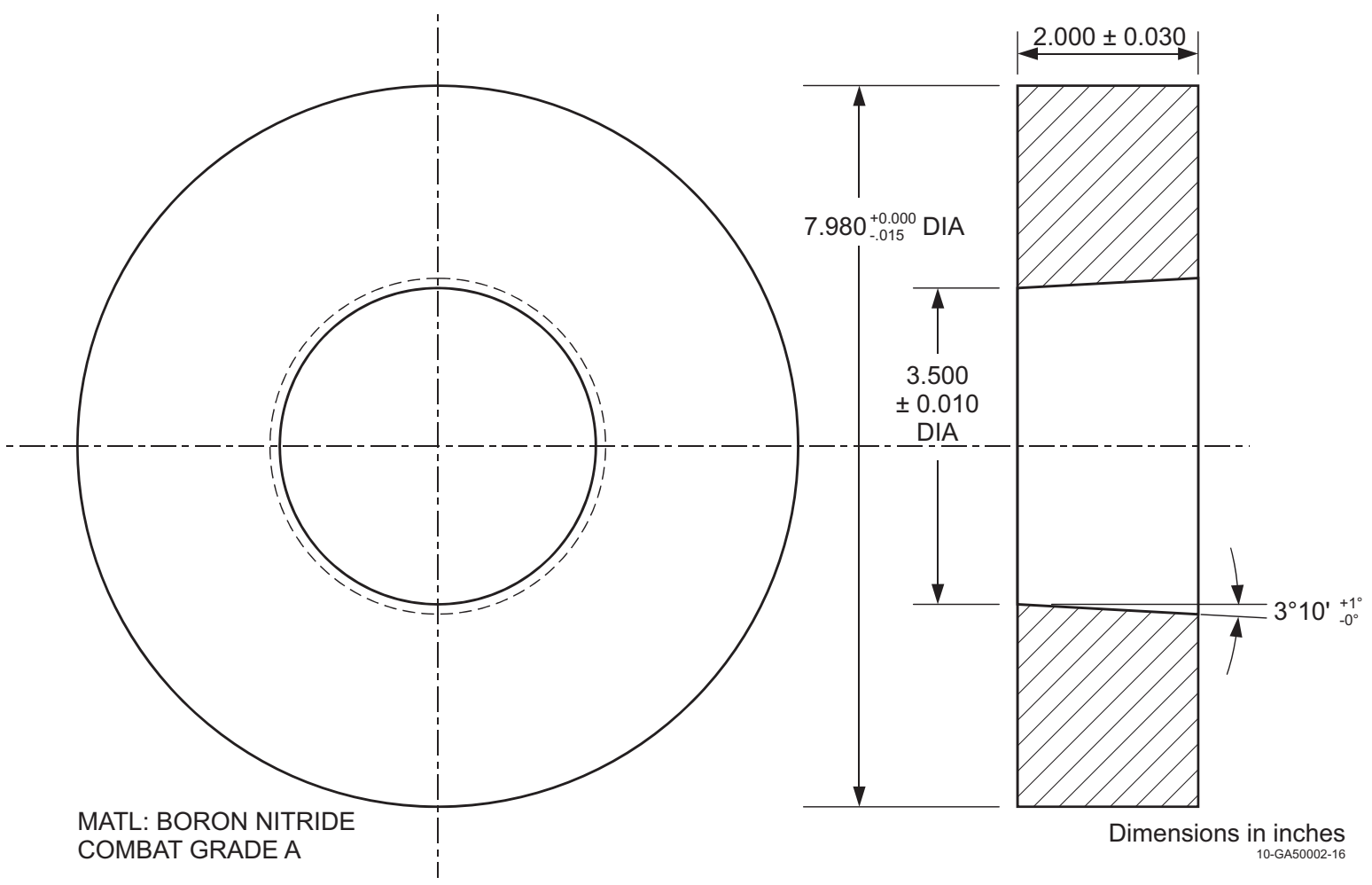

Figure 1.44. Fixed Disc Aperture Block. 


\section{NEA/NSC/DOC(2006)1}

Fundamental - FUND

NRAD-FUND-RESR-001 CRIT

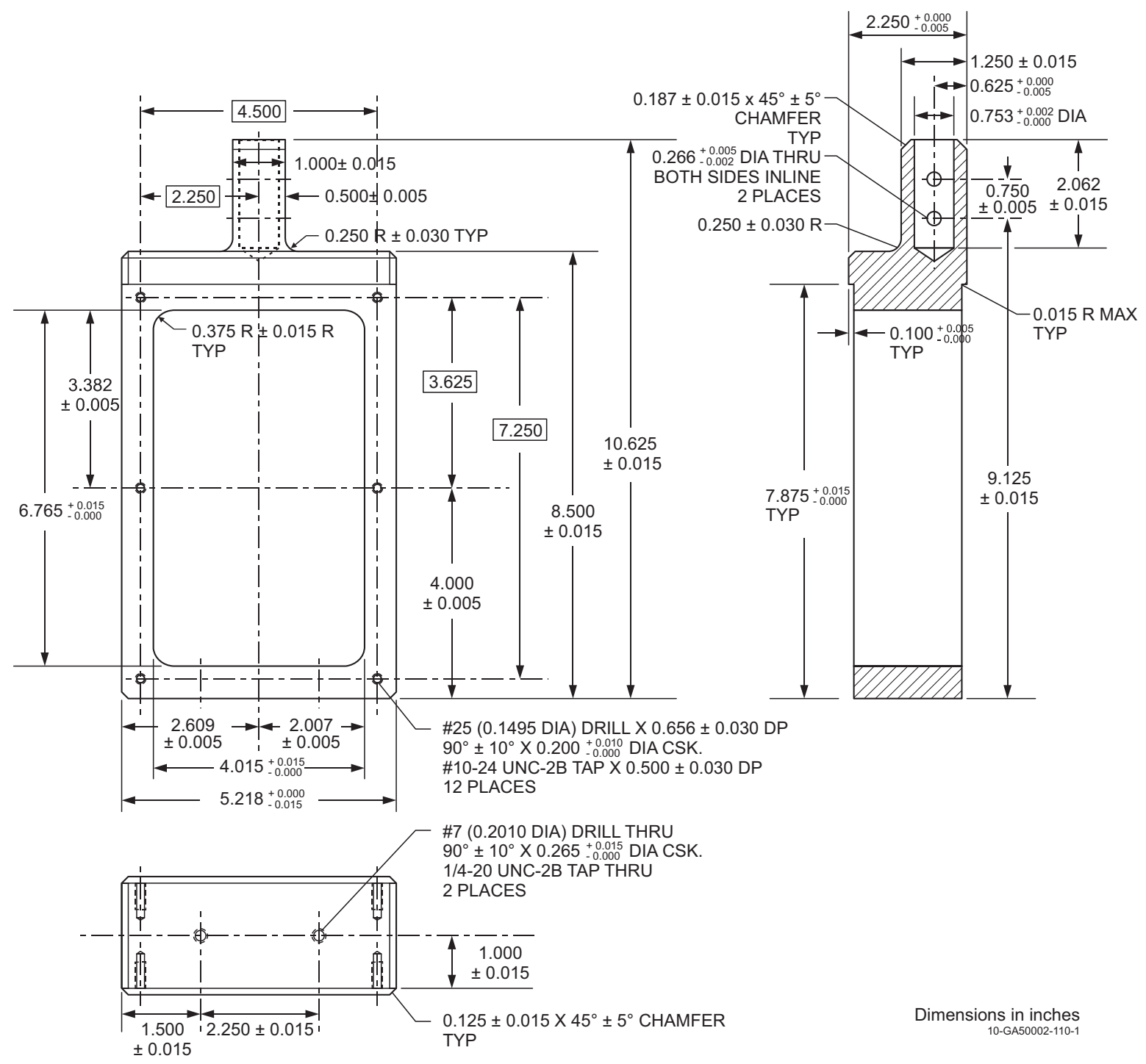

Figure 1.45a. Aperture Block Frame. 
NEA/NSC/DOC(2006)1

Fundamental - FUND

NRAD-FUND-RESR-001

CRIT

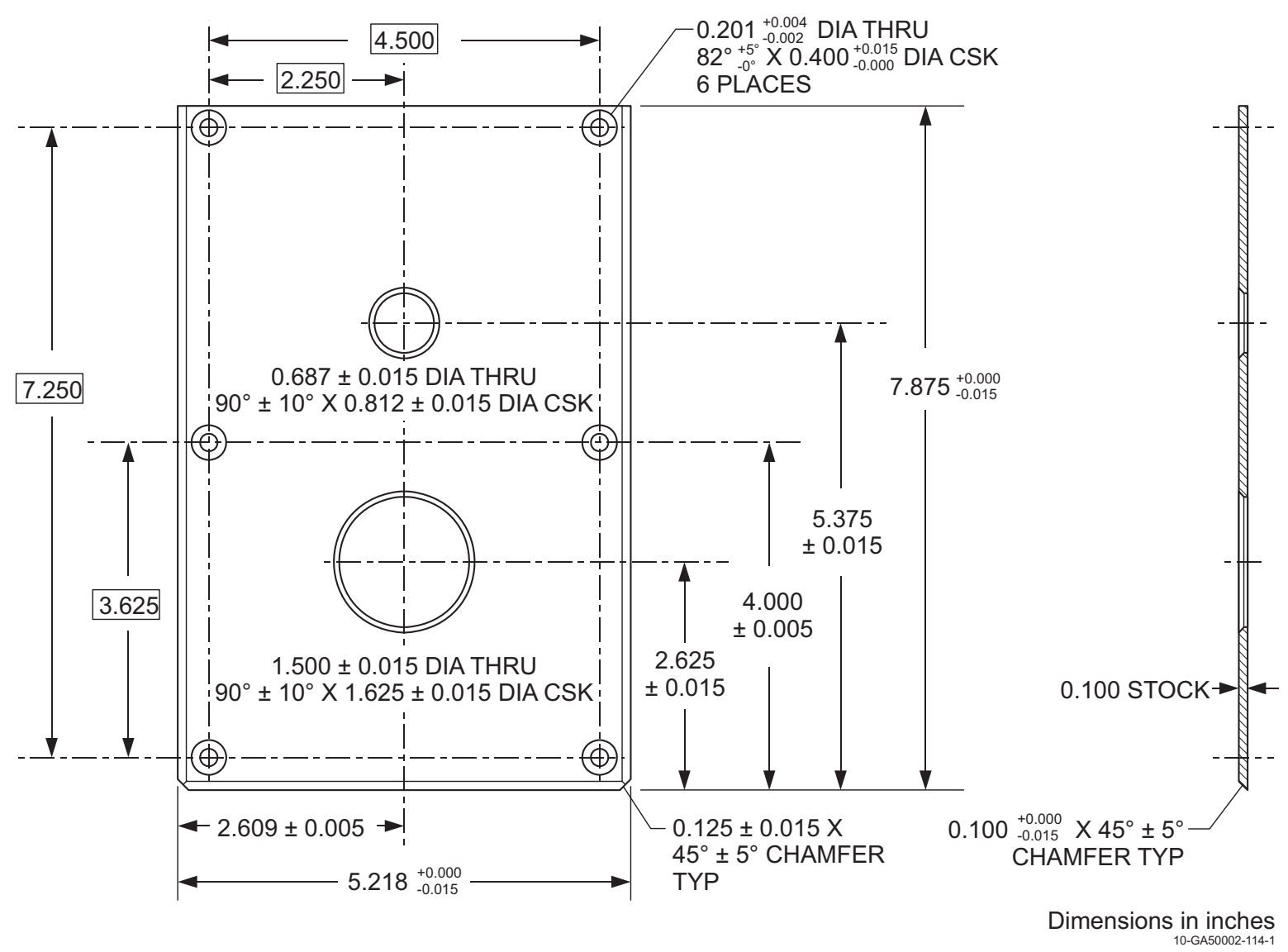

Figure 1.45b. Aperture Block Front Cover. 
NEA/NSC/DOC(2006)1

Fundamental - FUND

NRAD-FUND-RESR-001

CRIT

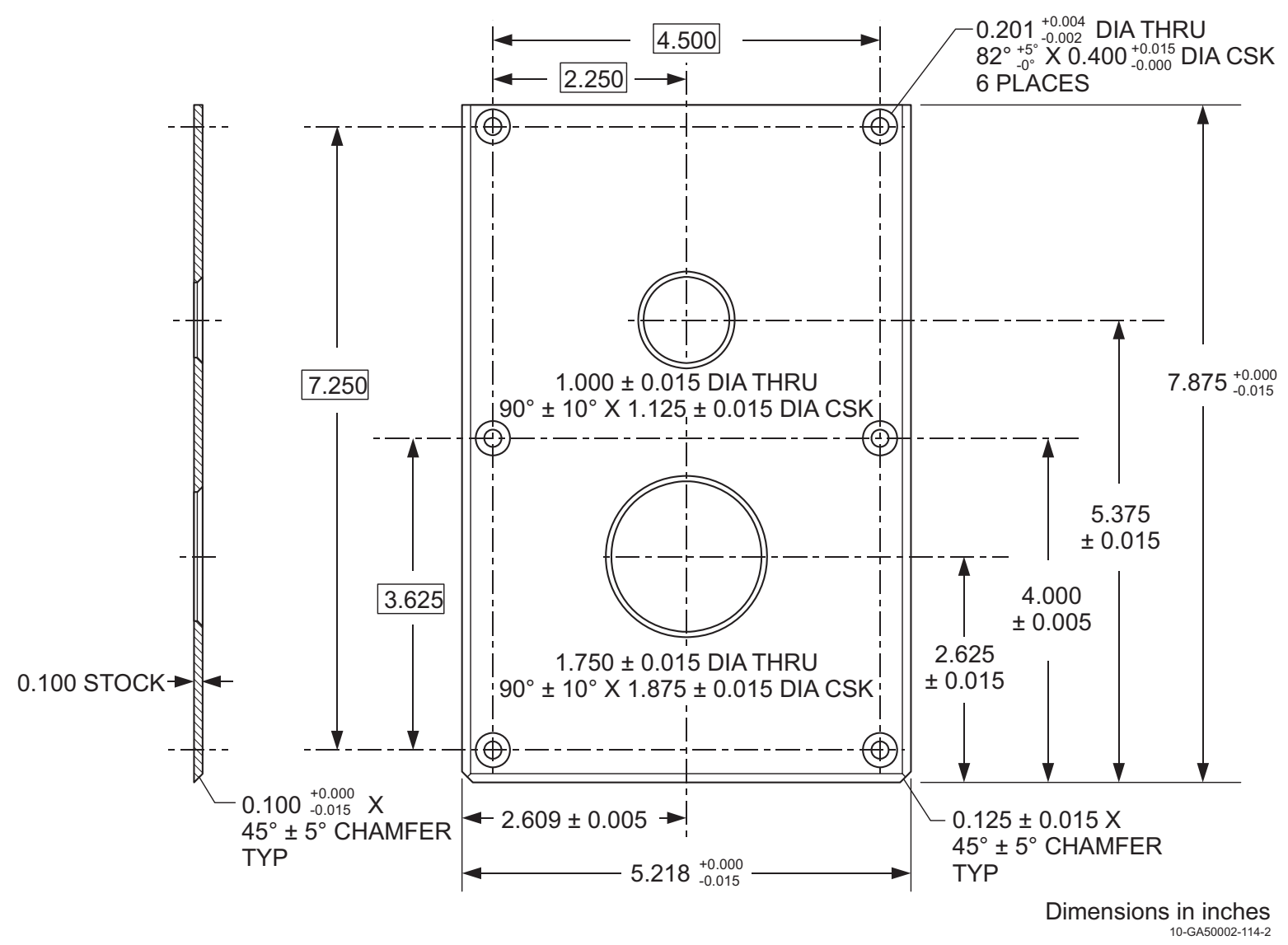

Figure 1.45c. Aperture Block Rear Cover. 
NEA/NSC/DOC(2006)1

Fundamental - FUND

NRAD-FUND-RESR-001

CRIT

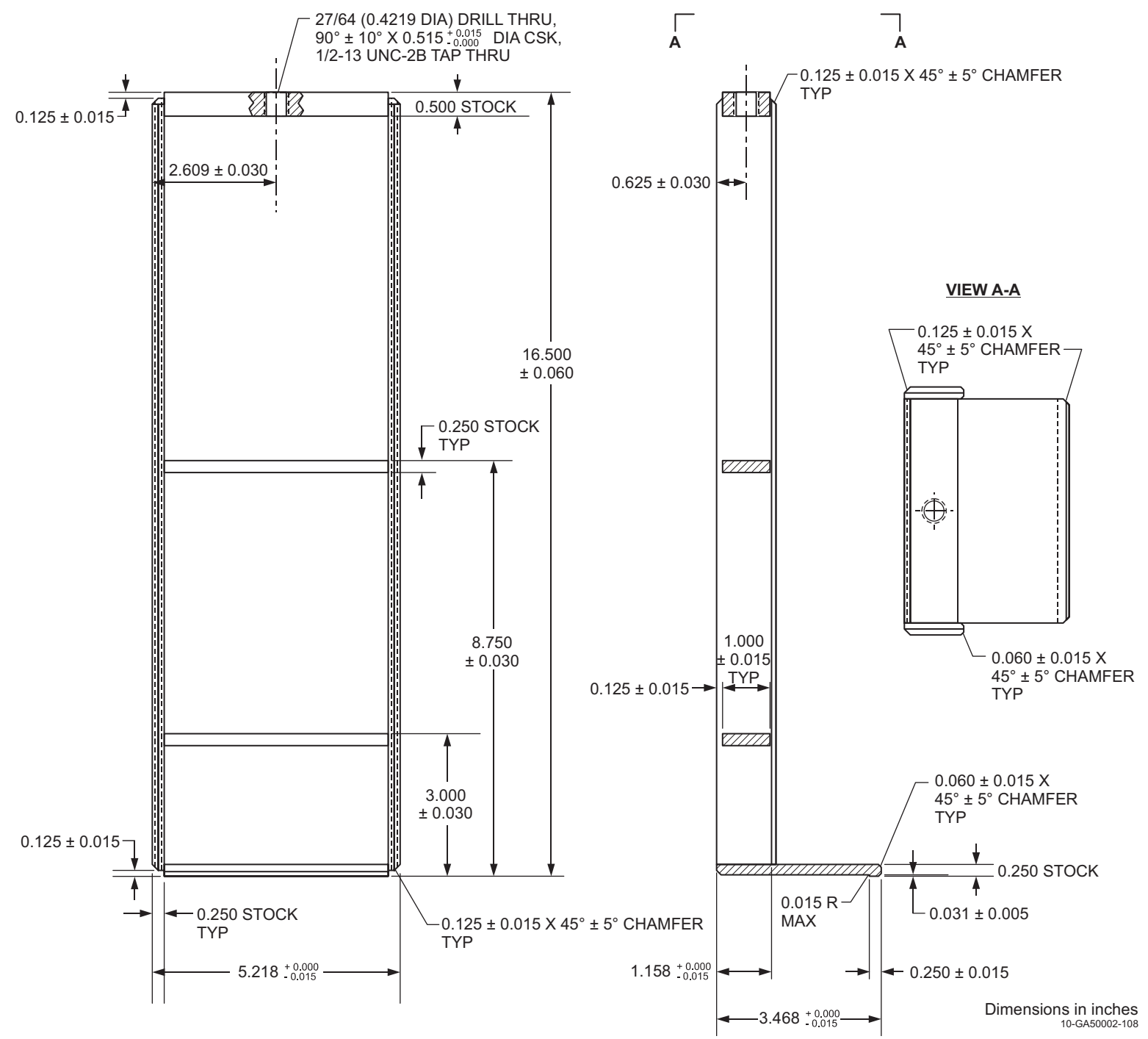

Figure 1.46. Aperture Block Guide.

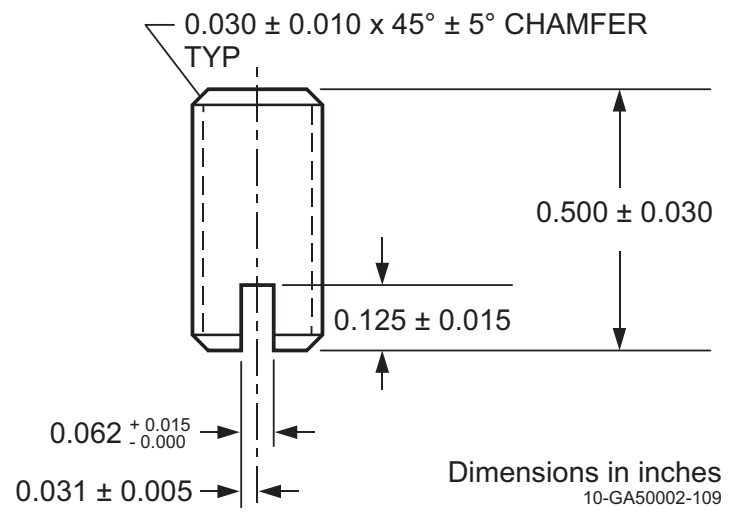

Figure 1.47. Aperture Block Adjusting Screw. 
NEA/NSC/DOC(2006)1

Fundamental - FUND

NRAD-FUND-RESR-001

CRIT
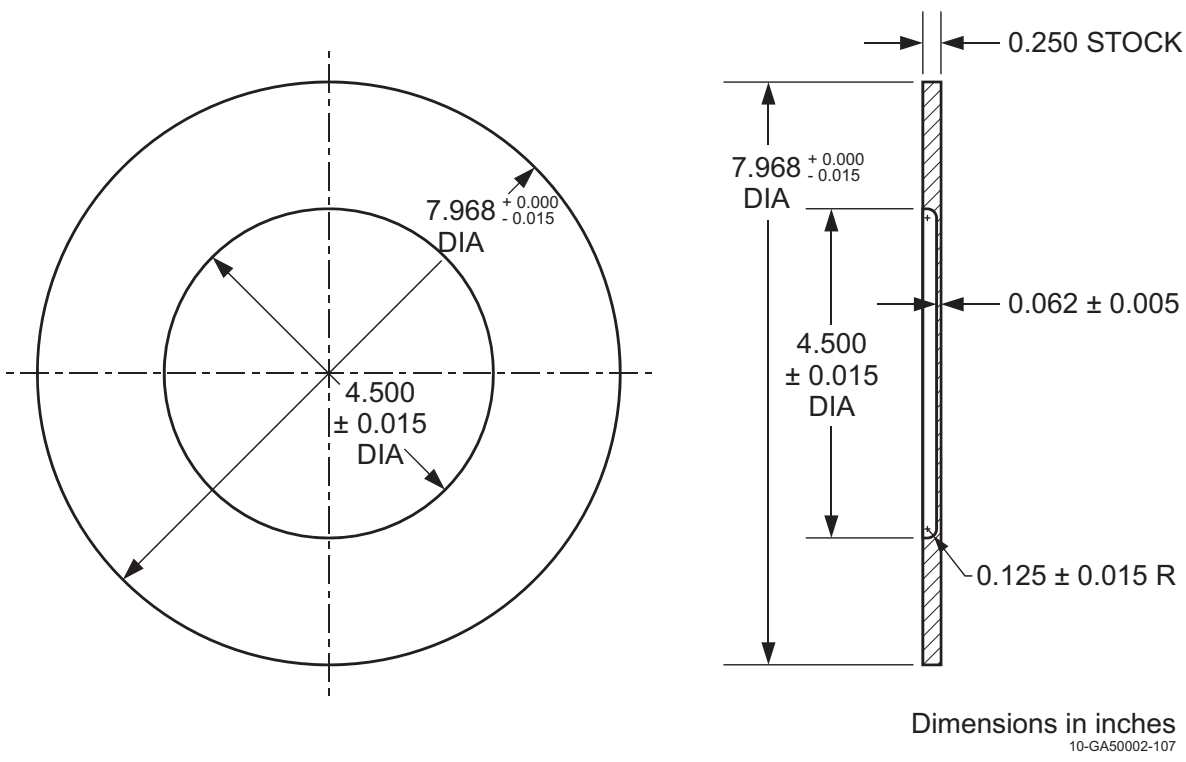

Figure 1.48. Lower Tube Seal Plate. 
Fundamental - FUND

NRAD-FUND-RESR-001

CRIT
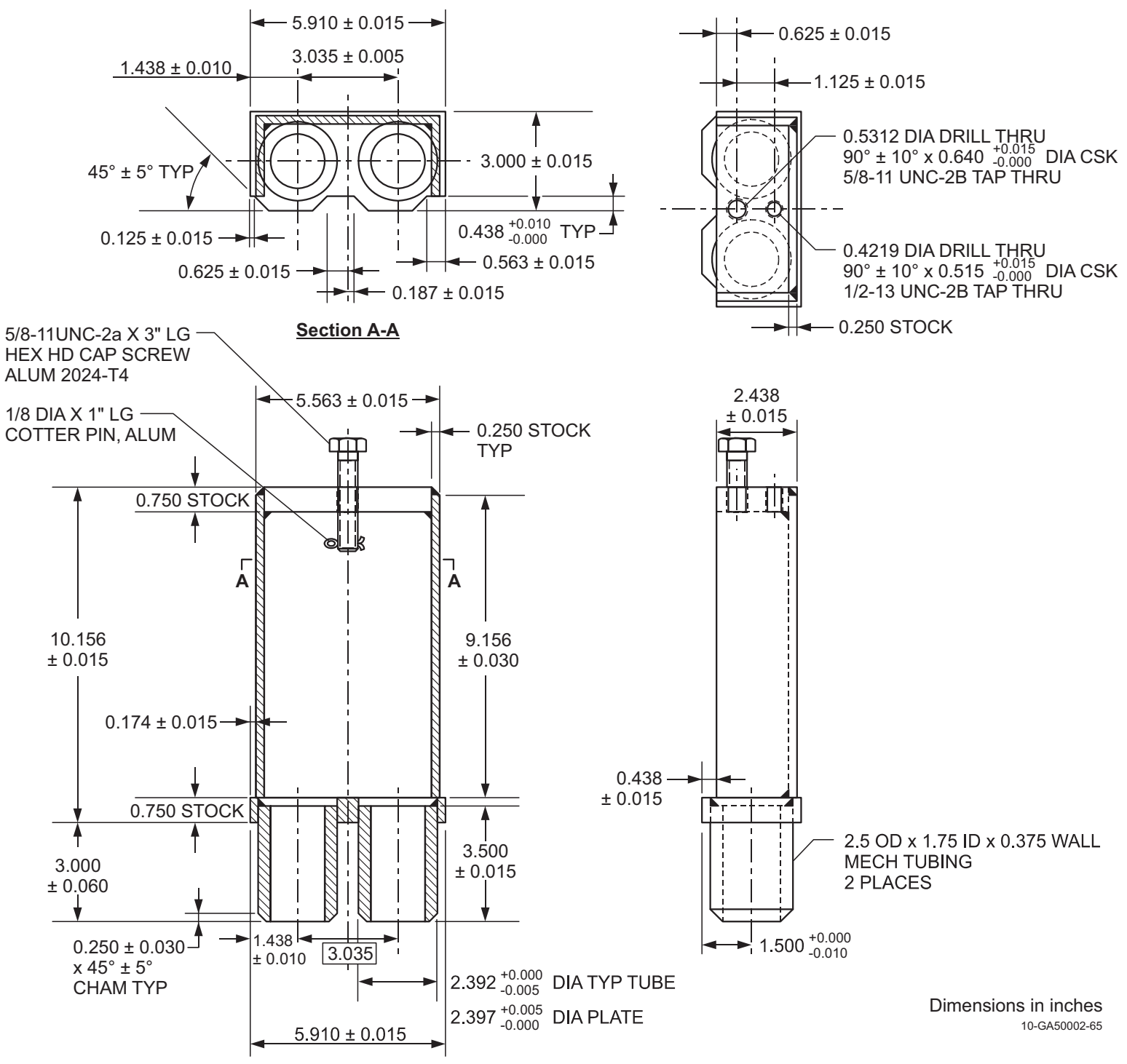

Figure 1.49. Beam Tube Support. 


\section{Water Hole (Irradiation Position)}

A water hole is provided as an irradiation experimental position (Grid position C-4 SW in Figure 6). It may eventually contain the experiment irradiation section of a pneumatic transfer system. A control rod guide tube (Figure 1.35) is currently located in the position to aid in the alignment of experiment samples. The guide tube was empty (except for water) during the approach to critical and initial core measurements.

\section{Start-Up Source}

The NRAD reactor uses a start-up source to produce a measureable reactor power level during startup. It is a $5 \mathrm{Ci} \mathrm{AmBe}$ source in a sealed stainless steel cylindrical container that is $1.3 \mathrm{in} .(3.302 \mathrm{~cm})$ long and 0.8 in. $(2.032 \mathrm{~cm})$ in diameter. Internal dimensions of the source are not available. The source is mounted in a special graphite reflector assembly (Figure 1.50) and emits $\sim 1 \times 10^{7}$ neutrons $/ \mathrm{sec}^{{ }^{\mathrm{a}}}$ The source was initially received on 5/10/1968 and was provided by Dayton Laboratory - Monsanto Research Corporation (currently Solutia Inc.).

The graphite block in Figure 1.50 replaces the typical graphite block in Figure 1.37 for a completed reflector assembly (Figure 1.51). The graphite reflector assembly containing the AmBe source is located in position F-3 of the NRAD core (Figure 1.6).

The start-up source is located within the graphite reflector assembly in the SE quadrant of the block approximately 14.125 in. $(35.8775 \mathrm{~cm})$ from the top of the graphite. The portions of the block not filled with pins and tie rods are filled with water. The source is placed within a source tube (Figure 1.52) with a cap (Figure 1.53). A wire rope is attached to the source tube cap so that it can be pulled out and moved around the tank. A special top assembly (Figure 1.54) is used to accommodate source placement in the graphite element.

The startup source is left in place during NRAD operations. It is only removed from the core to verify the source range instrument is operational before going to power. The source is swung off to the side of the tank to verify that log power decreases, and then reinstalled into its original position.

\footnotetext{
a "NRAD Reactor Fuel Core Conversion," DSA-005-NRAD-ADD-3 rev. 0, Idaho National Laboratory (April 2, 2009). [This reference is not available for public release.] 
NEA/NSC/DOC(2006)1

Fundamental - FUND

NRAD-FUND-RESR-001

CRIT

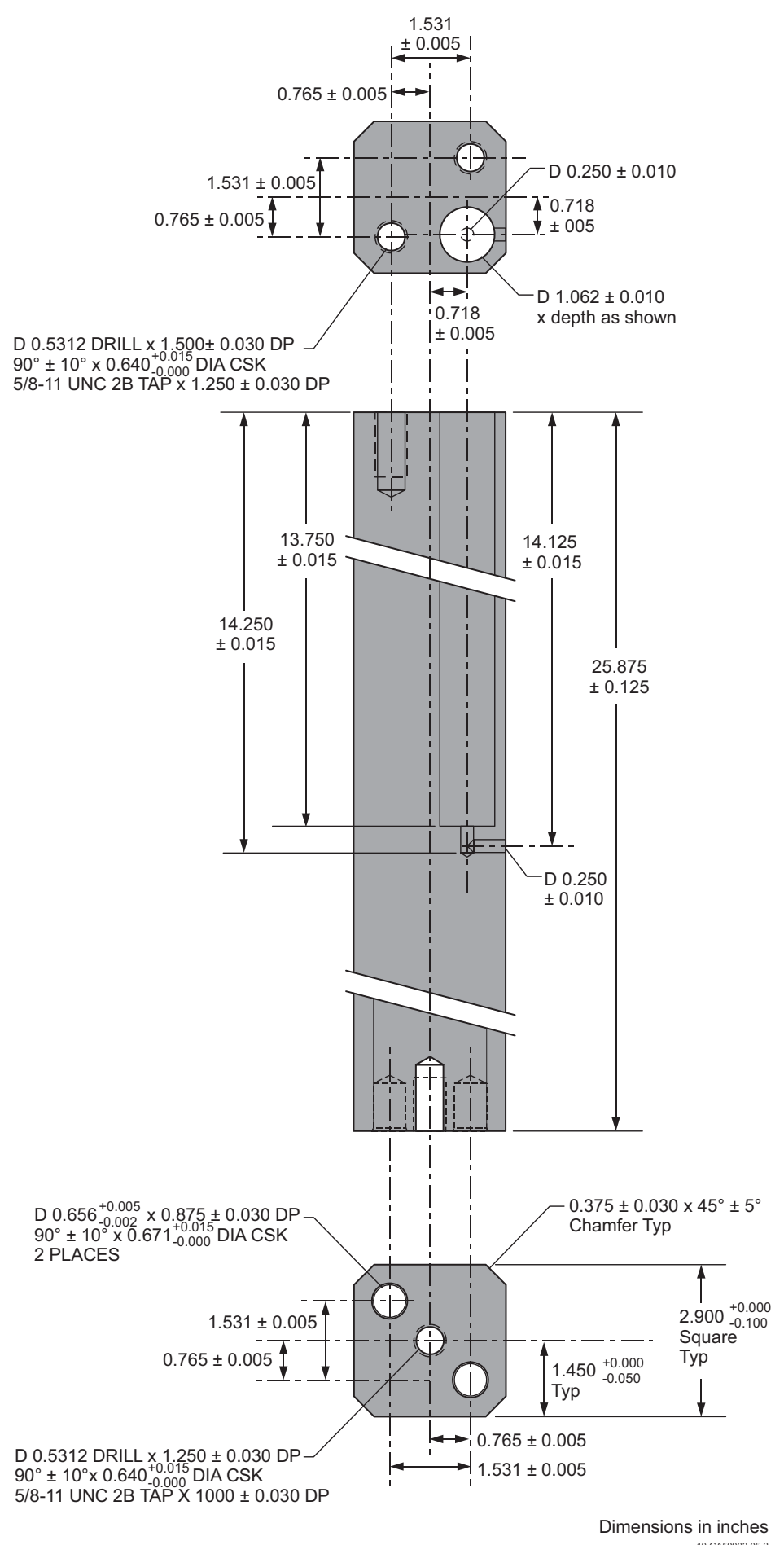

Figure 1.50. Graphite Reflector Block for Start-Up Source. 
NEA/NSC/DOC(2006)1

Fundamental - FUND

NRAD-FUND-RESR-001 CRIT

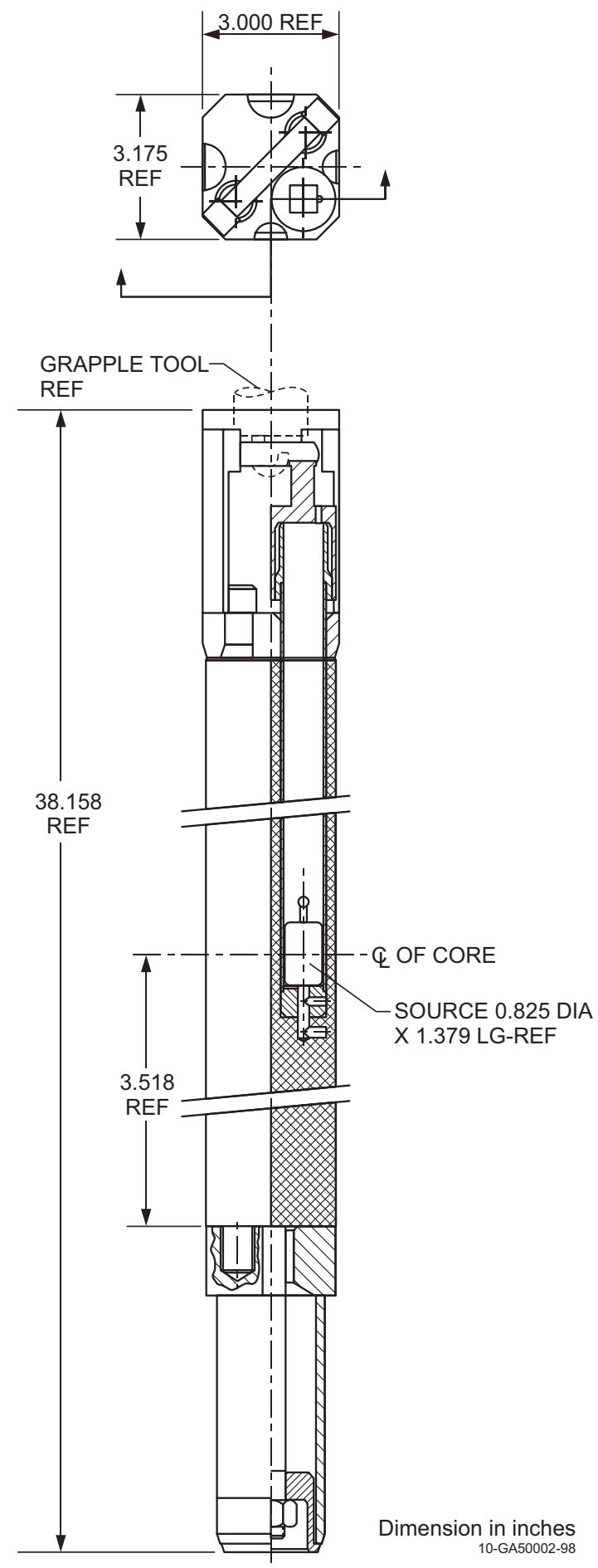

Figure 1.51. Graphite Element with Source Assembly. 
NEA/NSC/DOC(2006)1

Fundamental - FUND

NRAD-FUND-RESR-001 CRIT

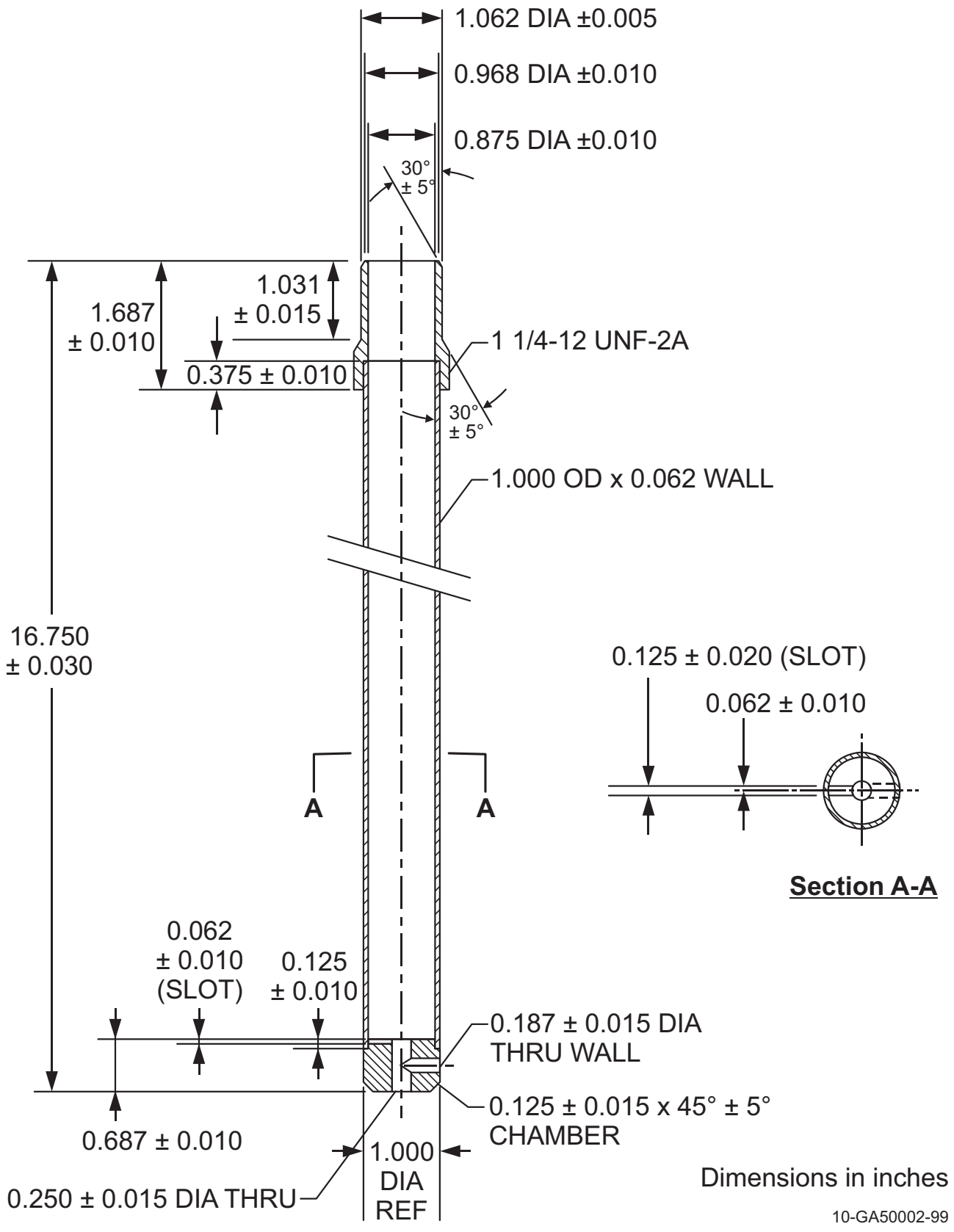

Figure 1.52. Source Tube. 
NEA/NSC/DOC(2006)1

Fundamental - FUND

NRAD-FUND-RESR-001

CRIT
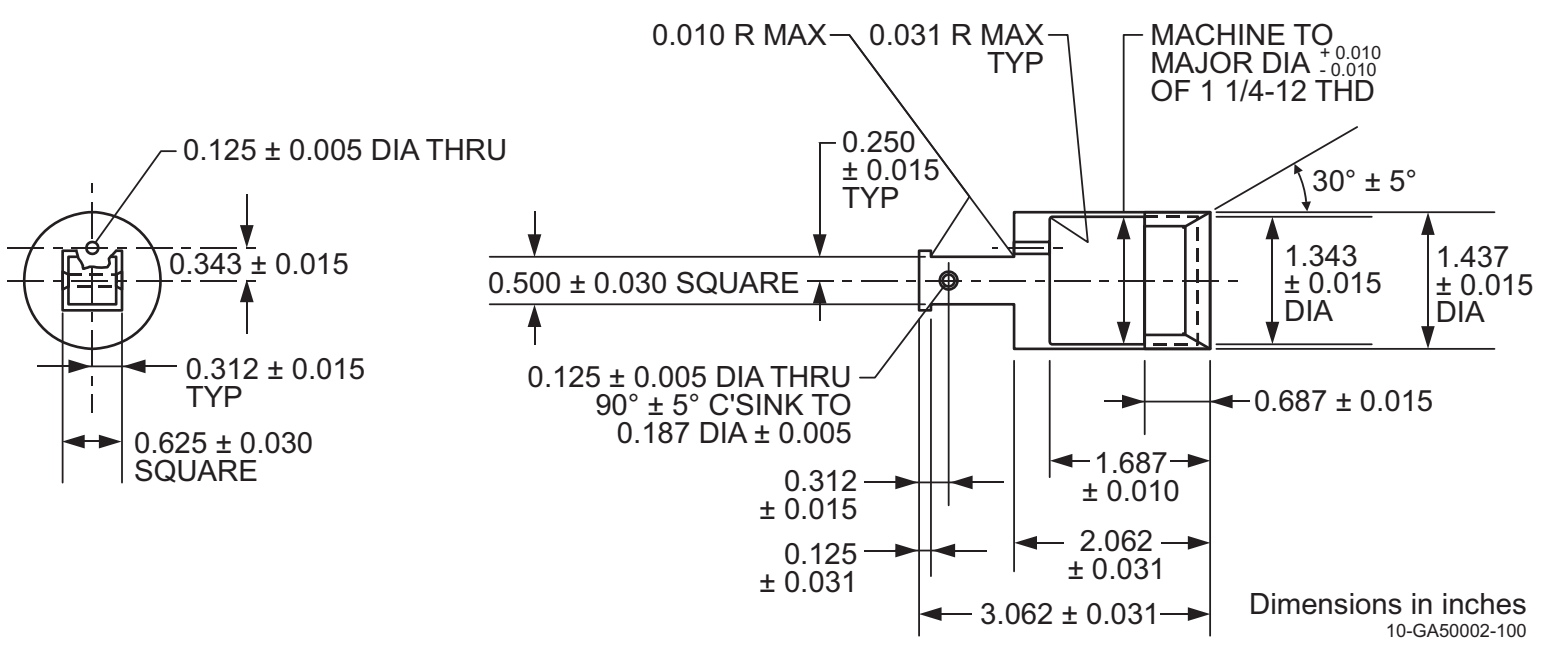

Figure 1.53. Source Tube Cap. 
NEA/NSC/DOC(2006)1

Fundamental - FUND

NRAD-FUND-RESR-001

CRIT
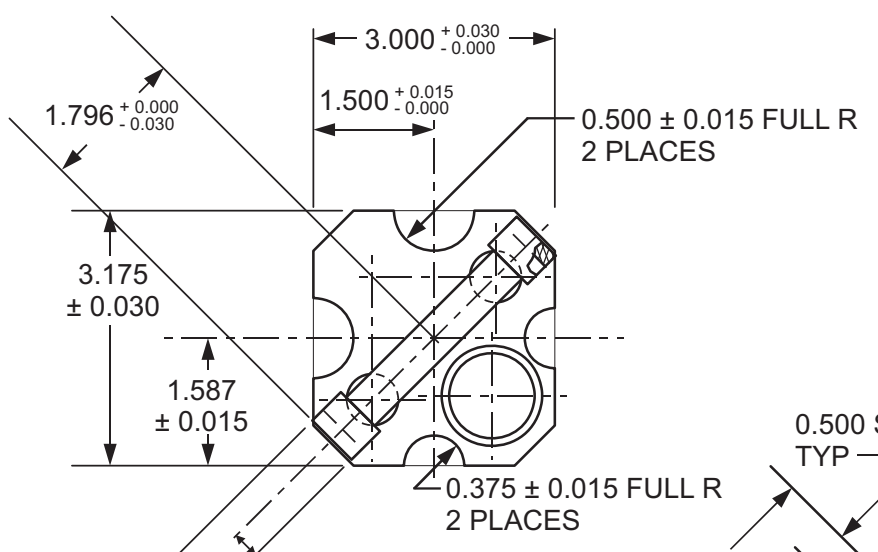

2 PLACE

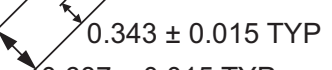

$0.687 \pm 0.015$ TYP
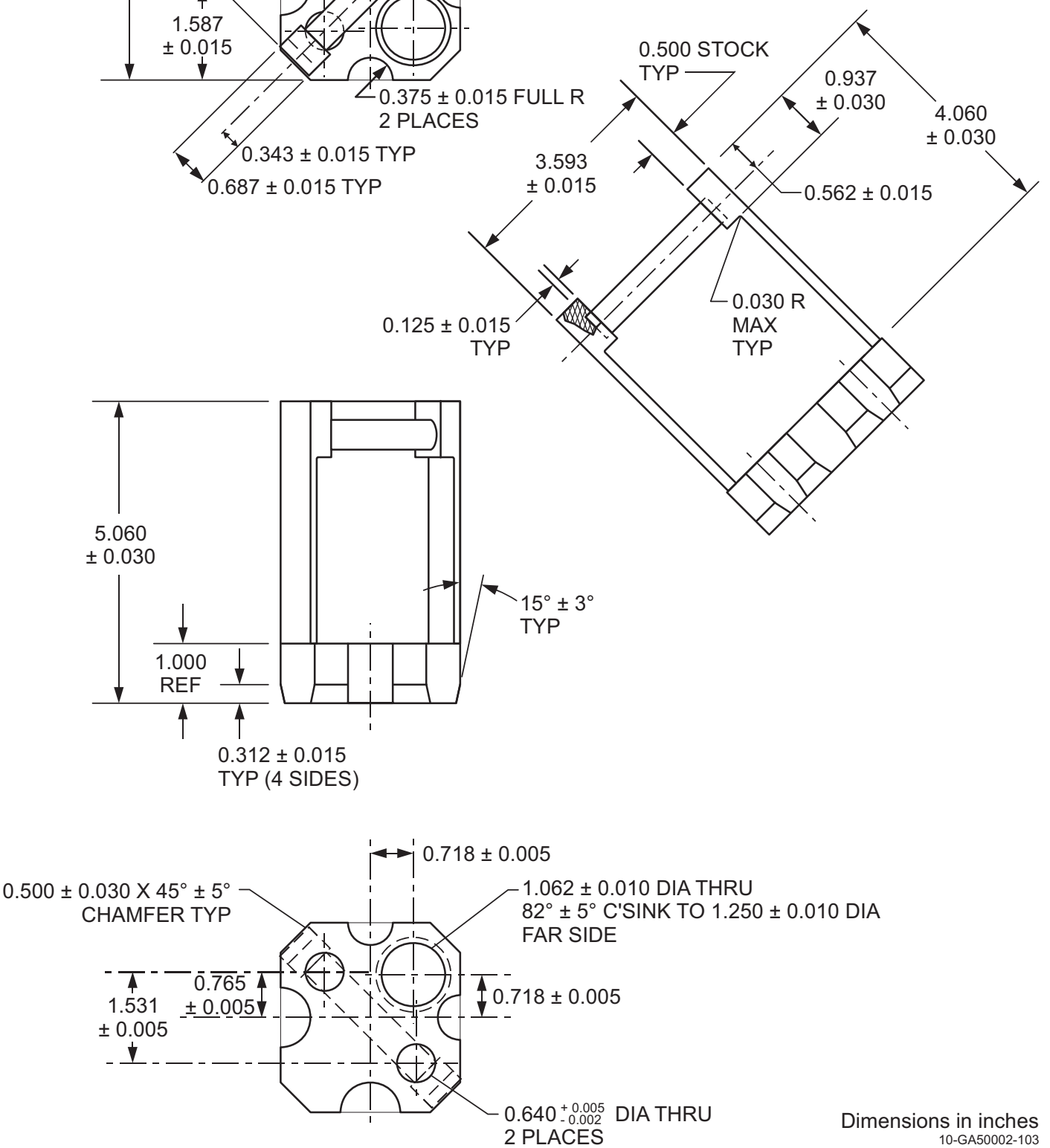

Dimensions in inches

Figure 1.54. Top Assembly for Graphite Element with Source Assembly. 


\section{Detectors}

The pool detectors are located to the south and north of the reactor core, near the edge of the pool (Figures 1.1 and 1.6). They consist of one linear, one log, and two safety channels. Horizontal and vertical placement of these detectors within the tank is shown with detail in Figures 1.55 and 1.56, respectively.

The wide-range (10 decade) log-power channel is a fission-chamber detector that provides indication of power and period from source level to $120 \%$ of design power. It uses both counting and Campbelling techniques to give an accurate log-power indication with very little gamma background error. Period measurements are from $-30 \mathrm{~s}$ to $+3 \mathrm{~s}$ over the full power range. ${ }^{\mathrm{a}}$

Two power-level-safety channels provide indication of reactor power from $0.001 \%$ to $120 \%$ of design power using uncompensated ion-chamber-type detectors. ${ }^{\text {a }}$

The linear-power channel uses an all-solid-state multirange picoammeter that obtains a current signal from a compensated ion chamber. Depending on the gamma background level, this channel can measure power over most of the operating range of the reactor. ${ }^{\text {a }}$

Detector power levels were calibrated on April 1, 2010 as part of the NRAD reactor startup procedures. ${ }^{b}$

\footnotetext{
a "HFEF/N Neutron Radiography Facility System Design Description,” W0170-0004-SA rev. 2, Idaho National Laboratory (June 1, 1978). [This reference is not available for public release.]

b "Startup Report for the NRAD Reactor," 911195 rev. 0, GA Project 39296, TRIGA Reactor Division of General Atomics (November 4, 2010). [This reference is not available for public release.]
} 
NEA/NSC/DOC(2006)1

Fundamental - FUND

NRAD-FUND-RESR-001 CRIT
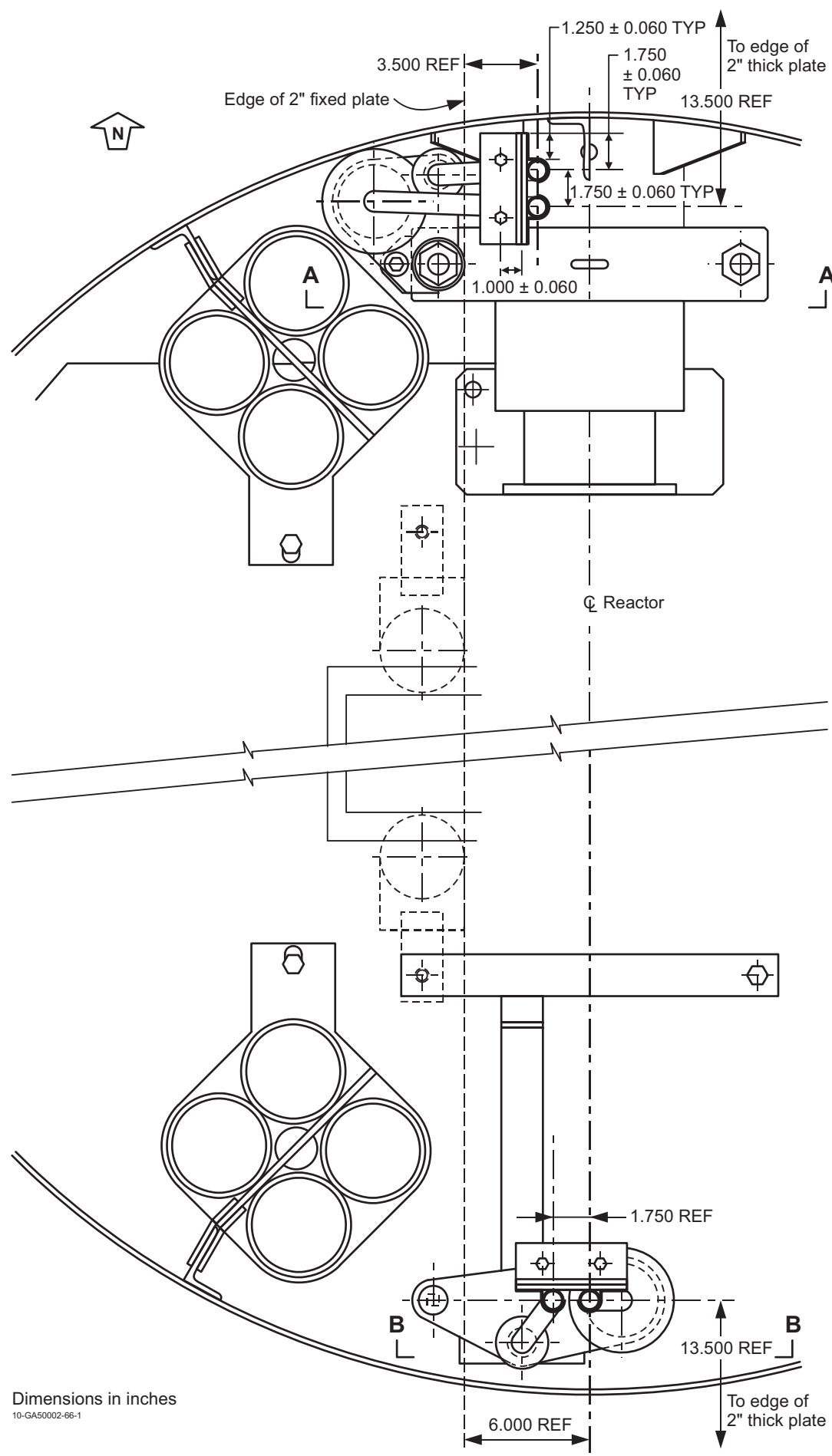

Figure 1.55. Horizontal Detector Placement in NRAD Tank. 
NEA/NSC/DOC(2006)1

Fundamental - FUND

NRAD-FUND-RESR-001

CRIT

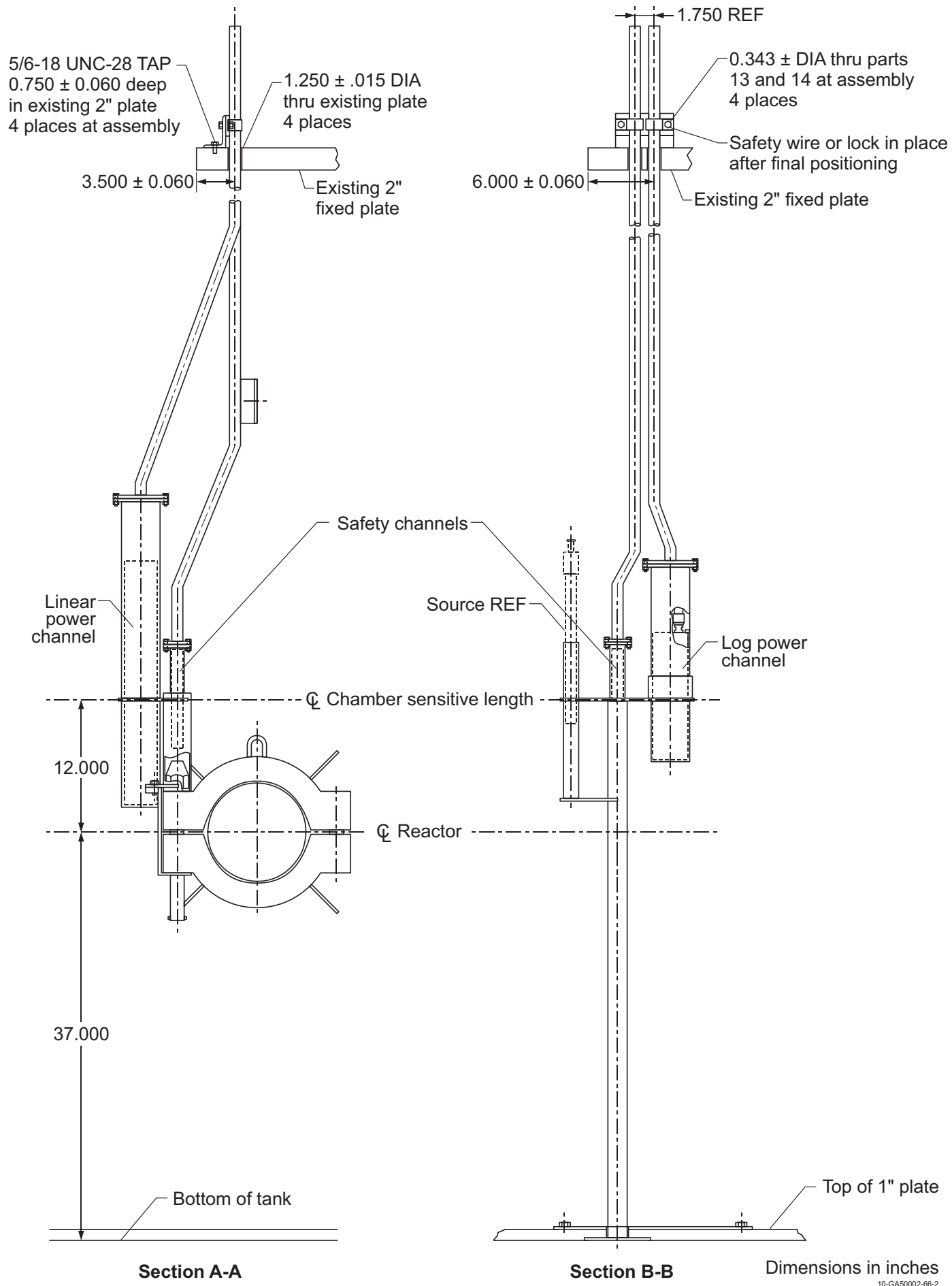

Figure 1.56. Vertical Detector Placement in NRAD Tank. 
NEA/NSC/DOC(2006)1

Fundamental - FUND

NRAD-FUND-RESR-001

CRIT

\section{Dry Tubes}

Dry tubes can be placed around the periphery of the core to allow for samples to be irradiated without getting them wet. Dry tubes were not installed during the initial critical measurements of the NRAD core. If dry tubes are used, they are typically placed in the corners of the core, as shown in position F-1 NE in Figure 1.6.

Dry tubes are aluminum pipes open at the top with an outside diameter of $1.875 \mathrm{in} .(4.7625 \mathrm{~cm})$ and an inside diameter of $1.6875 \mathrm{in}$. $(4.28625 \mathrm{~cm})$. The pipe extends from the grid plate attachment hardware to approximately 4 in. $(10.16 \mathrm{~cm})$ above the tank waterline. A fuel element end fitting threads into the pipe to attach it into a grid plate adapter. When installed in the F-1 NE position, it rests against the $90^{\circ}$ angle formed by the graphite blocks in positions E-1 and F-2. ${ }^{\mathrm{a}}$

\subsubsection{Experimental Procedure}

Fuel loading information for the NRAD core follows the initial startup plan provided by General Atomics $^{\mathrm{b}}$ and adapted by the NRAD staff. ${ }^{\mathrm{c}}$ As-built fuel data, and physical placement of fuel clusters in the core, are found in Appendices D and E, respectively. Actual measurements taken during the start-up of the NRAD LEU core are recorded in another General Atomics report. ${ }^{\mathrm{d}}$ The approach to critical measurements are also included in Appendix E.

Fission chamber counts and period measurements were used to monitor for criticality and the power of the core. The NRAD reactor is considered critical when the power level is sustained at $50 \mathrm{~W}$, the regulating rod position is stable, and the period is infinite. The linear power channel also monitors the power level during the measurement of the just-critical state. ${ }^{e}$

Initial criticality with 56 fuel elements (Figure 1.57) was achieved on March 19, 2010. The shim rods were fully withdrawn and the regulating rod height was $817 \pm 1$ units $(12.255 \pm 0.015$ in. or $31.1277 \pm$ $0.0381 \mathrm{~cm}$ ). Temporary start-up detector chambers were placed next to the reflector during this experiment in positions A-1 and A- 6 during startup (see bottom left and top left corners of photo in Figure E.2). These detectors were later removed.

On March 31, 2010, critical rod height and control rod reactivity measurements in the 56 element core configuration were re-performed both with and without the two startup detectors. The regulating rod height at critical was $775 \pm 1$ units $(11.625 \pm 0.015$ in. or $29.5275 \pm 0.0381 \mathrm{~cm})$ vs. the measurement of 817 units $(12.255$ in. or $31.1277 \mathrm{~cm}$ ) with the detector chambers next to the reflector. Control rod worth measurements, core excess reactivity, and shutdown margin were determined for this configuration.

The operational core of 60 fuel elements (Figure 1.58), at a power of $50 \mathrm{~W}$, went critical on March 31, 2010 , with both shim rods fully withdrawn and the regulating rod withdrawn $536 \pm 1$ units $(8.04 \pm 0.015$ in. or $20.4216 \pm 0.0381 \mathrm{~cm})$. The core cold excess reactivity was $\$ 1.19$. Control rod worth measurements, core excess reactivity, and shutdown margin were determined for this configuration.

\footnotetext{
a Personal communication with Ken Schreck at HFEF (July 1, 2010).

b "Neutron Radiography Reactor Analysis and Support: Startup Plan for the NRAD Reactor, Final Report," 911183 rev. 1, GA Project 39296, TRIGA Reactor Division of General Atomics (January 13, 2010). [This reference is not available for public release.]

c "Startup Plan for the NRAD Reactor Final Report," PLN-3285 rev. 3, Idaho National Laboratory (August 2010). [This reference is not available for public release.]

d "Startup Report for the NRAD Reactor," 911195 rev. 0, GA Project 39296, TRIGA Reactor Division of General Atomics (November 4, 2010). [This reference is not available for public release.]

e Personal communication with Ken Schreck at HFEF (September 29, 2010).
} 
Additional power calorimetric measurements were performed on April 1, 2010. Approximately 2 hours were spent at each of the power data points: $0.1,1,10,50,100,200$, and $250 \mathrm{~kW}$. At the end of the run, the regulating rod was withdrawn $882 \pm 1$ units $(13.23 \pm 0.015 \mathrm{in}$. or $33.6042 \pm 0.0381 \mathrm{~cm})$. At full operational power, $250 \mathrm{~kW}$, arriving quickly from a cold, clean state, the regulating rod was initially withdrawn $860 \pm 1$ units $(12.9 \pm 0.015$ in. or $32.766 \pm 0.0381 \mathrm{~cm})$ on June 6,2010 . Xenon poison buildup due to extended operations at elevated power are the primary cause for the difference of 22 units $(0.33$ in. or $0.8382 \mathrm{~cm})$ in the regulating rod position at these two full power measurements. Core excess reactivity was also determined at full power.

Additional reactivity worth measurements were performed for the removal of graphite reflector block assemblies to determine their worth prior to the termination of core startup procedures. Control rod worth measurements were performed after each block removal to determine the change in core excess reactivity. Then the graphite reflector was replaced.

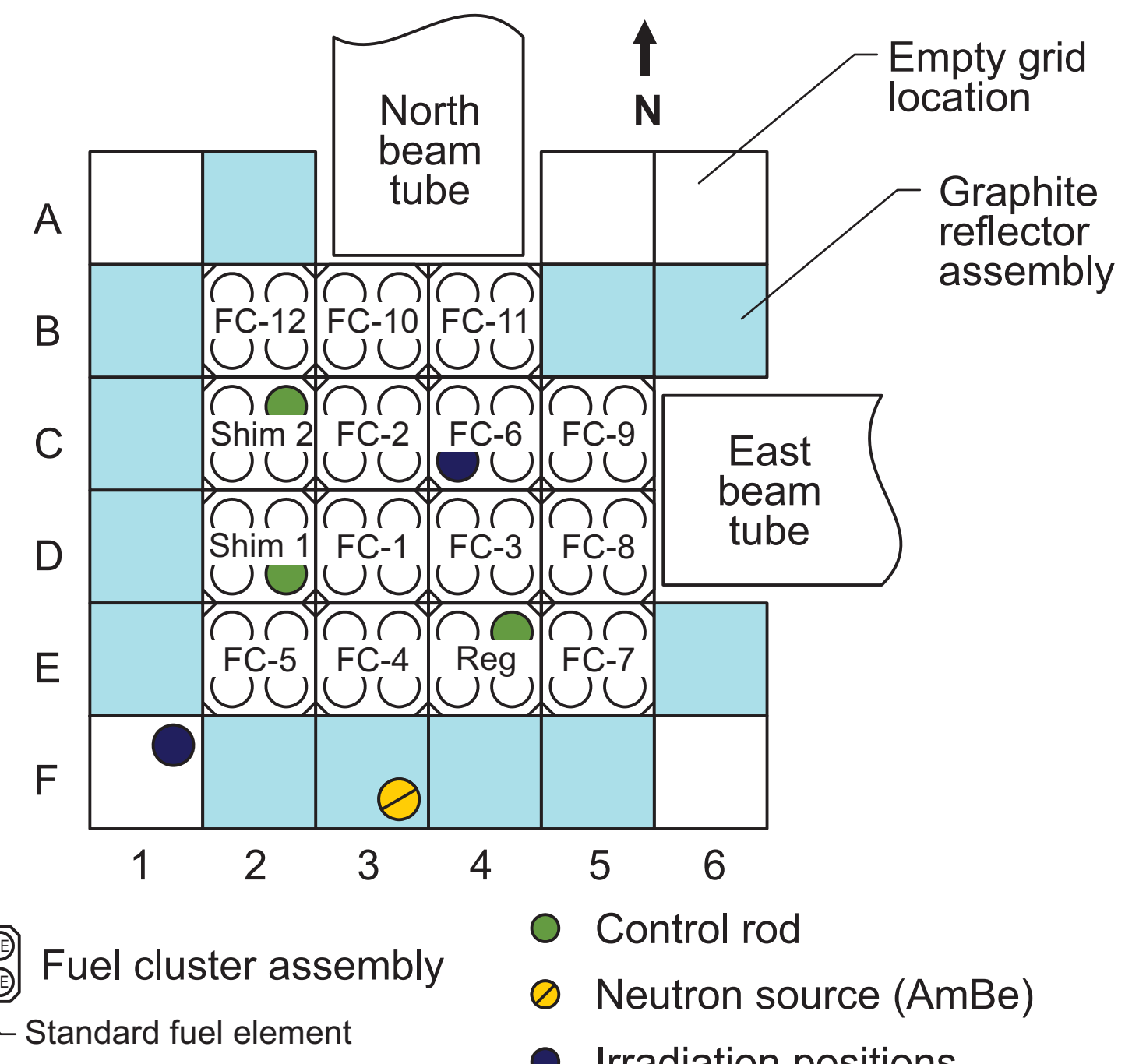

- Irradiation positions

10-GA50002-88-1

Figure 1.57. Initial Core Critical Configuration (56 Fuel Elements). 
NEA/NSC/DOC(2006)1

Fundamental - FUND

NRAD-FUND-RESR-001

CRIT

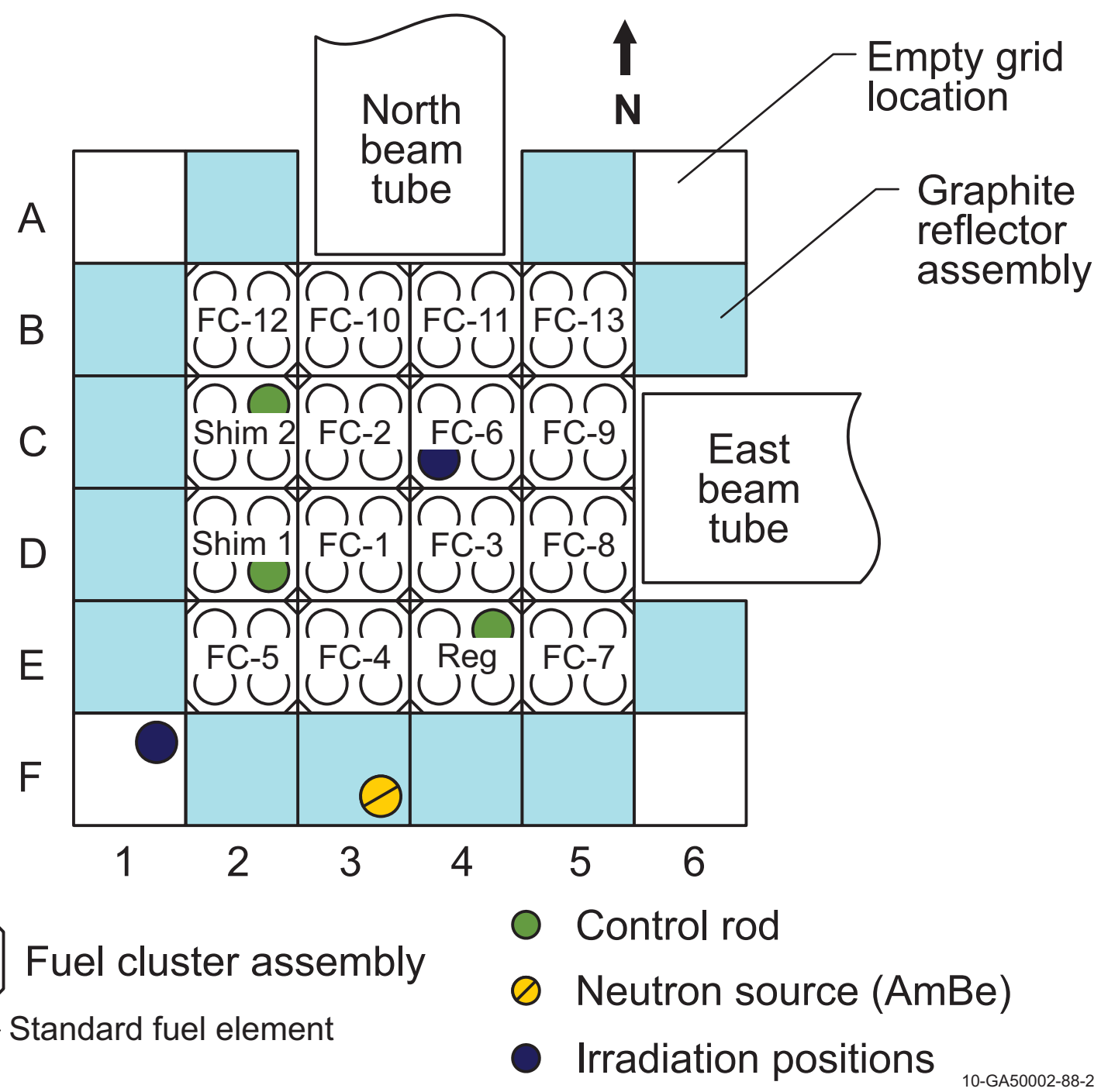

Figure 1.58. Fully Loaded Core Critical Configuration (60 Fuel Elements). 
NEA/NSC/DOC(2006)1

Fundamental - FUND

NRAD-FUND-RESR-001

CRIT

\subsubsection{Material Data}

\subsubsection{Facility Description}

\section{Site and Facility}

The rock layer below the HFEF basement is composed of natural lava rock.

The concrete is magnetite aggregate concrete with a density of about $220 \mathrm{lb} / \mathrm{ft}^{3}$ with additional steel plates and borated polyethylene to reduce radiation levels in adjacent rooms. ${ }^{\mathrm{a}}$

The concrete surrounding the reactor tank contains $120 \mathrm{lb} / \mathrm{yd}^{3}$ of boron frit. ${ }^{\mathrm{b}}$

\section{Reactor Containment}

The reactor tank is constructed from welded aluminum 6061-T6. ${ }^{\mathrm{c}}$

\section{Non-Nuclear Components}

The overflow and coolant system piping is comprised of aluminum 6061-T6.

\section{Moderator/Coolant}

The tank water temperature was between 26.0 and $26.2{ }^{\circ} \mathrm{C}$ during fuel loading for the initial critical with 56 fuel elements. A single thermistor, located approximately $1 \mathrm{ft}(\sim 30.48 \mathrm{~cm})$ below the surface of the tank water, is used to measure water temperature. It is nonlinear, very accurate, and calibrated to a tenth of a degree. Two additional thermistors are located before and after the coolant water heat exchanger to measure coolant temperature during power operations. They are calibrated to a hundredth of a degree. Full power operation is limited to $39{ }^{\circ} \mathrm{C}$. Startup temperatures are typically at $26{ }^{\circ} \mathrm{C}$ and at-power operations are typically performed at $37^{\circ} \mathrm{C}$.

For the initial critical with 60 elements the tank water temperature was $27.5{ }^{\circ} \mathrm{C}$; the tank water temperature was slightly elevated due to several days operating at low power.

The water in the NRAD tank goes through several deionizers to remove impurities. The water chemistry is monitored for conductivity and radioactivity content.

\subsubsection{Reactor Core}

\section{Core Support Structure}

The core support structure and core mounting pad are composed of aluminum 6061-T6. They are bolted together with cap screws also composed of aluminum 6061-T6.

\footnotetext{
a "NRAD Safety Analysis Report," DSA-005-NRAD rev. 5, Idaho National Laboratory (April 2, 2009). [This reference is not available for public release.]

b "HFEF/N Neutron Radiography Facility System Design Description,” W0170-0004-SA rev. 2, Idaho National Laboratory (June 1, 1978). [This reference is not available for public release.]

c "NRAD Reactor Fuel Core Conversion,” DSA-005-NRAD-ADD-3 rev. 0, Idaho National Laboratory (April 2, 2009). [This reference is not available for public release.]
} 
NEA/NSC/DOC(2006)1

Fundamental - FUND

NRAD-FUND-RESR-001

CRIT

\section{Grid Plate Assembly}

The grid plate assembly is composed of aluminum 1100. It is bolted to the support structure with aluminum 6061-T6 nuts and bolts. The skirt on the four sides of the grid plate is also aluminum 6061T6. The dowel pins used to align the cluster assemblies are stainless steel 304.

\section{Fuel Cluster Assembly}

A cluster of four fuel elements contains approximately $592 \pm 1 \mathrm{~g}$ of ${ }^{235} \mathrm{U}$.

The locking plates and locking bolts for the upper cluster attachments are stainless steel 304 or 304L. The threaded insert used in the top assemblies is either stainless steel 303 or 18-8. The bottom cluster fitting and remaining parts of the top assembly are aluminum 6061-T6.

\section{Fuel Elements}

The TRIGA fuel elements were manufactured in 2009-2010 by TRIGA International, a joint venture between General Atomics in San Diego, California, USA, and CERCA, a subsidiary of AREVA NP in Romans-sur-Isère, France, at the CERCA Fuel Fabrication Plant. A total of 64 low enriched fuel elements (four of which are spares) were fabricated for the NRAD reactor. A summary of the as-built fuel data (Appendix D) is provided in Table 1.5.

Table 1.5. Summary of As-Built Fuel Data per Average Fuel Element (Appendix D). ${ }^{(a)}$

\begin{tabular}{|c|c|c|c||}
\hline $\begin{array}{c}\text { Core Configuration } \\
\text { Number of Fuel Elements }\end{array}$ & 56 & 60 & 64 \\
\hline \hline Total Mass (g) & $2506.4 \pm 3.5$ & $2506.5 \pm 3.4$ & $2506.8 \pm 3.6$ \\
Uranium Mass (g) & $749.6 \pm 2.5$ & $749.9 \pm 2.7$ & $750.2 \pm 3.1$ \\
${ }^{235}$ U Mass (g) & $147.9 \pm 0.5$ & $148.0 \pm 0.6$ & $148.1 \pm 0.7$ \\
${ }^{235}$ U Enrichment (\%) & $19.74 \pm 0.01$ & $19.74 \pm 0.02$ & $19.74 \pm 0.02$ \\
U Mass Content (wt.\%) & $29.91 \pm 0.07$ & $29.92 \pm 0.09$ & $29.23 \pm 0.10$ \\
H/Zr Ratio & $1.58 \pm 0.01$ & $1.58 \pm 0.01$ & $1.58 \pm 0.01$ \\
Er Content (wt.\%) & $0.90 \pm 0.02$ & $0.90 \pm 0.02$ & $0.90 \pm 0.02$ \\
C Content (wt.\%) & $0.30 \pm 0.01$ & $0.30 \pm 0.02$ & $0.30 \pm 0.02$ \\
Fuel Element Length (mm) & $380.2 \pm 0.4$ & $380.2 \pm 0.4$ & $380.2 \pm 0.4$ \\
Fuel Element Diameter (mm) & $34.805 \pm 0.003$ & $34.805 \pm 0.003$ & $34.805 \pm 0.003$ \\
Cladding Inner Diameter (mm) & $34.894 \pm 0.005$ & $34.894 \pm 0.005$ & $34.894 \pm 0.005$ \\
Fuel-Clad Difference (mm) & $0.088 \pm 0.005$ & $0.089 \pm 0.005$ & $0.089 \pm 0.005$ \\
\hline
\end{tabular}

(a) The uncertainty in these values is $1 \sigma$ of the average population and not the average mean.

TRIGA fuel is a uranium-zirconium-hydride $\left(\mathrm{UZrH}_{\mathrm{x}}\right)$ fuel where the uranium is dispersed in a matrix of zirconium-hydride. Typically the $\mathrm{H} / \mathrm{Zr}$ ratio is $\sim 1.6$. The final fuel form is accomplished by hydriding uranium-zirconium alloy fuel sections to provide intrinsic moderation. A hole is drilled through the center of the fuel section to facilitate hydriding; then a zirconium rod is placed in the hole to prevent fuel damage during reactor operations. 
NEA/NSC/DOC(2006)1

\author{
Fundamental - FUND \\ NRAD-FUND-RESR-001 \\ CRIT
}

The uranium-zirconium alloy is cast in an induction furnace at high temperature under a controlled atmosphere. Prior to casting, all components (uranium, zirconium, erbium, and recycled material cast off from prior fuel fabrication batches) have been carefully weighed and checked. (Erbium is added in small quantities, as a burnable poison, to reduce initial core excess reactivity.) Components are melted in a graphite crucible and poured into a graphite mold to cool down to room temperature. A remelt is performed directly in the mold to improve the homogeneity and structural quality of the alloy. After cooling, the casting is removed from the mold and brought to the desired length and diameter on a lathe. Each fuel meat is then individually identified. After machining, chops are washed away to be used as recyclable material and as samples for chemical analysis. The fuel meats are then hydrided in an electrically heated furnace at high temperature under a hydrogen environment. A centerless grinder is used to bring the fuel meat to the final diameter and then cleaned to remove surface defects. The fuel meat is slid into the cladding with the other fuel element components and the end fittings are welded to the clad and Helium leak tested. ${ }^{\mathrm{a}}$

The fuel elements are clad in stainless steel 304 with end fittings of the same material.

Typical impurities in the fuel include carbon and hafnium in the zirconium and hydrogen in the erbium. There is $\sim 0.2$ wt.\% $\mathrm{Hf}$ in the fuel. The $\mathrm{H}: \mathrm{Zr}$ specification for the fuel only correlates hydrogen to zirconium and does not include the other constituents in the fuel. The raw material feed, uranium fuel from the Y-12 National Security Complex, is typically enriched to $\sim 19.75 \%{ }^{235} \mathrm{U}$. The molybdenum poison disc is composed of natural molybdenum and believed to be $\sim 100 \%$ pure. The axial graphite reflectors are comprised of nuclear grade graphite, possibly PGX ${ }^{\mathrm{TM}}$ (low ash, molded graphite) or $\mathrm{ECW}^{\mathrm{TM}}$ (highly purified, extruded graphite). ${ }^{\mathrm{b}}$

It is believed that a total of eleven batches of uranium metal were shipped from Y-12 to CERCA to be used in the fabrication of the NRAD fuel elements. ${ }^{\circ}$

Typically the hafnium content in the zirconium is $60 \mathrm{ppm}$ without a lot of variation. The carbon content in the fuel composition comes from the hydriding process in the graphite crucible. Variations in fuel content typically have very small effects on criticality. The most sensitive composition variations include hydrogen, ${ }^{167} \mathrm{Er}$, and ${ }^{235} \mathrm{U}$. All manufactured fuel was within the required fuel specifications. Variation of the loading pattern for the NRAD reactor core was calculated to have at most a $0.0012 \Delta \mathrm{k}_{\text {eff }}$ difference between the most and least reactive configurations. ${ }^{\mathrm{d}}$

Casting sprues, rejected meats, and fillings are all reprocessed at another AREVA facility and sent back to CERCA for use in new fuel fabrications. Reprocessed material must meet the Y-12 specifications (Table 1.6). ${ }^{\mathrm{e}}$

The nominal density of $\mathrm{UZrH}_{2}$ fuel containing $30 \mathrm{wt} . \%$ uranium content is $7.24 \mathrm{~g} / \mathrm{cm}^{3}$.

\footnotetext{
a G. Harbonnier and J-C. Ottone, "TRIGA International: A New TRIGA Fuel Fabrication Facility at CERCA," Proc. Test, Research, and Training Reactors (TRTR) - Annual Meeting 1997, Newport, Oregon (October 21-24, 1997).

${ }^{\mathrm{b}}$ Personal communication with John M. Bolin at General Atomics (November 3, 2009).

${ }^{c}$ Personal communication with John M. Bolin at General Atomics (October 20, 2010).

${ }^{\mathrm{d}}$ Presentation material with subsequent discussion at the American Nuclear Society 2010 Annual Meeting in regards to "Fuel Manufacturing Uncertainty Efffect on NRAD Criticality," by H. Choi, J. Bolin, and A. Veca (June $16,2010)$.

e Personal communication with Eric C. Woolstenhulme at INL (April 27, 2010).

${ }^{\mathrm{f}}$ N. Comte, B. Thievenaz, M. Doucet, E. Torlini, and T. Pin, "TRIGA A Widely Used Fuel - Assessments, Validation and Application of Criticality Standards," Proc. Nuclear Criticality Safety Division Topical Meeting, Richland, Washington (September 13-17, 2009).
} 
There is no bonding material between the cladding and fuel meat or other fuel elements components. ${ }^{\mathrm{a}}$

A fuel sample ( $\sim 15 \mathrm{~g})$ from a spare fuel element that was fabricated and shipped with the fuel elements placed in the NRAD reactor was sent to $\mathrm{Y}-12^{\mathrm{b}}$ for further material analysis. The sample was approximately $29.828 \mathrm{wt} . \%$ uranium $\left(19.75 \%{ }^{235} \mathrm{U}\right)$. Various tests were performed during July $7-26$, 2010, to determine the complete composition of the fuel. Results from the analyses are given in Table 1.7. Because of the variability in stock material used to fabricate all the TRIGA fuel elements, this sample provides a rough estimate of the fuel composition but does not necessarily represent the exact quantity of material in all fuel elements in the NRAD reactor. Tests to measure the oxygen, nitrogen, and hydrogen content in the sample using Leco methods could not be performed as the quantities exceeded the detection capability of the instrumentation. The fuel in the spare element was prepared in the same fuel batch as the four fuel elements not used in the operational core configuration.

a R. E. Smith, “TRIGA Fuel Summary Report,” ICP/INT-05-817, Idaho Cleanup Project, Idaho National Laboratory (March 2005). [This reference is not available for public release.]

${ }^{\mathrm{b}}$ Y-12 National Security Complex, Analytical Chemistry, Oak Ridge, Tennessee. 
NEA/NSC/DOC(2006)1

Fundamental - FUND

NRAD-FUND-RESR-001

CRIT

Table 1.6. Y-12 Chemical Specification of Uranium Metal Supplied to Research Reactors. ${ }^{(a)}$

\begin{tabular}{|c|c|c|c|}
\hline Element & Units & LEU & $\begin{array}{c}\text { EBC } \\
\text { Factor }\end{array}$ \\
\hline $\begin{array}{l}\text { Uranium } \\
\text { (Metal) }\end{array}$ & wt.\% & $\geq 99.880 \%$ & \\
\hline U-232 & $\mu \mathrm{g} / \mathrm{gU}$ & $\leq 0.002$ & \\
\hline U-234 & wt.\% & $\leq 0.260 \%$ & \\
\hline $\begin{array}{c}\text { U-235 } \\
( \pm 0.20 \text { wt. } \%)\end{array}$ & wt.\% & $19.75 \%$ & \\
\hline U-236 & $\mu \mathrm{g} / \mathrm{gU}$ & $\leq 4600$ & \\
\hline $\begin{array}{l}\text { Trans-U } \\
\text { (Alpha) }^{(\mathrm{b})}\end{array}$ & $\mathrm{Bq} / \mathrm{gU}$ & $\leq 100.0$ & \\
\hline $\begin{array}{l}\text { Activation } \\
\text { Products }\end{array}$ & $\mathrm{Bq} / \mathrm{gU}$ & $\leq 100.0$ & \\
\hline $\begin{array}{l}\text { Fission } \\
\text { Products }\end{array}$ & $\mathrm{Bq} / \mathrm{gU}$ & $\leq 600.0$ & \\
\hline Aluminum & $\mu \mathrm{g} / \mathrm{gU}$ & $\leq 150.0$ & 0.0000 \\
\hline Arsenic & $\mu \mathrm{g} / \mathrm{gU}$ & $\mathrm{TBR}^{(\mathrm{c})}$ & 0.0008 \\
\hline Beryllium & $\mu \mathrm{g} / \mathrm{gU}$ & $\leq 1.0$ & 0.0000 \\
\hline Boron & $\mu \mathrm{g} / \mathrm{gU}$ & $\leq 1.0$ & 1.0000 \\
\hline Cadmium & $\mu \mathrm{g} / \mathrm{gU}$ & $\leq 1.0$ & 0.3172 \\
\hline Calcium & $\mu \mathrm{g} / \mathrm{gU}$ & $\leq 100.0$ & 0.0002 \\
\hline Carbon & $\mu \mathrm{g} / \mathrm{gU}$ & $\leq 350.0$ & 0.0000 \\
\hline Chromium & $\mu \mathrm{g} / \mathrm{gU}$ & $\leq 50.0$ & 0.0008 \\
\hline Cobalt & $\mu \mathrm{g} / \mathrm{gU}$ & $\leq 5.0$ & 0.0089 \\
\hline Copper & $\mu \mathrm{g} / \mathrm{gU}$ & $\leq 50.0$ & 0.0008 \\
\hline Dysprosium & $\mu \mathrm{g} / \mathrm{gU}$ & $\leq 5.0$ & 0.0818 \\
\hline Europium & $\mu \mathrm{g} / \mathrm{gU}$ & $\leq 2.0$ & 0.4250 \\
\hline Gadolinium & $\mu \mathrm{g} / \mathrm{gU}$ & -1.0 & 4.3991 \\
\hline Iron & $\mu \mathrm{g} / \mathrm{gU}$ & $\leq 250.0$ & 0.0006 \\
\hline
\end{tabular}

\begin{tabular}{|c|c|c|c|}
\hline Element & Units & LEU & $\begin{array}{c}\text { EBC } \\
\text { Factor } \\
\end{array}$ \\
\hline Lead & $/ \mathrm{gU}$ & $\leq 5.0$ & .0000 \\
\hline Lithiu & $\mathrm{g} / \mathrm{gU}$ & 2.0 & .1469 \\
\hline Magnesium & $\mathrm{g} / \mathrm{gU}$ & $\leq 50.0$ & 0.0000 \\
\hline Manganese & $\mathrm{g} / \mathrm{gU}$ & $\leq 24.0$ & 0.0034 \\
\hline Molybd & $\mathrm{g} / \mathrm{gU}$ & $\leq 100.0$ & 0.0004 \\
\hline Nickel & $\mu \mathrm{g} / \mathrm{gU}$ & $\leq 100.0$ & 0.0011 \\
\hline Niobium & $\mu \mathrm{g} / \mathrm{gU}$ & TBR & 0.0002 \\
\hline Nitrogen & $\mu \mathrm{g} / \mathrm{gU}$ & TBR & 0.0019 \\
\hline Phos! & $\mu \mathrm{g} / \mathrm{gU}$ & $\leq 50.0$ & 0.0000 \\
\hline Potassium & $\mu \mathrm{g} / \mathrm{gU}$ & TBR & 0.0008 \\
\hline Sama & $\mu \mathrm{g} / \mathrm{gU}$ & $\leq 2.0$ & 0.5336 \\
\hline & $\mathrm{g} / \mathrm{gU}$ & $\leq 100.0$ & 0.0000 \\
\hline $\mathrm{Si}$ & $\mathrm{g} / \mathrm{gU}$ & TBR & 0.0083 \\
\hline Sodium & $\mu \mathrm{g} / \mathrm{gU}$ & $\leq 25.0$ & 0.0003 \\
\hline Tin & $\mu \mathrm{g} / \mathrm{gU}$ & $\leq 100.0$ & 0.0000 \\
\hline Tungsten & $\mu \mathrm{g} / \mathrm{gU}$ & $\leq 100.0$ & 0.0014 \\
\hline Vanadium & $\mu \mathrm{g} / \mathrm{gU}$ & $\leq 30.0$ & 0.0014 \\
\hline Zinc & $\mu \mathrm{g} / \mathrm{gU}$ & TBR & 0.0002 \\
\hline Zirconium & $\mu \mathrm{g} / \mathrm{gU}$ & $\leq 25.0$ & 0.0000 \\
\hline $\begin{array}{c}\text { Total } \\
\text { Impurities }\end{array}$ & $\mu \mathrm{g} / \mathrm{gU}$ & $\leq 1,200$ & \\
\hline \multicolumn{2}{|c|}{$\begin{array}{c}\text { Equivalent } \\
\text { Boron Content }{ }^{(\mathrm{d}),(\mathrm{e})}\end{array}$} & $\leq 3.0$ & \\
\hline
\end{tabular}

(a) "The Y-12 Standard Specification Low Enriched Uranium Metal Supply to Research and Test Reactors," Y/GNSS/05-05, Rev. 2, BWXT Y-12, Oak Ridge, Tennessee (August 2007).

(b) Alpha activity represents measured transuranium elements: Am-241, Cm-243/-244, Np-237, Pu238, and $\mathrm{Pu}-239 /-240$.

(c) TBR means that the value is "To Be Reported", when material measurements are performed.

(d) Equivalent Boron Content (EBC) factors are taken from ASTM C1233-03, "Standard Practice for Determining Equivalent Boron Contents of Nuclear Materials." EBC calculation will include B, $\mathrm{Cd}$, Dy, Eu, Gd, Li, and Sm. All other EBC factors are provided for information purposes only.

(e) The limit on EBC may restrict some elements to lower values than shown in the table above. 
NEA/NSC/DOC(2006)1

Fundamental - FUND

NRAD-FUND-RESR-001 CRIT

Table 1.7. Y-12 Analysis of U-Er-Zr-H Fuel. ${ }^{(a)}$

\begin{tabular}{|c|c|c|c|c|c|c|c|}
\hline Component & Value & $\begin{array}{c}\text { Unit of } \\
\text { Measure }\end{array}$ & $\begin{array}{c}\text { Test } \\
\text { Method } \\
\end{array}$ & Component & Value & $\begin{array}{c}\text { Unit of } \\
\text { Measure }\end{array}$ & $\begin{array}{c}\text { Test } \\
\text { Method } \\
\end{array}$ \\
\hline $\mathrm{C}$ & 2930 & $\mu \mathrm{g} / \mathrm{g}$ & Carbon Leco & $\mathrm{Er}$ & 4600 & $\mu \mathrm{g} / \mathrm{gU}$ & ICP-MS \\
\hline $\mathrm{U}$ & 296000 & $\mu \mathrm{g} / \mathrm{g}$ & \multirow{5}{*}{$\begin{array}{l}\text { Isotopic } \\
\text { Dilution }^{(\mathfrak{b})}\end{array}$} & $\mathrm{Eu}$ & 0.77 & $\mu \mathrm{g} / \mathrm{gU}$ & ICP-MS \\
\hline U-234 & 0.159 & wt. $\%$ & & $\mathrm{Fe}$ & 194 & $\mu \mathrm{g} / \mathrm{gU}$ & ICP-OES \\
\hline U-235 & 19.726 & wt. $\%$ & & $\mathrm{Ga}$ & $<1$ & $\mu \mathrm{g} / \mathrm{gU}$ & ICP-MS \\
\hline U-236 & 0.144 & wt. $\%$ & & $\mathrm{Gd}$ & $<0.3$ & $\mu \mathrm{g} / \mathrm{gU}$ & ICP-MS \\
\hline U-238 & 79.971 & wt. $\%$ & & $\mathrm{Ge}$ & $<1$ & $\mu \mathrm{g} / \mathrm{gU}$ & ICP-MS \\
\hline Am-241 & -32 & $\mathrm{pCi} / \mathrm{g}$ & \multirow{2}{*}{ CT-AM-5 $5^{(\mathrm{c})}$} & $\mathrm{Hf}$ & 34 & $\mu \mathrm{g} / \mathrm{gU}$ & ICP-MS \\
\hline $\mathrm{Cm}-243 / 244$ & 0 & $\mathrm{pCi} / \mathrm{g}$ & & $\mathrm{Hg}$ & $<1$ & $\mu \mathrm{g} / \mathrm{gU}$ & ICP-MS \\
\hline $\mathrm{Np}-237$ & -1.5 & $\mathrm{pCi} / \mathrm{g}$ & CT-NP-5 ${ }^{(\mathrm{c})}$ & Ho & $<1.1$ & $\mu \mathrm{g} / \mathrm{gU}$ & ICP-MS \\
\hline $\mathrm{Pu}-238$ & 35 & $\mathrm{pCi} / \mathrm{g}$ & \multirow{2}{*}{$\begin{array}{c}\text { Alpha } \\
\text { Spectrometry }^{(\mathrm{c})}\end{array}$} & In & $<1$ & $\mu \mathrm{g} / \mathrm{gU}$ & ICP-MS \\
\hline $\mathrm{Pu}-239 / 240$ & 34 & $\mathrm{pCi} / \mathrm{g}$ & & Ir & $<1$ & $\mu \mathrm{g} / \mathrm{gU}$ & ICP-MS \\
\hline Th-228 & 280 & $\mathrm{pCi} / \mathrm{g}$ & \multirow{3}{*}{$\begin{array}{c}\text { Alpha } \\
\text { Spectrometry }{ }^{(\mathrm{c})}\end{array}$} & $\mathrm{K}$ & 22 & $\mu \mathrm{g} / \mathrm{gU}$ & ICP-MS \\
\hline Th-230 & 42 & $\mathrm{pCi} / \mathrm{g}$ & & $\mathrm{La}$ & $<1$ & $\mu \mathrm{g} / \mathrm{gU}$ & ICP-MS \\
\hline Th-232 & 0 & $\mathrm{pCi} / \mathrm{g}$ & & $\mathrm{Li}$ & $<1$ & $\mu \mathrm{g} / \mathrm{gU}$ & ICP-MS \\
\hline U-234 & 3100000 & $\mathrm{pCi} / \mathrm{g}$ & \multirow{4}{*}{$\begin{array}{c}\text { Alpha } \\
\text { Spectrometry }^{(c)}\end{array}$} & $\mathrm{Lu}$ & $<1.1$ & $\mu \mathrm{g} / \mathrm{gU}$ & ICP-MS \\
\hline U-235 & 150000 & $\mathrm{pCi} / \mathrm{g}$ & & $\mathrm{Mg}$ & $<1$ & $\mu \mathrm{g} / \mathrm{gU}$ & ICP-OES \\
\hline $\mathrm{U}-236$ & 27000 & $\mathrm{pCi} / \mathrm{g}$ & & $\mathrm{Mn}$ & 7.7 & $\mu \mathrm{g} / \mathrm{gU}$ & HR-ICPMS \\
\hline U-238 & 92000 & $\mathrm{pCi} / \mathrm{g}$ & & Mo & 3.4 & $\mu \mathrm{g} / \mathrm{gU}$ & ICP-MS \\
\hline $\mathrm{Ag}$ & $<55$ & $\mu \mathrm{g} / \mathrm{gU}$ & $\mathrm{ICP}-M S^{(\mathrm{d})}$ & $\mathrm{Na}$ & $<5$ & $\mu \mathrm{g} / \mathrm{gU}$ & ICP-OES \\
\hline $\mathrm{Al}$ & $<10$ & $\mu \mathrm{g} / \mathrm{gU}$ & $\mathrm{ICP}-O E S^{(\mathrm{e})}$ & $\mathrm{Nb}$ & 1.3 & $\mu \mathrm{g} / \mathrm{gU}$ & ICP-MS \\
\hline As & $<10$ & $\mu \mathrm{g} / \mathrm{gU}$ & ICP-MS & $\mathrm{Nd}$ & $<1$ & $\mu \mathrm{g} / \mathrm{gU}$ & ICP-MS \\
\hline $\mathrm{Au}$ & $<5$ & $\mu \mathrm{g} / \mathrm{gU}$ & ICP-MS & $\mathrm{Ni}$ & 8.9 & $\mu \mathrm{g} / \mathrm{gU}$ & ICP-OES \\
\hline $\mathrm{B}$ & $<0.5$ & $\mu \mathrm{g} / \mathrm{gU}$ & ICP-MS & Os & $<1$ & $\mu \mathrm{g} / \mathrm{gU}$ & ICP-MS \\
\hline $\mathrm{Ba}$ & $<1$ & $\mu \mathrm{g} / \mathrm{gU}$ & ICP-MS & $\mathrm{P}$ & $<22$ & $\mu \mathrm{g} / \mathrm{gU}$ & ICP-MS \\
\hline $\mathrm{Be}$ & $<0.24$ & $\mu \mathrm{g} / \mathrm{gU}$ & ICP-OES & $\mathrm{Pb}$ & $<1$ & $\mu \mathrm{g} / \mathrm{gU}$ & ICP-MS \\
\hline $\mathrm{Bi}$ & $<1$ & $\mu \mathrm{g} / \mathrm{gU}$ & ICP-MS & $\mathrm{Pd}$ & 2.5 & $\mu \mathrm{g} / \mathrm{gU}$ & ICP-MS \\
\hline $\mathrm{Ca}$ & $<5$ & $\mu \mathrm{g} / \mathrm{gU}$ & ICP-OES & $\operatorname{Pr}$ & $<1$ & $\mu \mathrm{g} / \mathrm{gU}$ & ICP-MS \\
\hline $\mathrm{Cd}$ & $<1$ & $\mu \mathrm{g} / \mathrm{gU}$ & ICP-OES & $\mathrm{Pt}$ & $<1$ & $\mu \mathrm{g} / \mathrm{gU}$ & ICP-MS \\
\hline $\mathrm{Ce}$ & $<1$ & $\mu \mathrm{g} / \mathrm{gU}$ & ICP-MS & $\mathrm{Rb}$ & $<1$ & $\mu \mathrm{g} / \mathrm{gU}$ & ICP-MS \\
\hline Co & $<1$ & $\mu \mathrm{g} / \mathrm{gU}$ & ICP-OES & $\mathrm{Re}$ & $<1$ & $\mu \mathrm{g} / \mathrm{gU}$ & ICP-MS \\
\hline $\mathrm{Cr}$ & 21.8 & $\mu \mathrm{g} / \mathrm{gU}$ & ICP-OES & $\mathrm{Rh}$ & $<1$ & $\mu \mathrm{g} / \mathrm{gU}$ & ICP-MS \\
\hline $\mathrm{Cs}$ & $<1$ & $\mu \mathrm{g} / \mathrm{gU}$ & ICP-MS & $\mathrm{Ru}$ & $<1$ & $\mu \mathrm{g} / \mathrm{gU}$ & ICP-MS \\
\hline $\mathrm{Cu}$ & 3.1 & $\mu \mathrm{g} / \mathrm{gU}$ & ICP-OES & $\mathrm{Sb}$ & $<2$ & $\mu \mathrm{g} / \mathrm{gU}$ & ICP-MS \\
\hline Dy & 0.8 & $\mu \mathrm{g} / \mathrm{gU}$ & ICP-MS & $\mathrm{Sc}$ & $<525$ & $\mu \mathrm{g} / \mathrm{gU}$ & ICP-MS \\
\hline
\end{tabular}


NEA/NSC/DOC(2006)1

Fundamental - FUND

NRAD-FUND-RESR-001

CRIT

Table 1.7 (cont.). Y-12 Analysis of U-Er-Zr-H Fuel.

\begin{tabular}{|c|c|c|c|}
\hline \hline Component & Value & $\begin{array}{c}\text { Unit of } \\
\text { Measure }\end{array}$ & $\begin{array}{c}\text { Test } \\
\text { Method }\end{array}$ \\
\hline \hline $\mathrm{Se}$ & $<1$ & $\mu \mathrm{g} / \mathrm{gU}$ & ICP-MS \\
\hline $\mathrm{Si}$ & $<15$ & $\mu \mathrm{g} / \mathrm{gU}$ & ICP-OES \\
\hline $\mathrm{Sm}$ & $<0.31$ & $\mu \mathrm{g} / \mathrm{gU}$ & ICP-MS \\
\hline $\mathrm{Sn}$ & $<2$ & $\mu \mathrm{g} / \mathrm{gU}$ & ICP-MS \\
\hline $\mathrm{Sr}$ & $<1$ & $\mu \mathrm{g} / \mathrm{gU}$ & ICP-MS \\
\hline $\mathrm{Ta}$ & $<1$ & $\mu \mathrm{g} / \mathrm{gU}$ & ICP-MS \\
\hline $\mathrm{Tb}$ & $<2.4$ & $\mu \mathrm{g} / \mathrm{gU}$ & ICP-OES \\
\hline $\mathrm{Te}$ & $<60$ & $\mu \mathrm{g} / \mathrm{gU}$ & ICP-MS \\
\hline $\mathrm{Th}$ & $<2.2$ & $\mu \mathrm{g} / \mathrm{gU}$ & ICP-MS \\
\hline \hline
\end{tabular}

\begin{tabular}{|c|c|c|c||}
\hline Component & Value & $\begin{array}{c}\text { Unit of } \\
\text { Measure }\end{array}$ & $\begin{array}{c}\text { Test } \\
\text { Method }\end{array}$ \\
\hline \hline $\mathrm{Ti}$ & 19 & $\mu \mathrm{g} / \mathrm{gU}$ & ICP-OES \\
\hline $\mathrm{Tl}$ & $<2.2$ & $\mu \mathrm{g} / \mathrm{gU}$ & ICP-MS \\
\hline $\mathrm{Tm}$ & $<1.1$ & $\mu \mathrm{g} / \mathrm{gU}$ & ICP-MS \\
\hline $\mathrm{V}$ & $<1$ & $\mu \mathrm{g} / \mathrm{gU}$ & HR-ICPMS \\
\hline $\mathrm{W}$ & $<25$ & $\mu \mathrm{g} / \mathrm{gU}$ & ICP-MS \\
\hline $\mathrm{Y}$ & $<5$ & $\mu \mathrm{g} / \mathrm{gU}$ & ICP-OES \\
\hline $\mathrm{Yb}$ & $<1.1$ & $\mu \mathrm{g} / \mathrm{gU}$ & ICP-MS \\
\hline $\mathrm{Zn}$ & $<1$ & $\mu \mathrm{g} / \mathrm{gU}$ & ICP-OES \\
\hline $\mathrm{Zr}$ & 730000 & $\mu \mathrm{g} / \mathrm{gU}$ & ICP-MS \\
\hline
\end{tabular}

(a) Due to the $\%$ levels of $\mathrm{Zr}$, extreme effort was required to overcome the interferences inherent to each technique in such a complex measurement.

(b) The g/g 2-sigma relative uncertainty is typically within $0.2 \%$ and the absolute difference for ${ }^{235} \mathrm{U}$ wt. $\%$ is typically within $0.025 \%$ for HEU.

(c) The 2-sigma uncertainty for most of the radioisotope measurements is approximately the same as the reported value in the table. The 2-sigma uncertainty in the uranium alpha spectrometer measurements is approximately one order of magnitude less than the value reported in the table.

(d) Quadrupole ICSP-MS.

(e) Three separate analysis runs were performed.

Material samples were sent to Evans Analytical Group ${ }^{\circledR}(\mathrm{EAG})$ Labs for compositional analysis. A total of six samples were evaluated: graphite reflector block (Table 1.14), axial graphite reflector (Table 1.8), plating on molybdenum poison disc (Table 1.9), molybdenum poison disc (Table 1.10), stainless steel end fitting (Table 1.11), and zirconium rod (Table 1.12). These samples, except for the sample from the graphite reflector block, were analyzed from the same spare fuel element that was used for the fuel pellet material analysis. The samples were analyzed from April 16-21, 2010, using glow discharge mass spectrometry (GDMS). This process uses the sample as a cathode in a low pressure ( 100 Pa) gas discharge or plasma (typically argon). Positive gas ions are accelerated towards the sample surface with energies of hundreds to thousands of $\mathrm{eV}$, which results in the erosion and atomization of the upper atomic layers of the sample. The neutral species escape the cathode surface, diffuse into the plasma, and are ionized for mass spectrometry analysis. This method allows for high sensitivity, ease of calibration, and flexibility in sample analysis, and depth profiling for most samples (excludes volatile samples, organic materials, and polymers) with full periodic table coverage. ${ }^{\mathrm{a}}$

The $\mathrm{Zr}$ samples were filed and etched so that no cross-contamination from the stainless steel saw would occur. All samples were analyzed twice with five replicates during each analysis. The data were extremely stable during both analyses. Samples were also plasma-etched during the analysis. ${ }^{b}$

\footnotetext{
${ }^{a}$ SHIVA Technologies, 6707 Brooklawn Parkway, Syracuse, New York 13211, http://www.eaglabs.com/.

${ }^{b}$ Personal communication with Timothy Alex West at EAG Labs (April 29, 2010).
} 
Fundamental - FUND

NRAD-FUND-RESR-001 CRIT

Table 1.8. GDMS Analysis of Axial Graphite Reflector.

\begin{tabular}{|c|c|c|c|c|c|}
\hline Element & ppm (wt.) & Element & ppm (wt.) & Element & ppm (wt.) \\
\hline $\mathrm{Li}$ & $<0.05$ & $\mathrm{Ga}$ & $<0.01$ & $\mathrm{Nd}$ & $<0.05$ \\
\hline $\mathrm{Be}$ & $<0.05$ & $\mathrm{Ge}$ & $<0.05$ & $\mathrm{Sm}$ & $<0.01$ \\
\hline B & 0.35 & As & $<0.05$ & $\mathrm{Eu}$ & $<0.01$ \\
\hline $\mathrm{C}$ & Matrix & $\mathrm{Se}$ & $<0.05$ & $\mathrm{Gd}$ & $<0.01$ \\
\hline $\mathrm{N}$ & -- & $\mathrm{Br}$ & $<0.1$ & $\mathrm{~Tb}$ & $<0.01$ \\
\hline $\mathrm{O}$ & -- & $\mathrm{Rb}$ & $<0.05$ & Dy & $<0.01$ \\
\hline $\mathrm{F}$ & $<0.1$ & $\mathrm{Sr}$ & $<0.05$ & Но & $<0.01$ \\
\hline $\mathrm{Na}$ & $<0.05$ & Y & $<0.05$ & $\mathrm{Er}$ & $<0.01$ \\
\hline $\mathrm{Mg}$ & $<0.05$ & $\mathrm{Zr}$ & $<0.05$ & $\mathrm{Tm}$ & $<0.01$ \\
\hline $\mathrm{Al}$ & $<0.05$ & $\mathrm{Nb}$ & $<0.05$ & $\mathrm{Yb}$ & $<0.01$ \\
\hline $\mathrm{Si}$ & 0.75 & Mo & $<0.05$ & $\mathrm{Lu}$ & $<0.01$ \\
\hline $\mathrm{P}$ & $<0.1$ & $\mathrm{Ru}$ & $<0.05$ & Hf & $<0.01$ \\
\hline $\mathrm{S}$ & 0.92 & $\mathrm{Rh}$ & $<0.01$ & $\mathrm{Ta}$ & $<100$ \\
\hline $\mathrm{Cl}$ & 0.24 & $\mathrm{Pd}$ & $<0.05$ & W & $<0.05$ \\
\hline K & $<0.1$ & $\mathrm{Ag}$ & $<0.05$ & $\operatorname{Re}$ & $<0.01$ \\
\hline $\mathrm{Ca}$ & $<0.05$ & $\mathrm{Cd}$ & $<0.05$ & Os & $<0.01$ \\
\hline $\mathrm{Sc}$ & $<0.01$ & In & $<0.05$ & Ir & $<0.01$ \\
\hline $\mathrm{Ti}$ & $<0.01$ & $\mathrm{Sn}$ & $<0.05$ & $\mathrm{Pt}$ & $<0.01$ \\
\hline V & $<0.01$ & $\mathrm{Sb}$ & $<0.05$ & $\mathrm{Au}$ & $<0.1$ \\
\hline $\mathrm{Cr}$ & $<0.5$ & $\mathrm{Te}$ & $<0.05$ & $\mathrm{Hg}$ & $<0.1$ \\
\hline $\mathrm{Mn}$ & $<0.01$ & I & $<0.01$ & $\mathrm{Tl}$ & $<0.05$ \\
\hline $\mathrm{Fe}$ & $<0.01$ & $\mathrm{Cs}$ & $<0.05$ & $\mathrm{~Pb}$ & $<0.05$ \\
\hline Co & $<0.01$ & $\mathrm{Ba}$ & $<0.05$ & $\mathrm{Bi}$ & $<0.05$ \\
\hline $\mathrm{Ni}$ & $<0.01$ & $\mathrm{La}$ & $<0.05$ & Th & $<0.05$ \\
\hline $\mathrm{Cu}$ & $<0.05$ & $\mathrm{Ce}$ & $<0.05$ & $\mathrm{U}$ & $<0.05$ \\
\hline $\mathrm{Zn}$ & $<0.05$ & $\operatorname{Pr}$ & $<0.05$ & & \\
\hline
\end{tabular}


NEA/NSC/DOC(2006)1

Fundamental - FUND

NRAD-FUND-RESR-001 CRIT

Table 1.9. GDMS Analysis of Plating on Molybdenum Disc.

\begin{tabular}{|c|c|c|c|c|c|}
\hline Element & ppm (wt.) & Element & ppm (wt.) & Element & ppm (wt.) \\
\hline $\mathrm{Li}$ & $<0.01$ & $\mathrm{Ga}$ & $<0.05$ & $\mathrm{Nd}$ & $<0.01$ \\
\hline $\mathrm{Be}$ & $<0.01$ & $\mathrm{Ge}$ & $<0.1$ & $\mathrm{Sm}$ & $<0.01$ \\
\hline B & $<0.01$ & As & 0.35 & $\mathrm{Eu}$ & $<0.01$ \\
\hline $\mathrm{C}$ & Binder & $\mathrm{Se}$ & $<0.1$ & $\mathrm{Gd}$ & $<0.01$ \\
\hline $\mathrm{N}$ & -- & $\mathrm{Br}$ & $<0.01$ & $\mathrm{~Tb}$ & $<0.01$ \\
\hline $\mathrm{O}$ & -- & $\mathrm{Rb}$ & $<0.05$ & Dy & $<0.01$ \\
\hline $\mathrm{F}$ & $<0.01$ & $\mathrm{Sr}$ & $<0.5$ & Ho & $<0.01$ \\
\hline $\mathrm{Na}$ & 5 & Y & $<0.1$ & Er & $<0.01$ \\
\hline $\mathrm{Mg}$ & 0.45 & $\mathrm{Zr}$ & $<0.1$ & $\mathrm{Tm}$ & $<0.01$ \\
\hline $\mathrm{Al}$ & 0.55 & $\mathrm{Nb}$ & $<0.5$ & $\mathrm{Yb}$ & $<0.01$ \\
\hline $\mathrm{Si}$ & 2.7 & Mo & Matrix & $\mathrm{Lu}$ & $<0.01$ \\
\hline $\mathrm{P}$ & 0.75 & $\mathrm{Ru}$ & $<0.05$ & $\mathrm{Hf}$ & $<0.01$ \\
\hline $\mathrm{S}$ & 3.3 & $\mathrm{Rh}$ & $<0.05$ & $\mathrm{Ta}$ & $<10$ \\
\hline $\mathrm{Cl}$ & 0.2 & $\mathrm{Pd}$ & $<0.1$ & W & 130 \\
\hline K & $\sim 30$ & $\mathrm{Ag}$ & $<0.5$ & $\operatorname{Re}$ & 0.15 \\
\hline $\mathrm{Ca}$ & 2.5 & $\mathrm{Cd}$ & $<10$ & Os & $<0.05$ \\
\hline $\mathrm{Sc}$ & $<0.005$ & In & $<0.05$ & Ir & $<0.05$ \\
\hline $\mathrm{Ti}$ & $<10$ & Sn & 0.25 & $\mathrm{Pt}$ & $<0.05$ \\
\hline V & 1.1 & $\mathrm{Sb}$ & 1.5 & $\mathrm{Au}$ & $<0.05$ \\
\hline $\mathrm{Cr}$ & 4.3 & $\mathrm{Te}$ & $<0.05$ & $\mathrm{Hg}$ & $<0.05$ \\
\hline $\mathrm{Mn}$ & 0.43 & I & $<0.01$ & $\mathrm{Tl}$ & $<0.05$ \\
\hline $\mathrm{Fe}$ & 15 & Cs & $<0.05$ & $\mathrm{~Pb}$ & $<0.05$ \\
\hline Co & 0.15 & $\mathrm{Ba}$ & 15 & $\mathrm{Bi}$ & $<0.05$ \\
\hline $\mathrm{Ni}$ & 1.3 & $\mathrm{La}$ & 1.1 & Th & $<0.005$ \\
\hline $\mathrm{Cu}$ & 2.5 & $\mathrm{Ce}$ & 0.03 & $\mathrm{U}$ & 0.04 \\
\hline $\mathrm{Zn}$ & $<0.05$ & $\operatorname{Pr}$ & $<0.01$ & & \\
\hline
\end{tabular}


NEA/NSC/DOC(2006)1

Fundamental - FUND

NRAD-FUND-RESR-001 CRIT

Table 1.10. GDMS Analysis of Molybdenum Disc.

\begin{tabular}{|c|c|c|c|c|c|}
\hline Element & ppm (wt.) & Element & ppm (wt.) & Element & ppm (wt.) \\
\hline $\mathrm{Li}$ & $<0.01$ & $\mathrm{Ga}$ & $<0.05$ & $\mathrm{Nd}$ & $<0.01$ \\
\hline $\mathrm{Be}$ & $<0.01$ & $\mathrm{Ge}$ & $<0.1$ & $\mathrm{Sm}$ & $<0.01$ \\
\hline B & $<0.01$ & As & 0.35 & $\mathrm{Eu}$ & $<0.01$ \\
\hline $\mathrm{C}$ & -- & $\mathrm{Se}$ & $<0.1$ & Gd & $<0.01$ \\
\hline $\mathrm{N}$ & -- & $\mathrm{Br}$ & $<0.01$ & $\mathrm{~Tb}$ & $<0.01$ \\
\hline $\mathrm{O}$ & -- & $\mathrm{Rb}$ & $<0.05$ & Dy & $<0.01$ \\
\hline $\mathrm{F}$ & $<0.01$ & $\mathrm{Sr}$ & $<0.5$ & Но & $<0.01$ \\
\hline $\mathrm{Na}$ & 0.77 & Y & $<0.1$ & $\mathrm{Er}$ & $<0.01$ \\
\hline $\mathrm{Mg}$ & 0.29 & $\mathrm{Zr}$ & $<0.1$ & $\mathrm{Tm}$ & $<0.01$ \\
\hline $\mathrm{Al}$ & 0.33 & $\mathrm{Nb}$ & $<0.5$ & $\mathrm{Yb}$ & $<0.01$ \\
\hline $\mathrm{Si}$ & 1.3 & Mo & Matrix & $\mathrm{Lu}$ & $<0.01$ \\
\hline $\mathrm{P}$ & 0.27 & $\mathrm{Ru}$ & $<0.05$ & $\mathrm{Hf}$ & $<0.01$ \\
\hline S & 0.59 & $\mathrm{Rh}$ & $<0.05$ & $\mathrm{Ta}$ & $<10$ \\
\hline $\mathrm{Cl}$ & $<0.01$ & $\mathrm{Pd}$ & $<0.1$ & W & 120 \\
\hline K & $\sim 20$ & $\mathrm{Ag}$ & $<0.5$ & $\mathrm{Re}$ & 0.11 \\
\hline $\mathrm{Ca}$ & 1.1 & $\mathrm{Cd}$ & $<10$ & Os & $<0.05$ \\
\hline $\mathrm{Sc}$ & $<0.005$ & In & $<0.05$ & Ir & $<0.05$ \\
\hline $\mathrm{Ti}$ & $<10$ & $\mathrm{Sn}$ & 0.13 & $\mathrm{Pt}$ & $<0.05$ \\
\hline V & 1.1 & $\mathrm{Sb}$ & 1.1 & $\mathrm{Au}$ & $<0.05$ \\
\hline $\mathrm{Cr}$ & 3.3 & $\mathrm{Te}$ & $<0.05$ & $\mathrm{Hg}$ & $<0.05$ \\
\hline $\mathrm{Mn}$ & 0.43 & I & $<0.01$ & $\mathrm{Tl}$ & $<0.05$ \\
\hline $\mathrm{Fe}$ & 8.5 & Cs & $<0.05$ & $\mathrm{~Pb}$ & $<0.05$ \\
\hline Co & 0.13 & $\mathrm{Ba}$ & 15 & $\mathrm{Bi}$ & $<0.05$ \\
\hline $\mathrm{Ni}$ & 1.1 & $\mathrm{La}$ & 0.79 & Th & $<0.005$ \\
\hline $\mathrm{Cu}$ & 2.5 & $\mathrm{Ce}$ & 0.02 & $\mathrm{U}$ & 0.04 \\
\hline $\mathrm{Zn}$ & $<0.05$ & $\operatorname{Pr}$ & $<0.01$ & & \\
\hline
\end{tabular}


Fundamental - FUND

NRAD-FUND-RESR-001 CRIT

Table 1.11. GDMS Analysis of Stainless Steel End Fitting.

\begin{tabular}{|c|c|c|c|c|c|}
\hline Element & ppm (wt.) & Element & ppm (wt.) & Element & ppm (wt.) \\
\hline $\mathrm{Li}$ & $<0.01$ & $\mathrm{Ga}$ & 16 & $\mathrm{Nd}$ & $<0.005$ \\
\hline $\mathrm{Be}$ & $<0.01$ & $\mathrm{Ge}$ & 20 & $\mathrm{Sm}$ & $<0.005$ \\
\hline B & 2.5 & As & 35 & $\mathrm{Eu}$ & $<0.005$ \\
\hline $\mathrm{C}$ & -- & $\mathrm{Se}$ & $<0.1$ & $\mathrm{Gd}$ & $<0.005$ \\
\hline $\mathrm{N}$ & -- & $\mathrm{Br}$ & $<0.1$ & $\mathrm{~Tb}$ & $<0.005$ \\
\hline $\mathrm{O}$ & -- & $\mathrm{Rb}$ & $<0.5$ & Dy & $<0.005$ \\
\hline $\mathrm{F}$ & $<0.01$ & $\mathrm{Sr}$ & $<0.2$ & Но & $<0.005$ \\
\hline $\mathrm{Na}$ & $<0.01$ & Y & $<0.05$ & $\mathrm{Er}$ & $<0.005$ \\
\hline $\mathrm{Mg}$ & 1.8 & $\mathrm{Zr}$ & 1.8 & $\mathrm{Tm}$ & $<0.005$ \\
\hline $\mathrm{Al}$ & 12 & $\mathrm{Nb}$ & 110 & $\mathrm{Yb}$ & $<0.005$ \\
\hline $\mathrm{Si}$ & $\sim 0.4$ wt. $\%$ & Mo & $\sim 0.3$ wt. $\%$ & $\mathrm{Lu}$ & $<0.005$ \\
\hline $\mathrm{P}$ & 260 & $\mathrm{Ru}$ & $<0.1$ & $\mathrm{Hf}$ & $<0.01$ \\
\hline S & 22 & $\mathrm{Rh}$ & $<0.05$ & $\mathrm{Ta}$ & $<1$ \\
\hline $\mathrm{Cl}$ & $<0.05$ & $\mathrm{Pd}$ & $<0.05$ & $\mathrm{~W}$ & 160 \\
\hline K & $<0.01$ & $\mathrm{Ag}$ & $<0.5$ & $\operatorname{Re}$ & 0.25 \\
\hline $\mathrm{Ca}$ & 0.5 & $\mathrm{Cd}$ & $<0.1$ & Os & 0.09 \\
\hline $\mathrm{Sc}$ & $<0.005$ & In & $<0.5$ & Ir & 0.09 \\
\hline $\mathrm{Ti}$ & 20 & $\mathrm{Sn}$ & 55 & $\mathrm{Pt}$ & $<0.1$ \\
\hline V & $\sim 0.1$ wt. $\%$ & $\mathrm{Sb}$ & 8.9 & $\mathrm{Au}$ & $<0.05$ \\
\hline $\mathrm{Cr}$ & Matrix & $\mathrm{Te}$ & $<0.05$ & $\mathrm{Hg}$ & $<0.1$ \\
\hline $\mathrm{Mn}$ & Matrix & I & $<0.05$ & $\mathrm{Tl}$ & $<0.05$ \\
\hline $\mathrm{Fe}$ & Matrix & Cs & $<0.01$ & $\mathrm{~Pb}$ & 0.31 \\
\hline Co & 800 & $\mathrm{Ba}$ & $<0.05$ & $\mathrm{Bi}$ & $<0.01$ \\
\hline $\mathrm{Ni}$ & Matrix & $\mathrm{La}$ & $<0.01$ & Th & $<0.005$ \\
\hline $\mathrm{Cu}$ & $\sim 0.3$ wt. $\%$ & $\mathrm{Ce}$ & $<0.05$ & $\mathrm{U}$ & $<0.005$ \\
\hline $\mathrm{Zn}$ & 0.5 & $\operatorname{Pr}$ & $<0.005$ & & \\
\hline
\end{tabular}


NEA/NSC/DOC(2006)1

Fundamental - FUND

NRAD-FUND-RESR-001

CRIT

Table 1.12. GDMS Analysis of Zirconium Rod.

\begin{tabular}{|c|c|c|c|c|c|}
\hline Element & ppm (wt.) & Element & ppm (wt.) & Element & ppm (wt.) \\
\hline $\mathrm{Li}$ & $<0.005$ & As & 0.04 & $\mathrm{Sm}$ & $<0.005$ \\
\hline $\mathrm{Be}$ & $<0.005$ & $\mathrm{Se}$ & $<0.05$ & $\mathrm{Eu}$ & $<0.005$ \\
\hline B & 0.05 & $\mathrm{Br}$ & $<0.05$ & $\mathrm{Gd}$ & $<0.005$ \\
\hline $\mathrm{F}$ & $<1$ & $\mathrm{Rb}$ & $<0.05$ & $\mathrm{~Tb}$ & $<0.005$ \\
\hline $\mathrm{Na}$ & $<0.01$ & $\mathrm{Sr}$ & $<0.05$ & Dy & $<0.005$ \\
\hline $\mathrm{Mg}$ & $<0.005$ & Y & $<0.05$ & Но & $<0.005$ \\
\hline $\mathrm{Al}$ & 40 & $\mathrm{Zr}$ & Matrix & $\mathrm{Er}$ & $<0.005$ \\
\hline $\mathrm{Si}$ & 7.1 & $\mathrm{Nb}$ & 0.61 & $\mathrm{Tm}$ & $<0.005$ \\
\hline $\mathrm{P}$ & 0.79 & Mo & 2.2 & $\mathrm{Yb}$ & $<0.005$ \\
\hline S & 0.25 & $\mathrm{Ru}$ & $<0.05$ & $\mathrm{Lu}$ & $<0.005$ \\
\hline $\mathrm{Cl}$ & 0.23 & $\mathrm{Rh}$ & $<0.05$ & $\mathrm{Hf}$ & 55 \\
\hline K & $<0.1$ & $\mathrm{Pd}$ & $<0.5$ & $\mathrm{Ta}$ & $<5$ \\
\hline $\mathrm{Ca}$ & $<0.05$ & $\mathrm{Ag}$ & $<0.5$ & W & 0.12 \\
\hline $\mathrm{Sc}$ & $<5$ & $\mathrm{Cd}$ & $<0.5$ & $\operatorname{Re}$ & $<0.005$ \\
\hline $\mathrm{Ti}$ & 1.7 & In & $<0.1$ & Os & $<0.005$ \\
\hline V & 0.43 & $\mathrm{Sn}$ & 0.49 & Ir & $<0.005$ \\
\hline $\mathrm{Cr}$ & 120 & $\mathrm{Sb}$ & $<0.05$ & $\mathrm{Pt}$ & $<0.05$ \\
\hline $\mathrm{Mn}$ & 14 & $\mathrm{Te}$ & $<0.05$ & $\mathrm{Au}$ & $<0.05$ \\
\hline $\mathrm{Fe}$ & $\sim 0.15$ wt. $\%$ & I & $<0.1$ & $\mathrm{Hg}$ & $<0.05$ \\
\hline Co & 1.1 & Cs & $<0.005$ & $\mathrm{Tl}$ & $<0.01$ \\
\hline $\mathrm{Ni}$ & 63 & $\mathrm{Ba}$ & $<0.005$ & $\mathrm{~Pb}$ & 0.36 \\
\hline $\mathrm{Cu}$ & 13 & $\mathrm{La}$ & $<0.005$ & $\mathrm{Bi}$ & 0.16 \\
\hline $\mathrm{Zn}$ & 0.41 & $\mathrm{Ce}$ & $<0.005$ & Th & $<0.001$ \\
\hline $\mathrm{Ga}$ & 2.2 & $\operatorname{Pr}$ & $<0.005$ & $\mathrm{U}$ & 0.07 \\
\hline $\mathrm{Ge}$ & $<0.05$ & $\mathrm{Nd}$ & $<0.005$ & & \\
\hline
\end{tabular}


NEA/NSC/DOC(2006)1

Fundamental - FUND

NRAD-FUND-RESR-001

CRIT

\section{Control Rods}

The $\mathrm{B}_{4} \mathrm{C}$ poison material is hot pressed to a minimum density of $2.415 \mathrm{~g} / \mathrm{cm}^{3}$. The tubing material of the control rods is aluminum 6061-T6. ${ }^{\mathrm{a}}$ The extension rod, control rod connection fittings, and dowels are all aluminum 6061-T6. The bottom adapter fitting of the control rod guide tube is built from stainless steel 304 or $304 \mathrm{~L}$. The dowel pin used to fix the guide tube to this fitting is stainless steel 18-8. All other material in the control rod guide tube is aluminum 6061-T6.

Design drawings for the $\mathrm{B}_{4} \mathrm{C}$ material specify a minimum density of $2.48 \mathrm{~g} / \mathrm{cm}^{3}$ with a boron content of $78.0 \pm 1.0 \mathrm{wt} . \%$ with the naturally occurring isotope fraction of ${ }^{10} \mathrm{~B}(18.5 \pm 0.2 \mathrm{wt} . \%)$. The boron to carbon atom ratio in the finished pieces is $4.00 \pm 0.15$.

\section{Graphite Reflector Assembly}

The graphite in the reflector assemblies is considered nuclear/reactor grade. ${ }^{\mathrm{b}}$

Six graphite block samples were sent to IMR Test Labs Material Analysis Services ${ }^{c}$ to analyze the density of the graphite reflector blocks. The samples were measured between May 6-7, 2010, using ASTM C838-96 (2005) ${ }^{\mathrm{d}}$ methods for bulk density determination from mass and dimension measurements at room temperature. A graphite reflector block (similar to the one shown in Figure 1.39) was cut into sections. Pieces from three different axial locations of the block were cut out; at each axial location, a sample was taken from the side and center, such that homogeneity of the graphite density could be established. Results are shown in Table 1.13.

Table 1.13. Density Analysis of Graphite Reflector Block.

\begin{tabular}{|c|c|}
\hline Sample ID & $\begin{array}{c}\text { Density } \\
\left(\mathbf{k g} / \mathbf{m}^{\mathbf{3}} \mathbf{)}\right.\end{array}$ \\
\hline \hline A-Side & 1,570 \\
\hline A-Center & 1,570 \\
\hline B-Side & 1,560 \\
\hline B-Center & 1,580 \\
\hline C-Side & 1,560 \\
\hline C-Center & 1,580 \\
\hline
\end{tabular}

The results for the GDMS analysis, as described previously for fuel element components, of the graphite reflector block from EAG Labs is in Table 1.14.

The top and bottom assembly adapters are aluminum 6061-T6 and the associated hardware are aluminum 2011-T3 (also known as Toolrite 2011 ${ }^{\mathrm{TM}}$ ).

\footnotetext{
a "HFEF/N Neutron Radiography Facility System Design Description,” W0170-0004-SA rev. 2, Idaho National Laboratory (June 1, 1978). [This reference is not available for public release.]

${ }^{b}$ L. M. Montierth, "Criticality Safety Evaluation for the NRAD Core Conversion,” INL/INT-07-13231 rev. 1, Idaho National Laboratory (September 2008). [This reference is not available for public release.]

c 131 Woodsedge Drive, Lansing Business \& Technology Park, Lansing, New York 14882, http://www.imrtest.com/.

d ASTM C838-96, Standard Test Method for Bulk Density of As-Manufactured Carbon and Graphite Shapes.
} 
NEA/NSC/DOC(2006)1

Fundamental - FUND

NRAD-FUND-RESR-001 CRIT

Table 1.14. GDMS Analysis of Graphite Reflector Block.

\begin{tabular}{|c|c|c|c|c|c|}
\hline Element & ppm (wt.) & Element & ppm (wt.) & Element & ppm (wt.) \\
\hline $\mathrm{Li}$ & $<0.05$ & $\mathrm{Ga}$ & $<0.01$ & $\mathrm{Nd}$ & $<0.05$ \\
\hline $\mathrm{Be}$ & $<0.05$ & $\mathrm{Ge}$ & $<0.05$ & $\mathrm{Sm}$ & $<0.01$ \\
\hline B & 0.75 & As & $<0.05$ & $\mathrm{Eu}$ & $<0.01$ \\
\hline $\mathrm{C}$ & Matrix & $\mathrm{Se}$ & $<0.05$ & $\mathrm{Gd}$ & $<0.01$ \\
\hline $\mathrm{N}$ & -- & $\mathrm{Br}$ & $<0.1$ & $\mathrm{~Tb}$ & $<0.01$ \\
\hline $\mathrm{O}$ & -- & $\mathrm{Rb}$ & $<0.05$ & Dy & $<0.01$ \\
\hline $\mathrm{F}$ & $<0.1$ & $\mathrm{Sr}$ & 0.51 & Но & $<0.01$ \\
\hline $\mathrm{Na}$ & 0.15 & Y & $<0.05$ & $\mathrm{Er}$ & $<0.01$ \\
\hline $\mathrm{Mg}$ & 1.4 & $\mathrm{Zr}$ & 0.44 & $\mathrm{Tm}$ & $<0.01$ \\
\hline $\mathrm{Al}$ & 1.3 & $\mathrm{Nb}$ & $<0.05$ & $\mathrm{Yb}$ & $<0.01$ \\
\hline $\mathrm{Si}$ & 81 & Mo & $<0.05$ & $\mathrm{Lu}$ & $<0.01$ \\
\hline $\mathrm{P}$ & 1.8 & $\mathrm{Ru}$ & $<0.05$ & Hf & $<0.01$ \\
\hline $\mathrm{S}$ & 50 & $\mathrm{Rh}$ & $<0.01$ & $\mathrm{Ta}$ & $<100$ \\
\hline $\mathrm{Cl}$ & 2.3 & $\mathrm{Pd}$ & $<0.05$ & W & $<0.05$ \\
\hline K & $<0.1$ & $\mathrm{Ag}$ & $<0.05$ & $\operatorname{Re}$ & $<0.01$ \\
\hline $\mathrm{Ca}$ & 23 & $\mathrm{Cd}$ & $<0.05$ & Os & $<0.01$ \\
\hline $\mathrm{Sc}$ & 0.07 & In & $<0.05$ & Ir & $<0.01$ \\
\hline $\mathrm{Ti}$ & 18 & $\mathrm{Sn}$ & $<0.05$ & $\mathrm{Pt}$ & $<0.01$ \\
\hline V & 29 & $\mathrm{Sb}$ & $<0.05$ & $\mathrm{Au}$ & $<0.1$ \\
\hline $\mathrm{Cr}$ & $<0.5$ & $\mathrm{Te}$ & $<0.05$ & $\mathrm{Hg}$ & $<0.1$ \\
\hline $\mathrm{Mn}$ & 0.12 & I & $<0.01$ & $\mathrm{Tl}$ & $<0.05$ \\
\hline $\mathrm{Fe}$ & 55 & Cs & $<0.05$ & $\mathrm{~Pb}$ & $<0.05$ \\
\hline Co & $<0.01$ & $\mathrm{Ba}$ & $<0.05$ & $\mathrm{Bi}$ & $<0.05$ \\
\hline $\mathrm{Ni}$ & 3.5 & $\mathrm{La}$ & $<0.05$ & Th & $<0.05$ \\
\hline $\mathrm{Cu}$ & $<0.05$ & $\mathrm{Ce}$ & $<0.05$ & $\mathrm{U}$ & $<0.05$ \\
\hline $\mathrm{Zn}$ & $<0.05$ & $\operatorname{Pr}$ & $<0.05$ & & \\
\hline
\end{tabular}


NEA/NSC/DOC(2006)1

Fundamental - FUND

NRAD-FUND-RESR-001

CRIT

\section{Beam Ports}

The beam filter tubes are aluminum 6061-T6. The North tube is backpressure filled with helium gas and the East tube contains air. The beam tube support is also constructed from aluminum 6061-T6. The hex head cap screw attached to the top of the beam tube support is aluminum 2024-T4.

The East wet package can contain either air or helium and is currently operated with air. The aperture housings are maintained with a helium overpressure between 75 to 85 inches of water, which also includes the beam tube between the tank wall and the aperture housing. Outside the reactor tank on the east side, the beam line is filled with air all the way to the sample tube coming down from the HFEF main cell. The main cell sample tube is filled with Argon. The beam tube outside of the reactor tank up to the north radiography cell is filled with helium. ${ }^{a}$

The aperture assembly and source tube extending to the tank wall is aluminum 6061-T6. The aperture blocks are Combat Grade A boron nitride from The Carborundium Co., Graphite Products Division. The source tube inner lining is rolled Boral and the tube is filled with helium gas.

\section{Water Hole (Irradiation Position)}

The water hole position (within a control rod guide tube) in the core did not contain any experiments, detectors, or equipment, and thus was only filled with tank water.

\section{Start-Up Source}

The startup source is comprised of $\mathrm{AmBe}$ material in a sealed stainless steel container. The source tube and source tube cap are aluminum 6061.

\section{Detectors}

The pool detectors are placed in aluminum housings.

\section{Dry Tubes}

The aluminum 6061 dry tubes were not installed during the start-up measurements of the NRAD core.

\subsubsection{Temperature Data}

The tank water temperature was between 26.0 and $26.2{ }^{\circ} \mathrm{C}$ during fuel loading for the initial critical with 56 fuel elements. Startup temperatures are typically at $26^{\circ} \mathrm{C}$ and at-power operations are typically performed at $37^{\circ} \mathrm{C}$.

For the initial critical with 60 elements the tank water temperature was $27.5{ }^{\circ} \mathrm{C}$; the tank water temperature was slightly elevated due to several days operating at low power.

\subsubsection{Additional Information Relevant to Critical and Subcritical Measurements}

Additional information is not available.

\footnotetext{
${ }^{a}$ Personal communication with Ken Schreck at HFEF (April 29, 2010).
} 
NEA/NSC/DOC(2006)1

Fundamental - FUND

NRAD-FUND-RESR-001

CRIT

\subsection{Description of Buckling and Extrapolation Length Measurements}

Buckling and extrapolation length measurements were not made.

\subsection{Description of Spectral Characteristics Measurements}

Spectral characteristics measurements were not made.

\subsection{Description of Reactivity Effects Measurements}

Reactivity effects measurements were not made.

\subsection{Description of Reactivity Coefficient Measurements}

Reactivity coefficient measurements were not made.

\subsection{Description of Kinetics Measurements}

Kinetics measurements were not made.

\subsection{Description of Reaction-Rate Distribution Measurements}

Reaction-rate distribution measurements were not made.

\subsection{Description of Power Distribution Measurements}

Power distribution measurements were not made.

\subsection{Description of Isotopic Measurements}

Isotopic measurements were not made.

\subsection{Description of Other Miscellaneous Types of Measurements}

Other miscellaneous types of measurements were not made. 
NEA/NSC/DOC(2006)1

Fundamental - FUND

NRAD-FUND-RESR-001

CRIT

\subsection{EVALUATION OF EXPERIMENTAL DATA}

Monte Carlo n-Particle (MCNP) version 5.1.51 calculations were utilized to estimate the biases and uncertainties associated with the experimental results in this evaluation. MCNP is a general-purpose, continuous-energy, generalized-geometry, time-dependent, coupled n-particle Monte Carlo transport code. $^{a}$ The Evaluated Neutron Data File library, ENDF/B-VII.0, ${ }^{b}$ cross section data was also used in this evaluation. The statistical uncertainty in $\mathrm{k}_{\mathrm{eff}}$ and $\Delta \mathrm{k}_{\mathrm{eff}}$ is 0.00007 and 0.00010 , respectively. Calculations were performed with 1,550 generations with 100,000 neutrons per generation. The $\mathrm{k}_{\text {eff }}$ estimates did not include the first 50 generations and are the result of 150,000,000 neutron histories.

The benchmark model provided in Section 3, for the 60-fuel-element core configuration, was utilized with perturbations of the model parameters to estimate uncertainties in $k_{\text {eff }}$ due to uncertainties in parameter values defining the benchmark configuration. Some perturbations required more detail than that available in the benchmark model. A more detailed model (Appendix C) was used to evaluate these uncertainties. Transformation from the detailed model to the benchmark model is described in Section 3.1.1.1. Where applicable, comparison of the upper and lower perturbation $\mathrm{k}_{\mathrm{eff}}$ values to evaluate the uncertainty in the eigenvalue were utilized to minimize correlation effects, if any, induced by comparing all perturbations to the original benchmark model configuration, as discussed elsewhere. ${ }^{\mathrm{c}}$

An uncertainty analysis of the initial critical measured with the 56-fuel-element core is not currently evaluated as the purpose of this experiment was only a step in developing the 60 -fuel-element core for reactor operations.

Unless specifically stated otherwise, all uncertainty values in this section correspond to $1 \sigma$. When the change in $\mathrm{k}_{\text {eff }}$ between the base case and the perturbed model, or two perturbed models, is less than the statistical uncertainty of the Monte Carlo results, the changes in the variable are amplified, if possible, and the calculations repeated. The resulting calculated change is then scaled back corresponding to the actual uncertainty, assuming that it is linear, which should be adequate for these changes in $\mathrm{k}_{\mathrm{eff}}$.

Uncertainties less than or equal to 0.00010 are treated as negligible.

The total evaluated uncertainty in $\mathrm{k}_{\mathrm{eff}}$ for this experiment is provided in Section 2.1.12. The square root of the sum of the squares of all the individual uncertainties assessed in this section is used to obtain the total uncertainty in the experimental $\mathrm{k}_{\mathrm{eff}}$.

When evaluating parameters such as part diameters, heights, and mass, all parts of a given type are perturbed at the same time: e.g., the uranium mass in all fuel elements is simultaneously increased or decreased. Then the calculated uncertainty is reduced by the square root of the number of components perturbed, representative of a random uncertainty. For many of these uncertainties, there is insufficient information available to evaluate what portion of the total evaluated uncertainty is systematic instead of random. Random uncertainties are treated as $15 \%$ systematic in this evaluation, unless otherwise specified.

This assumption provides a basic prediction of the effect on $\mathrm{k}_{\mathrm{eff}}$ until additional information regarding systematic uncertainties can be better evaluated. Most systematic uncertainties should be below $50 \%$ of the total uncertainty and above the historic approach of ignoring the unknown systematic components

\footnotetext{
a X-5 Monte Carlo Team, "MCNP - a General Monte Carlo n-Particle Transport Code, version 5," LA-UR-031987, Los Alamos National Laboratory (2003).

${ }^{\mathrm{b}}$ M. B. Chadwick, et al., "ENDF/B-VII.0: Next Generation Evaluated Nuclear Data Library for Nuclear Science and Technology," Nucl. Data Sheets, 107: 2931-3060 (2006).

c D. Mennerdahl, "Statistical Noise for Nuclear Criticality Safety Specialists," Trans. Am. Nucl. Soc., 101: $465-466$ (2009).
} 
NEA/NSC/DOC(2006)1

Fundamental - FUND

NRAD-FUND-RESR-001

CRIT

(i.e., treat it with a $0 \%$ probability). In actuality, careful experimenters may have an unknown systematic uncertainty that is approximately $10-15 \%$ of their total reported uncertainty. Because significant effort has gone into obtaining and evaluating data for the NRAD reactor, a systematic uncertainty of $15 \%$ is assumed. Evaluated uncertainties are listed as calculated, such that the readers may themselves adjust results according to some desired systematic-to-random uncertainty ratio.

\subsection{Evaluation of Critical and / or Subcritical Configuration Data}

\subsubsection{Experimental Measurements}

\subsubsection{Temperature}

The thermistor used to directly measure the bulk tank water temperature has a calibrated accuracy of $0.1^{\circ} \mathrm{C}$. A larger uncertainty of $2{ }^{\circ} \mathrm{C}$ was assumed to represent a $1 \sigma$ uncertainty that includes possible uncertainty in bulk water temperature distribution, calibration standard uncertainty, and accuracy of the thermistor measurement. This value is also ten times the typical variability seen in the tank water temperature.

The temperature of the cold critical system directly impacts the density of the tank water and its effectiveness as a neutron moderator and reflector. Because this is a low power experiment, other temperature effects in neutron cross section data and material properties of reactor fuel, assemblies, and core components are assumed to be negligible compared to the effective change in the water density. This section addresses the effect of the temperature uncertainty on the water density while Section 2.1.9 provides further explanation regarding the physical properties of the tank water, including the correlation of water density with temperature.

To find the effect of this uncertainty on the $k_{\text {eff }}$ value, the measured temperature was adjusted by the $3 \sigma$ uncertainty. It should be noted that a perturbation of $\pm 6{ }^{\circ} \mathrm{C}$ does not invoke a linear response in the water density. An upper perturbation $\mathrm{k}_{\mathrm{eff}}$ value was found by increasing the water density by $0.0014 \mathrm{~g} / \mathrm{cm}^{3}$ and then decreasing by $0.0018 \mathrm{~g} / \mathrm{cm}^{3}$ to find a lower perturbation $k_{\text {eff }}$ value. Half of the difference between the upper and lower perturbation $\mathrm{k}_{\text {eff }}$ values was used to represent the variation in $\mathrm{k}_{\text {eff }}$ due to perturbing the measured temperature by $6{ }^{\circ} \mathrm{C}$. The calculated result was then scaled to obtain the $1 \sigma$ uncertainty. Results are shown in Table 2.1.

This uncertainty is treated as $100 \%$ systematic. The calculated uncertainty in the experiment temperature is considered negligible $(\leq 0.00010)$.

Table 2.1. Effect of Uncertainty in Temperature (Water Density).

\begin{tabular}{||c|ccc|c|ccc||}
\hline \hline Deviation & $\Delta \mathbf{k}$ & \pm & $\boldsymbol{\sigma}_{\Delta \mathbf{k}}$ & $\begin{array}{c}\text { Scaling } \\
\text { Factor }\end{array}$ & $\Delta \mathbf{k}_{\text {eff }}(\mathbf{1} \boldsymbol{\sigma})$ & \pm & $\boldsymbol{\sigma}_{\Delta \mathbf{k e f f}}$ \\
\hline \hline $\begin{array}{r} \pm{ }^{\circ} \mathrm{C}\left(+0.0018 \mathrm{~g} / \mathrm{cm}^{3}\right) \\
\left(-0.0014 \mathrm{~g} / \mathrm{cm}^{3}\right)\end{array}$ & -0.00011 & \pm & 0.00005 & 3 & -0.00004 & \pm & 0.00002 \\
\hline
\end{tabular}

\subsubsection{Control Rod Positions}

The uncertainty in the measurement of control rod position is \pm 4 units, $\pm 0.1524 \mathrm{~cm},(3 \sigma)$. The critical control rod positions for the shim 1 , shim 2 , and regulating rods were reported to be withdrawn 1000 , 1000 , and 536 units $(38.1,38.1$, and $20.4216 \mathrm{~cm})$, respectively. The rod position indication displays 0 1000 units of travel from a down limit switch to the up limit switch, respectively. Each unit of display is equal to 0.015 in. $(0.0381 \mathrm{~cm})$ of rod travel. 
NEA/NSC/DOC(2006)1

Fundamental - FUND

NRAD-FUND-RESR-001

CRIT

To find the effect of this uncertainty on the $\mathrm{k}_{\mathrm{eff}}$ value, the control rod positions were adjusted by a factor of 10 times the $1 \sigma$ uncertainty. An upper perturbation $\mathrm{k}_{\mathrm{eff}}$ value was found by simultaneously increasing the rod positions by $0.508 \mathrm{~cm}$ and then simultaneously decreasing by the same amount to find a lower perturbation $\mathrm{k}_{\text {eff }}$ value. Half of the difference between the upper and lower perturbation $\mathrm{k}_{\text {eff }}$ values was used to represent the variation in $\mathrm{k}_{\text {eff }}$ due to perturbing the measured control rod positions by $0.508 \mathrm{~cm}$. The calculated result was then scaled to obtain the $1 \sigma$ uncertainty. Results are shown in Table 2.2.

This uncertainty is treated as $100 \%$ systematic for two reasons: first, the uncertainty in the fully inserted and fully withdrawn positions is approximately the same as the uncertainty in the control rod position; second, two of the three control rods are fully withdrawn, and reactivity effects due to the variation in their absolute position are minor compared to those incurred by the movement of the regulating rod. The calculated uncertainty in the control rod positions is considered negligible $(\leq 0.00010)$.

Table 2.2. Effect of Uncertainty in Control Rod Positions.

\begin{tabular}{||c|ccc|c|ccc||}
\hline Deviation & $\Delta \mathbf{k}$ & \pm & $\boldsymbol{\sigma}_{\Delta \mathbf{k}}$ & $\begin{array}{c}\text { Scaling } \\
\text { Factor }\end{array}$ & $\Delta \mathbf{k}_{\text {eff }}(\mathbf{1 \sigma})$ & \pm & $\boldsymbol{\sigma}_{\Delta \mathbf{k e f f}}$ \\
\hline \hline $\pm 0.508 \mathrm{~cm}(10 \sigma)$ & 0.00062 & \pm & 0.00005 & 10 & 0.00006 & \pm & 0.00001 \\
\hline
\end{tabular}

\subsubsection{Measured Value of $\boldsymbol{k}_{\text {eff }}$}

There is no additional information regarding the accuracy of the $\mathrm{k}_{\mathrm{eff}}$ measurements for the critical core conditions. Fission counts, linear power, regulating control rod position, and reactor period were all monitored for stability to confirm the critical state of the NRAD reactor. This uncertainty is typically very small and can be considered negligible.

The AmBe source remains in the reactor core during operations. It emits neutrons at the rate of $\sim 1 \times 10^{7}$ neutrons $/ \mathrm{sec}$. The fission rate in the core at $50 \mathrm{~W}$ is $\sim 1 \times 10^{12}$ neutrons $/ \mathrm{sec}$. Because there are five orders of magnitude difference between the total fission rate and the AmBe source strength, the contribution of the $\mathrm{AmBe}$ source neutrons to the total neutron population is judged to be negligible and no additional bias or uncertainty was evaluated.

\subsubsection{Fuel Pellet - Uranium-Erbium-Zirconium-Hydride Fuel Properties}

The composition of the uranium-erbium-zirconium-hydride fuel is determined using the summary of asbuilt fuel data for the 60-fuel-element core configuration supplemented with additional information provided by General Atomics, Y-12, or CERCA. The average mass of uranium and ${ }^{235} \mathrm{U}$ can be compared to the total average mass of a single fuel element to obtain the weight fraction of uranium and enrichment (see Table 1.5). The average weight fractions of carbon and erbium are also available in Table 1.5.

The only ${ }^{234} \mathrm{U}$ and ${ }^{236} \mathrm{U}$ content measurements available are from the $\mathrm{Y}-12$ data for some of the NRAD fuel elements not currently used in the core (Table 1.7). They are 0.159 and 0.144 wt.\%, respectively, using isotopic dilution measurements, and 0.145 and $0.121 \mathrm{wt} . \%$, respectively, calculated from the alpha spectrometry measurement data. Additional data for the ${ }^{232} \mathrm{U},{ }^{234} \mathrm{U}$, and ${ }^{236} \mathrm{U}$ content were obtained regarding samples of Y-12 uranium fuel shipments (0.00004 ppm, 0.156 wt.\%, and 0.1289 wt.\%, respectively). Four samples from reprocessed material at CERCA for Texas A\&M University (TAMU) and Washington State University (WSU) TRIGA fuel production contained the following isotopic information: 
NEA/NSC/DOC(2006)1

Fundamental - FUND

NRAD-FUND-RESR-001

CRIT

- $\quad{ }^{232} \mathrm{U}: 0.05,0.05,0.24$, and $0.34 \mathrm{ppm}$;

- $\quad{ }^{234} \mathrm{U}: 0.21,0.21,0.2$, and 0.29 wt.\%; and

- ${ }^{236} \mathrm{U}: 0.07,0.07,0.41$, and 0.51 wt. $\%{ }^{\mathrm{a}}$

The average fuel content of ${ }^{232} \mathrm{U}$ is negligible and is not included in the fuel composition. The average ${ }^{234} \mathrm{U}$ and ${ }^{236} \mathrm{U}$ weight fractions are computed and ${ }^{238} \mathrm{U}$ represents the remaining uranium content in the fuel. Because of the limited data regarding ${ }^{234} U$ and ${ }^{236} U$ content in the fuel, values of $0.2 \mathrm{wt} . \%$ were selected for both isotopes; these values are approximately the average amount calculated using the aforementioned data.

It is important to note that there is no correlation between the ${ }^{232} \mathrm{U},{ }^{234} \mathrm{U}$, and ${ }^{236} \mathrm{U}$ content with fuel enrichment due to various enriching and downblending campaigns at Y-12 over time.

Impurities in the fuel are believed to be quite negligible. The results from the Y-12 analysis (Table 1.7) note that it was difficult to overcome interferences with the high quantities of zirconium. Oxygen and nitrogen levels were also not obtainable. Comparison of the zirconium and erbium measurements in Table 1.7 also does not match well with the reported as-built measurements. The ${ }^{235} \mathrm{U}, \mathrm{U}$, and $\mathrm{C}$ measurements do agree with the manufacture data. The as-built data for the fuel pellets are within the manufacturing specifications agreed upon between GA and CERCA. The transactinide measurements of the fuel are at the detection limits and the quantities appear to be negligible. The equivalent boron content (EBC) is computed for the reprocessed CERCA material. The average EBC is $\sim 1 \mathrm{ppm}$. This value is selected to represent the nominal quantity of impurities in the fuel except carbon and hafnium. A hafnium content of $0.2 \mathrm{~g}(\sim 0.008 \mathrm{wt} . \%)$ is used, per discussions with General Atomics. ${ }^{\mathrm{c}}$

The remaining fuel mass is the zirconium hydride material. The $\mathrm{H} / \mathrm{Zr}$ ratio is used to estimate the weight fractions of hydrogen and zirconium in the fuel. The actual quantity is slightly less due to the presence of impurities neglected by assuming hafnium, carbon, and a boron equivalent are the only impurities. However, minor variation in the zirconium hydride content is negligible compared to the variations performed when perturbing other components of the fuel matrix.

The mass density of the fuel can be obtained by dividing the total average fuel mass by the average fuel volume. The outer diameter of the fuel is $3.4805 \mathrm{~cm}$, the inner diameter is $0.635 \mathrm{~cm}$, and the total fuel element length is $38.02 \mathrm{~cm}$. The total computed volume of the fuel in a single fuel element is $\sim 349.69$ $\mathrm{cm}^{3}$; the average fuel mass density is $7.1678 \mathrm{~g} / \mathrm{cm}^{3}$. The average fuel composition is summarized in Table 2.3.

\footnotetext{
${ }^{a}$ Personal communication with Eric C. Woolstenhulme at INL (April 27, 2010).

${ }^{b}$ Personal communication with Calvin M. Hopper at ORNL-retired (April 9, 2010).

${ }^{\mathrm{c}}$ Personal communication with John M. Bolin at General Atomics (November 3, 2009).
} 
NEA/NSC/DOC(2006)1

Fundamental - FUND

NRAD-FUND-RESR-001

CRIT

Table 2.3. Average Composition of U-Er-Zr-H Fuel.

\begin{tabular}{|c|c|}
\hline Isotope/Element & wt.\% \\
\hline \hline $\mathrm{B}^{\text {(a) }}$ & 0.000104 \\
$\mathrm{C}$ & 0.3 \\
$\mathrm{Hf}$ & 0.007979 \\
$\mathrm{Er}$ & 0.9 \\
\hline $\mathrm{H}+\mathrm{Zr}$ & 1.181688 \\
\hline $\mathrm{H}$ & 67.692016 \\
$\mathrm{Zr}$ & 29.918213 \\
\hline $\mathrm{U}$ & 0 \\
\hline${ }^{232} \mathrm{U} / \mathrm{U}_{\text {tot }}$ & 0.2 \\
${ }^{234} \mathrm{U} / \mathrm{U}_{\text {tot }}$ & 19.74 \\
${ }^{235} \mathrm{U} / \mathrm{U}_{\text {tot }}$ & 0.2 \\
${ }^{236} \mathrm{U} / \mathrm{U}_{\text {tot }}$ & 79.86 \\
\hline${ }^{238} \mathrm{U} / \mathrm{U}_{\text {tot }}$ & \\
\hline
\end{tabular}

(a) All impurities, except hafnium and carbon, are treated as equivalent boron content.

\subsubsection{Total Fuel Element Mass}

The average fuel element mass in the 60-fuel-element core (Table 1.5), based on the actual measured values of the individual fuel element masses, is $2506.5 \pm 3.4 \mathrm{~g}$. There is very little information available regarding how the measurements were performed, how accurately they were measured, or what uncertainties were present. As-built mass data appears to be accurate to $\pm 0.01 \mathrm{~g}$, consistent with these data being reported to two decimal places (see Appendix D). While the Y-12 chemical specifications for the uranium fuel wt.\% are indicated to two or three decimal places, actual sample measurements of fuel shipped from Y-12 are reported to three or four decimal places. Reprocessed material at CERCA is reported to one or two decimal places (wt.\%). ${ }^{\mathrm{a}}$ An uncertainty of $\pm 0.1 \mathrm{~g}(1 \sigma)$ seems reasonable for uncertainty in measurements of the $\sim 2.5 \mathrm{~kg}$ fuel element masses.

To find the effect of the fuel element mass uncertainty on $\mathrm{k}_{\mathrm{eff}}$, the average fuel mass was adjusted, while maintaining the fuel element composition and dimensions constant, by a factor of 34 times the $1 \sigma$ uncertainty. An upper perturbation $\mathrm{k}_{\mathrm{eff}}$ value was found by simultaneously increasing the average fuel element mass in all fuel elements by $3.4 \mathrm{~g}$ and then simultaneously decreasing by the same amount to find a lower perturbation $\mathrm{k}_{\text {eff }}$ value. Half of the difference between the upper and lower perturbation $\mathrm{k}_{\text {eff }}$ values was used to represent the variation in $\mathrm{k}_{\mathrm{eff}}$ due to perturbing the average fuel mass by $3.4 \mathrm{~g}$. The calculated result was then scaled to obtain the $1 \sigma$ uncertainty (i.e. the uncertainty in $\mathrm{k}_{\text {eff }}$ corresponding to $\mathrm{a} \pm 0.1 \mathrm{~g}$ fuel mass). Results are shown in Table 2.4.

The calculated uncertainty in the total fuel mass is considered negligible $(\leq 0.00010)$. The total number of fuel elements in this configuration is 60 ; the random component of this uncertainty would typically be divided by $\sqrt{ } 60$; however, division into systematic and random components is irrelevant.

${ }^{a}$ Personal communication with Eric C. Woolstenhulme at INL (April 27, 2010). 
NEA/NSC/DOC(2006)1

Fundamental - FUND

NRAD-FUND-RESR-001

CRIT

Table 2.4. Effect of Uncertainty in Total Fuel Mass.

\begin{tabular}{|c|ccc|cccccc|c||}
\hline Deviation & $\Delta \mathbf{k}$ & \pm & $\sigma_{\Delta \mathbf{k}}$ & $\begin{array}{c}\text { Scaling } \\
\text { Factor }\end{array}$ & $\Delta \mathbf{k}_{\text {eff }}(\mathbf{1} \sigma)$ & \pm & $\sigma_{\Delta \mathbf{k e f f}}$ & $\begin{array}{c}\Delta \mathbf{k}_{\text {eff }} \\
\mathbf{( 1 5 \%} \\
\text { systematic) }\end{array}$ & $\begin{array}{c}\Delta \mathbf{k}_{\text {eff }} \\
\mathbf{( 8 5 \%} \\
\text { random) }\end{array}$ \\
\hline \hline $\pm 3.4 \mathrm{~g}$ & 0.00031 & \pm & 0.00005 & 34 & 0.00001 & \pm & negligible & negligible & negligible \\
\hline \hline
\end{tabular}

\subsubsection{Uranium Content}

The average uranium mass of the fuel elements in the 60 -fuel-element core (Table 1.5) is $749.9 \pm 2.7 \mathrm{~g}$, based on the reported measured values of the uranium mass of the individual fuel elements (Appendix D). This results in an average uranium mass content of approximately $29.92 \pm 0.11 \mathrm{wt} . \%$. As noted previously, there is very little information available regarding how the measurements were performed, how accurately they were measured, or what uncertainties were present. And as above, an uncertainty of $\pm 0.1 \mathrm{~g}(1 \sigma)$ seems reasonable for the uncertainty in measurements of $1-2 \mathrm{~kg}$ uranium masses in the blending of the uranium alloy.

To find the effect of this uncertainty on the $\mathrm{k}_{\text {eff }}$ value, the average uranium mass was adjusted by a factor of 27 times the $1 \sigma$ uncertainty. An upper perturbation $\mathrm{k}_{\mathrm{eff}}$ value was found by simultaneously increasing the average uranium mass in all fuel elements by $2.7 \mathrm{~g}$ and then simultaneously decreasing by the same amount to find a lower perturbation $\mathrm{k}_{\mathrm{eff}}$ value. Half of the difference between the upper and lower perturbation $\mathrm{k}_{\mathrm{eff}}$ values was used to represent the variation in $\mathrm{k}_{\text {eff }}$ due to perturbing the average uranium mass by $2.7 \mathrm{~g}$. The calculated result was then scaled to obtain the $1 \sigma$ uncertainty. Results are shown in Table 2.5.

Increasing or decreasing the total mass of uranium in the fuel effectively decreases or increases the total mass of zirconium hydride in the fuel, changing the $\mathrm{U} / \mathrm{Zr}-\mathrm{H}$ ratio. The ${ }^{235} \mathrm{U}$ enrichment $(19.74 \mathrm{wt} . \%)$ is conserved when perturbing the total uranium mass, which means the ${ }^{235} \mathrm{U} /{ }^{238} \mathrm{U}$ ratio remains unchanged with the perturbation of the total uranium mass. The calculated uncertainty in the total uranium mass is considered negligible $(\leq 0.00010)$. The total number of fuel elements in this configuration is 60 ; the random component of this uncertainty would typically be divided by $\sqrt{60}$; however, division into systematic and random components is irrelevant.

Table 2.5. Effect of Uncertainty in Uranium Mass.

\begin{tabular}{|c|ccc|c|ccc|c|c||}
\hline Deviation & $\Delta \mathbf{k}$ & \pm & $\sigma_{\Delta \mathbf{k}}$ & $\begin{array}{c}\text { Scaling } \\
\text { Factor }\end{array}$ & $\Delta \mathbf{k}_{\text {eff }}(\mathbf{1} \boldsymbol{\sigma})$ & \pm & $\boldsymbol{\sigma}_{\Delta \mathbf{k e f f}}$ & $\begin{array}{c}\Delta \mathbf{k}_{\text {eff }} \\
\mathbf{( 1 5 \%} \\
\text { systematic) }\end{array}$ & $\begin{array}{c}\Delta \mathbf{k}_{\text {eff }} \\
\mathbf{( 8 5 \%} \\
\text { random) }\end{array}$ \\
\hline \hline $\pm 2.7 \mathrm{~g}$ & 0.00028 & \pm & 0.00005 & 27 & 0.00001 & \pm & negligible & negligible & negligible \\
\hline \hline
\end{tabular}

\subsubsection{Uranium Isotopic Distribution}

The average isotopic abundance of ${ }^{235} \mathrm{U}$ for the fuel elements in the 60 -fuel-element core (Table 1.5) is $19.74 \pm 0.02 \mathrm{wt} . \%$, based on reported as-built values for the individual fuel elements (Appendix D). As noted previously, there is very little information available regarding how the measurements were performed, how accurately they were measured, or what uncertainties were present. Fuel specifications from Y-12 indicate an uncertainty of $\pm 0.20 \mathrm{wt} . \%$ (Table 1.6), which appears to represent bounding values for fuel acceptance. The variation in the reported enrichments is much smaller. The entire range of the reported ${ }^{235} \mathrm{U}$ enrichments is $0.07 \mathrm{wt} . \%$. Treating the quoted specification of $\pm 0.20 \mathrm{wt} . \%$ as a tolerance for acceptance, a reasonable estimate of the $1 \sigma$ uncertainty is 0.20 wt. $\% \div 2 \sqrt{3}$, or $\sim 0.05$ wt. $\%$. This uncertainty in the ${ }^{235} \mathrm{U}$ enrichment is equivalent to $\pm 0.43 \mathrm{~g}{ }^{235} \mathrm{U}$. 
NEA/NSC/DOC(2006)1

\author{
Fundamental - FUND \\ NRAD-FUND-RESR-001 \\ CRIT
}

Typical calibration standards for the evaluation of isotopic measurements of nominally $20 \%$ enriched uranium fuel had an uncertainty in ${ }^{235} U$ content of approximately $\pm 0.020 \mathrm{wt} . \%(2 \sigma),{ }^{\mathrm{a}}$ which is a $1 \sigma$ uncertainty of $\pm 0.11 \mathrm{~g}$. This uncertainty is approximately $25 \%$ of the uncertainty in the ${ }^{235} \mathrm{U}$ isotopic content of the fuel elements, and it is used to represent the systematic component of this uncertainty.

To find the effect of the uncertainty of the ${ }^{235} \mathrm{U}$ enrichment on the $\mathrm{k}_{\text {eff }}$ value, the average ${ }^{235} \mathrm{U}$ mass was adjusted by a factor of (1.8/0.43) times the $1 \sigma$ uncertainty of $\pm 0.43 \mathrm{~g}$. An upper perturbation $\mathrm{k}_{\text {eff }}$ value was found by simultaneously increasing the average ${ }^{235} \mathrm{U}$ mass in all fuel elements by $1.8 \mathrm{~g}$ and then simultaneously decreasing by the same amount to find a lower perturbation $\mathrm{k}_{\text {eff }}$ value. Half of the difference between the upper and lower perturbation $\mathrm{k}_{\mathrm{eff}}$ values was used to represent the variation in $\mathrm{k}_{\mathrm{eff}}$ due to perturbing the average ${ }^{235} \mathrm{U}$ mass by $1.8 \mathrm{~g}$. The calculated result was then scaled to obtain the $1 \sigma$ uncertainty. Results are shown in Table 2.6.

Increasing or decreasing the total mass of ${ }^{235} \mathrm{U}$ in the fuel effectively decreases or increases the total mass of ${ }^{238} \mathrm{U}$, changing the enrichment, as the total uranium mass is conserved. The isotopic quantities of the other uranium isotopes remain unchanged. Details of the enrichment batches were not provided for each of the individual fuel elements; it was reported that a total of eleven fuel batches of uranium metal were shipped from Y-12 to CERCA for use in the fabrication of the NRAD fuel elements. It appears that the fuel elements were fabricated from 11 or fewer (most likely 11) enrichment batches; therefore the random component of this uncertainty is divided by $\sqrt{ } 11$.

Table 2.6. Effect of Uncertainty in Uranium-235 Mass.

\begin{tabular}{|c|ccc|c|ccc|c|c||}
\hline \hline Deviation & $\Delta \mathbf{k}$ & \pm & $\sigma_{\Delta \mathrm{k}}$ & $\begin{array}{c}\text { Scaling } \\
\text { Factor }\end{array}$ & $\begin{array}{c}\Delta \mathbf{k}_{\text {eff }} \\
(\mathbf{1} \boldsymbol{\sigma})\end{array}$ & \pm & $\sigma_{\Delta \mathrm{keff}}$ & $\begin{array}{c}\Delta \mathbf{k}_{\text {eff }} \\
\mathbf{( 2 5 \%} \\
\text { systematic) }\end{array}$ & $\begin{array}{c}\Delta \mathbf{k}_{\text {eff }} \\
\mathbf{( 7 5 \%} \\
\text { random) }\end{array}$ \\
\hline \hline $1.8 \mathrm{~g}$ & 0.00228 & \pm & 0.00003 & $(1.8 / 0.43)$ & 0.00054 & \pm & 0.00001 & 0.00014 & 0.00012 \\
\hline
\end{tabular}

As discussed in Section 2.1.2, the quantity of ${ }^{232} \mathrm{U}$ in the fuel is negligible. Any uncertainty in the content would also have a negligible effect on $k_{\text {eff. }}$ The ${ }^{234} U$ and ${ }^{236} U$ contents were not typically measured except in some select fuel samples, some of which may not represent uranium used in the NRAD fuel. However, all samples discussed in Section 2.1.2 are from uranium material originating from Y-12. Approximate averages and $1 \sigma$ uncertainties are estimated from these fuel samples because of the ambiguity regarding actual content of these isotopes in the fuel.

The average ${ }^{234} \mathrm{U}$ content in the fuel, based on the discussion of available data in Section 2.1.2, is $0.181 \pm$ $0.027 \mathrm{wt} . \%(1 \sigma)$. This is the average of seven measurements: two from the extra fuel element, one from Y-12 fuel shipment data, and four from reprocessed CERCA material. A value of $0.2 \pm 0.033$ wt.\% $(1 \sigma)$ was selected for this analysis.

To find the effect of this uncertainty on the $\mathrm{k}_{\mathrm{eff}}$ value, a ${ }^{234} \mathrm{U}$ content of $0.2 \mathrm{wt} . \%$ was adjusted by a factor of 6 times the $1 \sigma$ uncertainty. An upper perturbation $\mathrm{k}_{\mathrm{eff}}$ value was found by simultaneously increasing the ${ }^{234} \mathrm{U}$ content in all fuel elements by $0.2 \mathrm{wt} . \%$ and then simultaneously decreasing by the same amount to find a lower perturbation $\mathrm{k}_{\text {eff }}$ value. Half of the difference between the upper and lower perturbation $\mathrm{k}_{\text {eff }}$ values was used to represent the variation in $\mathrm{k}_{\mathrm{eff}}$ due to perturbing the ${ }^{234} \mathrm{U}$ content by $0.2 \mathrm{wt} . \%$. The calculated result was then scaled to obtain the $1 \sigma$ uncertainty. Results are shown in Table 2.7.

\footnotetext{
${ }^{a}$ National Bureau of Standards Certificate of Analysis Standard Reference Material U-200 (SRM-U200), U.S. Department of Commerce (April 6, 1981).
} 
NEA/NSC/DOC(2006)1

Fundamental - FUND

NRAD-FUND-RESR-001

CRIT

Table 2.7. Effect of Uncertainty in Uranium-234 Content.

\begin{tabular}{||c|ccc|c|ccc||}
\hline Deviation & $\Delta \mathbf{k}$ & \pm & $\boldsymbol{\sigma}_{\Delta \mathbf{k}}$ & $\begin{array}{c}\text { Scaling } \\
\text { Factor }\end{array}$ & $\Delta \mathbf{k}_{\text {eff }}(\mathbf{1} \boldsymbol{\sigma})$ & \pm & $\boldsymbol{\sigma}_{\Delta \mathbf{k e f f}}$ \\
\hline \hline \pm 0.2 wt.\% & -0.00299 & \pm & 0.00005 & 6 & -0.00050 & \pm & 0.00001 \\
\hline
\end{tabular}

The average ${ }^{236} \mathrm{U}$ content is $0.208 \pm 0.177$ wt. $\%(1 \sigma)$. This is the average of seven measurements: two from the extra fuel element, one from Y-12 fuel shipment data, and four from reprocessed CERCA material. A value of $0.2 \pm 0.2 \mathrm{wt} . \%(1 \sigma)$ was selected for this analysis.

To find the effect of this uncertainty on the $\mathrm{k}_{\text {eff }}$ value, a ${ }^{236} \mathrm{U}$ content of $0.2 \mathrm{wt} . \%$ was adjusted by approximately the $1 \sigma$ uncertainty. An upper perturbation $k_{\text {eff }}$ value was found by simultaneously increasing the ${ }^{236} \mathrm{U}$ content in all fuel elements by $0.2 \mathrm{wt} . \%$ and then simultaneously decreasing by the same amount to find a lower perturbation $\mathrm{k}_{\text {eff }}$ value. Half of the difference between the upper and lower perturbation $\mathrm{k}_{\text {eff }}$ values was used to represent the variation in $\mathrm{k}_{\mathrm{eff}}$ due to perturbing the ${ }^{236} \mathrm{U}$ content by 0.2 wt.\%. Results are shown in Table 2.8 .

This uncertainty is treated as $100 \%$ systematic because the isotopic content of ${ }^{234} \mathrm{U}$ and ${ }^{236} \mathrm{U}$ is not recorded for any of the fuel elements in the NRAD core. Increasing or decreasing the total mass of ${ }^{232} \mathrm{U}$, ${ }^{234} \mathrm{U}$, or ${ }^{236} \mathrm{U}$ in the fuel effectively decreases or increases the total mass of ${ }^{238} \mathrm{U}$. The ${ }^{235} \mathrm{U}$ mass and enrichment remains unchanged. Total uranium mass and total fuel mass are conserved.

Table 2.8. Effect of Uncertainty in Uranium-236 Content.

\begin{tabular}{||c|ccc|c|ccc||}
\hline Deviation & $\Delta \mathbf{k}$ & \pm & $\boldsymbol{\sigma}_{\Delta \mathbf{k}}$ & $\begin{array}{c}\text { Scaling } \\
\text { Factor }\end{array}$ & $\Delta \mathbf{k}_{\text {eff }}(\mathbf{1} \boldsymbol{\sigma})$ & \pm & $\boldsymbol{\sigma}_{\Delta \mathbf{k e f f}}$ \\
\hline \hline \pm 0.2 wt. $\%$ & -0.00104 & \pm & 0.00005 & 1 & -0.00104 & \pm & 0.00005 \\
\hline
\end{tabular}

\subsubsection{Fuel Element Dimensions}

The average fuel element length and outer diameter in the 60 -fuel-element core (Table 1.5) are $38.02 \pm$ $0.04 \mathrm{~cm}(1 \sigma)$ and $3.4805 \pm 0.0003 \mathrm{~cm}(1 \sigma)$, respectively. The inner diameter of the fuel is $0.635 \mathrm{~cm}$, with manufacturing tolerance limits of +0.00 and $-0.0254 \mathrm{~cm}$.

To find the effect of this uncertainty on the $\mathrm{k}_{\text {eff }}$ value, the fuel dimensions were individually adjusted by their respective uncertainties. An upper perturbation $\mathrm{k}_{\text {eff }}$ value was found by simultaneously increasing the average dimension in all fuel elements and then simultaneously decreasing by the same amount to find a lower perturbation $k_{\text {eff }}$ value. Half of the difference between the upper and lower perturbation $k_{\text {eff }}$ values was used to represent the variation in $\mathrm{k}_{\text {eff }}$ due to perturbing the fuel dimensions. The calculated results were then scaled to obtain their $1 \sigma$ uncertainty. Results are shown in Tables 2.9, 2.10, and 2.11 for fuel element length, inner diameter, and outer diameter, respectively.

The total mass of the fuel elements is conserved when making adjustments to the fuel dimensions. Because the zirconium rod in the center of the fuel element represents part of the fuel element structure, changes in the length of the fuel element also affect the length of the zirconium rod. The zirconium rod dimensions remain unchanged when the inner and outer diameters of the fuel element is varied. The total number of fuel elements in this configuration is 60 ; therefore the random component of this uncertainty is divided by $\sqrt{60}$. The calculated uncertainty in all fuel element dimensions is considered negligible $(\leq 0.00010)$. 
NEA/NSC/DOC(2006)1

Fundamental - FUND

NRAD-FUND-RESR-001

CRIT

Table 2.9. Effect of Uncertainty in Fuel Length.

\begin{tabular}{||c|ccc|c|ccc|c|c||}
\hline \hline Deviation & $\Delta \mathbf{k}$ & \pm & $\sigma_{\Delta k}$ & $\begin{array}{c}\text { Scaling } \\
\text { Factor }\end{array}$ & $\Delta \mathbf{k}_{\text {eff }}(\mathbf{1} \boldsymbol{\sigma})$ & \pm & $\sigma_{\Delta \mathrm{keff}}$ & $\begin{array}{c}\Delta \mathbf{k}_{\text {eff }} \\
\mathbf{( 1 5 \%} \\
\text { systematic) }\end{array}$ & $\begin{array}{c}\Delta \mathbf{k}_{\text {eff }} \\
\mathbf{( 8 5 \%} \\
\text { random) }\end{array}$ \\
\hline \hline $\pm 0.12 \mathrm{~cm}$ & -0.00035 & \pm & 0.00005 & 3 & -0.00012 & \pm & 0.00002 & -0.00002 & -0.00001 \\
\hline
\end{tabular}

Table 2.10. Effect of Uncertainty in Fuel Inner Diameter.

\begin{tabular}{||c|ccc|c|ccc|c|c||}
\hline \hline Deviation & $\Delta \mathbf{k}$ & \pm & $\sigma_{\Delta \mathbf{k}}$ & $\begin{array}{c}\text { Scaling } \\
\text { Factor }\end{array}$ & $\Delta \mathbf{k}_{\text {eff }}(\mathbf{1} \sigma)$ & \pm & $\sigma_{\Delta k \text { eff }}$ & $\begin{array}{c}\Delta \mathbf{k}_{\text {eff }} \\
(\mathbf{1 5 \%} \\
\text { systematic) }\end{array}$ & $\begin{array}{c}\Delta \mathbf{k}_{\text {eff }} \\
\mathbf{( 8 5 \%} \\
\text { random) }\end{array}$ \\
\hline \hline$-0.0254 \mathrm{~cm}$ & -0.00027 & \pm & 0.00010 & $\sqrt{ } 3$ & -0.00016 & \pm & 0.00006 & 0.00002 & 0.00002 \\
\hline
\end{tabular}

Table 2.11. Effect of Uncertainty in Fuel Outer Diameter.

\begin{tabular}{||c|ccc|c|ccc|c|c||}
\hline Deviation & $\Delta \mathbf{k}$ & \pm & $\sigma_{\Delta \mathrm{k}}$ & $\begin{array}{c}\text { Scaling } \\
\text { Factor }\end{array}$ & $\Delta \mathbf{k}_{\text {eff }}(\mathbf{1 \sigma})$ & \pm & $\sigma_{\Delta \mathrm{keff}}$ & $\begin{array}{c}\Delta \mathbf{k}_{\text {eff }} \\
\mathbf{( 1 5 \%} \\
\text { systematic) }\end{array}$ & $\begin{array}{c}\Delta \mathbf{k}_{\text {eff }} \\
\mathbf{( 8 5 \%} \\
\text { random })\end{array}$ \\
\hline \hline $\pm 0.0009 \mathrm{~cm}$ & -0.00003 & \pm & 0.00005 & 3 & -0.00001 & \pm & 0.00002 & negligible & negligible \\
\hline \hline
\end{tabular}

\subsubsection{Hydride Ratio}

The average fuel $\mathrm{H} / \mathrm{Zr}$ ratio in the 60 -fuel-element core (Table 1.5) is $1.58 \pm 0.01(1 \sigma)$.

To find the effect of this uncertainty on the $\mathrm{k}_{\text {eff }}$ value, the average fuel hydride ratio was adjusted by the $3 \sigma$ uncertainty. An upper perturbation $\mathrm{k}_{\text {eff }}$ value was found by simultaneously increasing the hydride ratio in all fuel elements by 0.03 and then simultaneously decreasing by the same amount to find a lower perturbation $\mathrm{k}_{\text {eff }}$ value. Half of the difference between the upper and lower perturbation $\mathrm{k}_{\text {eff }}$ values was used to represent the variation in $k_{\text {eff }}$ due to perturbing the average fuel hydride ratio by 0.03 . The calculated result was then scaled to obtain the $1 \sigma$ uncertainty. Results are shown in Table 2.12.

Increasing or decreasing the hydride ratio does not affect the mass of any other fuel constituents. The total number of fuel elements in this configuration is 60 ; therefore the random component of this uncertainty is divided by $\sqrt{ } 60$.

Table 2.12. Effect of Uncertainty in Hydride Ratio.

\begin{tabular}{||c|ccc|c|ccc|c|c||}
\hline \hline Deviation & $\Delta \mathbf{k}$ & \pm & $\sigma_{\Delta \mathrm{k}}$ & $\begin{array}{c}\text { Scaling } \\
\text { Factor }\end{array}$ & $\Delta \mathbf{k}_{\text {eff }}(\mathbf{1} \boldsymbol{\sigma})$ & \pm & $\sigma_{\Delta \mathrm{keff}}$ & $\begin{array}{c}\Delta \mathbf{k}_{\text {eff }} \\
(\mathbf{1 5 \%} \\
\text { systematic })\end{array}$ & $\begin{array}{c}\Delta \mathbf{k}_{\text {eff }} \\
\mathbf{( 8 5 \%} \\
\text { random) }\end{array}$ \\
\hline \hline $\pm 0.03 \mathrm{H}: \mathrm{Zr}$ & 0.00295 & \pm & 0.00005 & 3 & 0.00098 & \pm & 0.00002 & 0.00015 & 0.00011 \\
\hline
\end{tabular}


NEA/NSC/DOC(2006)1

Fundamental - FUND

NRAD-FUND-RESR-001

CRIT

\subsubsection{Hydride Homogeneity}

It is unknown how homogenously throughout the fuel the hydrogen is distributed during the hydriding process. Diffusion of hydrogen in hollow cylinders of zirconium alloy exhibits a fairly flat concentration profile. However, there are slight nonlinear effects due to thermal stresses, such as can be incurred due to impurities in the metal alloy. ${ }^{a}$ Micrographs of fuel samples from the extra fuel element are in Appendix G. Neither carbon nor uranium has any effect on the hydrogen diffusion process for $\mathrm{H} / \mathrm{Zr}$ ratios between 1.5 and 1.8. Erbium and uranium can be uniformly melted into a zirconium alloy; there is no reason to believe that erbium would segregate, as it forms a stable hydride and stays uniformly dispersed. ${ }^{\text {b }}$ There is some indication that the distribution of hydrogen has on average a constant profile throughout a sample of hydride discs being used in thermal migration studies of hydrogen in zirconium-uranium-hydrogen alloys. Two discs nominally containing $\mathrm{ZrH}_{1.6} \mathrm{U}_{0.03}$ exhibited hydrogen-to-zirconium ratios of approximately 1.65, bound between 1.60 and 1.70. Another sample of just $\mathrm{ZrH}_{1.6}$ was sampled five times with the following ratios: $1.68,1.72,1.69,1.69$, and $1.65 .^{\mathrm{c}}$ The average ratio for the $\mathrm{ZrH}_{1.6}$ sample is $1.69 \pm 0.03(1 \sigma)$. If the bounding limits for the $\mathrm{ZrH}_{1.6} \mathrm{U}_{0.03}$ samples are converted to $1 \sigma$ by dividing the limit by $\sqrt{ } 3$, the average ratio is $\sim 1.65 \pm 0.03(1 \sigma)$. It is concluded that the as-built distribution of hydride throughout the fuel matrix is not completely homogenous and has a $1 \sigma$ uncertainty approximately three times greater than the variation in average ratios between the individual fuel elements. It is unclear how the $\mathrm{H} / \mathrm{Zr}$ ratio is measured for the fuel; therefore, this uncertainty is treated as an additional uncertainty in the hydride composition of the fuel.

Three methods were utilized to evaluate the uncertainty in the homogeneity of the hydride in the fuel. The first two analysis methods overestimate the actual uncertainty. They are retained in this document as the pathway towards analysis of this uncertainty.

\section{Method 1:}

This first method follows the same analysis procedure as described in Section 2.1.2.6, but with a larger uncertainty.

To find the effect of this uncertainty on the $\mathrm{k}_{\text {eff }}$ value, the average fuel hydride ratio was adjusted by the $1 \sigma$ uncertainty. An upper perturbation $\mathrm{k}_{\mathrm{eff}}$ value was found by simultaneously increasing the hydride ratio in all fuel elements by 0.03 and then simultaneously decreasing by the same amount to find a lower perturbation $\mathrm{k}_{\mathrm{eff}}$ value. Half of the difference between the upper and lower perturbation $\mathrm{k}_{\mathrm{eff}}$ values was used to represent the variation in $\mathrm{k}_{\mathrm{eff}}$ due to perturbing the average fuel hydride ratio by 0.03 . Results are shown in Table 2.13.

Increasing or decreasing the hydride ratio does not affect the mass of any other fuel constituents. The total number of fuel elements in this configuration is 60 ; therefore the random component of this uncertainty is divided by $\sqrt{ } 60$.

This method significantly overestimated the actual uncertainty in hydride homogeneity as it assumed the entire fuel meat was perturbed instead of random variation in localized ratios.

\footnotetext{
${ }^{a}$ N. M. Vlasov and V. A. Zaznoba, "Thermal Diffusion of Hydrogen in Zirconium with Allowance for Thermal Stresses," Tech. Phys., 54, 651-655 (2009).

b M. T. Simnad, "The U-ZrH $\mathrm{rH}_{\mathrm{x}}$ Alloy: Its Properties and Use in TRIGA Fuel," E-117-833, GA Project No. 4314, General Atomics (February 1980). [This reference is not available for public release.]

${ }^{\mathrm{c}}$ U. Merten, J. C. Bokros, D. G. Guggisberg, and A. P. Hatcher, "Thermal Migration of Hydrogen in ZirconiumUranium-Hydrogen Alloys," J. Nucl. Mater., 10, 201-208 (1963).
} 
NEA/NSC/DOC(2006)1

Fundamental - FUND

NRAD-FUND-RESR-001

CRIT

\section{Method 2:}

The approach of the second method was to divide the fuel meat radially into thirds (by volume). The average hydrogen-to-zirconium ratio of $1.58 \pm 0.03$ was preserved but the volumetric ratios were different. The center third of the fuel had a ratio of 1.61 while the other two thirds had a ratio of 1.565 . The $\mathrm{k}_{\mathrm{eff}}$ value was then calculated assuming all fuel rods have this distribution.

To find the effect of this uncertainty on the $\mathrm{k}_{\mathrm{eff}}$ value, the perturbed $\mathrm{k}_{\mathrm{eff}}$ value was compared to the unperturbed $k_{\text {eff }}$ value; the difference between the two $k_{\text {eff }}$ values was used to represent the variation in $\mathrm{k}_{\text {eff }}$ due to perturbing the average fuel hydride ratio by 0.03 . Results are shown in Table 2.13.

Increasing or decreasing the hydride ratio does not affect the mass of any other fuel constituents. The total number of fuel elements in this configuration is 60 ; therefore the random component of this uncertainty is divided by $\sqrt{ } 60$.

This method also overestimated the actual uncertainty in hydride homogeneity as it assumed the entire fuel meat was perturbed in large sections instead of by random variation in localized ratios. However, the effective uncertainty in this parameter appears to be negligible.

\section{Method 3:}

A final method was developed to confirm whether this uncertainty, as it appears in the analysis of Method 2, is negligible. A cube with dimensions of $0.06 \mathrm{~cm}$ on all sides was divided into 27 smaller cubes containing fuel material. Each cube contained fuel material that was identical except for the hydrogen-to-zirconium ratio. The average ratio of $1.58 \pm 0.03$ was preserved across the cube. The fuel in the model was divided into cubic grids with dimensions of $0.02 \mathrm{~cm}$ on all sides. This lattice is larger than the microlattice structure of the actual fuel material (Appendix G); a smaller lattice using this method, however, would have required a significant quantity of computing time that was deemed unnecessary to further refine this uncertainty analysis. The URAN card in MCNP5 ${ }^{\text {a }}$ was used to randomly pick material from the larger "cube" of materials to place within the smaller cubic lattice. The average hydrogen-to-zirconium ratio was preserved throughout the calculations.

To find the effect of this uncertainty on the $k_{\text {eff }}$ value, the perturbed $k_{\text {eff }}$ value was compared to the unperturbed $\mathrm{k}_{\mathrm{eff}}$ value; the difference between the two $\mathrm{k}_{\mathrm{eff}}$ values was used to represent the variation in $\mathrm{k}_{\text {eff }}$ due to perturbing the average fuel hydride ratio by 0.03 . Results are shown in Table 2.13 .

Increasing or decreasing the hydride ratio does not affect the mass of any other fuel constituents. The total number of fuel elements in this configuration is 60 ; therefore the random component of this uncertainty is divided by $\sqrt{ } 60$.

The calculated uncertainty in hydrogen homogeneity is considered negligible $(\leq 0.00010)$.

\footnotetext{
${ }^{\text {a }}$ X-5 Monte Carlo Team, "MCNP - A General Monte Carlo N-Particle Transport Code, Version 5, Volume II:

User's Guide,” LA-CP-03-0245, Los Alamos National Laboratory (October 3, 2005). 
NEA/NSC/DOC(2006)1

Fundamental - FUND

NRAD-FUND-RESR-001

CRIT

Table 2.13. Effect of Uncertainty in Hydride Homogeneity.

\begin{tabular}{||c|c|ccc|c|ccc|c|c||}
\hline \hline Method & Deviation & $\Delta \mathbf{k}$ & \pm & $\sigma_{\Delta \mathbf{k}}$ & $\begin{array}{c}\text { Scaling } \\
\text { Factor }\end{array}$ & $\begin{array}{c}\Delta \mathbf{k}_{\text {eff }} \\
(\mathbf{1} \boldsymbol{\sigma})\end{array}$ & \pm & $\boldsymbol{\sigma}_{\Delta \mathrm{keff}}$ & $\begin{array}{c}\Delta \mathbf{k}_{\text {eff }} \\
\mathbf{( 1 5 \%} \\
\text { systematic) }\end{array}$ & $\begin{array}{c}\Delta \mathbf{k}_{\text {eff }} \\
\mathbf{( 8 5 \%} \\
\text { random) }\end{array}$ \\
\hline \hline 1 & \pm 0.03 & 0.00295 & \pm & 0.00005 & 1 & 0.00295 & \pm & 0.00005 & 0.00044 & 0.00032 \\
3 & $\mathrm{H}: \mathrm{Zr}$ & 0.00024 & \pm & 0.00010 & 1 & 0.00024 & \pm & 0.00010 & 0.00003 & 0.00010 \\
& 0.00003 & \pm & 0.00010 & 1 & 0.00003 & \pm & 0.00010 & negligible & 0.00001 \\
\hline
\end{tabular}

\subsubsection{Erbium Content}

The average fuel erbium content in the 60 -fuel-element core (Table 1.5 ) is $0.90 \pm 0.02 \mathrm{wt} . \%(1 \sigma)$.

To find the effect of this uncertainty on the $\mathrm{k}_{\mathrm{eff}}$ value, the average fuel erbium content was adjusted by the $3 \sigma$ uncertainty. An upper perturbation $\mathrm{k}_{\mathrm{eff}}$ value was found by simultaneously increasing the average erbium content in all fuel elements by $0.06 \mathrm{wt} . \%$ and then simultaneously decreasing by the same amount to find a lower perturbation $\mathrm{k}_{\text {eff }}$ value. Half of the difference between the upper and lower perturbation $\mathrm{k}_{\text {eff }}$ values was used to represent the variation in $\mathrm{k}_{\text {eff }}$ due to perturbing the average fuel erbium content by 0.06 wt.\%. The calculated result was then scaled to obtain the $1 \sigma$ uncertainty. Results are shown in Table 2.14.

Increasing or decreasing the total erbium content in the fuel effectively decreases or increases the total mass of zirconium hydride in the fuel, changing the U/Zr-H ratio. The total number of fuel elements in this configuration is 60 ; therefore the random component of this uncertainty is divided by $\sqrt{60}$.

Table 2.14. Effect of Uncertainty in Erbium Content.

\begin{tabular}{||c|ccc|c|ccc|c|c||}
\hline Deviation & $\Delta \mathbf{k}$ & \pm & $\sigma_{\Delta \mathbf{k}}$ & $\begin{array}{c}\text { Scaling } \\
\text { Factor }\end{array}$ & $\Delta \mathbf{k}_{\text {eff }}(\mathbf{1} \boldsymbol{\sigma})$ & \pm & $\boldsymbol{\sigma}_{\Delta \mathbf{k e f f}}$ & $\begin{array}{c}\Delta \mathbf{k}_{\text {eff }} \\
(\mathbf{1 5 \%} \\
\text { systematic) }\end{array}$ & $\begin{array}{c}\Delta \mathbf{k}_{\text {eff }} \\
\mathbf{( 8 5 \%} \\
\mathbf{r a n d o m})\end{array}$ \\
\hline \hline \pm 0.06 wt.\% & -0.00797 & \pm & 0.00005 & 3 & -0.00266 & \pm & 0.00002 & -0.00040 & -0.00029 \\
\hline \hline
\end{tabular}

\subsubsection{Carbon Content}

The average fuel carbon content in the 60 -fuel-element core (Table 1.5) is $0.30 \pm 0.02 \mathrm{wt.} \%(1 \sigma)$.

To find the effect of this uncertainty on the $\mathrm{k}_{\text {eff }}$ value, the average fuel carbon content was adjusted by the $3 \sigma$ uncertainty. An upper perturbation $\mathrm{k}_{\text {eff }}$ value was found by simultaneously increasing the average carbon content in all fuel elements by $0.06 \mathrm{wt} . \%$ and then simultaneously decreasing by the same amount to find a lower perturbation $\mathrm{k}_{\text {eff }}$ value. Half of the difference between the upper and lower perturbation $\mathrm{k}_{\text {eff }}$ values was used to represent the variation in $\mathrm{k}_{\text {eff }}$ due to perturbing the average fuel carbon content by 0.06 wt.\%. The calculated result was then scaled to obtain the $1 \sigma$ uncertainty. Results are shown in Table 2.15 .

Increasing or decreasing the total carbon content in the fuel effectively decreases or increases the total mass of zirconium hydride in the fuel, changing the $\mathrm{U} / \mathrm{Zr}-\mathrm{H}$ ratio. The total number of fuel elements in this configuration is 60 ; therefore the random component of this uncertainty is divided by $\sqrt{ } 60$. The calculated uncertainty in the average fuel carbon content is considered negligible $(\leq 0.00010)$. 
NEA/NSC/DOC(2006)1

Fundamental - FUND

NRAD-FUND-RESR-001

CRIT

Table 2.15. Effect of Uncertainty in Carbon Content.

\begin{tabular}{||c|ccc|c|ccc|c|c||}
\hline \hline Deviation & $\Delta \mathbf{k}$ & \pm & $\sigma_{\Delta \mathbf{k}}$ & $\begin{array}{c}\text { Scaling } \\
\text { Factor }\end{array}$ & $\Delta \mathbf{k}_{\text {eff }}(\mathbf{1 \sigma})$ & \pm & $\boldsymbol{\sigma}_{\Delta \mathrm{keff}}$ & $\begin{array}{c}\Delta \mathbf{k}_{\text {eff }} \\
\mathbf{( 1 5 \%} \\
\text { systematic) }\end{array}$ & $\begin{array}{c}\Delta \mathbf{k}_{\text {eff }} \\
\mathbf{( 8 5 \%} \\
\text { random) }\end{array}$ \\
\hline \hline \pm 0.06 wt. $\%$ & -0.00003 & \pm & 0.00005 & 3 & -0.00001 & \pm 0.00002 & negligible & negligible \\
\hline \hline
\end{tabular}

\subsubsection{Additional Impurity Content}

The hafnium content in the fuel is not recorded and the uncertainty in the expected amount of $0.2 \mathrm{~g}$ $(\sim 0.008$ wt.\%) per fuel pellet is unknown. This value is perturbed by $\pm 100 \%$ as a bounding limit to evaluate the uncertainty in this parameter. Elsewhere the hafnium content was described as approximately $60 \mathrm{ppm}$ with little variation, ${ }^{\text {a }}$ however; the amount of variation was not discussed, and the assumed uncertainty encompasses this latter value.

To find the effect of this uncertainty on the $\mathrm{k}_{\text {eff }}$ value, the hafnium content was adjusted by the assumed bounding limit. An upper perturbation $\mathrm{k}_{\text {eff }}$ value was found by simultaneously increasing the hafnium content in all fuel elements by $0.008 \mathrm{wt} . \%$ and then simultaneously decreasing by the same amount to find a lower perturbation $\mathrm{k}_{\mathrm{eff}}$ value. Half of the difference between the upper and lower perturbation $\mathrm{k}_{\mathrm{eff}}$ values was used to represent the variation in $\mathrm{k}_{\text {eff }}$ due to perturbing the hafnium content by 0.008 wt.\%. The calculated result was then scaled to obtain the $1 \sigma$ uncertainty. Results are shown in Table 2.16.

As discussed in Section 2.1.2, the impurity content of the fuel, excluding carbon and hafnium, can be approximated with $\sim 1 \mathrm{ppm}$ EBC. The average EBC content is $1.04 \pm 0.15 \mathrm{ppm}(1 \sigma)$. An uncertainty of $\pm 0.167 \mathrm{ppm}(1 \sigma)$ was selected for this analysis.

To find the effect of this uncertainty on the $\mathrm{k}_{\mathrm{eff}}$ value, the EBC was adjusted by a factor of 6 times the $1 \sigma$ uncertainty. An upper perturbation $\mathrm{k}_{\text {eff }}$ value was found by simultaneously increasing the $\mathrm{EBC}$ in all fuel elements by $1 \mathrm{ppm}$ and then simultaneously decreasing by the same amount to find a lower perturbation $\mathrm{k}_{\text {eff }}$ value. Half of the difference between the upper and lower perturbation $\mathrm{k}_{\text {eff }}$ values was used to represent the variation in $\mathrm{k}_{\mathrm{eff}}$ due to perturbing the $\mathrm{EBC}$ by $1 \mathrm{ppm}$. The calculated result was then scaled to obtain the $1 \sigma$ uncertainty. Results are shown in Table 2.17.

This uncertainty is treated as $100 \%$ systematic because the actual impurity content is not recorded for any of the fuel elements in the NRAD core. Increasing or decreasing the impurity content in the fuel effectively decreases or increases the total mass of zirconium hydride in the fuel, changing the $\mathrm{U} / \mathrm{Zr}-\mathrm{H}$ ratio. The calculated uncertainty in the EBC is considered negligible $(\leq 0.00010)$.

Table 2.16. Effect of Uncertainty in Hafnium Content.

\begin{tabular}{||c|ccc|c|ccc||}
\hline \hline Deviation & $\Delta \mathbf{k}$ & \pm & $\sigma_{\Delta \mathbf{k}}$ & $\begin{array}{c}\text { Scaling } \\
\text { Factor }\end{array}$ & $\Delta \mathbf{k}_{\text {eff }}(\mathbf{1} \boldsymbol{\sigma})$ & \pm & $\boldsymbol{\sigma}_{\Delta \mathrm{keff}}$ \\
\hline \hline $\pm 100 \%$ & -0.00145 & \pm & 0.00005 & $\sqrt{ } 3$ & -0.00083 & \pm & 0.00003 \\
\hline
\end{tabular}

\footnotetext{
${ }^{a}$ Presentation material with subsequent discussion at the American Nuclear Society 2010 Annual Meeting in regards to "Fuel Manufacturing Uncertainty Efffect on NRAD Criticality," by H. Choi, J. Bolin, and A. Veca (June $16,2010)$.
} 
NEA/NSC/DOC(2006)1

Fundamental - FUND

NRAD-FUND-RESR-001

CRIT

Table 2.17. Effect of Uncertainty in Equivalent Boron Content.

\begin{tabular}{||c|ccc|c|ccc||}
\hline Deviation & $\Delta \mathbf{k}$ & \pm & $\sigma_{\Delta \mathbf{k}}$ & $\begin{array}{c}\text { Scaling } \\
\text { Factor }\end{array}$ & $\Delta \mathbf{k}_{\text {eff }}(\mathbf{1} \boldsymbol{\sigma})$ & \pm & $\boldsymbol{\sigma}_{\Delta \mathrm{keff}}$ \\
\hline \hline $\pm 1 \mathrm{ppm}$ & -0.00033 & \pm & 0.00005 & 6 & -0.00006 & \pm & 0.00001 \\
\hline
\end{tabular}

\subsubsection{Fuel Element - Non-Fuel Properties}

\subsubsection{Zirconium Rod}

\section{Composition}

The composition of the zirconium rods (Table 2.18) is obtained by reducing the quantity of zirconium to account for the impurities reported in Table 1.12. For elements that are listed only as detection limits, half of the detection limit is assumed to represent the quantity of that impurity in the zirconium material. 
NEA/NSC/DOC(2006)1

Fundamental - FUND

NRAD-FUND-RESR-001

CRIT

Table 2.18. Composition of Zirconium.

\begin{tabular}{|c|c|c|c|c|c|}
\hline Element & wt.\% & Element & wt.\% & Element & wt.\% \\
\hline $\mathrm{Li}$ & 0.00000025 & As & 0.000004 & $\mathrm{Sm}$ & 0.00000025 \\
\hline $\mathrm{Be}$ & 0.00000025 & $\mathrm{Se}$ & 0.0000025 & $\mathrm{Eu}$ & 0.00000025 \\
\hline B & 0.000005 & $\mathrm{Br}$ & 0.0000025 & $\mathrm{Gd}$ & 0.00000025 \\
\hline $\mathrm{F}$ & 0.00005 & $\mathrm{Rb}$ & 0.0000025 & $\mathrm{~Tb}$ & 0.00000025 \\
\hline $\mathrm{Na}$ & 0.0000005 & $\mathrm{Sr}$ & 0.0000025 & Dy & 0.00000025 \\
\hline $\mathrm{Mg}$ & 0.00000025 & $\mathrm{Y}$ & 0.0000025 & Ho & 0.00000025 \\
\hline $\mathrm{Al}$ & 0.004 & $\mathrm{Zr}$ & 99.8169797 & $\mathrm{Er}$ & 0.00000025 \\
\hline $\mathrm{Si}$ & 0.00071 & $\mathrm{Nb}$ & 0.000061 & $\mathrm{Tm}$ & 0.00000025 \\
\hline $\mathrm{P}$ & 0.000079 & Mo & 0.00022 & $\mathrm{Yb}$ & 0.00000025 \\
\hline S & 0.000025 & $\mathrm{Ru}$ & 0.0000025 & $\mathrm{Lu}$ & 0.00000025 \\
\hline $\mathrm{Cl}$ & 0.000023 & $\mathrm{Rh}$ & 0.0000025 & $\mathrm{Hf}$ & 0.0055 \\
\hline K & 0.000005 & $\mathrm{Pd}$ & 0.000025 & $\mathrm{Ta}$ & 0.00025 \\
\hline $\mathrm{Ca}$ & 0.0000025 & $\mathrm{Ag}$ & 0.000025 & W & 0.000012 \\
\hline $\mathrm{Sc}$ & 0.00025 & $\mathrm{Cd}$ & 0.000025 & $\operatorname{Re}$ & 0.00000025 \\
\hline $\mathrm{Ti}$ & 0.00017 & In & 0.000005 & Os & 0.00000025 \\
\hline V & 0.000043 & $\mathrm{Sn}$ & 0.000049 & Ir & 0.00000025 \\
\hline $\mathrm{Cr}$ & 0.012 & $\mathrm{Sb}$ & 0.0000025 & $\mathrm{Pt}$ & 0.00000025 \\
\hline $\mathrm{Mn}$ & 0.00014 & $\mathrm{Te}$ & 0.0000025 & $\mathrm{Au}$ & 0.0000025 \\
\hline $\mathrm{Fe}$ & 0.15 & I & 0.000005 & $\mathrm{Hg}$ & 0.0000025 \\
\hline Co & 0.00011 & Cs & 0.00000025 & $\mathrm{Tl}$ & 0.0000005 \\
\hline $\mathrm{Ni}$ & 0.0063 & $\mathrm{Ba}$ & 0.00000025 & $\mathrm{~Pb}$ & 0.000036 \\
\hline $\mathrm{Cu}$ & 0.0013 & $\mathrm{La}$ & 0.00000025 & $\mathrm{Bi}$ & 0.000016 \\
\hline $\mathrm{Zn}$ & 0.000041 & $\mathrm{Ce}$ & 0.00000025 & Th & 0.00000005 \\
\hline $\mathrm{Ga}$ & 0.00022 & $\operatorname{Pr}$ & 0.00000025 & $\mathrm{U}$ & 0.000007 \\
\hline $\mathrm{Ge}$ & 0.0000025 & $\mathrm{Nd}$ & 0.00000025 & & \\
\hline
\end{tabular}

\section{Density}

The density of the zirconium rods is not specified. Open literature sources report a density of both 6.506 $\mathrm{g} / \mathrm{cm}^{3}$ (Chart of the Nuclides) ${ }^{\mathrm{a}}$ and $6.52 \mathrm{~g} / \mathrm{cm}^{3}$ (CRC Handbook of Chemistry and Physics). ${ }^{\mathrm{b}}$ A density of $6.51 \pm 0.01 \mathrm{~g} / \mathrm{cm}^{3}(1 \sigma)$ was selected.

To find the effect of this uncertainty on the $k_{\text {eff }}$ value, the zirconium density was adjusted by the $3 \sigma$ uncertainty. An upper perturbation $k_{\text {eff }}$ value was found by simultaneously increasing the zirconium

\footnotetext{
${ }^{\text {a }}$ E. M. Baum, H. D. Knox, and T. R. Miller, Nuclides and Isotopes: $16^{\text {th }}$ Edition, Knolls Atomic Power Laboratory (2002).

${ }^{\mathrm{b}}$ D. R. Lide, ed., CRC Handbook of Chemistry and Physics, $90^{\text {th }}$ Edition (Internet Version 2010), CRC Press/Taylor and Francis, Boca Raton, FL (2010). 
NEA/NSC/DOC(2006)1

Fundamental - FUND

NRAD-FUND-RESR-001

CRIT

density by $0.03 \mathrm{~g} / \mathrm{cm}^{3}$ and then simultaneously decreasing by the same amount to find a lower perturbation $\mathrm{k}_{\mathrm{eff}}$ value. Half of the difference between the upper and lower perturbation $\mathrm{k}_{\text {eff }}$ values was used to represent the variation in $k_{\text {eff }}$ due to perturbing the zirconium density by $0.03 \mathrm{~g} / \mathrm{cm}^{3}$. The calculated result was then scaled to obtain the $1 \sigma$ uncertainty. Results are shown in Table 2.19.

This uncertainty is treated as $100 \%$ systematic. The calculated uncertainty in the zirconium rod density is considered negligible $(\leq 0.00010)$.

Table 2.19. Effect of Uncertainty in Zirconium Density.

\begin{tabular}{||c|ccc|c|ccc||}
\hline \hline Deviation & $\Delta \mathbf{k}$ & \pm & $\sigma_{\Delta \mathbf{k}}$ & $\begin{array}{c}\text { Scaling } \\
\text { Factor }\end{array}$ & $\Delta \mathbf{k}_{\text {eff }}(\mathbf{1} \boldsymbol{\sigma})$ & \pm & $\boldsymbol{\sigma}_{\Delta \mathbf{k e f f}}$ \\
\hline \hline $\pm 0.03 \mathrm{~g} / \mathrm{cm}^{3}$ & 0.00006 & \pm & 0.00005 & 3 & 0.00002 & \pm & 0.00002 \\
\hline \hline
\end{tabular}

\section{Dimensions}

The length of the zirconium rod is nominally equal to the average fuel element length (Table 1.5), which is $38.02 \pm 0.04 \mathrm{~cm}(1 \sigma)$. The outer diameter of the zirconium rod (Figure 1.26) is $0.5715 \mathrm{~cm}$ with manufacturing tolerance limits of +0.00 and $-0.0254 \mathrm{~cm}$.

Perturbations of the zirconium rod length was performed in conjunction with the assessment of the uncertainty in fuel element length and inner diameter. To find the effect of the uncertainty on the $\mathrm{k}_{\text {eff }}$ value due to the zirconium rod outer diameter, the zirconium rod diameter was adjusted by the $3 \sigma$ uncertainty. A lower perturbation $\mathrm{k}_{\text {eff }}$ value was found by simultaneously decreasing the zirconium rod diameter in all fuel elements by 0.0762 . The difference between the unperturbed and lower perturbation $\mathrm{k}_{\mathrm{eff}}$ values was used to represent the variation in $\mathrm{k}_{\mathrm{eff}}$ due to perturbing the zirconium rod diameter by $0.0762 \mathrm{~cm}$. The calculated result was then scaled to obtain the $1 \sigma$ uncertainty. Results are shown in Table 2.20

The total number of fuel elements in this configuration is 60 ; therefore the random component of this uncertainty is divided by $\sqrt{ } 60$. The calculated uncertainty in the zirconium dimensions is considered negligible $(\leq 0.00010)$.

Table 2.20. Effect of Uncertainty in Zirconium Rod Outer Diameter.

\begin{tabular}{||c|ccc|c|ccc|c|c||}
\hline \hline Deviation & $\Delta \mathbf{k}$ & \pm & $\sigma_{\Delta \mathbf{k}}$ & $\begin{array}{c}\text { Scaling } \\
\text { Factor }\end{array}$ & $\Delta \mathbf{k}_{\text {eff }}(\mathbf{1} \sigma)$ & \pm & $\sigma_{\Delta \mathrm{keff}}$ & $\begin{array}{c}\Delta \mathbf{k}_{\text {eff }} \\
(\mathbf{1 5 \%} \\
\text { systematic) }\end{array}$ & $\begin{array}{c}\Delta \mathbf{k}_{\text {eff }} \\
\mathbf{8 5 \%} \\
\text { random) }\end{array}$ \\
\hline \hline$-0.0254 \mathrm{~cm}$ & -0.00042 & \pm & 0.00010 & $3 \sqrt{ } 3$ & -0.00008 & \pm & 0.00002 & 0.00001 & 0.00001 \\
\hline
\end{tabular}

\section{Impurities}

The effective bias for removing impurities (Table 2.18) from the zirconium rod was determined to be negligible (Section 3.1.1.1). Therefore, an uncertainty analysis regarding impurities in the zirconium was judged to be unnecessary as the result would also be negligible. 
NEA/NSC/DOC(2006)1

Fundamental - FUND

NRAD-FUND-RESR-001

CRIT

\subsubsection{Molybdenum Poison Disc}

\section{Composition}

The composition of the molybdenum poison discs (Table 2.21) is obtained by reducing the quantity of molybdenum to account for the impurities reported in Tables 1.9 and 1.10. The average impurity content from these two tables is used to represent the quantity of materials in the entire molybdenum disc as no information is available regarding the amount of molybdenum carbide material coating present. Additionally, the total carbon content of the molybdenum is assumed to be $0.01 \mathrm{wt} . \%$. For elements that are listed only as detection limits, half of the detection limit is assumed to represent the quantity of that impurity in the molybdenum material.

Table 2.21. Composition of Molybdenum.

\begin{tabular}{|c|c|c|c|c|c|}
\hline Element & wt.\% & Element & wt.\% & Element & wt. $\%$ \\
\hline $\mathrm{Li}$ & 0.0000005 & $\mathrm{Ge}$ & 0.000005 & $\mathrm{Nd}$ & 0.0000005 \\
\hline $\mathrm{Be}$ & 0.0000005 & As & 0.000035 & $\mathrm{Sm}$ & 0.0000005 \\
\hline B & 0.0000005 & $\mathrm{Se}$ & 0.000005 & $\mathrm{Eu}$ & 0.0000005 \\
\hline $\mathrm{C}$ & 0.01 & $\mathrm{Br}$ & 0.0000005 & $\mathrm{Gd}$ & 0.0000005 \\
\hline $\mathrm{F}$ & 0.0000005 & $\mathrm{Rb}$ & 0.0000025 & $\mathrm{~Tb}$ & 0.0000005 \\
\hline $\mathrm{Na}$ & 0.0002885 & $\mathrm{Sr}$ & 0.000025 & Dy & 0.0000005 \\
\hline $\mathrm{Mg}$ & 0.000037 & Y & 0.000005 & Но & 0.0000005 \\
\hline $\mathrm{Al}$ & 0.000044 & $\mathrm{Zr}$ & 0.000005 & $\mathrm{Er}$ & 0.0000005 \\
\hline $\mathrm{Si}$ & 0.0002 & $\mathrm{Nb}$ & 0.000025 & $\mathrm{Tm}$ & 0.0000005 \\
\hline $\mathrm{P}$ & 0.000051 & Mo & 99.968464 & $\mathrm{Yb}$ & 0.0000005 \\
\hline $\mathrm{S}$ & 0.0001945 & $\mathrm{Ru}$ & 0.0000025 & $\mathrm{Lu}$ & 0.0000005 \\
\hline $\mathrm{Cl}$ & 0.000001 & $\mathrm{Rh}$ & 0.0000025 & $\mathrm{Hf}$ & 0.0000005 \\
\hline K & 0.0025 & $\mathrm{Pd}$ & 0.000005 & $\mathrm{Ta}$ & 0.0005 \\
\hline $\mathrm{Ca}$ & 0.00018 & $\mathrm{Ag}$ & 0.000025 & W & 0.0125 \\
\hline $\mathrm{Sc}$ & 0.00000025 & $\mathrm{Cd}$ & 0.0005 & $\operatorname{Re}$ & 0.000013 \\
\hline $\mathrm{Ti}$ & 0.0005 & In & 0.0000025 & Os & 0.0000025 \\
\hline V & 0.00011 & $\mathrm{Sn}$ & 0.000019 & Ir & 0.0000025 \\
\hline $\mathrm{Cr}$ & 0.00038 & $\mathrm{Sb}$ & 0.00013 & $\mathrm{Pt}$ & 0.0000025 \\
\hline $\mathrm{Mn}$ & 0.000043 & $\mathrm{Te}$ & 0.0000025 & $\mathrm{Au}$ & 0.0000025 \\
\hline $\mathrm{Fe}$ & 0.001175 & I & 0.0000005 & $\mathrm{Hg}$ & 0.0000025 \\
\hline Co & 0.000014 & Cs & 0.0000025 & $\mathrm{Tl}$ & 0.0000025 \\
\hline $\mathrm{Ni}$ & 0.00012 & $\mathrm{Ba}$ & 0.0015 & $\mathrm{~Pb}$ & 0.0000025 \\
\hline $\mathrm{Cu}$ & 0.00025 & $\mathrm{La}$ & 0.0000945 & $\mathrm{Bi}$ & 0.0000025 \\
\hline $\mathrm{Zn}$ & 0.0000025 & $\mathrm{Ce}$ & 0.0000025 & Th & 0.00000025 \\
\hline $\mathrm{Ga}$ & 0.0000025 & $\operatorname{Pr}$ & 0.0000005 & $\mathrm{U}$ & 0.000004 \\
\hline
\end{tabular}


NEA/NSC/DOC(2006)1

Fundamental - FUND

NRAD-FUND-RESR-001

CRIT

\section{Density}

The density of the molybdenum disc is not specified. Open literature sources report a density of both $10.22 \mathrm{~g} / \mathrm{cm}^{3}$ (Chart of the Nuclides) ${ }^{\mathrm{a}}$ and $10.2 \mathrm{~g} / \mathrm{cm}^{3}$ (CRC Handbook of Chemistry and Physics). ${ }^{\mathrm{b}}$ A density of $10.22 \pm 0.02 \mathrm{~g} / \mathrm{cm}^{3}(1 \sigma)$ was selected.

To find the effect of this uncertainty on the $k_{\text {eff }}$ value, the molybdenum density was adjusted by the $3 \sigma$ uncertainty. An upper perturbation $\mathrm{k}_{\text {eff }}$ value was found by simultaneously increasing the molybdenum density by $0.06 \mathrm{~g} / \mathrm{cm}^{3}$ and then simultaneously decreasing by the same amount to find a lower perturbation $k_{\text {eff }}$ value. Half of the difference between the upper and lower perturbation $k_{\text {eff }}$ values was used to represent the variation in $k_{\text {eff }}$ due to perturbing the molybdenum density by $0.06 \mathrm{~g} / \mathrm{cm}^{3}$. The calculated result was then scaled to obtain the $1 \sigma$ uncertainty. Results are shown in Table 2.22.

This uncertainty is treated as $100 \%$ systematic. The calculated uncertainty in the molybdenum disc density is considered negligible $(\leq 0.00010)$.

Table 2.22. Effect of Uncertainty in Molybdenum Density.

\begin{tabular}{||c|ccc|c|ccc||}
\hline \hline Deviation & $\Delta \mathbf{k}$ & \pm & $\boldsymbol{\sigma}_{\Delta \mathbf{k}}$ & $\begin{array}{c}\text { Scaling } \\
\text { Factor }\end{array}$ & $\Delta \mathbf{k}_{\text {eff }}(\mathbf{1} \boldsymbol{\sigma})$ & \pm & $\boldsymbol{\sigma}_{\Delta \mathrm{keff}}$ \\
\hline \hline $\pm 0.06 \mathrm{~g} / \mathrm{cm}^{3}$ & -0.00006 & \pm & 0.00005 & 3 & -0.00002 & \pm & 0.00002 \\
\hline
\end{tabular}

\section{Dimensions}

The molybdenum poison disc (Figure 1.27) thickness and outer diameter are $0.079375 \mathrm{~cm}$ (no reported uncertainty) and $3.46964 \mathrm{~cm}$ with manufacturing tolerance limits of +0.000 and $-0.0127 \mathrm{~cm}$.

To find the effect of this uncertainty on the $\mathrm{k}_{\mathrm{eff}}$ value, the molybdenum disc dimensions were adjusted by $>10 \sigma$ uncertainty. An upper perturbation $k_{\text {eff }}$ value was found by simultaneously doubling the molybdenum disc volume and then simultaneously decreasing by the same amount (i.e. removing it) to find a lower perturbation $\mathrm{k}_{\text {eff }}$ value. Half of the difference between the upper and lower perturbation $\mathrm{k}_{\text {eff }}$ values was used to represent the variation in $\mathrm{k}_{\text {eff }}$ due to perturbing the molybdenum disc dimensions. The calculated result was then scaled to obtain the $1 \sigma$ uncertainty. Results are shown in Table 2.23.

The total number of fuel elements in this configuration is 60 ; therefore the random component of this uncertainty is divided by $\sqrt{ } 60$. The calculated uncertainty in the molybdenum dimensions is considered negligible $(\leq 0.00010)$.

Table 2.23. Effect of Uncertainty in Molybdenum Dimensions.

\begin{tabular}{||c|ccc|c|ccc|c|c||}
\hline \hline Deviation & $\Delta \mathbf{k}$ & \pm & $\sigma_{\Delta \mathbf{k}}$ & $\begin{array}{c}\text { Scaling } \\
\text { Factor }\end{array}$ & $\Delta \mathbf{k}_{\text {eff }}(\mathbf{1} \sigma)$ & \pm & $\sigma_{\Delta \text { keff }}$ & $\begin{array}{c}\Delta \mathbf{k}_{\text {eff }} \\
(\mathbf{1 5 \%} \\
\text { systematic) }\end{array}$ & $\begin{array}{c}\Delta \mathbf{k}_{\text {eff }} \\
\mathbf{( 8 5 \%} \\
\text { random) }\end{array}$ \\
\hline \hline \pm 100 vol.\% & -0.00020 & \pm & 0.00005 & 10 & -0.00002 & \pm & 0.00001 & negligible & negligible \\
\hline \hline
\end{tabular}

\footnotetext{
${ }^{\text {a }}$ E. M. Baum, H. D. Knox, and T. R. Miller, Nuclides and Isotopes: $16^{\text {th }}$ Edition, Knolls Atomic Power Laboratory (2002).

${ }^{\mathrm{b}}$ D. R. Lide, ed., CRC Handbook of Chemistry and Physics, $90^{\text {th }}$ Edition (Internet Version 2010), CRC Press/Taylor and Francis, Boca Raton, FL (2010).
} 


\section{Impurities}

The effective bias for removing impurities (Table 2.21) from the molybdenum poison disc was determined to be negligible (Section 3.1.1.1). Therefore, an uncertainty analysis regarding impurities in the molybdenum was judged to be unnecessary as the result would also be negligible.

\subsubsection{Axial Graphite Reflector}

\section{Composition}

The composition of the axial graphite reflectors (Table 2.24) is obtained by reducing the quantity of graphite to account for the impurities reported in Table 1.8. For elements that are listed only as detection limits, half of the detection limit is assumed to represent the quantity of that impurity in the graphite material.

Table 2.24. Composition of Axial Graphite Reflector.

\begin{tabular}{|c|c|c|c|c|c|}
\hline Element & wt.\% & Element & wt.\% & Element & wt. $\%$ \\
\hline $\mathrm{Li}$ & 0.0000025 & $\mathrm{Ge}$ & 0.0000025 & $\mathrm{Nd}$ & 0.0000025 \\
\hline $\mathrm{Be}$ & 0.0000025 & As & 0.0000025 & $\mathrm{Sm}$ & 0.0000005 \\
\hline B & 0.000035 & $\mathrm{Se}$ & 0.0000025 & $\mathrm{Eu}$ & 0.0000005 \\
\hline $\mathrm{C}$ & 99.994614 & $\mathrm{Br}$ & 0.000005 & $\mathrm{Gd}$ & 0.0000005 \\
\hline $\mathrm{F}$ & 0.000005 & $\mathrm{Rb}$ & 0.0000025 & $\mathrm{~Tb}$ & 0.0000005 \\
\hline $\mathrm{Na}$ & 0.0000025 & $\mathrm{Sr}$ & 0.0000025 & Dy & 0.0000005 \\
\hline $\mathrm{Mg}$ & 0.0000025 & Y & 0.0000025 & Ho & 0.0000005 \\
\hline $\mathrm{Al}$ & 0.0000025 & $\mathrm{Zr}$ & 0.0000025 & $\mathrm{Er}$ & 0.0000005 \\
\hline $\mathrm{Si}$ & 0.000075 & $\mathrm{Nb}$ & 0.0000025 & $\mathrm{Tm}$ & 0.0000005 \\
\hline $\mathrm{P}$ & 0.000005 & Mo & 0.0000025 & $\mathrm{Yb}$ & 0.0000005 \\
\hline S & 0.000092 & $\mathrm{Ru}$ & 0.0000025 & $\mathrm{Lu}$ & 0.0000005 \\
\hline $\mathrm{Cl}$ & 0.000024 & $\mathrm{Rh}$ & 0.0000005 & Hf & 0.0000005 \\
\hline K & 0.00005 & $\mathrm{Pd}$ & 0.0000025 & $\mathrm{Ta}$ & 0.005 \\
\hline $\mathrm{Ca}$ & 0.0000025 & $\mathrm{Ag}$ & 0.0000025 & W & 0.0000025 \\
\hline $\mathrm{Sc}$ & 0.0000005 & $\mathrm{Cd}$ & 0.0000025 & $\operatorname{Re}$ & 0.0000005 \\
\hline $\mathrm{Ti}$ & 0.0000005 & In & 0.0000025 & Os & 0.0000005 \\
\hline V & 0.0000005 & $\mathrm{Sn}$ & 0.0000025 & Ir & 0.0000005 \\
\hline $\mathrm{Cr}$ & 0.000025 & $\mathrm{Sb}$ & 0.0000025 & $\mathrm{Pt}$ & 0.0000005 \\
\hline $\mathrm{Mn}$ & 0.0000005 & $\mathrm{Te}$ & 0.0000025 & $\mathrm{Au}$ & 0.000005 \\
\hline $\mathrm{Fe}$ & 0.0000005 & I & 0.0000005 & $\mathrm{Hg}$ & 0.000005 \\
\hline Co & 0.0000005 & Cs & 0.0000025 & $\mathrm{Tl}$ & 0.0000025 \\
\hline $\mathrm{Ni}$ & 0.0000005 & $\mathrm{Ba}$ & 0.0000025 & $\mathrm{~Pb}$ & 0.0000025 \\
\hline $\mathrm{Cu}$ & 0.0000025 & $\mathrm{La}$ & 0.0000025 & $\mathrm{Bi}$ & 0.0000025 \\
\hline $\mathrm{Zn}$ & 0.0000025 & $\mathrm{Ce}$ & 0.0000025 & Th & 0.0000025 \\
\hline $\mathrm{Ga}$ & 0.0000005 & $\operatorname{Pr}$ & 0.0000025 & $\mathrm{U}$ & 0.0000025 \\
\hline
\end{tabular}


NEA/NSC/DOC(2006)1

Fundamental - FUND

NRAD-FUND-RESR-001

CRIT

\section{Density}

The axial graphite reflectors are nuclear grade graphite, either PGX or ECW. The density of these two graphite types is nominally 1.73 or $1.74 \mathrm{~g} / \mathrm{cm}^{3}$, respectively. ${ }^{a}$ General Atomics uses a density of 1.73 $\mathrm{g} / \mathrm{cm}^{3}$ to represent the density of the axial graphite reflectors in their TRIGA reactor models. ${ }^{b}$ A $1 \sigma$ uncertainty of $\pm 0.01 \mathrm{~g} / \mathrm{cm}^{3}$ was selected for the density of the axial graphite reflectors.

To find the effect of this uncertainty on the $\mathrm{k}_{\text {eff }}$ value, the axial graphite reflector density was adjusted by the $3 \sigma$ uncertainty. An upper perturbation $\mathrm{k}_{\text {eff }}$ value was found by simultaneously increasing the graphite density by $0.03 \mathrm{~g} / \mathrm{cm}^{3}$ and then simultaneously decreasing by the same amount to find a lower perturbation $k_{\text {eff }}$ value. Half of the difference between the upper and lower perturbation $k_{\text {eff }}$ values was used to represent the variation in $\mathrm{k}_{\mathrm{eff}}$ due to perturbing the graphite density by $0.03 \mathrm{~g} / \mathrm{cm}^{3}$. The calculated result was then scaled to obtain the $1 \sigma$ uncertainty. Results are shown in Table 2.25.

This uncertainty is treated as $100 \%$ systematic. The calculated uncertainty in the axial graphite reflector density is considered negligible $(\leq 0.00010)$.

Table 2.25. Effect of Uncertainty in Axial Graphite Reflector Density.

\begin{tabular}{||c|ccc|c|ccc||}
\hline \hline Deviation & $\Delta \mathbf{k}$ & \pm & $\sigma_{\Delta \mathbf{k}}$ & $\begin{array}{c}\text { Scaling } \\
\text { Factor }\end{array}$ & $\Delta \mathbf{k}_{\text {eff }}(\mathbf{1} \boldsymbol{\sigma})$ & \pm & $\sigma_{\Delta \mathrm{keff}}$ \\
\hline \hline $\pm 0.03 \mathrm{~g} / \mathrm{cm}^{3}$ & 0.00026 & \pm & 0.00005 & 3 & 0.00009 & \pm & 0.00002 \\
\hline \hline
\end{tabular}

\section{Dimensions}

The axial graphite reflector (Figure 1.28) length and outer diameter are $8.6868 \pm 0.0254 \mathrm{~cm}$ (manufacturing tolerance) and $3.27914 \mathrm{~cm}$ with manufacturing tolerance limits of +0.00 and $-0.0127 \mathrm{~cm}$.

To find the effect of this uncertainty on the $\mathrm{k}_{\mathrm{eff}}$ value, the axial graphite reflector dimensions were adjusted by three times their respective tolerance limits. An upper perturbation $\mathrm{k}_{\mathrm{eff}}$ value was found by simultaneously increasing the graphite volume and then simultaneously decreasing by the same amount to find a lower perturbation $\mathrm{k}_{\text {eff }}$ value. Half of the difference between the upper and lower perturbation $\mathrm{k}_{\text {eff }}$ values was used to represent the variation in $\mathrm{k}_{\text {eff }}$ due to perturbing the graphite reflector dimensions. The calculated result was then scaled to obtain the $1 \sigma$ uncertainty. Results are shown in Table 2.26.

The axial graphite reflector diameter was increased in this perturbation analysis even though there is no positive manufacturing tolerance for this dimension. The total number of fuel elements in this configuration is 60 , each with two axial graphite reflectors; therefore the random component of this uncertainty is divided by $\sqrt{ } 120$. The calculated uncertainty in the total uranium mass is considered negligible $(\leq 0.00010)$.

Table 2.26. Effect of Uncertainty in Axial Graphite Reflector Dimensions.

\begin{tabular}{||c|ccc|c|ccc|c|c||}
\hline \hline Deviation & $\Delta \mathbf{k}$ & \pm & $\sigma_{\Delta \mathbf{k}}$ & $\begin{array}{c}\text { Scaling } \\
\text { Factor }\end{array}$ & $\Delta \mathbf{k}_{\text {eff }}(\mathbf{1} \boldsymbol{\sigma})$ & \pm & $\sigma_{\Delta \mathrm{keff}}$ & $\begin{array}{c}\Delta \mathbf{k}_{\text {eff }} \\
(\mathbf{1 5 \%} \\
\text { systematic) }\end{array}$ & $\begin{array}{c}\Delta \mathbf{k}_{\text {eff }} \\
\mathbf{( 8 5 \%} \\
\text { random) }\end{array}$ \\
\hline \hline $\pm 3 \times \mathrm{BL}$ & 0.00006 & \pm & 0.00005 & $3 \sqrt{ } 3$ & 0.00001 & \pm & 0.00001 & negligible & negligible \\
\hline
\end{tabular}

\footnotetext{
a Personal communication with Victor Leight at GrafTech International (April 5, 2010).

${ }^{\mathrm{b}}$ Personal communication with John M. Bolin at General Atomics (November 3, 2009). 
NEA/NSC/DOC(2006)1

Fundamental - FUND

NRAD-FUND-RESR-001

CRIT

\section{Impurities}

The effective bias for removing impurities (Table 2.24) from the axial graphite reflectors was determined to be negligible (Section 3.1.1.1). Therefore, an uncertainty analysis regarding impurities in the graphite was judged to be unnecessary as the result would also be negligible.

\subsubsection{Stainless Steel 304 Cladding and End Fittings}

\section{Composition}

The average stainless steel 304 or 304L composition is shown in Table 2.27. However, a sample of stainless steel material used in the fuel cladding provided additional information regarding impurity content. The composition of the stainless steel cladding (Table 2.28) is obtained by reducing the quantity of iron in the average steel composition (Table 2.27) to account for the impurities reported in Table 1.11. For elements that are listed only as detection limits, half of the detection limit is assumed to represent the quantity of that impurity in the graphite material.

To initially find the effect of the uncertainty in using an average stainless steel composition on the $\mathrm{k}_{\text {eff }}$ value, the steel composition was adjusted by minimizing or maximizing the iron content by increasing or decreasing the primary alloy constituents within their respective ranges (the impurity content remained unchanged). An upper perturbation $\mathrm{k}_{\mathrm{eff}}$ value was found by simultaneously maximizing the iron content and then simultaneously minimizing the iron content to find a lower perturbation $\mathrm{k}_{\mathrm{eff}}$ value. Half of the difference between the upper and lower perturbation $\mathrm{k}_{\text {eff }}$ values was used to represent the variation in $\mathrm{k}_{\text {eff }}$ due to perturbing the stainless steel composition. The calculated result was then scaled to obtain the $1 \sigma$ uncertainty. Results are shown in Table 2.29.

A total of five constituents were perturbed in this analysis: carbon, chromium, iron, manganese, and nickel. Therefore the eigenvalue uncertainty is reduced by the square root of four (N-1). This uncertainty is also treated as a bounding uncertainty with uniform distribution probability. The phosphorus, sulfur, and silicon constituents are included in the impurity analysis later in this section.

This uncertainty was reevaluated by individually perturbing the carbon, chromium, manganese, and nickel constituents between their maximum and minimum value while simultaneously decreasing or increasing, respectively, the iron content in the steel. Results are provided in Table 2.29. Because the uncertainty in the perturbation of the individual constituents is greater than the uncertainty calculated when performing simultaneous perturbations, the individual uncertainties are selected to represent the total uncertainty in the composition of the stainless steel. 


\section{NEA/NSC/DOC(2006)1}

Fundamental - FUND

NRAD-FUND-RESR-001

CRIT

Table 2.27 Typical Stainless Steel 304/304L Composition (wt.\%). ${ }^{(a)}$

\begin{tabular}{|c|c|c|c|}
\hline \hline Component & SS304 & SS304L & Average $^{(\mathbf{b})}$ \\
\hline $\mathrm{C}$ & $0.08 \mathrm{Max}$ & $0.03 \mathrm{Max}$ & 0.04 \\
$\mathrm{Cr}$ & $18-20$ & $18-20$ & 19 \\
$\mathrm{Fe}$ & Balance & Balance & 69.4225 \\
$\mathrm{Mn}$ & $2 \mathrm{Max}$ & $2 \mathrm{Max}$ & 1 \\
$\mathrm{Ni}$ & $8-10.5$ & $8-12$ & 10 \\
$\mathrm{P}$ & $0.045 \mathrm{Max}$ & $0.045 \mathrm{Max}$ & 0.0225 \\
$\mathrm{~S}$ & $0.03 \mathrm{Max}$ & $0.03 \mathrm{Max}$ & 0.015 \\
$\mathrm{Si}$ & $1 \mathrm{Max}$ & $1 \mathrm{Max}$ & 0.5 \\
\hline \hline Density $\left(\mathrm{g} / \mathbf{c m}^{\mathbf{3}}\right)$ & 8.00 & 8.00 & 8.00 \\
\hline
\end{tabular}

(a) ASM Aerospace Specification Metals, Inc., http://www.aerospacemetals.com/.

(b) Average based on the maximum range of each component. 
NEA/NSC/DOC(2006)1

Fundamental - FUND

NRAD-FUND-RESR-001

CRIT

Table 2.28. Stainless Steel 304/304L Cladding Composition (wt.\%).

\begin{tabular}{|cl||}
\hline Element & \multicolumn{1}{|c|}{ wt.\% } \\
\hline $\mathrm{Li}$ & 0.0000005 \\
$\mathrm{Be}$ & 0.0000005 \\
$\mathrm{~B}$ & 0.00025 \\
$\mathrm{C}$ & 0.04 \\
$\mathrm{~F}$ & 0.0000005 \\
$\mathrm{Na}$ & 0.0000005 \\
$\mathrm{Mg}$ & 0.00018 \\
$\mathrm{Al}$ & 0.0012 \\
$\mathrm{Si}$ & 0.4 \\
$\mathrm{P}$ & 0.026 \\
$\mathrm{~S}$ & 0.0022 \\
$\mathrm{Cl}$ & 0.0000025 \\
$\mathrm{~K}$ & 0.0000005 \\
$\mathrm{Ca}$ & 0.00005 \\
$\mathrm{Sc}$ & 0.00000025 \\
$\mathrm{Ti}$ & 0.002 \\
$\mathrm{~V}$ & 0.1 \\
$\mathrm{Cr}$ & 19 \\
$\mathrm{Mn}$ & 1 \\
$\mathrm{Fe}$ & 68.70712775 \\
$\mathrm{Co}$ & 0.08 \\
$\mathrm{Ni}$ & 10 \\
$\mathrm{Cu}$ & 0.3 \\
$\mathrm{Zn}$ & 0.00005 \\
$\mathrm{Ga}$ & 0.0016 \\
\hline
\end{tabular}

\begin{tabular}{|c|c|c|c|}
\hline Element & wt.\% & Element & wt.\% \\
\hline $\mathrm{Ge}$ & 0.002 & $\mathrm{Nd}$ & 0.00000025 \\
\hline As & 0.0035 & $\mathrm{Sm}$ & 0.00000025 \\
\hline $\mathrm{Se}$ & 0.000005 & $\mathrm{Eu}$ & 0.00000025 \\
\hline $\mathrm{Br}$ & 0.000005 & Gd & 0.00000025 \\
\hline $\mathrm{Rb}$ & 0.000025 & $\mathrm{~Tb}$ & 0.00000025 \\
\hline $\mathrm{Sr}$ & 0.00001 & Dy & 0.00000025 \\
\hline Y & 0.0000025 & Ho & 0.00000025 \\
\hline $\mathrm{Zr}$ & 0.00018 & Er & 0.00000025 \\
\hline $\mathrm{Nb}$ & 0.011 & $\mathrm{Tm}$ & 0.00000025 \\
\hline Mo & 0.3 & $\mathrm{Yb}$ & 0.00000025 \\
\hline $\mathrm{Ru}$ & 0.000005 & $\mathrm{Lu}$ & 0.00000025 \\
\hline $\mathrm{Rh}$ & 0.0000025 & $\mathrm{Hf}$ & 0.0000005 \\
\hline $\mathrm{Pd}$ & 0.0000025 & $\mathrm{Ta}$ & 0.00005 \\
\hline $\mathrm{Ag}$ & 0.000025 & W & 0.016 \\
\hline $\mathrm{Cd}$ & 0.000005 & $\operatorname{Re}$ & 0.000025 \\
\hline In & 0.000025 & Os & 0.000009 \\
\hline $\mathrm{Sn}$ & 0.0055 & Ir & 0.000009 \\
\hline $\mathrm{Sb}$ & 0.00089 & $\mathrm{Pt}$ & 0.000005 \\
\hline $\mathrm{Te}$ & 0.0000025 & $\mathrm{Au}$ & 0.0000025 \\
\hline I & 0.0000025 & $\mathrm{Hg}$ & 0.000005 \\
\hline Cs & 0.0000005 & $\mathrm{Tl}$ & 0.0000025 \\
\hline $\mathrm{Ba}$ & 0.0000025 & $\mathrm{~Pb}$ & 0.000031 \\
\hline $\mathrm{La}$ & 0.0000005 & $\mathrm{Bi}$ & 0.0000005 \\
\hline $\mathrm{Ce}$ & 0.00000025 & Th & 0.00000025 \\
\hline $\operatorname{Pr}$ & 0.00000025 & $\mathrm{U}$ & 0.00000025 \\
\hline
\end{tabular}

Table 2.29. Effect of Uncertainty in Stainless Steel Composition.

\begin{tabular}{||c|ccc|c|ccc||}
\hline Deviation & $\Delta \mathbf{k}$ & \pm & $\sigma_{\Delta \mathbf{k}}$ & Scaling Factor & $\Delta \mathbf{k}_{\text {eff }}(\mathbf{1 \sigma})$ & \pm & $\sigma_{\Delta \mathbf{k e f f}}$ \\
\hline \hline $\begin{array}{c}\text { Simultaneous Perturbation } \\
\text { of C, Cr, Mn, and Ni }\end{array}$ & -0.00159 & \pm & 0.00005 & $\sqrt{ } \sqrt{ } 3$ & -0.00041 & \pm & 0.00001 \\
\hline Max/Min Carbon Content & -0.00005 & \pm & 0.00005 & $\sqrt{3}$ & -0.00003 & \pm & 0.00003 \\
Max/Min Chromium Content & 0.00000 & \pm & 0.00005 & $\sqrt{ } 3$ & negligible & \pm & 0.00003 \\
Max/Min Manganese Content & -0.00114 & \pm & 0.00005 & $\sqrt{3}$ & -0.00066 & \pm & 0.00003 \\
Max/Min Nickel Content & -0.00024 & \pm & 0.00005 & $\sqrt{3}$ & -0.00014 & \pm & 0.00003 \\
\hline
\end{tabular}


NEA/NSC/DOC(2006)1

Fundamental - FUND

NRAD-FUND-RESR-001

CRIT

\section{Density}

As listed in Table 2.27, the density of stainless steel $304 / 304 \mathrm{~L}$ is $8.00 \mathrm{~g} / \mathrm{cm}^{3}$. A $1 \sigma$ uncertainty of 0.01 $\mathrm{g} / \mathrm{cm}^{3}$ is assumed to apply to the stainless steel density.

To find the effect of this uncertainty on the $\mathrm{k}_{\mathrm{eff}}$ value, the stainless steel density was adjusted by the $3 \sigma$ uncertainty. An upper perturbation $\mathrm{k}_{\text {eff }}$ value was found by simultaneously increasing the steel density by $0.03 \mathrm{~g} / \mathrm{cm}^{3}$ and then simultaneously decreasing by the same amount to find a lower perturbation $\mathrm{k}_{\text {eff }}$ value. Half of the difference between the upper and lower perturbation $\mathrm{k}_{\text {eff }}$ values was used to represent the variation in $k_{\text {eff }}$ due to perturbing the stainless steel density by $0.03 \mathrm{~g} / \mathrm{cm}^{3}$. The calculated result was then scaled to obtain the $1 \sigma$ uncertainty. Results are shown in Table 2.30 .

This uncertainty is treated as $100 \%$ systematic. The calculated uncertainty in the stainless steel density is considered negligible $(\leq 0.00010)$.

Table 2.30. Effect of Uncertainty in Stainless Steel Density.

\begin{tabular}{||c|ccc|c|ccc||}
\hline \hline Deviation & $\Delta \mathbf{k}$ & \pm & $\boldsymbol{\sigma}_{\Delta \mathbf{k}}$ & $\begin{array}{c}\text { Scaling } \\
\text { Factor }\end{array}$ & $\Delta \mathbf{k}_{\text {eff }}(\mathbf{1 \sigma})$ & \pm & $\boldsymbol{\sigma}_{\Delta \mathrm{keff}}$ \\
\hline \hline $\pm 0.03 \mathrm{~g} / \mathrm{cm}^{3}$ & -0.00011 & \pm & 0.00005 & 3 & -0.00004 & \pm & 0.00002 \\
\hline
\end{tabular}

\section{Dimensions - Cladding}

The average fuel clad inner diameter in the 60 -fuel-element core is $3.4894 \pm 0.0005 \mathrm{~cm}(1 \sigma)$. The cladding thickness is nominally $0.0508 \mathrm{~cm}$. The clad outer diameter has a nominal reference dimension of $3.59156 \mathrm{~cm}$. The reference clad tube length is $58.7375 \mathrm{~cm}$ (Figure 1.24). No uncertainties are provided for the reference outer diameter and length dimensions.

The effect of varying the nominal length of the fuel cladding is negligible. No perturbation analysis was performed to evaluate this parameter.

The clad inner diameter was adjusted by the $3 \sigma$ uncertainty. An upper perturbation $\mathrm{k}_{\text {eff }}$ value was found by simultaneously increasing the clad inner diameter by $0.0015 \mathrm{~cm}$ and then simultaneously decreasing by the same amount to find a lower perturbation $\mathrm{k}_{\mathrm{eff}}$ value. Half of the difference between the upper and lower perturbation $\mathrm{k}_{\text {eff }}$ values was used to represent the variation in $\mathrm{k}_{\text {eff }}$ due to perturbing the clad inner diameter by $0.0015 \mathrm{~cm}$. The calculated result was then scaled to obtain the $1 \sigma$ uncertainty. Results are shown in Table 2.31 .

The clad outer diameter was adjusted by the $3 \sigma$ uncertainty of the clad inner diameter. An upper perturbation $\mathrm{k}_{\text {eff }}$ value was found by simultaneously increasing the clad outer diameter by $0.0015 \mathrm{~cm}$ and then simultaneously decreasing by the same amount to find a lower perturbation $\mathrm{k}_{\text {eff }}$ value. Half of the difference between the upper and lower perturbation $\mathrm{k}_{\mathrm{eff}}$ values was used to represent the variation in $\mathrm{k}_{\text {eff }}$ due to perturbing the clad outer diameter by $0.0015 \mathrm{~cm}$. The calculated result was then scaled to obtain the $1 \sigma$ uncertainty. Results are shown in Table 2.32 .

The total number of fuel elements in this configuration is 60 ; therefore the random component of this uncertainty is divided by $\sqrt{ } 60$. The calculated uncertainty in the cladding dimensions is considered negligible $(\leq 0.00010)$.

To evaluate the thickness of the fuel cladding, the inner and outer diameters were independently varied, overestimating the total uncertainty in the cladding thickness. However, the uncertainty in the 
NEA/NSC/DOC(2006)1

Fundamental - FUND

NRAD-FUND-RESR-001

CRIT

perturbation of either of these two dimensions is negligible, indicating that the uncertainty in the thickness of the fuel cladding is also negligible.

Table 2.31. Effect of Uncertainty in Clad Inner Diameter.

\begin{tabular}{||c|ccc|c|ccc|c|c||}
\hline \hline Deviation & $\Delta \mathbf{k}$ & \pm & $\sigma_{\Delta \mathrm{k}}$ & $\begin{array}{c}\text { Scaling } \\
\text { Factor }\end{array}$ & $\Delta \mathbf{k}_{\text {eff }}(\mathbf{1} \sigma)$ & \pm & $\sigma_{\Delta k \text { eff }}$ & $\begin{array}{c}\Delta \mathbf{k}_{\text {eff }} \\
(\mathbf{1 5 \%} \\
\text { systematic) }\end{array}$ & $\begin{array}{c}\Delta \mathbf{k}_{\text {eff }} \\
\mathbf{( 8 5 \%} \\
\text { random) }\end{array}$ \\
\hline \hline $\pm 0.0015 \mathrm{~cm}$ & -0.00016 & \pm & 0.00005 & 3 & -0.00005 & \pm & 0.00002 & -0.00001 & -0.00001 \\
\hline \hline
\end{tabular}

Table 2.32. Effect of Uncertainty in Clad Outer Diameter.

\begin{tabular}{||c|ccc|c|ccc|c|c||}
\hline \hline Deviation & $\Delta \mathbf{k}$ & \pm & $\sigma_{\Delta \mathbf{k}}$ & $\begin{array}{c}\text { Scaling } \\
\text { Factor }\end{array}$ & $\Delta \mathbf{k}_{\text {eff }}(\mathbf{1} \sigma)$ & \pm & $\sigma_{\Delta \mathbf{k e f f}}$ & $\begin{array}{c}\Delta \mathbf{k}_{\text {eff }} \\
(\mathbf{1 5 \%} \\
\text { systematic) }\end{array}$ & $\begin{array}{c}\Delta \mathbf{k}_{\text {eff }} \\
\mathbf{( 8 5 \%} \\
\text { random) }\end{array}$ \\
\hline \hline $\pm 0.0015 \mathrm{~cm}$ & 0.00049 & \pm & 0.00005 & 3 & 0.00016 & \pm & 0.00002 & 0.00002 & 0.00002 \\
\hline
\end{tabular}

\section{Dimensions - End Fittings}

There is insufficient information regarding all dimensions and their respective manufacturing tolerances for the stainless steel end fittings (Figures 1.29 and 1.30). The few dimensions not specified in the drawings were estimated based on the other available dimensions and the assumption of proportionality of scale between the known and unknown dimensions.

To find the effect of this uncertainty on the $\mathrm{k}_{\text {eff }}$ value, the stainless steel end fittings were adjusted by $>10 \sigma$ uncertainty. An upper perturbation $\mathrm{k}_{\text {eff }}$ value was found by simultaneously doubling the end fitting volume and then simultaneously decreasing by the same amount (i.e. removing it) to find a lower perturbation $\mathrm{k}_{\text {eff }}$ value. Half of the difference between the upper and lower perturbation $\mathrm{k}_{\text {eff }}$ values was used to represent the variation in $\mathrm{k}_{\mathrm{eff}}$ due to perturbing the end fitting dimensions. The calculated result was then scaled to obtain the $1 \sigma$ uncertainty. Results are shown in Table 2.33.

The total number of fuel elements in this configuration is 60 , each with two stainless steel end fittings; therefore the random component of this uncertainty is divided by $\sqrt{ } 120$. The calculated uncertainty in the total uranium mass is considered negligible $(\leq 0.00010)$.

Table 2.33. Effect of Uncertainty in Stainless Steel End Fitting Dimensions.

\begin{tabular}{||c|ccc|c|ccc|c|c||}
\hline \hline Deviation & $\Delta \mathbf{k}$ & \pm & $\sigma_{\Delta \mathrm{k}}$ & $\begin{array}{c}\text { Scaling } \\
\text { Factor }\end{array}$ & $\Delta \mathbf{k}_{\text {eff }}(\mathbf{1 \sigma})$ & \pm & $\sigma_{\Delta \mathrm{keff}}$ & $\begin{array}{c}\Delta \mathbf{k}_{\text {eff }} \\
(\mathbf{1 5 \%} \\
\text { systematic) }\end{array}$ & $\begin{array}{c}\Delta \mathbf{k}_{\text {eff }} \\
\mathbf{( 8 5 \%} \\
\text { random) }\end{array}$ \\
\hline \hline \pm 100 vol.\% & -0.00035 & \pm & 0.00005 & 10 & -0.00004 & \pm & 0.00001 & -0.00001 & negligible \\
\hline \hline
\end{tabular}

\section{Impurities}

There is no additional information regarding the uncertainty in the measured stainless steel impurity values in Table 1.11. The impurity content for elements excluding carbon, chromium, manganese, and nickel (Table 2.28) are assumed to have a bounding uncertainty (with uniform probability distribution) of $\pm 100 \%$. The iron content in the steel is effectively adjusted to conserve mass while the other four elemental weight fractions mentioned above remain unchanged. 
NEA/NSC/DOC(2006)1

Fundamental - FUND

NRAD-FUND-RESR-001

CRIT

To find the effect of this uncertainty on the $\mathrm{k}_{\mathrm{eff}}$ value, the impurity content was adjusted by the assumed bounding limit. An upper perturbation $\mathrm{k}_{\mathrm{eff}}$ value was found by simultaneously increasing the impurity content in all steel cladding by $100 \%$ and then simultaneously decreasing by the same amount to find a lower perturbation $\mathrm{k}_{\mathrm{eff}}$ value. Half of the difference between the upper and lower perturbation $\mathrm{k}_{\text {eff }}$ values was used to represent the variation in $\mathrm{k}_{\text {eff }}$ due to perturbing the impurity content by $100 \%$. The calculated result was then scaled to obtain the $1 \sigma$ uncertainty. The calculated result was then scaled to obtain the $1 \sigma$ uncertainty. Results are shown in Table 2.34 .

This uncertainty is treated as $100 \%$ systematic because the actual impurity content is not recorded for any of the fuel elements in the NRAD core.

Table 2.34. Effect of Uncertainty in Stainless Steel Impurities.

\begin{tabular}{|c|ccc|c|ccc||}
\hline \hline Deviation & $\Delta \mathbf{k}$ & \pm & $\sigma_{\Delta \mathbf{k}}$ & $\begin{array}{c}\text { Scaling } \\
\text { Factor }\end{array}$ & $\Delta \mathbf{k}_{\text {eff }}(\mathbf{1 \sigma})$ & \pm & $\boldsymbol{\sigma}_{\Delta \mathrm{keff}}$ \\
\hline \hline $\pm 100 \%$ & -0.00060 & \pm & 0.00005 & $\sqrt{3}$ & -0.00035 & \pm & 0.00003 \\
\hline
\end{tabular}

\subsubsection{Air in Fuel/Cladding Gap}

The reference composition and density of air is shown in Table 2.35. One volume percent of water was added to the composition and the volumetric fractions were renormalized. The computed atomic density of air is provided in Table 2.36 .

Table 2.35. Typical Atmospheric Composition ${ }^{(a)}$ by Volume, Dry Air. ${ }^{(b)}$

\begin{tabular}{||c|c||}
\hline Molecular Component & Content (ppm by volume) $)^{(\mathbf{c})}$ \\
\hline \hline Nitrogen $\left(\mathrm{N}_{2}\right)$ & 780840 \\
Oxygen $\left(\mathrm{O}_{2}\right)$ & 209460 \\
Argon $(\mathrm{Ar})$ & 9340 \\
Carbon Dioxide $\left(\mathrm{CO}_{2}\right)$ & 380 \\
Neon $(\mathrm{Ne})$ & 18.18 \\
Helium $(\mathrm{He})$ & 5.24 \\
Methane $\left(\mathrm{CH}_{4}\right)$ & 1.7 \\
Krypton $(\mathrm{Kr})$ & 1.14 \\
Hydrogen $\left(\mathrm{H}_{2}\right)$ & 0.55 \\
\hline \hline Surface Density $\left(\mathbf{k g} / \mathbf{m}^{\mathbf{3}}\right)$ & 1.217 \\
\hline
\end{tabular}

(a) "Earth Fact Sheet," National Space Science Data Center, http://nssdc.gsfc.nasa.gov/planetary/factsheet/earthfact. html, (May 20, 2009).

(b) Water typically makes up about $1 \%$ of the composition.

(c) Numbers do not add up to exactly $100 \%$ due to round off error. 
NEA/NSC/DOC(2006)1

Fundamental - FUND

NRAD-FUND-RESR-001

CRIT

Table 2.36. Air Composition

and Atomic Density.

\begin{tabular}{|c|c|}
\hline Element & Atoms/b-cm \\
\hline \hline $\mathrm{H}$ & $5.0309 \mathrm{E}-07$ \\
$\mathrm{~N}$ & $3.9268 \mathrm{E}-05$ \\
$\mathrm{O}$ & $1.0804 \mathrm{E}-05$ \\
$\mathrm{Ar}$ & $2.3485 \mathrm{E}-07$ \\
$\mathrm{C}$ & $9.5977 \mathrm{E}-09$ \\
$\mathrm{Ne}$ & $4.5713 \mathrm{E}-10$ \\
$\mathrm{He}$ & $1.3176 \mathrm{E}-10$ \\
$\mathrm{Kr}$ & $2.8665 \mathrm{E}-11$ \\
\hline \hline Total & $5.0820 \mathrm{E}-05$ \\
\hline
\end{tabular}

The effective bias for removing air was determined to be negligible (Section 3.1.1.1). Therefore, any uncertainty analyses regarding air were judged to be unnecessary as the results would also be negligible.

\subsubsection{Control Rod Properties}

\subsubsection{Boron Carbide Absorber}

\section{Density}

There is conflicting information regarding the density of the boron carbide absorber material in the control rods. The minimum density specification of $2.415 \mathrm{~g} / \mathrm{cm}^{3}$ appears to represent a minimum requirement for NRAD operations ${ }^{a}$ while the specification of $2.48 \mathrm{~g} / \mathrm{cm}^{3}$ represents the manufacturing minimum limit as defined by General Atomics (from design drawings, see Appendix F). The theoretical density of boron carbide is $2.52 \mathrm{~g} / \mathrm{cm}^{3}$. The density of $2.48 \mathrm{~g} / \mathrm{cm}^{3}$ is selected to represent the nominal density of the control rods in the NRAD reactor. The difference between the nominal and theoretical density values, $+0.04 \mathrm{~g} / \mathrm{cm}^{3}$, is selected to represent the uncertainty (bounding with uniform distribution probability) in the density of the boron carbide material.

To find the effect of this uncertainty on the $\mathrm{k}_{\mathrm{eff}}$ value, the control rod absorber density was adjusted by three times the bounding limit. An upper perturbation $\mathrm{k}_{\mathrm{eff}}$ value was found by simultaneously increasing the absorber density by $0.12 \mathrm{~g} / \mathrm{cm}^{3}$ and then simultaneously decreasing by the same amount to find a lower perturbation $\mathrm{k}_{\text {eff }}$ value. Half of the difference between the upper and lower perturbation $\mathrm{k}_{\mathrm{eff}}$ values was used to represent the variation in $k_{\text {eff }}$ due to perturbing the absorber density by $0.12 \mathrm{~g} / \mathrm{cm}^{3}$. The calculated result was then scaled to obtain the $1 \sigma$ uncertainty. Results are shown in Table 2.37.

This uncertainty is treated as $100 \%$ systematic. The calculated uncertainty in the boron carbide density is considered negligible $(\leq 0.00010)$.

\footnotetext{
a "HFEF/N Neutron Radiography Facility System Design Description,” W0170-0004-SA rev. 2, Idaho National Laboratory (June 1, 1978). [This reference is not available for public release.]
} 
NEA/NSC/DOC(2006)1

Fundamental - FUND

NRAD-FUND-RESR-001

CRIT

Table 2.37. Effect of Uncertainty in Boron Carbide Density.

\begin{tabular}{||c|ccc|c|ccc|}
\hline \hline Deviation & $\Delta \mathbf{k}$ & \pm & $\sigma_{\Delta \mathbf{k}}$ & $\begin{array}{c}\text { Scaling } \\
\text { Factor }\end{array}$ & $\Delta \mathbf{k}_{\text {eff }}(\mathbf{1} \boldsymbol{\sigma})$ & \pm & $\sigma_{\Delta \mathrm{keff}}$ \\
\hline \hline $\pm 0.12 \mathrm{~g} / \mathrm{cm}^{3}$ & -0.00004 & \pm & 0.00005 & $3 \sqrt{ } 3$ & -0.00001 & \pm & 0.00001 \\
\hline \hline
\end{tabular}

\section{Boron Content}

The manufacturing tolerance specification of boron content in the $\mathrm{B}_{4} \mathrm{C}$ absorber (from design drawings, see Appendix F) is $78.0 \pm 1.0 \mathrm{wt} . \%$ with the natural occurrence of the isotope ${ }^{10} \mathrm{~B}(18.5 \pm 0.2 \mathrm{wt} . \%)$. The $1.0 \mathrm{wt} . \%$ uncertainty in the boron content of the absorber is assumed to be a manufacturing tolerance and will be treated as a bounding uncertainty with uniform distribution probability. A boron content of $\sim 78.3$ wt.\% is selected to represent the experiment, based on the stoichiometric ratio of boron to carbon in $\mathrm{B}_{4} \mathrm{C}$.

To find the effect of this uncertainty on the $\mathrm{k}_{\text {eff }}$ value, the control rod absorber boron content was adjusted by the three times the bounding limit. An upper perturbation $\mathrm{k}_{\mathrm{eff}}$ value was found by simultaneously increasing the boron content by $3 \mathrm{wt} . \%$ and then simultaneously decreasing by the same amount to find a lower perturbation $\mathrm{k}_{\mathrm{eff}}$ value. Half of the difference between the upper and lower perturbation $\mathrm{k}_{\mathrm{eff}}$ values was used to represent the variation in $\mathrm{k}_{\mathrm{eff}}$ due to perturbing the boron content by $3 \mathrm{wt} . \%$. The calculated result was then scaled to obtain the $1 \sigma$ uncertainty. Results are shown in Table 2.38 .

This uncertainty is treated as $100 \%$ systematic. The calculated uncertainty in the axial graphite reflector density is considered negligible $(\leq 0.00010)$.

Table 2.38. Effect of Uncertainty in Boron Content in Boron Carbide.

\begin{tabular}{||c|ccc|c|ccc||}
\hline Deviation & $\Delta \mathbf{k}$ & \pm & $\boldsymbol{\sigma}_{\Delta \mathbf{k}}$ & $\begin{array}{c}\text { Scaling } \\
\text { Factor }\end{array}$ & $\Delta \mathbf{k}_{\text {eff }}(\mathbf{1 \sigma})$ & \pm & $\boldsymbol{\sigma}_{\Delta \mathrm{keff}}$ \\
\hline \hline $\pm 3 \mathrm{wt.} \%$ & -0.00004 & \pm & 0.00005 & $3 \sqrt{ } 3$ & -0.00001 & \pm & 0.00001 \\
\hline
\end{tabular}

\section{Boron-10 Abundance}

The isotopic abundance of ${ }^{10} \mathrm{~B}$ in natural boron is between 19.1 and 20.3 at.\% with an average value of 19.9 at. $\%{ }^{a}{ }^{a}$ The manufacturing specification (from design drawings, see Appendix F) of $18.5 \pm 0.2$ wt. $\%$ represents a much tighter requirement. The atomic abundance of 19.9 at.\% ( 18.43 wt.\%) is selected to represent the nominal isotopic abundance of ${ }^{10} \mathrm{~B}$. The $\pm 0.2 \mathrm{wt} . \%$ uncertainty in the isotopic abundance of ${ }^{10} \mathrm{~B}$ is assumed to be bounding with uniform distribution probability.

To find the effect of this uncertainty on the $\mathrm{k}_{\mathrm{eff}}$ value, the control rod absorber ${ }^{10} \mathrm{~B}$ abundance was adjusted by the three times the bounding limit. An upper perturbation $k_{\text {eff }}$ value was found by simultaneously increasing the ${ }^{10} \mathrm{~B}$ content by $0.6 \mathrm{wt} . \%$ and then simultaneously decreasing by the same amount to find a lower perturbation $\mathrm{k}_{\mathrm{eff}}$ value. Half of the difference between the upper and lower perturbation $\mathrm{k}_{\mathrm{eff}}$ values was used to represent the variation in $\mathrm{k}_{\mathrm{eff}}$ due to perturbing the ${ }^{10} \mathrm{~B}$ isotopic abundance by 0.6 wt.\%. The calculated result was then scaled to obtain the $1 \sigma$ uncertainty. Results are shown in Table 2.39 .

This uncertainty is treated as $100 \%$ systematic. The calculated uncertainty in the isotopic abundance of ${ }^{10} \mathrm{~B}$ is considered negligible $(\leq 0.00010)$.

${ }^{a}$ E. M. Baum, H. D. Knox, and T. R. Miller, Nuclides and Isotopes: $16^{\text {th }}$ Edition, Knolls Atomic Power Laboratory (2002). 
NEA/NSC/DOC(2006)1

Fundamental - FUND

NRAD-FUND-RESR-001

CRIT

Table 2.39. Effect of Uncertainty in ${ }^{10} \mathrm{~B}$ Abundance in Boron Carbide.

\begin{tabular}{|c|ccc|c|ccc||}
\hline \hline Deviation & $\Delta \mathbf{k}$ & \pm & $\boldsymbol{\sigma}_{\Delta \mathbf{k}}$ & $\begin{array}{c}\text { Scaling } \\
\text { Factor }\end{array}$ & $\Delta \mathbf{k}_{\text {eff }}(\mathbf{1} \boldsymbol{\sigma})$ & \pm & $\boldsymbol{\sigma}_{\Delta \mathrm{keff}}$ \\
\hline \hline \pm 0.6 wt. $\%$ & -0.00004 & \pm & 0.00005 & $3 \sqrt{ } 3$ & -0.00001 & \pm & 0.00001 \\
\hline
\end{tabular}

\section{Dimensions}

The control rod absorber (Figure 1.31) length and outer diameter are $38.1 \mathrm{~cm}$ (no reported uncertainty) and $3.01498 \mathrm{~cm}$ with manufacturing tolerance limits of +0.000 and $-0.0762 \mathrm{~cm}$.

The effect of varying the nominal length of the control rod absorber is negligible. The manufacturing tolerance is most likely small and any uncertainty is within the uncertainty of the control rod positions (Section 2.1.1.2). No perturbation analysis was performed to evaluate this parameter.

The absorber diameter was adjusted by the twice the bounding limit. A lower perturbation $\mathrm{k}_{\text {eff }}$ value was found by simultaneously decreasing the clad inner diameter by $0.1524 \mathrm{~cm}$. The difference between the unperturbed and lower perturbation $\mathrm{k}_{\text {eff }}$ values was used to represent the variation in $\mathrm{k}_{\text {eff }}$ due to perturbing the absorber diameter by $0.1524 \mathrm{~cm}$. The calculated result was then scaled to obtain the $1 \sigma$ uncertainty. Results are shown in Table 2.40.

This uncertainty is treated as $100 \%$ systematic because two of the three control rods are fully withdrawn.

Table 2.40. Effect of Uncertainty in Absorber Diameter.

\begin{tabular}{||c|ccc|c|ccc||}
\hline \hline Deviation & $\Delta \mathbf{k}$ & \pm & $\sigma_{\Delta \mathbf{k}}$ & $\begin{array}{c}\text { Scaling } \\
\text { Factor }\end{array}$ & $\Delta \mathbf{k}_{\text {eff }}(\mathbf{1 \sigma})$ & \pm & $\sigma_{\Delta \mathbf{k e f f}}$ \\
\hline \hline $\pm 0.1524 \mathrm{~cm}$ & 0.00036 & \pm & 0.00010 & $2 \sqrt{ } 3$ & 0.00010 & \pm & 0.00003 \\
\hline
\end{tabular}

\section{Impurities}

No impurities were reported for the boron carbide absorber in the control rods. Impurity quantities in sintered boron carbide material used elsewhere in control rods, which have an equivalent boron content, Table 2.41, were used to evaluate the effective uncertainty due to impurities in the boron carbide.

The impurities reported in Table 2.41 were added to the composition of the absorber material. The difference between the unperturbed and perturbed $k_{\text {eff }}$ values was used to represent the variation in $k_{\text {eff }}$ due the inclusion of impurities in the boron carbide material. Results are shown in Table 2.42.

This uncertainty is treated as a $1 \sigma$ uncertainty and $100 \%$ systematic. Because the effect is practically negligible, the statistical uncertainty of 0.00010 is taken to represent the uncertainty in impurity content in the boron carbide absorber. 
NEA/NSC/DOC(2006)1

Fundamental - FUND

NRAD-FUND-RESR-001

CRIT

Table 2.41. Impurity in Sintered $\mathrm{B}_{4} \mathrm{C}$ Pellets. ${ }^{(\mathrm{a})}$

\begin{tabular}{|c|c||}
\hline Boron Content (wt.\%) & 78 \\
\hline \hline Impurity & $\begin{array}{c}\text { Quantity } \\
\text { (ppm wt.\%) }\end{array}$ \\
\hline \hline $\mathrm{Na}$ & $\sim 10$ \\
$\mathrm{Al}$ & $\sim 1000$ \\
$\mathrm{Si}$ & $\sim 1000$ \\
$\mathrm{Ca}$ & $\sim 100$ \\
$\mathrm{Ti}$ & $\sim 1000$ \\
$\mathrm{Mn}$ & $\sim 10$ \\
\hline
\end{tabular}

(a) K. Fujii, S. Nomura, H. Imai, and M. Shindo, "Corrosion Behavior of Sintered Pellet of Graphite and Boron Carbide in Helium Containing Water Vapor," IAEATECDOC-690, International Atomic Energy Agency, Vienna, pp. 169-176 (February 2003).

Table 2.42. Effect of Uncertainty in Boron Carbide Impurities.

\begin{tabular}{|c|ccc|c|ccc||}
\hline \hline Deviation & $\Delta \mathbf{k}$ & \pm & $\boldsymbol{\sigma}_{\Delta \mathbf{k}}$ & $\begin{array}{c}\text { Scaling } \\
\text { Factor }\end{array}$ & $\Delta \mathbf{k}_{\text {eff }}(\mathbf{1 \sigma})$ & \pm & $\boldsymbol{\sigma}_{\Delta \mathbf{k e f f}}$ \\
\hline \hline Added impurities & 0.00003 & \pm & 0.00010 & 1 & 0.00003 & \pm & 0.00010 \\
\hline \hline
\end{tabular}

\section{Burnup}

Evaluation of the effect of the reported burnup on the control rods would require additional information such as operation history, location of the rods within the core, neutron flux, and temperature. Without this information, the next best procedure would be to use rod worth measurements to adjust the rod composition. ${ }^{a}$ There is no information available to evaluate the burnup history of the control rods during their use at PRNC. Some information is available regarding total core operation of the NRAD reactor, but insufficient to provide a complete evaluation of control rod burnup. Essentially the PRNC core history included $0.5 \mathrm{MW}-\mathrm{yr}$ on 95 fuel pins and the HEU NRAD core history included $0.25 \mathrm{MW}$-yr on 61 (and later just 60 when the water irradiation position was installed) fuel pins. Because the uncertainty in the boron content and density of the control rods is negligible, it is assumed that changes in absorber composition due to burnup would also be negligible.

\subsubsection{Aluminum 6061 Components}

\section{Composition}

The typical composition of aluminum 6061 is reported in Table 2.43. An average value for each element is selected to represent the nominal composition of aluminum, with elemental aluminum representing the balance.

\footnotetext{
a Personal communication with Javier Ortensi at INL (April 13, 2010).
} 
NEA/NSC/DOC(2006)1

Fundamental - FUND

NRAD-FUND-RESR-001

CRIT

Table 2.43. Aluminum 6061-T6 Composition (wt.\%). ${ }^{(a)}$

\begin{tabular}{|c|c|c|}
\hline Component & Content & Average $^{(\mathbf{b})}$ \\
\hline $\mathrm{Al}$ & Balance & 97.23 \\
\hline $\mathrm{Cr}$ & $0.04-0.35$ & 0.195 \\
\hline $\mathrm{Cu}$ & $0.15-0.4$ & 0.275 \\
\hline $\mathrm{Fe}$ & 0.7 Max & 0.35 \\
\hline $\mathrm{Mg}$ & $0.8-1.2$ & 1 \\
\hline $\mathrm{Mn}$ & $0.15 \mathrm{Max}$ & 0.075 \\
\hline $\mathrm{Si}$ & $0.4-0.8$ & 0.6 \\
\hline $\mathrm{Ti}$ & $0.15 \mathrm{Max}$ & 0.075 \\
\hline $\mathrm{Zn}$ & $0.25 \mathrm{Max}$ & 0.125 \\
\hline $\mathrm{Co}^{(\mathrm{c})}$ & $0.05 \mathrm{Max}$ & 0.025 \\
\hline $\mathrm{Ni}^{(\mathrm{c})}$ & $0.05 \mathrm{Max}$ & 0.025 \\
\hline $\mathrm{Sn}^{(\mathrm{c})}$ & $0.05 \mathrm{Max}$ & 0.025 \\
\hline Density $\left(\mathrm{g} / \mathrm{cm}^{3}\right)$ & 2.70 & 2.70 \\
\hline
\end{tabular}

(a) ASM Aerospace Specification Metals, Inc., http://www.aerospacemetals.com/.

(b) Average based on the maximum range of each component.

(c) Reported "Other" components have a maximum of 0.15 wt. $\%$ total with no more than 0.05 wt. $\%$ per component. $\mathrm{Co}, \mathrm{Ni}$, and $\mathrm{Sn}$ were selected to represent impurities in Al6061.

The effective bias for removing non-aluminum elements (Table 2.43) from aluminum was determined to be negligible (Section 3.1.1.1). Therefore, any uncertainty analyses regarding the variation in composition of non-aluminum elements were judged to be unnecessary as the results would also be negligible.

\section{Density}

As listed in Table 2.43, the density of aluminum 6061 is $2.70 \mathrm{~g} / \mathrm{cm}^{3}$. A $1 \sigma$ uncertainty of $0.01 \mathrm{~g} / \mathrm{cm}^{3}$ is assumed to apply to the aluminum density.

To find the effect of this uncertainty on the $k_{\text {eff }}$ value, the aluminum density was adjusted by the $3 \sigma$ uncertainty. An upper perturbation $\mathrm{k}_{\text {eff }}$ value was found by simultaneously increasing the aluminum density by $0.03 \mathrm{~g} / \mathrm{cm}^{3}$ and then simultaneously decreasing by the same amount to find a lower perturbation $\mathrm{k}_{\text {eff }}$ value. Half of the difference between the upper and lower perturbation $\mathrm{k}_{\text {eff }}$ values was used to represent the variation in $k_{\text {eff }}$ due to perturbing the aluminum density by $0.03 \mathrm{~g} / \mathrm{cm}^{3}$. The calculated result was then scaled to obtain the $1 \sigma$ uncertainty. Results are shown in Table 2.44.

This uncertainty is treated as $100 \%$ systematic. The calculated uncertainty in the aluminum density is considered negligible $(\leq 0.00010)$. 
NEA/NSC/DOC(2006)1

Fundamental - FUND

NRAD-FUND-RESR-001

CRIT

Table 2.44. Effect of Uncertainty in Aluminum Density.

\begin{tabular}{||c|ccc|c|ccc||}
\hline \hline Deviation & $\Delta \mathbf{k}$ & \pm & $\boldsymbol{\sigma}_{\Delta \mathbf{k}}$ & $\begin{array}{c}\text { Scaling } \\
\text { Factor }\end{array}$ & $\Delta \mathbf{k}_{\text {eff }}(\mathbf{1} \boldsymbol{\sigma})$ & \pm & $\boldsymbol{\sigma}_{\Delta \mathrm{keff}}$ \\
\hline \hline $\pm 0.03 \mathrm{~g} / \mathrm{cm}^{3}$ & 0.00004 & \pm & 0.00005 & 3 & 0.00001 & \pm & 0.00002 \\
\hline
\end{tabular}

\section{Dimensions - Cladding}

The length of the aluminum cladding is between 59.055 and $59.436 \mathrm{~cm}$, with a total control rod reference length that includes end fittings of $60.96 \mathrm{~cm}$. The clad tube has an outer diameter of $3.175 \mathrm{~cm}$ and a wall thickness of $0.07112 \mathrm{~cm}$. No uncertainties are reported for the control rod cladding dimensions.

The effect of varying the nominal length of the control rod cladding is negligible, as any uncertainty is within the uncertainty of the control rod positions (Section 2.1.1.2). No perturbation analysis was performed to evaluate this parameter. The effect of varying the dimensions of the control rod aluminum end fittings would also be negligible.

The cladding thickness was adjusted by $>10 \sigma$ uncertainty. An upper perturbation $\mathrm{k}_{\mathrm{eff}}$ value was found by simultaneously doubling the clad thickness and then simultaneously decreasing by the same amount (i.e. removing it) to find a lower perturbation $\mathrm{k}_{\mathrm{eff}}$ value. Half of the difference between the upper and lower perturbation $\mathrm{k}_{\mathrm{eff}}$ values was used to represent the variation in $\mathrm{k}_{\mathrm{eff}}$ due to perturbing the cladding thickness. The calculated result was then scaled to obtain the $1 \sigma$ uncertainty. Results are shown in Table 2.45.

This uncertainty is treated as $100 \%$ systematic because two of the three control rods are fully withdrawn.

Table 2.45. Effect of Uncertainty in Clad Thickness.

\begin{tabular}{||c|ccc|c|ccc||}
\hline \hline Deviation & $\Delta \mathbf{k}$ & \pm & $\sigma_{\Delta \mathbf{k}}$ & $\begin{array}{c}\text { Scaling } \\
\text { Factor }\end{array}$ & $\Delta \mathbf{k}_{\text {eff }}(\mathbf{1} \boldsymbol{\sigma})$ & \pm & $\boldsymbol{\sigma}_{\Delta \mathbf{k e f f}}$ \\
\hline \hline $\pm 0.07112 \mathrm{~cm}$ & -0.00007 & \pm & 0.00005 & 10 & -0.00001 & \pm & 0.00001 \\
\hline \hline
\end{tabular}

\section{Dimensions - Guide Tubes}

Guide tube dimensions are in Figure 1.35. There is insufficient information regarding manufacturing tolerances in all parts of the guide tube. A 30 vol.\% $(1 \sigma)$ uncertainty was assumed.

To find the effect of this uncertainty on the $k_{\text {eff }}$ value, the guide tube volume was adjusted by the $1 \sigma$ uncertainty. An upper perturbation $\mathrm{k}_{\text {eff }}$ value was found by simultaneously increasing the guide tube volume by 30 vol.\% and then simultaneously decreasing by the same amount to find a lower perturbation $\mathrm{k}_{\text {eff }}$ value. Half of the difference between the upper and lower perturbation $\mathrm{k}_{\text {eff }}$ values was used to represent the variation in $\mathrm{k}_{\text {eff }}$ due to perturbing the guide tube volume by $30 \mathrm{vol} . \%$. Results are shown in Table 2.46.

The total number of guide tubes in this configuration is 4 ; therefore the random component of this uncertainty is divided by $\sqrt{ } 4$. The calculated uncertainty in the guide tube dimensions is considered negligible $(\leq 0.00010)$. 
NEA/NSC/DOC(2006)1

Fundamental - FUND

NRAD-FUND-RESR-001

CRIT

Table 2.46. Effect of Uncertainty in Guide Tube Dimensions.

\begin{tabular}{||c|ccc|c|ccc|c|c||}
\hline Deviation & $\Delta \mathbf{k}$ & \pm & $\sigma_{\Delta \mathbf{k}}$ & $\begin{array}{c}\text { Scaling } \\
\text { Factor }\end{array}$ & $\Delta \mathbf{k}_{\text {eff }}(\mathbf{1} \boldsymbol{\sigma})$ & \pm & $\sigma_{\Delta \mathrm{keff}}$ & $\begin{array}{c}\Delta \mathbf{k}_{\text {eff }} \\
(\mathbf{1 5 \%} \\
\text { systematic) }\end{array}$ & $\begin{array}{c}\Delta \mathbf{k}_{\text {eff }} \\
\mathbf{( 8 5 \%} \\
\text { random) }\end{array}$ \\
\hline \hline \pm 30 vol.\% $\%$ & -0.00007 & \pm & 0.00005 & 1 & -0.00007 & \pm & 0.00005 & -0.00001 & -0.00003 \\
\hline
\end{tabular}

\section{Dimensions - End Fittings}

The perturbation in the guide tube end fitting parameters was included as part of the uncertainty in the stainless steel end fittings evaluated for the fuel elements (Section 2.1.3.4), as their effective component of uncertainty is negligible.

\section{Dimensions - Other Fittings, Parts, and Fixtures}

The effective bias for removing the control rod extension rods, attachments, and internal rod fittings was determined to be negligible (Section 3.1.1.1). Therefore, any uncertainty analyses regarding these auxiliary aluminum components were judged to be unnecessary as the results would also be negligible.

\section{Impurities}

The effective bias for removing non-aluminum elements (Table 2.43) from aluminum was determined to be negligible (Section 3.1.1.1). Therefore, any uncertainty analyses regarding aluminum impurities were judged to be unnecessary as the results would also be negligible.

\subsubsection{Fuel Cluster Properties}

\subsubsection{Fuel Element Pitch in Assembly}

The square pitch between fuel elements within an assembly is $3.8862 \mathrm{~cm}$ (Figure 1.10). No uncertainty is reported for this pitch. However, the manufacturing specifications for the upper assembly components indicate a range for hole placement between 3.87604 and $3.90144 \mathrm{~cm}$. There is no uncertainty reported for the tolerance of the threaded end fitting at the bottom of each fuel element. However, the tolerance should be within the manufacturing specifications provided for the assembly components, as they were designed to accommodate fuel elements with a standard threaded end fitting.

To find the effect of this uncertainty on the $\mathrm{k}_{\text {eff }}$ value, the fuel element pitch was adjusted by the $1 \sigma$ uncertainty. An upper perturbation $\mathrm{k}_{\mathrm{eff}}$ value was found by simultaneously increasing the fuel element pitch by $0.01524 \mathrm{~cm}$ and then simultaneously decreasing by $0.01016 \mathrm{~cm}$ to find a lower perturbation $\mathrm{k}_{\mathrm{eff}}$ value. Half of the difference between the upper and lower perturbation $\mathrm{k}_{\text {eff }}$ values was used to represent the variation in $k_{\text {eff }}$ due to perturbing the fuel element pitch within an assembly. Results are shown in Table 2.47 .

The total number of fuel elements in this configuration is 60; therefore the random component of this uncertainty is divided by $\sqrt{ } 60$. The calculated uncertainty in the fuel element pitch within an assembly is considered negligible $(\leq 0.00010)$. 
NEA/NSC/DOC(2006)1

Fundamental - FUND

NRAD-FUND-RESR-001

CRIT

Table 2.47. Effect of Uncertainty in Fuel Element Pitch in Assembly.

\begin{tabular}{||c|ccc|c|ccc|c|c||}
\hline \hline Deviation & $\Delta \mathbf{k}$ & \pm & $\sigma_{\Delta \mathbf{k}}$ & $\begin{array}{c}\text { Scaling } \\
\text { Factor }\end{array}$ & $\Delta \mathbf{k}_{\text {eff }}(\mathbf{1} \boldsymbol{\sigma})$ & \pm & $\sigma_{\Delta \mathrm{keff}}$ & $\begin{array}{c}\Delta \mathbf{k}_{\text {eff }} \\
\mathbf{1 5 \%} \\
\text { systematic) }\end{array}$ & $\begin{array}{c}\Delta \mathbf{k}_{\text {eff }} \\
\mathbf{( 8 5 \%} \\
\text { random) }\end{array}$ \\
\hline \hline $\begin{array}{l}+0.01524 \mathrm{~cm} \\
-0.01016 \mathrm{~cm}\end{array}$ & 0.00022 & \pm & 0.00005 & 1 & 0.00022 & \pm & 0.00005 & 0.00003 & 0.00002 \\
\hline
\end{tabular}

This uncertainty was also evaluated using the URAN card in MCNP5. ${ }^{\text {a }}$ This card allows for the stoachastic sampling of components with random locations in a lattice. The fuel elements and control rods in each assembly were simulated with random placement within $\pm 0.01524 \mathrm{~cm}$ of their nominal (x, y) placement in the cluster assemblies. The eigenvalue calculated using this method was within the statistical $1 \sigma$ uncertainty of MCNP and considered negligible $(\leq 0.00010)$.

\subsubsection{Fuel Cluster Auxiliary Components}

\section{Steel Components}

The stainless steel 304/304L average composition and density described in Table 2.27 is used to represent the material properties of the steel assembly end fittings that attach the fuel elements and control rods to the fuel cluster assemblies.

The effective bias for removing the steel end fittings was determined to be very small (Section 3.1.1.1). Therefore, any uncertainty analyses regarding the assembly components were judged to be unnecessary as the results would also be negligible.

\section{Aluminum Components}

The aluminum 6061 composition and density described in Section 2.1.4.2 is used to represent the material properties of the aluminum assembly components of the fuel cluster assemblies.

The effective bias for removing top and bottom assemblies (Figures 1.14 through 1.23) was determined to be negligible (Section 3.1.1.1). Therefore, any uncertainty analyses regarding the assembly components were judged to be unnecessary as the results would also be negligible.

\subsubsection{Graphite Reflector Assembly Properties}

\subsubsection{Graphite Reflector Blocks}

\section{Composition}

The composition of the graphite block reflectors (Table 2.48) is obtained by reducing the quantity of graphite to account for the impurities reported in Table 1.14. For elements that are listed only as detection limits, half of the detection limit is assumed to represent the quantity of that impurity in the graphite material.

\footnotetext{
a X-5 Monte Carlo Team, "MCNP - A General Monte Carlo N-Particle Transport Code, Version 5, Volume II: User's Guide,” LA-CP-03-0245, Los Alamos National Laboratory (October 3, 2005).
} 
NEA/NSC/DOC(2006)1

Fundamental - FUND

NRAD-FUND-RESR-001

CRIT

Table 2.48. Composition of Graphite Reflector Blocks.

\begin{tabular}{|c|c|c|c|c|c|}
\hline Element & wt.\% & Element & wt.\% & Element & wt.\% \\
\hline $\mathrm{Li}$ & 0.0000025 & $\mathrm{Ge}$ & 0.0000025 & $\mathrm{Nd}$ & 0.0000025 \\
\hline $\mathrm{Be}$ & 0.0000025 & As & 0.0000025 & $\mathrm{Sm}$ & 0.0000005 \\
\hline B & 0.000075 & $\mathrm{Se}$ & 0.0000025 & $\mathrm{Eu}$ & 0.0000005 \\
\hline $\mathrm{C}$ & 99.968029 & $\mathrm{Br}$ & 0.000005 & $\mathrm{Gd}$ & 0.0000005 \\
\hline $\mathrm{F}$ & 0.000005 & $\mathrm{Rb}$ & 0.0000025 & $\mathrm{~Tb}$ & 0.0000005 \\
\hline $\mathrm{Na}$ & 0.000015 & $\mathrm{Sr}$ & 0.000051 & Dy & 0.0000005 \\
\hline $\mathrm{Mg}$ & 0.00014 & Y & 0.0000025 & Ho & 0.0000005 \\
\hline $\mathrm{Al}$ & 0.00013 & $\mathrm{Zr}$ & 0.000044 & $\mathrm{Er}$ & 0.0000005 \\
\hline $\mathrm{Si}$ & 0.0081 & $\mathrm{Nb}$ & 0.0000025 & $\mathrm{Tm}$ & 0.0000005 \\
\hline $\mathrm{P}$ & 0.00018 & Mo & 0.0000025 & $\mathrm{Yb}$ & 0.0000005 \\
\hline $\mathrm{S}$ & 0.005 & $\mathrm{Ru}$ & 0.0000025 & $\mathrm{Lu}$ & 0.0000005 \\
\hline $\mathrm{Cl}$ & 0.00023 & $\mathrm{Rh}$ & 0.0000005 & $\mathrm{Hf}$ & 0.0000005 \\
\hline K & 0.000005 & $\mathrm{Pd}$ & 0.0000025 & $\mathrm{Ta}$ & 0.005 \\
\hline $\mathrm{Ca}$ & 0.0023 & $\mathrm{Ag}$ & 0.0000025 & W & 0.0000025 \\
\hline $\mathrm{Sc}$ & 0.000007 & $\mathrm{Cd}$ & 0.0000025 & $\operatorname{Re}$ & 0.0000005 \\
\hline $\mathrm{Ti}$ & 0.0018 & In & 0.0000025 & Os & 0.0000005 \\
\hline V & 0.0029 & $\mathrm{Sn}$ & 0.0000025 & Ir & 0.0000005 \\
\hline $\mathrm{Cr}$ & 0.000025 & $\mathrm{Sb}$ & 0.0000025 & $\mathrm{Pt}$ & 0.0000005 \\
\hline $\mathrm{Mn}$ & 0.000012 & $\mathrm{Te}$ & 0.0000025 & $\mathrm{Au}$ & 0.000005 \\
\hline $\mathrm{Fe}$ & 0.0055 & I & 0.0000005 & $\mathrm{Hg}$ & 0.000005 \\
\hline Co & 0.0000005 & $\mathrm{Cs}$ & 0.0000025 & $\mathrm{Tl}$ & 0.0000025 \\
\hline $\mathrm{Ni}$ & 0.00035 & $\mathrm{Ba}$ & 0.0000025 & $\mathrm{~Pb}$ & 0.0000025 \\
\hline $\mathrm{Cu}$ & 0.0000025 & $\mathrm{La}$ & 0.0000025 & $\mathrm{Bi}$ & 0.0000025 \\
\hline $\mathrm{Zn}$ & 0.0000025 & $\mathrm{Ce}$ & 0.0000025 & Th & 0.0000025 \\
\hline $\mathrm{Ga}$ & 0.0000005 & $\operatorname{Pr}$ & 0.0000025 & $\mathrm{U}$ & 0.0000025 \\
\hline
\end{tabular}

\section{Density}

The average measured density of the graphite reflector blocks (Table 1.13$)$ is $1.570 \pm 0.009 \mathrm{~g} / \mathrm{cm}^{3}(1 \sigma)$. According to ASTM C838-96 (2005), ${ }^{\mathrm{a}}$ the within-laboratory variation on density is $0.28 \%$ with a between-laboratory variation of $0.81 \%$, indicating a possible, but unconfirmed, bias for the method used to determine the density of graphite. These percentages represent density uncertainties of \pm 0.004 and $\pm 0.013 \mathrm{~g} / \mathrm{cm}^{3}$, respectively.

To find the effect of this uncertainty on the $\mathrm{k}_{\text {eff }}$ value, the graphite reflector block density was adjusted by the $3 \sigma$ uncertainty. An upper perturbation $\mathrm{k}_{\text {eff }}$ value was found by simultaneously increasing the graphite density by $0.027 \mathrm{~g} / \mathrm{cm}^{3}$ and then simultaneously decreasing by the same amount to find a lower

\footnotetext{
a ASTM C838-96, Standard Test Method for Bulk Density of As-Manufactured Carbon and Graphite Shapes.
} 
NEA/NSC/DOC(2006)1

Fundamental - FUND

NRAD-FUND-RESR-001

CRIT

perturbation $\mathrm{k}_{\text {eff }}$ value. Half of the difference between the upper and lower perturbation $\mathrm{k}_{\text {eff }}$ values was used to represent the variation in $k_{\text {eff }}$ due to perturbing the graphite density by $0.027 \mathrm{~g} / \mathrm{cm}^{3}$. The calculated result was then scaled to obtain the $1 \sigma$ uncertainty. Results are shown in Table 2.49.

This uncertainty is treated as $100 \%$ systematic instead of $\sim 50 \%$ because it is not completely clear how much of a systematic uncertainty to expect when using this method. Furthermore, six samples were taken from a single block and it is assumed that all graphite blocks have the same density as the sampled block. Variation in density between blocks is unknown.

Table 2.49. Effect of Uncertainty in Graphite Block Density.

\begin{tabular}{||c|ccc|c|ccc||}
\hline \hline Deviation & $\Delta \mathbf{k}$ & \pm & $\sigma_{\Delta \mathbf{k}}$ & $\begin{array}{c}\text { Scaling } \\
\text { Factor }\end{array}$ & $\Delta \mathbf{k}_{\text {eff }}(\mathbf{1 \sigma})$ & \pm & $\sigma_{\Delta \mathrm{keff}}$ \\
\hline \hline $\pm 0.027 \mathrm{~g} / \mathrm{cm}^{3}$ & 0.00060 & \pm & 0.00005 & 3 & 0.00020 & \pm & 0.00002 \\
\hline
\end{tabular}

\section{Dimensions}

The length of the graphite portion of the graphite reflector blocks (Figure 1.37) is $65.7225 \pm 0.3175 \mathrm{~cm}$ (manufacturing tolerance). The square cross section of the block (Figure 1.37) is $7.366 \mathrm{~cm}$ with manufacturing tolerance limits of +0.000 and $-0.254 \mathrm{~cm}$. The four corners are chamfered: $0.9525 \pm$ $0.0762 \mathrm{~cm} \times 45 \pm 5^{\circ}$.

The graphite block length was adjusted by the manufacturing tolerance. An upper perturbation $\mathrm{k}_{\mathrm{eff}}$ value was found by simultaneously increasing the length of all graphite blocks by $0.3175 \mathrm{~cm}$ and then simultaneously decreasing by the same amount to find a lower perturbation $\mathrm{k}_{\mathrm{eff}}$ value. Half of the difference between the upper and lower perturbation $\mathrm{k}_{\mathrm{eff}}$ values was used to represent the variation in $\mathrm{k}_{\mathrm{eff}}$ due to perturbing the graphite block length by $0.3175 \mathrm{~cm}$. The calculated result was then scaled to obtain the $1 \sigma$ uncertainty. Results are shown in Table 2.50 .

The graphite block cross sectional area was adjusted by the manufacturing tolerance. A lower perturbation $\mathrm{k}_{\mathrm{eff}}$ value was found by simultaneously decreasing the square area by $0.254 \mathrm{~cm}$ and increasing the chamfer depth by $0.0762 \mathrm{~cm}$ for all graphite blocks. Half of the difference between the unperturbed and lower perturbation $\mathrm{k}_{\text {eff }}$ values was used to represent the variation in $\mathrm{k}_{\text {eff }}$ due to perturbing the graphite block cross sectional area. The calculated result was then scaled to obtain the $1 \sigma$ uncertainty. Results are shown in Table 2.51 .

The total number of graphite blocks in this configuration is 12 ; therefore the random component of this uncertainty is divided by $\sqrt{ } 12$. The uncertainty in the cross sectional area of the graphite blocks is divided by $\sqrt{ } 2$ to represent the two main sides of the block as being independently cut. No correction was implemented for the adjustment in chamfer dimensions. The angle of the chamfers was unchanged.

Table 2.50. Effect of Uncertainty in Graphite Block Length.

\begin{tabular}{||c|ccc|c|ccc|c|c||}
\hline \hline Deviation & $\Delta \mathbf{k}$ & \pm & $\sigma_{\Delta \mathbf{k}}$ & $\begin{array}{c}\text { Scaling } \\
\text { Factor }\end{array}$ & $\Delta \mathbf{k}_{\text {eff }}(\mathbf{1} \sigma)$ & \pm & $\sigma_{\Delta \mathbf{k e f f}}$ & $\begin{array}{c}\Delta \mathbf{k}_{\text {eff }} \\
\mathbf{( 1 5 \%} \\
\text { systematic) }\end{array}$ & $\begin{array}{c}\Delta \mathbf{k}_{\text {eff }} \\
\mathbf{( 8 5 \%} \\
\text { random) }\end{array}$ \\
\hline \hline $\pm 0.3175 \mathrm{~cm}$ & 0.00001 & \pm & 0.00010 & $\sqrt{3}$ & 0.00001 & \pm 0.00006 & 0.00001 & 0.00001 \\
\hline \hline
\end{tabular}


NEA/NSC/DOC(2006)1

Fundamental - FUND

NRAD-FUND-RESR-001

CRIT

Table 2.51. Effect of Uncertainty in Graphite Block Area.

\begin{tabular}{|c|ccc|c|ccc|c|c||}
\hline Deviation & $\Delta \mathbf{k}$ & \pm & $\sigma_{\Delta \mathbf{k}}$ & $\begin{array}{c}\text { Scaling } \\
\text { Factor }\end{array}$ & $\Delta \mathbf{k}_{\text {eff }}(\mathbf{1} \boldsymbol{\sigma})$ & \pm & $\sigma_{\Delta \mathrm{keff}}$ & $\begin{array}{c}\Delta \mathbf{k}_{\text {eff }} \\
(\mathbf{1 5 \%} \\
\text { systematic) }\end{array}$ & $\begin{array}{c}\Delta \mathbf{k}_{\text {eff }} \\
\mathbf{( 8 5 \%} \\
\text { random) }\end{array}$ \\
\hline \hline$\pm \mathrm{BL}$ & -0.00143 & \pm & 0.00010 & $\sqrt{ } 2 \sqrt{3}$ & -0.00058 & \pm & 0.00004 & -0.00009 & -0.00014 \\
\hline
\end{tabular}

The effective bias for removing aluminum 2011 parts, the AmBe source, and their respective holes was determined to be negligible (Section 3.1.1.1). Therefore, any uncertainty analyses regarding the holes in the graphite were judged to be unnecessary as the results would also be negligible.

\section{Impurities}

The effective bias for removing impurities from the graphite reflector (Table 1.48) was determined to be negligible (Section 3.1.1.1). Therefore, any uncertainty analyses regarding the impurities in the graphite were judged to be unnecessary as the results would also be negligible.

\section{Water Saturation Effects}

Many of the graphite blocks have been underwater since the original installation of the NRAD reactor ( $>30$ years) and a few others were added in 1981 and 1989 ( $>20$ years). The blocks were each removed once to exchange the top and bottom assembly adapters with newer components before being placed back into the tank. ${ }^{\mathrm{a}}$ It is currently unknown whether there is any saturation of water within the graphite matrix. The maximum possible amount of water saturation is $\sim 30$ vol. $\%$. This was estimated by dividing the mass density of the graphite reflector blocks, $1.57 \mathrm{~g} / \mathrm{cm}^{3}$, by the theoretical mass density of graphite, $\sim 2.25 \mathrm{~g} / \mathrm{cm}^{3}$, and subtracting the volume fraction from $100 \%$ to get the maximum theoretical void fraction. Calculations were performed with volumetric additions of water homogenously dispersed in the graphite reflector block matrix up to $30 \mathrm{vol} . \%$. The effective increase in core reactivity is shown in Table 2.52 and Figure 2.1.

Because it is uncertain how much water saturation, if any, exists in the graphite blocks, the maximum difference at $30 \mathrm{vol} \%$ is assumed to represent a bounding uncertainty with uniform distribution probability. This uncertainty is treated as $100 \%$ systematic because it is believed all graphite blocks would exhibit the same quantity of saturation. The effective uncertainty due to water saturation in the graphite blocks is shown in Table 2.53.

Table 2.52. Effect of Water Saturation of Graphite.

\begin{tabular}{||c|ccc||}
\hline \hline Deviation & $\Delta \mathbf{k}$ & \pm & $\sigma_{\Delta \mathbf{k}}$ \\
\hline \hline+5 vol. $\% \mathrm{H}_{2} \mathrm{O}$ & 0.00083 & \pm & 0.00010 \\
+10 vol. $\% \mathrm{H}_{2} \mathrm{O}$ & 0.00194 & \pm & 0.00010 \\
+15 vol. $\% \mathrm{H}_{2} \mathrm{O}$ & 0.00253 & \pm & 0.00010 \\
+20 vol. $\% \mathrm{H}_{2} \mathrm{O}$ & 0.00294 & \pm & 0.00010 \\
+25 vol. $\% \mathrm{H}_{2} \mathrm{O}$ & 0.00322 & \pm & 0.00010 \\
+30 vol. $\% \mathrm{H}_{2} \mathrm{O}$ & 0.00359 & \pm & 0.00010 \\
\hline
\end{tabular}

${ }^{\text {a }}$ Personal communication with Ken Schreck at HFEF (September 2, 2010). 
NRAD-FUND-RESR-001 CRIT

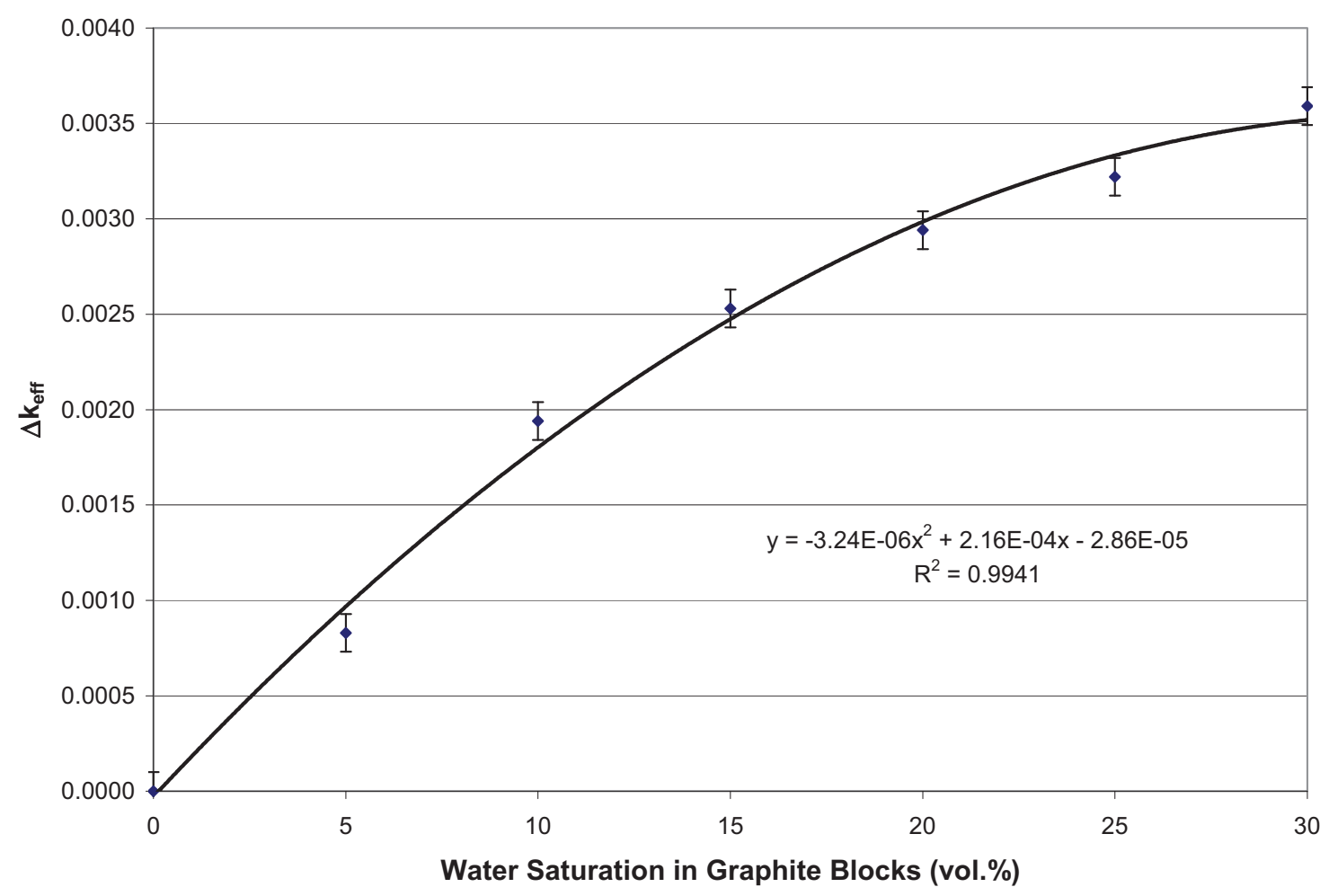

Figure 2.1. Effect of Water Saturation of Graphite.

Table 2.53. Effect of Uncertainty in Water Saturation of Graphite.

\begin{tabular}{||c|ccc|c|ccc||}
\hline Deviation & $\Delta \mathbf{k}$ & \pm & $\boldsymbol{\sigma}_{\Delta \mathbf{k}}$ & $\begin{array}{c}\text { Scaling } \\
\text { Factor }\end{array}$ & $\Delta \mathbf{k}_{\text {eff }}(\mathbf{1} \boldsymbol{\sigma})$ & \pm & $\boldsymbol{\sigma}_{\Delta \mathbf{k e f f}}$ \\
\hline \hline+30 vol. $\% \mathrm{H}_{2} \mathrm{O}$ & 0.00359 & \pm & 0.00010 & $\sqrt{ } 3$ & 0.00207 & \pm 0.00006 \\
\hline
\end{tabular}

\subsubsection{Graphite Reflector Assembly Auxiliary Components}

\section{Aluminum 2011-T3 Components}

The composition and density of aluminum 2011-T3 is reported in Table 2.54. An average composition was selected to represent the tie rod, dowel, and screw components in the graphite reflector block assemblies. 
NEA/NSC/DOC(2006)1

Fundamental - FUND

NRAD-FUND-RESR-001

CRIT

Table 2.54. Aluminum 2011-T3 Composition (wt.\%).

\begin{tabular}{|c|c|c|c|}
\hline Component & Content $1^{(a)}$ & Content $2^{(\mathrm{b})}$ & Average $^{(\mathrm{c})}$ \\
\hline $\mathrm{Al}$ & 93.7 & Balance & 92.925 \\
\hline $\mathrm{Bi}$ & $0.20-0.60$ & $0.2-0.6$ & 0.4 \\
\hline $\mathrm{Cu}$ & $5.0-6.0$ & $5-6$ & 5.5 \\
\hline $\mathrm{Fe}$ & $0.70 \mathrm{Max}$ & $0.7 \mathrm{Max}$ & 0.35 \\
\hline $\mathrm{Si}$ & $0.40 \mathrm{Max}$ & $0.4 \mathrm{Max}$ & 0.2 \\
\hline $\mathrm{Pb}$ & $0.20-0.60$ & $0.2-0.6$ & 0.4 \\
\hline $\mathrm{Zn}$ & $0.30 \mathrm{Max}$ & $0.3 \mathrm{Max}$ & 0.15 \\
\hline $\mathrm{Co}^{(\mathrm{d})}$ & -- & 0.05 Max & 0.025 \\
\hline $\mathrm{Ni}^{(\mathrm{d})}$ & -- & 0.05 Max & 0.025 \\
\hline $\mathrm{Sn}^{(\mathrm{d})}$ & -- & $0.05 \mathrm{Max}$ & 0.025 \\
\hline Density $\left(\mathrm{g} / \mathrm{cm}^{3}\right)$ & 2.82 & 2.83 & 2.82 \\
\hline
\end{tabular}

(a) Alcoa Toolrite 2011®-T3 Aluminum, MatWeb Material Property Data, http://www.matweb.com/.

(b) Metal Suppliers Online, http://www.metalsuppliersonline.com/.

(c) Average based on the maximum range of each component. Values of 0.25 wt. $\%$ are selected for Fe and Si to satisfy the combined maximum requirement of $<0.95 \mathrm{wt} . \%$ and an $\mathrm{Al}$ content of $>99$ wt. $\%$.

(d) Reported "Other" components have a maximum of 0.15 wt.\% total with no more than 0.05 wt.\% per component. Co, Ni, and Sn were selected to represent impurities in Al6061.

The effective bias for removing aluminum 2011 parts (Figure 1.36) and their respective holes was determined to be negligible (Section 3.1.1.1). Therefore, any uncertainty analyses regarding the aluminum 2011 parts were judged to be unnecessary as the results would also be negligible.

\section{Aluminum 6061 Components}

The aluminum 6061 composition and density described in Section 2.1.4.2 is used to represent the material properties of the aluminum assembly components of the graphite reflector block assemblies.

The effective bias for removing top and bottom assemblies (Figures 1.14, 1.36, and 1.38) was determined to be negligible (Section 3.1.1.1). Therefore, any uncertainty analyses regarding the assembly components were judged to be unnecessary as the results would also be negligible.

\subsubsection{Americium-Beryllium Source and Tube}

\section{AmBe Source and Steel Cladding}

The only information available regarding the source (Figure 1.51) is the source strength of $5 \mathrm{Ci}\left(\sim 1 \times 10^{7}\right.$ neutrons/sec) on 5/10/1968 and a stainless steel container that is $3.302 \mathrm{~cm}$ long and $2.032 \mathrm{~cm}$ in outer diameter. In the design drawing for the graphite reflector assembly containing the source, the container is $3.50266 \mathrm{~cm}$ long with an outer diameter of $2.0955 \mathrm{~cm}$. It is assumed that the stainless steel cladding is SS304/304L material with the average composition and density found in Table 2.27. The cladding is assumed to be one-sixteenth inches thick $(0.15875 \mathrm{~cm})$ on all sides and the source container is a right cylinder with no additional features. Therefore the approximate volume of the source and cladding is $12.08 \mathrm{~cm}^{3}$ and the approximate volume of just the source region within the clad is $7.91 \mathrm{~cm}^{3}$. 
NEA/NSC/DOC(2006)1

Fundamental - FUND

NRAD-FUND-RESR-001

CRIT

The activity of the source was evaluated by decaying the $5 \mathrm{Ci}$ source from the initial date to $3 / 30 / 2010$ (41.92 years) with an americium half-life of 432.7 years. The source had, at the time of the initial experiments, a strength of $\sim 4.7 \mathrm{Ci}\left(1.73 \times 10^{11}\right.$ alphas/s). This is equivalent to a neutron emission rate of approximately $5.2 \times 10^{6}$ neutrons/s assuming 30 neutrons are emitted per one million alpha particles in an AmBe source. ${ }^{\mathrm{a}}$

The exact chemical composition of the AmBe source is unknown. A different $5 \mathrm{Ci}$ source of unspecified origin (purchased in 1986) was dismantled, sampled (sub-sampled), and analyzed using inductively coupled plasma mass spectrometry (ICP-MS) at the Idaho National Laboratory. The source was comprised of three separate pellets of varying thickness and mass. Each pellet was sub-sampled to provide 10 samples ranging in size from 6 to $15 \mathrm{mg}$. ${ }^{\mathrm{b}}$ The results of the analyses are in Table 2.55.

Table 2.55. Example AmBe Source Properties. ${ }^{(a)}$

\begin{tabular}{|c|c|}
\hline Be:Am Ratio & $6.30 \pm 52 \%(1 \sigma)$ \\
\hline$\% \mathrm{Pu}$ in ${ }^{241} \mathrm{Am}$ & 0.157 \\
\hline$\%^{239} \mathrm{Pu}$ & $72.7 \pm 0.4 \%$ \\
\hline$\%^{240} \mathrm{Pu}$ & $27.3 \pm 2 \%$ \\
\hline U:Pu Ratio & $0.177 \pm 120 \%$ \\
\hline${ }^{238}$ U Isotopic Content ${ }^{(b)}$ & $90 \pm 1 \%$ \\
\hline Impurities $^{(\mathbf{c})}$ & $\mathrm{ng} / \mathrm{mg}{ }^{241} \mathrm{Am}($ or ppm) $\pm 10 \%(2 \sigma)$ \\
\hline $\mathrm{Sc}$ & 1470 \\
\hline $\mathrm{Sr}$ & 1590 \\
\hline Y & 1480 \\
\hline $\mathrm{Zr}$ & 1610 \\
\hline Mo & 1830 \\
\hline $\mathrm{Ba}$ & 1830 \\
\hline $\mathrm{W}$ & 313 \\
\hline
\end{tabular}

(a) J. Sommers, M. Jimenez, M. Adamic, J. Giglio, and K. Carney, "Characterization of a Sealed AmericiumBeryllium (AmBe) Source by Inductively Coupled Plasma Mass Spectrometry," J. Radioanal. Nucl. Chem., 282, 929-932 (2009).

(b) This value represents a variance weighted average of the original data: $98 \pm 2 \%, 84 \pm 3 \%, 95 \pm 3 \%$, and $88 \pm$ $1 \%$.

(c) Only the impurities of significant measurable content were reported.

Assuming the AmBe source is homogenously distributed under vacuum conditions within the interior volume of the source cladding, the atomic density of the americium can be calculated directly from the

\footnotetext{
${ }^{a}$ D. R. Lide, ed., CRC Handbook of Chemistry and Physics, $90^{\text {th }}$ Edition (Internet Version 2010), CRC Press/Taylor and Francis, Boca Raton, FL (2010).

b J. Sommers, M. Jimenez, M. Adamic, J. Giglio, and K. Carney, "Characterization of a Sealed AmericiumBeryllium (AmBe) Source by Inductively Coupled Plasma Mass Spectrometry," J. Radioanal. Nucl. Chem., 282, 929-932 (2009).
} 


\section{Fundamental - FUND \\ NRAD-FUND-RESR-001 \\ CRIT}

current activity of the source at the time of the experiments. The additional data provided in Table 2.55 can be used to estimate the approximate composition of the AmBe source material. There is assumed to be no ${ }^{237} \mathrm{~Np}$ in the initial source, and that all ${ }^{237} \mathrm{~Np}$ is obtained via the decay of ${ }^{241} \mathrm{Am}$ with no decay of any other radioisotopes in the source. It is assumed that all actinides are in the dioxide form such that an approximate content of oxygen can be included in the material composition. The estimated composition of the AmBe source is shown in Table 2.56. The approximate mass density of this homogenized source is $0.251 \mathrm{~g} / \mathrm{cm}^{3}$.

Table 2.56. Smeared AmBe Source Composition and Atomic Density.

\begin{tabular}{|c|c||}
\hline Isotope/Element & Atoms/b-cm \\
\hline \hline${ }^{241} \mathrm{Am}$ & $4.3062 \mathrm{E}-04$ \\
$\mathrm{Be}$ & $2.7129 \mathrm{E}-03$ \\
${ }^{237} \mathrm{~Np}$ & $2.9906 \mathrm{E}-05$ \\
${ }^{239} \mathrm{Pu}$ & $4.9228 \mathrm{E}-07$ \\
${ }^{240} \mathrm{Pu}$ & $1.8486 \mathrm{E}-07$ \\
${ }^{235} \mathrm{U}$ & $1.1985 \mathrm{E}-08$ \\
${ }^{238} \mathrm{U}$ & $1.0787 \mathrm{E}-07$ \\
$\mathrm{O}$ & $9.2265 \mathrm{E}-04$ \\
$\mathrm{Sc}$ & $3.3943 \mathrm{E}-06$ \\
$\mathrm{Sr}$ & $1.8837 \mathrm{E}-06$ \\
$\mathrm{Y}$ & $1.7280 \mathrm{E}-06$ \\
$\mathrm{Zr}$ & $1.8320 \mathrm{E}-06$ \\
$\mathrm{Mo}$ & $1.9800 \mathrm{E}-06$ \\
$\mathrm{Ba}$ & $1.3833 \mathrm{E}-06$ \\
$\mathrm{~W}$ & $1.7672 \mathrm{E}-07$ \\
\hline \hline Total & $4.1093 \mathrm{E}-03$ \\
\hline
\end{tabular}

The effective bias for removing the encapsulated AmBe source (Figure 1.51), source tube (Figure 1.52), and cap (Figure 1.53) was determined to be negligible (Section 3.1.1.1). Therefore, any uncertainty analyses regarding the AmBe source were judged to be unnecessary as the results would also be negligible.

\section{Source Tube and Cap}

The composition of the source tube and source tube cap is aluminum 6061 with the composition and density as described in Table 2.43 .

The effective bias for removing the encapsulated AmBe source (Figure 1.51), source tube (Figure 1.52), and cap (Figure 1.53) was determined to be negligible (Section 3.1.1.1). Therefore, any uncertainty analyses regarding the source tube and cap were judged to be unnecessary as the results would also be negligible. 
NEA/NSC/DOC(2006)1

Fundamental - FUND

NRAD-FUND-RESR-001

CRIT

\subsubsection{Grid Plate Properties}

\subsubsection{Aluminum 1100}

The composition and density of aluminum 1100 is reported in Table 2.57. An average composition was selected to represent the core grid plate material properties.

Table 2.57. Aluminum 1100 Composition (wt.\%).

\begin{tabular}{|c|c|c|c|}
\hline Component & Content $1^{(a)}$ & 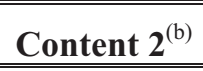 & Average $^{(\mathrm{c})}$ \\
\hline $\mathrm{Al}$ & $99.00 \mathrm{Min}$ & 99 Min & 99.225 \\
\hline $\mathrm{Cu}$ & $0.05-0.20$ & $0.05-0.2$ & 0.125 \\
\hline $\mathrm{Fe}$ & 1.0 Max & -- & 0.25 \\
\hline $\mathrm{Mn}$ & 0.05 Max & $0.05 \mathrm{Max}$ & 0.025 \\
\hline $\mathrm{Si}$ & 1.0 Max & -- & 0.25 \\
\hline $\mathrm{Zn}$ & 0.10 Max & 0.1 Max & 0.05 \\
\hline $\mathrm{Fe}+\mathrm{Si}$ & -- & $0.95 \mathrm{Max}$ & 0.5 \\
\hline $\mathrm{Co}^{(\mathrm{d})}$ & 0.05 & 0.05 & 0.025 \\
\hline $\mathrm{Ni}^{(\mathrm{d})}$ & 0.05 & 0.05 & 0.025 \\
\hline $\mathrm{Sn}^{(\mathrm{d})}$ & 0.05 & 0.05 & 0.025 \\
\hline Density $\left(\mathrm{g} / \mathrm{cm}^{3}\right)$ & - & 2.71 & 2.71 \\
\hline
\end{tabular}

(a) All Metals \& Forge, http://www.steelforge.com/.

(b) Metal Suppliers Online, http://www.metalsuppliersonline.com/.

(c) Average based on the maximum range of each component. Values of 0.25 wt. $\%$ are selected for $\mathrm{Fe}$ and Si to satisfy the combined maximum requirement of $<0.95 \mathrm{wt} . \%$ and an $\mathrm{Al}$ content of $>99$ wt. $\%$.

(d) Reported "Other" components have a maximum of 0.15 wt.\% total with no more than 0.05 wt.\% per component. $\mathrm{Co}, \mathrm{Ni}$, and $\mathrm{Sn}$ were selected to represent impurities in Al6061.

The effective bias for removing the grid plate (Figure 1.10) was determined to be negligible (Section 3.1.1.1). Therefore, any uncertainty analyses regarding the grid plate itself were judged to be unnecessary as the results would also be negligible.

\subsubsection{Assembly Pitch in Grid Plate}

The square pitch between fuel elements within an assembly is $8.10006 \mathrm{~cm}$ in the East-West direction and $7.7089 \mathrm{~cm}$ in the North-South direction (Figure 1.11). No uncertainty is reported for this pitch. However, the manufacturing specifications for the grid plate assembly indicate a manufacturing tolerance of $\pm 0.0127 \mathrm{~cm}$ in the location of the center of each hole (Figure 1.10). The assembly hole diameter in the grid plate is $6.1722 \mathrm{~cm}$ with manufacturing tolerance limits of +0.01778 and $-0.00508 \mathrm{~cm}$ (Figure 1.10). The bottom assembly adapters (Figure 1.14) have a diameter of $6.0706 \pm 0.0254 \mathrm{~cm}$ (manufacturing limit).

To find the effect of this uncertainty on the $\mathrm{k}_{\text {eff }}$ value, the assembly pitch in the grid plate was adjusted by twice the bounding limit of $\pm 0.1016 \mathrm{~cm}$, which represents the difference between the nominal diameters 
NEA/NSC/DOC(2006)1

\author{
Fundamental - FUND \\ NRAD-FUND-RESR-001 \\ CRIT
}

of the bottom assembly adapters and the assembly holes in the grid plate. An upper perturbation $\mathrm{k}_{\text {eff }}$ value was found by simultaneously increasing the assembly pitch by $0.1016 \mathrm{~cm}$ and then simultaneously decreasing by the same amount to find a lower perturbation $\mathrm{k}_{\mathrm{eff}}$ value. Half of the difference between the upper and lower perturbation $\mathrm{k}_{\mathrm{eff}}$ values was used to represent the variation in $\mathrm{k}_{\mathrm{eff}}$ due to perturbing the assembly pitch by $0.1016 \mathrm{~cm}$. The calculated result was then scaled to obtain the $1 \sigma$ uncertainty. Results are shown in Table 2.58.

The calculated uncertainty in the nominal pitch is then scaled to account for uncertainties in the location of the holes drilled into the grid plate, the diameter of the assembly holes in the grid plate, and the diameter of the bottom assembly adapters. The uncertainty in the location of the drilled holes is accounted for twice because it is assumed that the location of one hole is independent from the location of an adjacent hole. All uncertainties related to the assembly pitch are believed to exhibit some randomness. However, the uncertainty in the diameter of the holes in the grid plate is assumed to be $100 \%$ systematic, as a single drill bit would have been used to make them.

The total number of assemblies in this configuration is 28 (16 fuel clusters and 12 graphite blocks); therefore the random component of this uncertainty is divided by $\sqrt{2} 2$. The calculated uncertainty in the assembly pitch is considered negligible $(\leq 0.00010)$ except for that due to the difference in assembly adapter and hole dimensions and the drilled diameter of the holes in the grid plate.

Table 2.58. Effect of Uncertainty in Fuel Assembly Pitch.

\begin{tabular}{|c|c|c|c|c|c|c|c|c|c|}
\hline Deviation & $\Delta \mathbf{k}$ & \pm & $\sigma_{\Delta \mathbf{k}}$ & $\begin{array}{l}\text { Scaling } \\
\text { Factor }\end{array}$ & $\Delta \mathbf{k}_{\text {eff }}(1 \sigma)$ & \pm & $\sigma_{\Delta \mathrm{keff}}$ & $\begin{array}{c}\Delta \mathbf{k}_{\text {eff }} \\
(15 \% \\
\text { systematic }) \\
\end{array}$ & $\begin{array}{c}\Delta \mathrm{k}_{\mathrm{eff}} \\
(85 \% \\
\text { random }) \\
\end{array}$ \\
\hline \multirow{5}{*}{ $\pm 0.1066 \mathrm{~cm}$} & \multirow{5}{*}{0.00278} & \multirow{5}{*}{ \pm} & \multirow{5}{*}{0.00005} & $2 \sqrt{ } 3^{(a)}$ & 0.00080 & \pm & 0.00001 & 0.00012 & 0.00013 \\
\hline & & & & $8 \sqrt{ } 3^{(b)}$ & 0.00020 & \pm & 0.00000 & 0.00003 & 0.00003 \\
\hline & & & & $8 \sqrt{ } 3^{(b)}$ & 0.00020 & \pm & 0.00000 & 0.00003 & 0.00003 \\
\hline & & & & $5.7 \times 2 \sqrt{ } 3^{(\mathrm{c})}$ & 0.00014 & \pm & 0.00000 & -- & -- \\
\hline & & & & $4 \times 2 \sqrt{ } 3^{(\mathrm{d})}$ & 0.00019 & \pm & 0.00000 & 0.00003 & 0.00003 \\
\hline
\end{tabular}

(a) This scaling factor represents adjustment of the perturbed quantity to the uncertainty in assembly placement due to the difference in assembly bottom diameter and grid plate hole diameter.

(b) This scaling factor represents adjustment of the perturbed quantity to the uncertainty in the location of the grid position in the grid plate.

(c) This scaling factor represents adjustment of the perturbed quantity to the uncertainty in the diameter of assembly holes drilled into the grid plate.

(d) This scaling factor represents adjustment of the perturbed quantity to the uncertainty in the diameter of the bottom assembly adapter.

This uncertainty was also evaluated using the URAN card in MCNP5. ${ }^{\text {a }}$ This card allows for the stochastic sampling of components with random locations in a lattice. The fuel and graphite assemblies in the core were simulated with random placement within $\pm 0.01066 \mathrm{~cm}$ of their nominal (x,y) placement in the grid plate. The effect calculated using this method was $0.00005 \pm 0.00003 \Delta \mathrm{k}_{\text {eff }}(1 \sigma)$, which is negligible $(\leq 0.00010)$. Analysis using this method indicates that the method employed to obtain the results in Table 2.58 may overestimate the total effective uncertainty in the assembly pitch. However, the calculated uncertainty in the assembly pitch is still quite small compared to other uncertainties in this reactor configuration.

\footnotetext{
a X-5 Monte Carlo Team, "MCNP - A General Monte Carlo N-Particle Transport Code, Version 5, Volume II: User's Guide,” LA-CP-03-0245, Los Alamos National Laboratory (October 3, 2005).
} 
NEA/NSC/DOC(2006)1

Fundamental - FUND

NRAD-FUND-RESR-001

CRIT

\subsubsection{Ex-Core Structural Support Properties}

\subsubsection{Grid Support Structure}

The aluminum 6061 composition and density described in Section 2.1.4.2 is used to represent the material properties of the aluminum grid support structure.

The effective bias for removing the grid support structure (Figure 1.8) was determined to be negligible (Section 3.1.1.1). Therefore, any uncertainty analyses regarding the support structure were judged to be unnecessary as the results would also be negligible.

\subsubsection{Mounting Pad}

The aluminum 6061 composition and density described in Section 2.1.4.2 are used to represent the material properties of the aluminum mounting pad.

The effective bias for removing the mounting pad (Figures 1.5 and 1.9) was determined to be negligible (Section 3.1.1.1). Therefore, any uncertainty analyses regarding the mounting pad were judged to be unnecessary as the results would also be negligible.

\subsubsection{Reactor Tank}

The aluminum 6061 composition and density described in Section 2.1.4.2 is used to represent the material properties of the aluminum reactor tank.

The effective bias for removing the reactor tank (Figures 1.5 and 1.9) was determined to be negligible (Section 3.1.1.1). Therefore, any uncertainty analyses regarding the mounting pad were judged to be unnecessary as the results would also be negligible.

\subsubsection{Tank Water Properties}

\section{Composition}

The tank water composition is assumed to be pure with the stoichiometric ratio of hydrogen to oxygen. 2:1.

\section{Density}

The density of water, at a given temperature in degrees Celsius, can be obtained by interpolation of data tables provided in the $90^{\text {th }}$ edition of the CRC Handbook of Chemistry and Physics, ${ }^{\text {a }}$ or calculated using an equation provided in the $70^{\text {th }}$ edition of the handbook: ${ }^{\mathrm{b}}$

$$
\rho\left(\frac{\mathrm{kg}}{\mathrm{m}^{3}}\right)=\frac{\left(\begin{array}{c}
999.83952+16.945176 \cdot T-7.9870401 \cdot 10^{-3} \cdot T^{2}-46.170461 \cdot 10^{-6} \cdot T^{3} \\
+105.56302 \cdot 10^{-9} \cdot T^{4}-280.54253 \cdot 10^{-12} \cdot T^{5}
\end{array}\right)}{\left(1+16.879850 \cdot 10^{-3} \cdot T\right)}
$$

\footnotetext{
${ }^{a}$ D. R. Lide, ed., CRC Handbook of Chemistry and Physics, $90^{\text {th }}$ Edition (Internet Version 2010), CRC Press/Taylor and Francis, Boca Raton, FL (2010).

${ }^{\mathrm{b}}$ R. C. Weast and D. R. Lide, eds., CRC Handbook of Chemistry and Physics, $70^{\text {th }}$ Edition, CRC Press, Boca Raton, FL (1990). 
NEA/NSC/DOC(2006)1

Fundamental - FUND

NRAD-FUND-RESR-001

CRIT

Use of either method provides a density within less than $0.0006 \%$ of the density obtained using the other method. The density of water at the temperature of $27.2^{\circ} \mathrm{C}$ is $0.9965 \mathrm{~g} / \mathrm{cm}^{3}$. The uncertainty in water density is evaluated and discussed as the uncertainty in the experiment temperature (Section 2.1.1.1). Any additional uncertainty incurred through use of the handbook data or equation for water density is assumed to be negligible.

\section{Impurities}

The tank water in the Advanced Test Reactor (ATR, ATR-FUND-RESR-001) is considered "dirtier" than the NRAD tank water. The reported impurity concentration for the ATR is found in Table 2.59.

The impurities reported in Table 2.59 were added to the composition of the tank water. The difference between the unperturbed and perturbed $\mathrm{k}_{\text {eff }}$ values was used to represent the variation in $\mathrm{k}_{\text {eff }}$ due to the inclusion of impurities in the water. Results are shown in Table 2.60.

This uncertainty is treated as a $1 \sigma$ uncertainty and $100 \%$ systematic. Because the effect is practically negligible, the statistical uncertainty of 0.00010 is taken to represent the uncertainty in impurity content in the water.

Table 2.59. Impurities in ATR Tank Water. ${ }^{(a)}$

\begin{tabular}{|c|c|}
\hline Element & Concentration (ppb) \\
\hline \hline $\mathrm{Fe}$ & 0.84 \\
$\mathrm{Al}$ & 2.02 \\
$\mathrm{Ca}$ & 49.00 \\
$\mathrm{Mg}$ & 5.30 \\
$\mathrm{Mb}$ & 0.37 \\
$\mathrm{Si}$ & 29.40 \\
$\mathrm{Na}$ & 36.10 \\
$\mathrm{Cu}$ & 0.33 \\
$\mathrm{~Pb}$ & 0.20 \\
$\mathrm{Be}$ & 0.23 \\
$\mathrm{Cr}$ & 54.50 \\
$\mathrm{Sr}$ & 0.35 \\
$\mathrm{Ni}$ & 175.00 \\
$\mathrm{Co}$ & 0.30 \\
\hline
\end{tabular}

(a) ATR-FUND-RESR-001.

Table 2.60. Effect of Uncertainty in Water Impurities.

\begin{tabular}{|c|ccc|c|ccc||}
\hline Deviation & $\Delta \mathbf{k}$ & \pm & $\boldsymbol{\sigma}_{\Delta \mathbf{k}}$ & $\begin{array}{c}\text { Scaling } \\
\text { Factor }\end{array}$ & $\Delta \mathbf{k}_{\text {eff }}(\mathbf{1} \boldsymbol{\sigma})$ & \pm & $\boldsymbol{\sigma}_{\Delta \mathbf{k e f f}}$ \\
\hline \hline Added impurities & 0.00003 & \pm & 0.00010 & 1 & 0.00003 & \pm & 0.00010 \\
\hline
\end{tabular}


NEA/NSC/DOC(2006)1

Fundamental - FUND

NRAD-FUND-RESR-001

CRIT

\subsubsection{Beam Tube Properties}

\subsubsection{Aluminum 6061}

\section{Composition and Density}

The aluminum 6061 composition and density described in Section 2.1.4.2 is used to represent the material properties of the aluminum reactor tank.

\section{Dimensions - Beam Filter Tube}

The outer height of the East and North beam filter tubes (Figure 1.42) is $16.51 \mathrm{~cm}$ with a manufacturing tolerance for the East tube is +0.000 and $-0.0254 \mathrm{~cm}$, and $\pm 0.0762 \mathrm{~cm}$ for the North tube. The top and bottom aluminum walls are manufactured from $0.635-\mathrm{cm}$-thick stock material. The width of both tubes is $13.97 \mathrm{~cm}$ with a manufacturing tolerance of +0.000 and $-0.0254 \mathrm{~cm}$, with the side aluminum walls manufactured from $0.3175-\mathrm{cm}$-thick stock material. The front face aluminum plate, placed near the core, is manufactured from 0.2286 - $\mathrm{cm}$-thick stock material. No tolerances are available for the stock material thicknesses. It is assumed that all beam filter tube dimensions are bound, with uniform probability distribution, within a tolerance of $\pm 0.0762 \mathrm{~cm}$, which is the largest manufacturing uncertainty tolerance for the aluminum parts comprising the beam filter tubes.

The beam tube aluminum volume was adjusted by the maximum manufacturing tolerance. An upper perturbation $\mathrm{k}_{\mathrm{eff}}$ value was found by simultaneously increasing the outside dimensions (and decreasing the inside dimensions) by $0.0762 \mathrm{~cm}$ and then simultaneously decreasing (increasing) by the same amount to find a lower perturbation $\mathrm{k}_{\text {eff }}$ value. Half of the difference between the upper and lower perturbation $\mathrm{k}_{\mathrm{eff}}$ values was used to represent the variation in $\mathrm{k}_{\text {eff }}$ due to perturbing the beam tube volume by $0.0762 \mathrm{~cm}$. The calculated result was then scaled to obtain the $1 \sigma$ uncertainty. Results are shown in Table 2.61.

The total number of beam tubes in this configuration is 2 ; therefore the random component of this uncertainty is divided by $\sqrt{ } 2$. The uncertainty in the beam tube dimensions is divided by $\sqrt{ } 4$ to correct for the thickness of four main sides of each tube being perturbed simultaneously. The uncertainty in the placement of the beam tube in relation to the core face is assessed in Section 2.1.10.4. The calculated uncertainty in the beam tube aluminum dimensions is negligible $(\leq 0.00010)$.

Table 2.61. Effect of Uncertainty in Aluminum Thickness.

\begin{tabular}{||c|ccc|c|ccc|c|c||}
\hline Deviation & $\Delta \mathbf{k}$ & \pm & $\sigma_{\Delta \mathbf{k}}$ & $\begin{array}{c}\text { Scaling } \\
\text { Factor }\end{array}$ & $\Delta \mathbf{k}_{\text {eff }}(\mathbf{1 \sigma})$ & \pm & $\sigma_{\Delta \mathrm{keff}}$ & $\begin{array}{c}\Delta \mathbf{k}_{\text {eff }} \\
\mathbf{( 1 5 \%} \\
\text { systematic) }\end{array}$ & $\begin{array}{c}\Delta \mathbf{k}_{\text {eff }} \\
\mathbf{8 5 \%} \\
\text { random) }\end{array}$ \\
\hline \hline $\pm 0.0762 \mathrm{~cm}$ & 0.00006 & \pm & 0.00005 & $\sqrt{ } 4 \sqrt{3}$ & 0.00002 & \pm & 0.00001 & negligible & 0.00002 \\
\hline \hline
\end{tabular}

\section{Dimensions - Other Aluminum Beam Tube Components}

The effective bias for removing the beam tube aluminum (Figures 1.40 through 1.49), excluding the beam filter tube, was determined to be negligible (Section 3.1.1.1). Therefore, any uncertainty analyses regarding aluminum dimensions of the beam tube components (excluding the beam filter tube) were judged to be unnecessary as the results would also be negligible. 


\section{Impurities}

The effective bias for removing non-aluminum elements (Table 2.43) from aluminum was determined to be negligible (Section 3.1.1.1). Therefore, any uncertainty analyses regarding aluminum impurities were judged to be unnecessary as the results would also be negligible.

\subsubsection{Gas Content in Beam Filter Tubes}

The gas content in the East beam filter tube is air with a composition and density as described in Section 2.1.3.5. The gas content in the North beam filter tube and both beam line aperture mechanism housing and beam tubes is helium with a pressure of approximately $0.2 \mathrm{~atm}$ at $300.35 \mathrm{~K}$. The helium is assumed to be pure gas with a calculated atomic density of $1.2209 \times 10^{-6}$ atoms $/ \mathrm{b}-\mathrm{cm}$ (mass density of $8.1149 \times 10^{-6}$ $\mathrm{g} / \mathrm{cm}^{3}$.

$$
\begin{gathered}
\frac{n}{V}=\frac{P \cdot N_{A}}{R \cdot T}=\frac{(0.2 \mathrm{~atm}) \cdot\left(0.60221 \frac{\mathrm{atoms} \cdot \mathrm{cm}^{2}}{\mathrm{~mol} \cdot \mathrm{b}}\right)}{\left(82.05746 \frac{\mathrm{cm} \cdot \mathrm{atm}}{\mathrm{mol} \cdot \mathrm{K}}\right) \cdot(300.35 \mathrm{~K})}=1.2209 \cdot 10^{-6} \frac{\mathrm{atoms}}{\mathrm{b} \cdot \mathrm{cm}} . \\
\rho=\frac{n}{V} \cdot \frac{M}{N_{A}}=1.2209 \cdot 10^{-6} \frac{\mathrm{atoms}}{\mathrm{b} \cdot \mathrm{cm}} \cdot \frac{4.0026 \frac{\mathrm{g}}{\mathrm{mol}}}{\left(0.60221 \frac{\mathrm{atoms} \cdot \mathrm{cm}^{2}}{\mathrm{~mol} \cdot \mathrm{b}}\right)}=8.1149 \cdot 10^{-6} \frac{\mathrm{g}}{\mathrm{cm}^{3}} .
\end{gathered}
$$

The effective bias for removing air and helium was determined to be negligible (Section 3.1.1.1). Therefore, any uncertainty analyses regarding air were judged to be unnecessary as the results would also be negligible.

\subsubsection{Boron Nitride Apertures}

The aperture blocks are Combat Grade A boron nitride from the graphite products division of The Carborundium Co., which is now Saint-Gobain. ${ }^{a}$ Typical impurities and the physical density for this material is provided in Table 2.62 .

\footnotetext{
${ }^{\text {a }}$ Saint-Gobain Advanced Ceramics, Boron Nitride Products, 168 Creekside Drive, Amherst, New York 14228, http://www.bn.saint-gobain.com.
} 
NEA/NSC/DOC(2006)1

Fundamental - FUND

NRAD-FUND-RESR-001

CRIT

Table 2.62. Composition of Combat

Grade A Boron Nitride. ${ }^{(a)}$

\begin{tabular}{|c|c|}
\hline Component & Average ppm (wt.\%) \\
\hline $\mathrm{Al}$ & 14.6 \\
\hline $\mathrm{Au}$ & 1 \\
\hline $\mathrm{Be}$ & 1 \\
\hline $\mathrm{Ca}$ & 620.8 \\
\hline $\mathrm{Cr}$ & 22.8 \\
\hline $\mathrm{Cu}$ & 1 \\
\hline $\mathrm{Fe}$ & 1 \\
\hline K & 23 \\
\hline $\mathrm{Mg}$ & 1 \\
\hline $\mathrm{Mn}$ & 1.4 \\
\hline Mo & 1 \\
\hline $\mathrm{Na}$ & 20 \\
\hline $\mathrm{Ni}$ & 1 \\
\hline $\mathrm{Pb}$ & 1 \\
\hline $\mathrm{Si}$ & 2410.6 \\
\hline $\mathrm{Sn}$ & 1 \\
\hline $\mathrm{Ti}$ & 1 \\
\hline $\mathrm{V}$ & 1 \\
\hline W & 1 \\
\hline $\mathrm{Zn}$ & 1 \\
\hline $\mathrm{Zr}$ & 1 \\
\hline $\mathrm{B}_{2} \mathrm{O}_{3}^{(b)}$ & 4.56 wt. $\%$ \\
\hline $\mathrm{O}_{2}{ }^{(\mathrm{b})}$ & 4.30 wt. $\%$ \\
\hline $\mathrm{BN}$ & Balance \\
\hline Density $\left(\mathrm{g} / \mathrm{cm}^{3}\right)$ & $2.09^{(\mathrm{c})}$ \\
\hline
\end{tabular}

(a) Personal communication with Steve Lyle at Saint-Gobain Boron Nitride (April 21, 2010).

(b) The oxygen quantities overlap some between these two measurements.

(c) Density in a single billet can vary as much as $7-8 \%$ from this average value within the billet.

The effective bias for removing the boron nitride apertures (Figures 1.43 and 1.44) was determined to be negligible (Section 3.1.1.1). Therefore, any uncertainty analyses regarding boron nitride were judged to be unnecessary as the results would also be negligible. 
NEA/NSC/DOC(2006)1

Fundamental - FUND

NRAD-FUND-RESR-001

CRIT

\subsubsection{Placement of Beam Lines Relative to Core Fuel Elements}

The front face of the beam line filter tubes (Figures 1.41 and 1.42) was approximately $2.032 \mathrm{~cm}$ from the outside clad face of the outermost fuel elements in the core. There is no reported uncertainty in this parameter. This distance is a function of core properties such as fuel element pitch within an assembly, fuel assembly pitch, and fuel element outer diameter and beam line properties such is total beam filter tube length, thickness of the beam filter tube attachment region, total thickness of the beam aperture mechanism region, alignment accuracy of the beam mechanism region to the beam tube support stand, and alignment accuracy of the beam line support stand attached to the floor with respect to the location of the core.

The uncertainties due to core parameters are already included with the evaluation of their respective uncertainties in previous sections. The uncertainty in the length of the beam filter tube is $\pm 0.0381 \mathrm{~cm}$. The uncertainty in the thickness of the beam filter tube attachment plate is $\pm 0.00762 \mathrm{~cm}$. The uncertainty in the thickness of the front face aluminum sheet of the aperture mechanism region is assumed to be $\pm 0.0762 \mathrm{~cm}$. The uncertainty in the thickness of the beam aperture mechanism region is assumed to be half of the tolerance value: $\pm 0.0381 / 2(0.01905) \mathrm{cm}$. The uncertainty is the alignment accuracy of the attachment of the aperture mechanism region to the support stand and the support stand to the tank floor, with respect to the core, are both assumed to be $\pm 0.0762 \mathrm{~cm}$. All of these uncertainties are treated as bounding uncertainties with uniform probability distribution. The total maximum position uncertainty for the distance between the core face and the face of the beam filter tube is \pm 0.29337 . Assuming that each aspect of the beam line hardware manufacture and placement is independent, this maximum value is divided by the square-root of the number of components, six (6), and the actual bounding uncertainty in the distance between the core and beam filter tube is approximately $\pm 0.12 \mathrm{~cm}$. This uncertainty is equivalent to assuming a $0.05 \mathrm{in}$. uncertainty in the original $0.8 \mathrm{in}$. approximate distance.

To find the effect of this uncertainty on the $\mathrm{k}_{\mathrm{eff}}$ value, the locations of the beam lines were adjusted by their estimated bounding limit. An upper perturbation $\mathrm{k}_{\mathrm{eff}}$ value was found by simultaneously increasing the distance by $0.12 \mathrm{~cm}$ and then simultaneously decreasing by the same amount to find a lower perturbation $\mathrm{k}_{\mathrm{eff}}$ value. Half of the difference between the upper and lower perturbation $\mathrm{k}_{\mathrm{eff}}$ values was used to represent the variation in $\mathrm{k}_{\text {eff }}$ due to perturbing the locations of the beam lines. The calculated result was then scaled to obtain the $1 \sigma$ uncertainty. Results are shown in Table 2.63 .

The total number of beam tubes in this configuration is 2 ; therefore the random component of this uncertainty is divided by $\sqrt{2}$. The calculated uncertainty in the beam tube placement is negligible $(\leq 0.00010)$.

Table 2.63. Effect of Uncertainty in Beam Line Placement.

\begin{tabular}{||c|ccc|c|ccc|c|c||}
\hline Deviation & $\Delta \mathbf{k}$ & \pm & $\sigma_{\Delta \mathbf{k}}$ & $\begin{array}{c}\text { Scaling } \\
\text { Factor }\end{array}$ & $\Delta \mathbf{k}_{\text {eff }}(\mathbf{1 \sigma})$ & \pm & $\sigma_{\Delta \mathrm{keff}}$ & $\begin{array}{c}\Delta \mathbf{k}_{\text {eff }} \\
\mathbf{( 1 5 \%} \\
\text { systematic) }\end{array}$ & $\begin{array}{c}\Delta \mathbf{k}_{\text {eff }} \\
\mathbf{( 8 5 \%} \\
\text { random) }\end{array}$ \\
\hline \hline $\pm 0.12 \mathrm{~cm}$ & 0.00040 & \pm & 0.00005 & $\sqrt{ } 3$ & 0.00023 & \pm 0.00003 & 0.00003 & 0.00014 \\
\hline
\end{tabular}

Uncertainty in the centerline alignment of the beam line with the core fuel is expected to be small and have a negligible effect on the total $\mathrm{k}_{\text {eff }}$ uncertainty. Any uncertainty due to centerline alignment of the beam tube would already be included in the dimensional analysis of the beam filter tube aluminum walls. 
NEA/NSC/DOC(2006)1

Fundamental - FUND

NRAD-FUND-RESR-001

CRIT

\subsubsection{Instrumentation and Detector Properties}

\subsubsection{Dry Tubes, Detectors, etc.}

Dry tubes were not installed during the initial critical measurements of the NRAD core; uncertainty analyses were therefore not performed.

The effective bias for removing the detectors and their housings from the benchmark model was not performed because they are beyond the water reflector boundaries determined in Section 3.1.1.1. The detectors are sufficiently distanced from the core so as to not directly influence criticality. Therefore, any uncertainty analyses regarding the detectors were judged to be unnecessary as the results would be negligible.

\subsubsection{Total Experimental Uncertainty}

A compilation of the total evaluated uncertainty in the 60-fuel element core critical configuration of the NRAD reactor is shown in Table 2.64. As discussed earlier, uncertainties that are not treated as $100 \%$ systematic because perturbation analyses were simultaneously applied to multiple components are treated as $15 \%$ systematic (to preserve some uncertainty due to possible, yet unknown, systematic effects) and $85 \%$ random. In the case of the ${ }^{235} \mathrm{U}$ enrichment, the systematic component of the uncertainty was determined to be $25 \%$. The random portion of the uncertainty is then divided by the square root of the number of perturbed components. The root-mean square of each subcomponent is taken to determine the uncertainty in either the random or systematic components of the total evaluated uncertainty. The total evaluated uncertainty is then the root-mean square of the random and systematic uncertainties.

Uncertainties $\leq 0.00010$ are reported as negligible (neg) and those with no evaluated random component of the total uncertainty are noted with "--". The most significant contribution to the overall uncertainty is the degree of water saturation in the graphite reflector blocks. All uncertainties providing at least 0.04 $\% \Delta \mathrm{k}_{\mathrm{eff}}$ are highlighted in gray. 
NEA/NSC/DOC(2006)1

Fundamental - FUND

NRAD-FUND-RESR-001

CRIT

Table 2.64. Total Experimental Uncertainty of the 60-Fuel-Element NRAD Core.

\begin{tabular}{|c|c|c|c|c|}
\hline Perturbed Parameter & $\begin{array}{c}\text { Parameter } \\
\text { Value } \\
\end{array}$ & $\begin{array}{c}1 \sigma \\
\text { Uncertainty } \\
\end{array}$ & $\begin{array}{l} \pm \Delta \mathrm{k}_{\text {eff }}(1 \sigma) \\
\text { Systematic } \\
\end{array}$ & $\begin{array}{c}\Delta \mathbf{k}_{\text {eff }}(1 \sigma) \\
\text { Random } \\
\end{array}$ \\
\hline Temperature $\left({ }^{\circ} \mathrm{C}\right)$ & 26 & \pm 2 & neg & -- \\
\hline Control Rod Positions (cm) & $38.1,38.1,20.4216$ & \pm 0.0508 & neg & -- \\
\hline Total Fuel Element Mass (g) & 2506.5 & \pm 0.1 & neg & neg \\
\hline Uranium Mass (g) & 749.9 & \pm 0.1 & neg & neg \\
\hline${ }^{235} \mathrm{U}$ Mass (g) & 148.0 & \pm 0.43 & 0.00014 & 0.00012 \\
\hline${ }^{232}$ U Content (wt.\%) & $\sim 0$ & -- & neg & -- \\
\hline${ }^{234}$ U Content (wt.\%) & 0.2 & \pm 0.03 & 0.00050 & -- \\
\hline${ }^{236}$ U Content (wt.\%) & 0.2 & \pm 0.2 & 0.00104 & -- \\
\hline Fuel Element Length $(\mathrm{cm})$ & 38.02 & \pm 0.04 & neg & neg \\
\hline Fuel Element ID $(\mathrm{cm})$ & 0.635 & $+0,-0.0254 / \sqrt{ } 3$ & neg & neg \\
\hline Fuel Element OD (cm) & 3.4805 & \pm 0.0003 & neg & neg \\
\hline Hydrogen/Zirconium Ratio & 1.58 & \pm 0.01 & 0.00015 & 0.00011 \\
\hline Hydride Homogeneity & 1.58 & \pm 0.03 & neg & neg \\
\hline Erbium Content in Fuel (wt.\%) & 0.90 & \pm 0.02 & 0.00040 & 0.00029 \\
\hline Carbon Content in Fuel (wt.\%) & 0.30 & \pm 0.02 & neg & neg \\
\hline Hafnium Content in Fuel (wt.\%) & 0.008 & $\pm 0.008 / \sqrt{ } 3$ & 0.00083 & -- \\
\hline EBC in Fuel (wt.\%) & 0.000104 & 0.000015 & neg & -- \\
\hline Zirconium Density $\left(\mathrm{g} / \mathrm{cm}^{3}\right)$ & 6.51 & \pm 0.01 & neg & -- \\
\hline Zirconium Rod Diameter (cm) & 0.5715 & $+0,-0.0254 / \sqrt{ } 3$ & neg & neg \\
\hline Zirconium Impurities & Table 2.18 & $-100 \%$ & neg & -- \\
\hline Molybdenum Density $\left(\mathrm{g} / \mathrm{cm}^{3}\right)$ & 10.22 & \pm 0.02 & neg & -- \\
\hline Molybdenum Volume & Figure 1.27 & -- & neg & neg \\
\hline Molybdenum Impurities & Table 2.21 & $-100 \%$ & neg & -- \\
\hline Axial Graphite Density $\left(\mathrm{g} / \mathrm{cm}^{3}\right)$ & 1.73 & \pm 0.01 & neg & -- \\
\hline Axial Graphite Volume & Figure 1.28 & -- & neg & neg \\
\hline Axial Graphite Impurities & Table 2.24 & $-100 \%$ & neg & -- \\
\hline Stainless Steel Carbon Content & Table 2.27 & Table 2.27 & neg & -- \\
\hline Stainless Steel Chromium Content & Table 2.27 & Table 2.27 & neg & -- \\
\hline Stainless Steel Manganese Content & Table 2.27 & Table 2.27 & 0.00066 & -- \\
\hline Stainless Steel Nickel Content & Table 2.27 & Table 2.27 & 0.00014 & -- \\
\hline Stainless Steel Density $\left(\mathrm{g} / \mathrm{cm}^{3}\right)$ & 8.00 & \pm 0.01 & neg & -- \\
\hline Steel Cladding Length $(\mathrm{cm})$ & 58.7375 & -- & neg & neg \\
\hline Steel Cladding ID $(\mathrm{cm})$ & 3.4894 & $\pm 0.0005 / \sqrt{ } 3$ & neg & neg \\
\hline Steel Cladding OD (cm) & 3.59156 & $\pm 0.0005 / \sqrt{ } 3$ & neg & neg \\
\hline Steel End Fitting Volume & Figures 1.29 and 1.30 & $\pm 100 \%$ & neg & neg \\
\hline
\end{tabular}


NEA/NSC/DOC(2006)1

Fundamental - FUND

NRAD-FUND-RESR-001

CRIT

Table 2.64 (cont.). Total Experimental Uncertainty of the 60-Fuel-Element NRAD Core.

\begin{tabular}{|c|c|c|c|c|}
\hline Perturbed Parameter & $\begin{array}{l}\text { Parameter } \\
\text { Value }\end{array}$ & $\begin{array}{c}1 \sigma \\
\text { Uncertainty }\end{array}$ & $\begin{array}{l} \pm \Delta \mathbf{k}_{\text {eff }}(1 \sigma) \\
\text { Systematic }\end{array}$ & $\begin{array}{c} \pm \mathbf{k}_{\text {eff }} \\
(1 \sigma) \\
\text { Random }\end{array}$ \\
\hline Stainless Steel Impurities & Table 2.28 & $\pm 100 \%$ & 0.00035 & -- \\
\hline Air Composition and Density & $\begin{array}{c}\text { Tables } 2.35 \text { and } \\
2.36\end{array}$ & -- & neg & -- \\
\hline Boron Carbide Density $\left(\mathrm{g} / \mathrm{cm}^{3}\right)$ & 2.48 & $+0.04 / \sqrt{ } 3$ & neg & -- \\
\hline $\mathrm{B}_{4} \mathrm{C}$ Boron Content (wt.\%) & 78.3 & $\pm 1.0 / \sqrt{ } 3$ & neg & neg \\
\hline${ }^{10} \mathrm{~B}$ Abundance (wt.\%) & 18.43 & $\pm 0.2 / \sqrt{ } 3$ & neg & -- \\
\hline Absorber Length (cm) & 38.1 & -- & neg & neg \\
\hline Absorber Diameter $(\mathrm{cm})$ & 3.01498 & $\begin{array}{c}+0,- \\
0.0762 / \sqrt{ } 3\end{array}$ & neg & -- \\
\hline $\mathrm{B}_{4} \mathrm{C}$ Impurities & none & Table 2.41 & 0.00010 & neg \\
\hline Control Rod Burnup & -- & -- & neg & -- \\
\hline Aluminum 6061 Composition & Table 2.43 & -- & neg & -- \\
\hline Aluminum 6061 Density $\left(\mathrm{g} / \mathrm{cm}^{3}\right)$ & 2.70 & \pm 0.01 & neg & -- \\
\hline Aluminum Clad Length $(\mathrm{cm})$ & 60.96 & -- & neg & neg \\
\hline Aluminum Clad Thickness $(\mathrm{cm})$ & 0.07112 & $\pm 100 \%$ & neg & -- \\
\hline Guide Tube Volume (vol.\%) & Figure 1.35 & $\pm 30 \%$ & neg & neg \\
\hline Guide Tube End Fitting Volume & Figure 1.35 & $\pm 100 \%$ & neg & neg \\
\hline Auxiliary Control Rod Parts & $\begin{array}{l}\text { Figures } 1.31 \\
\text { and } 1.33\end{array}$ & $-100 \%$ & neg & -- \\
\hline Aluminum 6061 Impurities & Table 2.43 & $-100 \%$ & neg & -- \\
\hline $\begin{array}{l}\text { Fuel Element Pitch in Assembly } \\
(\mathrm{cm})\end{array}$ & 3.8862 & $\begin{array}{l}+0.01524 / \sqrt{ } 3 \\
-0.01016 / \sqrt{ } 3\end{array}$ & neg & neg \\
\hline Fuel Cluster Assembly Parts & $\begin{array}{l}\text { Figures } 1.14 \\
\text { through } 1.18\end{array}$ & $-100 \%$ & neg & neg \\
\hline Graphite Block Density $\left(\mathrm{g} / \mathrm{cm}^{3}\right)$ & 1.570 & \pm 0.009 & 0.00020 & -- \\
\hline Graphite Block Length (cm) & 65.7225 & $\pm 0.3175 / \sqrt{ } 3$ & neg & neg \\
\hline Graphite Block Cross Section $\left(\mathrm{cm}^{2}\right)$ & Figure 1.37 & Figure 1.37 & neg & 0.00014 \\
\hline Graphite Block Impurities & Table 2.48 & $-100 \%$ & neg & neg \\
\hline $\begin{array}{l}\text { Water Saturation of Graphite } \\
(\text { vol. } \%)\end{array}$ & 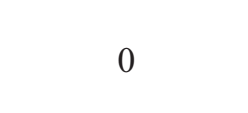 & $+30 \% / \sqrt{ } 3$ & 0.00207 & -- \\
\hline Aluminum 2011 Components & $\begin{array}{l}\text { Figure } 1.36 \text { and } \\
\text { Table } 2.54\end{array}$ & $-100 \%$ & neg & -- \\
\hline Graphite Assembly Parts & $\begin{array}{l}\text { Figures } 1.14 \\
\text { and } 1.38\end{array}$ & $-100 \%$ & neg & -- \\
\hline AmBe Source Properties & $\begin{array}{c}\text { Figure } 1.51 \text { and } \\
\text { Table } 2.56 \\
\text { Figures } 1.52\end{array}$ & $-100 \%$ & neg & -- \\
\hline Source Tube and Cap Properties & $\begin{array}{c}\text { and } 1.53 \\
\text { and Table } 2.43\end{array}$ & $-100 \%$ & neg & -- \\
\hline
\end{tabular}


Table 2.64 (cont.). Total Experimental Uncertainty of the 60-Fuel-Element NRAD Core.

\begin{tabular}{|c|c|c|c|c|}
\hline Perturbed Parameter & $\begin{array}{c}\text { Parameter } \\
\text { Value }\end{array}$ & $\begin{array}{c}1 \sigma \\
\text { Uncertainty } \\
\end{array}$ & $\begin{array}{l} \pm \Delta \mathrm{k}_{\text {eff }}(1 \sigma) \\
\text { Systematic }\end{array}$ & $\begin{array}{c} \pm \Delta \mathrm{k}_{\text {eff }}(1 \sigma) \\
\text { Random } \\
\end{array}$ \\
\hline Aluminum 1100 Grid Plate & $\begin{array}{c}\text { Figure } 1.9 \text { and } \\
\text { Table } 2.57\end{array}$ & $-100 \%$ & neg & -- \\
\hline Assembly Pitch in Grid Plate $(\mathrm{cm})$ & $\begin{array}{c}8.10006 \mathrm{E}-\mathrm{W} \\
7.7089 \mathrm{~N}-\mathrm{S}\end{array}$ & $\pm 0.0533 / \sqrt{ } 3$ & 0.00012 & 0.00013 \\
\hline Location of Holes in Grid Plate $(\mathrm{cm})$ & Figure 1.10 & $\pm 0.0127 / \sqrt{ } 3$ & neg & neg \\
\hline Assembly Hole Diameter (cm) & 6.1722 & $\begin{array}{l}+0.01778 / \sqrt{ } 3 \\
-0.00508 / \sqrt{ } 3\end{array}$ & 0.00014 & -- \\
\hline Bottom Assembly Diameter $(\mathrm{cm})$ & 6.0706 & $\pm 0.0254 / \sqrt{ } 3$ & neg & neg \\
\hline Grid Plate Support Structure & Figure 1.8 & $-100 \%$ & neg & -- \\
\hline Mounting Pad & Figure 1.5 & $-100 \%$ & neg & -- \\
\hline Reactor Tank & Figure 1.5 & $-100 \%$ & neg & -- \\
\hline Water Impurities & none & Table 2.59 & 0.00010 & -- \\
\hline Beam Tube Aluminum Properties & Table 2.43 & -- & neg & -- \\
\hline Beam Filter Tube Dimensions (cm) & Figure 1.42 & $\pm 0.0762 / \sqrt{ } 4 / \sqrt{ } 3$ & neg & neg \\
\hline Other Beam Tube Aluminum Parts & Figures 1.41 & -- & neg & -- \\
\hline Beam Tube Aluminum Impurities & Table 2.43 & -- & neg & -- \\
\hline Gas Content in Beam Tubes & -- & $-100 \%$ & neg & -- \\
\hline Boron Nitride Apertures & $\begin{array}{c}\text { Figures } 1.43 \text { and } \\
1.44 \text { and } \\
\text { Table } 2.62\end{array}$ & $-100 \%$ & neg & -- \\
\hline Placement of Beam Lines $(\mathrm{cm})$ & 2.032 & $\pm 0.12 / \sqrt{ } 3$ & neg & 0.00014 \\
\hline Instrumentation and Detectors & $\begin{array}{l}\text { Figures } 1.55 \\
\text { and } 1.56 \\
\end{array}$ & -- & neg & neg \\
\hline Uncertainty by Type & -- & -- & 0.00268 & 0.00041 \\
\hline Total Experimental Uncertainty & -- & -- & 0.00271 & -- \\
\hline
\end{tabular}


NEA/NSC/DOC(2006)1

Fundamental - FUND

NRAD-FUND-RESR-001

CRIT

\subsection{Evaluation of Buckling and Extrapolation Length Data}

Buckling and extrapolation length measurements were not made.

\subsection{Evaluation of Spectral Characteristics Data}

Spectral characteristics measurements were not made.

\subsection{Evaluation of Reactivity Effects Data}

Reactivity effects measurements were not made.

\subsection{Evaluation of Reactivity Coefficient Data}

Reactivity coefficient measurements were not made.

\subsection{Evaluation of Kinetics Measurements Data}

Kinetics measurements were not made.

\subsection{Evaluation of Reaction-Rate Distributions}

Reaction-rate distribution measurements were not made.

\subsection{Evaluation of Power Distribution Data}

Power distribution measurements were not made.

\subsection{Evaluation of Isotopic Measurements}

Isotopic measurements were not made.

\subsection{Evaluation of Other Miscellaneous Types of Measurements}

Other miscellaneous types of measurements were not made. 
NEA/NSC/DOC(2006)1

Fundamental - FUND

NRAD-FUND-RESR-001

CRIT

\subsection{BENCHMARK SPECIFICATIONS}

\subsection{Benchmark-Model Specifications for Critical and / or Subcritical Measurements}

The 60-fuel-element operational core configuration of the NRAD reactor has been evaluated as a benchmark experiment. The initial core critical configuration created during fuel loading, which contains 56 fuel elements, has not been evaluated because it is very similar to the evaluated core configuration. Some basic calculations were performed in support of start-up core analysis; these are summarized in Appendix H.

\subsubsection{Description of the Benchmark Model Simplifications}

A detailed model (see Appendix C) of the NRAD reactor 60-fuel-element core configuration was prepared to evaluate biases in the benchmark model. Because the effects of many of the model simplifications produced small or otherwise negligible biases in the benchmark model, description of a detailed benchmark model was unnecessary. Many of the detailed model components, such as assembly fittings, grid plate, and support structures, were homogenized in the detailed model to facilitate computational analyses. Removal of these homogenized components from the model produced negligible bias effects; detailed analysis regarding homogenization effects, biases, and their associated uncertainties was judged to be unnecessary.

\subsubsection{Evaluation of Benchmark Model Biases}

Various simplifications were individually evaluated to determine their effective contribution as a model bias to the benchmark model. A summary of evaluated biases is listed in Table 3.1. The effective bias for the reduction in tank water moderator thickness surrounding the core both radially (Figure 3.1) and axially (Figure 3.2) was also evaluated.

Figure 3.1 shows the bias in reducing the effective radial reflector boundary. A tank water diameter $\geq 90$ $\mathrm{cm}$ is sufficient for modeling the reactor without incurring any additional bias. The uncertainty is negligible as it is the statistical uncertainty in the MCNP calculations. Figure 3.2 shows the bias in reducing the effective axial reflector thickness as a function of top and bottom reflector thickness with respect to the bottom surface of the bottom axial graphite reflector in the fuel elements and the top surface of the top axial graphite reflector. The effective bias is negligible as all calculations are approximately within the statistical noise. An axial distance of approximately $25 \mathrm{~cm}$ from these two surfaces is selected for the benchmark model. Because the NRAD reactor core is contained within a large quantity of reflecting material, room return calculations were unnecessary.

Some possible benchmark biases were evaluated as uncertainties due to a lack of information. They include the following: water saturation of graphite (Section 2.1.6.1), impurities in the tank water (2.1.9), and impurities in the boron carbide absorber (Section 2.1.4.1).

The AmBe source remains in the reactor core during operations. It emits neutrons at the rate of $\sim 1 \times 10^{7}$ neutrons $/ \mathrm{sec}$. The fission rate in the core at $50 \mathrm{~W}$ is $\sim 1 \times 10^{12}$ neutrons/sec. Because there are five orders of magnitude difference between the total fission rate and the AmBe source strength, the contribution of the AmBe source neutrons to the total neutron population is judged to be negligible and no additional bias or uncertainty was evaluated.

Evaluated biases with an absolute value $\leq 0.00010$, the $1 \sigma$ statistical MCNP uncertainty, are considered negligible. Biases with absolute values $>0.00010$ and $\leq 0.00030(3 \sigma)$ are considered negligible as a bias but treated instead as additional simplification uncertainty. Biases $>0.00030$ are treated as a bias with an uncertainty equivalent to one-third of the magnitude of the calculated bias. 
NEA/NSC/DOC(2006)1

Fundamental - FUND

NRAD-FUND-RESR-001

CRIT

Detailed discussion of the evaluated biases are as follows:

- Full Model

1. All locations in the core (fuel elements and beam lines) containing air were replaced with void.

2. All locations in the core (control rods, assembly attachments, core structure, beam lines, etc.) containing aluminum $(1100,2011$, or 6061$)$ had all non-aluminum elements replaced with void.

- Fuel Assemblies

3. All lower fuel assembly adapters were replaced with water.

4. All upper fuel assembly adapters were replaced with water.

5. All bottom fuel end fittings protruding from the fuel clad were replaced with water.

6. All top fuel end fittings protruding from the fuel clad were replaced with water.

7. The impurities in all stainless steel fuel clad and end fittings were replaced with void.

8. Individual fuel compositions were replaced with an average fuel composition for the core.

9. The impurities in all axial graphite reflectors were replaced with void.

10. The impurities in all molybdenum poison discs were replaced with void.

11. The impurities in all zirconium rods were replaced with void.

- Control Rods

12. All control rod extension rods and associated attachments were replaced with water.

13. All control rod guide tubes, and the guide tube in the empty irradiation position, were replaced with water.

14. All internal aluminum parts in the control rods were replaced with void.

- Graphite Reflector Block Assemblies

15. All lower graphite assembly adapters were replaced with water.

16. All upper graphite assembly adapters were replaced with water.

17. Tie rods, dowels, and screws (Al-2011 parts) in the graphite reflector blocks

A. All Al-2011 parts were replaced with water.

B. All Al-2011 parts internal to the graphite blocks, and their affiliated orifices, were replaced with graphite block material.

18. AmBe source, source tube, and source tube cap

A. The AmBe source and its affiliated hardware are replaced with water.

B. The AmBe source and its affiliated hardware internal to the graphite block, and the affiliated orifice, were replaced with graphite block material.

19. All impurities in the graphite block reflectors were replaced with void.

- Core/Tank Structure

20. The core grid plate was replaced with water.

21. The core grid support structure was replaced with water.

22. The mounting pad was replaced with water.

23. The reactor tank was replaced with water.

- Neutron Beam Lines

24. All helium in the beam lines was replaced with void.

25. All boron nitride apertures were replaced with void.

26. All beam line supports in the core were replaced with water.

27. Beam line aluminum structure

A. All beam line aluminum structural material was replaced with void.

B. All beam line aluminum structural material, excluding the beam filter tubes, were replaced with void.

C. The aluminum structural material of both beam filter tubes was replaced with void.

- Comprehensive Benchmark Simplification

28. The simplifications outlined in Table 3.1 were applied to the benchmark model. The effective tank water boundary was also reduced radially and axially. The diameter of the tank water in the benchmark model is $90 \mathrm{~cm}$ and the effective water height above and 
below the axial graphite reflectors in the fuel elements is $25 \mathrm{~cm}$. The effective bias for incorporating all of these simplifications into the benchmark model was calculated to be $0.00120 \pm 0.00010$.

Individual biases may be positive or negative and many are comparable to the statistical uncertainties. Correlating effects in bias analysis simplifications may also contribute to the difference between the summation of the individual biases and the bias calculated for the benchmark model when all simplifications are performed simultaneously. This difference, however, is within the estimated $1 \sigma$ bias uncertainty. The bias computed with all simplifications included together is the best representative of the true bias. The uncertainty in that bias is obtained from the individual analysis of each simplification. 
NEA/NSC/DOC(2006)1

Fundamental - FUND

NRAD-FUND-RESR-001

CRIT

Table 3.1. Evaluated Benchmark Model Simplification Biases.

\begin{tabular}{|c|c|c|c|c|c|c|c|}
\hline \multirow{2}{*}{ No. } & \multirow{2}{*}{ Evaluated Simplifications } & \multicolumn{3}{|c|}{ Calculated Bias } & \multicolumn{3}{|c|}{ Benchmark Bias } \\
\hline & & $\Delta \mathbf{k}_{\text {eff }}$ & \pm & $1 \sigma$ & $\Delta \mathbf{k}_{\text {eff }}$ & \pm & 10 \\
\hline \multicolumn{8}{|c|}{ Full Model } \\
\hline 1 & Replace air with void & 0.00001 & \pm & 0.00010 & neg & & \\
\hline 2 & $\begin{array}{l}\text { Replace non-aluminum elements } \\
\text { in aluminum materials with void }\end{array}$ & 0.00004 & \pm & 0.00010 & neg & & \\
\hline \multicolumn{8}{|c|}{ Fuel Assemblies } \\
\hline 3 & Replace lower fuel assembly adapters with water & 0.00026 & \pm & 0.00010 & & \pm & 0.00026 \\
\hline 4 & Replace upper fuel assembly adapters with water & -0.00007 & \pm & 0.00010 & neg & & \\
\hline 5 & $\begin{array}{l}\text { Replace fuel bottom end fittings (external to } \\
\text { cladding) with water }\end{array}$ & 0.00056 & \pm & 0.00010 & 0.00056 & \pm & 0.00019 \\
\hline 6 & $\begin{array}{l}\text { Replace fuel top end fittings (external of } \\
\text { cladding) with water }\end{array}$ & 0.00038 & \pm & 0.00010 & 0.00038 & \pm & 0.00013 \\
\hline 7 & $\begin{array}{l}\text { Replace stainless steel clad and end fitting } \\
\text { impurities with void }\end{array}$ & 0.00079 & \pm & 0.00010 & 0.00079 & \pm & 0.00026 \\
\hline 8 & $\begin{array}{l}\text { Replace individual fuel compositions with } \\
\text { average fuel composition }\end{array}$ & -0.00061 & \pm & 0.00010 & -0.00061 & \pm & 0.00020 \\
\hline 9 & $\begin{array}{l}\text { Replace axial graphite reflector impurities with } \\
\text { void }\end{array}$ & 0.00006 & \pm & 0.00010 & neg & & \\
\hline 10 & $\begin{array}{l}\text { Replace molybdenum poison disc impurities with } \\
\text { void }\end{array}$ & -0.00001 & \pm & 0.00010 & neg & & \\
\hline 11 & Replace zirconium rod impurities with void & 0.00006 & \pm & 0.00010 & neg & & \\
\hline \multicolumn{8}{|c|}{ Control Rods } \\
\hline 12 & $\begin{array}{l}\text { Replace control rod extension rods and } \\
\text { attachments with water }\end{array}$ & 0.00000 & \pm & 0.00010 & neg & & \\
\hline 13 & Replace guide tubes with water & 0.00148 & \pm & 0.00010 & 0.00148 & \pm & 0.00049 \\
\hline 14 & $\begin{array}{l}\text { Replace internal fittings within control rods with } \\
\text { void }\end{array}$ & 0.00011 & \pm & 0.00010 & & \pm & 0.00011 \\
\hline \multicolumn{8}{|c|}{ Graphite Reflector Block Assemblies } \\
\hline 15 & $\begin{array}{l}\text { Replace lower graphite assembly adapters with } \\
\text { water }\end{array}$ & -0.00005 & \pm & 0.00010 & neg & & \\
\hline 16 & $\begin{array}{l}\text { Replace upper graphite assembly adapters with } \\
\text { water }\end{array}$ & 0.00016 & \pm & 0.00010 & & \pm & 0.00016 \\
\hline $17 \mathrm{~A}$ & $\begin{array}{l}\text { Replace graphite assembly Al-2011 parts with } \\
\text { water }\end{array}$ & 0.00014 & \pm & 0.00010 & & \pm & 0.00014 \\
\hline 17B & $\begin{array}{l}\text { Replace graphite assembly Al-2011 parts and } \\
\text { holes with graphite }\end{array}$ & -0.00001 & \pm & 0.000010 & neg & & \\
\hline $18 \mathrm{~A}$ & $\begin{array}{l}\text { Replace AmBe source and steel source tube with } \\
\text { water }\end{array}$ & 0.00024 & \pm & 0.00010 & & \pm & 0.00024 \\
\hline $18 \mathrm{~B}$ & $\begin{array}{l}\text { Replace AmBe graphite reflector block with } \\
\text { normal block }\end{array}$ & 0.00026 & \pm & 0.00010 & & \pm & 0.00026 \\
\hline 19 & $\begin{array}{l}\text { Replace graphite reflector block impurities with } \\
\text { void }\end{array}$ & -0.00004 & \pm & 0.00010 & neg & & \\
\hline
\end{tabular}


NEA/NSC/DOC(2006)1

Fundamental - FUND

NRAD-FUND-RESR-001

CRIT

Table 3.1 (cont.). Evaluated Benchmark Model Simplification Biases.

\begin{tabular}{|c|c|c|c|c|c|c|c|}
\hline \multirow{2}{*}{ No. } & \multirow{2}{*}{ Evaluated Simplifications } & \multicolumn{3}{|c|}{ Calculated Bias } & \multicolumn{3}{|c|}{ Benchmark Bias } \\
\hline & & $\Delta \mathbf{k}_{\text {eff }}$ & \pm & $1 \sigma$ & $\Delta \mathbf{k}_{\text {eff }}$ & \pm & 10 \\
\hline \multicolumn{8}{|c|}{ Core/Tank Structure } \\
\hline 20 & Replace grid plate with water & 0.00008 & \pm & 0.00010 & neg & & \\
\hline 21 & Replace grid support structure with water & -0.00008 & \pm & 0.00010 & neg & & \\
\hline 22 & Replace mounting pad with water & 0.00000 & \pm & 0.00010 & neg & & \\
\hline 23 & Replace reactor tank with water & -0.00015 & \pm & 0.00010 & & \pm & 0.00015 \\
\hline \multicolumn{8}{|c|}{ Neutron Beam Lines } \\
\hline 24 & Replace helium with void & 0.00014 & \pm & 0.00010 & & \pm & 0.00014 \\
\hline 25 & Replace boron nitride apertures with void & -0.00010 & \pm & 0.00010 & neg & & \\
\hline 26 & Replace beam line supports with water & -0.00020 & \pm & 0.00010 & & \pm & 0.00020 \\
\hline $27 \mathrm{~A}$ & $\begin{array}{l}\text { Replace beam line aluminum structure with } \\
\text { void }\end{array}$ & -0.00085 & \pm & 0.00010 & -0.00085 & \pm & 0.00028 \\
\hline 27B & $\begin{array}{l}\text { Replace beam line aluminum (excluding } \\
\text { beam filter tube) with void }\end{array}$ & -0.00008 & \pm & 0.00010 & & -- & \\
\hline $27 \mathrm{C}$ & $\begin{array}{l}\text { Replace beam filter tube aluminum } \\
\text { with void }\end{array}$ & -0.00070 & \pm & 0.00010 & & -- & \\
\hline-- & Summation of Individual Biases & & -- & & 0.00175 & \pm & 0.00090 \\
\hline 28 & Complete Benchmark Model Simplification & 0.00120 & \pm & 0.00010 & 0.00120 & \pm & 0.00090 \\
\hline
\end{tabular}

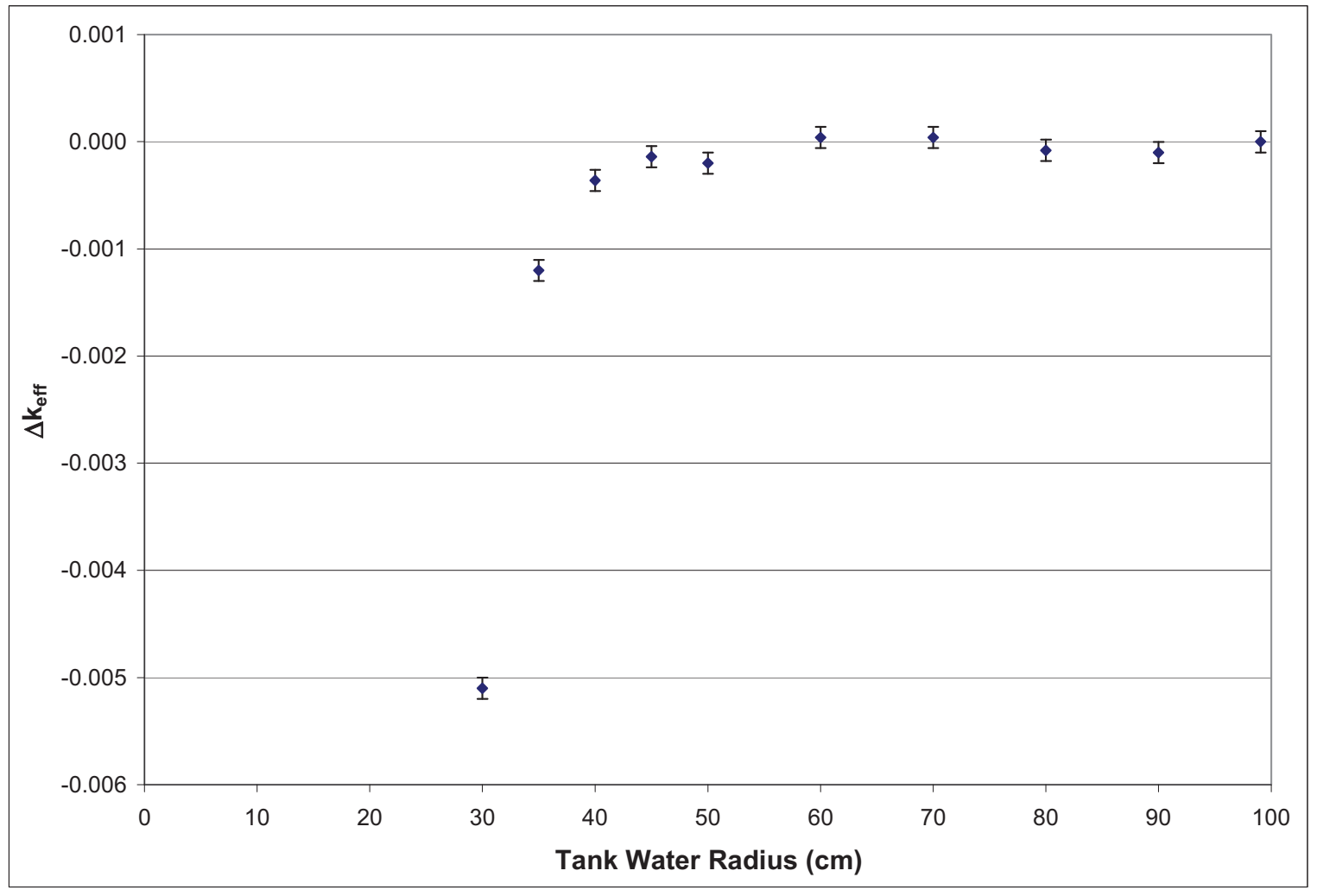

Figure 3.1. Effective Bias Due to Tank Water Radial Boundary. 
NRAD-FUND-RESR-001 CRIT

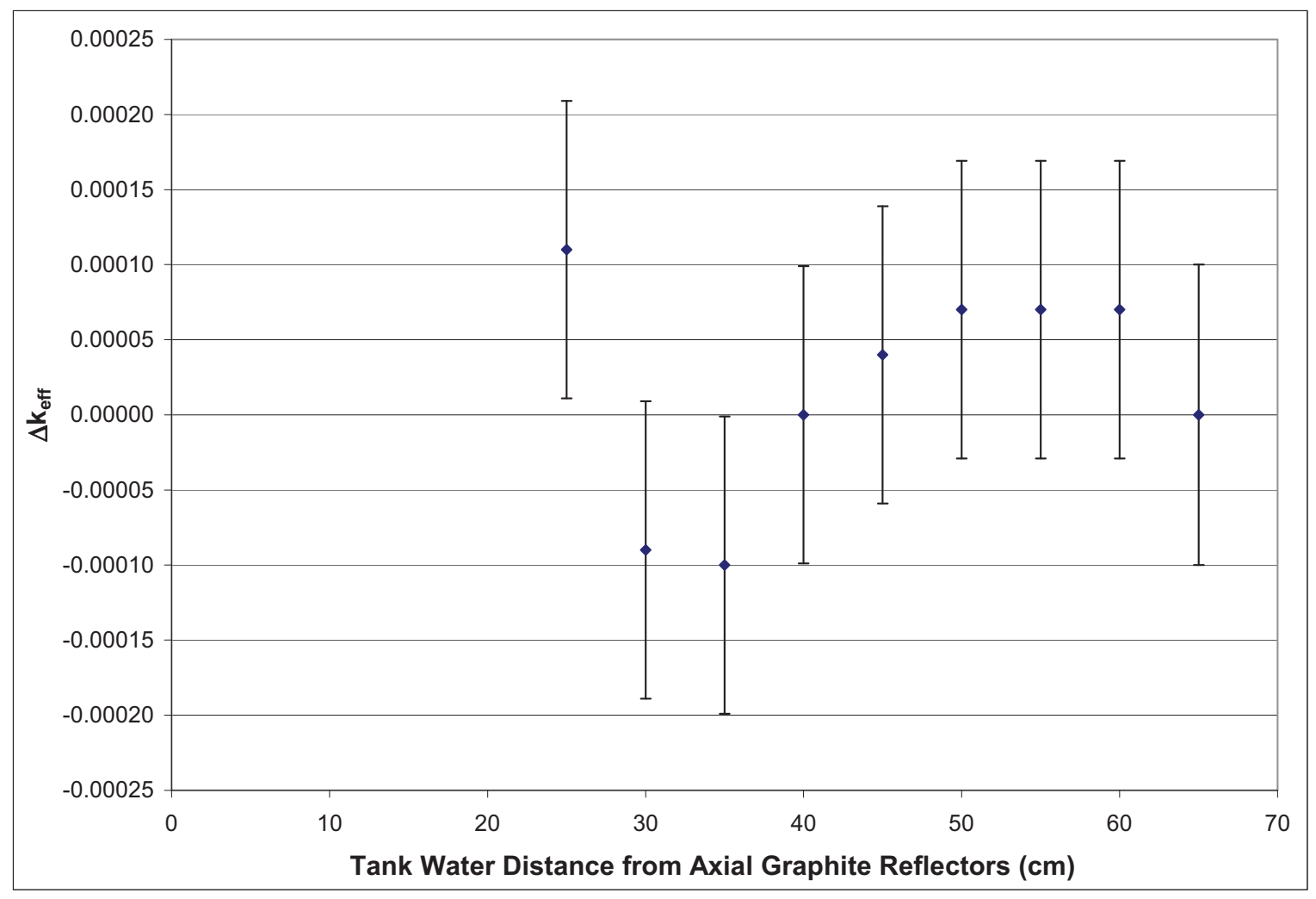

Figure 3.2. Effective Bias Due to Tank Water Axial Boundary.

\subsubsection{Dimensions}

The NRAD reactor is a square-pitched TRIGA conversion reactor with various assemblies. The primary assemblies are four-fuel-element clusters and graphite reflector blocks. A three-fuel-element cluster assembly replaces the empty fuel position with either a control rod or water. Empty core positions contain water and two void regions extend from the core on the East and North ends, representative of beam lines used in neutron radiography experiments. 


\section{NEA/NSC/DOC(2006)1}

Fundamental - FUND

NRAD-FUND-RESR-001

\section{CRIT}

\subsubsection{Graphite Reflector Block}

The graphite reflector block assembly consists of high purity graphite with overall block dimensions shown in Figure 3.3.

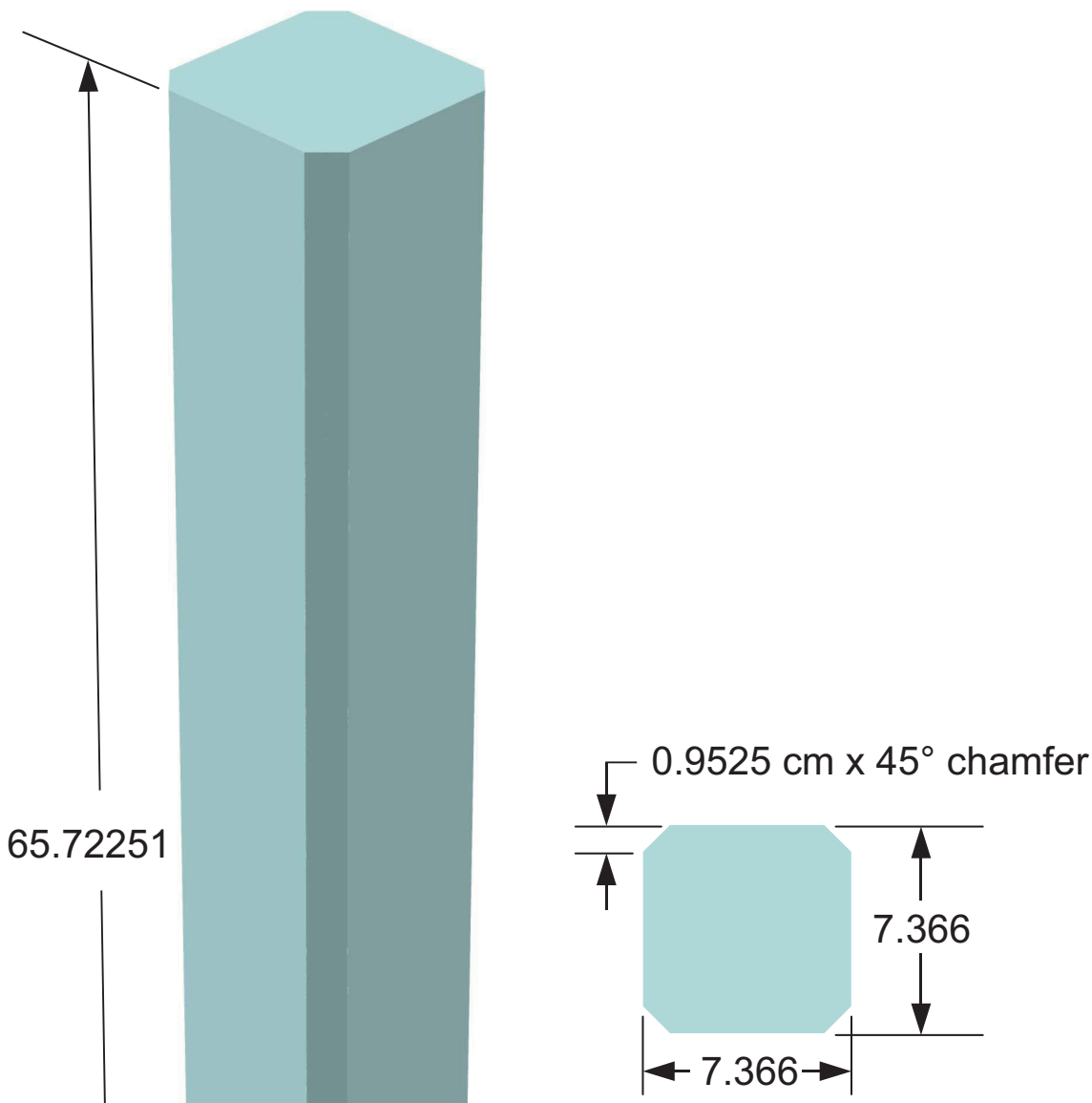

$\underline{\text { Top View }}$

Dimensions in $\mathrm{cm}$

10-GA50002-145-3

Figure 3.3. Graphite Reflector Block. 


\subsubsection{Fuel Element}

The TRIGA fuel element (Figure 3.4) consists of uranium-erbium-zirconium-hydride fuel with axial high-purity graphite reflectors above and below the fuel. A thin molybdenum poison disc is located between the fuel and the bottom axial reflector. A zirconium rod is located coaxially within the fuel meat. The components are contained within stainless steel cladding with end fixtures. The regions surrounding the fuel element components and within the steel cladding is void.

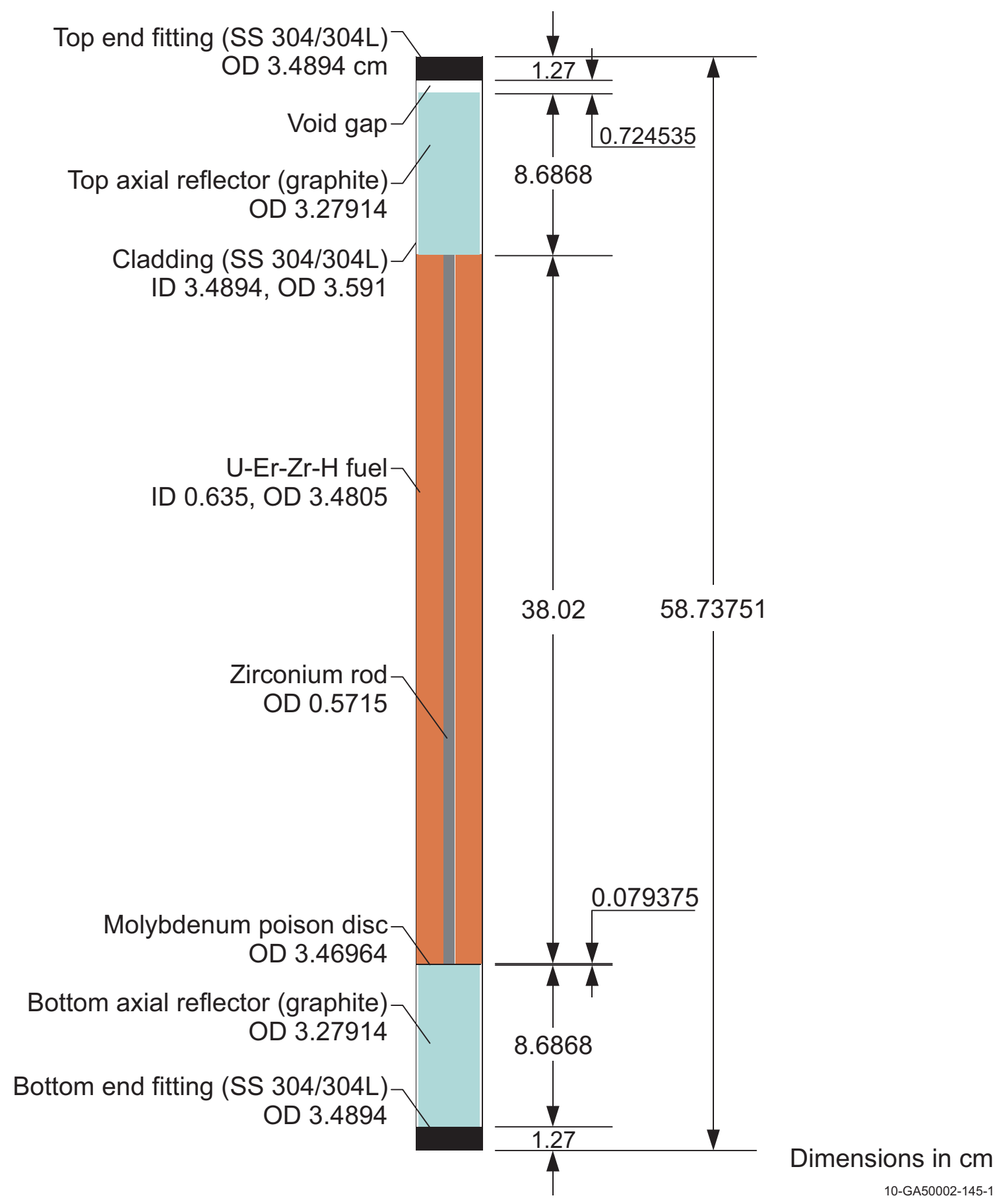

Figure 3.4. TRIGA Fuel Element. 


\section{NEA/NSC/DOC(2006)1}

Fundamental - FUND

NRAD-FUND-RESR-001

CRIT

\subsubsection{Control Rod}

The TRIGA control rod (Figure 3.5) consists of a boron carbide, $\mathrm{B}_{4} \mathrm{C}$, absorber rod contained within aluminum cladding with end fixtures. The region surrounding the absorber rod and within the aluminum cladding is void.

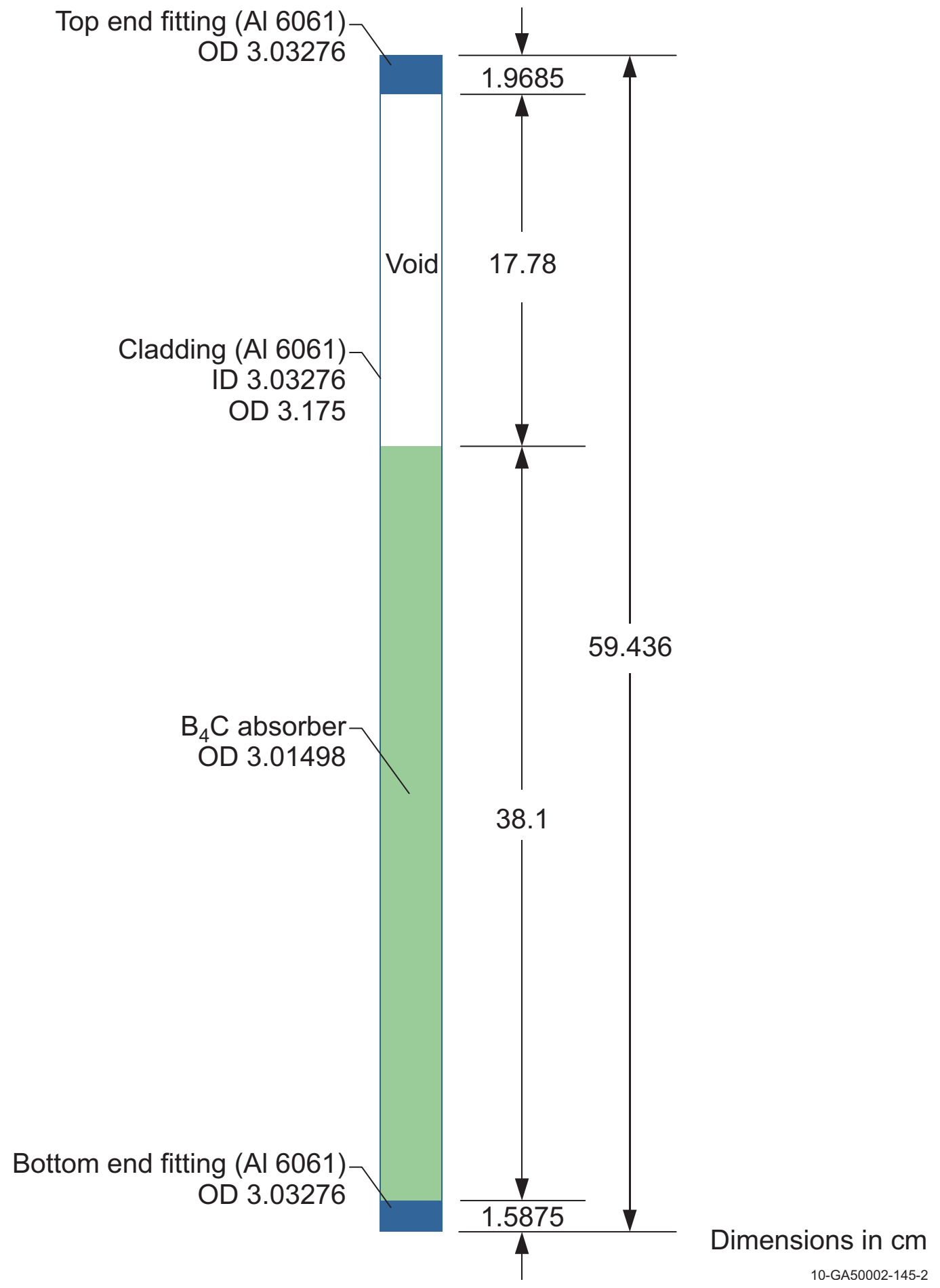

Figure 3.5. TRIGA Control Rod. 


\section{NEA/NSC/DOC(2006)1}

Fundamental - FUND

NRAD-FUND-RESR-001

CRIT

\subsubsection{Four-Element Fuel Cluster}

A four-element fuel cluster assembly consists of four fuel elements, as described in Section 3.1.2.2, placed in the configuration shown in Figure 3.6.

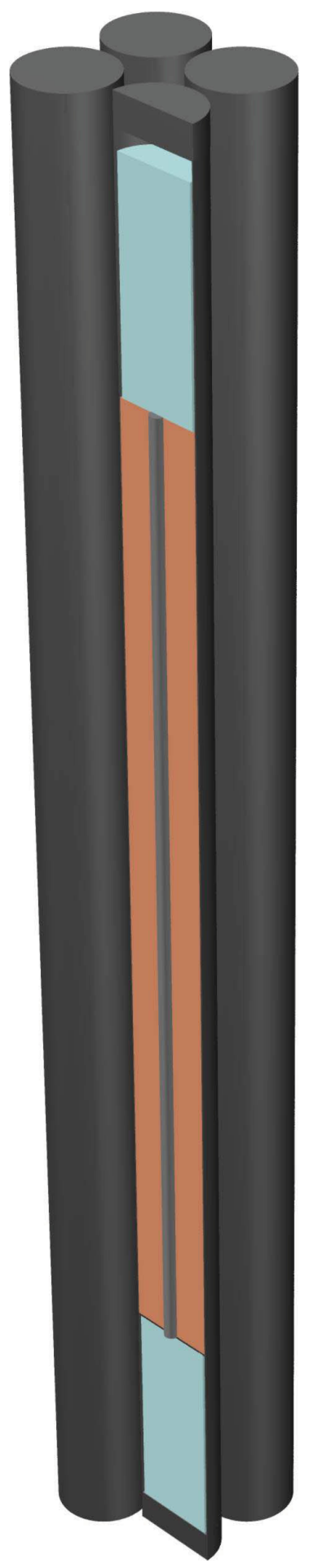

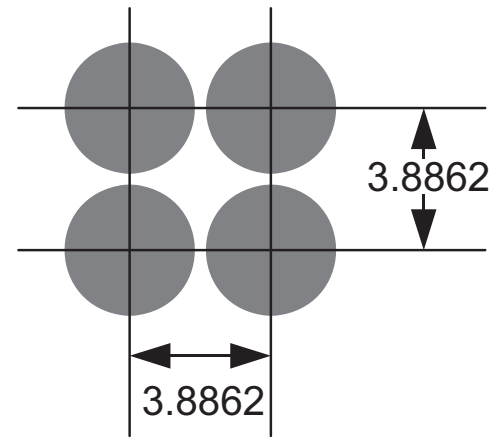

Top View

\section{Dimensions in $\mathrm{cm}$}

10-GA50002-145-4

Figure 3.6. Four-Element Fuel Cluster. 


\subsubsection{Three-Element Fuel Cluster}

A three-element fuel cluster is identical in configuration to the four-element fuel cluster described in Section 3.1.2.4. However, one of the fuel elements is removed and replaced by either a control rod or water (experiment irradiation position). For the locations of three-element fuel clusters in the NRAD reactor core, see Figure 3.8.

\subsubsection{Assembly Pitch}

The pitch between assemblies, whether graphite reflector blocks, four-element fuel clusters, or threeelement fuel clusters, is shown in Figure 3.7. The pitch is shorter in the North-South direction than in the East-West direction.
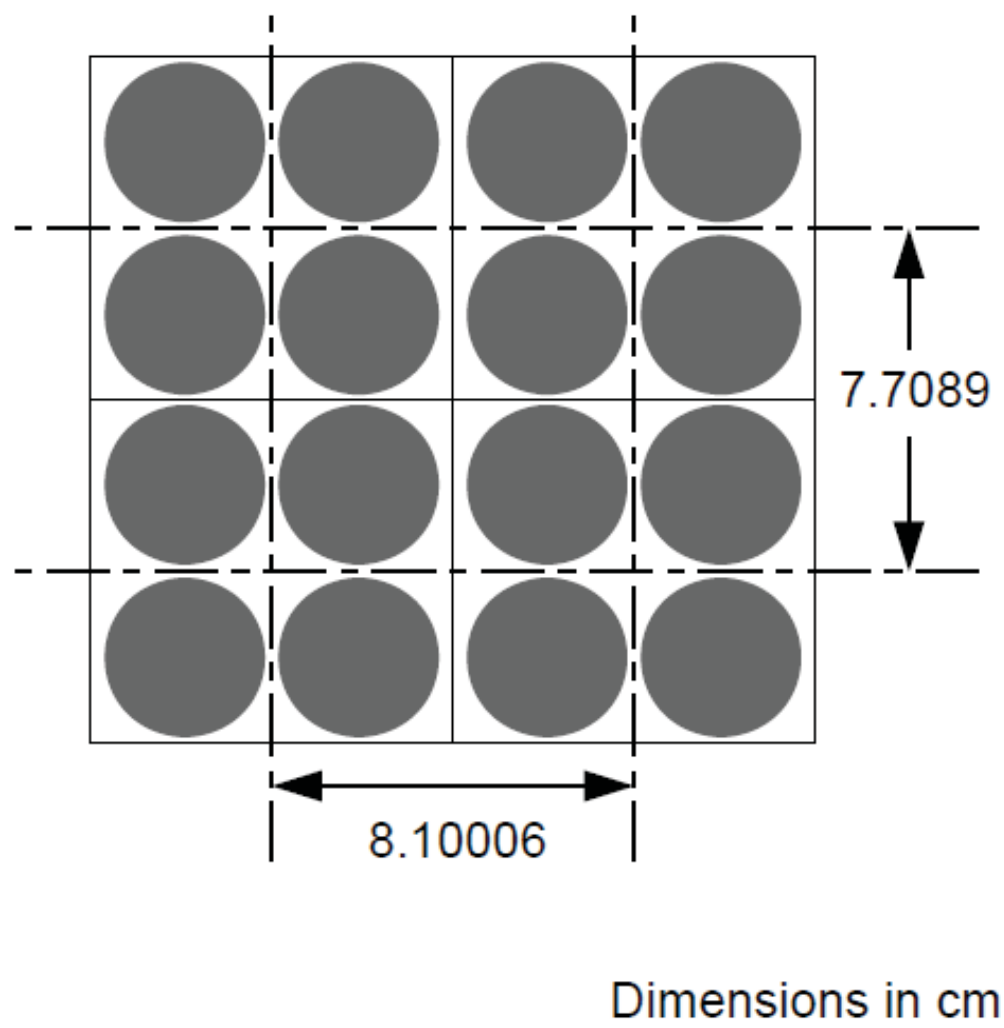

10-GA50002-145-5

Figure 3.7. NRAD Core Assembly Pitch.

\subsubsection{Core Configuration}

The NRAD reactor core configuration is shown in Figures 3.8 and 3.9. The core contains 60 fuel elements, three control rods (two shims and a regulating rod), 12 graphite reflector blocks, one empty fuel position, and four empty assembly positions. Beam lines extend from the East and North faces of the core (Figure 3.10) and are centered along the core fuel midplane. The beams are represented as voids in the benchmark model and extend to the model radial boundary. All model locations not containing fuel elements, control rods, graphite, or void, as previously described in this section, contain water. A comparison of the vertical placement of different reactor components is shown in Figure 3.11. 
The shim 1, shim 2, and regulating control rods are withdrawn $38.1,38.1$, and $20.4216 \mathrm{~cm}$, respectively (use Figure 3.8 for placement in the core and Figure 3.11 for reference vertical placement).

The measurement of $2.032 \mathrm{~cm}$ in Figures 3.9 and 3.10 represents the distance between the outer cladding surface of the fuel elements closest to the beam filter tube and the face of the beam filter tube adjacent to the core.

The measurement of $0.123825 \mathrm{~cm}$ in Figure 3.11 represents the difference between the bottom of the fuel meat (top of the molybdenum poison disc) in the fuel elements and the bottom of the control rod absorber material when the control rod is fully inserted into the core. The bottom of the fully-inserted control rod absorber material is positioned slightly above the bottom of the fuel meat.

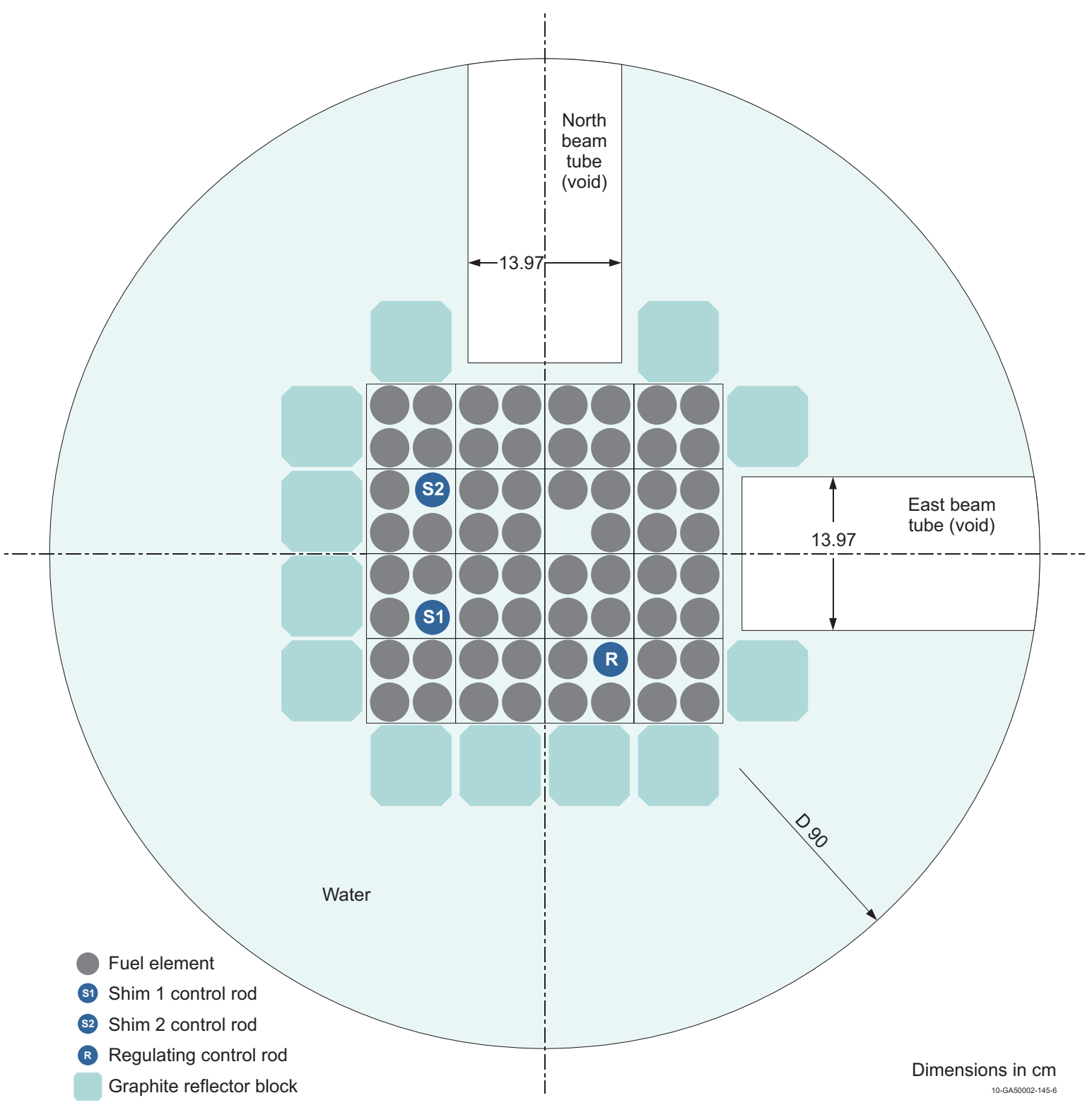

Figure 3.8. Midplane Cross Section View of NRAD Reactor Core. 
Fundamental - FUND

NRAD-FUND-RESR-001

CRIT

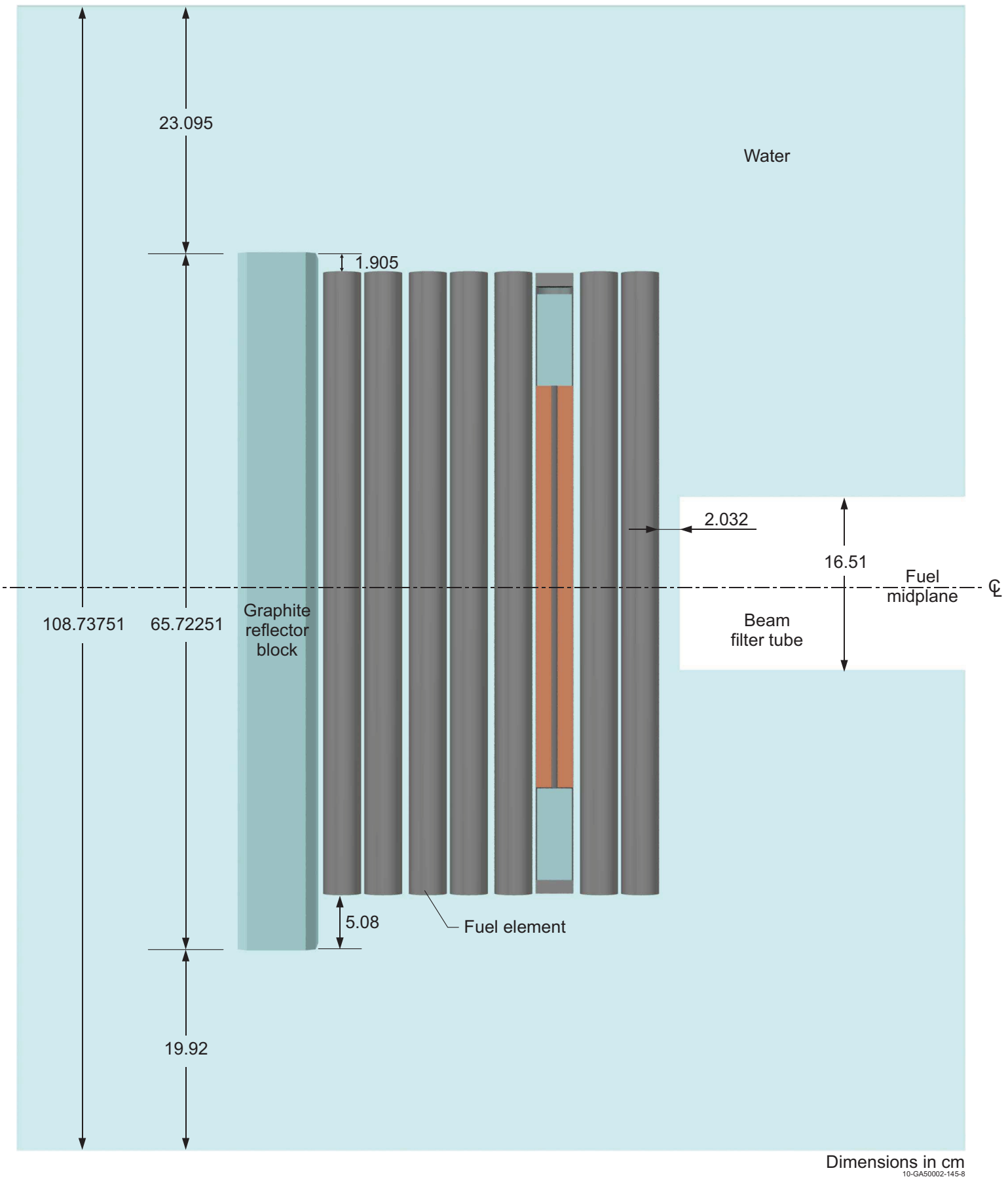

Figure 3.9. Vertical Cross Section View of NRAD Reactor Core through the Centerline of the Fuel Elements Located in the North Half of the Third Row (from the Top) of Fueled Assemblies. 
NEA/NSC/DOC(2006)1

Fundamental - FUND

NRAD-FUND-RESR-001

CRIT

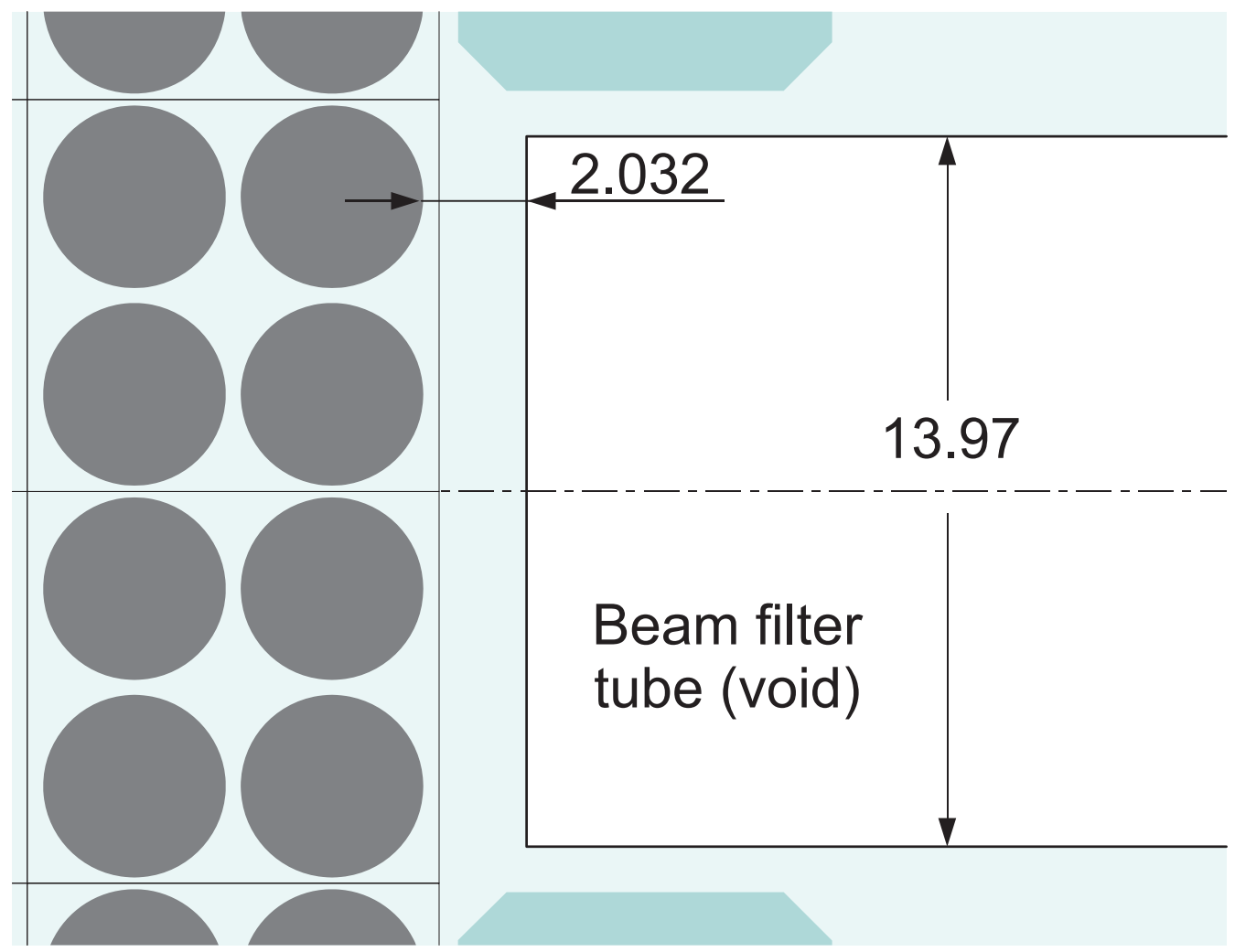

Dimensions in $\mathrm{cm}$

10-GA50002-145-7

Figure 3.10. Beam Filter Tube Placement. 


\section{NEA/NSC/DOC(2006)1}

Fundamental - FUND

NRAD-FUND-RESR-001

CRIT

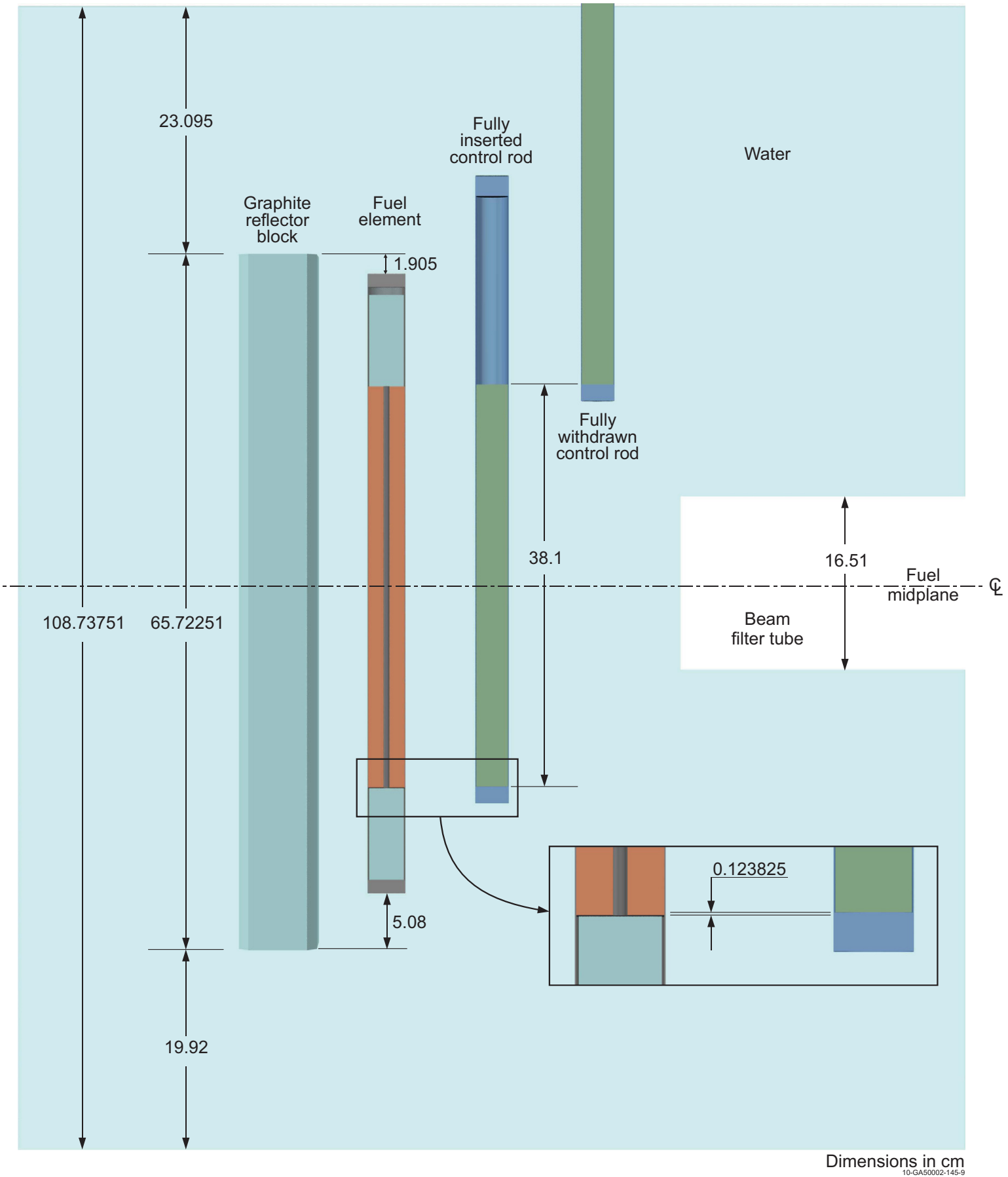

Figure 3.11. NRAD Reactor Core Reference Vertical Placement. 


\subsubsection{Material Data}

\subsubsection{Graphite Reflector Block}

The graphite reflector block consists of high purity graphite with a mass density of $1.570 \mathrm{~g} / \mathrm{cm}^{3}$. Impurities in the graphite have been removed from the benchmark model (Section 2.1.6.1 and 3.1.1.1). The atomic density and composition of the graphite are shown in Table 3.2.

Table 3.2. Graphite Reflector Block Density.

\begin{tabular}{|c|c|c|}
\hline Isotope/Element & Composition (wt.\%) & Atoms/barn-cm \\
\hline \hline C & 99.968029 & $7.8692 \mathrm{E}-02$ \\
\hline \hline Total & $99.968029^{(\mathrm{a})}$ & $7.8692 \mathrm{E}-02$ \\
\hline
\end{tabular}

(a) Total weight fraction has been reduced due to the removal of material impurities.

\subsubsection{Uranium-Erbium-Zirconium-Hydride Fuel}

The uranium-erbium-zirconium-hydride fuel has a mass density of $7.1678 \mathrm{~g} / \mathrm{cm}^{3}$. Evaluation of the average fuel composition for use in benchmark model is discussed in Section 2.1.2. The atomic density and composition of the fuel are shown in Table 3.3.

Table 3.3. Uranium-Erbium-Zirconium-Hydride Fuel Atomic Density
\begin{tabular}{||c|c|c||}
\hline \hline Isotope/Element & Composition (wt.\%) & Atoms/barn-cm \\
\hline \hline $\mathrm{H}$ & 1.18169 & $5.0608 \mathrm{E}-02$ \\
$\mathrm{~B}$ & 0.00010 & $4.1524 \mathrm{E}-07$ \\
$\mathrm{C}$ & 0.30000 & $1.0781 \mathrm{E}-03$ \\
$\mathrm{Zr}$ & 67.69202 & $3.2030 \mathrm{E}-02$ \\
$\mathrm{Er}$ & 0.90000 & $2.3226 \mathrm{E}-04$ \\
$\mathrm{Hf}$ & 0.00798 & $1.9297 \mathrm{E}-06$ \\
${ }^{234} \mathrm{U}$ & 0.05984 & $1.1036 \mathrm{E}-05$ \\
${ }^{235} \mathrm{U}$ & 5.90465 & $1.0844 \mathrm{E}-03$ \\
${ }^{236} \mathrm{U}$ & 0.05984 & $1.0942 \mathrm{E}-05$ \\
${ }^{238} \mathrm{U}$ & 23.89389 & $4.3326 \mathrm{E}-03$ \\
\hline \hline Total & 100.00000 & $8.9390 \mathrm{E}-02$ \\
\hline
\end{tabular}

\subsubsection{Axial Graphite Reflector}

The axial graphite reflector consists of high purity graphite with a mass density of $1.73 \mathrm{~g} / \mathrm{cm}^{3}$. Impurities in the graphite have been removed from the benchmark model (Section 2.1.3.3 and 3.1.1.1). The atomic density and composition of the graphite are shown in Table 3.4. 
NEA/NSC/DOC(2006)1

Fundamental - FUND

NRAD-FUND-RESR-001

CRIT

Table 3.4. Axial Graphite Reflector Atomic Density.

\begin{tabular}{||c|c|c||}
\hline Isotope/Element & Composition (wt.\%) & Atoms/barn-cm \\
\hline \hline $\mathrm{C}$ & 99.994614 & $8.6734 \mathrm{E}-02$ \\
\hline \hline Total & $99.994614^{(\mathrm{a})}$ & $8.6734 \mathrm{E}-02$ \\
\hline
\end{tabular}

(a) Total weight fraction has been reduced due to the removal of material impurities.

\subsubsection{Molybdenum Poison Disc}

The molybdenum poison disc has a mass density of $10.22 \mathrm{~g} / \mathrm{cm}^{3}$. Impurities in the molybdenum have been removed from the benchmark model (Section 2.1.3.2 and 3.1.1.1). The atomic density and composition of the molybdenum are shown in Table 3.5 .

Table 3.5. Molybdenum Poison Disc Atomic Density.

\begin{tabular}{|c|c|c|}
\hline Isotope/Element & Composition (wt.\%) & Atoms/barn-cm \\
\hline \hline Mo & 99.968464 & $6.4130 \mathrm{E}-02$ \\
\hline \hline Total & $99.968464^{(\mathrm{a})}$ & $6.4130 \mathrm{E}-02$ \\
\hline
\end{tabular}

(a) Total weight fraction has been reduced due to the removal of material impurities.

\subsubsection{Zirconium Rod}

The zirconium rod has a mass density of $6.51 \mathrm{~g} / \mathrm{cm}^{3}$. Impurities in the zirconium have been removed from the benchmark model (Section 2.1.3.1 and 3.1.1.1). The atomic density and composition of the zirconium are shown in Table 3.6.

Table 3.6. Zirconium Rod Atomic Density.

\begin{tabular}{|c|c|c|}
\hline Isotope/Element & Composition (wt.\%) & Atoms/barn-cm \\
\hline \hline $\mathrm{Zr}$ & 91.817 & $4.2897 \mathrm{E}-02$ \\
\hline \hline Total & $91.817^{(\mathrm{a})}$ & $4.2897 \mathrm{E}-02$ \\
\hline
\end{tabular}

(a) Total weight fraction has been reduced due to the removal of material impurities.

\subsubsection{Stainless Steel}

The stainless steel 304/304L cladding and end fittings have a mass density of $8.00 \mathrm{~g} / \mathrm{cm}^{3}$. Impurities in the stainless steel have been removed from the benchmark model (Section 2.1.3.4 and 3.1.1.1). The atomic density and composition of the stainless steel are shown in Table 3.7. 
NEA/NSC/DOC(2006)1

Fundamental - FUND

NRAD-FUND-RESR-001

CRIT

Table 3.7. Stainless Steel Atomic Density.

\begin{tabular}{|c|c|c||}
\hline \hline Isotope/Element & Composition (wt.\%) & Atoms/barn-cm \\
\hline \hline $\mathrm{C}$ & 0.04 & $1.6044 \mathrm{E}-04$ \\
$\mathrm{Si}$ & 0.4 & $6.8614 \mathrm{E}-04$ \\
$\mathrm{P}$ & 0.026 & $4.0441 \mathrm{E}-05$ \\
$\mathrm{~S}$ & 0.0022 & $3.3049 \mathrm{E}-06$ \\
$\mathrm{Cr}$ & 19 & $1.7604 \mathrm{E}-02$ \\
$\mathrm{Mn}$ & 1 & $8.7693 \mathrm{E}-04$ \\
$\mathrm{Fe}$ & 68.70712775 & $5.9271 \mathrm{E}-02$ \\
$\mathrm{Ni}$ & 10 & $8.2087 \mathrm{E}-03$ \\
\hline \hline Total & $99.17532775^{(\mathrm{a})}$ & $8.6851 \mathrm{E}-02$ \\
\hline \hline
\end{tabular}

(a) Total weight fraction has been reduced due to the removal of material impurities.

\subsubsection{Boron Carbide Absorber}

The boron carbide absorber has a mass density of $2.48 \mathrm{~g} / \mathrm{cm}^{3}$. The atomic density and composition of the boron carbide are shown in Table 3.8.

Table 3.8. Boron Carbide Absorber Atomic Density.

\begin{tabular}{||c|c|c||}
\hline Isotope/Element & Composition (wt.\%) & Atoms/barn-cm \\
\hline \hline${ }^{10} \mathrm{~B}$ & & $2.1515 \mathrm{E}-02$ \\
${ }^{11} \mathrm{~B}$ & 78.2626 & $8.6601 \mathrm{E}-02$ \\
$\mathrm{C}$ & 21.7374 & $2.7029 \mathrm{E}-02$ \\
\hline \hline Total & 100.0000 & $1.3514 \mathrm{E}-01$ \\
\hline
\end{tabular}

\subsubsection{Aluminum}

The aluminum 6061 cladding and end fittings have a mass density of $2.70 \mathrm{~g} / \mathrm{cm}^{3}$. Non-aluminum elements in the aluminum material have been removed from the benchmark model (Section 2.1.4.2 and 3.1.1.1). The atomic density and composition of the aluminum are shown in Table 3.9.

Table 3.9. Aluminum Atomic Density.

\begin{tabular}{||c|c|c|}
\hline Isotope/Element & Composition (wt.\%) & Atoms/barn-cm \\
\hline \hline $\mathrm{Al}$ & 97.23 & $5.8593 \mathrm{E}-02$ \\
\hline \hline Total & $97.23^{(\mathrm{a})}$ & $5.8593 \mathrm{E}-02$ \\
\hline
\end{tabular}

(a) Total weight fraction has been reduced due to the removal of material impurities. 
NRAD-FUND-RESR-001

CRIT

\subsubsection{Water}

The water has a mass density of $0.9965 \mathrm{~g} / \mathrm{cm}^{3}$. The atomic density and composition of the water are shown in Table 3.10.

Table 3.10. Water Atomic Density.

\begin{tabular}{|c|c|c||}
\hline \hline Isotope/Element & Composition (wt.\%) & Atoms/barn-cm \\
\hline $\mathrm{H}$ & 11.1894 & $6.6619 \mathrm{E}-02$ \\
$\mathrm{O}$ & 88.8106 & $3.3309 \mathrm{E}-02$ \\
\hline \hline Total & 100.0000 & $9.9928 \mathrm{E}-02$ \\
\hline
\end{tabular}

\subsubsection{Temperature Data}

The benchmark model temperature is $300 \mathrm{~K}$.

\subsubsection{Experimental and Benchmark-Model $\mathbf{k}_{\mathrm{eff}}$ and / or Subcritical Parameters}

The experimental $\mathrm{k}_{\text {eff }}$ was approximately at unity, made to delayed critical with a $1 \sigma$ uncertainty of $\pm 0.0027 \Delta \mathrm{k}_{\text {eff }}$ (see Table 2.64 for a breakdown of the uncertainty in $\mathrm{k}_{\text {eff }}$ ). Simplification biases and uncertainties, as discussed in Section 3.1.1.1 were applied to the benchmark model. The benchmark $\mathrm{k}_{\text {eff }}$ is $1.0012 \pm 0.0029(1 \sigma)$ for the 60 -fuel element core configuration. The uncertainty in the benchmark $\mathrm{k}_{\mathrm{eff}}$ value is obtained by summing under quadrature the total experimental uncertainty (Table 2.64) and the estimated bias uncertainty (Table 3.1). 
NEA/NSC/DOC(2006)1

Fundamental - FUND

NRAD-FUND-RESR-001

CRIT

\subsection{Benchmark-Model Specifications for Buckling and Extrapolation-Length Measurements}

Buckling and extrapolation length measurements were not made.

\subsection{Benchmark-Model Specifications for Spectral Characteristics Measurements}

Spectral characteristics measurements were not made.

\subsection{Benchmark-Model Specifications for Reactivity Effects Measurements}

Reactivity effects measurements were not made.

\subsection{Benchmark-Model Specifications for Reactivity Coefficient Measurements}

Reactivity coefficient measurements were not made.

\subsection{Benchmark-Model Specifications for Kinetics Measurements}

Kinetics measurements were not made.

\subsection{Benchmark-Model Specifications for Reaction-Rate Distribution Measurements}

Reaction-rate distribution measurements were not made.

\subsection{Benchmark-Model Specifications for Power Distribution Measurements}

Power distribution measurements were not made.

\subsection{Benchmark-Model Specifications for Isotopic Measurements}

Isotopic measurements were not made.

\subsection{Benchmark-Model Specifications for Other Miscellaneous Types of Measurements}

Other miscellaneous types of measurements were not made. 
NEA/NSC/DOC(2006)1

Fundamental - FUND

NRAD-FUND-RESR-001

CRIT

\subsection{RESULTS OF SAMPLE CALCULATIONS}

\subsection{Results of Calculations of the Critical or Subcritical Configurations}

The benchmark model described in Section 3, which is the 60-fuel-element core configuration, was modeled using MCNP5 (see Appendix A.1 for input deck) and ENDF/B-VII.0 neutron cross section data. Calculations were performed with 1,550 generations with 100,000 neutrons per generation. The $\mathrm{k}_{\text {eff }}$ estimates did not include the first 50 generations and are the result of $150,000,000$ neutron histories. Eigenvalues were also computed using JEFF-3.1 and JENDL-3.3 libraries for comparison. The JENDL3.3 analysis was performed with the inclusion of ENDF/B-VII.0 thermal neutron scattering data because it was not available in the JENDL-3.3 library. Thermal neutron scattering, or $S(\alpha, \beta)$, adjusts the neutron cross sections for neutron upscatter at thermal energies and provides scattering data for elements bound with specific materials. ENDF/B-VI.8 results were also provided for comparison against ENDF/B-VII.0 calculations; erbium cross sections were unavailable in ENDF/B-VI.8, so ENDF/B-VII.0 cross sections were used.

An average pitch of $3.95224 \mathrm{~cm}$ was used with the KENO-VI analysis with the 238-group ENDF/BVII.0 data.

Calculated results are shown in Table 4.1. All calculated eigenvalues are greater than the benchmark value but within $1 \%$ and within the $3 \sigma$ uncertainty.

The calculation bias using MCNP5 with ENDF/B-VII amd JEFF-3.1 data is comparable to calculations performed $^{\mathrm{a}}$ using the benchmark of the Slovenian TRIGA reactor. ${ }^{\mathrm{b}}$ The calculated experimental uncertainty in the Slovenian reactor is approximately double the uncertainty in this benchmark experiment. The two reactor core designs are fundamentally different and this may have some effect on the calculated results. Monte Carlo analysis of the TRIGA Mark-II reactor at the Musashi Institute of Technology in Japan using MCNP4A and ENDF/B-V data indicated a computational bias in eigenvalue calculations of about $1.0 \% \Delta \mathrm{k} / \mathrm{k}$. Worth calculations, however, were in good agreement with experimental results. ${ }^{c}$ MCNP modeling of other LEU converted TRIGA reactors also exhibit biases of approximately $\pm 1 \% \Delta \mathrm{k} / \mathrm{k} .^{\mathrm{d}}$

The initial core critical configuration created during fuel loading, which contains 56 fuel elements, has not been evaluated as a benchmark because it is very similar to the evaluated core configuration. Some basic calculations were performed in support of start-up core analysis; these are summarized in Appendix $\mathrm{H}$.

\footnotetext{
${ }^{a}$ Personal communications with Luka Snoj at the Jozef Stefan Institute (October 20, 2010).

${ }^{\mathrm{b}}$ R. Jeraj and M. Ravnik, "TRIGA Mark II Reactor: U(20) - Zirconium Hydride Fuel Rods in Water with Graphite Reflector," Rev. 0 (September 30, 1999), IEU-COMP-THERM-003, International Handbook of Evaluated Criticality Safety Benchmark Experiments, NEA/NSC/DOC(95)03, OECD-NEA (2010).

${ }^{\mathrm{c}}$ Matsumoto, T. and Hayakawa, N., "Benchmark Analysis of TRIGA Mark II Reactivity Experiment Using a Continuous Energy Monte Carlo Code MCNP,” J. Nucl. Sci. Technol., 37, 1082-1087 (2000).

${ }^{\mathrm{d}}$ Personal communications with Chris Ellis at General Atomics and Eric C. Woolstenhulme, Ken Schreck, Randy Damiana, and Ann Marie Philips at INL (August 4, 2010).
} 
NEA/NSC/DOC(2006)1

Fundamental - FUND

NRAD-FUND-RESR-001

CRIT

Table 4.1. Comparison of Benchmark Eigenvalues.

\begin{tabular}{|c|c|c|c|c|c|c|c|c|}
\hline \multirow{2}{*}{$\begin{array}{c}\text { Analysis } \\
\text { Code }\end{array}$} & \multirow{2}{*}{$\begin{array}{l}\text { Neutron Cross } \\
\text { Section Library }\end{array}$} & \multicolumn{3}{|c|}{ Calculated } & \multicolumn{3}{|c|}{ Benchmark } & \multirow{2}{*}{$\frac{C-E}{E}(\%)$} \\
\hline & & $\mathbf{k}_{\text {eff }}$ & \pm & $\boldsymbol{\sigma}$ & $\mathbf{k}_{\text {eff }}$ & \pm & $\sigma$ & \\
\hline \multirow{4}{*}{ MCNP5 } & ENDF/B-VII.0 & 1.00925 & \pm & 0.00007 & \multirow{6}{*}{$1.0012=$} & \multirow{6}{*}{\multicolumn{2}{|c|}{$\pm \quad 0.0029$}} & 0.80 \\
\hline & JEFF-3.1 ${ }^{\text {(a) }}$ & 1.00719 & \pm & 0.00007 & & & & 0.60 \\
\hline & JENDL-3.3 $3^{(b)}$ & 1.00633 & \pm & 0.00007 & & & & 0.51 \\
\hline & ENDF/B-VI. $8^{(\mathrm{c})}$ & 1.00458 & \pm & 0.00007 & & & & 0.34 \\
\hline \multirow[b]{2}{*}{ KENO-VI } & $\begin{array}{l}\text { ENDF/B-VII.0 } \\
\text { (238-group) }\end{array}$ & 1.008741 & \pm & 0.000066 & & & & 0.75 \\
\hline & $\begin{array}{c}\text { ENDF/B-VII.0 }{ }^{(\mathrm{d})} \\
\text { (continuous energy) }^{\text {conous }}\end{array}$ & 1.004496 & \pm & 0.000076 & & & & 0.33 \\
\hline
\end{tabular}

(a) JEFF-3.1 results provided by Luka Snoj at the Jozef Stefan Institute.

(b) $\mathrm{S}(\alpha, \beta)$ data from the ENDF/B-VII.0 library was used with the JENDL-3.3 cross section data because $S(\alpha, \beta)$ data for JENDL-3.3 was unavailable.

(c) Using ENDF/B-VII.0 cross section data for erbium isotopes.

(d) Continuous energy results for KENO-VI provided by Steve Bowman at Oak Ridge National Laboratory. 
NEA/NSC/DOC(2006)1

Fundamental - FUND

NRAD-FUND-RESR-001

CRIT

\subsection{Results of Buckling and Extrapolation Length Calculations}

Buckling and extrapolation length measurements were not made.

\subsection{Results of Spectral-Characteristics Calculations}

Spectral characteristics measurements were not made.

\subsection{Results of Reactivity-Effects Calculations}

Reactivity effects measurements were not made.

\subsection{Results of Reactivity Coefficient Calculations}

Reactivity coefficient measurements were not made.

\subsection{Results of Kinetics Parameter Calculations}

Kinetics measurements were not made.

\subsection{Results of Reaction-Rate Distribution Calculations}

Reaction-rate distribution measurements were not made.

\subsection{Results of Power Distribution Calculations}

Power distribution measurements were not made.

\subsection{Results of Isotopic Calculations}

Isotopic measurements were not made.

\subsection{Results of Calculations for Other Miscellaneous Types of Measurements}

Other miscellaneous types of measurements were not made. 
NEA/NSC/DOC(2006)1

Fundamental - FUND

NRAD-FUND-RESR-001

CRIT

\subsection{REFERENCES}

There are no available public references. 
NEA/NSC/DOC(2006)1

Fundamental - FUND

NRAD-FUND-RESR-001

CRIT

\section{APPENDIX A: COMPUTER CODES, CROSS SECTIONS, AND TYPICAL INPUT LISTINGS}

\section{A.1 Critical/Subcritical Configurations}

\section{A.1.1 Name(s) of code system(s) used.}

1. Monte Carlo n-Particle, version 5.1.51 (MCNP5).

2. KENO-VI (SCALE 6.0)

\section{A.1.2 Bibliographic references for the codes used.}

1. X-5 Monte Carlo Team, "MCNP - a General Monte Carlo n-Particle Transport Code, version 5," LA-UR-03-1987, Los Alamos National Laboratory (2003).

2. D. F. Hollenbach, L. M. Petrie, S. Goluoglu, N. F. Landers, and M. E. Dunn, "KENO-VI: A General Quadratic Version of the KENO Program," ORNL/TM-2005/39 Version 6 Vol. II, Sect. F17, Oak Ridge National Laboratory (January 2009).

\section{A.1.3 Origin of cross-section data.}

The Evaluated Neutron Data File library, ENDF/B-VII.0 a was utilized in the benchmark model analysis. The European Joint Evaluated Fission and Fusion File, JEFF-3.1, the Japanese Evaluated Nuclear Data Library, JENDL-3.3, ${ }^{\mathrm{c}}$ and ENDF/B-VI. ${ }^{\mathrm{d}}$ were also included for a basic evaluative comparison. The JENDL-3.3 analysis was performed with the inclusion of ENDF/BVII.0 thermal neutron scattering data because it was not available with the JENDL-3.3 library. Thermal neutron scattering, or $S(\alpha, \beta)$, adjusts the neutron cross sections for neutron upscatter at thermal energies and provides scattering data for elements bound within specific materials.

\section{A.1.4 Spectral calculations and data reduction methods used.}

Not applicable.

\section{A.1.5 Number of energy groups or if continuous-energy cross sections are used in the different phases of calculation.}

1. Continuous-energy cross sections (MCNP5 and KENO-VI).

2. 238-group cross sections (KENO-VI).

\footnotetext{
${ }^{a}$ M. B. Chadwick, et al., "ENDF/B-VII.0: Next Generation Evaluated Nuclear Data Library for Nuclear Science and Technology," Nucl. Data Sheets, 107: 2931-3060 (2006).

${ }^{\text {b }}$ A. Koning, R. Forrest, M. Kellett, R. Mills, H. Henriksson, and Y. Rugama, "The JEFF-3.1 Nuclear Data Library," JEFF Report 21, Organisation for Economic Co-operation and Development, Paris (2006).

c K. Shibata, et al., "Japanese Evaluated Nuclear Data Library Version 3 Revision3: JENDL-3.3,” J. Nucl. Sci. Tech., 39: 1125-1136 (November 2002).

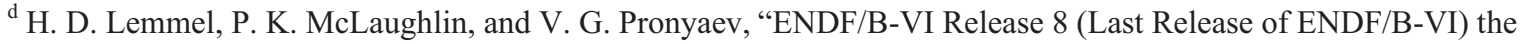
U.S. Evaluated Nuclear Data Library for Neutron Reaction Data," IAEA-NDS-100 Rev. 11, International Atomic Energy Agency, Vienna (November 2001).
} 


\section{A.1.6 Component calculations.}

- Type of cell calculation - Reactor core, reflectors, and moderator

- Geometry - Fuel pin and assembly lattice

- Theory used - Not applicable

- Method used - Monte Carlo

- Calculation characteristics

- MCNP5 and KENO-VI - histories/cycles/cycles skipped $=100,000 / 1,550 / 50$

continuous-energy cross sections

- KENO-VI - histories/cycles/cycles skipped $=100,000 / 1,550 / 50$

238-group cross sections

\section{A.1.7 Other assumptions and characteristics.}

Not applicable.

\section{A.1.8 Typical input listings for each code system type.}

MCNP5 Input Deck for the 60-fuel-element operational core configuration:

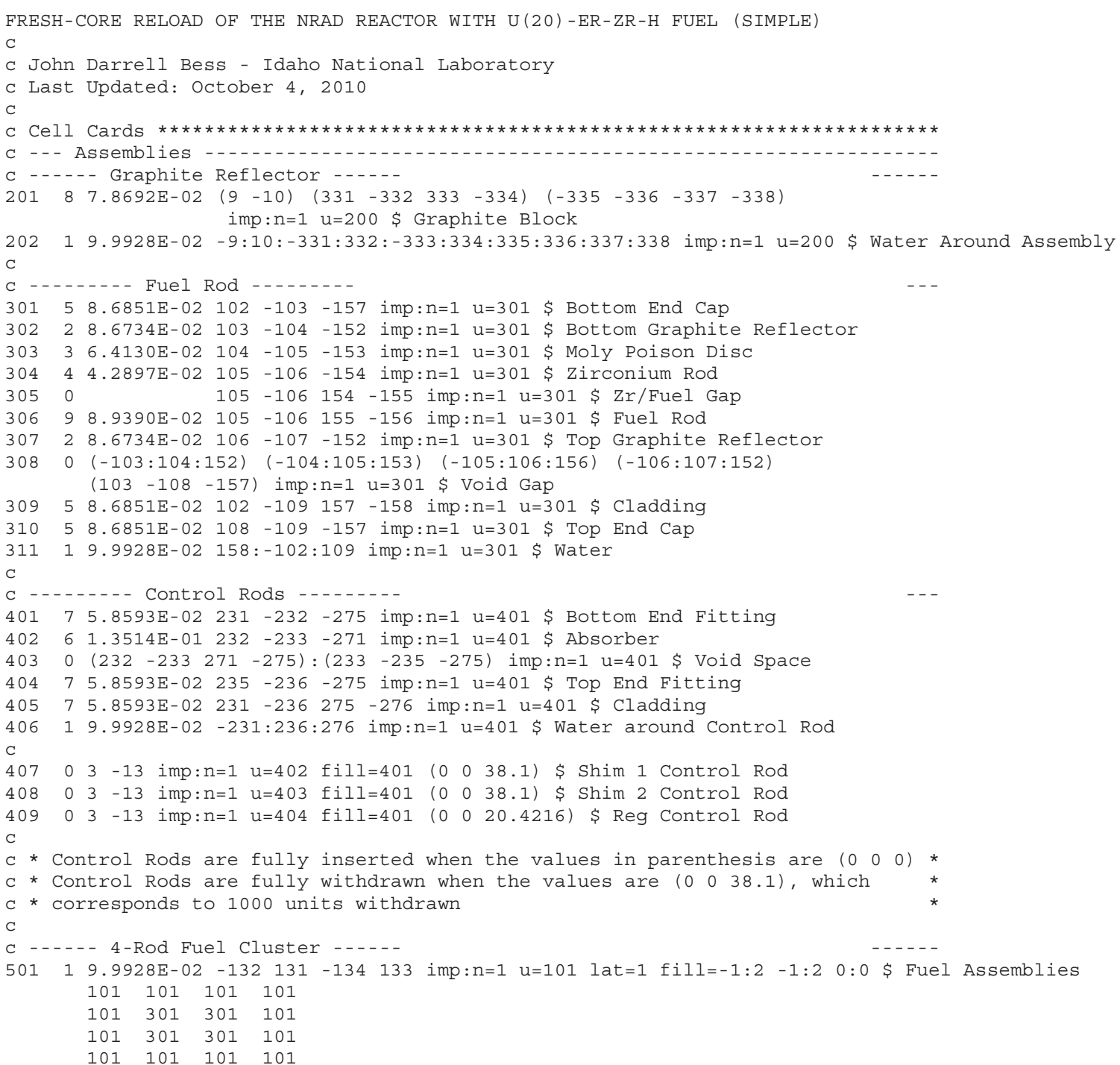


NEA/NSC/DOC(2006)1

Fundamental - FUND

NRAD-FUND-RESR-001 CRIT

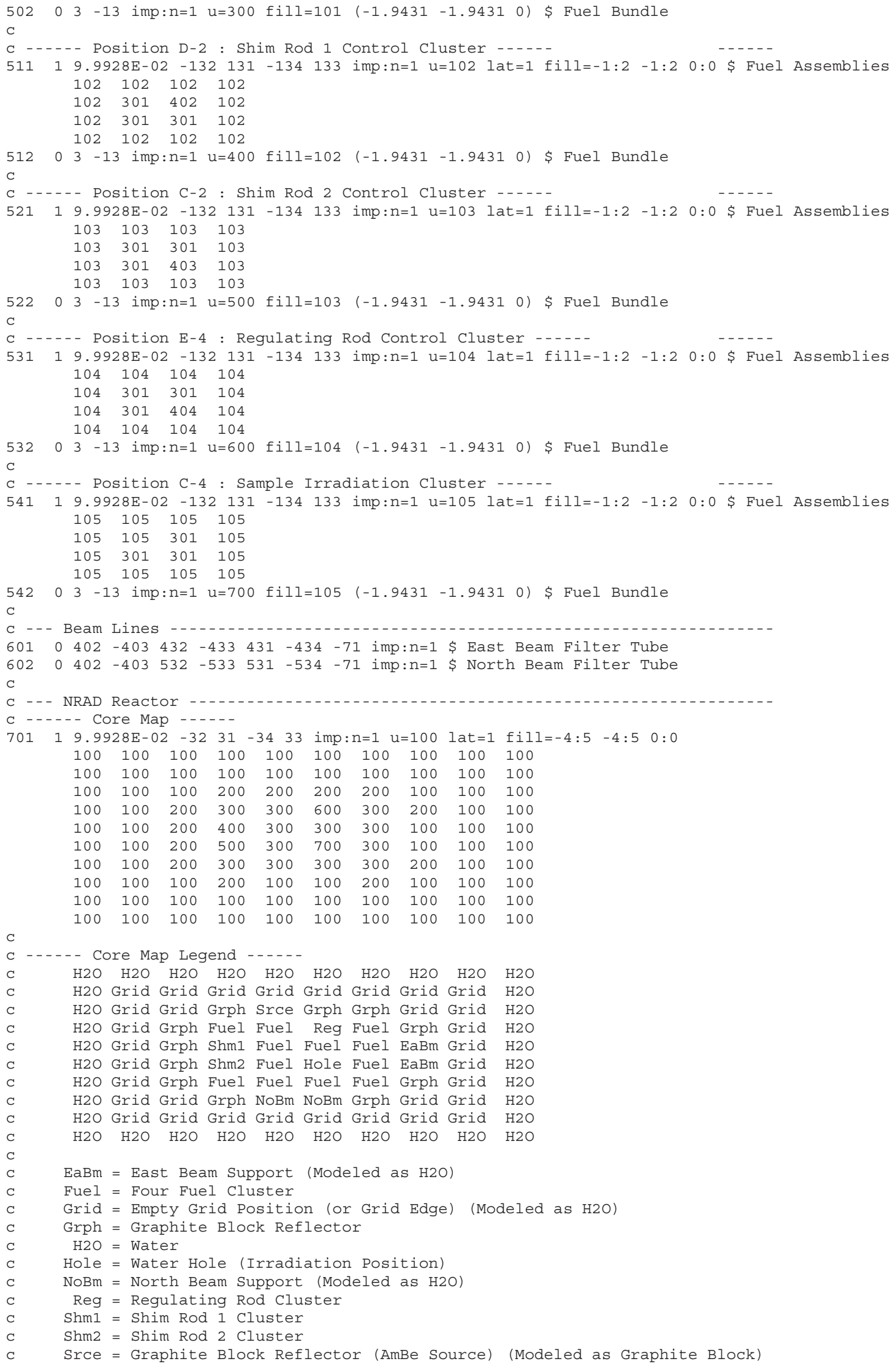


NEA/NSC/DOC(2006)1

Fundamental - FUND

NRAD-FUND-RESR-001

CRIT

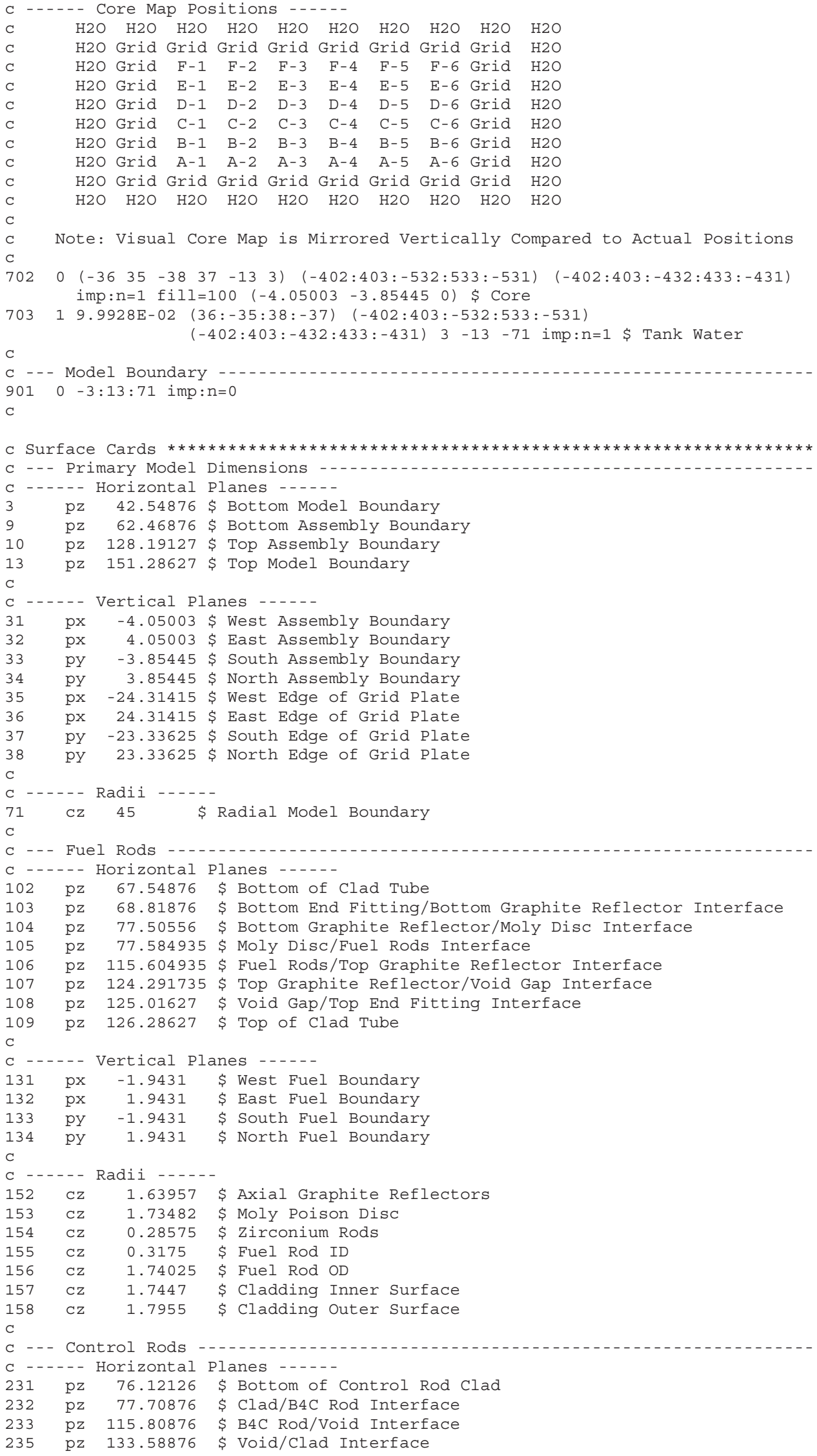


NEA/NSC/DOC(2006)1

Fundamental - FUND

NRAD-FUND-RESR-001

CRIT

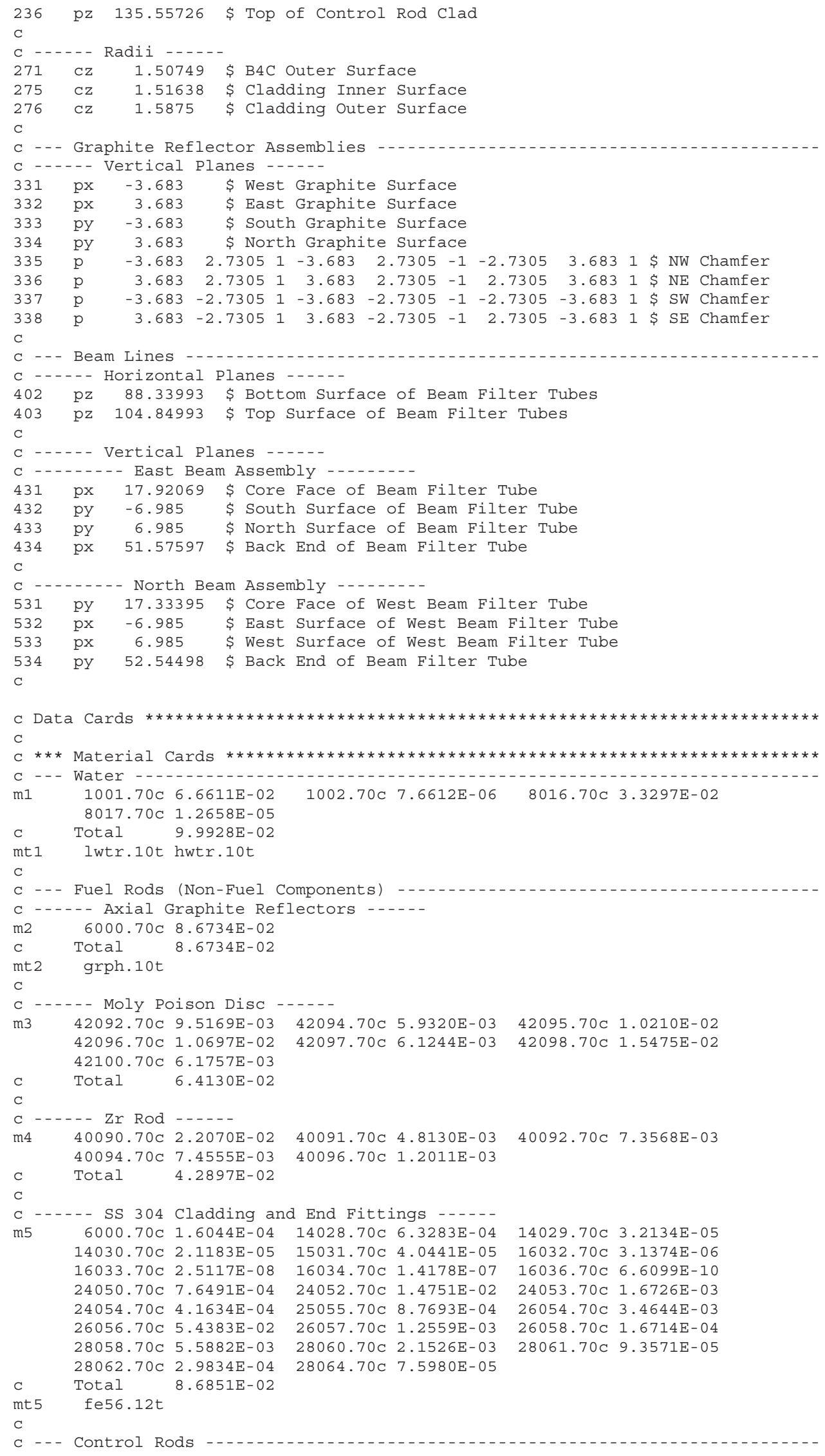


NEA/NSC/DOC(2006)1

\section{Fundamental - FUND}

\section{NRAD-FUND-RESR-001 \\ CRIT}

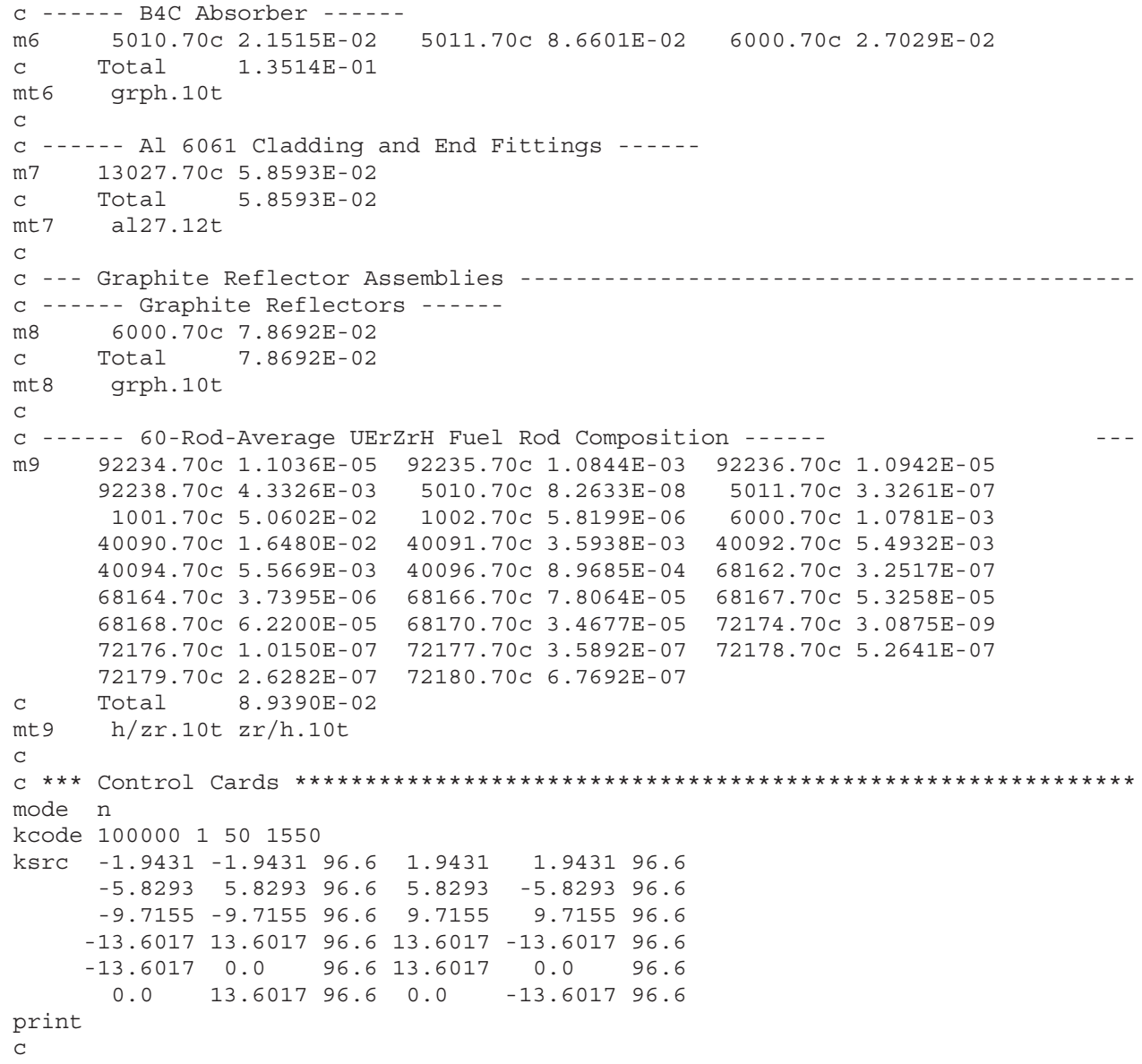




\section{NEA/NSC/DOC(2006)1}

\section{Fundamental - FUND}

\section{NRAD-FUND-RESR-001 CRIT}

KENO Input Deck for the 60-fuel-element operational core configuration:

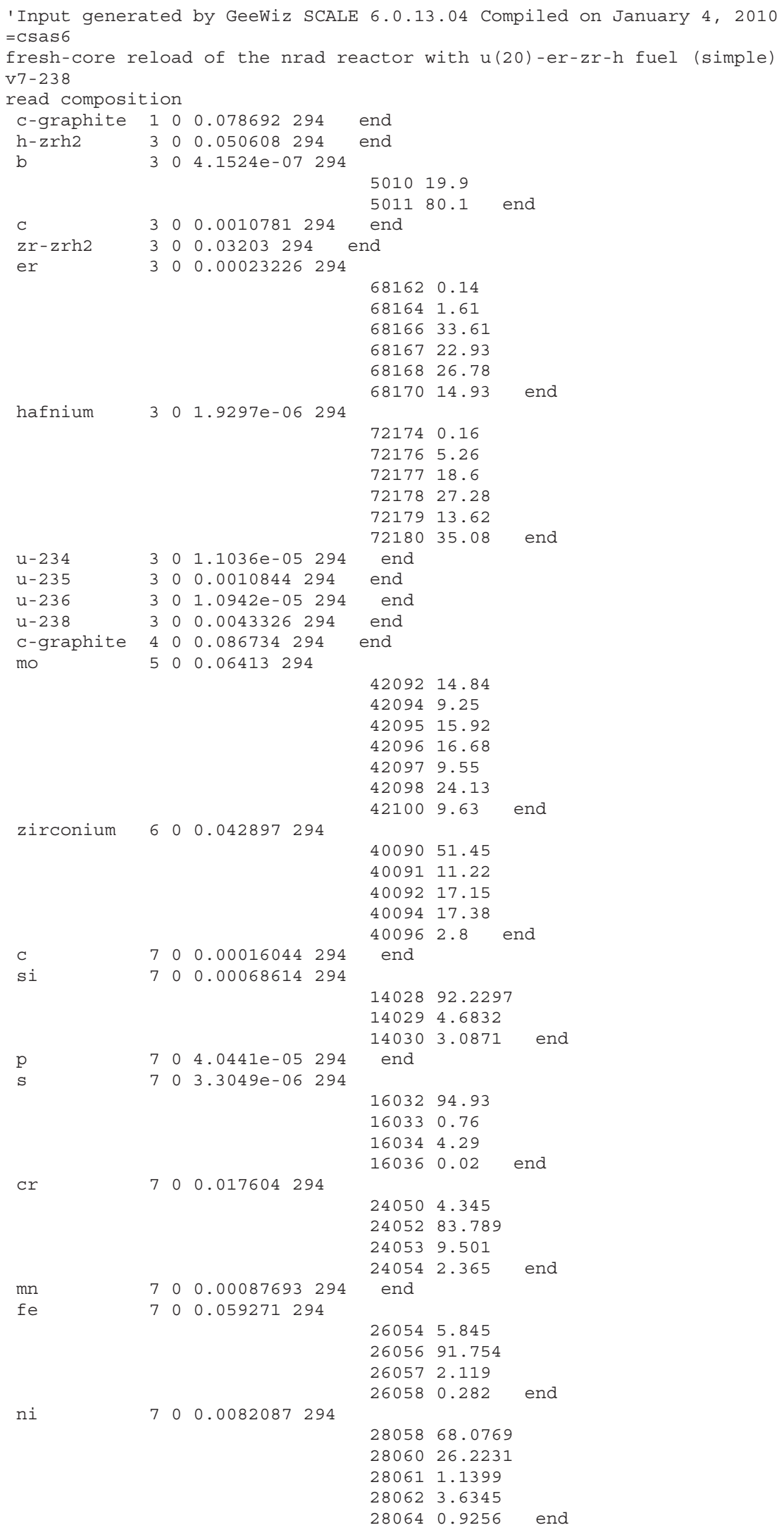


NEA/NSC/DOC(2006)1

Fundamental - FUND

NRAD-FUND-RESR-001

CRIT

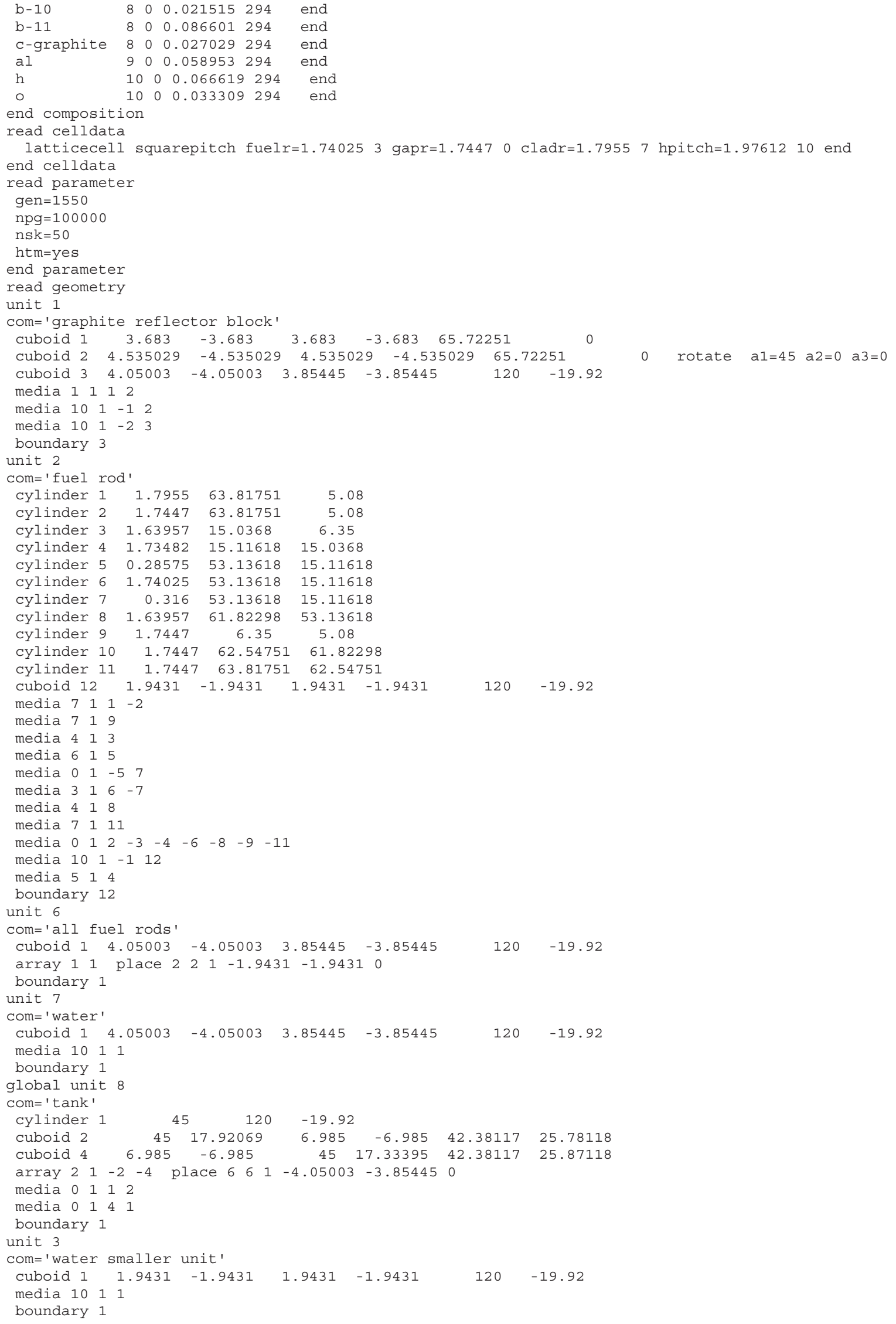


Fundamental - FUND

NRAD-FUND-RESR-001 CRIT

unit 9

com=' shim'

cylinder $1 \quad 1.51638 \quad 53.34 \quad 51.7525$

cylinder $2 \quad 1.50749 \quad 91.44 \quad 53.34$

cylinder $3 \quad 1.51638 \quad 111.1885 \quad 109.22$

cylinder $4 \quad 1.51638 \quad 111.1885 \quad 51.7525$

cylinder $5 \quad 1.5875 \quad 111.1885 \quad 51.7525$

$\begin{array}{lllllll}\text { cuboid } 6 & 1.9431 & -1.9431 & 1.9431 & -1.9431 & 120 & -19.92\end{array}$

media $9 \begin{array}{llll} & 1 & 5 & -4\end{array}$

media $9 \begin{array}{lll}1 & 1\end{array}$

media 8 r 12

media $9 \begin{array}{lll} & 3\end{array}$

$\begin{array}{lllllll}\text { media } & 0 & 1 & 4 & -1 & -2 & -3\end{array}$

media $10 \quad 1 \quad 6 \quad-5$

boundary 6

unit 10

$\mathrm{com}=$ ' reg $^{\prime}$

cylinder $1 \quad 1.51638 \quad 35.6616 \quad 34.0741$

cylinder $2 \quad 1.50749 \quad 73.7616 \quad 35.6616$

cylinder $3 \quad 1.51638 \quad 93.5101 \quad 91.5416$

cylinder $4 \quad 1.51638 \quad 93.5101 \quad 34.0741$

cylinder $5 \quad 1.5875 \quad 93.5101 \quad 34.0741$

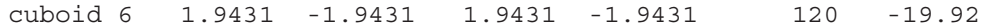

$\begin{array}{lllll}\text { media } & 9 & 1 & 5 & -4\end{array}$

media $9 \begin{array}{lll}1 & 1\end{array}$

media 8 12

media $9 \begin{array}{lll} & 3\end{array}$

media $0 \begin{array}{llllll} & 1 & 4 & -1 & -2 & -3\end{array}$

media $10 \begin{array}{llll}1 & 6 & -5\end{array}$

boundary 6

unit 11

com='shim 2 cluster'

$\begin{array}{lllll}\text { cuboid } 1 & 4.05003 & -4.05003 & 3.85445 & -3.85445\end{array}$

array 31 place $2201-1.9431-1.94310$

boundary 1

unit 12

com=' shim 1 cluster'

$\begin{array}{lllll}\text { cuboid } 1 & 4.05003 & -4.05003 & 3.85445 & -3.85445\end{array}$

array 41 place $2 \quad 2 \quad 1-1.9431-1.9431 \quad 0$

boundary 1

unit 13

com='reg rod cluster'

$\begin{array}{lllll}\text { cuboid } 1 & 4.05003 & -4.05003 & 3.85445 & -3.85445\end{array}$

array 51 place $221-1.9431-1.94310$

boundary 1

unit 14

com='three rod cluster'

$\begin{array}{lllll}\text { cuboid } 1 & 4.05003 & -4.05003 & 3.85445 & -3.85445\end{array}$

array 61 place $2201-1.9431-1.94310$

boundary 1

end geometry

read array

ara=1 nux=4 nuy=4 nuz=1 typ=square

$\mathrm{com}={ }^{\prime}$ '

fill

$\begin{array}{llll}3 & 3 & 3 & 3\end{array}$

$\begin{array}{llll}3 & 2 & 2 & 3\end{array}$

$\begin{array}{llll}3 & 2 & 2 & 3 \\ 3 & 3 & 3 & 3\end{array}$ end fill

ara=2 nux=12 nuy=12 nuz=1 typ=square gbl=2

$\mathrm{com}={ }^{\prime}$ '

fill

$\begin{array}{rrrrrrrr}7 & 7 & 7 & 7 & 7 & 7 & 7 & 7 \\ 7 & 7 & 7 & 7 & 7 & 7 & 7 & 7 \\ 7 & 7 & 7 & 7 & 7 & 7 & 7 & 7 \\ 7 & 7 & 7 & 7 & 1 & 1 & 1 & 1 \\ 7 & 7 & 7 & 1 & 6 & 6 & 13 & 6 \\ 7 & 7 & 7 & 1 & 12 & 6 & 6 & 6 \\ 7 & 7 & 7 & 1 & 11 & 6 & 14 & 6 \\ 7 & 7 & 7 & 1 & 6 & 6 & 6 & 6 \\ 7 & 7 & 7 & 7 & 1 & 7 & 7 & 1 \\ 7 & 7 & 7 & 7 & 7 & 7 & 7 & 7 \\ 7 & 7 & 7 & 7 & 7 & 7 & 7 & 7 \\ 7 & 7 & 7 & 7 & 7 & 7 & 7 & 7\end{array}$

ara=3 nux=4 nuy=4 nuz=1 typ=square

$\mathrm{com}=$ ' shim rod 2 '

$120-19.92$

$120-19.92$

$120-19.92$

$120-19.92$ 
Fundamental - FUND

NRAD-FUND-RESR-001 CRIT

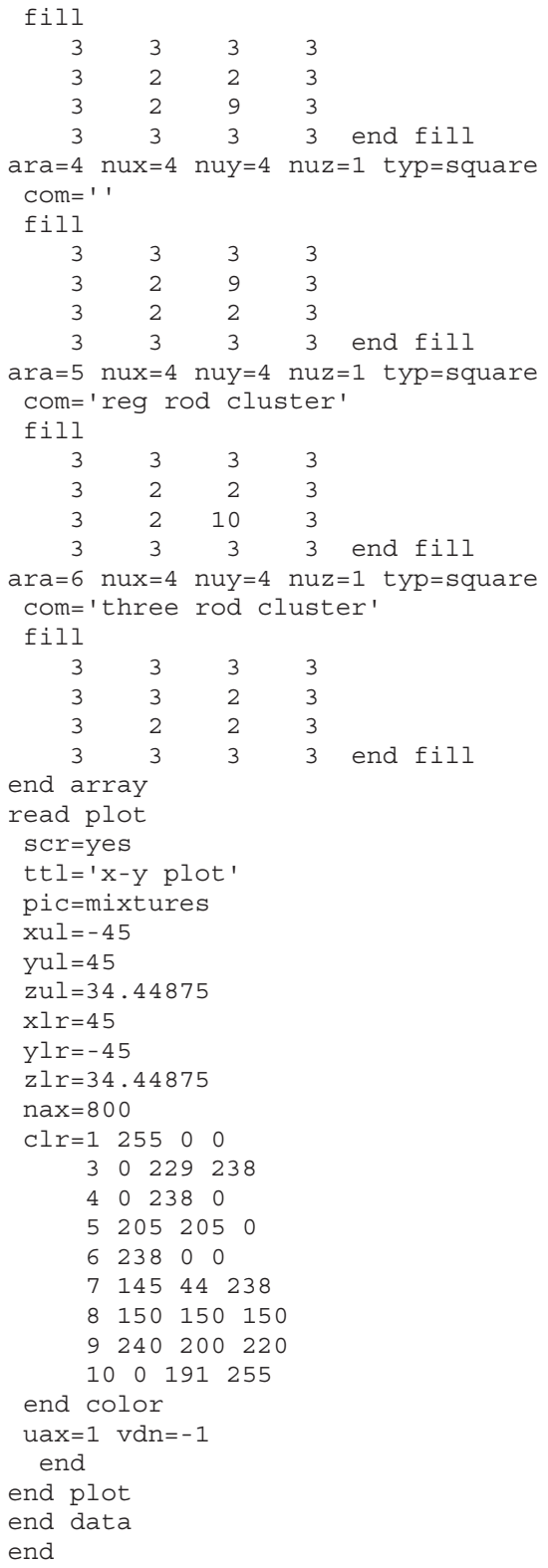


NEA/NSC/DOC(2006)1

Fundamental - FUND

NRAD-FUND-RESR-001

CRIT

\section{A.2 Buckling and Extrapolation Length Configurations}

Buckling and extrapolation length measurements were not made.

\section{A.3 Spectral-Characteristics Configurations}

Spectral characteristics measurements were not made.

\section{A.4 Reactivity-Effects Configurations}

Reactivity effects measurements were not made.

\section{A.5 Reactivity Coefficient Configurations}

Reactivity coefficient measurements were not made.

\section{A.6 Kinetics Parameter Configurations}

Kinetics measurements were not made.

\section{A.7 Reaction-Rate Configurations}

Reaction-rate distribution measurements were not made.

\section{A.8 Power Distribution Configurations}

Power distribution measurements were not made.

\section{A.9 Isotopic Configurations}

Isotopic measurements were not made.

\section{A.10 Configurations of Other Miscellaneous Types of Measurements}

Other miscellaneous types of measurements were not made. 


\section{APPENDIX B: CALCULATED SPECTRAL DATA}

The neutron spectral calculations provided below were obtained from the output files for the input decks provided in Appendix A.1 and results in Section 4.1. Only spectral data using the ENDF/B-VII.0, JEFF3.1, and JENDL-3.3 neutron cross section libraries are provided here for the MCNP5 analyses and the ENDF/B-VII.0 (238-group) library for the KENO analyses. The cross sections are all continuous in the MCNP5 analyses.

\section{B.1 MCNP-Calculated Spectral Data}

A summary of the computed neutron spectral data using MCNP5 for the benchmark model is provided in Table B.1.

Table B.1. Neutron Spectral Data for Benchmark Model (MCNP5).

\begin{tabular}{|c|c|c|c|c|c|}
\hline \multicolumn{2}{|c|}{$\begin{array}{l}\text { Neutron Cross } \\
\text { Section Library }\end{array}$} & ENDF/B-VII.0 & JEFF-3.1 & JENDL-3.3 & ENDF/B-VI.8 \\
\hline \multicolumn{2}{|r|}{$\mathbf{k}_{\mathrm{eff}}$} & 1.00925 & 1.00719 & 1.00633 & 1.00458 \\
\hline \multicolumn{2}{|c|}{$\pm \sigma_{k}$} & 0.00007 & 0.00007 & 0.00007 & 0.00007 \\
\hline \multicolumn{2}{|c|}{ Neutron Leakage $(\%)^{(\mathrm{a})}$} & 2.21 & 2.19 & 2.22 & 2.22 \\
\hline \multirow{3}{*}{$\begin{array}{l}\text { Fission Fraction, } \\
\text { by Energy (\%) }\end{array}$} & Thermal $(<0.625 \mathrm{eV})$ & 80.52 & 80.55 & 80.52 & 80.46 \\
\hline & Intermediate & 16.47 & 16.44 & 16.44 & 16.47 \\
\hline & Fast $(>100 \mathrm{keV})$ & 3.01 & 3.01 & 3.05 & 3.07 \\
\hline \multirow{4}{*}{$\begin{array}{l}\text { Fission Fraction, } \\
\text { by Isotope (\%) }\end{array}$} & ${ }^{234} \mathbf{U}$ & 0.015 & 0.015 & 0.016 & 0.016 \\
\hline & ${ }^{235} \mathbf{U}$ & 98.732 & 98.732 & 98.719 & 98.699 \\
\hline & ${ }^{236} \mathbf{U}$ & 0.009 & 0.009 & 0.009 & 0.009 \\
\hline & ${ }^{238} \mathbf{U}$ & 1.244 & 1.244 & 1.256 & 1.275 \\
\hline \multicolumn{2}{|c|}{$\begin{array}{l}\text { Average Number of } \\
\text { Neutrons Produced } \\
\text { per Fission }\end{array}$} & 2.444 & 2.444 & 2.443 & 2.444 \\
\hline \multicolumn{2}{|c|}{$\begin{array}{c}\text { Energy of Average } \\
\text { Neutron Lethargy } \\
\text { Causing Fission (eV) }\end{array}$} & 0.26859 & 0.26856 & 0.26942 & 0.27964 \\
\hline
\end{tabular}

(a) The neutron leakage is calculated using the neutron balance tables provided in the MCNP output file. The weight fraction of neutrons lost due to escaping the boundaries of the benchmark model are divided by the total weight fraction of neutron loss. 
NRAD-FUND-RESR-001

\section{CRIT}

\section{B.2 KENO-Calculated Spectral Data}

A summary of the computed neutron spectral data using KENO-VI for the benchmark model is provided in Table B.2.

Table B.2. Neutron Spectral Data for Benchmark Model (KENO).

\begin{tabular}{|c|c|c||}
\hline $\begin{array}{c}\text { Neutron Cross } \\
\text { Section Library }\end{array}$ & $\begin{array}{c}\text { ENDF/B-VII.0 } \\
\text { (238-group) }\end{array}$ & $\begin{array}{c}\text { ENDF/B-VII.0 } \\
\text { (continuous energy) }\end{array}$ \\
\hline $\begin{array}{c}\mathbf{k}_{\text {eff }} \\
\pm \boldsymbol{\sigma}_{\mathbf{k}}\end{array}$ & 1.008741 & 1.004496 \\
0.000066 & 0.000076 \\
\hline $\begin{array}{c}\text { Average Number of } \\
\text { Neutrons Produced } \\
\text { per Fission }\end{array}$ & 2.44392 & 2.44397 \\
\hline $\begin{array}{c}\text { Energy of Average } \\
\text { Neutron Lethargy } \\
\text { Causing Fission (eV) }\end{array}$ & 0.258973 & 0.275682 \\
\hline Mean Free Path (cm) & 0.687796 & 0.688822 \\
\hline
\end{tabular}


NEA/NSC/DOC(2006)1

Fundamental - FUND

NRAD-FUND-RESR-001

CRIT

\section{APPENDIX C: APPROXIMATE DETAILED MODEL INPUT DECK}

\section{C.1 Detailed MCNP Model of the NRAD Reactor (NOT BENCHMARKED)}

A detailed model of the NRAD reactor 60 -fuel-element core configuration was prepared to evaluate biases in the benchmark model. Because the effects of many of the model simplifications produced small or otherwise negligible biases (in regards to criticality) in the benchmark model, development of a detailed benchmark model was unnecessary. The MCNP5 input deck, using ENDF/B-VII.0 neutron cross section data, is preserved in this appendix for future use. Calculations were performed with 1,550 generations with 100,000 neutrons per generation. The $\mathrm{k}_{\text {eff }}$ estimates did not include the first 50 generations and are the result of 150,000,000 neutron histories. Calculated results obtained with this input deck are provided in Table C.1. Figures C.1 through C.5 provide various views of the complexity incorporated into the detailed model.

This model uses a tank water temperature of $26.0^{\circ} \mathrm{C}\left(0.9968 \mathrm{~g} / \mathrm{cm}^{3}\right)$.

Table C.1. Neutron Spectral Data for Detailed Benchmark Model.

\begin{tabular}{|c|c|c|}
\hline \multicolumn{2}{|c|}{$\begin{array}{c}\text { Neutron Cross } \\
\text { Section Library }\end{array}$} & ENDF/B-VII.0 \\
\hline \multicolumn{2}{|r|}{$\mathbf{k}_{\text {eff }}$} & 1.00805 \\
\hline \multicolumn{2}{|c|}{$\pm \boldsymbol{\sigma}_{\mathrm{k}}$} & 0.00007 \\
\hline \multicolumn{2}{|c|}{ Neutron Leakage $(\%)^{(a)}$} & 0.03 \\
\hline \multirow{3}{*}{$\begin{array}{c}\text { Fission Fraction, } \\
\text { by Energy (\%) }\end{array}$} & Thermal $(<0.625 \mathrm{eV})$ & 80.38 \\
\hline & Intermediate & 16.60 \\
\hline & Fast $(>100 \mathrm{keV})$ & 3.02 \\
\hline \multirow{4}{*}{$\begin{array}{c}\text { Fission Fraction, } \\
\text { by Isotope }(\%)\end{array}$} & ${ }^{234} \mathbf{U}$ & 0.015 \\
\hline & ${ }^{235} \mathbf{U}$ & 98.727 \\
\hline & ${ }^{236} \mathbf{U}$ & 0.009 \\
\hline & ${ }^{238} \mathbf{U}$ & 1.249 \\
\hline \multicolumn{2}{|c|}{$\begin{array}{c}\text { Average Number of } \\
\text { Neutrons Produced } \\
\text { per Fission }\end{array}$} & 2.444 \\
\hline \multicolumn{2}{|c|}{$\begin{array}{c}\text { Energy of Average } \\
\text { Neutron Lethargy } \\
\text { Causing Fission (eV) } \\
\end{array}$} & 0.27218 \\
\hline
\end{tabular}

(a) The neutron leakage is calculated using the neutron balance tables provided in the MCNP output file. The weight fraction of neutrons lost due to escaping the boundaries of the benchmark model are divided by the total weight fraction of neutron loss. 
NEA/NSC/DOC(2006)1

Fundamental - FUND

NRAD-FUND-RESR-001

CRIT

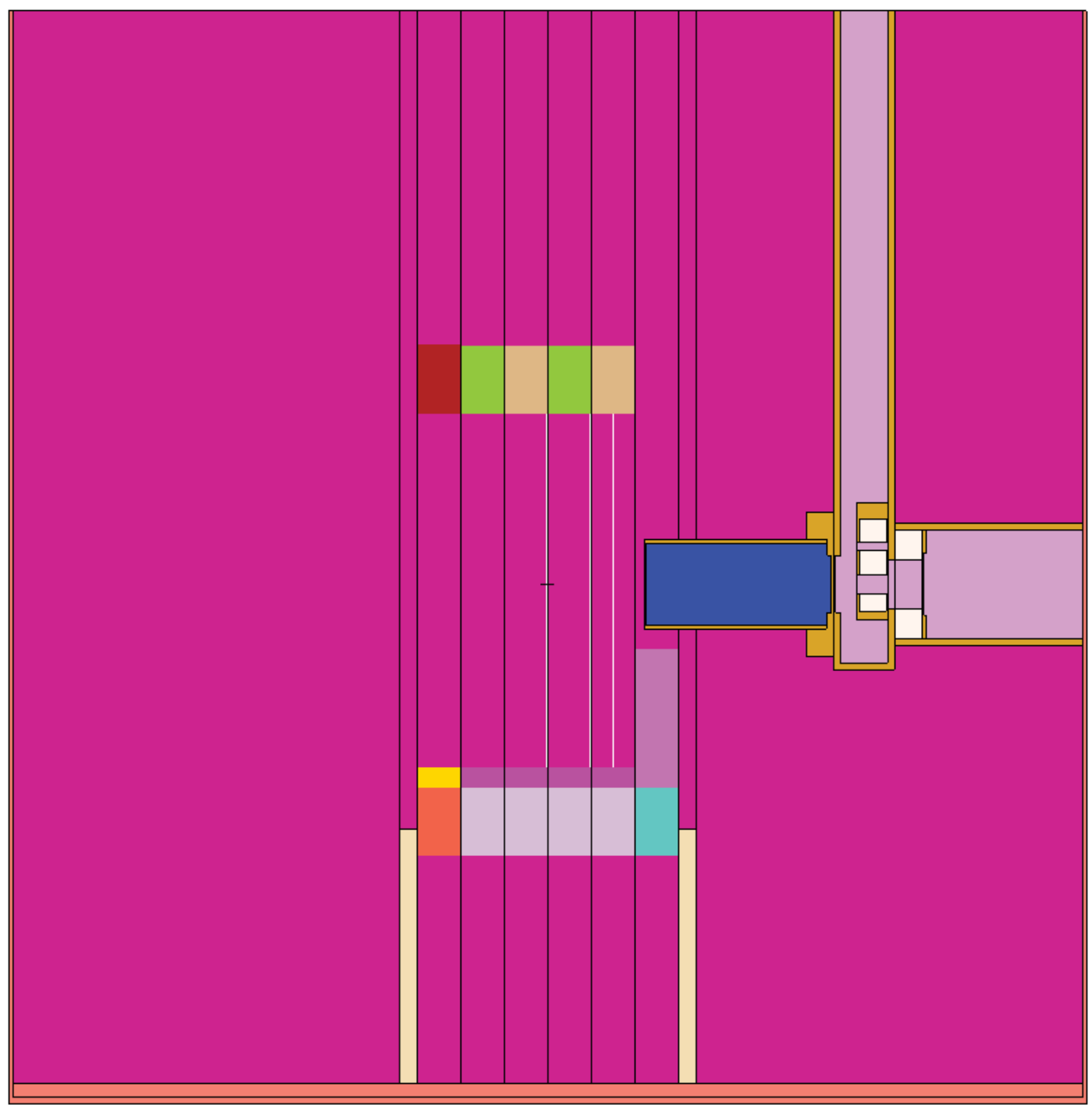

Figure C.1. Vertical Cross Section of Detailed NRAD Model. 
NEA/NSC/DOC(2006)1

Fundamental - FUND

NRAD-FUND-RESR-001

CRIT

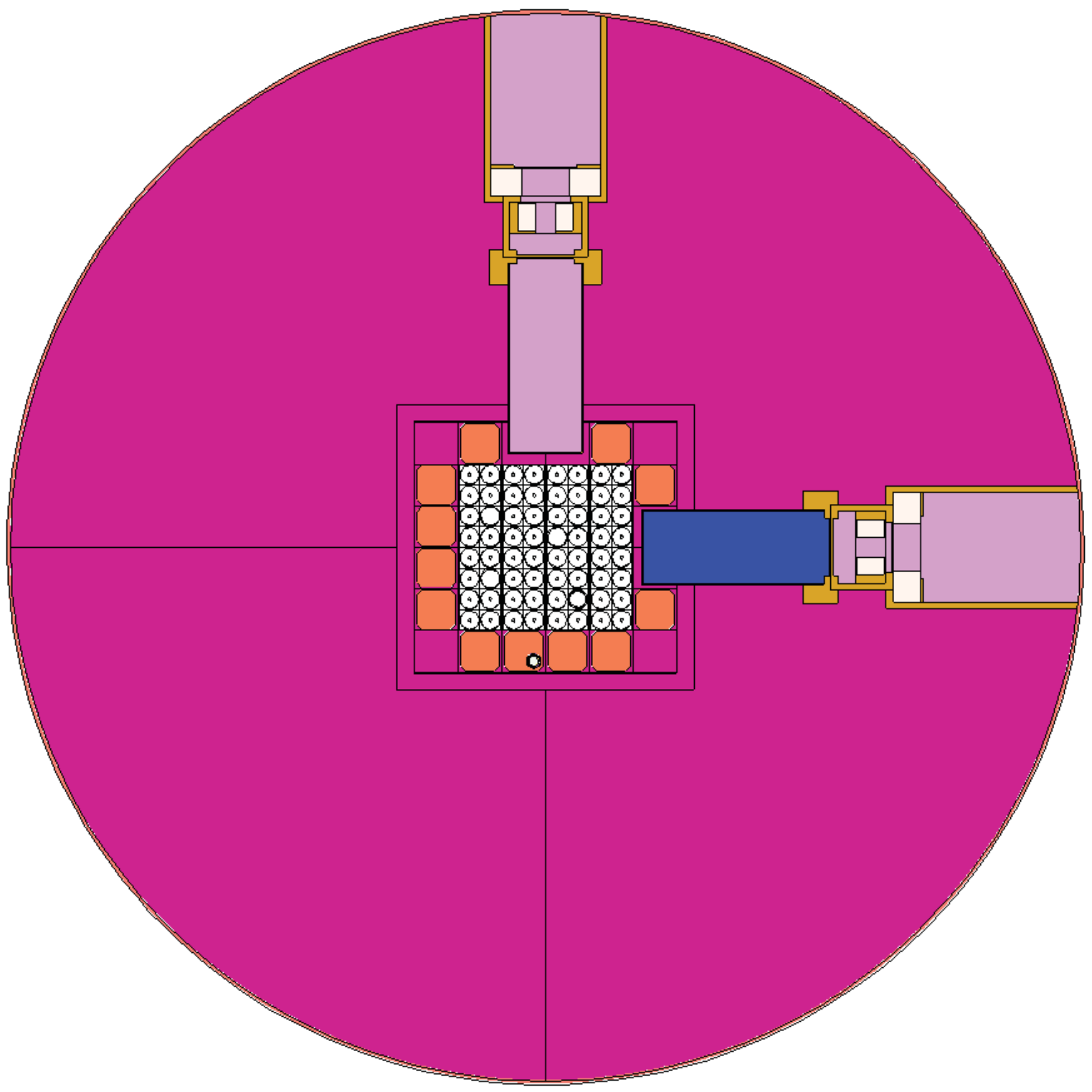

Figure C.2. Horizontal Cross Section of Detailed NRAD Model at Fuel Midplane. 
NEA/NSC/DOC(2006)1

Fundamental - FUND

NRAD-FUND-RESR-001

CRIT

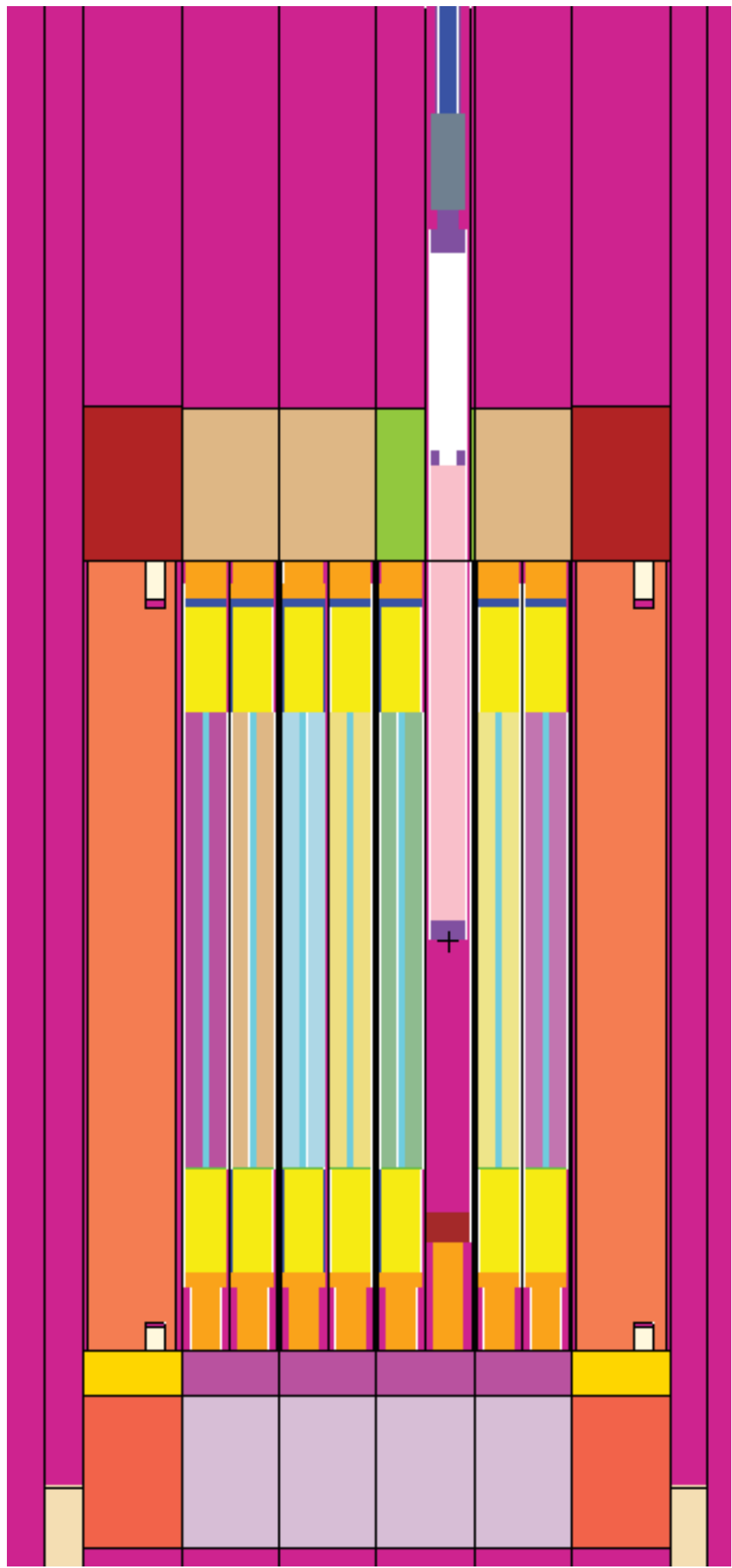

Figure C.3. Fuel Element and Reg Rod View of Detailed NRAD Model. 
NEA/NSC/DOC(2006)1

Fundamental - FUND

NRAD-FUND-RESR-001

CRIT

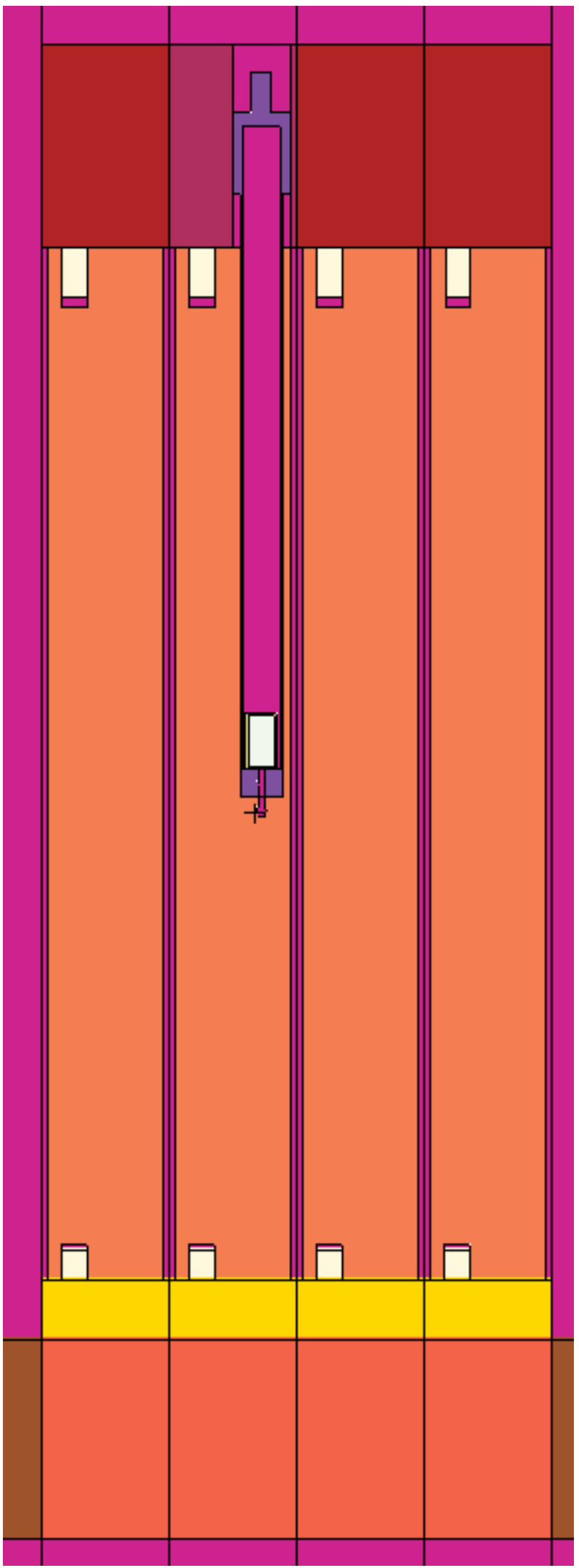

Figure C.4. Graphite Block and AmBe Source View of Detailed NRAD Model. 
Fundamental - FUND

NRAD-FUND-RESR-001

CRIT

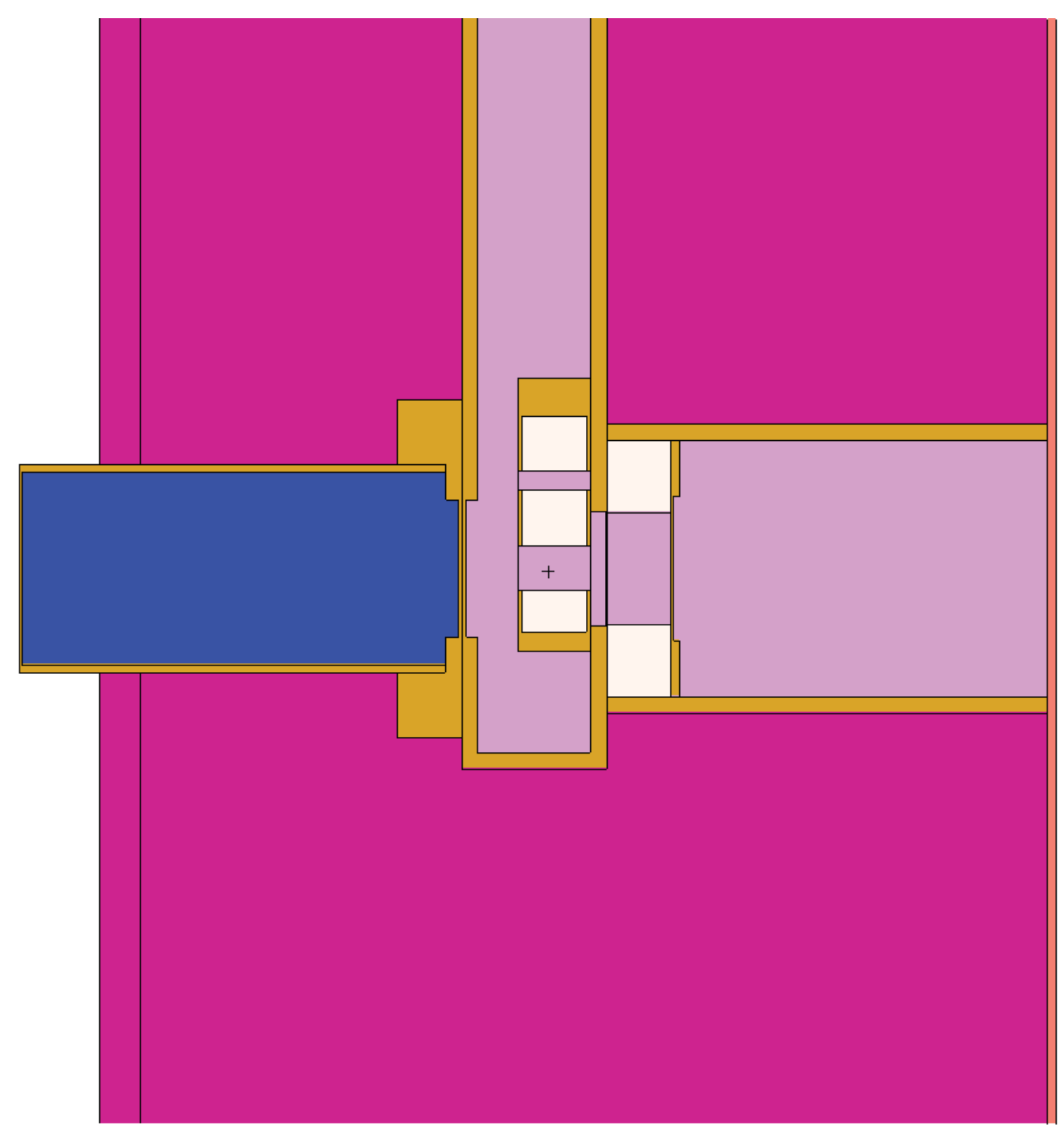

Figure C.5. East Beam Line View of Detailed NRAD Model.

\section{C.2 Input Listing for Detailed Model}

MCNP5 Input Deck for the 60-fuel-element operational core configuration:

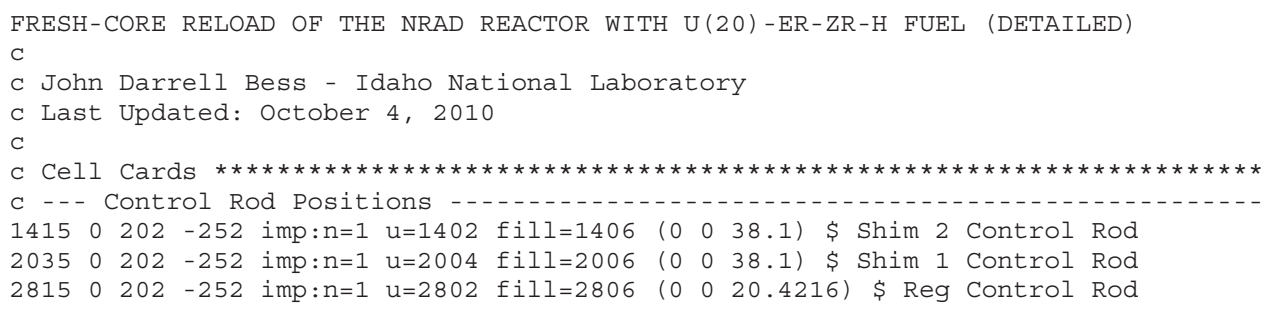


NEA/NSC/DOC(2006)1

Fundamental - FUND

NRAD-FUND-RESR-001 CRIT

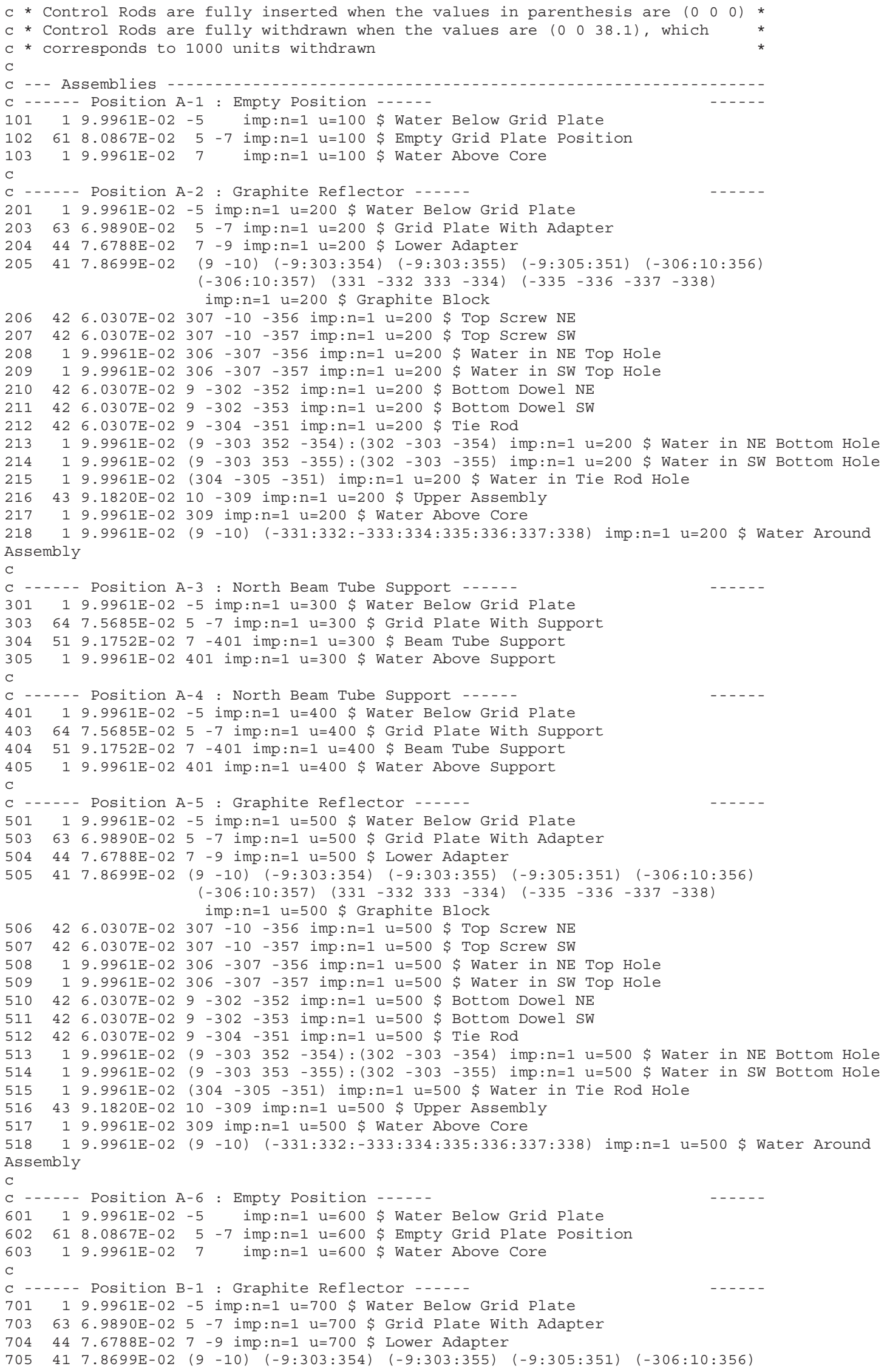


NEA/NSC/DOC(2006)1

Fundamental - FUND

NRAD-FUND-RESR-001 CRIT

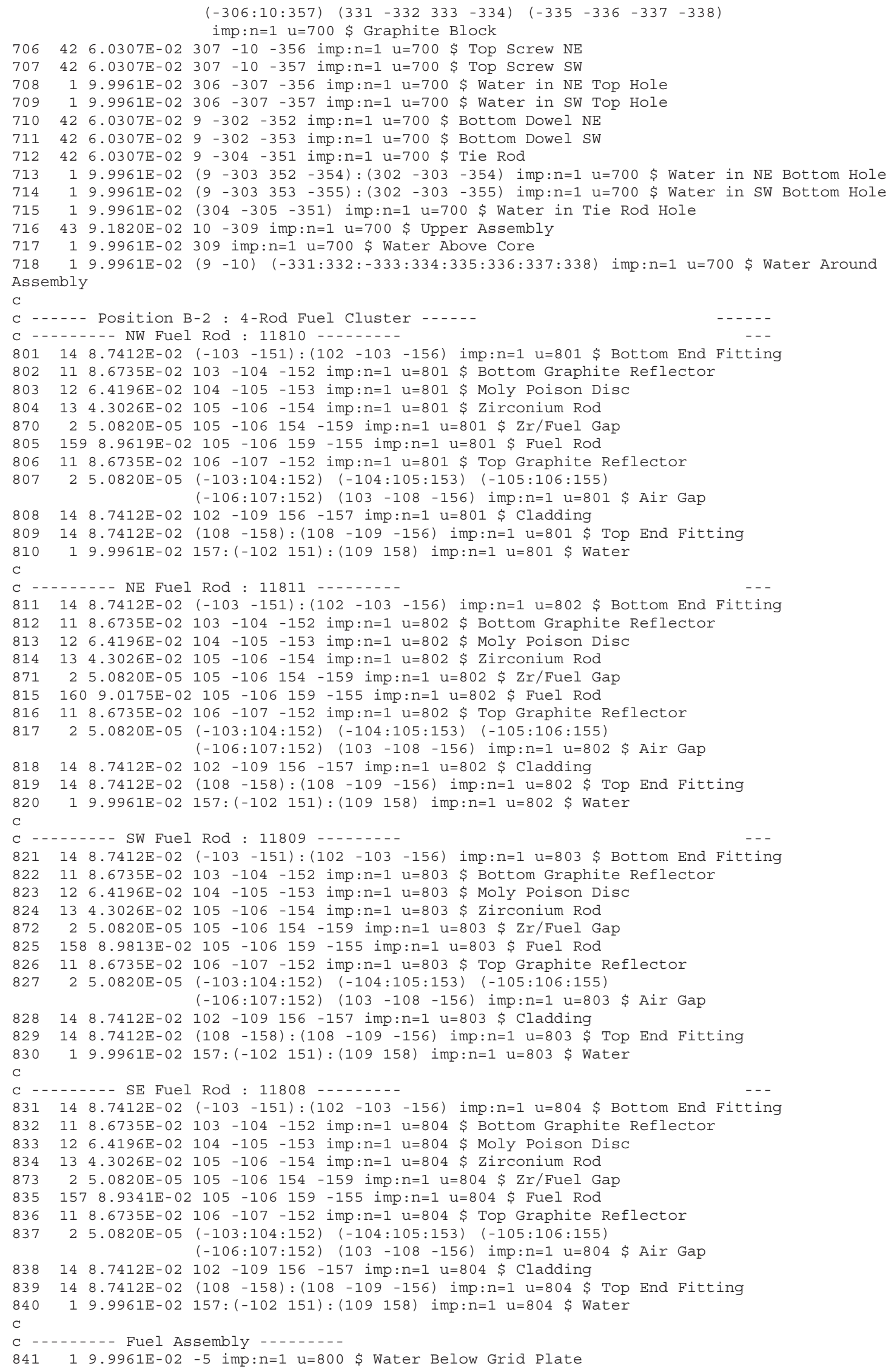


NEA/NSC/DOC(2006)1

Fundamental - FUND

NRAD-FUND-RESR-001 CRIT

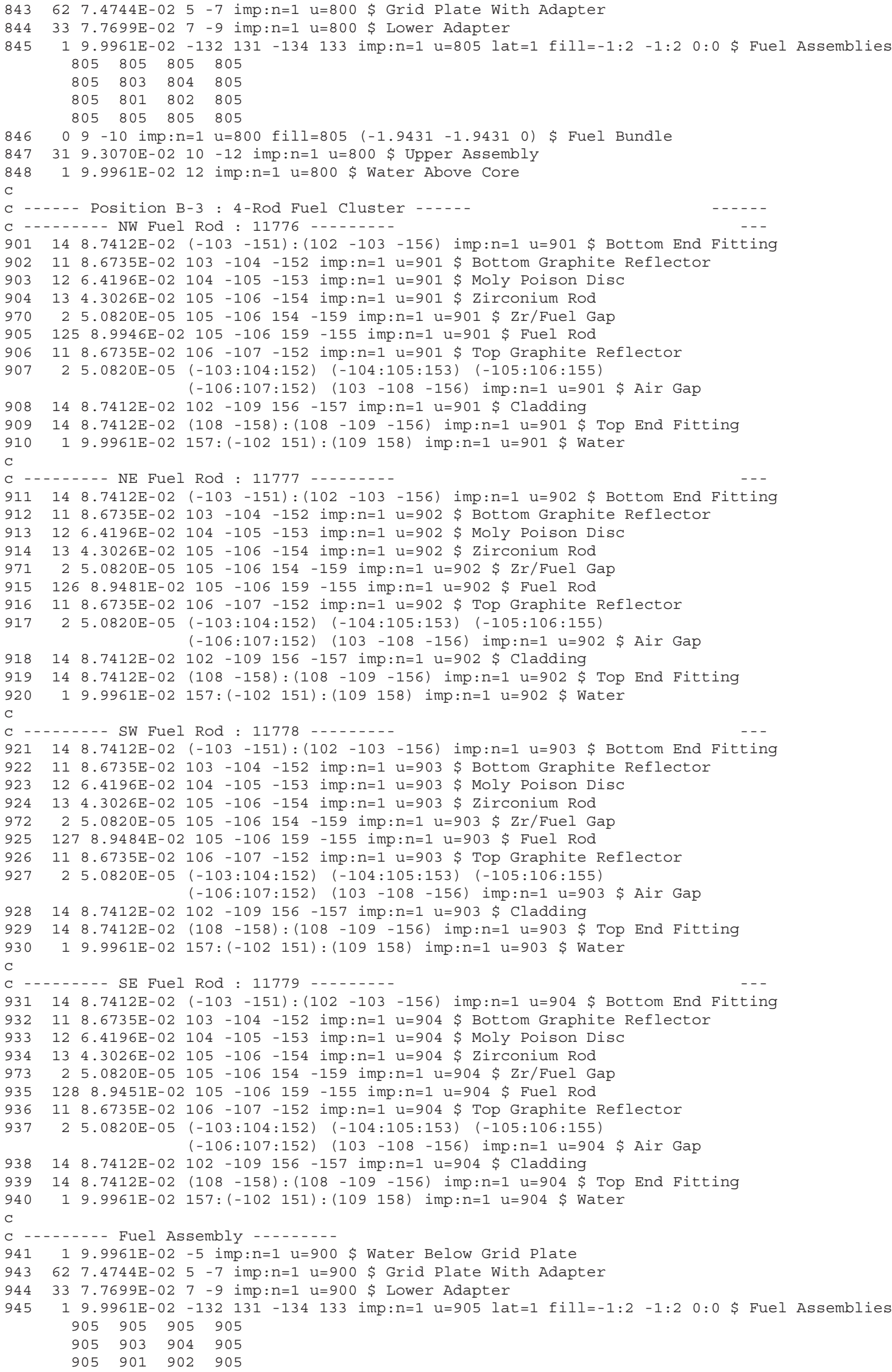




\section{NEA/NSC/DOC(2006)1}

\section{Fundamental - FUND \\ NRAD-FUND-RESR-001 CRIT}

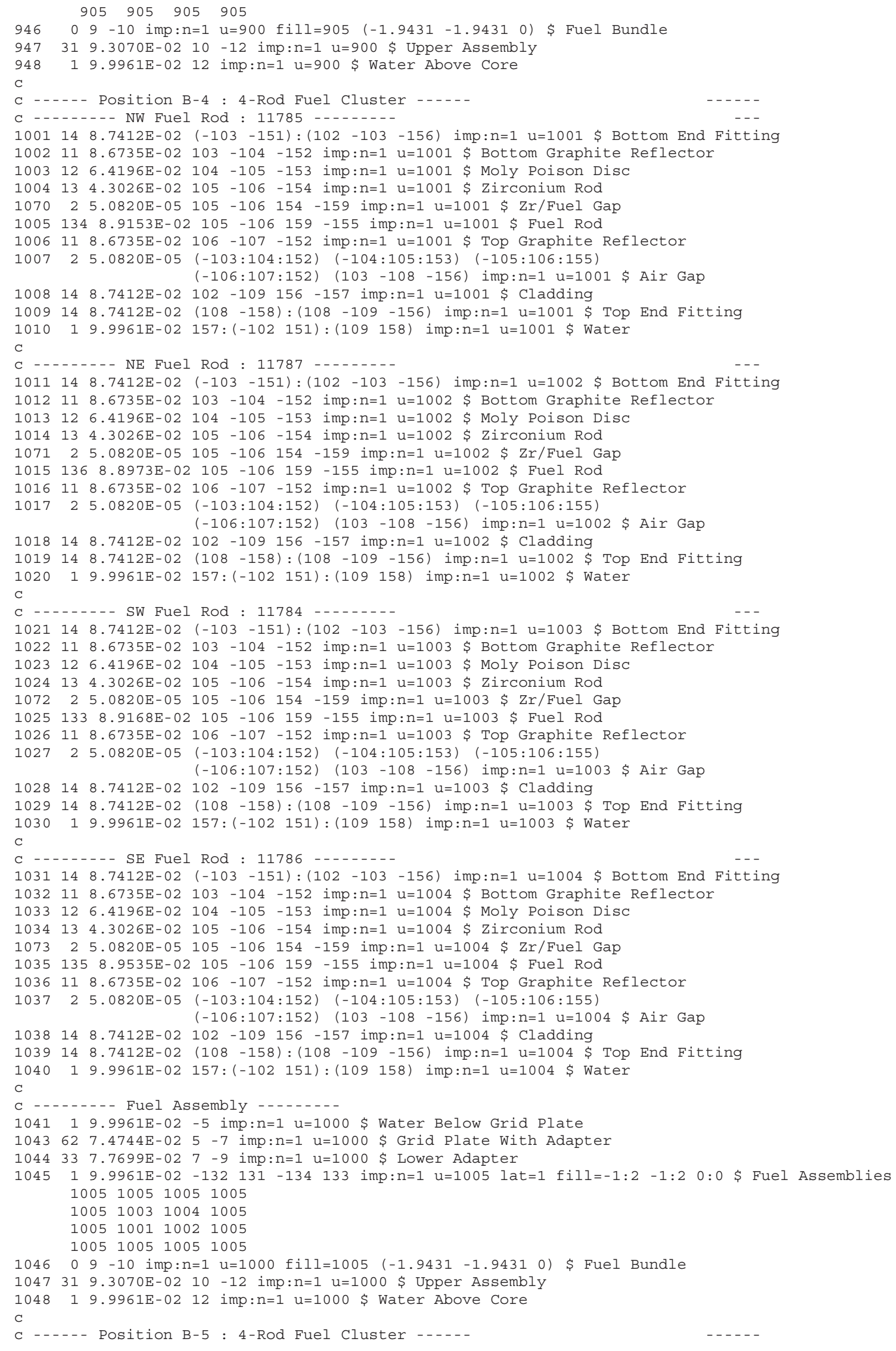


NEA/NSC/DOC(2006)1

Fundamental - FUND

NRAD-FUND-RESR-001 CRIT

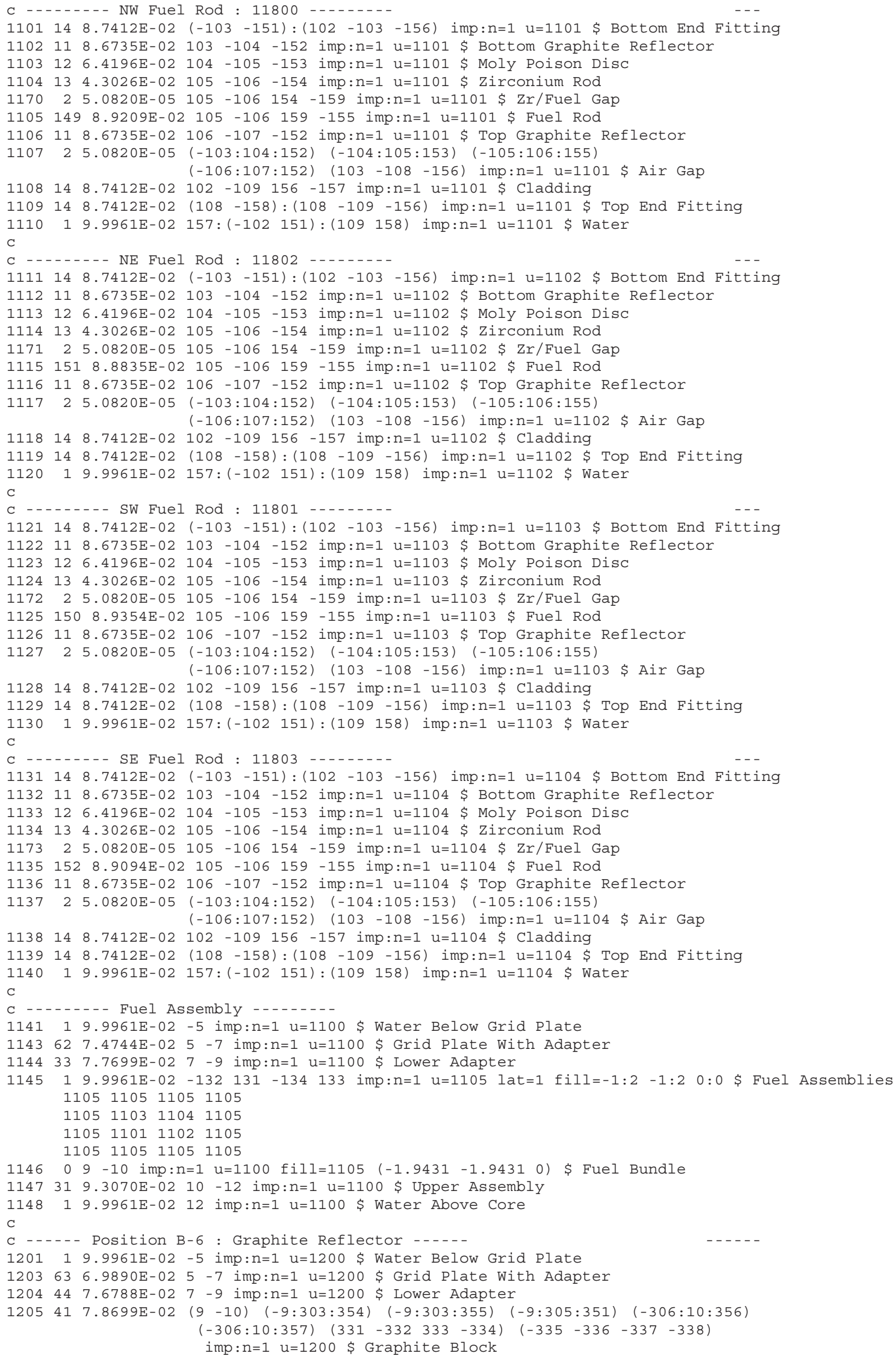




\section{NEA/NSC/DOC(2006)1}

\section{Fundamental - FUND}

\section{NRAD-FUND-RESR-001 CRIT}

$1206426.0307 \mathrm{E}-02307-10-356$ imp:n=1 u=1200 \$ Top Screw NE $1207426.0307 \mathrm{E}-02307-10-357$ imp:n=1 u=1200 \$ Top Screw SW

$120819.9961 \mathrm{E}-02306-307-356$ imp:n=1 u=1200 \$ Water in NE Top Hole

$120919.9961 \mathrm{E}-02306-307-357$ imp: $\mathrm{n}=1 \mathrm{u}=1200$ \$ Water in SW Top Hole

$1210426.0307 \mathrm{E}-029-302-352$ imp:n=1 u=1200 \$ Bottom Dowel NE

$1211426.0307 E-02 \quad 9-302-353$ imp:n=1 u=1200 \$ Bottom Dowel SW

$1212426.0307 \mathrm{E}-029-304-351$ imp:n=1 u=1200 \$ Tie Rod

$121319.9961 E-02(9-303352-354):(302-303-354)$ imp:n=1 u=1200 \$ Water in NE Bottom Hole $121419.9961 E-02(9-303$ 353-355):(302-303-355) imp:n=1 u=1200 \$ Water in sW Bottom Hole $121519.9961 \mathrm{E}-02$ (304-305 -351) imp:n=1 u=1200 \$ Water in Tie Rod Hole

$1216439.1820 \mathrm{E}-0210-309 \mathrm{imp}: \mathrm{n}=1 \mathrm{u}=1200$ \$ Upper Assembly

$121719.9961 \mathrm{E}-02309$ imp:n=1 u=1200 \$ Water Above Core

$121819.9961 \mathrm{E}-02(9-10)(-331: 332:-333: 334: 335: 336: 337: 338)$ imp:n=1 u=1200 $\$$ Water Around Assembly

C -...- Position C-1 : Graphite Reflector -....

$130119.9961 \mathrm{E}-02$-5 imp:n=1 u=1300 \$ Water Below Grid Plate

$1303636.9890 \mathrm{E}-025-7$ imp:n=1 u=1300 \$ Grid Plate With Adapter

$1304447.6788 \mathrm{E}-02 \quad 7-9$ imp:n=1 u=1300 \$ Lower Adapter

$1305417.8699 \mathrm{E}-02(9-10)(-9: 303: 354)(-9: 303: 355) \quad(-9: 305: 351) \quad(-306: 10: 356)$

$(-306: 10: 357)(331-332 \quad 333-334)(-335-336-337-338)$

imp: $\mathrm{n}=1 \mathrm{u}=1300$ \$ Graphite Block

$1306426.0307 \mathrm{E}-02307-10-356$ imp:n=1 u=1300 \$ Top Screw NE

$1307426.0307 \mathrm{E}-02307-10-357$ imp:n=1 u=1300 \$ Top Screw SW

$130819.9961 \mathrm{E}-02306-307-356$ imp:n=1 u=1300 \$ Water in NE Top Hole

$130919.9961 \mathrm{E}-02306-307-357$ imp:n=1 u=1300 \$ Water in SW Top Hole

$1310426.0307 E-029-302-352$ imp:n=1 u=1300 \$ Bottom Dowel NE

$131142 \quad 6.0307 E-02 \quad 9-302-353$ imp:n=1 u=1300 \$ Bottom Dowel SW

$1312426.0307 \mathrm{E}-029-304-351$ imp:n=1 u=1300 \$ Tie Rod

$131319.9961 \mathrm{E}-02(9-303352-354):(302-303-354)$ imp:n=1 u=1300 \$ Water in NE Bottom Hole

$131419.9961 E-02(9-303$ 353-355):(302 -303-355) imp:n=1 u=1300 \$ Water in sW Bottom Hole

$131519.9961 \mathrm{E}-02$ (304-305 -351) imp:n=1 u=1300 \$ Water in Tie Rod Hole

$1316439.1820 \mathrm{E}-0210-309$ imp:n=1 u=1300 \$ Upper Assembly

$131719.9961 \mathrm{E}-02309 \mathrm{imp}: \mathrm{n}=1 \mathrm{u}=1300$ \$ Water Above Core

$131819.9961 \mathrm{E}-02(9-10)(-331: 332:-333: 334: 335: 336: 337: 338)$ imp:n=1 u=1300 $\$$ Water Around Assembly

C -.-- Position C-2 : Shim Rod 2 Control Cluster -..-.

C -..... NW Fuel Rod : 11752 .......

$1401148.7412 \mathrm{E}-02$ (-103-151):(102 -103-156) imp:n=1 u=1401 \$ Bottom End Fitting

$1402118.6735 \mathrm{E}-02103-104-152$ imp:n=1 u=1401 \$ Bottom Graphite Reflector

$1403126.4196 \mathrm{E}-02104-105-153$ imp:n=1 u=1401 \$ Moly Poison Disc

$1404134.3026 \mathrm{E}-02105-106-154$ imp:n=1 u=1401 \$ Zirconium Rod

$147025.0820 \mathrm{E}-05105-106154-159 \mathrm{imp}: \mathrm{n}=1 \mathrm{u}=1401$ \$r/Fuel Gap

$14051018.9399 \mathrm{E}-02105-106159-155$ imp:n=1 u=1401 \$ Fuel Rod

$1406118.6735 \mathrm{E}-02106-107-152$ imp:n=1 u=1401 \$ Top Graphite Reflector

$140725.0820 \mathrm{E}-05(-103: 104: 152)(-104: 105: 153) \quad(-105: 106: 155)$

$(-106: 107: 152) \quad(103-108-156)$ imp:n=1 u=1401 \$ Air Gap

$1408148.7412 \mathrm{E}-02102-109156-157$ imp:n=1 u=1401 \$ Cladding

$1409148.7412 \mathrm{E}-02$ (108-158):(108-109-156) imp:n=1 u=1401 \$ Top End Fitting

$141019.9961 \mathrm{E}-02$ 157:(-102 151):(109 158) imp:n=1 u=1401 \$ Water

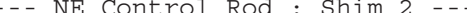

$1411148.7412 \mathrm{E}-02-201-251$ imp:n=1 u=1402 \$ Bottom End Fitting

141223 6.7723E-02 201 -202 -253 imp:n=1 u=1402 \$ Guide Tube Bottom

$1413256.1351 \mathrm{E}-02202-203252$-253 imp:n=1 u=1402 \$ Guide Tube

$141419.9961 \mathrm{E}-02(-201$ 251):253:(203 252) imp:n=1 u=1402 \$ Water Outside Guide Tube

$1450225.9939 \mathrm{E}-02 \quad 231-232-275$ imp:n=1 u=1406 \$ Bottom End Fitting

145121 1.3514E-01 $232-233-271$ imp:n=1 u=1406 \$ Absorber

145222 5.9939E-02 $233-234272$-271 imp:n=1 u=1406 \$ Spacer Disc

$1453225.9939 \mathrm{E}-02234-235273-274$ imp:n=1 u=1406 \$ Spacer Tube

$14540\left(\begin{array}{lllll}232 & -234 & 271 & -275\end{array}\right):\left(\begin{array}{llll}233 & -234 & -272\end{array}\right):\left(\begin{array}{lllll}234 & -235 & -273\end{array}\right):\left(\begin{array}{lllll}234 & -235 & 274 & -275\end{array}\right)$

imp:n=1 u=1406 \$ Void Space

$1455225.9939 \mathrm{E}-02(235-236-275):(236-237-277)$ imp:n=1 u=1406 \$ Top End Fitting

$145622 \quad 5.9939 \mathrm{E}-02 \quad 231-236 \quad 275$-276 imp:n=1 u=1406 \$ Cladding

$1457246.8709 \mathrm{E}-02 \quad 237-238-278$ imp:n=1 u=1406 \$ Attachment Interface

$145825.0820 \mathrm{E}-05238-239-279$ imp:n=1 u=1406 \$ Inside Extension Rod

$1459225.9939 E-02238-239279-280$ imp:n=1 u=1406 \$ Extension Rod

$146019.9961 E-02(-231-276):(276):\left(\begin{array}{lll}236 & 278\end{array}\right):(238$ 280 $):\left(\begin{array}{llll}236 & -237 & 277\end{array}\right):(239)$

imp:n=1 u=1406 \$ Water around Control Rod

C -....... SW Fuel Rod: $11753 \ldots \ldots$

$1421148.7412 \mathrm{E}-02$ (-103 -151):(102 -103-156) imp:n=1 u=1403 \$ Bottom End Fitting

142211 8.6735E-02 103-104-152 imp:n=1 u=1403 \$ Bottom Graphite Reflector

142312 6.4196E-02 $104-105-153$ imp:n=1 u=1403 \$ Moly Poison Disc 


\section{NEA/NSC/DOC(2006)1}

\section{Fundamental - FUND}

\section{NRAD-FUND-RESR-001 CRIT}

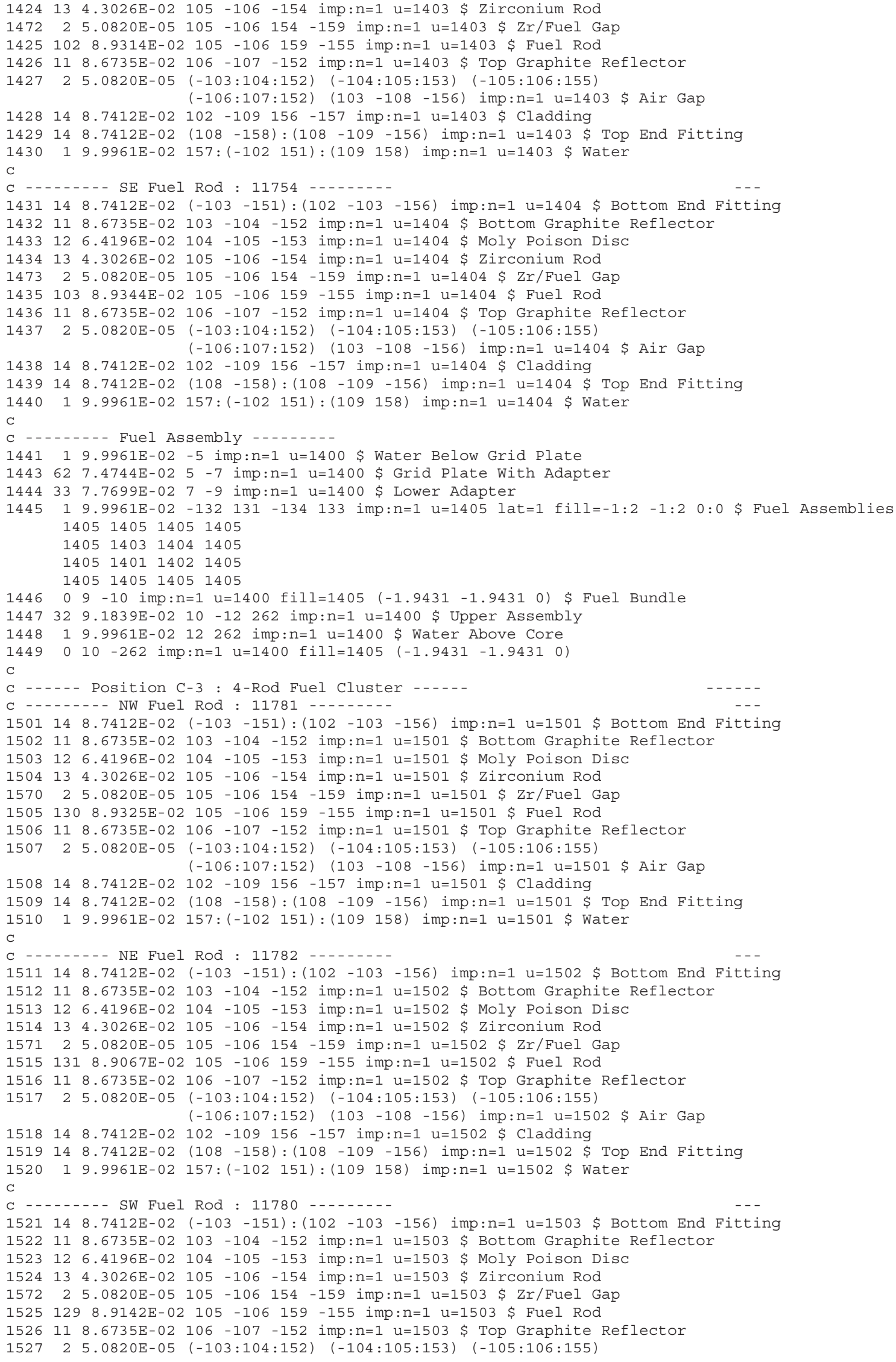


NEA/NSC/DOC(2006)1

Fundamental - FUND

NRAD-FUND-RESR-001 CRIT

$(-106: 107: 152) \quad(103-108-156)$ imp:n=1 u=1503 \$ Air Gap

$152814 \quad 8.7412 \mathrm{E}-02 \quad 102-109 \quad 156-157$ imp:n=1 u=1503 \$ Cladding

$152914 \quad 8.7412 \mathrm{E}-02 \quad(108-158):(108-109-156)$ imp:n=1 u=1503 \$ Top End Fitting

$153019.9961 \mathrm{E}-02$ 157:(-102 151):(109 158) imp:n=1 u=1503 \$ Water

$\mathrm{C}$

C -...... SE Fuel Rod : 11783 -......

$1531148.7412 \mathrm{E}-02 \quad(-103-151):(102-103-156)$ imp:n=1 u=1504 \$ Bottom End Fitting

153211 8.6735E-02 $103-104-152$ imp:n=1 u=1504 \$ Bottom Graphite Reflector

$1533126.4196 \mathrm{E}-02104-105$-153 imp:n=1 $u=1504$ \$ Moly Poison Disc

$153413 \quad 4.3026 \mathrm{E}-02 \quad 105-106-154$ imp:n=1 u=1504 \$ Zirconium Rod

$157325.0820 \mathrm{E}-05 \quad 105-106 \quad 154-159$ imp:n=1 u=1504 \$ $\mathrm{Zr} / \mathrm{Fuel}$ Gap

$1535132 \quad 8.9077 \mathrm{E}-02 \quad 105-106159-155$ imp:n=1 u=1504 \$ Fuel Rod

153611 8.6735E-02 $106-107-152$ imp:n=1 u=1504 \$ Top Graphite Reflector

$153725.0820 \mathrm{E}-05(-103: 104: 152)(-104: 105: 153)(-105: 106: 155)$

$(-106: 107: 152) \quad(103-108-156)$ imp:n=1 u=1504 \$ Air Gap

$153814 \quad 8.7412 \mathrm{E}-02 \quad 102-109 \quad 156-157 \quad \mathrm{imp}: \mathrm{n}=1 \mathrm{u}=1504 \quad$ \$ Cladding

$153914 \quad 8.7412 \mathrm{E}-02$ (108 - 158):(108 - 109 -156) imp:n=1 u=1504 \$ Top End Fitting

$154019.9961 \mathrm{E}-02$ 157:(-102 151):(109 158) imp:n=1 u=1504 \$ Water

$\mathrm{C}$

C -...... Fuel Assembly -.......

$154119.9961 \mathrm{E}-02$-5 imp:n=1 u=1500 \$ Water Below Grid Plate

154362 7.4744E-02 5 -7 imp:n=1 u=1500 \$ Grid Plate With Adapter

154433 7.7699E-02 7 -9 imp:n=1 u=1500 \$ Lower Adapter

$154519.9961 \mathrm{E}-02-132$ 131 - 134 133 imp:n=1 u=1505 lat=1 fill=-1:2 -1:2 0:0 \$ Fuel Assemblies

1505150515051505

$150515031504 \quad 1505$

1505150115021505

1505150515051505

$154609-10$ imp:n=1 u=1500 fill=1505 (-1.9431 -1.9431 0) \$ Fuel Bundle

$1547319.3070 \mathrm{E}-02 \quad 10-12$ imp:n=1 u=1500 \$ Upper Assembly

$154819.9961 \mathrm{E}-0212$ imp:n=1 u=1500 \$ Water Above Core

$\mathrm{C}$

C ----- Position C-4 : Sample Irradiation Cluster -.-.--

C -...... NW Fuel Rod : 11761 ........

160211 8.6735E-02 103 -104 -152 imp:n=1 u=1601 \$ Bottom Graphite Reflector

$1603126.4196 \mathrm{E}-02104-105$-153 imp:n=1 u=1601 \$ Moly Poison Disc

$160413 \quad 4.3026 \mathrm{E}-02 \quad 105-106-154$ imp:n=1 u=1601 \$ Zirconium Rod

$167025.0820 \mathrm{E}-05105-106 \quad 154-159$ imp:n=1 u=1601 \$ Zr/Fuel Gap

$16051108.9141 \mathrm{E}-02105-106159-155$ imp:n=1 u=1601 \$ Fuel Rod

$1606118.6735 \mathrm{E}-02106-107-152$ imp:n=1 u=1601 \$ Top Graphite Reflector

$160725.0820 \mathrm{E}-05(-103: 104: 152)(-104: 105: 153)(-105: 106: 155)$

$(-106: 107: 152) \quad(103-108-156)$ imp:n=1 u=1601 \$ Air Gap

$160814 \quad 8.7412 \mathrm{E}-02 \quad 102-109 \quad 156-157 \quad \mathrm{imp}: \mathrm{n}=1 \mathrm{u}=1601$ \$ Cladding

160914 8.7412E-02 (108 -158):(108 -109 -156) imp:n=1 u=1601 \$ Top End Fitting

$161019.9961 \mathrm{E}-02$ 157:(-102 151):(109 158) imp:n=1 u=1601 \$ Water

C

C - - . - NE Fuel Rod : 11762

$1611148.7412 \mathrm{E}-02(-103-151):(102-103-156)$ imp:n=1 u=1602 \$ Bottom End Fitting

161211 8.6735E-02 $103-104-152$ imp:n=1 u=1602 \$ Bottom Graphite Reflector

$1613126.4196 \mathrm{E}-02104-105-153$ imp:n=1 u=1602 \$ Moly Poison Disc

$161413 \quad 4.3026 \mathrm{E}-02 \quad 105-106$-154 imp:n=1 u=1602 \$ Zirconium Rod

$167125.0820 \mathrm{E}-05105-106154-159$ imp:n=1 u=1602 \$ Zr/Fuel Gap

$16151118.9222 \mathrm{E}-02105-106159-155 \mathrm{imp}: \mathrm{n}=1 \mathrm{u}=1602$ \$ Fuel Rod

161611 8.6735E-02 $106-107-152$ imp:n=1 u=1602 \$ Top Graphite Reflector

$161725.0820 \mathrm{E}-05(-103: 104: 152)(-104: 105: 153)(-105: 106: 155)$

$(-106: 107: 152) \quad(103-108-156)$ imp:n=1 u=1602 \$ Air Gap

$161814 \quad 8.7412 \mathrm{E}-02 \quad 102-109156-157$ imp:n=1 u=1602 \$ Cladding

161914 8.7412E-02 (108 -158):(108 -109 -156) imp:n=1 u=1602 \$ Top End Fitting

$162019.9961 \mathrm{E}-02$ 157:(-102 151):(109 158) imp:n=1 u=1602 \$ Water

C -...-. SW Water Hole (Irradiation Position) -.......

$162114 \quad 8.7412 \mathrm{E}-02-201-251$ imp:n=1 u=1603 \$ Bottom End Fitting

$1622236.7723 \mathrm{E}-02 \quad 201-202-253$ imp:n=1 u=1603 \$ Guide Tube Bottom

$1623256.1351 \mathrm{E}-02 \quad 202-203252-253$ imp:n=1 u=1603 \$ Guide Tube

$1624 \quad 1 \quad 9.9961 \mathrm{E}-02 \quad(-201251): 253:(203252)$ imp:n=1 u=1603 \$ Water Outside Guide Tube

$162519.9961 \mathrm{E}-02202-252$ imp:n=1 u=1603 \$ Water Hole

$\mathrm{C}$

C -...... SE Fuel Rod : 11763 -......

$1631148.7412 \mathrm{E}-02(-103-151):(102-103-156)$ imp:n=1 u=1604 \$ Bottom End Fitting

163211 8.6735E-02 $103-104-152$ imp:n=1 u=1604 \$ Bottom Graphite Reflector

$1633126.4196 \mathrm{E}-02104-105$-153 imp:n=1 u=1604 \$ Moly Poison Disc

$163413 \quad 4.3026 \mathrm{E}-02 \quad 105-106-154$ imp:n=1 u=1604 \$ Zirconium Rod

$167325.0820 \mathrm{E}-05105-106 \quad 154-159$ imp:n=1 u=1604 \$ $\mathrm{Zr} / \mathrm{Fuel}$ Gap

$16351128.9222 \mathrm{E}-02105-106159-155 \mathrm{imp}: \mathrm{n}=1 \mathrm{u}=1604$ \$ Fuel Rod

$1636118.6735 \mathrm{E}-02106-107-152$ imp:n=1 u=1604 \$ Top Graphite Reflector 
NEA/NSC/DOC(2006)1

Fundamental - FUND

NRAD-FUND-RESR-001 CRIT

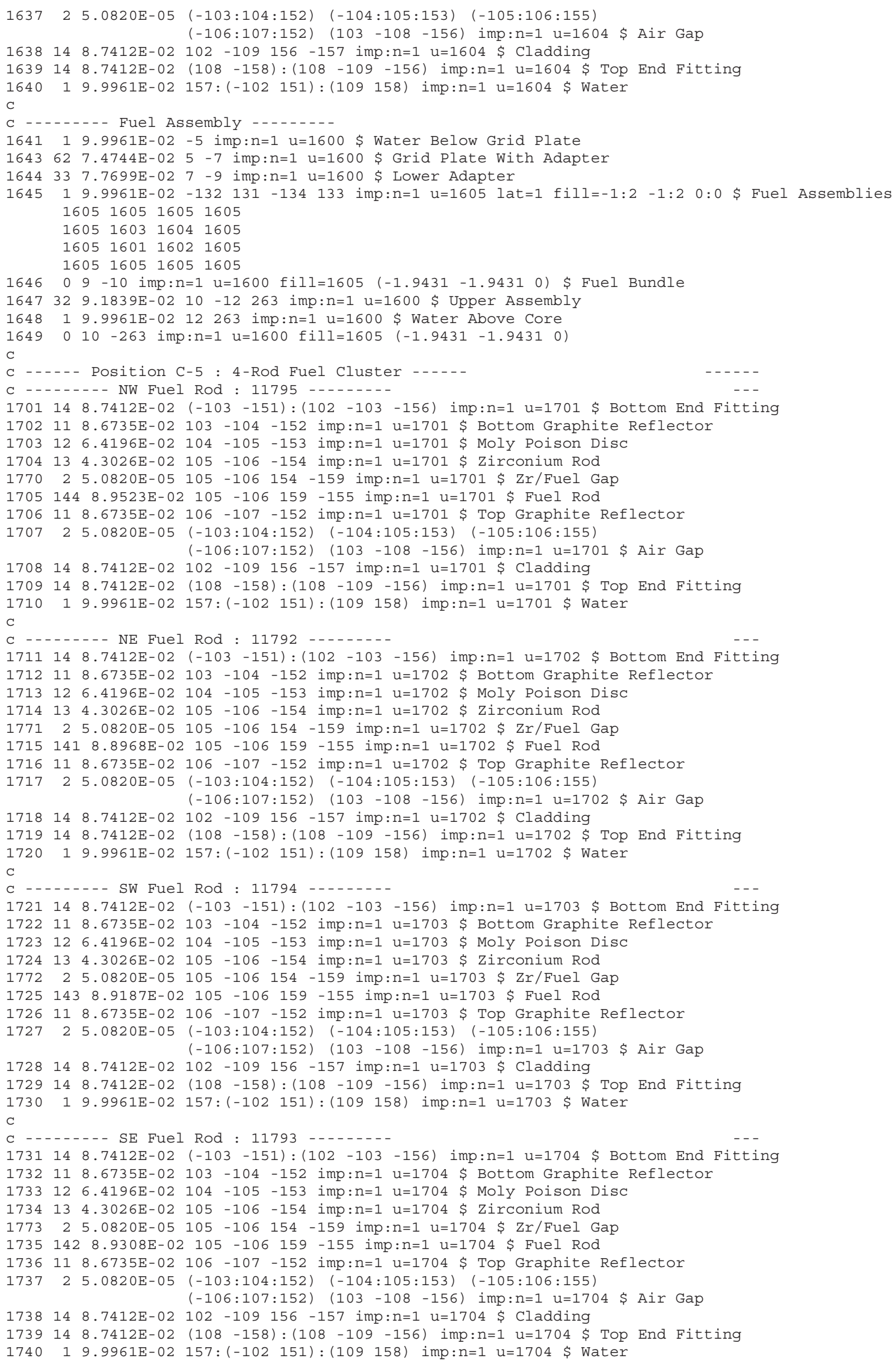


NEA/NSC/DOC(2006)1

\section{Fundamental - FUND}

\section{NRAD-FUND-RESR-001} CRIT

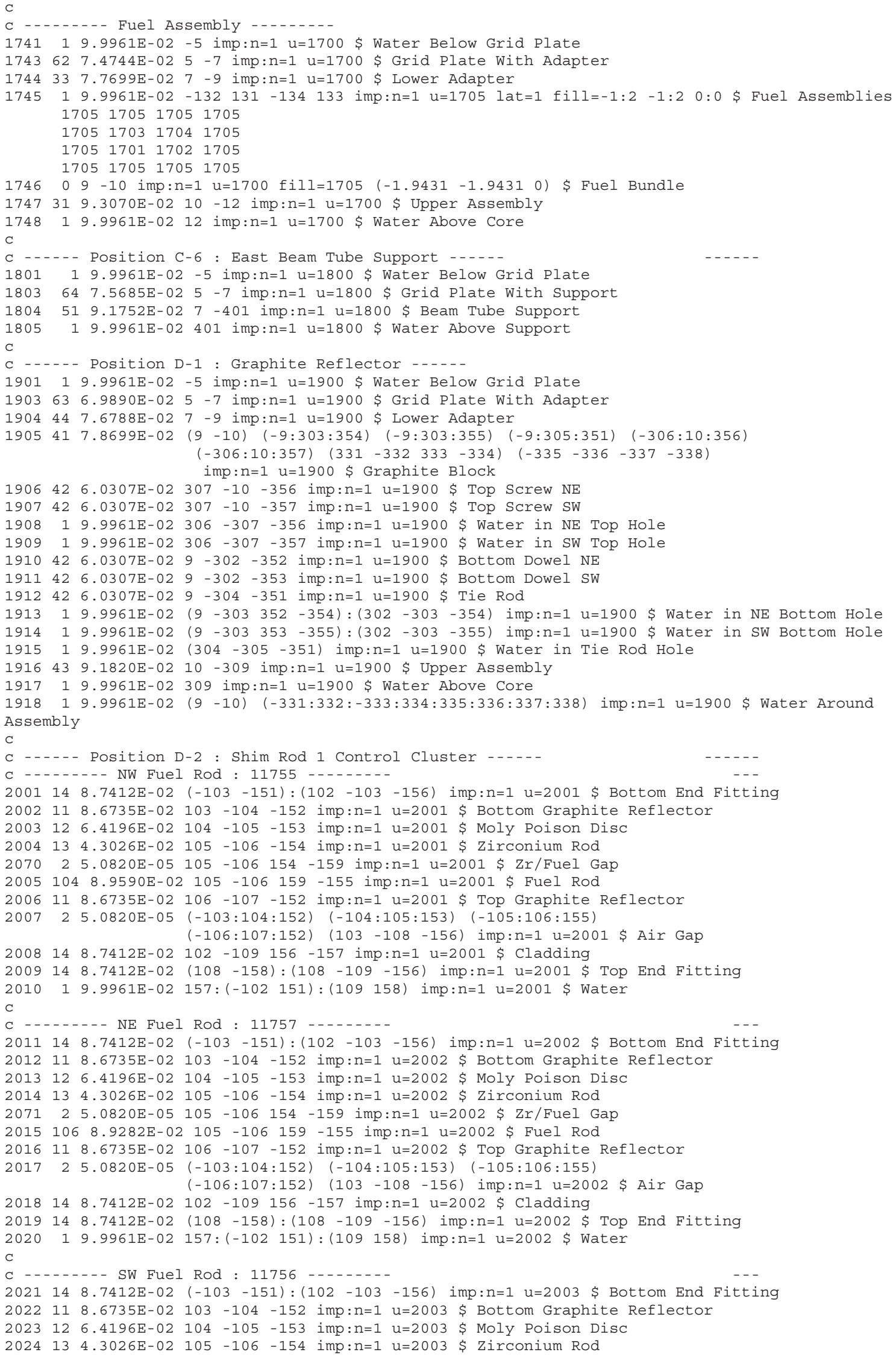




\section{NEA/NSC/DOC(2006)1}

\section{Fundamental - FUND}

\section{NRAD-FUND-RESR-001 CRIT}

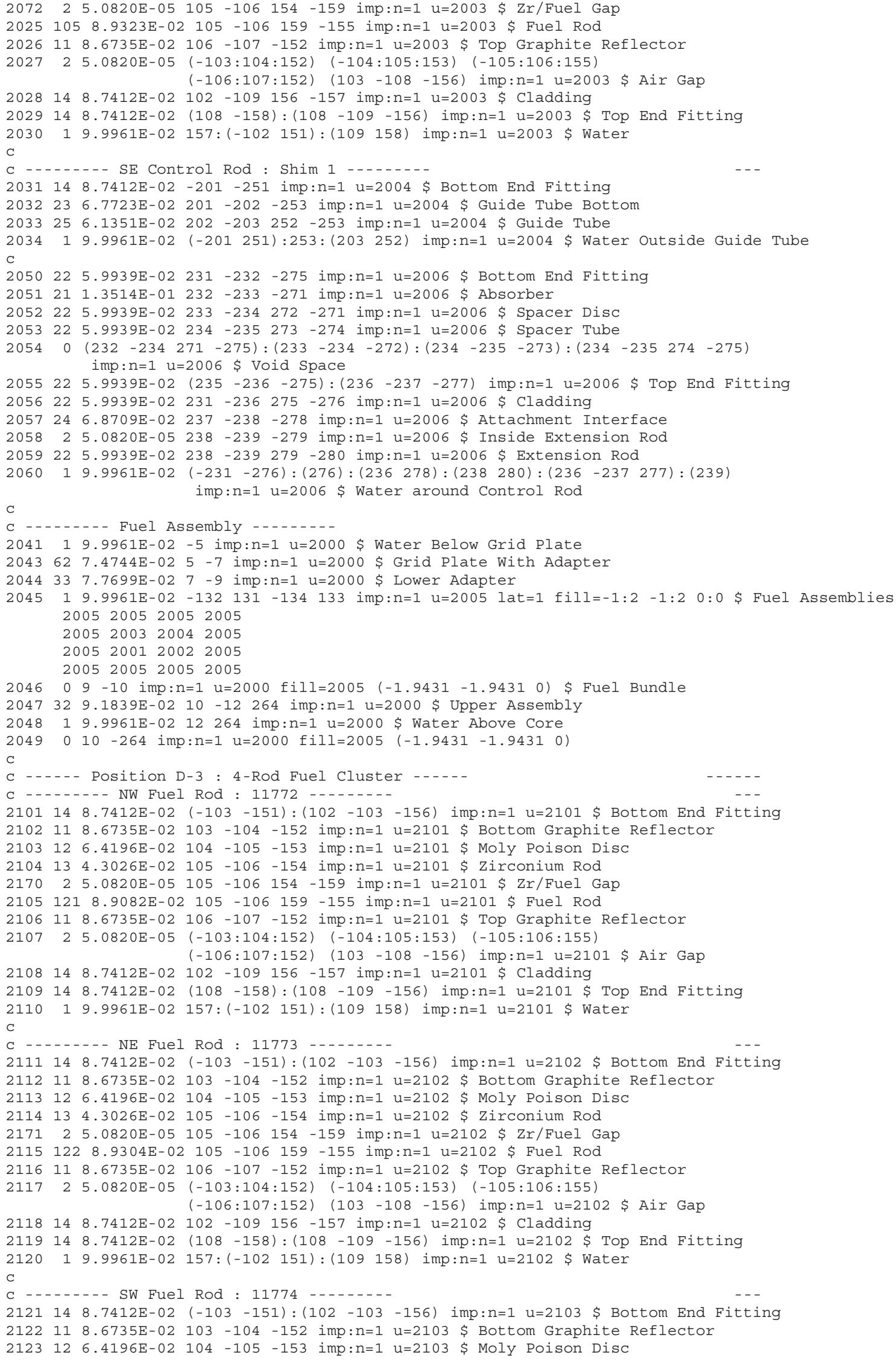




\section{NEA/NSC/DOC(2006)1}

\section{Fundamental - FUND}

\section{NRAD-FUND-RESR-001 CRIT}

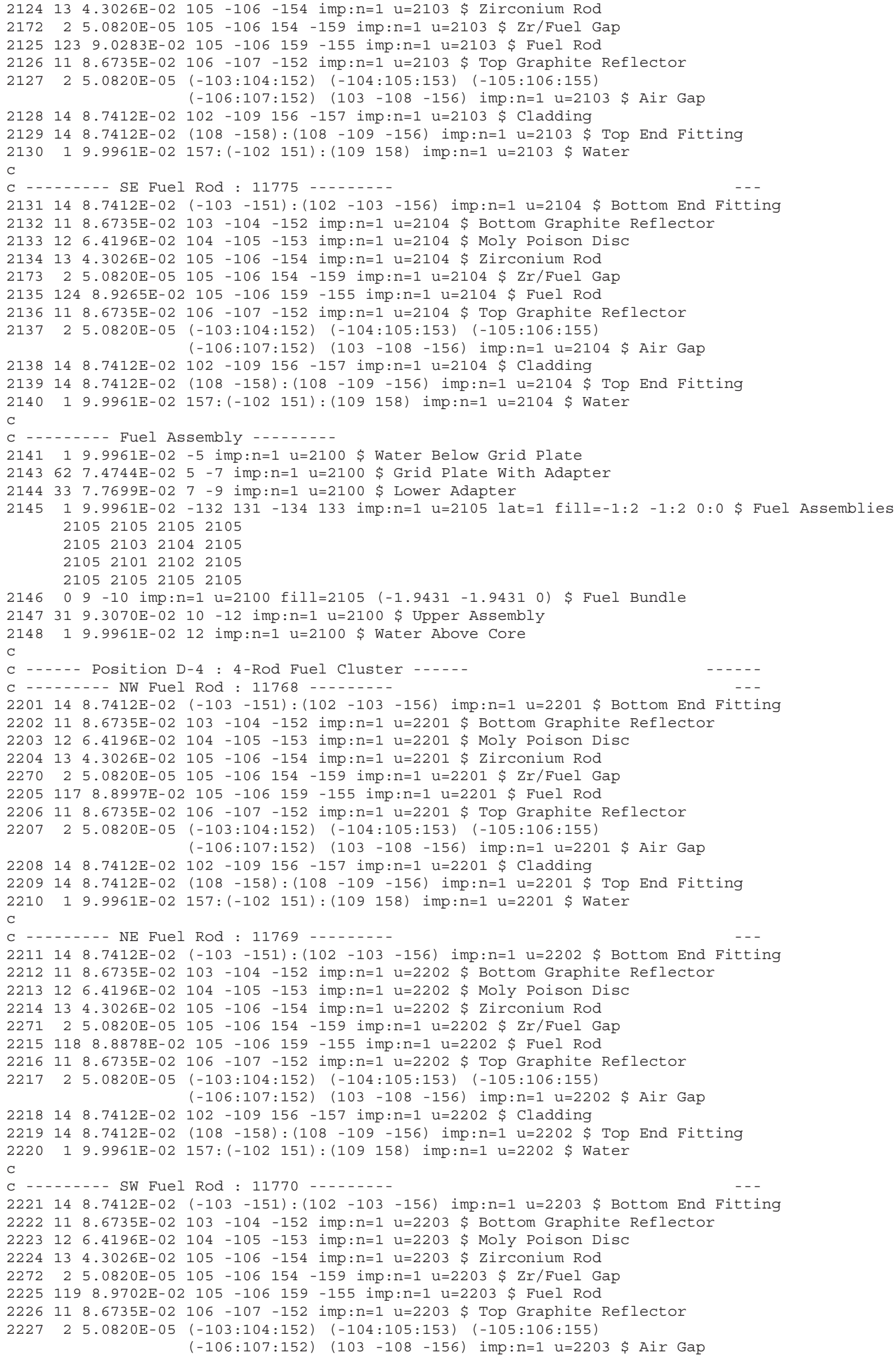


NEA/NSC/DOC(2006)1

Fundamental - FUND

NRAD-FUND-RESR-001 CRIT

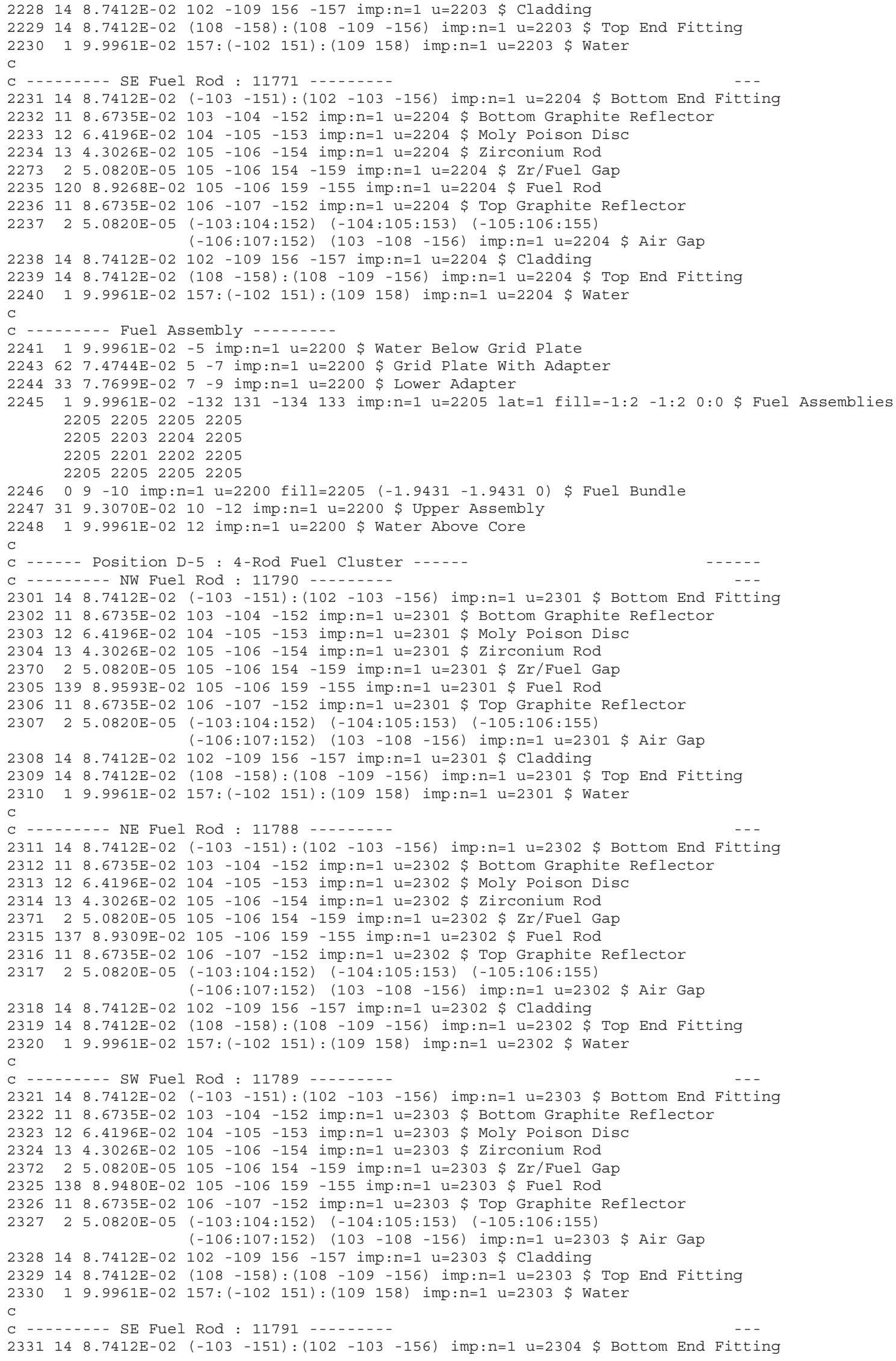




\section{NEA/NSC/DOC(2006)1}

\section{Fundamental - FUND}

\section{NRAD-FUND-RESR-001 CRIT}

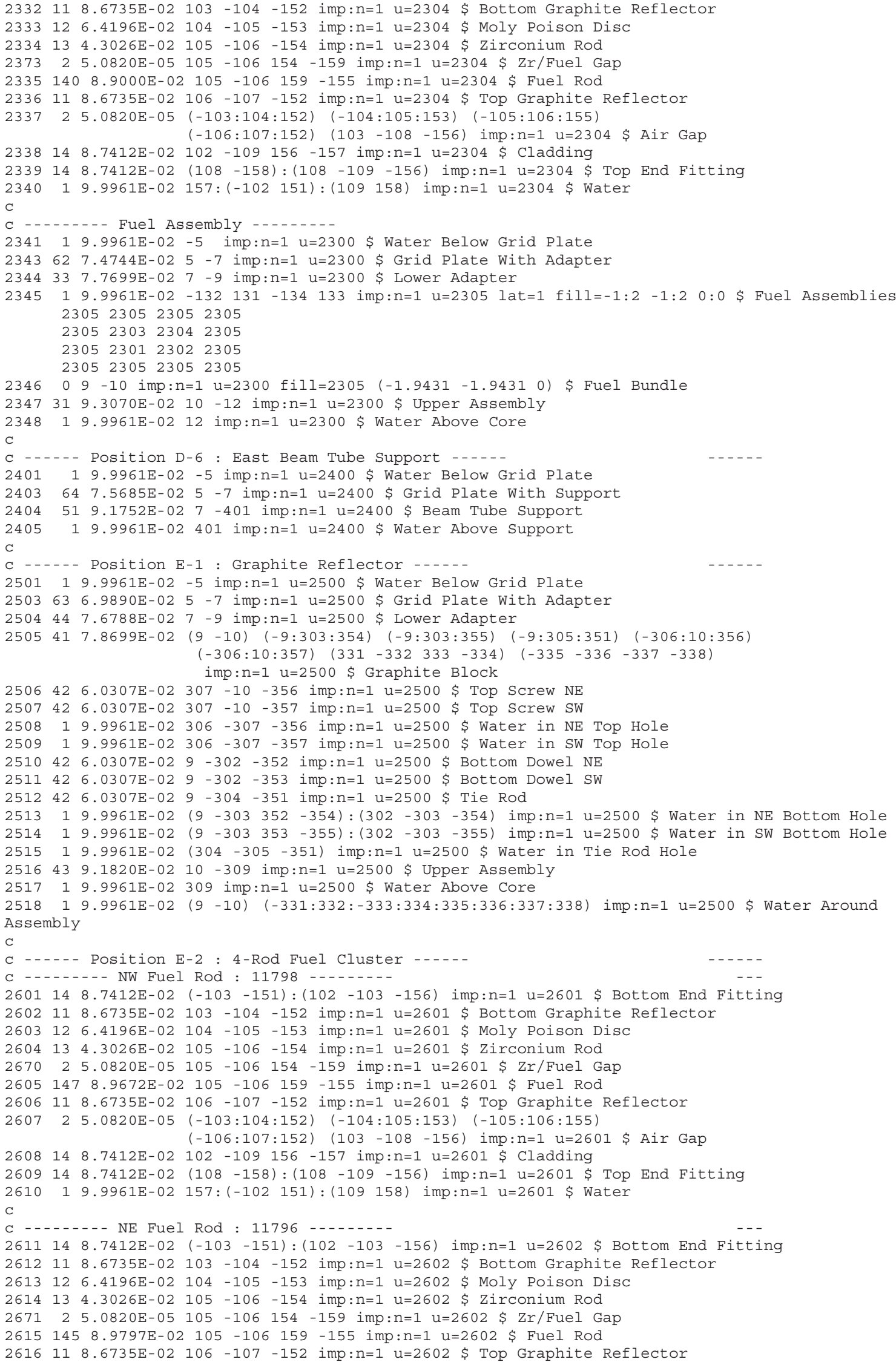


NEA/NSC/DOC(2006)1

Fundamental - FUND

NRAD-FUND-RESR-001 CRIT

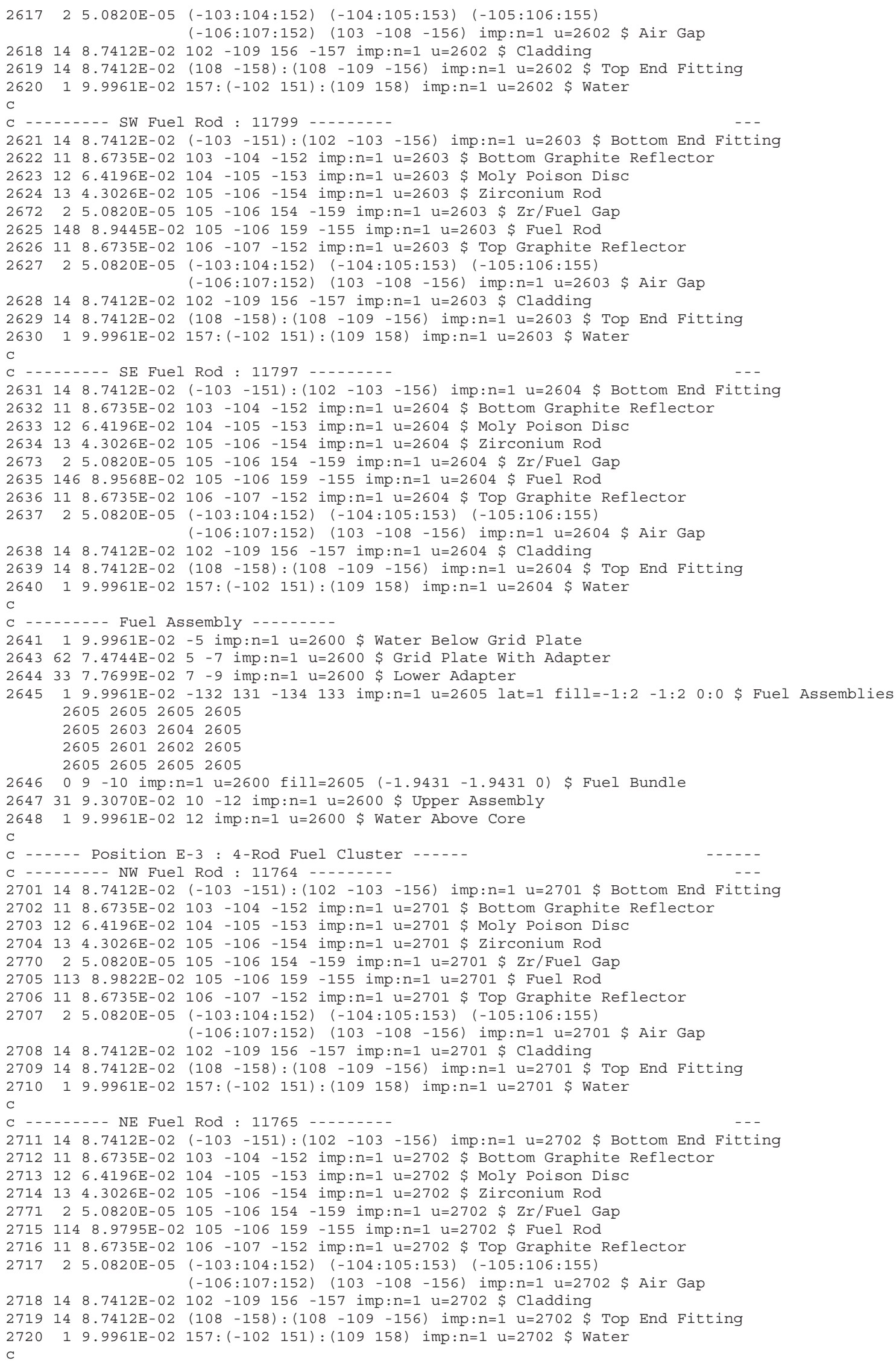




\section{NEA/NSC/DOC(2006)1}

\section{Fundamental - FUND}

\section{NRAD-FUND-RESR-001 CRIT}

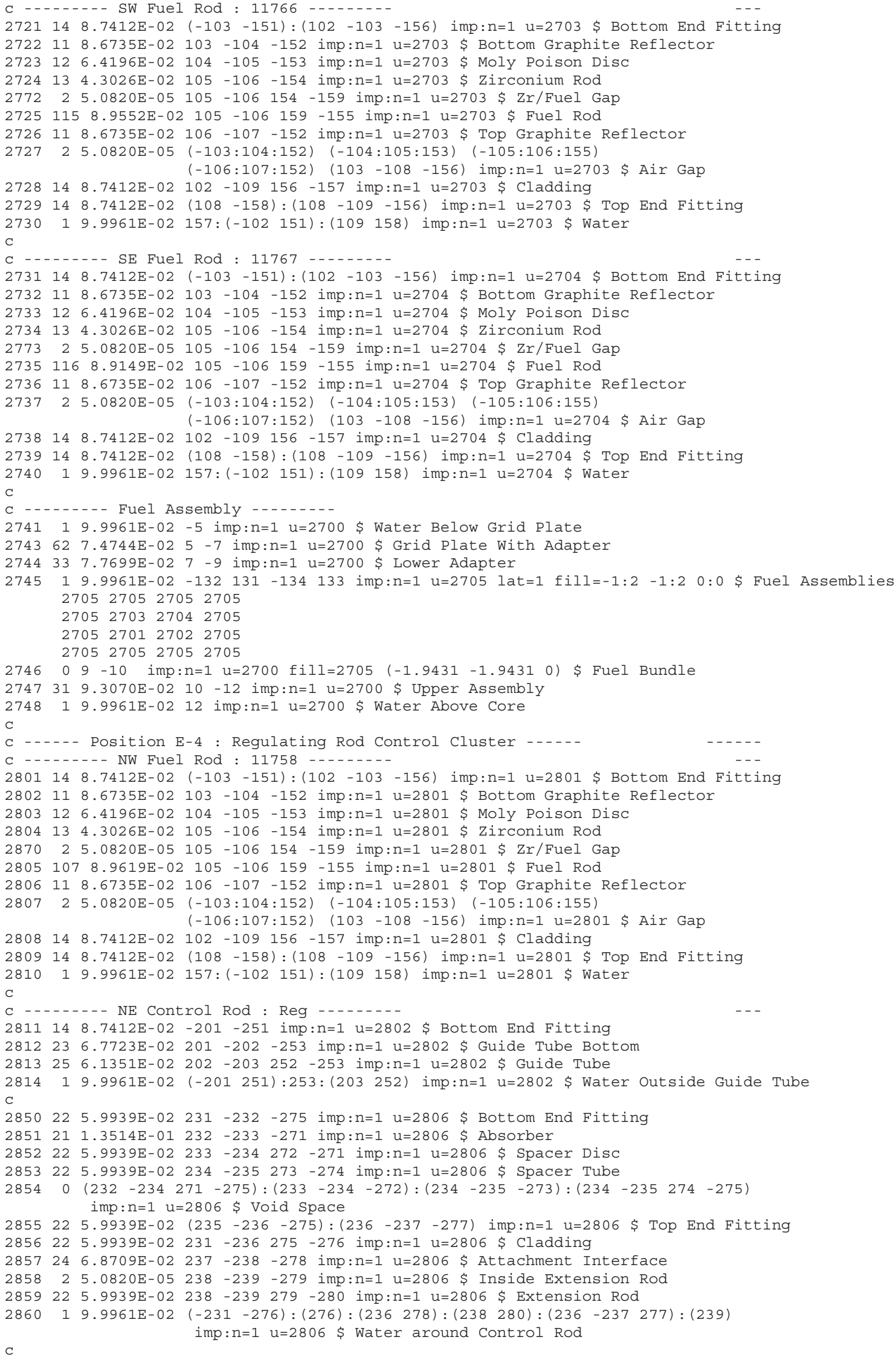




\section{NEA/NSC/DOC(2006)1}

\section{Fundamental - FUND}

\section{NRAD-FUND-RESR-001 CRIT}

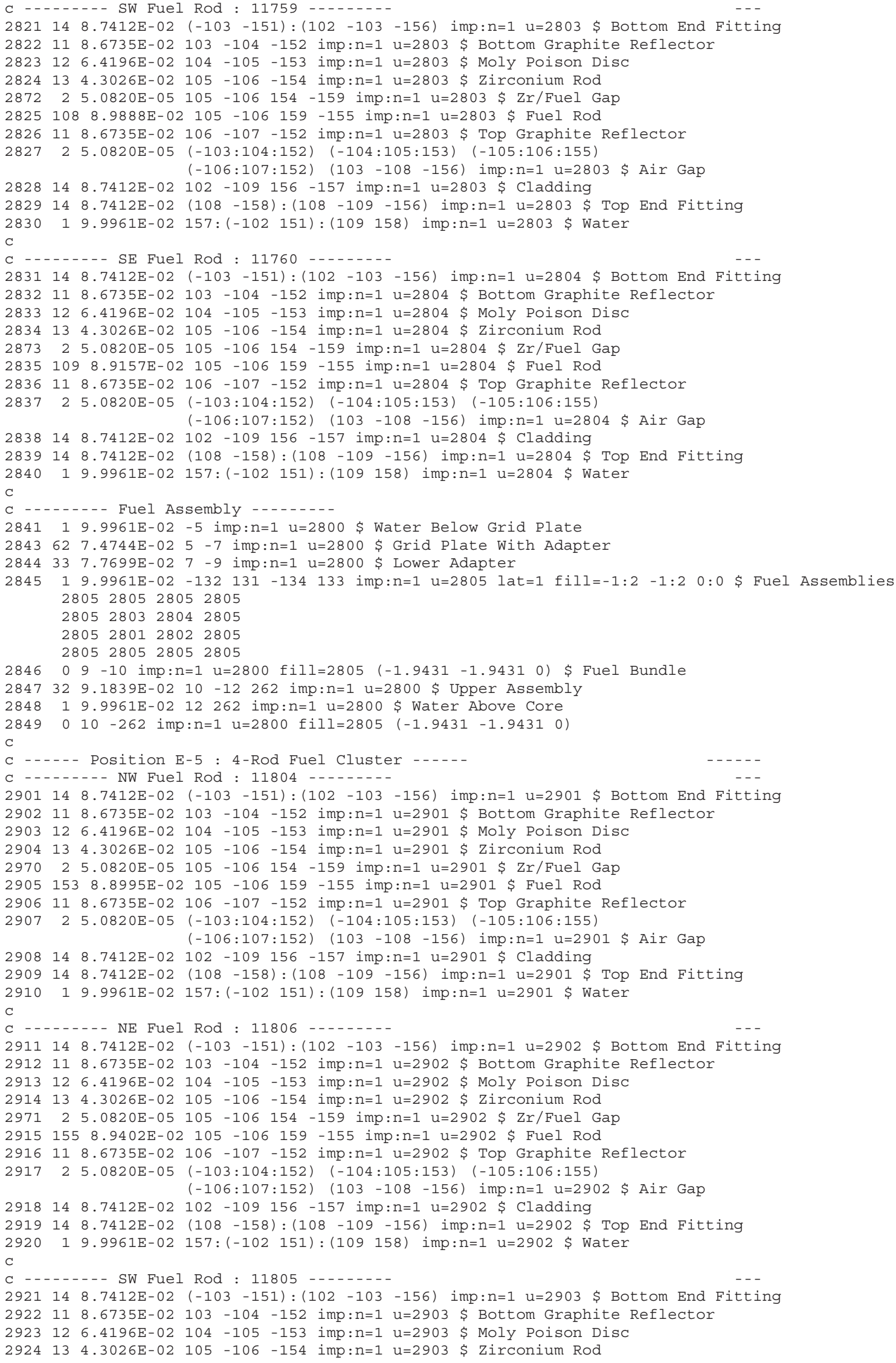




\section{NEA/NSC/DOC(2006)1}

\section{Fundamental - FUND}

\section{NRAD-FUND-RESR-001 CRIT}

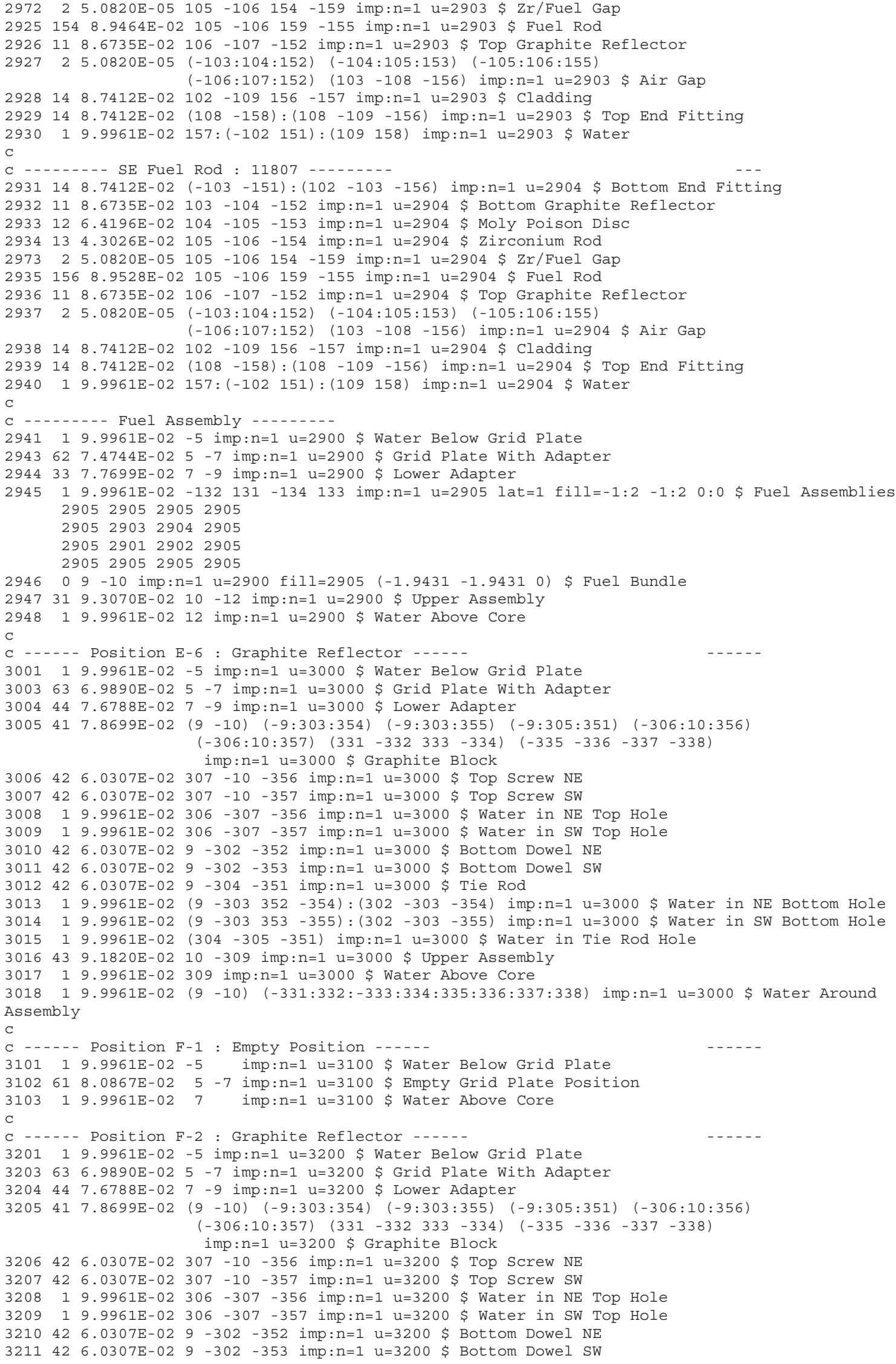


NEA/NSC/DOC(2006)1

Fundamental - FUND

NRAD-FUND-RESR-001

CRIT

$3212426.0307 \mathrm{E}-02 \quad 9-304-351$ imp:n=1 u=3200 \$ Tie Rod

$321319.9961 \mathrm{E}-02(9-303 \quad 352-354):(302-303-354)$ imp:n=1 u=3200 \$ Water in NE Bottom Hole $321419.9961 \mathrm{E}-02(9-303 \quad 353-355):(302-303-355)$ imp:n=1 u=3200 \$ Water in sW Bottom Hole $321519.9961 \mathrm{E}-02(304-305-351)$ imp:n=1 $u=3200$ \$ Water in Tie Rod Hole

$3216439.1820 \mathrm{E}-02 \quad 10-309$ imp:n=1 u=3200 \$ Upper Assembly

$321719.9961 \mathrm{E}-02309$ imp:n=1 u=3200 \$ Water Above Core

$321819.9961 \mathrm{E}-02$ (9 -10) (-331:332:-333:334:335:336:337:338) imp:n=1 u=3200 \$ Water Around Assembly

$\mathrm{C}$

C --.-- Position F-3 : Graphite Reflector (AmBe Source) -...--

$330119.9961 \mathrm{E}-02$ - 5 imp:n=1 u=3300 \$ Water Below Grid Plate

$3303636.9890 \mathrm{E}-025-7$ imp:n=1 u=3300 \$ Grid Plate With Adapter

$3304447.6788 \mathrm{E}-027-9$ imp:n=1 u=3300 \$ Lower Adapter

$3305417.8699 \mathrm{E}-02(9-10)(-9: 303: 354)(-9: 303: 355) \quad(-9: 305: 351) \quad(-306: 10: 356)$

$(-306: 10: 357)(331-332 \quad 333-334)(-335-336-337-338)$

$(-321: 322: 372)(341: 376)(-322: 371)$ imp:n=1 u=3300 \$ Graphite Block

$3306426.0307 \mathrm{E}-02 \quad 307-10-356$ imp:n=1 u=3300 \$ Top Screw NE

$3307426.0307 \mathrm{E}-02 \quad 307-10-357$ imp:n=1 u=3300 \$ Top Screw SW

$330819.9961 \mathrm{E}-02306-307-356$ imp:n=1 $u=3300$ \$ Water in NE Top Hole

$330919.9961 \mathrm{E}-02306-307-357$ imp:n=1 u=3300 \$ Water in SW Top Hole

$3310426.0307 \mathrm{E}-029-302-352$ imp:n=1 u=3300 \$ Bottom Dowel NE

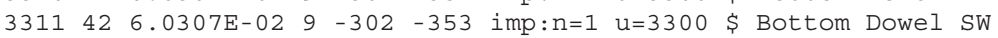

$331242 \quad 6.0307 \mathrm{E}-02 \quad 9-304-351$ imp:n=1 u=3300 \$ Tie Rod

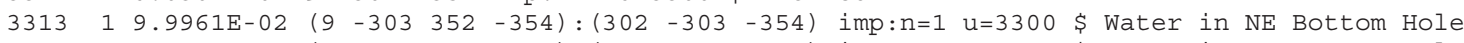

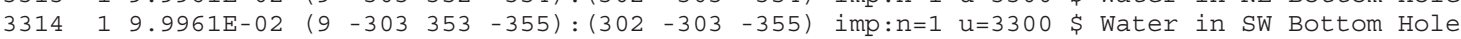

$331519.9961 \mathrm{E}-02(304-305-351)$ imp:n=1 $u=3300$ \$ Water in Tie Rod Hole

$3316479.0981 \mathrm{E}-0210-309375 \mathrm{imp}: \mathrm{n}=1 \mathrm{u}=3300$ \$ Upper Assembly

$331719.9961 \mathrm{E}-02309$ imp:n=1 u=3300 \$ Water Above Core

$331819.9961 \mathrm{E}-02(9-10)(-331: 332:-333: 334: 335: 336: 337: 338)$ imp:n=1 u=3300 \$ Water Around Assembly

C

$\left.\begin{array}{llllll}3331 & 1 & 9.9961 E-02 & (-341 & 333 & -376\end{array}\right):\left(\begin{array}{llll}321 & -322 & -372\end{array}\right):\left(\begin{array}{llll}373 & -371 & 322 & -324\end{array}\right)$

imp: $\mathrm{n}=1 \mathrm{u}=3300$ \$ Water in Source Hole

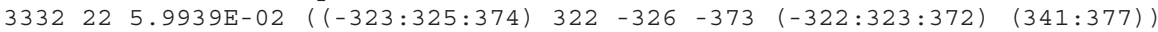

$:\left(\begin{array}{llllll}326 & -327 & 342 & -343 & 344 & -345\end{array}\right):\left(\begin{array}{llll}324 & -326 & -375 & 373\end{array}\right)$

imp:n=1 u=3300 \$ Source Tube

$333319.9961 \mathrm{E}-02\left((-341-371-377):\left(\begin{array}{llll}322 & -323 & -372\end{array}\right):(323-325-374)\right)$

$(-323: 313: 362):(10-324371-375)$ imp: $n=1 \quad u=3300$ \$ water in Source Tube

$333419.9961 \mathrm{E}-02(-326: 327:-342: 343:-344: 345) 326-309-375 \mathrm{imp}: \mathrm{n}=1 \mathrm{u}=3300$ \$ Water Above Source

Tube

$3335468.7653 \mathrm{E}-02 \quad(-311: 312: 361) \quad 323-313-362$ imp:n=1 u=3300 \$ Source Capsule

$3336454.1093 \mathrm{E}-03311-312-361$ imp:n=1 u=3300 \$ Smeared AmBe Source

C

C -...- Position F-4 : Graphite Reflector -...-.

3401 1 9.9961E-02 -5 imp:n=1 u=3400 \$ Water Below Grid Plate

$3403636.9890 \mathrm{E}-025$-7 imp:n=1 u=3400 \$ Grid Plate With Adapter

$3404447.6788 \mathrm{E}-027-9$ imp:n=1 u=3400 \$ Lower Adapter

$3405417.8699 \mathrm{E}-02(9-10)(-9: 303: 354)(-9: 303: 355)(-9: 305: 351) \quad(-306: 10: 356)$

$(-306: 10: 357)(331-332 \quad 333-334)(-335-336-337-338)$

imp:n=1 u=3400 \$ Graphite Block

$3406426.0307 \mathrm{E}-02 \quad 307-10-356$ imp:n=1 u=3400 \$ Top Screw NE

$3407426.0307 \mathrm{E}-02 \quad 307-10-357 \quad \mathrm{imp}: \mathrm{n}=1 \quad \mathrm{u}=3400 \quad \$$ Top Screw SW

$340819.9961 \mathrm{E}-02306-307-356$ imp:n=1 u=3400 \$ Water in NE Top Hole

$340919.9961 \mathrm{E}-02 \quad 306-307-357$ imp:n=1 u=3400 \$ Water in SW Top Hole

$3410426.0307 \mathrm{E}-02 \quad 9-302-352$ imp:n=1 u=3400 \$ Bottom Dowel NE

$3411426.0307 \mathrm{E}-02 \quad 9-302-353$ imp:n=1 u=3400 \$ Bottom Dowel SW

$3412426.0307 \mathrm{E}-02 \quad 9-304-351$ imp:n=1 u=3400 \$ Tie Rod

$341319.9961 E-02(9-303 \quad 352-354):(302-303-354)$ imp:n=1 u=3400 \$ Water in NE Bottom Hole

$341419.9961 \mathrm{E}-02(9-303 \quad 353-355):(302-303-355)$ imp:n=1 u=3400 \$ Water in sw Bottom Hole

$341519.9961 \mathrm{E}-02(304-305-351)$ imp:n=1 $u=3400$ \$ Water in Tie Rod Hole

$3416439.1820 \mathrm{E}-02 \quad 10-309$ imp:n=1 u=3400 \$ Upper Assembly

$341719.9961 \mathrm{E}-02309 \mathrm{imp}: \mathrm{n}=1 \mathrm{u}=3400$ \$ Water Above Core

$341819.9961 \mathrm{E}-02(9-10)(-331: 332:-333: 334: 335: 336: 337: 338)$ imp:n=1 u=3400 \$ Water Around

Assembly

C

C -..-.- Position F-5 : Graphite Reflector -....-

$350119.9961 \mathrm{E}-02-5$ imp:n=1 u=3500 \$ Water Below Grid Plate

$3503636.9890 \mathrm{E}-025$-7 imp:n=1 u=3500 \$ Grid Plate With Adapter

$3504447.6788 \mathrm{E}-027-9$ imp:n=1 u=3500 \$ Lower Adapter

$3505417.8699 \mathrm{E}-02(9-10)(-9: 303: 354)(-9: 303: 355)(-9: 305: 351) \quad(-306: 10: 356)$

$(-306: 10: 357)(331-332 \quad 333-334)(-335-336-337-338)$

imp: $n=1 \mathrm{u}=3500$ \$ Graphite Block

$3506426.0307 \mathrm{E}-02 \quad 307-10-356$ imp:n=1 u=3500 \$ Top Screw NE

$3507426.0307 \mathrm{E}-02 \quad 307-10-357$ imp:n=1 u=3500 \$ Top Screw SW

$350819.9961 \mathrm{E}-02306-307-356$ imp:n=1 u=3500 \$ Water in NE Top Hole

$350919.9961 \mathrm{E}-02306-307-357$ imp:n=1 $u=3500$ \$ Water in SW Top Hole 


\section{NEA/NSC/DOC(2006)1}

\section{Fundamental - FUND \\ NRAD-FUND-RESR-001 \\ CRIT}

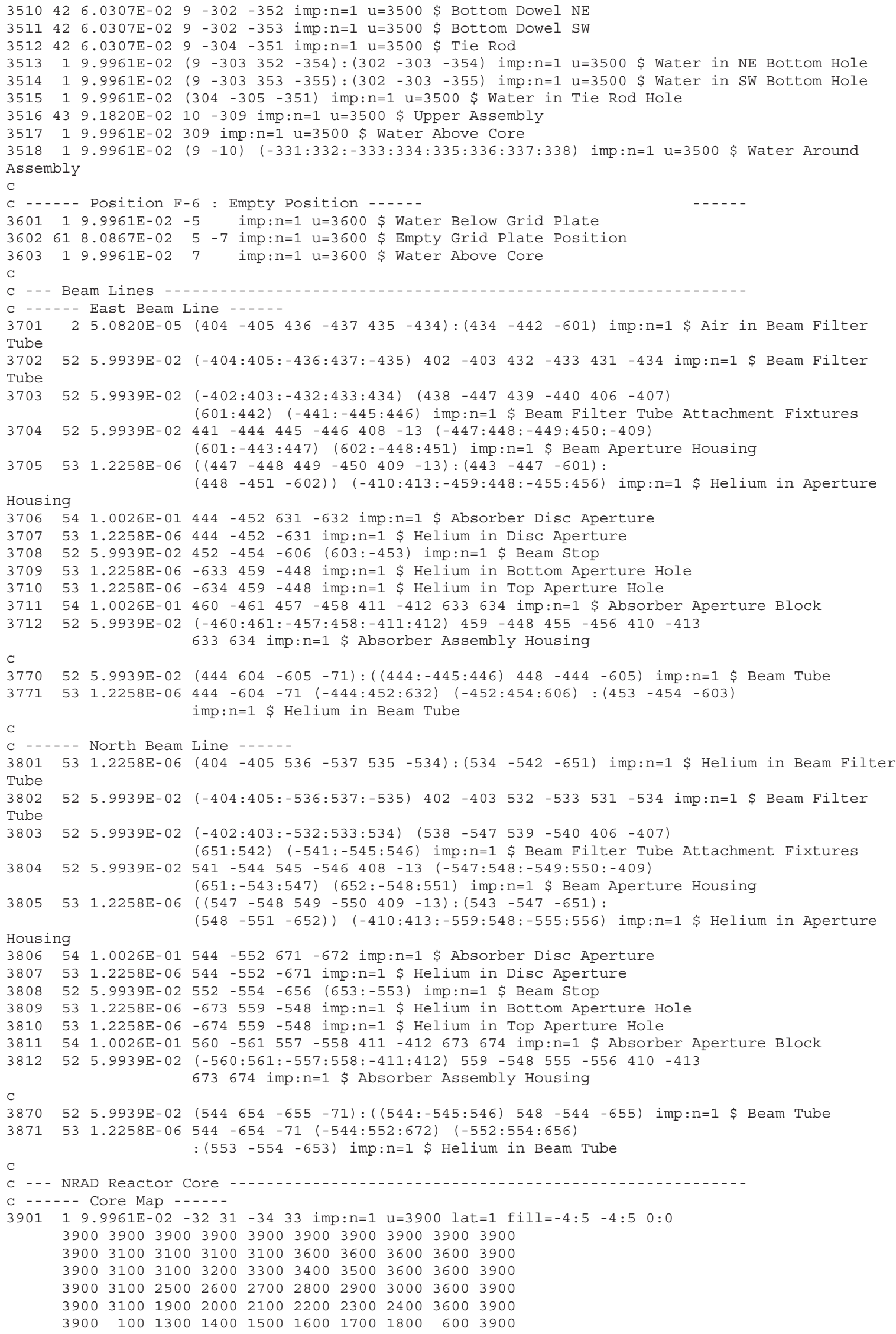


NEA/NSC/DOC(2006)1

Fundamental - FUND

NRAD-FUND-RESR-001

CRIT

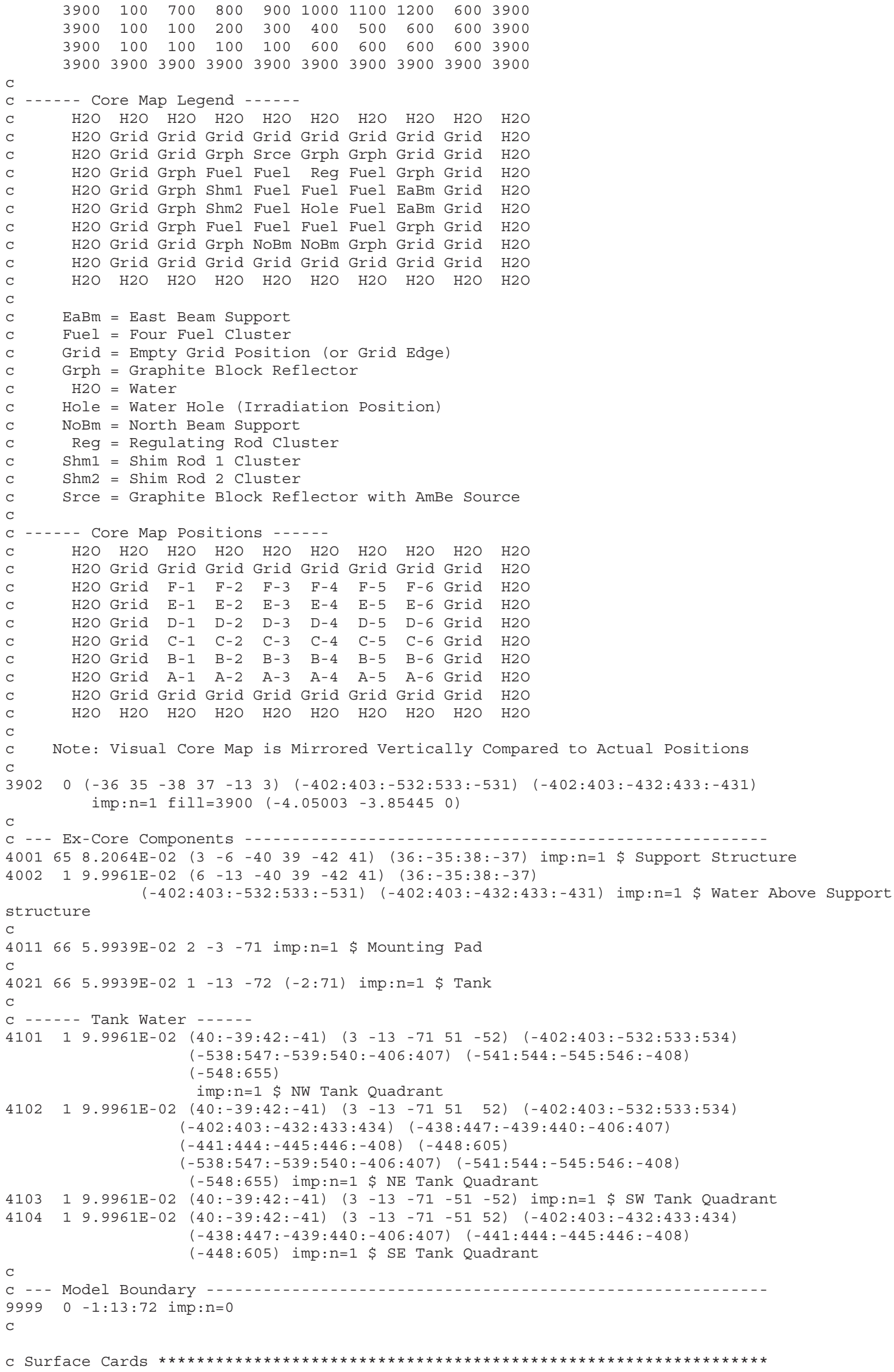


NEA/NSC/DOC(2006)1

Fundamental - FUND

NRAD-FUND-RESR-001

CRIT

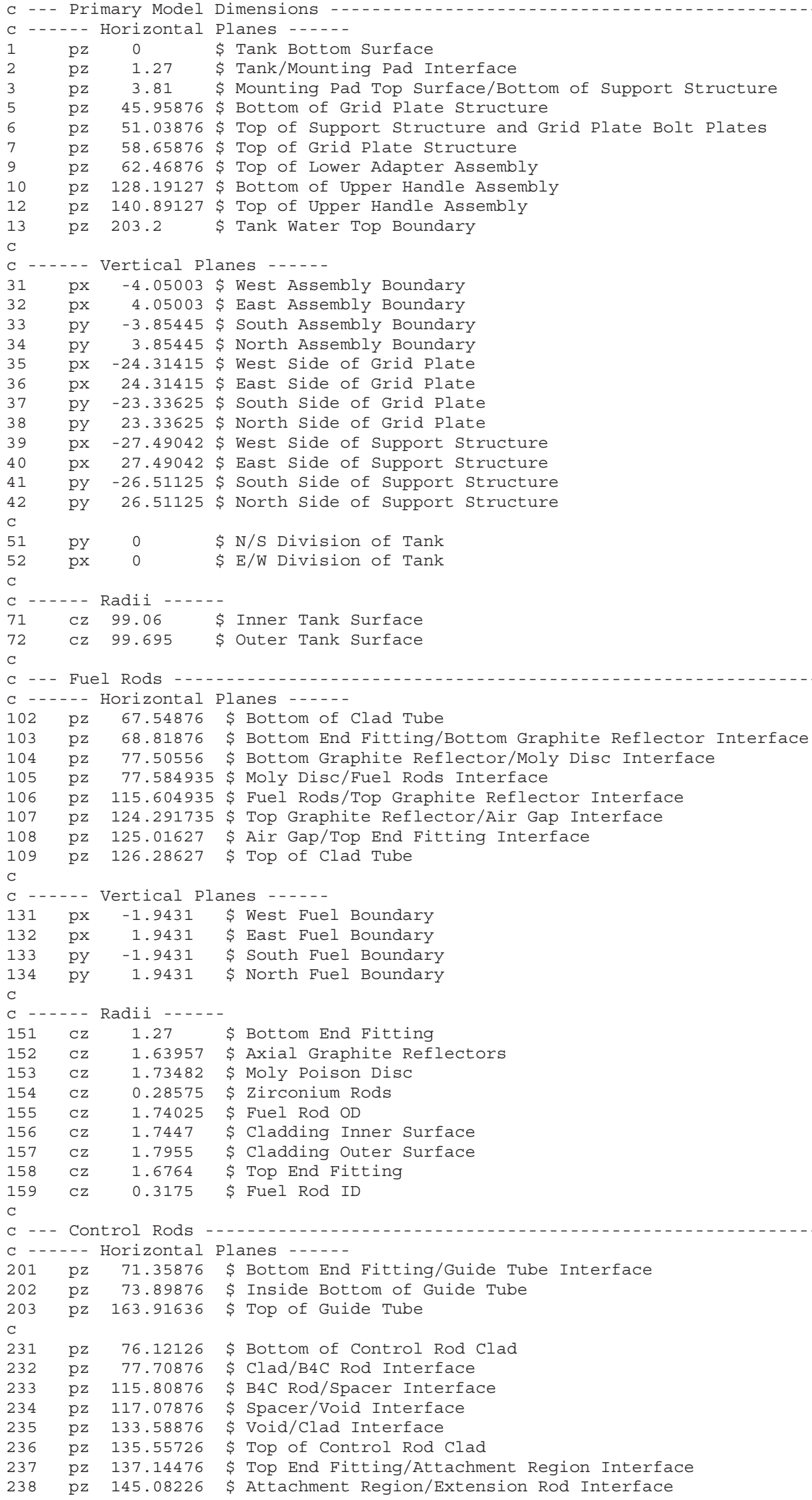


NEA/NSC/DOC(2006)1

Fundamental - FUND

NRAD-FUND-RESR-001

CRIT

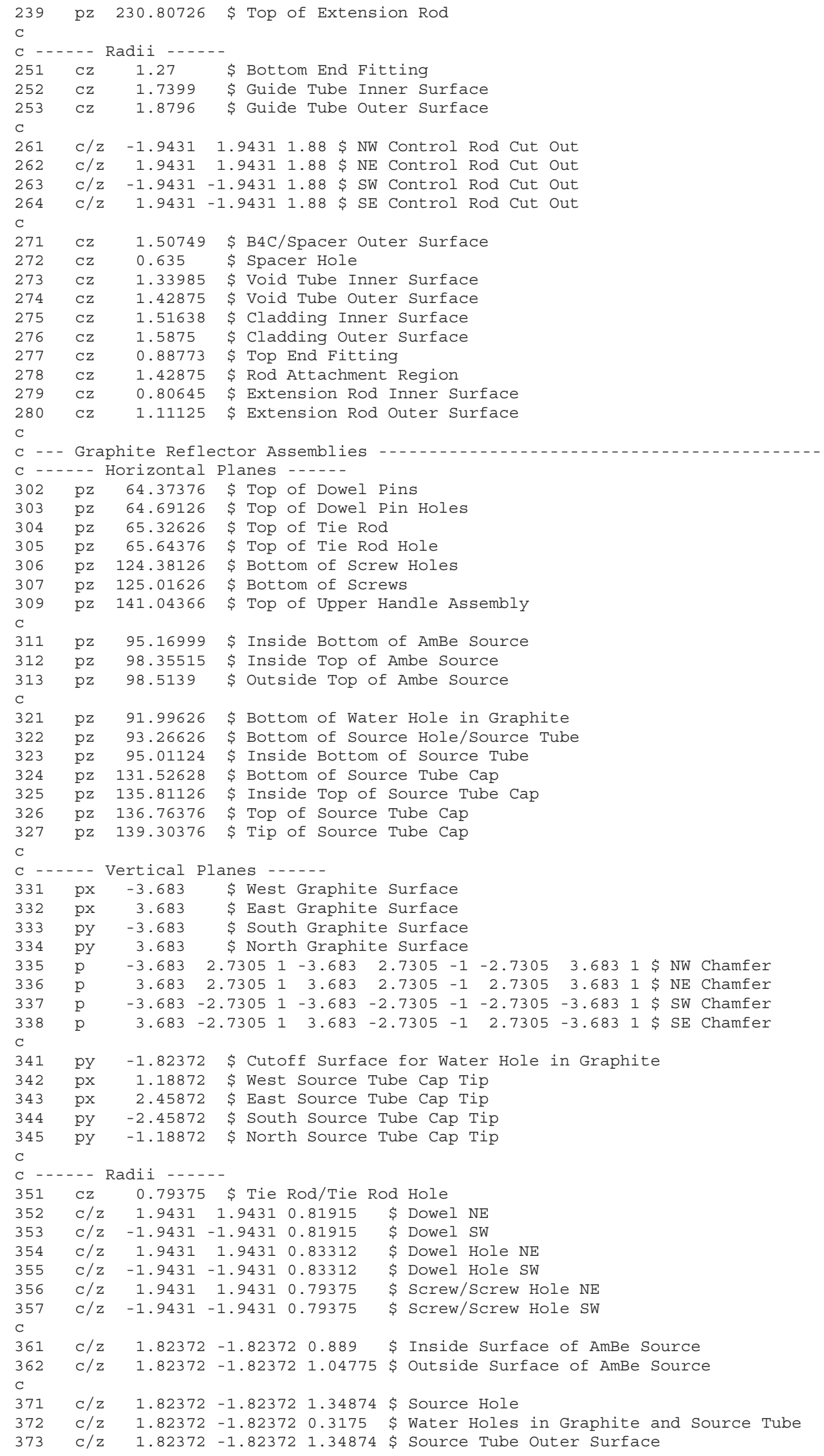


NEA/NSC/DOC(2006)1

Fundamental - FUND

NRAD-FUND-RESR-001 CRIT

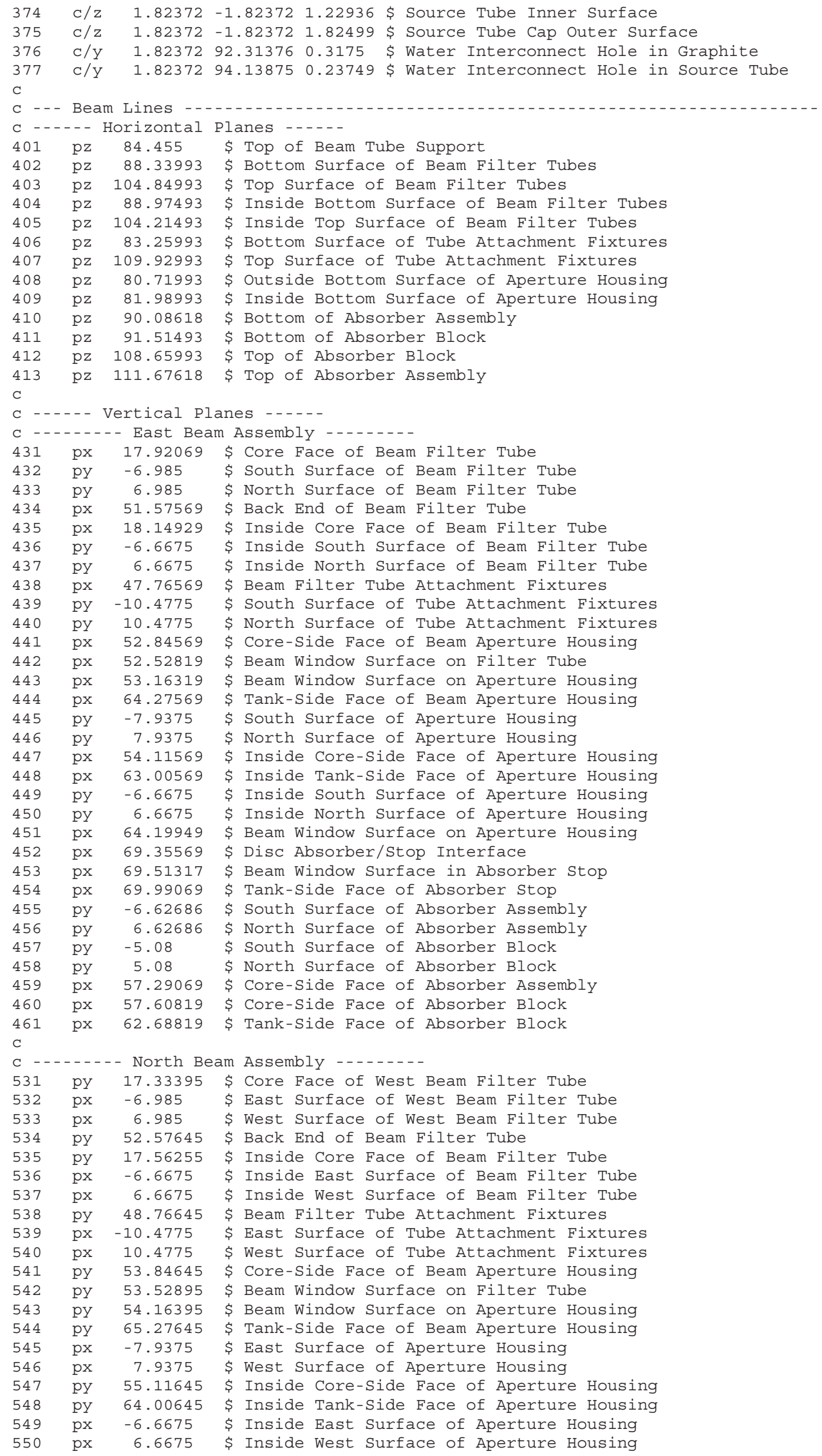


NEA/NSC/DOC(2006)1

\section{Fundamental - FUND}

\section{NRAD-FUND-RESR-001 CRIT}

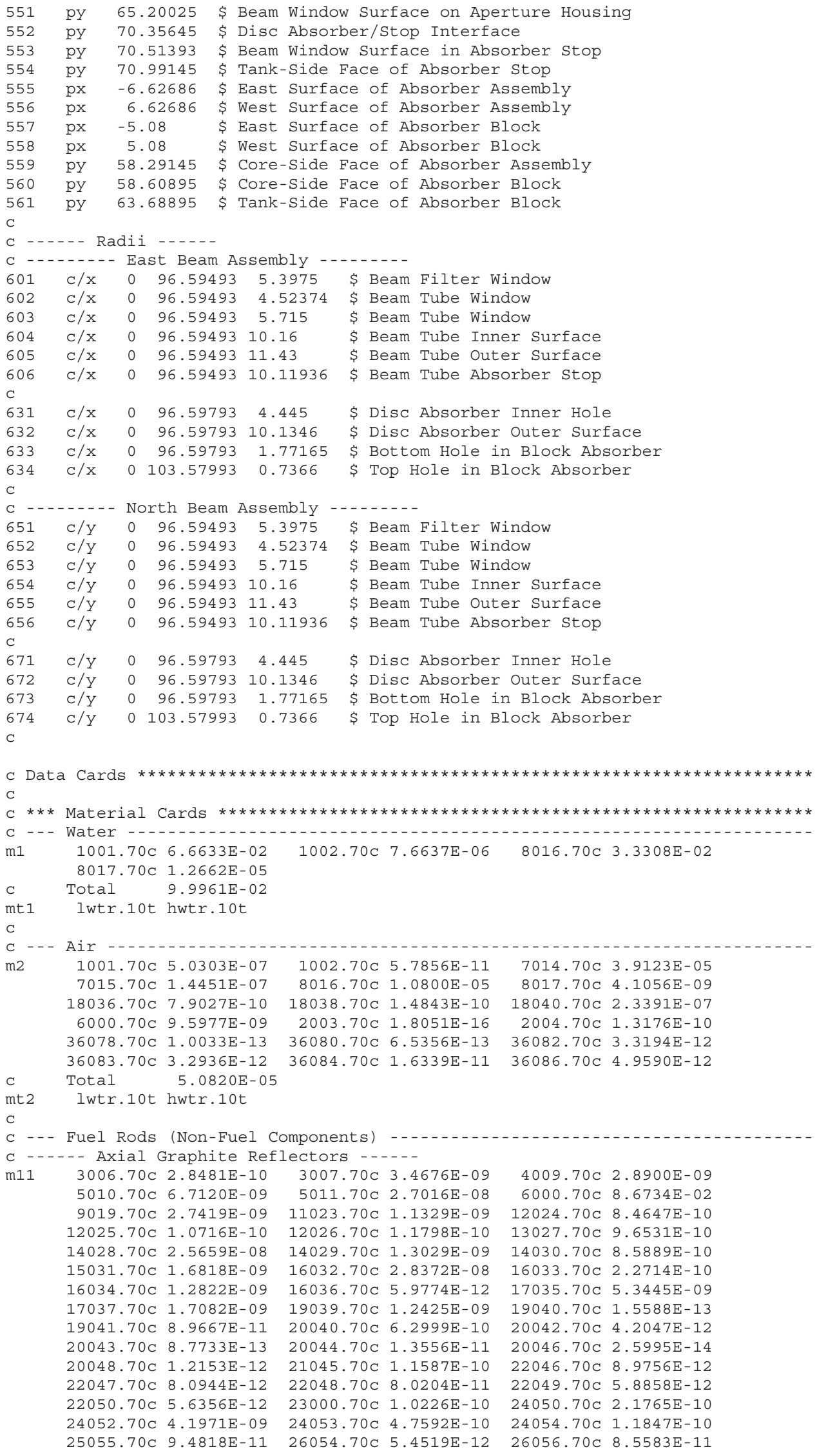


NEA/NSC/DOC(2006)1

Fundamental - FUND

NRAD-FUND-RESR-001 CRIT

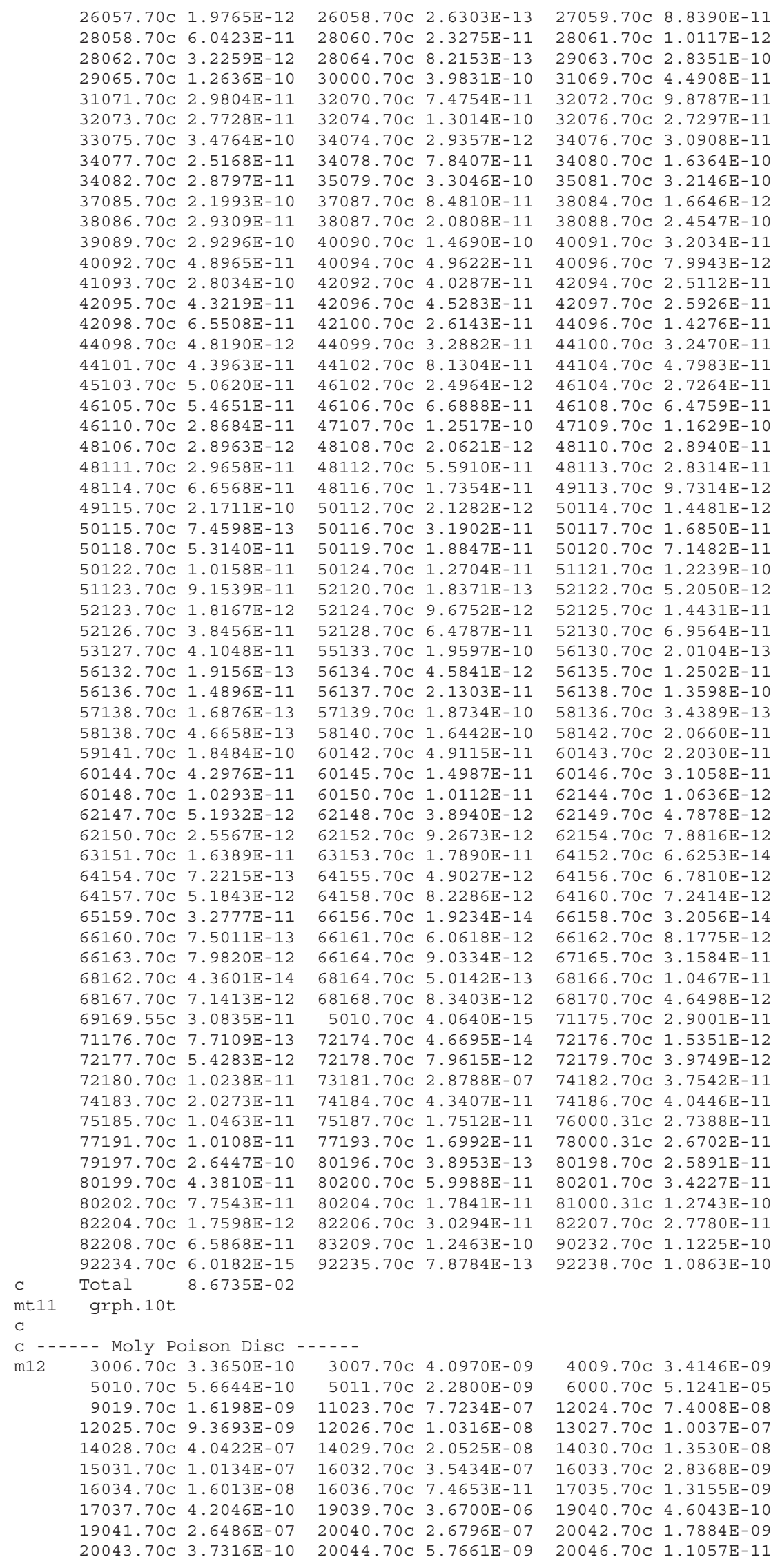


NEA/NSC/DOC(2006)1

Fundamental - FUND

NRAD-FUND-RESR-001 CRIT

$20048.70 \mathrm{C} 5.1690 \mathrm{E}-10$ $22047.70 \mathrm{C} 4.7818 \mathrm{E}-08$ $22050.70 \mathrm{C} 3.3292 \mathrm{E}-08$ $24052.70 \mathrm{C} \quad 3.7688 \mathrm{E}-07$ $25055.70 \mathrm{C} \quad 4.8172 \mathrm{E}-08$ $26057.70 \mathrm{C} 2.7439 \mathrm{E}-08$ $28058.70 \mathrm{C} \quad 8.5667 \mathrm{E}-08$ $28062.70 \mathrm{C} 4.5736 \mathrm{E}-09$ $29065.70 \mathrm{C} 7.4649 \mathrm{E}-08$ $31071.70 \mathrm{C} 8.8034 \mathrm{E}-10$ $32073.70 \mathrm{C} 3.2761 \mathrm{E}-10$ $33075.70 \mathrm{C} 2.8751 \mathrm{E}-08$ $34077.70 \mathrm{C} 2.9736 \mathrm{E}-10$ $34082.70 \mathrm{C} 3.4023 \mathrm{E}-10$ $37085.70 \mathrm{C}$ 1.2993E-09 $38086.70 \mathrm{C} 1.7315 \mathrm{E}-09$ $39089.70 \mathrm{C} 3.4613 \mathrm{E}-09$ $40092.70 \mathrm{C} 5.7853 \mathrm{E}-10$ $41093.70 \mathrm{C} 1.6561 \mathrm{E}-08$ $42095.70 \mathrm{C}$ 1.0210E-02 $42098.70 \mathrm{C} 1.5475 \mathrm{E}-02$ $44098.70 \mathrm{C} 2.8468 \mathrm{E}-11$ $44101.70 \mathrm{C} 2.5971 \mathrm{E}-10$ $45103.70 \mathrm{C} 1.4952 \mathrm{E}-09$ $46105.70 \mathrm{C}$ 6.4571E-10 $46110.70 \mathrm{C} 3.3890 \mathrm{E}-10$ $48106.70 \mathrm{C} 3.4220 \mathrm{E}-09$ $48111.70 \mathrm{C} 3.5041 \mathrm{E}-08$ $48114.70 \mathrm{C} 7.8650 \mathrm{E}-08$ $49115.70 \mathrm{C} 1.2826 \mathrm{E}-09$ $50115.70 \mathrm{C} 3.3492 \mathrm{E}-11$ $50118.70 \mathrm{C} 2.3858 \mathrm{E}-09$ $50122.70 \mathrm{C} 4.5609 \mathrm{E}-10$ $51123.70 \mathrm{C} 2.8120 \mathrm{E}-08$ $52123.70 \mathrm{C} 1.0732 \mathrm{E}-11$ $52126.70 \mathrm{C} 2.2718 \mathrm{E}-10$ $53127.70 \mathrm{C} 2.4249 \mathrm{E}-10$ $56132.70 \mathrm{C}$ 6.7898E-10 $56136.70 \mathrm{C} 5.2799 \mathrm{E}-08$ $57138.70 \mathrm{C} 3.7684 \mathrm{E}-11$ $58138.70 \mathrm{C} 2.7563 \mathrm{E}-12$ $59141.70 \mathrm{C} 2.1839 \mathrm{E}-10$ $60144.70 \mathrm{C} 5.0776 \mathrm{E}-11$ $60148.70 \mathrm{C} 1.2161 \mathrm{E}-11$ $62147.70 \mathrm{C} 3.0679 \mathrm{E}-11$ $62150.70 \mathrm{C} 1.5104 \mathrm{E}-11$ $63151.70 \mathrm{C} 9.6818 \mathrm{E}-11$ 64154.70C 4.2661E-12 $64157.70 \mathrm{C} 3.0626 \mathrm{E}-11$ $65159.70 \mathrm{C} 1.9363 \mathrm{E}-10$ $66160.70 \mathrm{C} 4.4313 \mathrm{E}-12$ $66163.70 \mathrm{C} 4.7154 \mathrm{E}-11$ $68162.70 \mathrm{C} 2.5758 \mathrm{E}-13$ $68167.70 \mathrm{C} 4.2187 \mathrm{E}-11$ $69169.55 \mathrm{C} 1.8216 \mathrm{E}-10$ $71176.70 \mathrm{C} \quad 4.5553 \mathrm{E}-12$ $72177.70 \mathrm{C} \quad 3.2068 \mathrm{E}-11$ $72180.70 \mathrm{C} \quad 6.0480 \mathrm{E}-11$ $74183.70 \mathrm{C} 5.9880 \mathrm{E}-07$ $75185.70 \mathrm{C} \quad 1.6070 \mathrm{E}-09$ $77191.70 \mathrm{C} 2.9857 \mathrm{E}-10$ $79197.70 \mathrm{C} 7.8117 \mathrm{E}-10$ $80199.70 \mathrm{C} 1.2940 \mathrm{E}-10$ $80202.70 \mathrm{C} 2.2904 \mathrm{E}-10$ $82204.70 \mathrm{C} 1.0396 \mathrm{E}-11$ $82208.70 \mathrm{C} 3.8912 \mathrm{E}-10$ $92234.70 \mathrm{C} 5.6884 \mathrm{E}-14$ C Total 6.4196E-02 C _..... Zr Rod ......

m13 3006.70C 1.0717E-10 $5010.70 \mathrm{C} 3.6082 \mathrm{E}-09$ $11023.70 \mathrm{C} 8.5264 \mathrm{E}-10$ $12026.70 \mathrm{C} 4.4398 \mathrm{E}-11$ $14029.70 \mathrm{C} 4.6414 \mathrm{E}-08$ $16032.70 \mathrm{C} 2.9012 \mathrm{E}-08$
$21045.70 \mathrm{C} 3.4226 \mathrm{E}-10$ $22048.70 \mathrm{C} 4.7381 \mathrm{E}-07$ $23000.70 \mathrm{C} 1.3290 \mathrm{E}-07$ $24053.70 \mathrm{C} 4.2735 \mathrm{E}-08$ $26054.70 \mathrm{C} 7.5687 \mathrm{E}-08$ $26058.70 \mathrm{C} 3.6516 \mathrm{E}-09$ $28060.70 \mathrm{C} 3.2999 \mathrm{E}-08$ $28064.70 \mathrm{C} 1.1648 \mathrm{E}-09$ $30000.70 \mathrm{C} 2.3530 \mathrm{E}-09$ $32070.70 \mathrm{C} 8.8322 \mathrm{E}-10$ $32074.70 \mathrm{C} 1.5376 \mathrm{E}-09$ $34074.70 \mathrm{C} 3.4686 \mathrm{E}-11$ $34078.70 \mathrm{C} 9.2638 \mathrm{E}-10$ $35079.70 \mathrm{C} 1.9522 \mathrm{E}-10$ $37087.70 \mathrm{C} 5.0101 \mathrm{E}-10$ $38087.70 \mathrm{C} 1.2292 \mathrm{E}-09$ $40090.70 \mathrm{C} 1.7356 \mathrm{E}-09$ $40094.70 \mathrm{C} 5.8629 \mathrm{E}-10$ $42092.70 \mathrm{C} 9.5169 \mathrm{E}-03$ $42096.70 \mathrm{C} 1.0697 \mathrm{E}-02$ $42100.70 \mathrm{C} \quad 6.1757 \mathrm{E}-03$ $44099.70 \mathrm{C} 1.9425 \mathrm{E}-10$ $44102.70 \mathrm{C} 4.8030 \mathrm{E}-10$ $46102.70 \mathrm{C} 2.9495 \mathrm{E}-11$ $46106.70 \mathrm{C} 7.9029 \mathrm{E}-10$ $47107.70 \mathrm{C} \quad 7.3944 \mathrm{E}-09$ $48108.70 \mathrm{C} 2.4364 \mathrm{E}-09$ $48112.70 \mathrm{C} \quad 6.6057 \mathrm{E}-08$ $48116.70 \mathrm{C} 2.0504 \mathrm{E}-08$ $50112.70 \mathrm{C} 9.5551 \mathrm{E}-11$ $50116.70 \mathrm{C} 1.4323 \mathrm{E}-09$ $50119.70 \mathrm{C} 8.4617 \mathrm{E}-10$ $50124.70 \mathrm{C} 5.7035 \mathrm{E}-10$ $52120.70 \mathrm{C} 1.0853 \mathrm{E}-12$ $52124.70 \mathrm{C} 5.7157 \mathrm{E}-11$ $52128.70 \mathrm{C} 3.8273 \mathrm{E}-10$ $55133.70 \mathrm{C} 1.1577 \mathrm{E}-09$ $56134.70 \mathrm{C} 1.6248 \mathrm{E}-08$ $56137.70 \mathrm{C} 7.5508 \mathrm{E}-08$ $57139.70 \mathrm{C} 4.1833 \mathrm{E}-08$ $58140.70 \mathrm{C} 9.7130 \mathrm{E}-10$ $60142.70 \mathrm{C} 5.8030 \mathrm{E}-11$ $60145.70 \mathrm{C} 1.7708 \mathrm{E}-11$ $60150.70 \mathrm{C} 1.1947 \mathrm{E}-11$ $62148.70 \mathrm{C} 2.3004 \mathrm{E}-11$ $62152.70 \mathrm{C} 5.4747 \mathrm{E}-11$ $63153.70 \mathrm{C} 1.0569 \mathrm{E}-10$ $64155.70 \mathrm{C} 2.8963 \mathrm{E}-11$ $64158.70 \mathrm{C} 4.8610 \mathrm{E}-11$ $66156.70 \mathrm{C} 1.1362 \mathrm{E}-13$ $66161.70 \mathrm{C} 3.5810 \mathrm{E}-11$ $66164.70 \mathrm{C} 5.3365 \mathrm{E}-11$ $68164.70 \mathrm{C} 2.9621 \mathrm{E}-12$ $68168.70 \mathrm{C} 4.9271 \mathrm{E}-11$ $5010.70 \mathrm{C} 2.4008 \mathrm{E}-14$ $72174.70 \mathrm{C} \quad 2.7585 \mathrm{E}-13$ $72178.70 \mathrm{C} 4.7033 \mathrm{E}-11$ $73181.70 \mathrm{C}$ 1.7007E-07 $74184.70 \mathrm{C} 1.2821 \mathrm{E}-06$ $75187.70 \mathrm{C} 2.6898 \mathrm{E}-09$ $77193.70 \mathrm{C} 5.0189 \mathrm{E}-10$ $80196.70 \mathrm{C} 1.1506 \mathrm{E}-12$ $80200.70 \mathrm{C} 1.7719 \mathrm{E}-10$ $80204.70 \mathrm{C} 5.2697 \mathrm{E}-11$ $82206.70 \mathrm{C} 1.7896 \mathrm{E}-10$ $83209.70 \mathrm{C} 7.3626 \mathrm{E}-10$ $92235.70 \mathrm{C} 7.4467 \mathrm{E}-12$

$3007.70 \mathrm{C} \quad 1.3049 \mathrm{E}-09$ $5011.70 \mathrm{C} 1.4523 \mathrm{E}-08$ $12024.70 \mathrm{C} 3.1853 \mathrm{E}-10$ $13027.70 \mathrm{C} 5.8120 \mathrm{E}-06$ $14030.70 \mathrm{C} 3.0596 \mathrm{E}-08$ $16033.70 \mathrm{C} 2.3226 \mathrm{E}-10$
$22046.70 \mathrm{C} 5.3024 \mathrm{E}-08$ $22049.70 \mathrm{C} 3.4771 \mathrm{E}-08$ $24050.70 \mathrm{C} 1.9543 \mathrm{E}-08$ $24054.70 \mathrm{C} 1.0638 \mathrm{E}-08$ $26056.70 \mathrm{C} 1.1881 \mathrm{E}-06$ $27059.70 \mathrm{C} 1.4621 \mathrm{E}-08$ $28061.70 \mathrm{C} 1.4344 \mathrm{E}-09$ $29063.70 \mathrm{C} 1.6748 \mathrm{E}-07$ $31069.70 \mathrm{C} 1.3265 \mathrm{E}-09$ $32072.70 \mathrm{C} 1.1672 \mathrm{E}-09$ $32076.70 \mathrm{C} 3.2252 \mathrm{E}-10$ $34076.70 \mathrm{C} 3.6518 \mathrm{E}-10$ $34080.70 \mathrm{C} 1.9334 \mathrm{E}-09$ $35081.70 \mathrm{C} 1.8990 \mathrm{E}-10$ $38084.70 \mathrm{C} 9.8339 \mathrm{E}-11$ $38088.70 \mathrm{C} 1.4501 \mathrm{E}-08$ $40091.70 \mathrm{C} 3.7849 \mathrm{E}-10$ $40096.70 \mathrm{C} 9.4453 \mathrm{E}-11$ $42094.70 \mathrm{C} 5.9320 \mathrm{E}-03$ $42097.70 \mathrm{C} 6.1244 \mathrm{E}-03$ $44096.70 \mathrm{C} 8.4339 \mathrm{E}-11$ $44100.70 \mathrm{C} 1.9182 \mathrm{E}-10$ $44104.70 \mathrm{C} 2.8346 \mathrm{E}-10$ $46104.70 \mathrm{C} 3.2213 \mathrm{E}-10$ $46108.70 \mathrm{C} 7.6513 \mathrm{E}-10$ $47109.70 \mathrm{C} \quad 6.8697 \mathrm{E}-09$ $48110.70 \mathrm{C} \quad 3.4192 \mathrm{E}-08$ $48113.70 \mathrm{C} 3.3453 \mathrm{E}-08$ $49113.70 \mathrm{C} 5.7488 \mathrm{E}-11$ $50114.70 \mathrm{C} 6.5014 \mathrm{E}-11$ $50117.70 \mathrm{C} 7.5653 \mathrm{E}-10$ $50120.70 \mathrm{C} 3.2093 \mathrm{E}-09$ $51121.70 \mathrm{C} 3.7596 \mathrm{E}-08$ $52122.70 \mathrm{C} 3.0749 \mathrm{E}-11$ $52125.70 \mathrm{C} 8.5253 \mathrm{E}-11$ $52130.70 \mathrm{C} 4.1095 \mathrm{E}-10$ $56130.70 \mathrm{C} 7.1259 \mathrm{E}-10$ $56135.70 \mathrm{C} 4.4315 \mathrm{E}-08$ $56138.70 \mathrm{C} 4.8199 \mathrm{E}-07$ $58136.70 \mathrm{C} 2.0315 \mathrm{E}-12$ $58142.70 \mathrm{C} 1.2205 \mathrm{E}-10$ $60143.70 \mathrm{C} 2.6028 \mathrm{E}-11$ $60146.70 \mathrm{C} 3.6695 \mathrm{E}-11$ $62144.70 \mathrm{C}$ 6.2831E-12 $62149.70 \mathrm{C} 2.8284 \mathrm{E}-11$ $62154.70 \mathrm{C} 4.6561 \mathrm{E}-11$ $64152.70 \mathrm{C} 3.9139 \mathrm{E}-13$ $64156.70 \mathrm{C} 4.0059 \mathrm{E}-11$ $64160.70 \mathrm{C} 4.2779 \mathrm{E}-11$ $66158.70 \mathrm{C} 1.8937 \mathrm{E}-13$ $66162.70 \mathrm{C} 4.8309 \mathrm{E}-11$ $67165.70 \mathrm{C} 1.8658 \mathrm{E}-10$ $68166.70 \mathrm{C} 6.1837 \mathrm{E}-11$ $68170.70 \mathrm{C} 2.7469 \mathrm{E}-11$ $71175.70 \mathrm{C} 1.7132 \mathrm{E}-10$ $72176.70 \mathrm{C} 9.0686 \mathrm{E}-12$ $72179.70 \mathrm{C} \quad 2.3482 \mathrm{E}-11$ $74182.70 \mathrm{C} 1.1089 \mathrm{E}-06$ $74186.70 \mathrm{C} 1.1947 \mathrm{E}-06$ $76000.31 \mathrm{C} 8.0896 \mathrm{E}-10$ $78000.31 \mathrm{C} 7.8873 \mathrm{E}-10$ $80198.70 \mathrm{C} 7.6476 \mathrm{E}-11$ $80201.70 \mathrm{C} 1.0110 \mathrm{E}-10$ $81000.31 \mathrm{C} 7.5282 \mathrm{E}-10$ $82207.70 \mathrm{C} 1.6411 \mathrm{E}-10$ $90232.70 \mathrm{C} 6.6310 \mathrm{E}-11$ $92238.70 \mathrm{C} 1.0268 \mathrm{E}-09$

4009.70C 1.0875E-09 $9019.70 \mathrm{C} 1.0318 \mathrm{E}-07$ $12025.70 \mathrm{C} 4.0325 \mathrm{E}-11$ $14028.70 \mathrm{C} 9.1406 \mathrm{E}-07$ $15031.70 \mathrm{C} 9.9991 \mathrm{E}-08$ $16034.70 \mathrm{C} 1.3111 \mathrm{E}-09$ 
NEA/NSC/DOC(2006)1

Fundamental - FUND

NRAD-FUND-RESR-001 CRIT

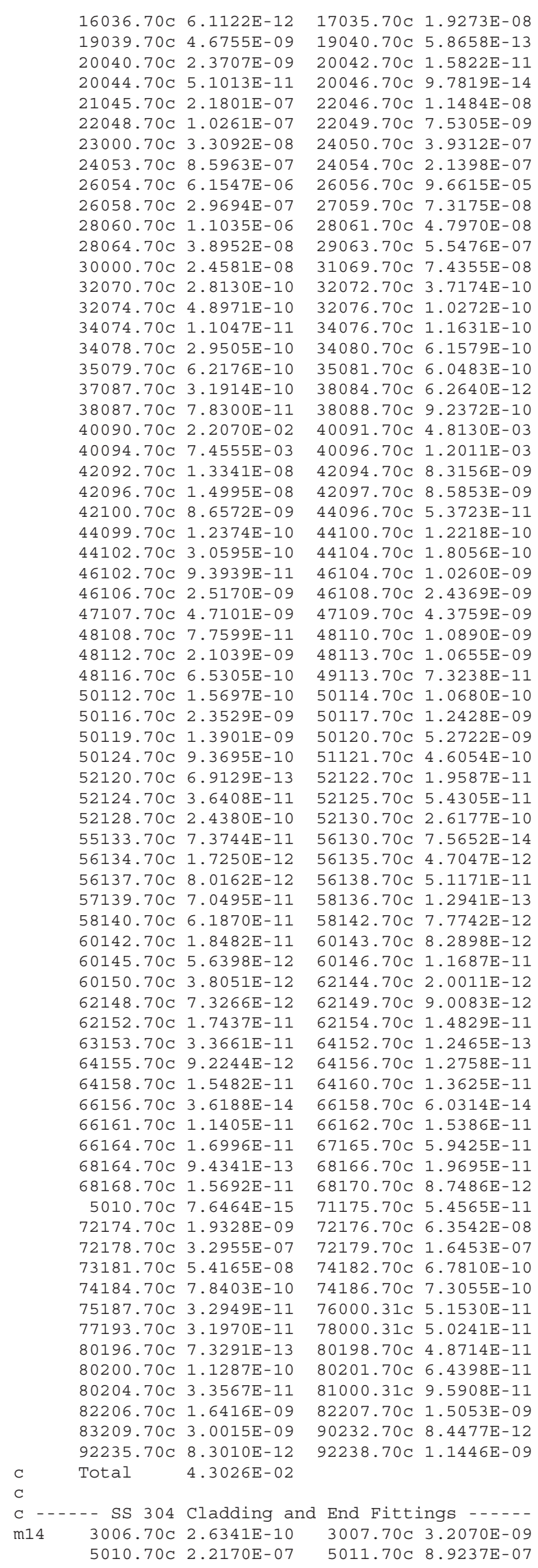

$16036.70 \mathrm{C} \quad 6.1122 \mathrm{E}-12$ $19039.70 \mathrm{C} 4.6755 \mathrm{E}-0$ $040.70 \mathrm{C} 2.3707 \mathrm{E}-09$ $\mathrm{E}-0$ $9 \mathrm{E}-0$ $.70 \mathrm{C} 6.5305 \mathrm{E}-10$ $5137.70 \mathrm{C} 8.0162 \mathrm{E}-12$ $6156.70 \mathrm{C} 3.6188 \mathrm{E}-14$ $161.70 \mathrm{C} 1.1405 \mathrm{E}-11$ $.2955 \mathrm{E}-07$ $181.70 \mathrm{C} 5.4165 \mathrm{E}-08$ $.70 \mathrm{C} 7.8403 \mathrm{E}-10$ $80196.70 \mathrm{C} 7.3291 \mathrm{E}-13$ $80200.70 \mathrm{C} 1.1287 \mathrm{E}-10$ C $1.6416 \mathrm{E}-09$ $.70 \mathrm{C} 3.0015 \mathrm{E}-0$ $92235.70 \mathrm{C} 8.3010 \mathrm{E}-12$ $3006.70 \mathrm{C} 2.6341 \mathrm{E}-10$ $5010.70 \mathrm{C} 2.2170 \mathrm{E}-07$ $5011.70 \mathrm{C} 8.9237 \mathrm{E}-07$
17037.70C 6.1600E-09 $19041.70 \mathrm{C} 3.3742 \mathrm{E}-10$ $20043.70 \mathrm{C} 3.3014 \mathrm{E}-12$ $20048.70 \mathrm{C} 4.5730 \mathrm{E}-12$ $22047.70 \mathrm{C} 1.0356 \mathrm{E}-08$ $22050.70 \mathrm{C} 7.2103 \mathrm{E}-09$ $24052.70 \mathrm{C} 7.5810 \mathrm{E}-06$ $25055.70 \mathrm{C} 9.9904 \mathrm{E}-07$ $26057.70 \mathrm{C} 2.2313 \mathrm{E}-06$ $28058.70 \mathrm{C} 2.8649 \mathrm{E}-06$ $28062.70 \mathrm{C} 1.5295 \mathrm{E}-07$ $29065.70 \mathrm{C} 2.4726 \mathrm{E}-07$ $31071.70 \mathrm{C} 4.9347 \mathrm{E}-08$ $32073.70 \mathrm{C} 1.0434 \mathrm{E}-10$ $33075.70 \mathrm{C} 2.0931 \mathrm{E}-09$ $34077.70 \mathrm{C} 9.4708 \mathrm{E}-11$ $34082.70 \mathrm{C} 1.0836 \mathrm{E}-10$ $37085.70 \mathrm{C} 8.2761 \mathrm{E}-10$ $38086.70 \mathrm{C} 1.1029 \mathrm{E}-10$ $39089.70 \mathrm{C} 1.1024 \mathrm{E}-09$ $40092.70 \mathrm{C} 7.3568 \mathrm{E}-03$ $41093.70 \mathrm{C} 2.5740 \mathrm{E}-08$ $42095.70 \mathrm{C} 1.4312 \mathrm{E}-08$ $42098.70 \mathrm{C} 2.1692 \mathrm{E}-08$ $44098.70 \mathrm{C} 1.8134 \mathrm{E}-11$ $44101.70 \mathrm{C} 1.6543 \mathrm{E}-10$ $45103.70 \mathrm{C} 9.5242 \mathrm{E}-10$ $46105.70 \mathrm{C} 2.0565 \mathrm{E}-09$ $46110.70 \mathrm{C} 1.0794 \mathrm{E}-09$ $48106.70 \mathrm{C} 1.0899 \mathrm{E}-10$ $48111.70 \mathrm{C} 1.1160 \mathrm{E}-09$ $48114.70 \mathrm{C} 2.5050 \mathrm{E}-09$ 49115.70C 1.6339E-09 $50115.70 \mathrm{C} 5.5020 \mathrm{E}-11$ 50118.70C 3.9193E-09 $50122.70 \mathrm{C} 7.4924 \mathrm{E}-10$ $51123.70 \mathrm{C} 3.4446 \mathrm{E}-10$ $52123.70 \mathrm{C} 6.8361 \mathrm{E}-12$ $52126.70 \mathrm{C} 1.4471 \mathrm{E}-10$ 53127.70C 1.5446E-09 $56132.70 \mathrm{C} 7.2083 \mathrm{E}-14$ $56136.70 \mathrm{C} 5.6054 \mathrm{E}-12$ $57138.70 \mathrm{C} \quad 6.3503 \mathrm{E}-14$ $58138.70 \mathrm{C}$ 1.7557E-13 $59141.70 \mathrm{C}$ 6.9556E-11 $60144.70 \mathrm{C} 1.6172 \mathrm{E}-11$ $60148.70 \mathrm{C} 3.8731 \mathrm{E}-12$ $62147.70 \mathrm{C} 9.7710 \mathrm{E}-12$ $62150.70 \mathrm{C} 4.8105 \mathrm{E}-12$ $63151.70 \mathrm{C} 3.0836 \mathrm{E}-11$ $64154.70 \mathrm{C} 1.3587 \mathrm{E}-12$ $64157.70 \mathrm{C} 9.7542 \mathrm{E}-12$ $65159.70 \mathrm{C} 6.1670 \mathrm{E}-11$ $66160.70 \mathrm{C} 1.4113 \mathrm{E}-12$ $66163.70 \mathrm{C} 1.5018 \mathrm{E}-11$ $68162.70 \mathrm{C} 8.2036 \mathrm{E}-14$ $68167.70 \mathrm{C} 1.3436 \mathrm{E}-11$ $69169.55 \mathrm{C} 5.8016 \mathrm{E}-11$ $71176.70 \mathrm{C} 1.4508 \mathrm{E}-12$ $72177.70 \mathrm{C} \quad 2.2469 \mathrm{E}-07$ $72180.70 \mathrm{C} \quad 4.2378 \mathrm{E}-07$ $74183.70 \mathrm{C} 3.6617 \mathrm{E}-10$ 75185.70C 1.9685E-11 $77191.70 \mathrm{C} 1.9019 \mathrm{E}-11$ $79197.70 \mathrm{C} 4.9760 \mathrm{E}-10$ $80199.70 \mathrm{C} 8.2428 \mathrm{E}-11$ $80202.70 \mathrm{C} 1.4590 \mathrm{E}-10$ $82204.70 \mathrm{C} 9.5361 \mathrm{E}-11$ $82208.70 \mathrm{C} 3.5692 \mathrm{E}-09$ $92234.70 \mathrm{C} 6.3410 \mathrm{E}-14$

$4009.70 \mathrm{C} 2.6729 \mathrm{E}-09$ $6000.70 \mathrm{C} \quad 1.6044 \mathrm{E}-04$ 
NEA/NSC/DOC(2006)1

Fundamental - FUND

NRAD-FUND-RESR-001 CRIT

$9019.70 \mathrm{C} 1.2679 \mathrm{E}-09$ $12025.70 \mathrm{C} \quad 3.5679 \mathrm{E}-08$ $14028.70 \mathrm{C} \quad 6.3283 \mathrm{E}-04$ $15031.70 \mathrm{C} 4.0441 \mathrm{E}-05$ $16034.70 \mathrm{C} \quad 1.4178 \mathrm{E}-07$ $17037.70 \mathrm{C} 8.2281 \mathrm{E}-10$ $19041.70 \mathrm{C} 4.1465 \mathrm{E}-11$ $20043.70 \mathrm{C} 8.1140 \mathrm{E}-11$ $20048.70 \mathrm{C} 1.1239 \mathrm{E}-10$ $22047.70 \mathrm{C} 1.4972 \mathrm{E}-07$ $22050.70 \mathrm{C} 1.0424 \mathrm{E}-07$ $24052.70 \mathrm{C} 1.4751 \mathrm{E}-02$ $25055.70 \mathrm{C} 8.7693 \mathrm{E}-04$ $26057.70 \mathrm{C} 1.2559 \mathrm{E}-03$ $28058.70 \mathrm{C} 5.5882 \mathrm{E}-03$ $28062.70 \mathrm{C} 2.9834 \mathrm{E}-04$ $29065.70 \mathrm{C} 7.0120 \mathrm{E}-05$ $31071.70 \mathrm{C} 4.4103 \mathrm{E}-07$ $32073.70 \mathrm{C} 1.0258 \mathrm{E}-07$ $33075.70 \mathrm{C} 2.2506 \mathrm{E}-06$ $34077.70 \mathrm{C} \quad 2.3277 \mathrm{E}-10$ $34082.70 \mathrm{C} 2.6633 \mathrm{E}-10$ $37085.70 \mathrm{C} 1.0170 \mathrm{E}-08$ $38086.70 \mathrm{C} 5.4214 \mathrm{E}-10$ $39089.70 \mathrm{C} 1.3547 \mathrm{E}-09$ $40092.70 \mathrm{C} 1.6303 \mathrm{E}-08$ $41093.70 \mathrm{C} 5.7041 \mathrm{E}-06$ $42095.70 \mathrm{C} 2.3983 \mathrm{E}-05$ $42098.70 \mathrm{C} 3.6351 \mathrm{E}-05$ $44098.70 \mathrm{C} 4.4568 \mathrm{E}-11$ $44101.70 \mathrm{C} 4.0660 \mathrm{E}-10$ $45103.70 \mathrm{C} 1.1704 \mathrm{E}-09$ $46105.70 \mathrm{C} 2.5272 \mathrm{E}-10$ $46110.70 \mathrm{C} 1.3264 \mathrm{E}-10$ $48106.70 \mathrm{C} 2.6786 \mathrm{E}-11$ $48111.70 \mathrm{C} 2.7429 \mathrm{E}-10$ $48114.70 \mathrm{C} 6.1566 \mathrm{E}-10$ $49115.70 \mathrm{C} 1.0040 \mathrm{E}-08$ $50115.70 \mathrm{C} 7.5891 \mathrm{E}-09$ 50118.70C 5.4061E-07 50122.70C 1.0335E-07 $51123.70 \mathrm{C} 1.5070 \mathrm{E}-07$ $52123.70 \mathrm{C} 8.4007 \mathrm{E}-12$ $52126.70 \mathrm{C} 1.7783 \mathrm{E}-10$ $53127.70 \mathrm{C} 9.4908 \mathrm{E}-10$ $56132.70 \mathrm{C} 8.8582 \mathrm{E}-13$ $56136.70 \mathrm{C} 6.8883 \mathrm{E}-11$ $57138.70 \mathrm{C} 1.5607 \mathrm{E}-13$ $58138.70 \mathrm{C} \quad 2.1576 \mathrm{E}-12$ $59141.70 \mathrm{C} 8.5476 \mathrm{E}-11$ $60144.70 \mathrm{C} 1.9873 \mathrm{E}-11$ $60148.70 \mathrm{C} 4.7596 \mathrm{E}-12$ $62147.70 \mathrm{C} 1.2007 \mathrm{E}-11$ $62150.70 \mathrm{C} \quad 5.9116 \mathrm{E}-12$ $63151.70 \mathrm{C} 3.7894 \mathrm{E}-11$ $64154.70 \mathrm{C} 1.6697 \mathrm{E}-12$ $64157.70 \mathrm{C} 1.1987 \mathrm{E}-11$ $65159.70 \mathrm{C} 7.5785 \mathrm{E}-11$ $66160.70 \mathrm{C} 1.7344 \mathrm{E}-12$ $66163.70 \mathrm{C} 1.8455 \mathrm{E}-11$ $68162.70 \mathrm{C} 1.0081 \mathrm{E}-13$ $68167.70 \mathrm{C} 1.6512 \mathrm{E}-11$ $69169.55 \mathrm{C} 7.1295 \mathrm{E}-11$ $71176.70 \mathrm{C}$ 1.7829E-12 $72177.70 \mathrm{C} 2.5102 \mathrm{E}-11$ $72180.70 \mathrm{C} \quad 4.7343 \mathrm{E}-11$ $74183.70 \mathrm{C} 5.9998 \mathrm{E}-07$ $75185.70 \mathrm{C} 2.4191 \mathrm{E}-09$ $77191.70 \mathrm{C} 8.4138 \mathrm{E}-10$ $79197.70 \mathrm{C}$ 6.1148E-10 $80199.70 \mathrm{C} 2.0259 \mathrm{E}-10$ $80202.70 \mathrm{C} 3.5858 \mathrm{E}-10$ $82204.70 \mathrm{C} 1.0091 \mathrm{E}-10$ $82208.70 \mathrm{C} 3.7769 \mathrm{E}-09$ $92234.70 \mathrm{C} 2.7830 \mathrm{E}-15$
$11023.70 \mathrm{C} 1.0478 \mathrm{E}-09$ $12026.70 \mathrm{C} 3.9283 \mathrm{E}-08$ $14029.70 \mathrm{C} 3.2134 \mathrm{E}-05$ $16032.70 \mathrm{C} 3.1374 \mathrm{E}-06$ $16036.70 \mathrm{C} 6.6099 \mathrm{E}-10$ $19039.70 \mathrm{C} 5.7456 \mathrm{E}-10$ $20040.70 \mathrm{C} 5.8265 \mathrm{E}-08$ $20044.70 \mathrm{C} 1.2538 \mathrm{E}-09$ $21045.70 \mathrm{C} 2.6791 \mathrm{E}-10$ $22048.70 \mathrm{C} 1.4835 \mathrm{E}-06$ $23000.70 \mathrm{C} 9.4573 \mathrm{E}-05$ $24053.70 \mathrm{C} 1.6726 \mathrm{E}-03$ $26054.70 \mathrm{C} \quad 3.4644 \mathrm{E}-03$ $26058.70 \mathrm{C} \quad 1.6714 \mathrm{E}-04$ $28060.70 \mathrm{C} 2.1526 \mathrm{E}-03$ $28064.70 \mathrm{C} 7.5980 \mathrm{E}-05$ $30000.70 \mathrm{C} 3.6838 \mathrm{E}-08$ $32070.70 \mathrm{C} 2.7655 \mathrm{E}-07$ $32074.70 \mathrm{C} \quad 4.8144 \mathrm{E}-07$ $34074.70 \mathrm{C} 2.7151 \mathrm{E}-11$ $34078.70 \mathrm{C} \quad 7.2515 \mathrm{E}-10$ $35079.70 \mathrm{C} 1.5281 \mathrm{E}-09$ $37087.70 \mathrm{C} 3.9218 \mathrm{E}-09$ $38087.70 \mathrm{C} 3.8489 \mathrm{E}-10$ $40090.70 \mathrm{C} 4.8909 \mathrm{E}-08$ $40094.70 \mathrm{C} 1.6522 \mathrm{E}-08$ $42092.70 \mathrm{C} 2.2356 \mathrm{E}-05$ $42096.70 \mathrm{C} 2.5128 \mathrm{E}-05$ $42100.70 \mathrm{C} 1.4507 \mathrm{E}-05$ $44099.70 \mathrm{C} 3.0411 \mathrm{E}-10$ $44102.70 \mathrm{C} 7.5194 \mathrm{E}-10$ $46102.70 \mathrm{C} 1.1544 \mathrm{E}-11$ $46106.70 \mathrm{C} 3.0931 \mathrm{E}-10$ $47107.70 \mathrm{C} 5.7882 \mathrm{E}-09$ $48108.70 \mathrm{C} 1.9072 \mathrm{E}-11$ $48112.70 \mathrm{C} 5.1708 \mathrm{E}-10$ $48116.70 \mathrm{C} \quad 1.6050 \mathrm{E}-10$ $50112.70 \mathrm{C} 2.1651 \mathrm{E}-08$ $50116.70 \mathrm{C} 3.2455 \mathrm{E}-07$ $50119.70 \mathrm{C} \quad 1.9174 \mathrm{E}-07$ $50124.70 \mathrm{C} 1.2924 \mathrm{E}-07$ $52120.70 \mathrm{C} 8.4951 \mathrm{E}-13$ $52124.70 \mathrm{C} \quad 4.4741 \mathrm{E}-11$ $52128.70 \mathrm{C} 2.9959 \mathrm{E}-10$ $55133.70 \mathrm{C} 1.8124 \mathrm{E}-10$ $56134.70 \mathrm{C} 2.1198 \mathrm{E}-11$ $56137.70 \mathrm{C} 9.8510 \mathrm{E}-11$ $57139.70 \mathrm{C} 1.7326 \mathrm{E}-10$ $58140.70 \mathrm{C} 7.6031 \mathrm{E}-10$ $60142.70 \mathrm{C} 2.2712 \mathrm{E}-11$ $60145.70 \mathrm{C} 6.9306 \mathrm{E}-12$ $60150.70 \mathrm{C} \quad 4.6761 \mathrm{E}-12$ $62148.70 \mathrm{C} 9.0035 \mathrm{E}-12$ $62152.70 \mathrm{C} 2.1427 \mathrm{E}-11$ $63153.70 \mathrm{C} 4.1365 \mathrm{E}-11$ $64155.70 \mathrm{C} 1.1336 \mathrm{E}-11$ $64158.70 \mathrm{C} 1.9026 \mathrm{E}-11$ $66156.70 \mathrm{C} 4.4471 \mathrm{E}-14$ $66161.70 \mathrm{C} 1.4016 \mathrm{E}-11$ $66164.70 \mathrm{C} 2.0886 \mathrm{E}-11$ $68164.70 \mathrm{C} 1.1593 \mathrm{E}-12$ $68168.70 \mathrm{C} 1.9284 \mathrm{E}-11$ $5010.70 \mathrm{C} 9.3965 \mathrm{E}-15$ $72174.70 \mathrm{C} 2.1593 \mathrm{E}-13$ $72178.70 \mathrm{C} 3.6816 \mathrm{E}-11$ $73181.70 \mathrm{C} 1.3312 \mathrm{E}-08$ $74184.70 \mathrm{C} 1.2846 \mathrm{E}-06$ $75187.70 \mathrm{C} 4.0491 \mathrm{E}-09$ $77193.70 \mathrm{C} 1.4143 \mathrm{E}-09$ $80196.70 \mathrm{C} 1.8013 \mathrm{E}-12$ $80200.70 \mathrm{C} 2.7740 \mathrm{E}-10$ $80204.70 \mathrm{C} 8.2500 \mathrm{E}-11$ $82206.70 \mathrm{C} 1.7371 \mathrm{E}-09$ $83209.70 \mathrm{C} 1.1527 \mathrm{E}-10$ $92235.70 \mathrm{C} 3.6432 \mathrm{E}-13$
$12024.70 \mathrm{C} 2.8183 \mathrm{E}-07$ $13027.70 \mathrm{C} 2.1427 \mathrm{E}-06$ $14030.70 \mathrm{C} 2.1183 \mathrm{E}-05$ $16033.70 \mathrm{C} 2.5117 \mathrm{E}-08$ $17035.70 \mathrm{C} 2.5744 \mathrm{E}-09$ $19040.70 \mathrm{C} 7.2084 \mathrm{E}-14$ $20042.70 \mathrm{C} 3.8887 \mathrm{E}-10$ $20046.70 \mathrm{C} 2.4042 \mathrm{E}-12$ $22046.70 \mathrm{C} 1.6602 \mathrm{E}-07$ $22049.70 \mathrm{C}$ 1.0887E-07 $24050.70 \mathrm{C} 7.6491 \mathrm{E}-04$ $24054.70 \mathrm{C} 4.1634 \mathrm{E}-04$ $26056.70 \mathrm{C} 5.4383 \mathrm{E}-02$ $27059.70 \mathrm{C} 6.5399 \mathrm{E}-05$ $28061.70 \mathrm{C} 9.3571 \mathrm{E}-05$ $29063.70 \mathrm{C} 1.5732 \mathrm{E}-04$ $31069.70 \mathrm{C} \quad 6.6453 \mathrm{E}-07$ $32072.70 \mathrm{C} 3.6546 \mathrm{E}-07$ $32076.70 \mathrm{C} 1.0098 \mathrm{E}-07$ $34076.70 \mathrm{C} 2.8585 \mathrm{E}-10$ $34080.70 \mathrm{C} 1.5135 \mathrm{E}-09$ $35081.70 \mathrm{C} 1.4865 \mathrm{E}-09$ $38084.70 \mathrm{C} \quad 3.0791 \mathrm{E}-11$ $38088.70 \mathrm{C} 4.5406 \mathrm{E}-09$ $40091.70 \mathrm{C} 1.0666 \mathrm{E}-08$ $40096.70 \mathrm{C} 2.6617 \mathrm{E}-09$ $42094.70 \mathrm{C} 1.3935 \mathrm{E}-05$ $42097.70 \mathrm{C} 1.4387 \mathrm{E}-05$ $44096.70 \mathrm{C} 1.3204 \mathrm{E}-10$ $44100.70 \mathrm{C} 3.0030 \mathrm{E}-10$ $44104.70 \mathrm{C} 4.4378 \mathrm{E}-10$ $46104.70 \mathrm{C} 1.2608 \mathrm{E}-10$ $46108.70 \mathrm{C} 2.9946 \mathrm{E}-10$ $47109.70 \mathrm{C} 5.3775 \mathrm{E}-09$ $48110.70 \mathrm{C} 2.6765 \mathrm{E}-10$ $48113.70 \mathrm{C} 2.6186 \mathrm{E}-10$ $49113.70 \mathrm{C} 4.5001 \mathrm{E}-10$ $50114.70 \mathrm{C} 1.4732 \mathrm{E}-08$ $50117.70 \mathrm{C} 1.7143 \mathrm{E}-07$ $50120.70 \mathrm{C} \quad 7.2722 \mathrm{E}-07$ $51121.70 \mathrm{C} 2.0148 \mathrm{E}-07$ $52122.70 \mathrm{C} 2.4070 \mathrm{E}-11$ $52125.70 \mathrm{C} \quad 6.6734 \mathrm{E}-11$ $52130.70 \mathrm{C} 3.2168 \mathrm{E}-10$ $56130.70 \mathrm{C} 9.2967 \mathrm{E}-13$ $56135.70 \mathrm{C} 5.7815 \mathrm{E}-11$ $56138.70 \mathrm{C} 6.2882 \mathrm{E}-10$ $58136.70 \mathrm{C} \quad 1.5902 \mathrm{E}-12$ $58142.70 \mathrm{C} 9.5535 \mathrm{E}-11$ $60143.70 \mathrm{C} 1.0187 \mathrm{E}-11$ $60146.70 \mathrm{C} 1.4362 \mathrm{E}-11$ $62144.70 \mathrm{C} 2.4591 \mathrm{E}-12$ $62149.70 \mathrm{C} 1.1070 \mathrm{E}-11$ $62154.70 \mathrm{C} 1.8223 \mathrm{E}-11$ $64152.70 \mathrm{C} 1.5319 \mathrm{E}-13$ $64156.70 \mathrm{C} 1.5679 \mathrm{E}-11$ $64160.70 \mathrm{C} 1.6743 \mathrm{E}-11$ $66158.70 \mathrm{C} 7.4118 \mathrm{E}-14$ $66162.70 \mathrm{C} 1.8908 \mathrm{E}-11$ $67165.70 \mathrm{C} 7.3026 \mathrm{E}-11$ $68166.70 \mathrm{C} 2.4202 \mathrm{E}-11$ $68170.70 \mathrm{C} 1.0751 \mathrm{E}-11$ $71175.70 \mathrm{C} 6.7054 \mathrm{E}-11$ $72176.70 \mathrm{C} 7.0987 \mathrm{E}-12$ $72179.70 \mathrm{C} 1.8381 \mathrm{E}-11$ $74182.70 \mathrm{C}$ 1.1111E-06 $74186.70 \mathrm{C} 1.1970 \mathrm{E}-06$ $76000.31 \mathrm{C} 2.2797 \mathrm{E}-09$ $78000.31 \mathrm{C} 1.2348 \mathrm{E}-09$ $80198.70 \mathrm{C} 1.1973 \mathrm{E}-10$ $80201.70 \mathrm{C} 1.5828 \mathrm{E}-10$ $81000.31 \mathrm{C} 5.8929 \mathrm{E}-10$ $82207.70 \mathrm{C} 1.5930 \mathrm{E}-09$ $90232.70 \mathrm{C} 5.1906 \mathrm{E}-11$ $92238.70 \mathrm{C} 5.0233 \mathrm{E}-11$ 
NEA/NSC/DOC(2006)1

Fundamental - FUND

NRAD-FUND-RESR-001

CRIT

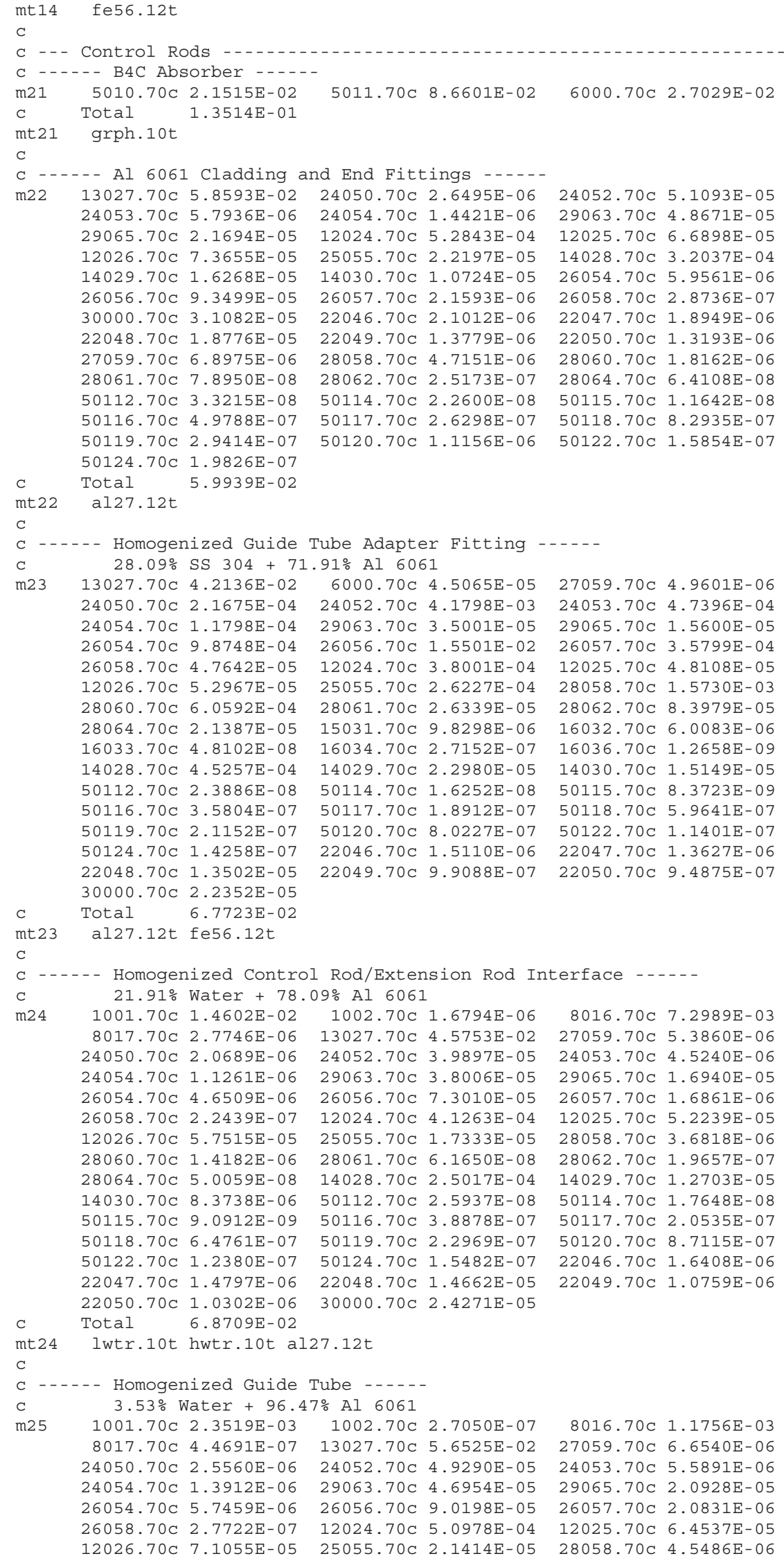

$8016.70 \mathrm{C} \quad 1.1756 \mathrm{E}-03$ $27059.70 \mathrm{C} \quad 6.6540 \mathrm{E}-06$ $24053.70 \mathrm{C} 5.5891 \mathrm{E}-06$ $29065.70 \mathrm{C} 2.0928 \mathrm{E}-05$ $26057.70 \mathrm{C} 2.0831 \mathrm{E}-06$ $12025.70 \mathrm{C} \quad 6.4537 \mathrm{E}-05$ $28058.70 \mathrm{C} 4.5486 \mathrm{E}-06$ 
NEA/NSC/DOC(2006)1

Fundamental - FUND

NRAD-FUND-RESR-001 CRIT

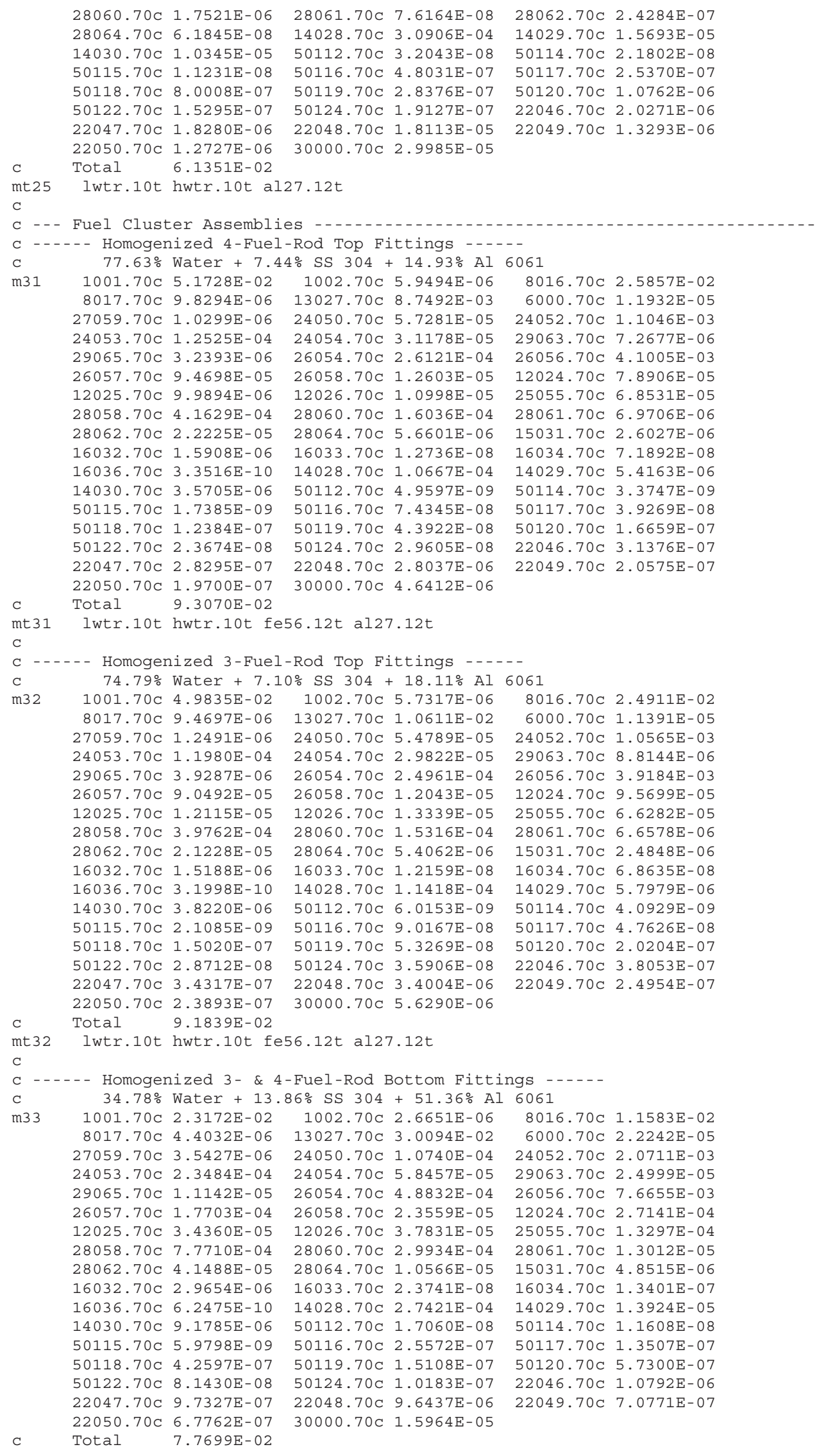


NEA/NSC/DOC(2006)1

Fundamental - FUND

NRAD-FUND-RESR-001

CRIT

mt33 lwtr.10t hwtr.10t fe56.12t al27.12t

C

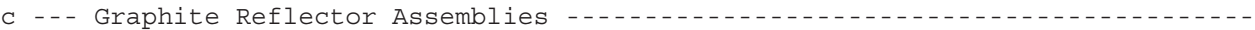

C -...- Graphite Reflectors -....

m41 3006.70C 2.5847E-10 3007.70C 3.1469E-09 $5010.70 \mathrm{C} 1.3053 \mathrm{E}-08 \quad 5011.70 \mathrm{C} 5.2538 \mathrm{E}-08$ $9019.70 \mathrm{C} 2.4883 \mathrm{E}-09$ 11023.70C 6.1688E-09 $12025.70 \mathrm{C} 5.4460 \mathrm{E}-09 \quad 12026.70 \mathrm{C} 5.9961 \mathrm{E}-09$ $14028.70 \mathrm{C} 2.5149 \mathrm{E}-06 \quad 14029.70 \mathrm{C} \quad 1.2770 \mathrm{E}-07$ $15031.70 \mathrm{C} \quad 5.4945 \mathrm{E}-08 \quad 16032.70 \mathrm{C} \quad 1.3993 \mathrm{E}-06$ $16034.70 \mathrm{C} \quad 6.3238 \mathrm{E}-08 \quad 16036.70 \mathrm{C} 2.9481 \mathrm{E}-10$ $17037.70 \mathrm{C} 1.4856 \mathrm{E}-08 \quad 19039.70 \mathrm{C} 1.1276 \mathrm{E}-09$ $19041.70 \mathrm{C} \quad 8.1374 \mathrm{E}-11 \quad 20040.70 \mathrm{C} \quad 5.2599 \mathrm{E}-07$ $20043.70 \mathrm{C} \quad 7.3249 \mathrm{E}-10 \quad 20044.70 \mathrm{C} 1.1318 \mathrm{E}-08$ $20048.70 \mathrm{C} 1.0146 \mathrm{E}-09 \quad 21045.70 \mathrm{C}$ 1.4722E-09 $22047.70 \mathrm{C} 2.6445 \mathrm{E}-08 \quad 22048.70 \mathrm{C} 2.6203 \mathrm{E}-07$ $22050.70 \mathrm{C} 1.8412 \mathrm{E}-08 \quad 23000.70 \mathrm{C} \quad 5.3824 \mathrm{E}-07$ $24052.70 \mathrm{C} 3.8089 \mathrm{E}-09 \quad 24053.70 \mathrm{C} 4.3190 \mathrm{E}-10$ $25055.70 \mathrm{C} 2.0652 \mathrm{E}-09 \quad 26054.70 \mathrm{C} 5.4425 \mathrm{E}-08$ $26057.70 \mathrm{C} 1.9731 \mathrm{E}-08 \quad 26058.70 \mathrm{C} 2.6258 \mathrm{E}-09$ $28058.70 \mathrm{C} \quad 3.8384 \mathrm{E}-08 \quad 28060.70 \mathrm{C} \quad 1.4785 \mathrm{E}-08$ $28062.70 \mathrm{C} 2.0493 \mathrm{E}-09 \quad 28064.70 \mathrm{C} 5.2189 \mathrm{E}-10$ $29065.70 \mathrm{C} 1.1468 \mathrm{E}-10 \quad 30000.70 \mathrm{C} \quad 3.6147 \mathrm{E}-10$ $31071.70 \mathrm{C} \quad 2.7048 \mathrm{E}-11 \quad 32070.70 \mathrm{C} \quad 6.7840 \mathrm{E}-11$ $32073.70 \mathrm{C} 2.5163 \mathrm{E}-11 \quad 32074.70 \mathrm{C} 1.1810 \mathrm{E}-10$ $33075.70 \mathrm{C} \quad 3.1549 \mathrm{E}-10 \quad 34074.70 \mathrm{C} \quad 2.6642 \mathrm{E}-12$ $34077.70 \mathrm{C} \quad 2.2840 \mathrm{E}-11 \quad 34078.70 \mathrm{C} \quad 7.1156 \mathrm{E}-11$ $34082.70 \mathrm{C} 2.6133 \mathrm{E}-11 \quad 35079.70 \mathrm{C} 2.9990 \mathrm{E}-10$ $37085.70 \mathrm{C} \quad 1.9959 \mathrm{E}-10 \quad 37087.70 \mathrm{C} \quad 7.6966 \mathrm{E}-11$ $38086.70 \mathrm{C} \quad 5.4261 \mathrm{E}-10 \quad 38087.70 \mathrm{C} \quad 3.8522 \mathrm{E}-10$ $39089.70 \mathrm{C} 2.6586 \mathrm{E}-10 \quad 40090.70 \mathrm{C} \quad 2.3463 \mathrm{E}-09$ $40092.70 \mathrm{C} \quad 7.8209 \mathrm{E}-10 \quad 40094.70 \mathrm{C} \quad 7.9258 \mathrm{E}-10$ $41093.70 \mathrm{C} \quad 2.5441 \mathrm{E}-10 \quad 42092.70 \mathrm{C} \quad 3.6561 \mathrm{E}-11$ $42095.70 \mathrm{C} 3.9222 \mathrm{E}-11 \quad 42096.70 \mathrm{C} \quad 4.1095 \mathrm{E}-11$ $42098.70 \mathrm{C} \quad 5.9449 \mathrm{E}-11 \quad 42100.70 \mathrm{C} \quad 2.3725 \mathrm{E}-11$ $44098.70 \mathrm{C} 4.3733 \mathrm{E}-12 \quad 44099.70 \mathrm{C} 2.9841 \mathrm{E}-11$ $44101.70 \mathrm{C} \quad 3.9897 \mathrm{E}-11 \quad 44102.70 \mathrm{C} \quad 7.3784 \mathrm{E}-11$ $45103.70 \mathrm{C}$ 4.5939E-11 46102.70C $2.2655 \mathrm{E}-12$ $46105.70 \mathrm{C}$ 4.9597E-11 46106.70C 6.0702E-11 $46110.70 \mathrm{C} \quad 2.6031 \mathrm{E}-11 \quad 47107.70 \mathrm{C} 1.1359 \mathrm{E}-10$ $48106.70 \mathrm{C} \quad 2.6284 \mathrm{E}-12 \quad 48108.70 \mathrm{C} \quad 1.8714 \mathrm{E}-12$ $48111.70 \mathrm{C} \quad 2.6915 \mathrm{E}-11 \quad 48112.70 \mathrm{C} \quad 5.0739 \mathrm{E}-11$ 48114.70C 6.0411E-11 48116.70C $1.5749 \mathrm{E}-11$ $49115.70 \mathrm{C} 1.9703 \mathrm{E}-10 \quad 50112.70 \mathrm{C} 1.9314 \mathrm{E}-12$ $50115.70 \mathrm{C} \quad 6.7699 \mathrm{E}-13 \quad 50116.70 \mathrm{C} \quad 2.8951 \mathrm{E}-11$ $50118.70 \mathrm{C}$ 4.8225E-11 50119.70C $1.7104 \mathrm{E}-11$ $50122.70 \mathrm{C} 9.2189 \mathrm{E}-12 \quad 50124.70 \mathrm{C} 1.1529 \mathrm{E}-11$ $51123.70 \mathrm{C} \quad 8.3073 \mathrm{E}-11 \quad 52120.70 \mathrm{C} \quad 1.6672 \mathrm{E}-13$ $52123.70 \mathrm{C} \quad 1.6486 \mathrm{E}-12 \quad 52124.70 \mathrm{C} \quad 8.7804 \mathrm{E}-12$ $52126.70 \mathrm{C} 3.4899 \mathrm{E}-11 \quad 52128.70 \mathrm{C} 5.8795 \mathrm{E}-11$ $53127.70 \mathrm{C} \quad 3.7251 \mathrm{E}-11 \quad 55133.70 \mathrm{C} 1.7785 \mathrm{E}-10$ $56132.70 \mathrm{C} 1.7384 \mathrm{E}-13 \quad 56134.70 \mathrm{C} \quad 4.1601 \mathrm{E}-12$ $56136.70 \mathrm{C} 1.3518 \mathrm{E}-11 \quad 56137.70 \mathrm{C} 1.9333 \mathrm{E}-11$ $57138.70 \mathrm{C} \quad 1.5315 \mathrm{E}-13 \quad 57139.70 \mathrm{C} \quad 1.7001 \mathrm{E}-10$ $58138.70 \mathrm{C} \quad 4.2343 \mathrm{E}-13 \quad 58140.70 \mathrm{C} 1.4921 \mathrm{E}-10$ $59141.70 \mathrm{C} \quad 1.6775 \mathrm{E}-10 \quad 60142.70 \mathrm{C} \quad 4.4573 \mathrm{E}-11$ $60144.70 \mathrm{C} 3.9001 \mathrm{E}-11 \quad 60145.70 \mathrm{C} 1.3601 \mathrm{E}-11$ $60148.70 \mathrm{C} \quad 9.3406 \mathrm{E}-12 \quad 60150.70 \mathrm{C} \quad 9.1768 \mathrm{E}-12$ $62147.70 \mathrm{C} \quad 4.7129 \mathrm{E}-12 \quad 62148.70 \mathrm{C} \quad 3.5339 \mathrm{E}-12$ $62150.70 \mathrm{C} 2.3203 \mathrm{E}-12 \quad 62152.70 \mathrm{C} \quad 8.4103 \mathrm{E}-12$ $63151.70 \mathrm{C} 1.4873 \mathrm{E}-11 \quad 63153.70 \mathrm{C} 1.6236 \mathrm{E}-11$ $64154.70 \mathrm{C} \quad 6.5537 \mathrm{E}-13 \quad 64155.70 \mathrm{C} \quad 4.4493 \mathrm{E}-12$ $64157.70 \mathrm{C} \quad 4.7048 \mathrm{E}-12 \quad 64158.70 \mathrm{C} \quad 7.4676 \mathrm{E}-12$ $65159.70 \mathrm{C} 2.9746 \mathrm{E}-11 \quad 66156.70 \mathrm{C} \quad 1.7455 \mathrm{E}-14$ $66160.70 \mathrm{C} \quad 6.8074 \mathrm{E}-13 \quad 66161.70 \mathrm{C} \quad 5.5012 \mathrm{E}-12$ $66163.70 \mathrm{C} \quad 7.2438 \mathrm{E}-12 \quad 66164.70 \mathrm{C} \quad 8.1979 \mathrm{E}-12$ $68162.70 \mathrm{C} \quad 3.9569 \mathrm{E}-14 \quad 68164.70 \mathrm{C} \quad 4.5504 \mathrm{E}-13$ $68167.70 \mathrm{C} \quad 6.4808 \mathrm{E}-12 \quad 68168.70 \mathrm{C} \quad 7.5690 \mathrm{E}-12$ $69169.55 \mathrm{C} 2.7983 \mathrm{E}-11 \quad 5010.70 \mathrm{C} 3.6881 \mathrm{E}-15$ $71176.70 \mathrm{C} \quad 6.9978 \mathrm{E}-13 \quad 72174.70 \mathrm{C} \quad 4.2376 \mathrm{E}-14$ $72177.70 \mathrm{C} \quad 4.9263 \mathrm{E}-12 \quad 72178.70 \mathrm{C} \quad 7.2252 \mathrm{E}-12$ $72180.70 \mathrm{C} \quad 9.2910 \mathrm{E}-12 \quad 73181.70 \mathrm{C} \quad 2.6125 \mathrm{E}-07$ $74183.70 \mathrm{C} \quad 1.8398 \mathrm{E}-11 \quad 74184.70 \mathrm{C} \quad 3.9392 \mathrm{E}-11$ $75185.70 \mathrm{C} \quad 9.4950 \mathrm{E}-12 \quad 75187.70 \mathrm{C} \quad 1.5893 \mathrm{E}-11$ $77191.70 \mathrm{C}$ 9.1733E-12 77193.70C $1.5420 \mathrm{E}-11$

$79197.70 \mathrm{C} 2.4001 \mathrm{E}-10$ $77193.70 \mathrm{C} 1.5420 \mathrm{E}-11$ $80196.70 \mathrm{C} 3.5351 \mathrm{E}-13$

$4009.70 \mathrm{C} 2.6227 \mathrm{E}-09$ $6000.70 \mathrm{C} 7.8692 \mathrm{E}-02$ $12024.70 \mathrm{C} 4.3018 \mathrm{E}-08$ $13027.70 \mathrm{C} \quad 4.5554 \mathrm{E}-08$ $14030.70 \mathrm{C} 8.4181 \mathrm{E}-08$ $16033.70 \mathrm{C} \quad 1.1203 \mathrm{E}-08$ $17035.70 \mathrm{C} 4.6481 \mathrm{E}-08$ $19040.70 \mathrm{C} 1.4146 \mathrm{E}-13$ $20042.70 \mathrm{C} 3.5105 \mathrm{E}-09$ $20046.70 \mathrm{C} 2.1703 \mathrm{E}-11$ $22046.70 \mathrm{C} 2.9324 \mathrm{E}-08$ $22049.70 \mathrm{C} 1.9229 \mathrm{E}-08$ $24050.70 \mathrm{C} 1.9752 \mathrm{E}-10$ $24054.70 \mathrm{C} 1.0751 \mathrm{E}-10$ $26056.70 \mathrm{C} 8.5435 \mathrm{E}-07$ $27059.70 \mathrm{C} 8.0215 \mathrm{E}-11$ $28061.70 \mathrm{C} 6.4271 \mathrm{E}-10$ $29063.70 \mathrm{C} 2.5729 \mathrm{E}-10$ $31069.70 \mathrm{C} 4.0754 \mathrm{E}-11$ $32072.70 \mathrm{C} 8.9651 \mathrm{E}-11$ $32076.70 \mathrm{C} 2.4773 \mathrm{E}-11$ $34076.70 \mathrm{C} 2.8049 \mathrm{E}-11$ $34080.70 \mathrm{C} 1.4851 \mathrm{E}-10$ $35081.70 \mathrm{C} 2.9173 \mathrm{E}-10$ $38084.70 \mathrm{C} 3.0818 \mathrm{E}-11$ $38088.70 \mathrm{C} 4.5445 \mathrm{E}-09$ $40091.70 \mathrm{C} 5.1166 \mathrm{E}-10$ $40096.70 \mathrm{C} 1.2769 \mathrm{E}-10$ $42094.70 \mathrm{C} \quad 2.2789 \mathrm{E}-11$ $42097.70 \mathrm{C} 2.3528 \mathrm{E}-11$ $44096.70 \mathrm{C} 1.2956 \mathrm{E}-11$ $44100.70 \mathrm{C} 2.9467 \mathrm{E}-11$ $44104.70 \mathrm{C}$ 4.3546E-11 $46104.70 \mathrm{C} 2.4743 \mathrm{E}-11$ $46108.70 \mathrm{C} 5.8770 \mathrm{E}-11$ $47109.70 \mathrm{C} 1.0553 \mathrm{E}-10$ $48110.70 \mathrm{C} 2.6263 \mathrm{E}-11$ $48113.70 \mathrm{C} 2.5695 \mathrm{E}-11$ $49113.70 \mathrm{C} 8.8314 \mathrm{E}-12$ $50114.70 \mathrm{C} 1.3141 \mathrm{E}-12$ $50117.70 \mathrm{C} 1.5292 \mathrm{E}-11$ $50120.70 \mathrm{C} 6.4871 \mathrm{E}-11$ $51121.70 \mathrm{C} 1.1107 \mathrm{E}-10$ $52122.70 \mathrm{C} 4.7236 \mathrm{E}-12$ $52125.70 \mathrm{C} 1.3097 \mathrm{E}-11$ $52130.70 \mathrm{C} 6.3130 \mathrm{E}-11$ $56130.70 \mathrm{C} 1.8245 \mathrm{E}-13$ $56135.70 \mathrm{C} 1.1346 \mathrm{E}-11$ $56138.70 \mathrm{C} 1.2341 \mathrm{E}-10$ $58136.70 \mathrm{C} 3.1209 \mathrm{E}-13$ $58142.70 \mathrm{C} 1.8749 \mathrm{E}-11$ $60143.70 \mathrm{C} 1.9992 \mathrm{E}-11$ $60146.70 \mathrm{C} 2.8186 \mathrm{E}-11$ $62144.70 \mathrm{C} 9.6521 \mathrm{E}-13$ $62149.70 \mathrm{C} 4.3450 \mathrm{E}-12$ $62154.70 \mathrm{C} 7.1526 \mathrm{E}-12$ $64152.70 \mathrm{C} 6.0125 \mathrm{E}-14$ $64156.70 \mathrm{C} 6.1538 \mathrm{E}-12$ $64160.70 \mathrm{C} \quad 6.5717 \mathrm{E}-12$ $66158.70 \mathrm{C} 2.9091 \mathrm{E}-14$ $66162.70 \mathrm{C} 7.4212 \mathrm{E}-12$ $67165.70 \mathrm{C} 2.8663 \mathrm{E}-11$ $68166.70 \mathrm{C} 9.4994 \mathrm{E}-12$ $68170.70 \mathrm{C} 4.2197 \mathrm{E}-12$ $71175.70 \mathrm{C} 2.6319 \mathrm{E}-11$ $72176.70 \mathrm{C} \quad 1.3931 \mathrm{E}-12$ $72179.70 \mathrm{C} 3.6073 \mathrm{E}-12$ $74182.70 \mathrm{C} 3.4070 \mathrm{E}-11$ $74186.70 \mathrm{C} 3.6705 \mathrm{E}-11$ $76000.31 \mathrm{C} 2.4855 \mathrm{E}-11$ $78000.31 \mathrm{C} 2.4233 \mathrm{E}-11$ $80198.70 \mathrm{C} 2.3497 \mathrm{E}-11$ 
NEA/NSC/DOC(2006)1

Fundamental - FUND

NRAD-FUND-RESR-001 CRIT

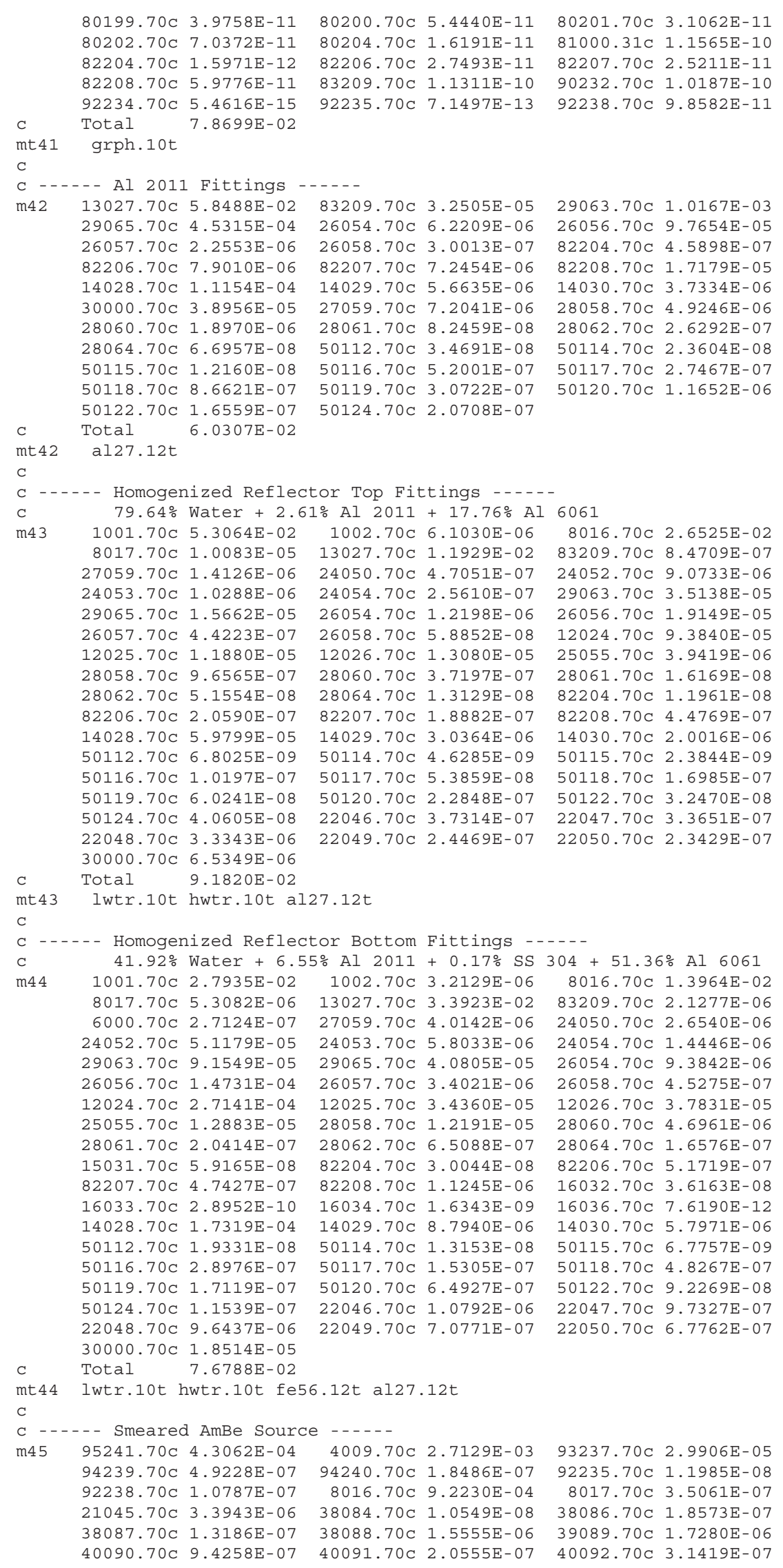

$80199.70 \mathrm{C} \quad 3.9758 \mathrm{E}-11$ $14029.70 \mathrm{C} 5.6635 \mathrm{E}-06$ $559.70 \mathrm{C} 7.2041 \mathrm{E}-06$ $\begin{array}{llll}50118.70 \mathrm{C} & 8.6621 \mathrm{E}-07 & 50119.70 \mathrm{C} & 3.0722 \mathrm{E}-07 \\ 50122.70 \mathrm{C} & 1.6559 \mathrm{E}-07 & 50124.70 \mathrm{C} & 2.0708 \mathrm{E}-07\end{array}$ Total $6.0307 \mathrm{E}-02$
$80201.70 \mathrm{C} 3.1062 \mathrm{E}-11$ $81000.31 \mathrm{C} 1.1565 \mathrm{E}-10$ 2207.70C 2.5211E-11 $90232.70 \mathrm{C} 1.0187 \mathrm{E}-10$

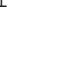


NEA/NSC/DOC(2006)1

Fundamental - FUND

NRAD-FUND-RESR-001 CRIT

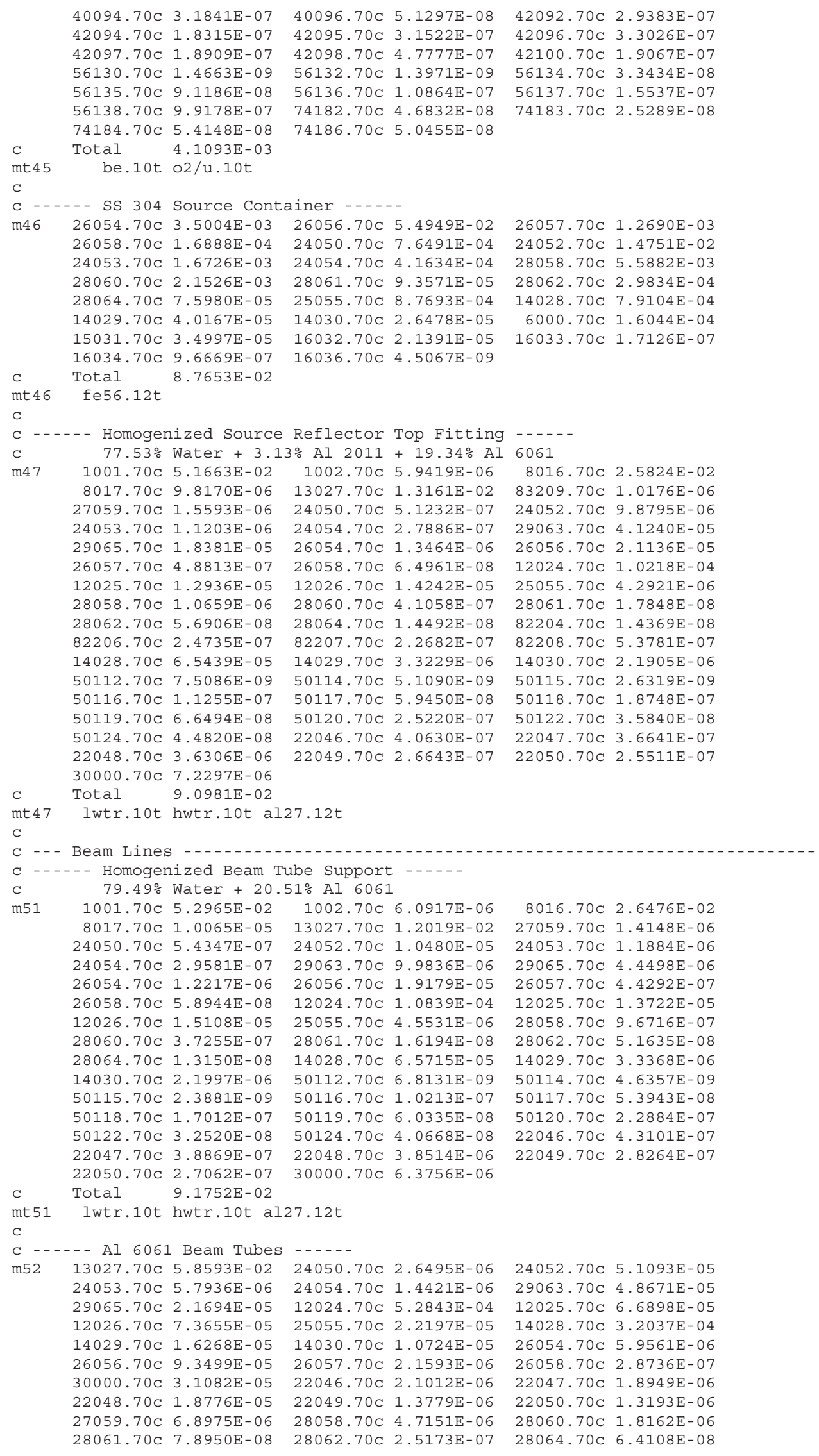


NEA/NSC/DOC(2006)1

\section{Fundamental - FUND}

\section{NRAD-FUND-RESR-001} CRIT

\begin{tabular}{|c|c|c|c|c|c|c|}
\hline & $50112.70 \mathrm{C}$ & $3.3215 E-08$ & $50114.70 \mathrm{C}$ & $2.2600 \mathrm{E}-08$ & $50115.70 \mathrm{C}$ & 1. $1642 \mathrm{E}-08$ \\
\hline & $50116.70 \mathrm{C}$ & $4.9788 E-07$ & $50117.70 \mathrm{C}$ & $2.6298 E-07$ & $50118.70 \mathrm{C}$ & $8.2935 E-07$ \\
\hline & $50119.70 \mathrm{C}$ & $2.9414 \mathrm{E}-07$ & $50120.70 \mathrm{C}$ & 1. $1156 \mathrm{E}-06$ & $50122.70 \mathrm{C}$ & $1.5854 \mathrm{E}-07$ \\
\hline & $50124.70 \mathrm{C}$ & $1.9826 E-07$ & & & & \\
\hline C & Total & $5.9939 \mathrm{E}-02$ & & & & \\
\hline mt 52 & al27.12t & & & & & \\
\hline $\mathrm{C}$ & & & & & & \\
\hline$C--$ & -- Helium & ----- & & & & \\
\hline m53 & $2003.70 \mathrm{C}$ & $1.6794 \mathrm{E}-12$ & $2004.70 \mathrm{C}$ & $1.2258 \mathrm{E}-06$ & & \\
\hline C & Total & $1.2258 \mathrm{E}-06$ & & & & \\
\hline C & & & & & & \\
\hline C - & -- Boron & Nitride ---- & & & & \\
\hline m54 & $5010.70 \mathrm{C}$ & $9.6267 E-03$ & $5011.70 \mathrm{C}$ & 3. $8749 \mathrm{E}-02$ & $7014.70 \mathrm{C}$ & $4.8197 \mathrm{E}-02$ \\
\hline & $7015.70 \mathrm{C}$ & $1.7802 \mathrm{E}-04$ & $13027.70 \mathrm{C}$ & $6.8105 E-07$ & $79197.70 \mathrm{C}$ & $6.3900 E-09$ \\
\hline & $4009.70 \mathrm{C}$ & $1.3966 \mathrm{E}-07$ & $20040.70 \mathrm{C}$ & 1.8899E-05 & $20042.70 \mathrm{C}$ & $1.2614 \mathrm{E}-07$ \\
\hline & $20043.70 \mathrm{C}$ & $2.6319 E-08$ & $20044.70 \mathrm{C}$ & $4.0668 E-07$ & $20046.70 \mathrm{C}$ & $7.7983 E-10$ \\
\hline & $20048.70 \mathrm{C}$ & $3.6457 \mathrm{E}-08$ & $24050.70 \mathrm{C}$ & $2.3980 \mathrm{E}-08$ & $24052.70 \mathrm{C}$ & $4.6243 E-07$ \\
\hline & $24053.70 \mathrm{C}$ & $5.2436 E-08$ & $24054.70 \mathrm{C}$ & $1.3052 \mathrm{E}-08$ & $29063.70 \mathrm{C}$ & $1.3700 E-08$ \\
\hline & $29065.70 \mathrm{C}$ & $6.1063 E-09$ & $26054.70 \mathrm{C}$ & 1. $3173 E-09$ & $26056.70 \mathrm{C}$ & $2.0679 \mathrm{E}-08$ \\
\hline & $26057.70 \mathrm{C}$ & $4.7756 \mathrm{E}-10$ & $26058.70 \mathrm{C}$ & $6.3554 \mathrm{E}-11$ & $19039.70 \mathrm{C}$ & $6.9048 E-07$ \\
\hline & $19040.70 \mathrm{C}$ & $8.6626 E-11$ & $19041.70 \mathrm{C}$ & $4.9830 E-08$ & $12024.70 \mathrm{C}$ & $4.0904 \mathrm{E}-08$ \\
\hline & $12025.70 \mathrm{C}$ & $5.1784 E-09$ & $12026.70 \mathrm{C}$ & $5.7015 E-09$ & $25055.70 \mathrm{C}$ & $3.2074 E-08$ \\
\hline & $42092.70 \mathrm{C}$ & $1.9468 \mathrm{E}-09$ & $42094.70 \mathrm{C}$ & 1.2135E-09 & $42095.70 \mathrm{C}$ & $2.0885 E-09$ \\
\hline & $42096.70 \mathrm{C}$ & $2.1882 \mathrm{E}-09$ & $42097.70 \mathrm{C}$ & 1. 2528E-09 & $42098.70 \mathrm{C}$ & $3.1656 \mathrm{E}-09$ \\
\hline & $42100.70 \mathrm{C}$ & $1.2633 E-09$ & $11023.70 \mathrm{C}$ & $1.0949 E-06$ & $28058.70 \mathrm{C}$ & $1.4599 E-08$ \\
\hline & $28060.70 \mathrm{C}$ & $5.6236 \mathrm{E}-09$ & $28061.70 \mathrm{C}$ & $2.4445 \mathrm{E}-10$ & $28062.70 \mathrm{C}$ & $7.7943 E-10$ \\
\hline & $28064.70 \mathrm{C}$ & $1.9850 \mathrm{E}-10$ & $82204.70 \mathrm{C}$ & $8.5042 \mathrm{E}-11$ & $82206.70 \mathrm{C}$ & $1.4639 E-09$ \\
\hline & $82207.70 \mathrm{C}$ & $1.3424 \mathrm{E}-09$ & $82208.70 \mathrm{C}$ & $3.1830 \mathrm{E}-09$ & $14028.70 \mathrm{C}$ & $9.9634 \mathrm{E}-05$ \\
\hline & $14029.70 \mathrm{C}$ & $5.0592 \mathrm{E}-06$ & $14030.70 \mathrm{C}$ & $3.3350 \mathrm{E}-06$ & $50112.70 \mathrm{C}$ & $1.0284 \mathrm{E}-10$ \\
\hline & $50114.70 \mathrm{C}$ & $6.9976 \mathrm{E}-11$ & $50115.70 \mathrm{C}$ & $3.6048 \mathrm{E}-11$ & $50116.70 \mathrm{C}$ & $1.5416 \mathrm{E}-09$ \\
\hline & $50117.70 \mathrm{C}$ & $8.1427 \mathrm{E}-10$ & $50118.70 \mathrm{C}$ & $2.5679 \mathrm{E}-09$ & $50119.70 \mathrm{C}$ & $9.1075 E-10$ \\
\hline & $50120.70 \mathrm{C}$ & $3.4543 E-09$ & $50122.70 \mathrm{C}$ & $4.9089 \mathrm{E}-10$ & $50124.70 \mathrm{C}$ & $6.1388 \mathrm{E}-10$ \\
\hline & $22046.70 \mathrm{C}$ & $2.1687 E-09$ & $22047.70 \mathrm{C}$ & $1.9557 \mathrm{E}-09$ & $22048.70 \mathrm{C}$ & $1.9379 \mathrm{E}-08$ \\
\hline & $22049.70 \mathrm{C}$ & $1.4221 \mathrm{E}-09$ & $22050.70 \mathrm{C}$ & 1.3617E-09 & $23000.70 \mathrm{C}$ & $2.4707 E-08$ \\
\hline & $74182.70 \mathrm{C}$ & $1.8142 \mathrm{E}-09$ & $74183.70 \mathrm{C}$ & $9.7965 \mathrm{E}-10$ & $74184.70 \mathrm{C}$ & $2.0976 \mathrm{E}-09$ \\
\hline & $74186.70 \mathrm{C}$ & $1.9545 \mathrm{E}-09$ & $30000.70 \mathrm{C}$ & 1. $9248 E-08$ & $40090.70 \mathrm{C}$ & $7.0986 E-09$ \\
\hline & $40091.70 \mathrm{C}$ & $1.5480 \mathrm{E}-09$ & $40092.70 \mathrm{C}$ & $2.3662 \mathrm{E}-09$ & $40094.70 \mathrm{C}$ & $2.3979 \mathrm{E}-09$ \\
\hline & $40096.70 \mathrm{C}$ & $3.8632 \mathrm{E}-10$ & $8016.70 \mathrm{C}$ & $3.3814 \mathrm{E}-03$ & $8017.70 \mathrm{C}$ & $1.2854 \mathrm{E}-06$ \\
\hline C & Total & $1.0026 \mathrm{E}-01$ & & & & \\
\hline C & & & & & & \\
\hline C - & structura & 1 Materials & --- & ---- & & \\
\hline C - & -- Homoge & nized Empty & Grid Plate & ----- & & \\
\hline C & $51.85 \%$ & Water + 48 . & $15 \% \mathrm{Al} 1100$ & & & \\
\hline m61 & $1001.70 \mathrm{c}$ & $3.4550 \mathrm{E}-02$ & $1002.70 \mathrm{C}$ & $3.9738 \mathrm{E}-06$ & $8016.70 \mathrm{C}$ & $1.7271 \mathrm{E}-02$ \\
\hline & $8017.70 \mathrm{c}$ & $6.5653 E-06$ & $13027.70 \mathrm{C}$ & $2.8897 \mathrm{E}-02$ & $27059.70 \mathrm{C}$ & $3.3333 E-06$ \\
\hline & $29063.70 \mathrm{c}$ & $1.0691 \mathrm{E}-05$ & $29065.70 \mathrm{C}$ & $4.7653 E-06$ & $26054.70 \mathrm{C}$ & $2.0560 \mathrm{E}-06$ \\
\hline & $26056.70 c$ & $3.2275 E-05$ & $26057.70 \mathrm{C}$ & $7.4537 \mathrm{E}-07$ & $26058.70 \mathrm{C}$ & $9.9194 \mathrm{E}-08$ \\
\hline & $25055.70 c$ & $3.5757 E-06$ & $28058.70 \mathrm{C}$ & $2.2786 \mathrm{E}-06$ & $28060.70 \mathrm{C}$ & $8.7772 \mathrm{E}-07$ \\
\hline & $28061.70 c$ & $3.8154 \mathrm{E}-08$ & $28062.70 \mathrm{C}$ & 1. $2165 \mathrm{E}-07$ & $28064.70 \mathrm{C}$ & $3.0981 E-08$ \\
\hline & $14028.70 \mathrm{c}$ & $6.4510 E-05$ & $14029.70 \mathrm{C}$ & $3.2757 E-06$ & $14030.70 \mathrm{C}$ & $2.1593 E-06$ \\
\hline & $50112.70 \mathrm{c}$ & $1.6052 \mathrm{E}-08$ & $50114.70 \mathrm{C}$ & $1.0922 \mathrm{E}-08$ & $50115.70 \mathrm{C}$ & $5.6264 \mathrm{E}-09$ \\
\hline & $50116.70 c$ & $2.4061 E-07$ & $50117.70 \mathrm{C}$ & 1.2709E-07 & $50118.70 \mathrm{C}$ & $4.0080 E-07$ \\
\hline & $50119.70 \mathrm{c}$ & $1.4215 \mathrm{E}-07$ & $50120.70 \mathrm{C}$ & $5.3914 \mathrm{E}-07$ & $50122.70 \mathrm{C}$ & $7.6618 \mathrm{E}-08$ \\
\hline & $50124.70 c$ & $9.5814 E-08$ & $30000.70 \mathrm{C}$ & $6.0084 \mathrm{E}-06$ & & \\
\hline C & Total & $8.0867 \mathrm{E}-02$ & & & & \\
\hline mt 61 & lwtr.10t & hwtr.10t al & $27.12 t$ & & & \\
\hline & & & & & & \\
\hline C - & - Homoge & nized Grid P & late with $\mathrm{F}$ & Fuel Assembly & y Fitting & ------ \\
\hline C & $36.52 \%$ & Water + 48 & $15 \% \mathrm{Al} 1100$ & $0+0.05 \% \mathrm{SS}$ & $304+15.2$ & $28 \% \mathrm{Al} \quad 6061$ \\
\hline $\mathrm{m} 62$ & $1001.70 \mathrm{c}$ & $2.4333 \mathrm{E}-02$ & $1002.70 \mathrm{C}$ & $2.7987 \mathrm{E}-06$ & $8016.70 \mathrm{C}$ & $1.2163 E-02$ \\
\hline & $8017.70 \mathrm{c}$ & $4.6239 E-06$ & $13027.70 \mathrm{C}$ & $3.7852 \mathrm{E}-02$ & $6000.70 \mathrm{C}$ & $8.1372 \mathrm{E}-08$ \\
\hline & $27059.70 \mathrm{c}$ & $4.3874 \mathrm{E}-06$ & $24050.70 \mathrm{C}$ & $7.9286 \mathrm{E}-07$ & $24052.70 \mathrm{C}$ & $1.5289 \mathrm{E}-05$ \\
\hline & $24053.70 c$ & $1.7337 \mathrm{E}-06$ & $24054.70 \mathrm{C}$ & 4. 3156E-07 & $29063.70 \mathrm{C}$ & $1.8130 E-05$ \\
\hline & $29065.70 c$ & $8.0807 E-06$ & $26054.70 \mathrm{C}$ & $4.7416 \mathrm{E}-06$ & $26056.70 \mathrm{C}$ & $7.4433 E-05$ \\
\hline & $26057.70 \mathrm{c}$ & $1.7190 E-06$ & $26058.70 \mathrm{C}$ & $2.2876 \mathrm{E}-07$ & $12024.70 \mathrm{C}$ & $8.0758 E-05$ \\
\hline & $12025.70 \mathrm{c}$ & $1.0224 \mathrm{E}-05$ & $12026.70 \mathrm{C}$ & $1.1256 \mathrm{E}-05$ & $25055.70 \mathrm{C}$ & $7.4128 \mathrm{E}-06$ \\
\hline & $28058.70 c$ & $5.8334 \mathrm{E}-06$ & $28060.70 \mathrm{C}$ & $2.2470 \mathrm{E}-06$ & $28061.70 \mathrm{C}$ & $9.7676 E-08$ \\
\hline & $28062.70 \mathrm{c}$ & $3.1144 \mathrm{E}-07$ & $28064.70 \mathrm{C}$ & $7.9313 E-08$ & $15031.70 \mathrm{C}$ & $1.7749 \mathrm{E}-08$ \\
\hline & $16032.70 c$ & $1.0849 E-08$ & $16033.70 \mathrm{C}$ & $8.6856 \mathrm{E}-11$ & $16034.70 \mathrm{C}$ & $4.9028 E-10$ \\
\hline & $16036.70 \mathrm{c}$ & $2.2857 \mathrm{E}-12$ & $14028.70 \mathrm{C}$ & $1.1387 \mathrm{E}-04$ & $14029.70 \mathrm{C}$ & $5.7822 E-06$ \\
\hline & $14030.70 \mathrm{c}$ & $3.8116 \mathrm{E}-06$ & $50112.70 \mathrm{C}$ & $2.1128 \mathrm{E}-08$ & $50114.70 \mathrm{C}$ & $1.4376 \mathrm{E}-08$ \\
\hline & $50115.70 c$ & $7.4057 \mathrm{E}-09$ & $50116.70 \mathrm{C}$ & $3.1670 \mathrm{E}-07$ & $50117.70 \mathrm{C}$ & $1.6728 E-07$ \\
\hline & $50118.70 c$ & $5.2754 \mathrm{E}-07$ & $50119.70 \mathrm{C}$ & $1.8710 \mathrm{E}-07$ & $50120.70 \mathrm{C}$ & $7.0964 \mathrm{E}-07$ \\
\hline & $50122.70 \mathrm{c}$ & $1.0085 \mathrm{E}-07$ & $50124.70 \mathrm{C}$ & 1.2611E-07 & $22046.70 \mathrm{C}$ & $3.2112 \mathrm{E}-07$ \\
\hline & $22047.70 \mathrm{c}$ & $2.8959 E-07$ & $22048.70 \mathrm{C}$ & $2.8695 E-06$ & $22049.70 \mathrm{C}$ & $2.1058 \mathrm{E}-07$ \\
\hline & $22050.70 c$ & $2.0163 E-07$ & $30000.70 \mathrm{C}$ & $1.0759 \mathrm{E}-05$ & & \\
\hline
\end{tabular}


NEA/NSC/DOC(2006)1

\section{Fundamental - FUND}

\section{NRAD-FUND-RESR-001 CRIT}

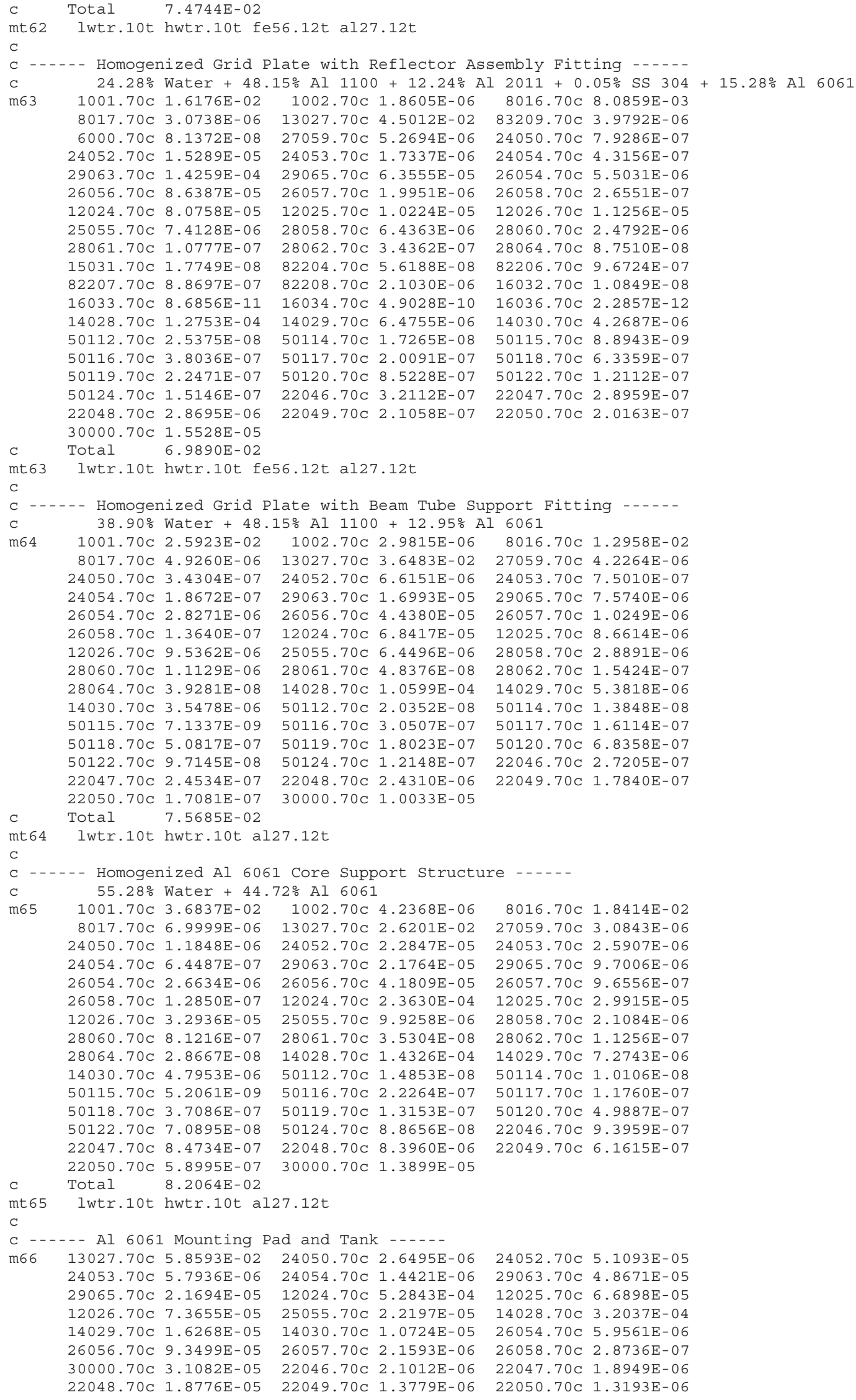
$22049.70 \mathrm{C} 1.3779 \mathrm{E}-06 \quad 22050.70 \mathrm{C} 1.3193 \mathrm{E}-06$

$24052.70 \mathrm{C} 5.1093 \mathrm{E}-05$ $29063.70 \mathrm{C} 4.8671 \mathrm{E}-05$ $12025.70 \mathrm{C} \quad 6.6898 \mathrm{E}-05$ $14028.70 \mathrm{C} \quad 3.2037 \mathrm{E}-04$ $26054.70 \mathrm{C} 5.9561 \mathrm{E}-06$ $26058.70 \mathrm{C} 2.8736 \mathrm{E}-07$ 
NEA/NSC/DOC(2006)1

\section{Fundamental - FUND}

\section{NRAD-FUND-RESR-001 CRIT}

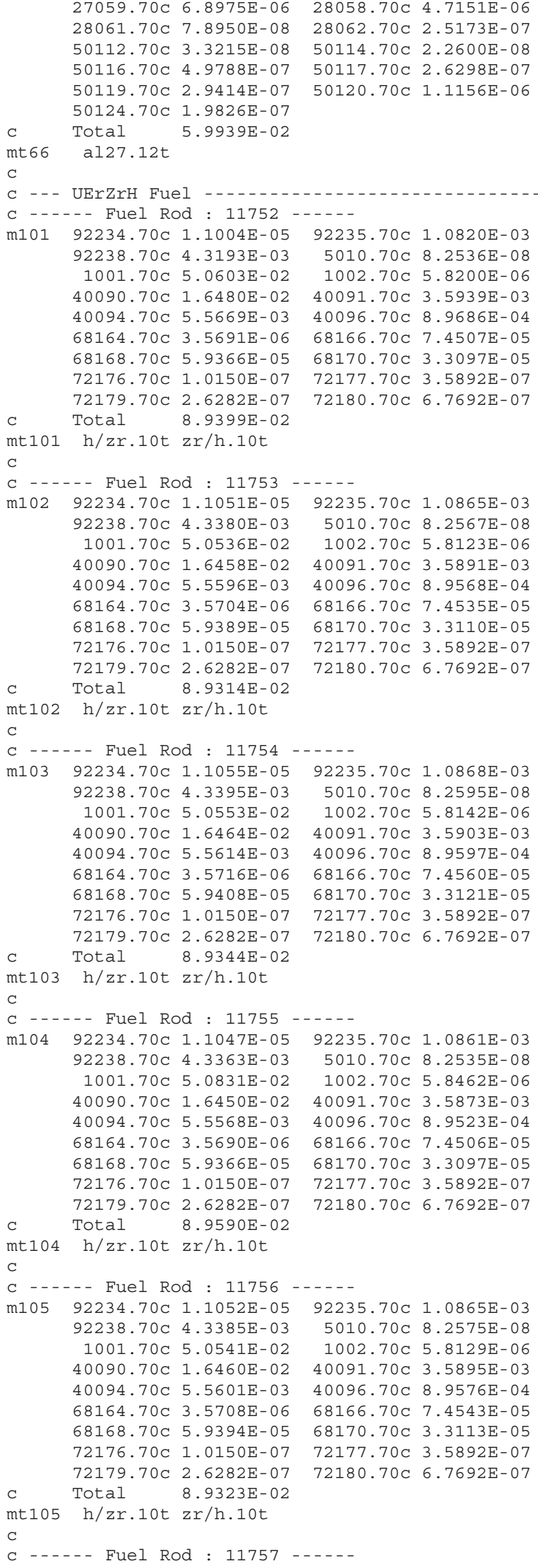

$92236.70 \mathrm{C} \quad 1.0953 \mathrm{E}-05$ $5011.70 \mathrm{C} 3.3221 \mathrm{E}-07$ $6000.70 \mathrm{C} 1.1128 \mathrm{E}-03$ $40092.70 \mathrm{C} 5.4833 \mathrm{E}-03$ $68162.70 \mathrm{C} 3.1035 \mathrm{E}-07$ $68167.70 \mathrm{C} 5.0831 \mathrm{E}-05$ $72174.70 \mathrm{C} \quad 3.0875 \mathrm{E}-09$ $72178.70 \mathrm{C} 5.2641 \mathrm{E}-07$

$92236.70 \mathrm{C} 1.0958 \mathrm{E}-05$ $5011.70 \mathrm{C} \quad 3.3238 \mathrm{E}-07$ $6000.70 \mathrm{C} 1.1133 \mathrm{E}-03$ $40092.70 \mathrm{C} 5.4866 \mathrm{E}-03$ $68162.70 \mathrm{C} 3.1050 \mathrm{E}-07$ $68167.70 \mathrm{C} 5.0856 \mathrm{E}-05$ $72174.70 \mathrm{C} \quad 3.0875 \mathrm{E}-09$ $72178.70 \mathrm{C} \quad 5.2641 \mathrm{E}-07$ 
NEA/NSC/DOC(2006)1

Fundamental - FUND

NRAD-FUND-RESR-001 CRIT

m10692234.70C 1.1047E-05 $92238.70 \mathrm{C} 4.3365 \mathrm{E}-03$ $1001.70 \mathrm{C} 5.0518 \mathrm{E}-02$ $40090.70 \mathrm{C} 1.6452 \mathrm{E}-02$ $40094.70 \mathrm{C} 5.5576 \mathrm{E}-03$ $68164.70 \mathrm{C} 3.5692 \mathrm{E}-06$ $68168.70 \mathrm{C} 5.9368 \mathrm{E}-05$ $72176.70 \mathrm{C} \quad 1.0150 \mathrm{E}-07$ $72179.70 \mathrm{C} 2.6282 \mathrm{E}-07$ C Total 8.9282E-02 mt106 h/zr.10t zr/h.10t $\mathrm{C}$ C ----- Fuel Rod : 11758 m107 92234.70C 1.1050E-05 $92238.70 \mathrm{C} \quad 4.3377 \mathrm{E}-03$ $1001.70 \mathrm{C} 5.0847 \mathrm{E}-02$ $40090.70 \mathrm{C} 1.6455 \mathrm{E}-02$ $40094.70 \mathrm{C} 5.5586 \mathrm{E}-03$ $68164.70 \mathrm{C} 3.5702 \mathrm{E}-06$ $68168.70 \mathrm{C} 5.9385 \mathrm{E}-05$ $72176.70 \mathrm{C} \quad 1.0150 \mathrm{E}-07$ $72179.70 \mathrm{C} \quad 2.6282 \mathrm{E}-07$ C Total 8.9619E-02 mt107 h/zr.10t zr/h.10t C C -...- Fuel Rod : 11759 m108 92234.70C 1.1045E-05 92235 $92238.70 \mathrm{C} 4.3357 \mathrm{E}-03$ $1001.70 \mathrm{C} 5.1137 \mathrm{E}-02$ $40090.70 \mathrm{C} 1.6446 \mathrm{E}-02$ $40094.70 \mathrm{C} 5.5554 \mathrm{E}-03$ $68164.70 \mathrm{C} 3.5685 \mathrm{E}-06$ $68168.70 \mathrm{C} 5.9357 \mathrm{E}-05$ $72176.70 \mathrm{C} 1.0150 \mathrm{E}-07$ $72179.70 \mathrm{C} 2.6282 \mathrm{E}-07$ C Total $8.9888 \mathrm{E}-02$ mt108 h/zr.10t $\mathrm{zr} / \mathrm{h} .10 \mathrm{t}$

C C -...- Fuel Rod : 11760 m109 $92234.70 \mathrm{c} 1.1062 \mathrm{E}-05$ $92238.70 \mathrm{C} \quad 4.3423 \mathrm{E}-03 \quad 5010.70 \mathrm{C} 8.2694 \mathrm{E}-08$ $1001.70 \mathrm{C} 5.0259 \mathrm{E}-02 \quad 1002.70 \mathrm{C} 5.7805 \mathrm{E}-06$ $40090.70 \mathrm{C} \quad 1.6472 \mathrm{E}-02 \quad 40091.70 \mathrm{C} \quad 3.5922 \mathrm{E}-03$ $40094.70 \mathrm{C} \quad 5.5644 \mathrm{E}-03 \quad 40096.70 \mathrm{C} \quad 8.9645 \mathrm{E}-04$ $68164.70 \mathrm{C} \quad 3.7838 \mathrm{E}-06 \quad 68166.70 \mathrm{C} \quad 7.8989 \mathrm{E}-05$ $68168.70 \mathrm{C} \quad 6.2938 \mathrm{E}-05 \quad 68170.70 \mathrm{C} \quad 3.5088 \mathrm{E}-05$ $72176.70 \mathrm{C} \quad 1.0150 \mathrm{E}-07 \quad 72177.70 \mathrm{C} \quad 3.5892 \mathrm{E}-07$ $72179.70 \mathrm{C} \quad 2.6282 \mathrm{E}-07 \quad 72180.70 \mathrm{C} \quad 6.7692 \mathrm{E}-07$ C Total 8.9157E-02 mt109 h/zr.10t zr/h.10t

C C -...-Fuel Rod : 11761 .....

m110 92234.70C $1.1023 \mathrm{E}-05 \quad 92235.70 \mathrm{C} 1.0826 \mathrm{E}-03$ $92238.70 \mathrm{C} 4.3282 \mathrm{E}-03$ $1001.70 \mathrm{C} 5.0307 \mathrm{E}-02$ $40090.70 \mathrm{C} 1.6488 \mathrm{E}-02$ $40094.70 \mathrm{C} 5.5697 \mathrm{E}-03$ $68164.70 \mathrm{C} 3.7396 \mathrm{E}-06$ $68168.70 \mathrm{C} \quad 6.2203 \mathrm{E}-05$ $72176.70 \mathrm{C} \quad 1.0150 \mathrm{E}-07$ $72179.70 \mathrm{C} 2.6282 \mathrm{E}-07$ C Total $8.9141 \mathrm{E}-02$ mt110 h/zr.10t $\mathrm{zr} / \mathrm{h} .10 \mathrm{t}$ C C ---.- Fuel Rod : 11762 m11192234.70C 1.1039E-05 $92238.70 \mathrm{C} 4.3352 \mathrm{E}-03$ $1001.70 \mathrm{C} 5.0395 \mathrm{E}-02$ $40090.70 \mathrm{C} \quad 1.6517 \mathrm{E}-02$ $40094.70 \mathrm{C} 5.5794 \mathrm{E}-03$ $68164.70 \mathrm{C} 3.7450 \mathrm{E}-06$ $68168.70 \mathrm{C} 6.2293 \mathrm{E}-05$ $72176.70 \mathrm{C} \quad 1.0150 \mathrm{E}-07$ $72179.70 \mathrm{C} \quad 2.6282 \mathrm{E}-07$ C Total 8.9222E-0 mt111 h/zr.10t zr/h.10t $72180.70 \mathrm{C} \quad 6.7692 \mathrm{E}-07$ $92235.70 \mathrm{C} \quad 1.0874 \mathrm{E}-03$

$92236.70 \mathrm{C} 1.0953 \mathrm{E}-05$ $5011.70 \mathrm{C} 3.3223 \mathrm{E}-07$ $6000.70 \mathrm{C} 1.1128 \mathrm{E}-03$ $40092.70 \mathrm{C} 5.4841 \mathrm{E}-03$ $68162.70 \mathrm{C} 3.1036 \mathrm{E}-07$ $68167.70 \mathrm{C} 5.0833 \mathrm{E}-05$ $72174.70 \mathrm{C} 3.0875 \mathrm{E}-09$ $72178.70 \mathrm{C} 5.2641 \mathrm{E}-07$

$92236.70 \mathrm{C} \quad 1.0957 \mathrm{E}-05$ $5011.70 \mathrm{C} 3.3232 \mathrm{E}-07$ $6000.70 \mathrm{C} 1.1131 \mathrm{E}-03$ $40092.70 \mathrm{C} 5.4851 \mathrm{E}-03$ $68162.70 \mathrm{C} 3.1045 \mathrm{E}-07$ $68167.70 \mathrm{C} 5.0848 \mathrm{E}-05$ $72174.70 \mathrm{C} 3.0875 \mathrm{E}-09$ $72178.70 \mathrm{C} 5.2641 \mathrm{E}-07$

$92236.70 \mathrm{C} \quad 1.0951 \mathrm{E}-05$ $5011.70 \mathrm{C} \quad 3.3217 \mathrm{E}-07$ $6000.70 \mathrm{C} 1.1126 \mathrm{E}-03$ $40092.70 \mathrm{C} 5.4819 \mathrm{E}-03$ $68162.70 \mathrm{C} 3.1031 \mathrm{E}-07$ $68167.70 \mathrm{C} 5.0824 \mathrm{E}-05$ $72174.70 \mathrm{C} 3.0875 \mathrm{E}-09$ $72178.70 \mathrm{C} 5.2641 \mathrm{E}-07$

$92236.70 \mathrm{C} \quad 1.0968 \mathrm{E}-05$ $5011.70 \mathrm{C} 3.3285 \mathrm{E}-07$ $6000.70 \mathrm{C} 1.1868 \mathrm{E}-03$ $40092.70 \mathrm{C} 5.4908 \mathrm{E}-03$ $68162.70 \mathrm{C} 3.2902 \mathrm{E}-07$ $68167.70 \mathrm{C} 5.3890 \mathrm{E}-05$ $72174.70 \mathrm{C} 3.0875 \mathrm{E}-09$ $72178.70 \mathrm{C}$ 5.2641E-07

$92236.70 \mathrm{C} 1.0930 \mathrm{E}-05$ $5011.70 \mathrm{C} \quad 3.3262 \mathrm{E}-07$ $6000.70 \mathrm{C} 1.1141 \mathrm{E}-03$ $40092.70 \mathrm{C} 5.4960 \mathrm{E}-03$ $68162.70 \mathrm{C} \quad 3.2518 \mathrm{E}-07$ $68167.70 \mathrm{C} 5.3260 \mathrm{E}-05$ $72174.70 \mathrm{C} 3.0875 \mathrm{E}-09$ $72178.70 \mathrm{C} 5.2641 \mathrm{E}-07$

$92235.70 \mathrm{C} 1.0835 \mathrm{E}-03$ $5010.70 \mathrm{C} 8.2756 \mathrm{E}-08$ $1002.70 \mathrm{C} 5.7960 \mathrm{E}-06$ $40091.70 \mathrm{C} 3.6019 \mathrm{E}-03$ $40096.70 \mathrm{C} \quad 8.9886 \mathrm{E}-04$ $68166.70 \mathrm{C} 7.8180 \mathrm{E}-05$ $68170.70 \mathrm{C} 3.4729 \mathrm{E}-05$ $72177.70 \mathrm{C} \quad 3.5892 \mathrm{E}-07$
$92236.70 \mathrm{C} \quad 1.0946 \mathrm{E}-05$ $5011.70 \mathrm{C} 3.3310 \mathrm{E}-07$ $6000.70 \mathrm{C} 1.0437 \mathrm{E}-03$ $40092.70 \mathrm{C} 5.5055 \mathrm{E}-03$ $68162.70 \mathrm{C} \quad 3.2565 \mathrm{E}-07$ $68167.70 \mathrm{C} 5.3337 \mathrm{E}-05$ $72174.70 \mathrm{C} 3.0875 \mathrm{E}-09$ $72178.70 \mathrm{C}$ 5.2641E-07 
NEA/NSC/DOC(2006)1

Fundamental - FUND

NRAD-FUND-RESR-001

CRIT

$\mathrm{C}$ $\begin{array}{lrrrr}\text { C - - Fuel Rod : } 11763 & --- & \\ \text { m112 } & 92234.70 \mathrm{C} & 1.1039 \mathrm{E}-05 & 92235.70 \mathrm{C} & 1.0835 \mathrm{E}-03 \\ & 92238.70 \mathrm{C} & 4.3352 \mathrm{E}-03 & 5010.70 \mathrm{C} & 8.2756 \mathrm{E}-08 \\ & 1001.70 \mathrm{C} & 5.0395 \mathrm{E}-02 & 1002.70 \mathrm{C} & 5.7960 \mathrm{E}-06 \\ & 40090.70 \mathrm{C} & 1.6517 \mathrm{E}-02 & 40091.70 \mathrm{C} & 3.6019 \mathrm{E}-03 \\ & 40094.70 \mathrm{C} & 5.5794 \mathrm{E}-03 & 40096.70 \mathrm{C} & 8.9886 \mathrm{E}-04 \\ & 68164.70 \mathrm{C} & 3.7450 \mathrm{E}-06 & 68166.70 \mathrm{C} & 7.8180 \mathrm{E}-05 \\ & 68168.70 \mathrm{C} & 6.2293 \mathrm{E}-05 & 68170.70 \mathrm{C} & 3.4729 \mathrm{E}-05 \\ & 72176.70 \mathrm{C} & 1.0150 \mathrm{E}-07 & 72177.70 \mathrm{C} & 3.5892 \mathrm{E}-07 \\ & 72179.70 \mathrm{C} & 2.6282 \mathrm{E}-07 & 72180.70 \mathrm{C} & 6.7692 \mathrm{E}-07 \\ \mathrm{C} & \text { Total } & 8.9222 \mathrm{E}-02 & & \end{array}$ mt112 h/zr.10t zr/h.10t

$\mathrm{C}$

C -...-. Fuel Rod : $11764 \ldots \ldots$

m113 92234.70C 1.1036E-05 92235.70C $1.0832 \mathrm{E}-03$ $92238.70 \mathrm{C} 4.3341 \mathrm{E}-03 \quad 5010.70 \mathrm{C} 8.2733 \mathrm{E}-08$ $1001.70 \mathrm{C} 5.1012 \mathrm{E}-02 \quad 1002.70 \mathrm{C} \quad 5.8670 \mathrm{E}-06$ 40090.70C 1.6509E-02 40091.70C 3.6001E-03 $40094.70 \mathrm{C} \quad 5.5767 \mathrm{E}-03 \quad 40096.70 \mathrm{C} \quad 8.9843 \mathrm{E}-04$ $68164.70 \mathrm{C} \quad 3.7440 \mathrm{E}-06 \quad 68166.70 \mathrm{C} \quad 7.8159 \mathrm{E}-05$ 68168.70 C $6.2276 \mathrm{E}-05 \quad 68170.70 \mathrm{C} \quad 3.4719 \mathrm{E}-05$ $72176.70 \mathrm{C} 1.0150 \mathrm{E}-07 \quad 72177.70 \mathrm{C} \quad 3.5892 \mathrm{E}-07$ $\begin{array}{lllll}72179.70 \mathrm{C} & 2.6282 \mathrm{E}-07 & 72180.70 \mathrm{C} & 6.7692 \mathrm{E}-07\end{array}$ C Total $8.9822 \mathrm{E}-02$ mt113 h/zr.10t zr/h.10t

$$
\text { C }
$$
$92238.70 \mathrm{C} 4.3328 \mathrm{E}-03 \quad 5010.70 \mathrm{C} 8.2709 \mathrm{E}-08$ $1001.70 \mathrm{C} 5.0997 \mathrm{E}-02 \quad 1002.70 \mathrm{C} 5.8653 \mathrm{E}-06$ $40090.70 \mathrm{C} \quad 1.6504 \mathrm{E}-02 \quad 40091.70 \mathrm{C} \quad 3.5990 \mathrm{E}-03$ $40094.70 \mathrm{C} \quad 5.5750 \mathrm{E}-03 \quad 40096.70 \mathrm{C} \quad 8.9815 \mathrm{E}-04$ $68164.70 \mathrm{C} 3.7429 \mathrm{E}-06 \quad 68166.70 \mathrm{C} 7.8136 \mathrm{E}-05$ $\begin{array}{llll}68168.70 \mathrm{C} & 6.2258 \mathrm{E}-05 & 68170.70 \mathrm{C} & 3.4709 \mathrm{E}-05\end{array}$ $72176.70 \mathrm{C} \quad 1.0150 \mathrm{E}-07 \quad 72177.70 \mathrm{C} \quad 3.5892 \mathrm{E}-07$ 72179.70C $2.6282 \mathrm{E}-07 \quad 72180.70 \mathrm{C} \quad 6.7692 \mathrm{E}-07$ C Total $8.9795 \mathrm{E}-02$ mt114 h/zr.10t zr/h.10t

$$
\text { C --1-- Fuel Rod : } 11766 \text {-..-.- }
$$

m115 92234.70C $1.1042 \mathrm{E}-05 \quad 92235.70 \mathrm{C} \quad 1.0836 \mathrm{E}-03$ 92238.70C $4.3361 \mathrm{E}-03 \quad 5010.70 \mathrm{C} \quad 8.2772 \mathrm{E}-08$ $1001.70 \mathrm{C} \quad 5.0720 \mathrm{E}-02 \quad 1002.70 \mathrm{C} 5.8335 \mathrm{E}-06$ $40090.70 \mathrm{C} 1.6518 \mathrm{E}-02 \quad 40091.70 \mathrm{C} 3.6022 \mathrm{E}-03$ $40094.70 \mathrm{C} \quad 5.5799 \mathrm{E}-03 \quad 40096.70 \mathrm{C} \quad 8.9894 \mathrm{E}-04$ $68164.70 \mathrm{C} \quad 3.7458 \mathrm{E}-06 \quad 68166.70 \mathrm{C} \quad 7.8196 \mathrm{E}-05$ $68168.70 \mathrm{C} \quad 6.2305 \mathrm{E}-05 \quad 68170.70 \mathrm{C} 3.4735 \mathrm{E}-05$ $\begin{array}{llll}72176.70 \mathrm{C} & 1.0150 \mathrm{E}-07 & 72177.70 \mathrm{C} & 3.5892 \mathrm{E}-07\end{array}$ 72179.70C $2.6282 \mathrm{E}-07 \quad 72180.70 \mathrm{C} \quad 6.7692 \mathrm{E}-07$ C Total $8.9552 \mathrm{E}-02$ mt115 h/zr.10t zr/h.10t

$$
\text { C }
$$
$40096.70 \mathrm{C} 8.9813 \mathrm{E}-04$ $68166.70 \mathrm{C} 7.8116 \mathrm{E}-05$ $68170.70 \mathrm{C} 3.4700 \mathrm{E}-05$ $72177.70 \mathrm{C} 3.5892 \mathrm{E}-07$ C Total 8.9149E-02 $72180.70 \mathrm{C} \quad 6.7692 \mathrm{E}-07$

$92236.70 \mathrm{C} \quad 1.0946 \mathrm{E}-05$ $5011.70 \mathrm{C} 3.3310 \mathrm{E}-07$ $6000.70 \mathrm{C} 1.0437 \mathrm{E}-03$ $40092.70 \mathrm{C} 5.5055 \mathrm{E}-03$ $68162.70 \mathrm{C} 3.2565 \mathrm{E}-07$ $68167.70 \mathrm{C} 5.3337 \mathrm{E}-05$ $72174.70 \mathrm{C} 3.0875 \mathrm{E}-09$ $72178.70 \mathrm{C} 5.2641 \mathrm{E}-07$

$92236.70 \mathrm{C} 1.0943 \mathrm{E}-05$ $5011.70 \mathrm{C} \quad 3.3301 \mathrm{E}-07$ $6000.70 \mathrm{C} 1.0435 \mathrm{E}-03$ $40092.70 \mathrm{C} \quad 5.5029 \mathrm{E}-03$ $68162.70 \mathrm{C} 3.2557 \mathrm{E}-07$ $68167.70 \mathrm{C} \quad 5.3323 \mathrm{E}-05$ $72174.70 \mathrm{C} 3.0875 \mathrm{E}-09$ $72178.70 \mathrm{C} 5.2641 \mathrm{E}-07$

$92236.70 \mathrm{C} \quad 1.0940 \mathrm{E}-05$ $5011.70 \mathrm{C} \quad 3.3291 \mathrm{E}-07$ $6000.70 \mathrm{C} \quad 1.0432 \mathrm{E}-03$ $40092.70 \mathrm{C} 5.5012 \mathrm{E}-03$ $68162.70 \mathrm{C} \quad 3.2547 \mathrm{E}-07$ $68167.70 \mathrm{C} 5.3307 \mathrm{E}-05$ $72174.70 \mathrm{C} 3.0875 \mathrm{E}-09$ $72178.70 \mathrm{C} 5.2641 \mathrm{E}-07$

$92236.70 \mathrm{C} \quad 1.0948 \mathrm{E}-05$ $5011.70 \mathrm{C} \quad 3.3317 \mathrm{E}-07$ $6000.70 \mathrm{C} \quad 1.0440 \mathrm{E}-03$ $40092.70 \mathrm{C} 5.5060 \mathrm{E}-03$ $68162.70 \mathrm{C} 3.2572 \mathrm{E}-07$ $68167.70 \mathrm{C} 5.3348 \mathrm{E}-05$ $72174.70 \mathrm{C} 3.0875 \mathrm{E}-09$ $72178.70 \mathrm{C} 5.2641 \mathrm{E}-07$

$92236.70 \mathrm{C} \quad 1.0937 \mathrm{E}-05$ $5011.70 \mathrm{C} \quad 3.3283 \mathrm{E}-07$ $6000.70 \mathrm{C} \quad 1.0429 \mathrm{E}-03$ $40092.70 \mathrm{C} 5.5010 \mathrm{E}-03$ $68162.70 \mathrm{C} 3.2539 \mathrm{E}-07$ $68167.70 \mathrm{C} \quad 5.3294 \mathrm{E}-05$ $72174.70 \mathrm{C} 3.0875 \mathrm{E}-09$ $72178.70 \mathrm{C} 5.2641 \mathrm{E}-07$ mt116 h/zr.10t zr/h.10t C C -.... Fuel Rod : $11768 \ldots$

m117 92234.70 1.1021E-05 92235.70C 1.0832E-03 $92238.70 \mathrm{C} \quad 4.3267 \mathrm{E}-03$ $1001.70 \mathrm{C} \quad 5.0288 \mathrm{E}-02$ $40090.70 \mathrm{C} \quad 1.6481 \mathrm{E}-02$ $40094.70 \mathrm{C} 5.5675 \mathrm{E}-03$ $68164.70 \mathrm{C} \quad 3.6953 \mathrm{E}-06$ $68168.70 \mathrm{C} \quad 6.1467 \mathrm{E}-05$ $72176.70 \mathrm{C} \quad 1.0150 \mathrm{E}-07$ $72179.70 \mathrm{C} \quad 2.6282 \mathrm{E}-07$ $5010.70 \mathrm{C} 8.2576 \mathrm{E}-08$ $1002.70 \mathrm{C} \quad 5.7837 \mathrm{E}-06$ $40091.70 \mathrm{C} \quad 3.5942 \mathrm{E}-03$ $40096.70 \mathrm{C} 8.9695 \mathrm{E}-04$ $68166.70 \mathrm{C} 7.7143 \mathrm{E}-05$ $68170.70 \mathrm{C} 3.4268 \mathrm{E}-05$ $72177.70 \mathrm{C} \quad 3.5892 \mathrm{E}-07$ $72180.70 \mathrm{C} \quad 6.7692 \mathrm{E}-07$

$92236.70 \mathrm{C} \quad 1.0928 \mathrm{E}-05$ $5011.70 \mathrm{C} 3.3238 \mathrm{E}-07$ $6000.70 \mathrm{C} 1.0056 \mathrm{E}-03$ $40092.70 \mathrm{C} \quad 5.4938 \mathrm{E}-03$ $68162.70 \mathrm{C} 3.2133 \mathrm{E}-07$ 68167.70C $5.2630 \mathrm{E}-05$ $72174.70 \mathrm{C} 3.0875 \mathrm{E}-09$ $72178.70 \mathrm{C} 5.2641 \mathrm{E}-07$ 
NEA/NSC/DOC(2006)1

\section{Fundamental - FUND}

\section{NRAD-FUND-RESR-001} CRIT

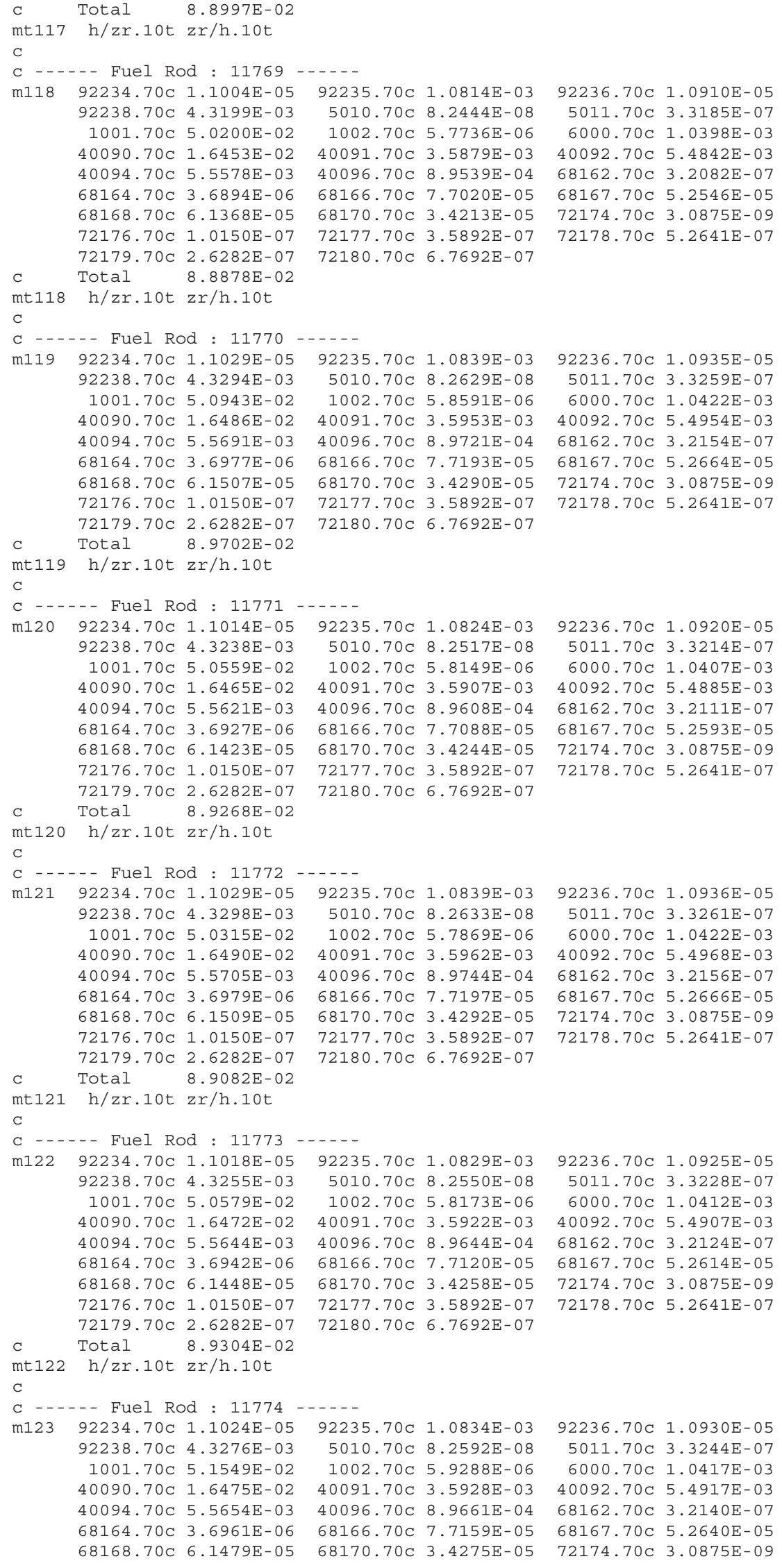

$92236.70 \mathrm{C} 1.0920 \mathrm{E}-05$ $5011.70 \mathrm{C} 3.3214 \mathrm{E}-07$ $6000.70 \mathrm{C} 1.0407 \mathrm{E}-03$ $40092.70 \mathrm{C} 5.4885 \mathrm{E}-03$ $68162.70 \mathrm{C} 3.2111 \mathrm{E}-07$ $68167.70 \mathrm{C} 5.2593 \mathrm{E}-05$ $72174.70 \mathrm{C} 3.0875 \mathrm{E}-09$ $72178.70 \mathrm{C} 5.2641 \mathrm{E}-07$

$92236.70 \mathrm{C} \quad 1.0936 \mathrm{E}-05$ $5011.70 \mathrm{C} 3.3261 \mathrm{E}-07$ $6000.70 \mathrm{C} 1.0422 \mathrm{E}-03$ $40092.70 \mathrm{C} 5.4968 \mathrm{E}-03$ $68162.70 \mathrm{C} 3.2156 \mathrm{E}-07$ $68167.70 \mathrm{C} 5.2666 \mathrm{E}-05$ $72174.70 \mathrm{C} 3.0875 \mathrm{E}-09$ $72178.70 \mathrm{C} 5.2641 \mathrm{E}-07$

$92236.70 \mathrm{C} 1.0925 \mathrm{E}-05$ $5011.70 \mathrm{C} 3.3228 \mathrm{E}-07$ $6000.70 \mathrm{C} 1.0412 \mathrm{E}-03$ $40092.70 \mathrm{C} 5.4907 \mathrm{E}-03$ $68162.70 \mathrm{C} 3.2124 \mathrm{E}-07$ $68167.70 \mathrm{C} 5.2614 \mathrm{E}-05$ $72174.70 \mathrm{C} \quad 3.0875 \mathrm{E}-09$ $72178.70 \mathrm{C} 5.2641 \mathrm{E}-07$

mt122 h/zr.10t zr/h.10t

C C -...-Fuel Rod : $11774 \ldots \ldots$

m12392234.70C 1.1024E-05 92235.70C $1.0834 \mathrm{E}-03$ $92238.70 \mathrm{C} \quad 4.3276 \mathrm{E}-03 \quad 5010.70 \mathrm{C} 8.2592 \mathrm{E}-08$ $1001.70 \mathrm{C} \quad 5.1549 \mathrm{E}-02 \quad 1002.70 \mathrm{C} 5.9288 \mathrm{E}-06$ $40090.70 \mathrm{C} \quad 1.6475 \mathrm{E}-02 \quad 40091.70 \mathrm{C} \quad 3.5928 \mathrm{E}-03$ $40094.70 \mathrm{C} \quad 5.5654 \mathrm{E}-03 \quad 40096.70 \mathrm{C} \quad 8.9661 \mathrm{E}-04$ $68164.70 \mathrm{C} \quad 3.6961 \mathrm{E}-06 \quad 68166.70 \mathrm{C} \quad 7.7159 \mathrm{E}-05$ $68168.70 \mathrm{C} \quad 6.1479 \mathrm{E}-05 \quad 68170.70 \mathrm{C} \quad 3.4275 \mathrm{E}-05$

$92236.70 \mathrm{C} \quad 1.0930 \mathrm{E}-05$ $5011.70 \mathrm{C} 3.3244 \mathrm{E}-07$ $6000.70 \mathrm{C} 1.0417 \mathrm{E}-03$ $40092.70 \mathrm{C} 5.4917 \mathrm{E}-03$ $68162.70 \mathrm{C} 3.2140 \mathrm{E}-07$ $68167.70 \mathrm{C} 5.2640 \mathrm{E}-05$ $72174.70 \mathrm{C} 3.0875 \mathrm{E}-09$ 
NEA/NSC/DOC(2006)1

\section{Fundamental - FUND}

\section{NRAD-FUND-RESR-001 CRIT}

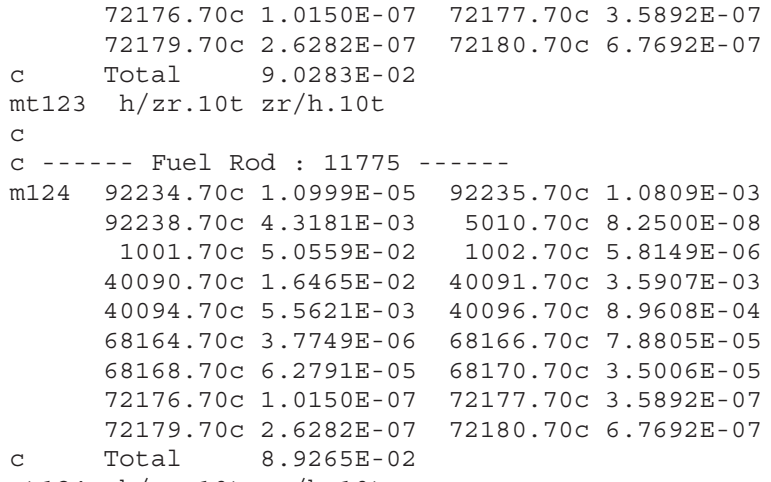

$92236.70 \mathrm{C} \quad 1.0906 \mathrm{E}-05$ $5011.70 \mathrm{C} 3.3207 \mathrm{E}-07$ $6000.70 \mathrm{C} 1.0405 \mathrm{E}-03$ $40092.70 \mathrm{C} 5.4885 \mathrm{E}-03$ $68162.70 \mathrm{C} \quad 3.2826 \mathrm{E}-07$ $68167.70 \mathrm{C} 5.3764 \mathrm{E}-05$ $72174.70 \mathrm{C} 3.0875 \mathrm{E}-09$ $72178.70 \mathrm{C} \quad 5.2641 \mathrm{E}-07$

$92236.70 \mathrm{C} 1.0933 \mathrm{E}-05$ $5011.70 \mathrm{C} 3.3327 \mathrm{E}-07$ $6000.70 \mathrm{C} 1.0803 \mathrm{E}-03$ $40092.70 \mathrm{C} 5.5086 \mathrm{E}-03$ $68162.70 \mathrm{C} \quad 3.3306 \mathrm{E}-07$ $68167.70 \mathrm{C} 5.4550 \mathrm{E}-05$ $72174.70 \mathrm{C} \quad 3.0875 \mathrm{E}-09$ $72178.70 \mathrm{C} \quad 5.2641 \mathrm{E}-07$

$92236.70 \mathrm{C} \quad 1.0855 \mathrm{E}-05$ 5011.70C 3.3219E-07 $6000.70 \mathrm{C} 1.0768 \mathrm{E}-03$ $40092.70 \mathrm{C} 5.5022 \mathrm{E}-03$ $68162.70 \mathrm{C} \quad 3.2476 \mathrm{E}-07$ $68167.70 \mathrm{C} 5.3191 \mathrm{E}-05$ $72174.70 \mathrm{C} 3.0875 \mathrm{E}-09$ $72178.70 \mathrm{C}$ 5.2641E-07

$92236.70 \mathrm{C} 1.0932 \mathrm{E}-05$ $5011.70 \mathrm{C} 3.3268 \mathrm{E}-07$ $6000.70 \mathrm{C} 1.1503 \mathrm{E}-03$ $40092.70 \mathrm{C} 5.4948 \mathrm{E}-03$ $68162.70 \mathrm{C} 3.2886 \mathrm{E}-07$ $68167.70 \mathrm{C} 5.3862 \mathrm{E}-05$ $72174.70 \mathrm{C} 3.0875 \mathrm{E}-09$ $72178.70 \mathrm{C} 5.2641 \mathrm{E}-07$

$92236.70 \mathrm{C} \quad 1.0851 \mathrm{E}-05$ $5011.70 \mathrm{C} 3.3207 \mathrm{E}-07$ $6000.70 \mathrm{C} 1.0764 \mathrm{E}-03$ $40092.70 \mathrm{C} 5.5004 \mathrm{E}-03$ $68162.70 \mathrm{C} 3.2465 \mathrm{E}-07$ $68167.70 \mathrm{C} 5.3173 \mathrm{E}-05$ $72174.70 \mathrm{C} 3.0875 \mathrm{E}-09$ $72178.70 \mathrm{C} \quad 5.2641 \mathrm{E}-07$

$92236.70 \mathrm{C} 1.0928 \mathrm{E}-05$ $5011.70 \mathrm{C} 3.3257 \mathrm{E}-07$ $6000.70 \mathrm{C} 1.1499 \mathrm{E}-03$ $40092.70 \mathrm{C} 5.4935 \mathrm{E}-03$ $68162.70 \mathrm{C} \quad 3.2874 \mathrm{E}-07$ 
NEA/NSC/DOC(2006)1

\section{Fundamental - FUND}

\section{NRAD-FUND-RESR-001} CRIT

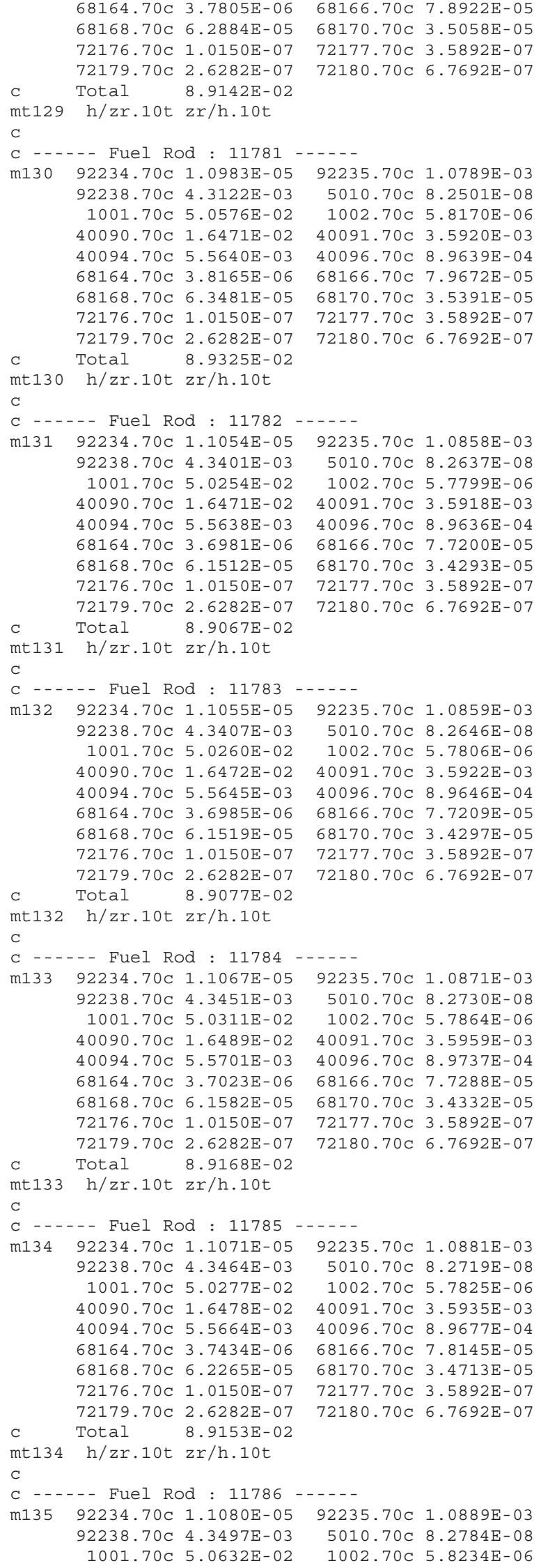

$92236.70 \mathrm{C} 1.0890 \mathrm{E}-05$ $5011.70 \mathrm{C} 3.3208 \mathrm{E}-07$ $6000.70 \mathrm{C} 1.0764 \mathrm{E}-03$ $40092.70 \mathrm{C} 5.4904 \mathrm{E}-03$ $68162.70 \mathrm{C} \quad 3.3187 \mathrm{E}-07$ $68167.70 \mathrm{C} 5.4355 \mathrm{E}-05$ $72174.70 \mathrm{C} 3.0875 \mathrm{E}-09$ $72178.70 \mathrm{C} \quad 5.2641 \mathrm{E}-07$

$92236.70 \mathrm{C} \quad 1.0960 \mathrm{E}-05$ $5011.70 \mathrm{C} 3.3262 \mathrm{E}-07$ $6000.70 \mathrm{C} \quad 1.1141 \mathrm{E}-03$ $40092.70 \mathrm{C} 5.4902 \mathrm{E}-03$ $68162.70 \mathrm{C} \quad 3.2157 \mathrm{E}-07$ $68167.70 \mathrm{C} \quad 5.2669 \mathrm{E}-05$ $72174.70 \mathrm{C} 3.0875 \mathrm{E}-09$ $72178.70 \mathrm{C}$ 5.2641E-07

$92236.70 \mathrm{C} 1.0962 \mathrm{E}-05$ $5011.70 \mathrm{C} 3.3266 \mathrm{E}-07$ $6000.70 \mathrm{C} 1.1143 \mathrm{E}-03$ $40092.70 \mathrm{C} 5.4908 \mathrm{E}-03$ $68162.70 \mathrm{C} 3.2161 \mathrm{E}-07$ $68167.70 \mathrm{C} 5.2675 \mathrm{E}-05$ $72174.70 \mathrm{C} 3.0875 \mathrm{E}-09$ $72178.70 \mathrm{C} 5.2641 \mathrm{E}-07$

$92236.70 \mathrm{C} \quad 1.0973 \mathrm{E}-05$ $5011.70 \mathrm{C} 3.3300 \mathrm{E}-07$ $6000.70 \mathrm{C} 1.1154 \mathrm{E}-03$ $40092.70 \mathrm{C} 5.4964 \mathrm{E}-03$ $68162.70 \mathrm{C} \quad 3.2194 \mathrm{E}-07$ $68167.70 \mathrm{C} 5.2729 \mathrm{E}-05$ $72174.70 \mathrm{C} 3.0875 \mathrm{E}-09$ $72178.70 \mathrm{C} 5.2641 \mathrm{E}-07$

$92236.70 \mathrm{C}$ 1.0977E-05 $5011.70 \mathrm{C} 3.3295 \mathrm{E}-07$ $6000.70 \mathrm{C} 1.1512 \mathrm{E}-03$ $40092.70 \mathrm{C} 5.4927 \mathrm{E}-03$ $68162.70 \mathrm{C} 3.2551 \mathrm{E}-07$ $68167.70 \mathrm{C} 5.3314 \mathrm{E}-05$ $72174.70 \mathrm{C} 3.0875 \mathrm{E}-09$ $72178.70 \mathrm{C} 5.2641 \mathrm{E}-07$ 
NEA/NSC/DOC(2006)1

\section{Fundamental - FUND}

\section{NRAD-FUND-RESR-001} CRIT

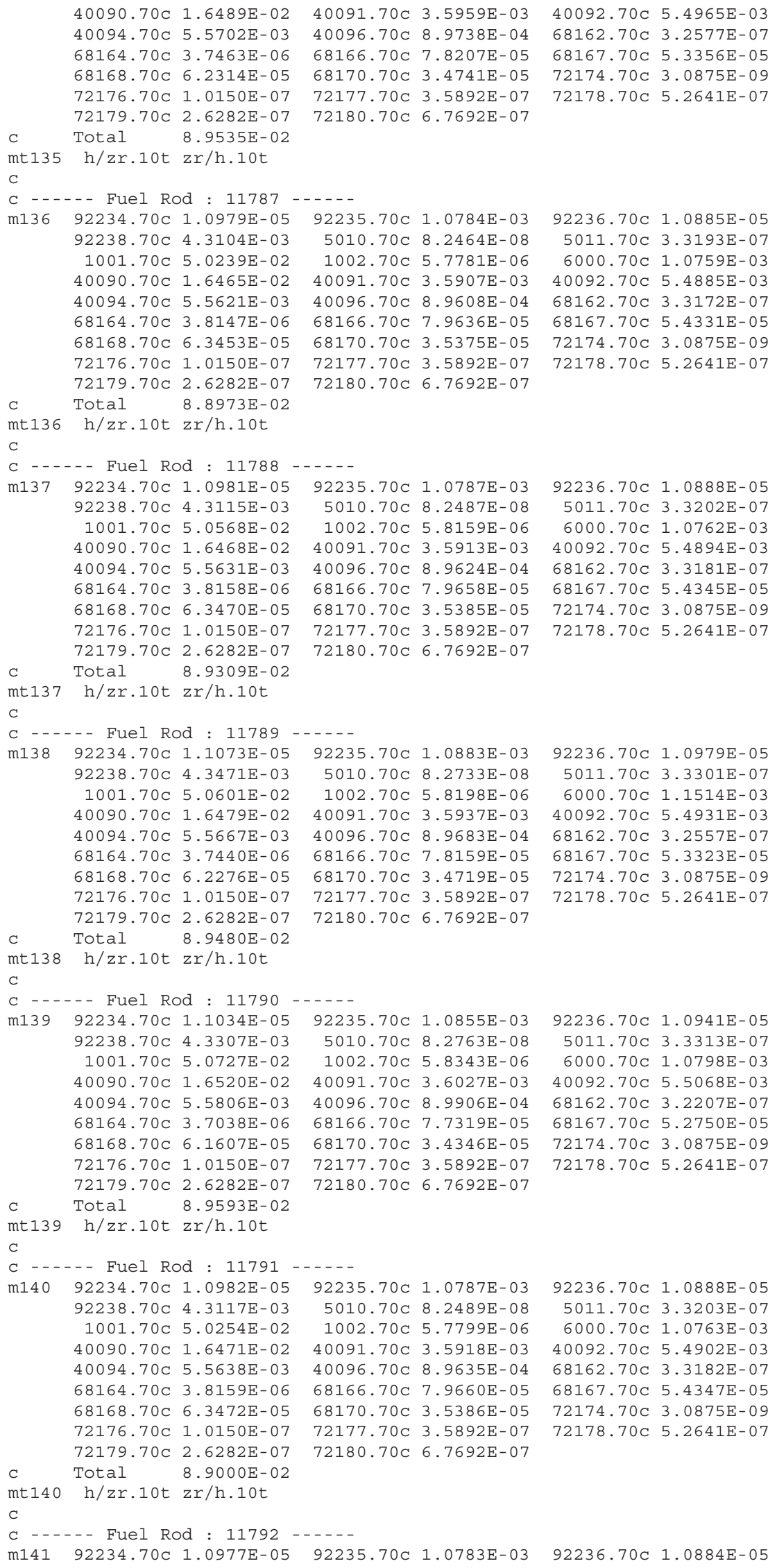

$92236.70 \mathrm{C} 1.0941 \mathrm{E}-05$ $5011.70 \mathrm{C} \quad 3.3313 \mathrm{E}-07$ $6000.70 \mathrm{C} 1.0798 \mathrm{E}-03$ $40092.70 \mathrm{C} 5.5068 \mathrm{E}-03$ $68162.70 \mathrm{C} \quad 3.2207 \mathrm{E}-07$ $68167.70 \mathrm{C} 5.2750 \mathrm{E}-05$ $72174.70 \mathrm{C} 3.0875 \mathrm{E}-09$ $72178.70 \mathrm{C} \quad 5.2641 \mathrm{E}-07$

$92236.70 \mathrm{C} \quad 1.0888 \mathrm{E}-05$ $5011.70 \mathrm{C} \mathrm{3.3203E-07}$ $6000.70 \mathrm{C} 1.0763 \mathrm{E}-03$ $40092.70 \mathrm{C} 5.4902 \mathrm{E}-03$ $68162.70 \mathrm{C} 3.3182 \mathrm{E}-07$ $68167.70 \mathrm{C} \quad 5.4347 \mathrm{E}-05$ $72174.70 \mathrm{C} 3.0875 \mathrm{E}-09$ $72178.70 \mathrm{C} \quad 5.2641 \mathrm{E}-07$ 
NEA/NSC/DOC(2006)1

\section{Fundamental - FUND}

\section{NRAD-FUND-RESR-001} CRIT

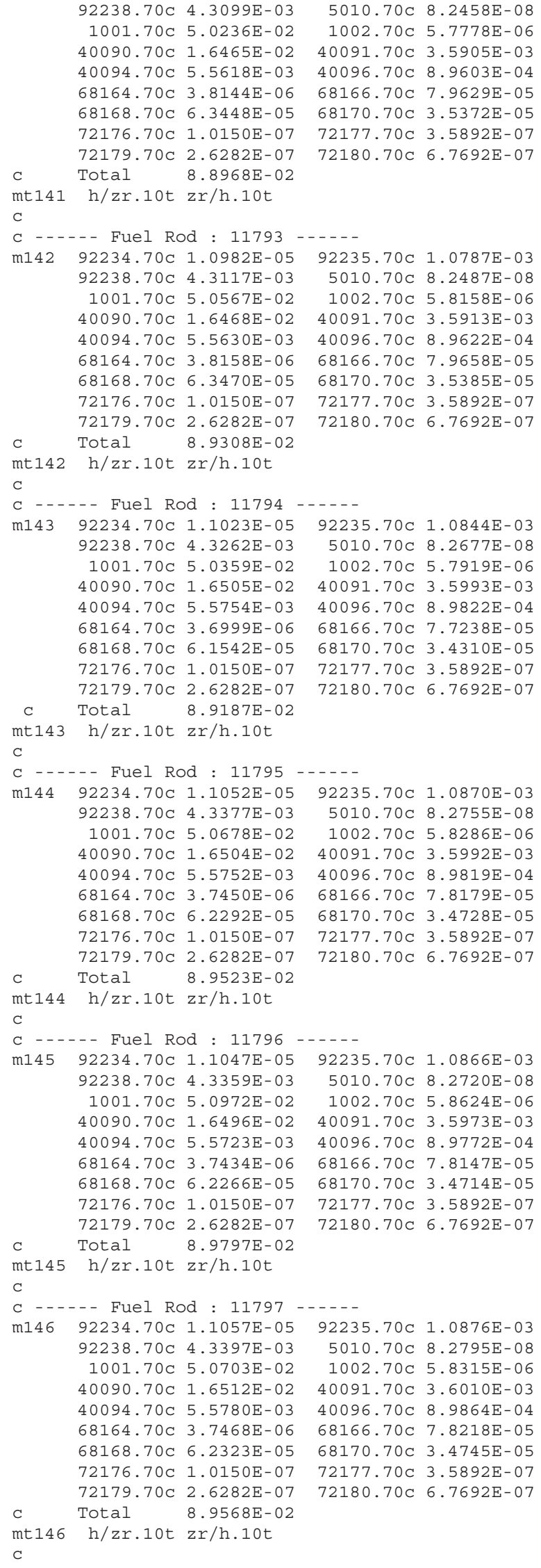

$92236.70 \mathrm{C} 1.0888 \mathrm{E}-05$ $5011.70 \mathrm{C} 3.3202 \mathrm{E}-07$ $6000.70 \mathrm{C} 1.0762 \mathrm{E}-03$ $40092.70 \mathrm{C} \quad 5.4894 \mathrm{E}-03$ $68162.70 \mathrm{C} 3.3181 \mathrm{E}-07$ $68167.70 \mathrm{C} \quad 5.4345 \mathrm{E}-05$ $72174.70 \mathrm{C} 3.0875 \mathrm{E}-09$ $72178.70 \mathrm{C} \quad 5.2641 \mathrm{E}-07$

$92236.70 \mathrm{C} \quad 1.0929 \mathrm{E}-05$ $5011.70 \mathrm{C} \quad 3.3278 \mathrm{E}-07$ $6000.70 \mathrm{C} 1.0787 \mathrm{E}-03$ $40092.70 \mathrm{C} 5.5016 \mathrm{E}-03$ $68162.70 \mathrm{C} 3.2173 \mathrm{E}-07$ $68167.70 \mathrm{C} 5.2694 \mathrm{E}-05$ $72174.70 \mathrm{C} 3.0875 \mathrm{E}-09$ $72178.70 \mathrm{C}$ 5.2641E-07

$92236.70 \mathrm{C} 1.0958 \mathrm{E}-05$ $5011.70 \mathrm{C} 3.3310 \mathrm{E}-07$ $6000.70 \mathrm{C} 1.0797 \mathrm{E}-03$ $40092.70 \mathrm{C} 5.5014 \mathrm{E}-03$ $68162.70 \mathrm{C} 3.2565 \mathrm{E}-07$ $68167.70 \mathrm{C} 5.3337 \mathrm{E}-05$ $72174.70 \mathrm{C} 3.0875 \mathrm{E}-09$ $72178.70 \mathrm{C} \quad 5.2641 \mathrm{E}-07$

$92236.70 \mathrm{C} \quad 1.0953 \mathrm{E}-05$ $5011.70 \mathrm{C} 3.3296 \mathrm{E}-07$ $6000.70 \mathrm{C} 1.0793 \mathrm{E}-03$ $40092.70 \mathrm{C} 5.4985 \mathrm{E}-03$ $68162.70 \mathrm{C} \quad 3.2551 \mathrm{E}-07$ $68167.70 \mathrm{C} \quad 5.3315 \mathrm{E}-05$ $72174.70 \mathrm{C} 3.0875 \mathrm{E}-09$ $72178.70 \mathrm{C} \quad 5.2641 \mathrm{E}-07$

$92236.70 \mathrm{C} 1.0963 \mathrm{E}-05$ $5011.70 \mathrm{C} 3.3326 \mathrm{E}-07$ $6000.70 \mathrm{C} 1.0803 \mathrm{E}-03$ $40092.70 \mathrm{C} 5.5041 \mathrm{E}-03$ $68162.70 \mathrm{C} 3.2581 \mathrm{E}-07$ $68167.70 \mathrm{C} \quad 5.3363 \mathrm{E}-05$ $72174.70 \mathrm{C} 3.0875 \mathrm{E}-09$ $72178.70 \mathrm{C} \quad 5.2641 \mathrm{E}-07$ 
NEA/NSC/DOC(2006)1

\section{Fundamental - FUND}

\section{NRAD-FUND-RESR-001} CRIT

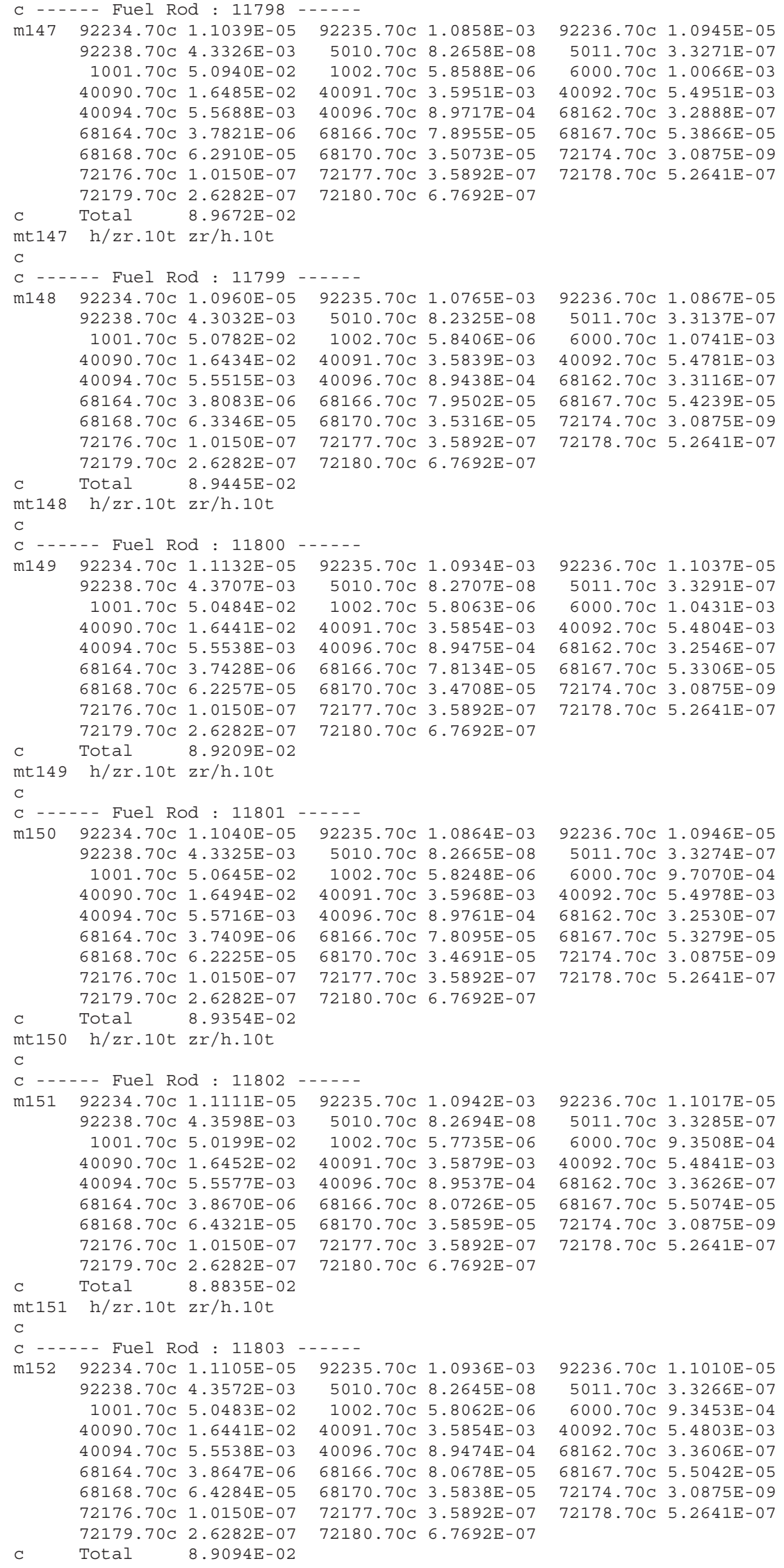

$92236.70 \mathrm{C} 1.1010 \mathrm{E}-05$ $5011.70 \mathrm{C} 3.3266 \mathrm{E}-07$ $6000.70 \mathrm{C} 9.3453 \mathrm{E}-04$ $40092.70 \mathrm{C} 5.4803 \mathrm{E}-03$ $68162.70 \mathrm{C} 3.3606 \mathrm{E}-07$ $68167.70 \mathrm{C} 5.5042 \mathrm{E}-05$ $72174.70 \mathrm{C} 3.0875 \mathrm{E}-09$ $72178.70 \mathrm{C} \quad 5.2641 \mathrm{E}-07$

C Total $8.9094 \mathrm{E}-02$ 
NEA/NSC/DOC(2006)1

Fundamental - FUND

NRAD-FUND-RESR-001

CRIT

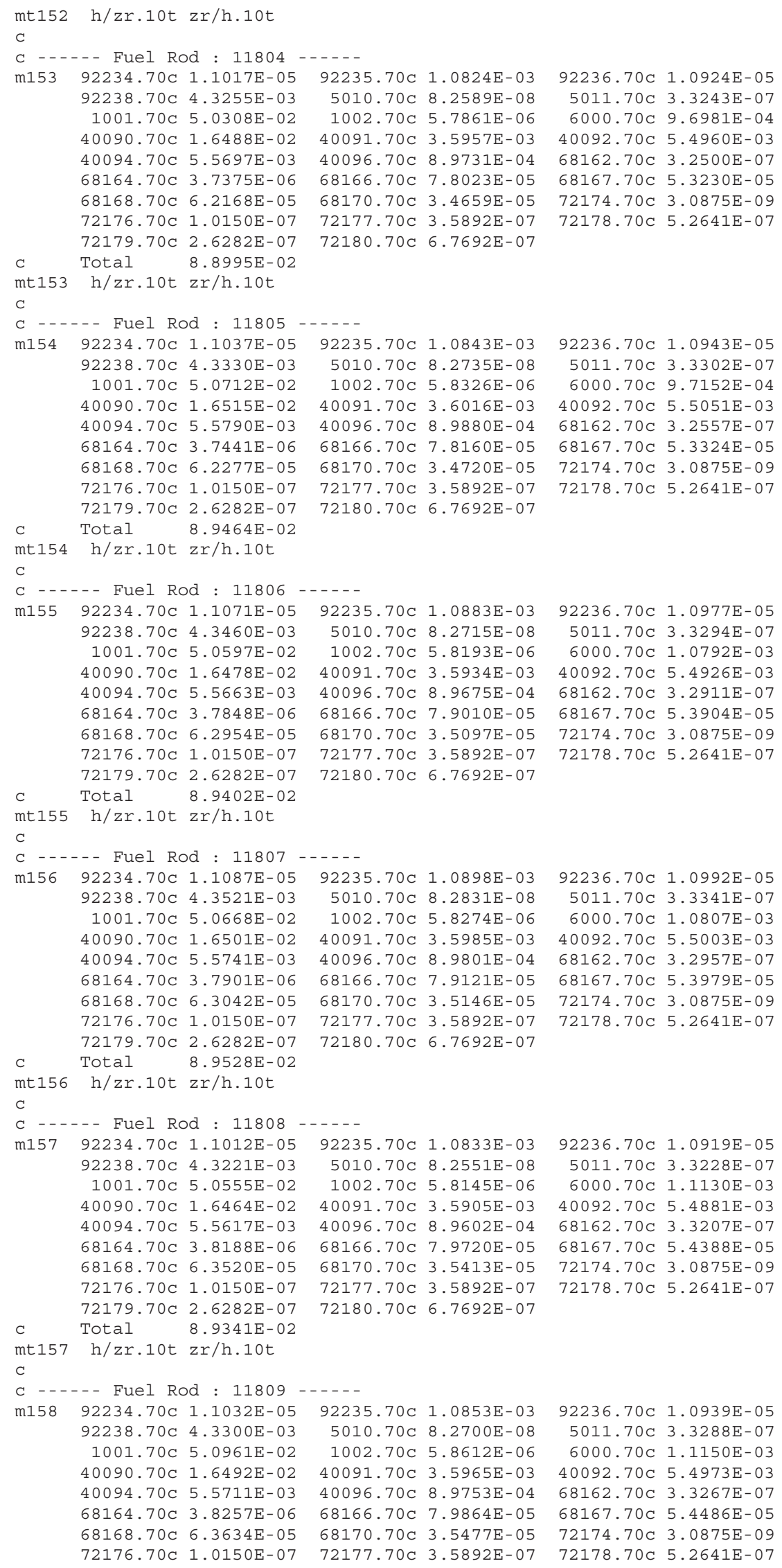

$92236.70 \mathrm{C} 1.0924 \mathrm{E}-05$ $5011.70 \mathrm{C} 3.3243 \mathrm{E}-07$ $6000.70 \mathrm{C} 9.6981 \mathrm{E}-04$ $40092.70 \mathrm{C} 5.4960 \mathrm{E}-03$ $68162.70 \mathrm{C} \quad 3.2500 \mathrm{E}-07$ $68167.70 \mathrm{C} 5.3230 \mathrm{E}-05$ $72174.70 \mathrm{C} 3.0875 \mathrm{E}-09$ $72178.70 \mathrm{C} \quad 5.2641 \mathrm{E}-07$

$92236.70 \mathrm{C} \quad 1.0943 \mathrm{E}-05$ $5011.70 \mathrm{C} 3.3302 \mathrm{E}-07$ $6000.70 \mathrm{C} 9.7152 \mathrm{E}-04$ $40092.70 \mathrm{C} 5.5051 \mathrm{E}-03$ $68162.70 \mathrm{C} \quad 3.2557 \mathrm{E}-07$ $68167.70 \mathrm{C} \quad 5.3324 \mathrm{E}-05$ $72174.70 \mathrm{C} 3.0875 \mathrm{E}-09$ $72178.70 \mathrm{C} \quad 5.2641 \mathrm{E}-07$

$92236.70 \mathrm{C} 1.0977 \mathrm{E}-05$ $5011.70 \mathrm{C} \quad 3.3294 \mathrm{E}-07$ $6000.70 \mathrm{C} 1.0792 \mathrm{E}-03$ $40092.70 \mathrm{C} 5.4926 \mathrm{E}-03$ $68162.70 \mathrm{C} 3.2911 \mathrm{E}-07$ $68167.70 \mathrm{C} 5.3904 \mathrm{E}-05$ $72174.70 \mathrm{C} 3.0875 \mathrm{E}-09$ $72178.70 \mathrm{C}$ 5.2641E-07

$92236.70 \mathrm{C} 1.0992 \mathrm{E}-05$ $5011.70 \mathrm{C} 3.3341 \mathrm{E}-07$ $6000.70 \mathrm{C} 1.0807 \mathrm{E}-03$ $40092.70 \mathrm{C} 5.5003 \mathrm{E}-03$ $68162.70 \mathrm{C} 3.2957 \mathrm{E}-07$ $68167.70 \mathrm{C} \quad 5.3979 \mathrm{E}-05$ $72174.70 \mathrm{C} 3.0875 \mathrm{E}-09$ $72178.70 \mathrm{C} \quad 5.2641 \mathrm{E}-07$

$92236.70 \mathrm{C} 1.0919 \mathrm{E}-05$ $5011.70 \mathrm{C} \quad 3.3228 \mathrm{E}-07$ $6000.70 \mathrm{C} 1.1130 \mathrm{E}-03$ $40092.70 \mathrm{C} 5.4881 \mathrm{E}-03$ $68162.70 \mathrm{C} \quad 3.3207 \mathrm{E}-07$ $68167.70 \mathrm{C} 5.4388 \mathrm{E}-05$ $72174.70 \mathrm{C} 3.0875 \mathrm{E}-09$ $72178.70 \mathrm{C} \quad 5.2641 \mathrm{E}-07$

$92236.70 \mathrm{C} 1.0939 \mathrm{E}-05$ $5011.70 \mathrm{C} \quad 3.3288 \mathrm{E}-07$ $6000.70 \mathrm{C} 1.1150 \mathrm{E}-03$ $40092.70 \mathrm{C} 5.4973 \mathrm{E}-03$ $68162.70 \mathrm{C} \quad 3.3267 \mathrm{E}-07$ $68167.70 \mathrm{C} \quad 5.4486 \mathrm{E}-05$ $72174.70 \mathrm{C} 3.0875 \mathrm{E}-09$ $72178.70 \mathrm{C} 5.2641 \mathrm{E}-07$ 
NEA/NSC/DOC(2006)1

\section{Fundamental - FUND}

\section{NRAD-FUND-RESR-001 CRIT}

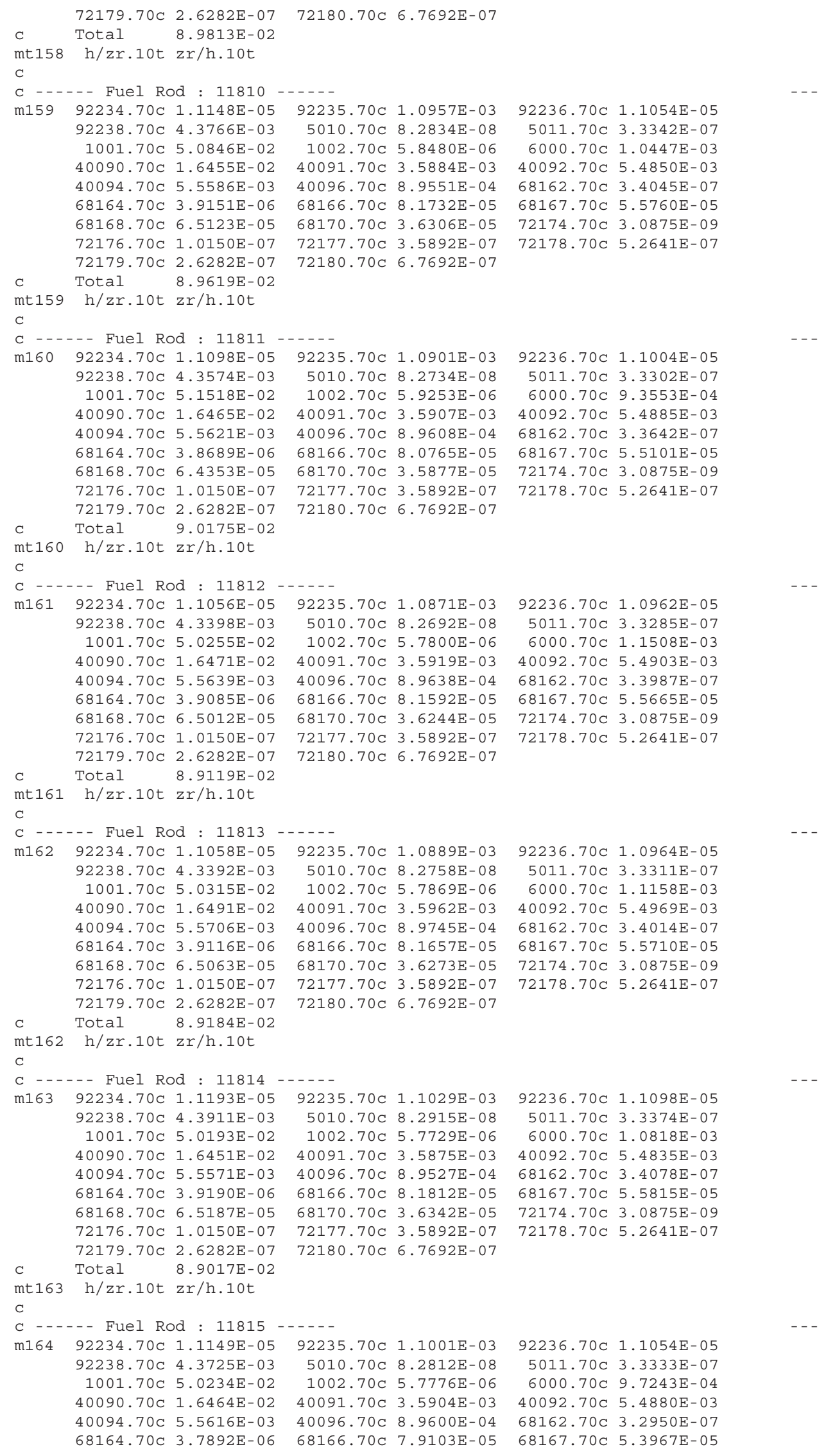


NEA/NSC/DOC(2006)1

Fundamental - FUND

NRAD-FUND-RESR-001

CRIT

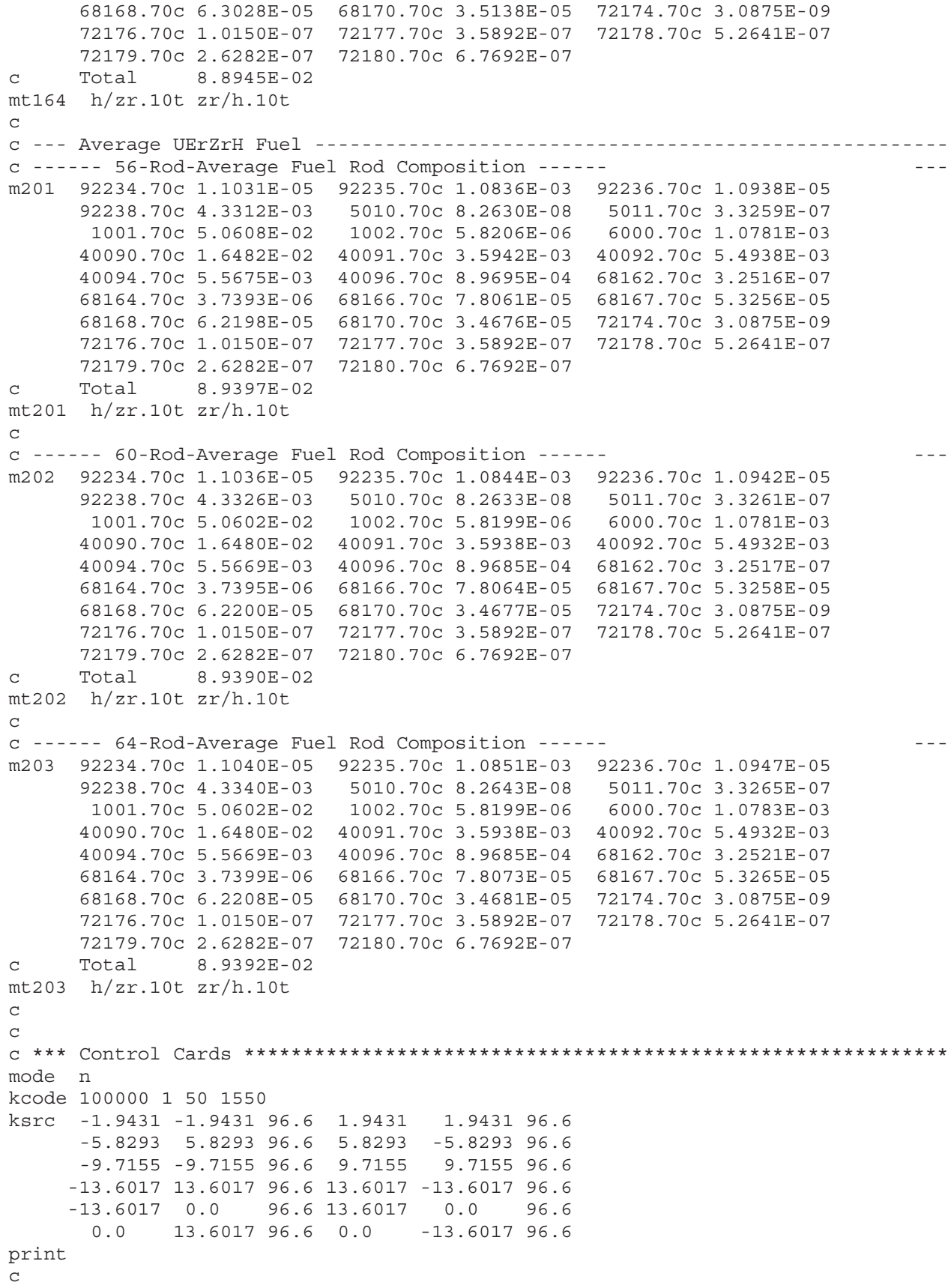




\section{NEA/NSC/DOC(2006)1}

Fundamental - FUND

NRAD-FUND-RESR-001

CRIT

\section{APPENDIX D: AS-BUILT FUEL DATA}

A summary of the as-built fuel data obtained from the shipping documentation for the NRAD fuel elements is provided in this appendix. Table D.1 contains data specific to the uranium content of the fuel. Table D.2 contains a summary of additional fuel measurements.

Table D.1. As-Built Fuel Data (Uranium Content).

\begin{tabular}{|c|c|c|c|c|c|}
\hline $\begin{array}{l}\text { Element } \\
\text { Number }\end{array}$ & $\begin{array}{c}\text { Total } \\
\text { Mass (g) }\end{array}$ & $\begin{array}{l}\text { Uranium } \\
\text { Mass (g) }\end{array}$ & $\begin{array}{c}{ }^{235} \mathrm{U} \\
\text { Mass (g) }\end{array}$ & $\begin{array}{c}{ }^{235} \mathrm{U} \\
\text { Enrichment (\%) }\end{array}$ & $\begin{array}{c}\text { Uranium } \\
\text { Content (wt.\%) }\end{array}$ \\
\hline 11752 & 2503.57 & 747.73 & 147.68 & 19.75 & 29.87 \\
\hline 11753 & 2504.51 & 750.94 & 148.29 & 19.75 & 29.98 \\
\hline 11754 & 2505.34 & 751.19 & 148.33 & 19.75 & 29.98 \\
\hline 11755 & 2503.53 & 750.64 & 148.23 & 19.75 & 29.98 \\
\hline 11756 & 2504.75 & 751.01 & 148.29 & 19.75 & 29.98 \\
\hline 11757 & 2503.62 & 750.67 & 148.23 & 19.75 & 29.98 \\
\hline 11758 & 2504.35 & 750.89 & 148.28 & 19.75 & 29.98 \\
\hline 11759 & 2503.18 & 750.54 & 148.21 & 19.75 & 29.98 \\
\hline 11760 & 2508.34 & 751.67 & 148.42 & 19.75 & 29.97 \\
\hline 11761 & 2506.59 & 749.05 & 147.76 & 19.73 & 29.88 \\
\hline 11762 & 2510.22 & 750.14 & 147.88 & 19.71 & 29.88 \\
\hline 11763 & 2511.18 & 750.42 & 147.93 & 19.71 & 29.88 \\
\hline 11764 & 2509.55 & 749.94 & 147.84 & 19.71 & 29.88 \\
\hline 11765 & 2508.80 & 749.72 & 147.79 & 19.71 & 29.88 \\
\hline 11766 & 2510.72 & 750.29 & 147.90 & 19.71 & 29.88 \\
\hline 11767 & 2508.16 & 749.52 & 147.76 & 19.71 & 29.88 \\
\hline 11768 & 2504.76 & 748.92 & 147.84 & 19.74 & 29.90 \\
\hline 11769 & 2500.76 & 747.73 & 147.60 & 19.74 & 29.90 \\
\hline 11770 & 2506.39 & 749.40 & 147.94 & 19.74 & 29.90 \\
\hline 11771 & 2502.98 & 748.40 & 147.73 & 19.74 & 29.90 \\
\hline 11772 & 2506.50 & 749.45 & 147.94 & 19.74 & 29.90 \\
\hline 11773 & 2504.00 & 748.71 & 147.80 & 19.74 & 29.90 \\
\hline 11774 & 2505.26 & 749.07 & 147.87 & 19.74 & 29.90 \\
\hline 11775 & 2502.48 & 747.41 & 147.52 & 19.74 & 29.87 \\
\hline 11776 & 2511.48 & 749.28 & 147.76 & 19.72 & 29.83 \\
\hline 11777 & 2503.32 & 743.92 & 146.75 & 19.73 & 29.72 \\
\hline 11778 & 2507.07 & 749.21 & 147.75 & 19.72 & 29.88 \\
\hline 11779 & 2502.48 & 743.66 & 146.70 & 19.73 & 29.72 \\
\hline 11780 & 2506.19 & 748.93 & 147.69 & 19.72 & 29.88 \\
\hline 11781 & 2502.51 & 746.33 & 147.26 & 19.73 & 29.82 \\
\hline 11782 & 2506.61 & 751.14 & 148.20 & 19.73 & 29.97 \\
\hline 11783 & 2506.90 & 751.23 & 148.21 & 19.73 & 29.97 \\
\hline 11784 & 2509.46 & 752.01 & 148.37 & 19.73 & 29.97 \\
\hline 11785 & 2509.11 & 752.32 & 148.51 & 19.74 & 29.98 \\
\hline 11786 & 2511.09 & 752.90 & 148.62 & 19.74 & 29.98 \\
\hline 11787 & 2501.38 & 746.01 & 147.19 & 19.73 & 29.82 \\
\hline 11788 & 2502.06 & 746.19 & 147.22 & 19.73 & 29.82 \\
\hline 11789 & 2509.55 & 752.45 & 148.54 & 19.74 & 29.98 \\
\hline 11790 & 2510.46 & 749.80 & 148.16 & 19.76 & 29.87 \\
\hline 11791 & 2502.13 & 746.22 & 147.23 & 19.73 & 29.82 \\
\hline 11792 & 2501.18 & 745.91 & 147.17 & 19.73 & 29.82 \\
\hline 11793 & 2502.06 & 746.22 & 147.23 & 19.73 & 29.82 \\
\hline 11794 & 2507.83 & 749.01 & 148.00 & 19.76 & 29.87 \\
\hline
\end{tabular}




\section{NEA/NSC/DOC(2006)1}

Fundamental - FUND

NRAD-FUND-RESR-001 CRIT

Table D.1 (cont.). As-Built Fuel Data (Uranium Content).

\begin{tabular}{|c|c|c|c|c|c|}
\hline $\begin{array}{l}\text { Element } \\
\text { Number }\end{array}$ & $\begin{array}{c}\text { Total } \\
\text { Mass (g) }\end{array}$ & $\begin{array}{l}\text { Uranium } \\
\text { Mass (g) }\end{array}$ & $\begin{array}{c}{ }^{235} \mathrm{U} \\
\text { Mass (g) }\end{array}$ & $\begin{array}{c}{ }^{235} \mathrm{U} \\
\text { Enrichment (\%) }\end{array}$ & $\begin{array}{c}\text { Uranium } \\
\text { Content (wt.\%) } \\
\end{array}$ \\
\hline 11795 & 2510.20 & 750.97 & 148.36 & 19.76 & 29.92 \\
\hline 11796 & 2509.15 & 750.66 & 148.30 & 19.76 & 29.92 \\
\hline 11797 & 2511.43 & 751.33 & 148.44 & 19.76 & 29.92 \\
\hline 11798 & 2507.25 & 750.09 & 148.19 & 19.76 & 29.92 \\
\hline 11799 & 2497.17 & 744.75 & 146.93 & 19.73 & 29.82 \\
\hline 11800 & 2508.76 & 756.42 & 149.23 & 19.73 & 30.15 \\
\hline 11801 & 2507.48 & 750.16 & 148.28 & 19.77 & 29.92 \\
\hline 11802 & 2508.35 & 755.02 & 149.34 & 19.78 & 30.10 \\
\hline 11803 & 2506.88 & 754.58 & 149.26 & 19.78 & 30.10 \\
\hline 11804 & 2505.18 & 748.64 & 147.73 & 19.73 & 29.88 \\
\hline 11805 & 2509.59 & 749.95 & 147.99 & 19.73 & 29.88 \\
\hline 11806 & 2508.99 & 752.29 & 148.53 & 19.74 & 29.98 \\
\hline 11807 & 2512.51 & 753.35 & 148.74 & 19.74 & 29.98 \\
\hline 11808 & 2504.02 & 748.30 & 147.86 & 19.76 & 29.88 \\
\hline 11809 & 2508.54 & 749.67 & 148.13 & 19.76 & 29.88 \\
\hline 11810 & 2512.59 & 757.55 & 149.54 & 19.74 & 30.15 \\
\hline 11811 & 2509.58 & 754.12 & 148.78 & 19.73 & 30.05 \\
\hline 11812 & 2508.30 & 751.27 & 148.37 & 19.75 & 29.95 \\
\hline 11813 & 2510.30 & 751.43 & 148.62 & 19.78 & 29.93 \\
\hline 11814 & 2515.05 & 760.56 & 150.53 & 19.79 & 30.24 \\
\hline 11815 & 2511.94 & 757.60 & 150.15 & 19.82 & 30.16 \\
\hline $\begin{array}{c}\text { Average } \\
\text { (56 Rods) }^{(\mathrm{a})}\end{array}$ & 2506.4 & 749.6 & 147.9 & 19.74 & 29.91 \\
\hline $\begin{array}{c} \pm 1 \sigma^{(\mathrm{b})} \\
(56 \text { Rods })^{(\mathrm{a})} \\
\end{array}$ & 3.5 & 2.5 & 0.5 & 0.01 & 0.07 \\
\hline $\begin{array}{c}\text { Average } \\
(60 \text { Rods })^{(c)}\end{array}$ & 2506.5 & 749.9 & 148.0 & 19.74 & 29.92 \\
\hline $\begin{array}{c} \pm 1 \sigma^{(\mathrm{b})} \\
(60 \text { Rods })^{(\mathrm{c})} \\
\end{array}$ & 3.4 & 2.7 & 0.6 & 0.02 & 0.09 \\
\hline $\begin{array}{l}\text { Average } \\
\text { (64 Rods) }\end{array}$ & 2506.8 & 750.2 & 148.1 & 19.74 & 29.93 \\
\hline $\begin{array}{c} \pm 1 \sigma^{(\mathrm{b})} \\
\text { (64 Rods) } \\
\end{array}$ & 3.6 & 3.1 & 0.7 & 0.02 & 0.10 \\
\hline
\end{tabular}

(a) Fifty-six elements are in the initial core critical. Excluded elements include 11800, -801, $-802,-803,-812,-813,-814$, and -815 .

(b) The uncertainty in these values is $1 \sigma$ of the average population and not the average mean.

(c) Sixty elements are in the fully loaded core critical. Excluded elements include -812, $813,-814$, and -815 . 
NEA/NSC/DOC(2006)1

Fundamental - FUND

NRAD-FUND-RESR-001

CRIT

Table D.2. As-Built Fuel Data (Additional Measurements).

\begin{tabular}{|c|c|c|c|c|c|c|c|}
\hline $\begin{array}{l}\text { Element } \\
\text { Number }\end{array}$ & $\begin{array}{l}\mathrm{H} / \mathrm{Zr} \\
\text { Ratio }\end{array}$ & $\begin{array}{c}\text { Er } \\
\text { Content } \\
(w t . \%) \\
\end{array}$ & $\begin{array}{c}\mathrm{C} \\
\text { Content } \\
(w t . \%) \\
\end{array}$ & $\begin{array}{c}\begin{array}{c}\text { Fuel } \\
\text { Length } \\
(\mathrm{mm})\end{array} \\
\end{array}$ & $\begin{array}{c}\text { Fuel } \\
\text { Diameter } \\
(\mathrm{mm}) \\
\end{array}$ & $\begin{array}{l}\text { Cladding } \\
\text { ID (mm) }\end{array}$ & $\begin{array}{c}\text { Fuel-Clad } \\
\text { Difference } \\
(\mathrm{mm}) \\
\end{array}$ \\
\hline 11752 & 1.58 & 0.86 & 0.31 & 380.4 & 34.800 & 34.89 & $\begin{array}{c}0.090 \\
\end{array}$ \\
\hline 11753 & 1.58 & 0.86 & 0.31 & 380.0 & 34.800 & 34.89 & 0.090 \\
\hline 11754 & 1.58 & 0.86 & 0.31 & 380.1 & 34.800 & 34.89 & 0.090 \\
\hline 11755 & 1.59 & 0.86 & 0.31 & 379.8 & 34.800 & 34.89 & 0.090 \\
\hline 11756 & 1.58 & 0.86 & 0.31 & 380.1 & 34.800 & 34.89 & 0.090 \\
\hline 11757 & 1.58 & 0.86 & 0.31 & 380.2 & 34.800 & 34.90 & 0.100 \\
\hline 11758 & 1.59 & 0.86 & 0.31 & 379.9 & 34.800 & 34.89 & 0.090 \\
\hline 11759 & 1.60 & 0.86 & 0.31 & 379.7 & 34.800 & 34.89 & 0.090 \\
\hline 11760 & 1.57 & 0.91 & 0.33 & 380.0 & 34.800 & 34.89 & 0.090 \\
\hline 11761 & 1.57 & 0.90 & 0.31 & 379.2 & 34.803 & 34.89 & 0.087 \\
\hline 11762 & 1.57 & 0.90 & 0.29 & 380.0 & 34.807 & 34.89 & 0.083 \\
\hline 11763 & 1.58 & 0.90 & 0.29 & 379.6 & 34.807 & 34.89 & 0.083 \\
\hline 11764 & 1.59 & 0.90 & 0.29 & 380.0 & 34.807 & 34.89 & 0.083 \\
\hline 11765 & 1.59 & 0.90 & 0.29 & 379.8 & 34.807 & 34.89 & 0.083 \\
\hline 11766 & 1.58 & 0.90 & 0.29 & 380.0 & 34.807 & 34.90 & 0.093 \\
\hline 11767 & 1.57 & 0.90 & 0.29 & 379.6 & 34.803 & 34.89 & 0.087 \\
\hline 11768 & 1.57 & 0.89 & 0.28 & 380.2 & 34.803 & 34.89 & 0.087 \\
\hline 11769 & 1.57 & 0.89 & 0.29 & 379.9 & 34.803 & 34.89 & 0.087 \\
\hline 11770 & 1.59 & 0.89 & 0.29 & 379.9 & 34.807 & 34.89 & 0.083 \\
\hline 11771 & 1.58 & 0.89 & 0.29 & 379.8 & 34.803 & 34.89 & 0.087 \\
\hline 11772 & 1.57 & 0.89 & 0.29 & 380.0 & 34.800 & 34.90 & 0.100 \\
\hline 11773 & 1.58 & 0.89 & 0.29 & 379.8 & 34.803 & 34.90 & 0.097 \\
\hline 11774 & 1.61 & 0.89 & 0.29 & 380.0 & 34.803 & 34.90 & 0.097 \\
\hline 11775 & 1.58 & 0.91 & 0.29 & 380.1 & 34.807 & 34.90 & 0.093 \\
\hline 11776 & 1.59 & 0.92 & 0.30 & 380.4 & 34.810 & 34.90 & 0.090 \\
\hline 11777 & 1.58 & 0.90 & 0.30 & 380.8 & 34.807 & 34.90 & 0.093 \\
\hline 11778 & 1.58 & 0.91 & 0.32 & 380.9 & 34.807 & 34.90 & 0.093 \\
\hline 11779 & 1.58 & 0.90 & 0.30 & 381.0 & 34.803 & 34.89 & 0.087 \\
\hline 11780 & 1.57 & 0.91 & 0.32 & 380.6 & 34.807 & 34.89 & 0.083 \\
\hline 11781 & 1.58 & 0.92 & 0.30 & 380.5 & 34.807 & 34.89 & 0.083 \\
\hline 11782 & 1.57 & 0.89 & 0.31 & 380.3 & 34.810 & 34.90 & 0.090 \\
\hline 11783 & 1.57 & 0.89 & 0.31 & 380.5 & 34.810 & 34.89 & 0.080 \\
\hline 11784 & 1.57 & 0.89 & 0.31 & 380.4 & 34.807 & 34.89 & 0.083 \\
\hline 11785 & 1.57 & 0.90 & 0.32 & 380.6 & 34.810 & 34.89 & 0.080 \\
\hline 11786 & 1.58 & 0.90 & 0.32 & 380.7 & 34.807 & 34.90 & 0.093 \\
\hline 11787 & 1.57 & 0.92 & 0.30 & 380.5 & 34.810 & 34.89 & 0.080 \\
\hline 11788 & 1.58 & 0.92 & 0.30 & 380.4 & 34.807 & 34.89 & 0.083 \\
\hline 11789 & 1.58 & 0.90 & 0.32 & 380.7 & 34.803 & 34.89 & 0.087 \\
\hline 11790 & 1.58 & 0.89 & 0.30 & 380.6 & 34.803 & 34.89 & 0.087 \\
\hline 11791 & 1.57 & 0.92 & 0.30 & 380.5 & 34.803 & 34.89 & 0.087 \\
\hline 11792 & 1.57 & 0.92 & 0.30 & 380.2 & 34.807 & 34.89 & 0.083 \\
\hline 11793 & 1.58 & 0.92 & 0.30 & 380.4 & 34.807 & 34.90 & 0.093 \\
\hline 11794 & 1.57 & 0.89 & 0.30 & 380.6 & 34.803 & 34.90 & 0.097 \\
\hline
\end{tabular}




\section{NEA/NSC/DOC(2006)1}

Fundamental - FUND

NRAD-FUND-RESR-001 CRIT

Table D.2 (cont.). As-Built Fuel Data (Additional Measurements).

\begin{tabular}{|c|c|c|c|c|c|c|c|}
\hline $\begin{array}{l}\text { Element } \\
\text { Number }\end{array}$ & $\begin{array}{l}\mathrm{H} / \mathrm{Zr} \\
\text { Ratio }\end{array}$ & $\begin{array}{c}\text { Er } \\
\text { Content } \\
\text { (wt.\%) }\end{array}$ & $\begin{array}{c}\mathrm{C} \\
\text { Content } \\
\text { (wt.\%) }\end{array}$ & $\begin{array}{c}\text { Fuel } \\
\text { Length } \\
\text { (mm) }\end{array}$ & $\begin{array}{c}\text { Fuel } \\
\text { Diameter } \\
(\mathbf{m m})\end{array}$ & $\begin{array}{l}\text { Cladding } \\
\text { ID (mm) }\end{array}$ & $\begin{array}{c}\text { Fuel-Clad } \\
\text { Difference } \\
(\mathrm{mm})\end{array}$ \\
\hline 11795 & 1.58 & 0.90 & 0.30 & 380.7 & 34.810 & 34.89 & 0.080 \\
\hline 11796 & 1.59 & 0.90 & 0.30 & 380.8 & 34.810 & 34.90 & 0.090 \\
\hline 11797 & 1.58 & 0.90 & 0.30 & 380.9 & 34.807 & 34.90 & 0.093 \\
\hline 11798 & 1.59 & 0.91 & 0.28 & 380.9 & 34.807 & 34.90 & 0.093 \\
\hline 11799 & 1.59 & 0.92 & 0.30 & 380.1 & 34.803 & 34.89 & 0.087 \\
\hline 11800 & 1.58 & 0.90 & 0.29 & 380.1 & 34.807 & 34.90 & 0.093 \\
\hline 11801 & 1.58 & 0.90 & 0.27 & 380.2 & 34.803 & 34.89 & 0.087 \\
\hline 11802 & 1.57 & 0.93 & 0.26 & 380.2 & 34.800 & 34.89 & 0.090 \\
\hline 11803 & 1.58 & 0.93 & 0.26 & 380.1 & 34.800 & 34.90 & 0.100 \\
\hline 11804 & 1.57 & 0.90 & 0.27 & 380.0 & 34.810 & 34.90 & 0.090 \\
\hline 11805 & 1.58 & 0.90 & 0.27 & 380.3 & 34.810 & 34.90 & 0.090 \\
\hline 11806 & 1.58 & 0.91 & 0.30 & 380.5 & 34.807 & 34.90 & 0.093 \\
\hline 11807 & 1.58 & 0.91 & 0.30 & 380.8 & 34.810 & 34.90 & 0.090 \\
\hline 11808 & 1.58 & 0.92 & 0.31 & 380.1 & 34.810 & 34.89 & 0.080 \\
\hline 11809 & 1.59 & 0.92 & 0.31 & 380.2 & 34.807 & 34.90 & 0.093 \\
\hline 11810 & 1.59 & 0.94 & 0.29 & 380.3 & 34.810 & 34.90 & 0.090 \\
\hline 11811 & 1.61 & 0.93 & 0.26 & 379.6 & 34.810 & 34.89 & 0.080 \\
\hline 11812 & 1.57 & 0.94 & 0.32 & 380.0 & 34.803 & 34.90 & 0.097 \\
\hline 11813 & 1.57 & 0.94 & 0.31 & 380.3 & 34.807 & 34.90 & 0.093 \\
\hline 11814 & 1.57 & 0.94 & 0.30 & 380.2 & 34.810 & 34.90 & 0.090 \\
\hline 11815 & 1.57 & 0.91 & 0.27 & 380.4 & 34.810 & 34.90 & 0.090 \\
\hline $\begin{array}{c}\text { Average } \\
(56 \text { Rods })^{(\mathrm{a})}\end{array}$ & 1.58 & 0.90 & 0.30 & 380.2 & 34.805 & 34.894 & 0.088 \\
\hline $\begin{array}{c} \pm 1 \sigma^{(\mathrm{b})} \\
(56 \text { Rods })^{(\mathrm{a})}\end{array}$ & 0.01 & 0.02 & 0.01 & 0.4 & 0.003 & 0.005 & 0.005 \\
\hline $\begin{array}{c}\text { Average } \\
(60 \text { Rods })^{(\mathrm{c})}\end{array}$ & 1.58 & 0.90 & 0.30 & 380.2 & 34.805 & 34.894 & 0.089 \\
\hline $\begin{array}{c} \pm 1 \sigma^{(b)} \\
(60 \text { Rods })^{(\mathrm{c})} \\
\end{array}$ & 0.01 & 0.02 & 0.02 & 0.4 & 0.003 & 0.005 & 0.005 \\
\hline $\begin{array}{l}\text { Average } \\
\text { (64 Rods) }\end{array}$ & 1.58 & 0.90 & 0.30 & 380.2 & 34.805 & 34.894 & 0.089 \\
\hline $\begin{array}{c} \pm 1 \sigma^{(\mathrm{b})} \\
\text { (64 Rods) }\end{array}$ & 0.01 & 0.02 & 0.02 & 0.4 & 0.003 & 0.005 & 0.005 \\
\hline
\end{tabular}

(a) Fifty-six elements are in the initial core critical. Excluded elements include 11800, -801, -802, -803, -812, $-813,-814$, and -815 .

(b) The uncertainty in these values is $1 \sigma$ of the average population and not the average mean.

(c) Sixty elements are in the fully loaded core critical. Excluded elements include $-812,-813,-814$, and -815 . 
NEA/NSC/DOC(2006)1

Fundamental - FUND

NRAD-FUND-RESR-001

CRIT

\section{APPENDIX E: CORE LOADING AND APPROACH TO CRITICAL}

Core fuel loading specifications were provided by General Atomics. ${ }^{a}$ The core loading arrangement was prepared using a detailed analysis of the as-built fuel data to optimize core excess reactivity.

Positions in the grid are identified with a letter-number pair. For example, the location of the in-core irradiation assembly is identified as C-4. The location of a specific position within an assembly is further designated by its location with respect to the center of the assembly. The location of the in-core irradiation position is identified as C-4 SW.

The initial core loading with nine fuel elements surrounding the control rods prior to the approach to critical is shown in Figure E.1. Figure E.2 shows the location of the two startup detectors used during fuel loading and the initial critical measurements and the position of two of the control rods (Shim 2 and Reg) without the initial fuel elements with the third control rod (Shim 1) fuel element cluster placed in position without a control rod. The core configuration with fuel cluster (FC) loading positions for the initial core critical and the operational core critical are shown in Figures E.3 and E.4, respectively. Figure 1.1 shows a photograph of the completed NRAD reactor core. Table E.1 contains the fuel element identifications for each position, which correspond with the as-built fuel data provided in Tables D.1 and D.2.

Count rates and multiplication factor measurements taken during the course of fuel loading are shown in Table E.2 and Figure E.5. The NRAD reactor was estimated to achieve criticality with 53.57 fuel elements.

\footnotetext{
a "Neutron Radiography Reactor Analysis and Support: Startup Plan for the NRAD Reactor, Final Report," 911183 rev. 1, GA Project 39296, TRIGA Reactor Division of General Atomics (January 13, 2010). [This reference is not available for public release.]
} 
NEA/NSC/DOC(2006)1

Fundamental - FUND

NRAD-FUND-RESR-001

CRIT

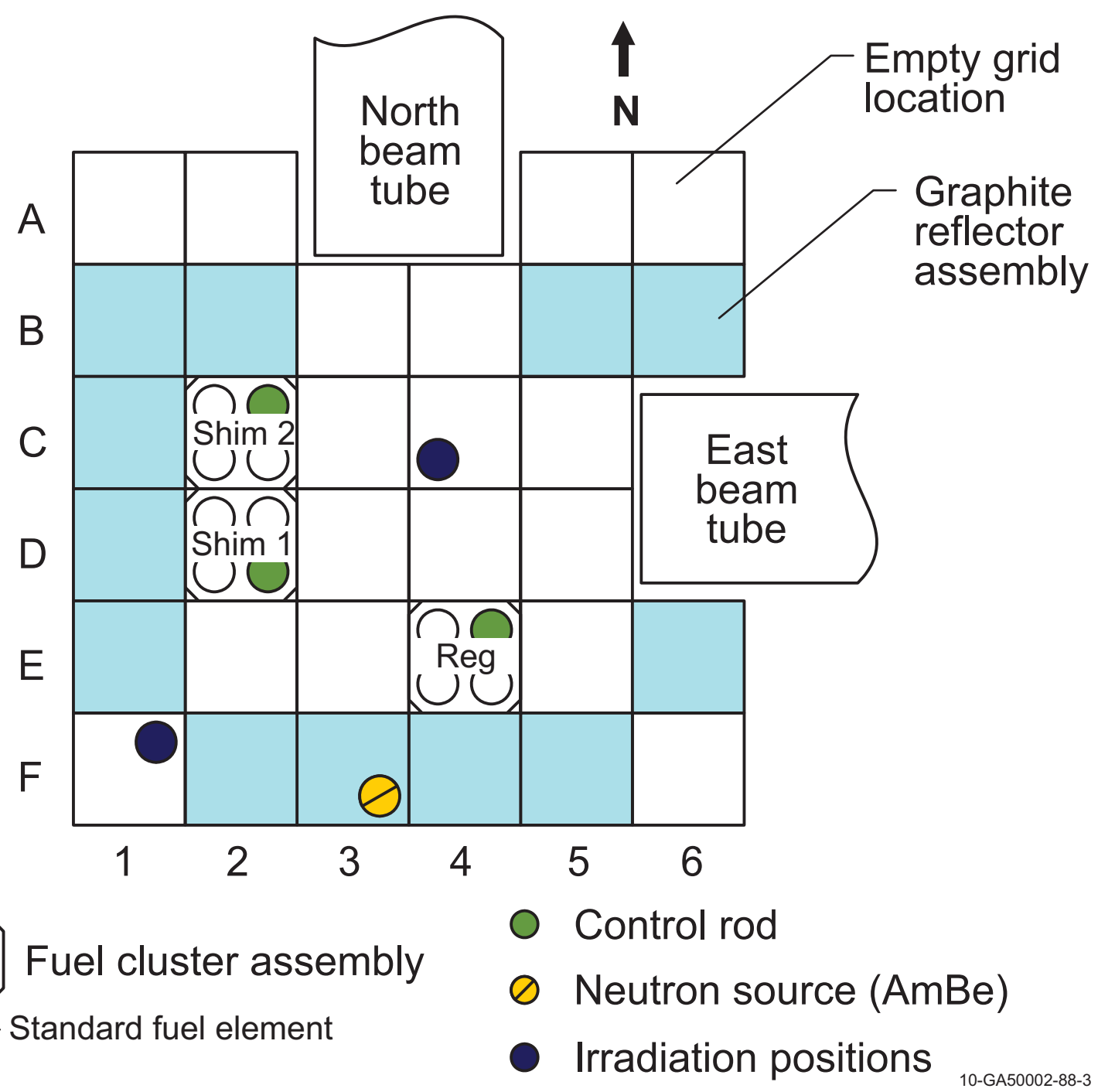

Figure E.1. Core Loading Prior to Startup (9 Fuel Elements). 
NEA/NSC/DOC(2006)1

Fundamental - FUND

NRAD-FUND-RESR-001

CRIT

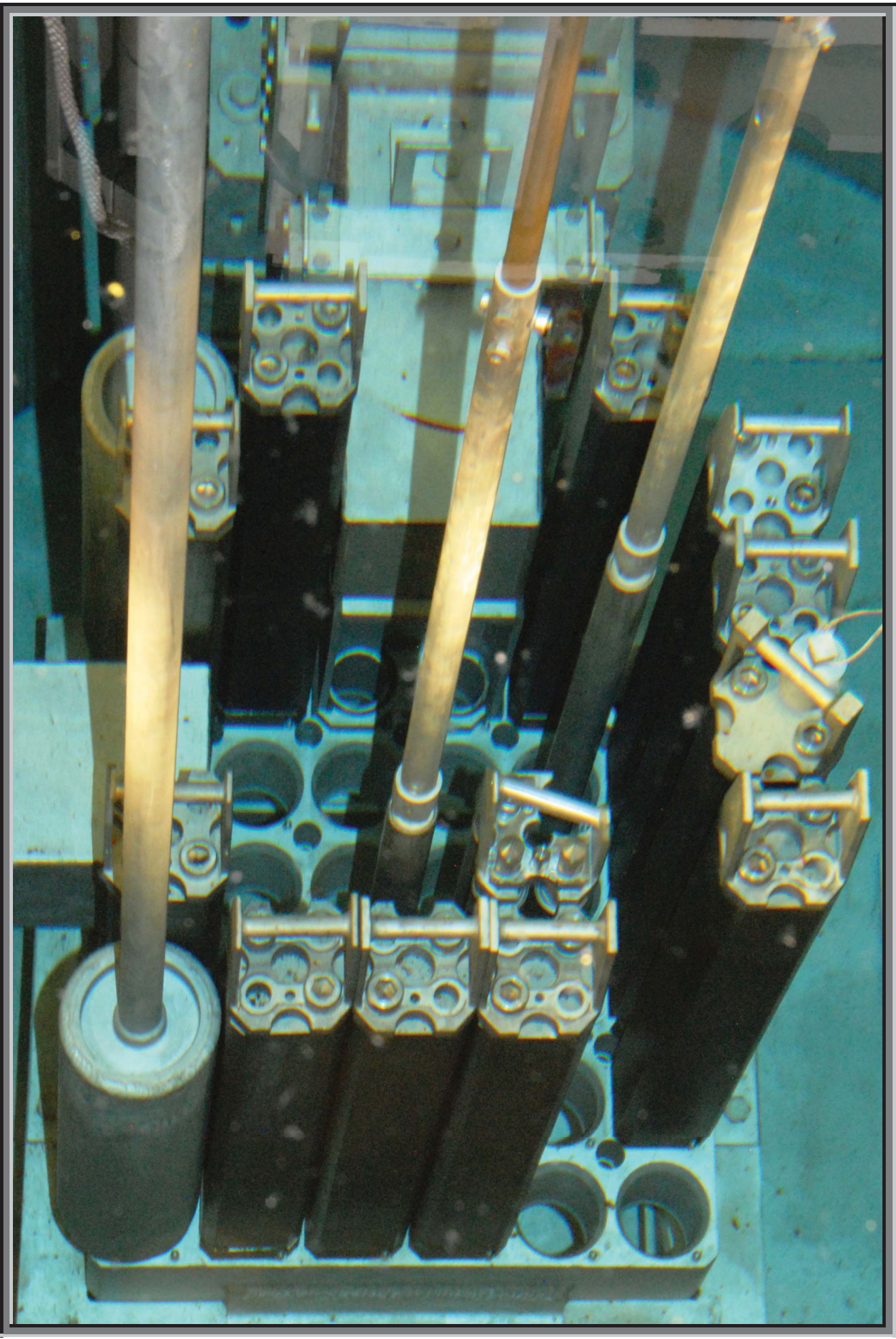

Figure E.2. Photograph of Core Loading Prior to Startup. 
NEA/NSC/DOC(2006)1

Fundamental - FUND

NRAD-FUND-RESR-001

CRIT

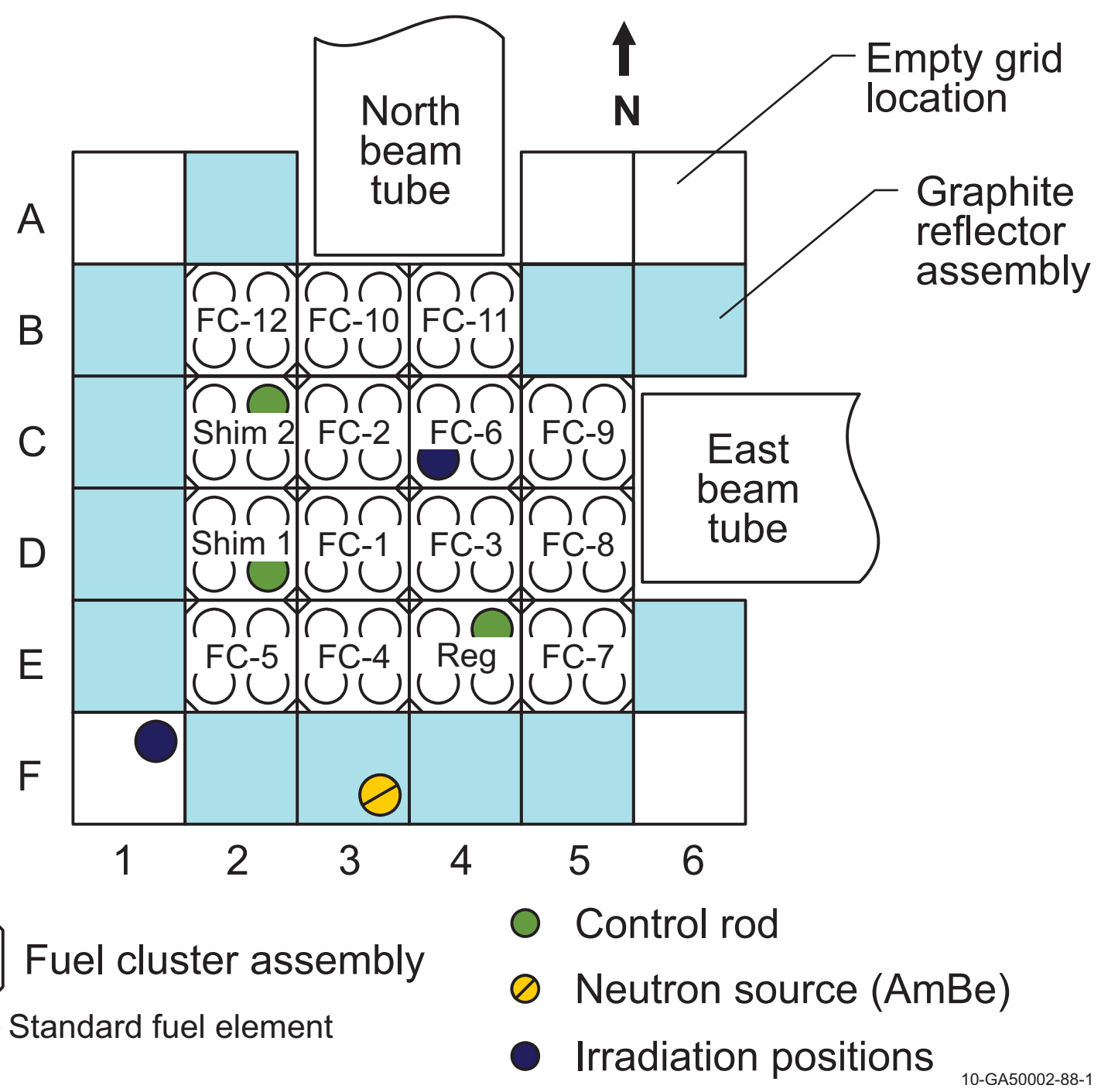

Figure E.3. Initial Core Critical Configuration (56 Fuel Elements). 
NEA/NSC/DOC(2006)1

Fundamental - FUND

NRAD-FUND-RESR-001

CRIT

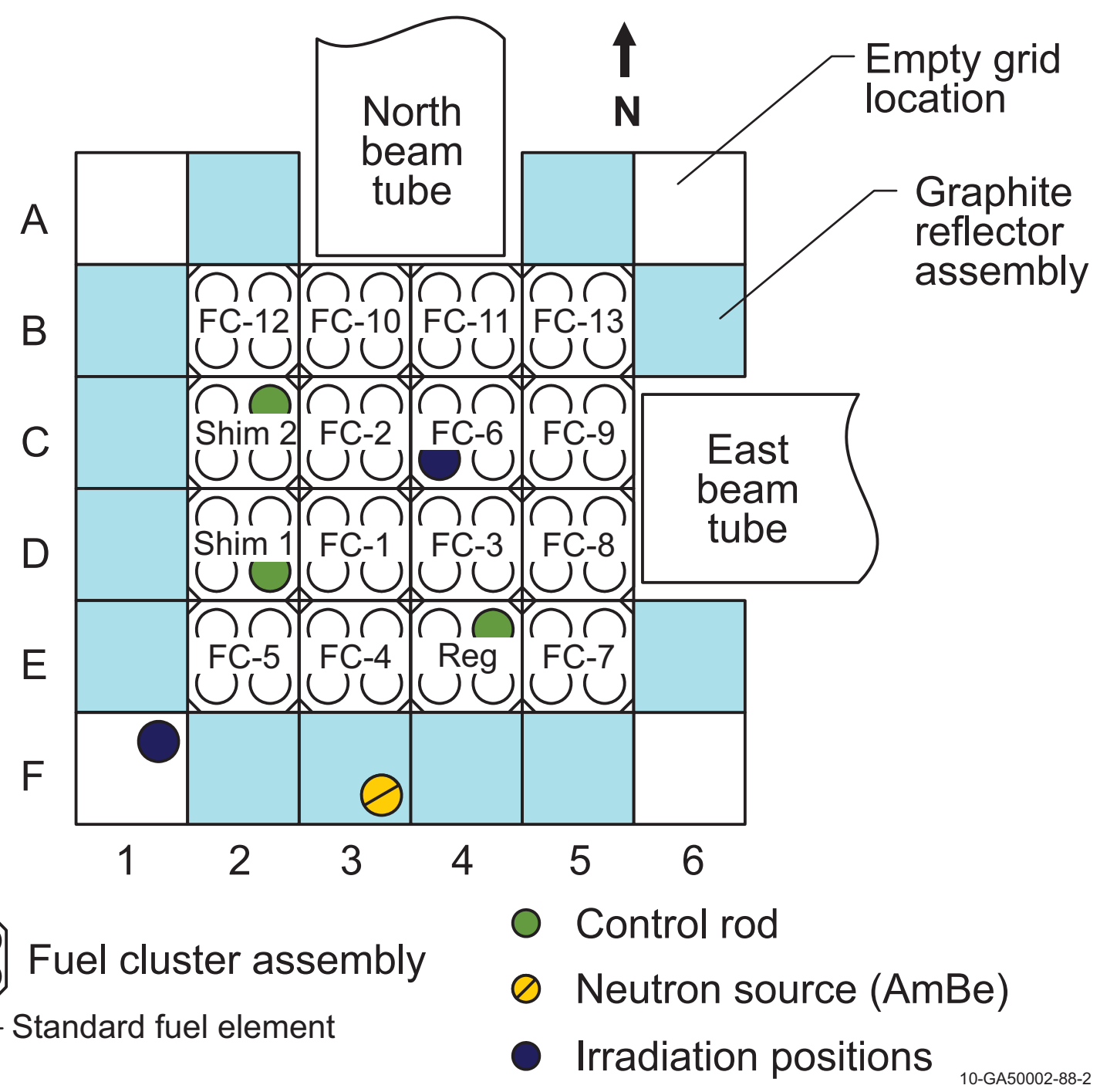

Figure E.4. Fully Loaded Core Critical Configuration (60 Fuel Elements). 
NEA/NSC/DOC(2006)1

Fundamental - FUND

NRAD-FUND-RESR-001 CRIT

Table E.1. As-Built Fuel Positions in Core.

\begin{tabular}{||ccc|}
\hline \hline Cluster & Location & $\begin{array}{c}\text { Element } \\
\text { Number }\end{array}$ \\
\hline \hline Shim 1 & D-2 NW & 11755 \\
& D-2 NE & 11757 \\
& D-2 SE & Shim 1 \\
& D-2 SW & 11756 \\
\hline Shim 2 & C-2 NW & 11752 \\
& C-2 NE & Shim 2 \\
& C-2 SE & 11754 \\
& C-2 SW & 11753 \\
\hline Reg & E-4 NW & 11758 \\
& E-4 NE & Reg Rod \\
& E-4 SE & 11760 \\
& E-4 SW & 11759 \\
& & \\
\hline FC-1 & D-3 NW & 11772 \\
& D-3 NE & 11773 \\
& D-3 SE & 11775 \\
& D-3 SW & 11774 \\
\hline FC-2 & C-3 NW & 11781 \\
& C-3 NE & 11782 \\
& C-3 SE & 11783 \\
& C-3 SW & 11780 \\
\hline FC-3 & D-4 NW & 11768 \\
& D-4 NE & 11769 \\
& D-4 SE & 11771 \\
& D-4 SW & 11770 \\
\hline \hline
\end{tabular}

\begin{tabular}{|ccc||}
\hline Cluster & Location & $\begin{array}{c}\text { Element } \\
\text { Number }\end{array}$ \\
\hline \hline FC-4 & E-3 NW & 11764 \\
& E-3 NE & 11765 \\
& E-3 SE & 11767 \\
& E-3 SW & 11766 \\
\hline FC-5 & E-2 NW & 11798 \\
& E-2 NE & 11796 \\
& E-2 SE & 11797 \\
& E-2 SW & 11799 \\
\hline FC-6 & C-4 NW & 11761 \\
& C-4 NE & 11762 \\
& C-4 SE & 11763 \\
& C-4 SW & Irradiation \\
& Position \\
\hline FC-7 & E-5 NW & 11804 \\
& E-5 NE & 11806 \\
& E-5 SE & 11807 \\
& E-5 SW & 11805 \\
\hline FC-8 & D-5 NW & 11790 \\
& D-5 NE & 11788 \\
& D-5 SE & 11791 \\
& D-5 SW & 11789 \\
\hline FC-9 & C-5 NW & 11795 \\
& C-5 NE & 11792 \\
& C-5 SE & 11793 \\
& C-5 SW & 11794 \\
\hline \hline
\end{tabular}

\begin{tabular}{|ccc|}
\hline \hline Cluster & Location & $\begin{array}{c}\text { Element } \\
\text { Number }\end{array}$ \\
\hline \hline FC-10 & B-3 NW & 11776 \\
& B-3 NE & 11777 \\
& B-3 SE & 11779 \\
& B-3 SW & 11778 \\
\hline FC-11 & B-4 NW & 11785 \\
& B-4 NE & 11787 \\
& B-4 SE & 11786 \\
& B-4 SW & 11784 \\
\hline FC-12 & B-2 NW & 11810 \\
& B-2 NE & 11811 \\
& B-2 SE & 11808 \\
& B-2 SW & 11809 \\
\hline FC-13 ${ }^{\text {(a) }}$ & B-5 NW & 11800 \\
& B-5 NE & 11802 \\
& B-5 SE & 11803 \\
& B-5 SW & 11801 \\
\hline
\end{tabular}

(a) This fuel cluster is only in the fully loaded core configuration (60 fuel elements) and not the initial critical configuration using only 56 fuel elements. 


\section{NEA/NSC/DOC(2006)1}

Fundamental - FUND

NRAD-FUND-RESR-001 CRIT

Table E.2. NRAD LEU Core Approach to Critical.

\begin{tabular}{|c|c|c|c|c|c|c||}
\hline \multirow{2}{*}{ \# of Elements } & \multicolumn{3}{|c|}{ Channel \#1 } & \multicolumn{3}{c|}{ Channel \#2 } \\
\cline { 2 - 7 } & CR (cpm) & $1 / \mathrm{M}$ & $\mathrm{k}$ & $\mathrm{CR}(\mathrm{cpm})$ & $1 / \mathrm{M}$ & $\mathrm{k}$ \\
\hline 9 & 221 & 1.000 & 0.000 & 72 & 1.000 & 0.000 \\
\hline 21 & 715 & 0.309 & 0.691 & 204 & 0.353 & 0.647 \\
\hline 25 & 1276 & 0.173 & 0.827 & 342 & 0.211 & 0.789 \\
\hline 29 & 2220 & 0.100 & 0.900 & 511 & 0.141 & 0.859 \\
\hline 32 & 2787 & 0.079 & 0.921 & 928 & 0.078 & 0.922 \\
\hline 36 & 3673 & 0.060 & 0.940 & 1430 & 0.050 & 0.950 \\
\hline 40 & 4875 & 0.045 & 0.955 & 2488 & 0.029 & 0.971 \\
\hline 44 & 6140 & 0.036 & 0.964 & 4634 & 0.016 & 0.984 \\
\hline 48 & 13305 & 0.017 & 0.983 & 7406 & 0.010 & 0.990 \\
\hline 52 & 37642 & 0.006 & 0.994 & 24526 & 0.003 & 0.997 \\
\hline
\end{tabular}

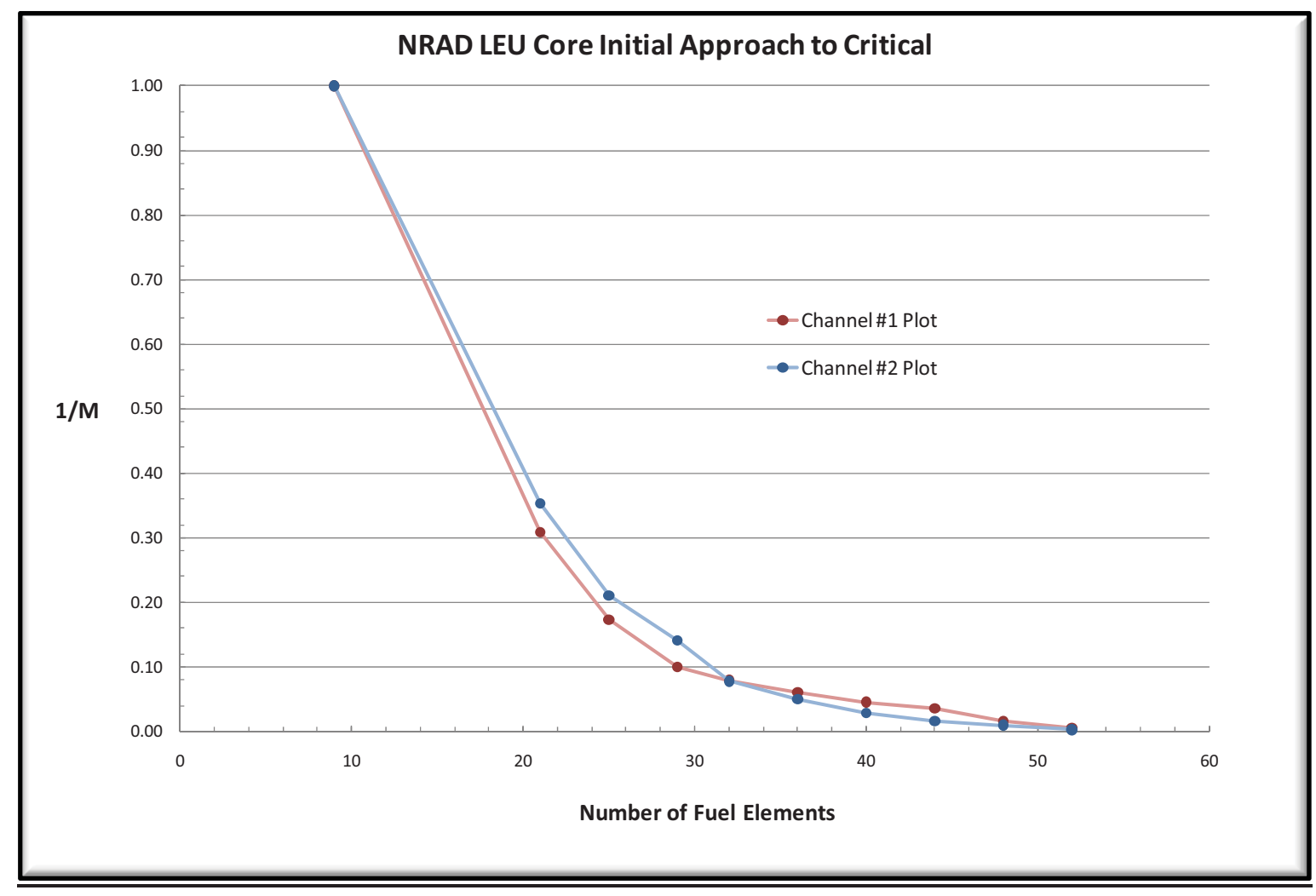

Figure E.5. NRAD LEU Core Approach to Critical. 
NEA/NSC/DOC(2006)1

Fundamental - FUND

NRAD-FUND-RESR-001

CRIT

\section{APPENDIX F: NRAD AND TRIGA FUEL DESIGN DRAWINGS}

This appendix contains a list of the drawings utilized to develop a detailed model of the NRAD reactor, evaluate uncertainties in the experimental measurements, and then develop a simplified benchmark model. These drawings are not available for public release.

- DWG-734030 rev. 2 (W0170-0108-DE) - Aperture Mechanism Final Design Layout

- DWG-734032 rev. 2 (W0170-0110-DD) - 4 Rod Fuel Cluster Assembly

- DWG-734033 (W0170-0111-DD) - Fuel Rod Assembly

- DWG-734034 rev. 2 (W0170-0112-DD) - Locking Plate for 4 Rod Fuel Cluster Assembly

- DWG-734035 rev. 2 (W0170-0113-DD) - Locking Bolt for 4 Rod Fuel Cluster Assembly

- DWG-734401 rev. 0 (W0170-0195-EE) - NRAD Cluster Fitting Layout

- DWG-734402 rev. 2 (W0170-0196-ED) - NRAD Cluster Fitting for NRAD Assembly

- DWG-735784 rev. 5 (W0170-0845-ED) - Top Handle for 4 Rod Fuel Cluster Assembly

- DWG-735785 rev. 4 (W0170-0846-ED) - Top Handle C2, C4 for 3 Element Top Handle Assembly

- DWG-735786 rev. 5 (W0170-0847-ED) - Top Handle D2, D4 for 3 Element Top Handle Assembly

- DWG-735877 rev. 2 (W0170-0849-EC) - C2, C4 3 Element Locking Plate

- DWG-735789 rev. 2 (W0170-0850-EC) - D2, D4 3 Element Locking Plate

- DWG-735790 rev. 2 (W0170-0851-ED) - D2, D4 3 Element Top Handle Assembly

- DWG-735791 rev. 2 (W0170-0852-ED) - C2, C4 3 Element Top Handle Assembly

- DWG-760123 rev. 4 - Control Rod Guide Tube for 3 Rod Fuel Cluster Assembly

- T0S210B212G - Reflector Fuel Element

- T0S210B213C - Fuel - 15" SST Fuel Element

- T0S210B217E - Rod - Fuel Element

- T0S210B229- Disc

- T0S250B147C - Top Fitting - Control Rod

- T0S250B148C - Bottom Fitting - Control Rod

- T0S250B226C - Poison - Control Rod

- T4R250B136 - Spacer - Control Rod

- T4R250D135 - Control Rod

- T4S210C107 - Top Fitting - Fuel Rod

- T4S210C108 - Bottom Fitting - Fuel Rod

- T4S210D105 - Fuel Rod Assembly - 4 Rod Fuel Cluster

- W0170-0084-DE-00 - Graphite Element - Reactor Core, NRAD Layout

- W0170-0088-DD-00 - Graphite Element

- W0170-0089-DD-01 - Handle - Graphite Element Assembly

- W0170-0108-DE-02 - Aperture Mechanism Final Design Layout

- W0170-0115-DE-01 - Grid Plate, Core Support, and Instrumentation Thimble Final Design Layout

- W0170-0139-DE-01 - Grid Plate for NRAD Facility

- W0170-0141-DE-00 - Core Support for NRAD Facility

- W0170-0634-DE-00 - Control Rod Drive Installation Final Design Layout

- W0170-0635-DE-02 - Graphite Element with Source Assembly

- W0170-0636-DD-02 - Handle, Graphite Element Source Assembly

- W0170-0637-DD-00 - Graphite Element - Graphite Element Source Assembly

- W0170-0638-DD-01 - Source Tube

- W0170-0639-DC-01 - Source Tube Cap

- W0170-0687-DE-01 - Aperture Mechanism Assembly

- W0170-0688-DE-01 - Lower Beam Tube

- W0170-0689-DE-00 - Upper Beam Tube

- W0170-0694-DE-01 - East Beam Chamber Assembly

- W0170-0698-DD-00 - Support - Beam Chamber Support Assembly 
- W0170-0726-DC-00 - Lower Tube Seal Plate for Aperture Mechanism Assembly

- W0170-0730-DD-01 - Aperture Block Guide

- W0170-0731-DE-00 - Aperture Block Assembly

- W0170-0732-DE-00 - Aperture Block Frame

- W0170-0733-DC-00 - Aperture Block

- W0170-0734-DC-00 - Aperture Block Front Cover

- W0170-0735-DA-00 - Aperture Block Adjusting Screw

- W0170-0742-DC-00 - Aperture Disc

- W0170-0770-DC-00 - Aperture Block Rear Cover

- W0170-0837-EE-00 - 3 Rod Fuel Cluster Assembly

- W0170-4351-EE-01 - North Beam Chamber Assembly

- W0170-4352-ED-01 - Aperture Block Assembly - NRS

- W0170-4353-ED-01 - Aperture Block Frame - NRS

- W0170-4354-EC-01 - Aperture Block - NRS

- W0170-4355-EC-00 - Aperture Block Front Cover - NRS

- W0170-4356-EC-00 - Aperture Block Rear Cover - NRS

- W0170-4644-EE-02 - NRAD Detector Housing Installation 


\section{NEA/NSC/DOC(2006)1}

Fundamental - FUND

\section{NRAD-FUND-RESR-001 CRIT}

\section{APPENDIX G: EXAMPLE TRIGA FUEL MICROGRAPHS}

The extra fuel element received by INL with the last NRAD reactor fuel shipment was examined with an electron microscope; example micrographs are shown in Figures G.1 through G.5. The microstructure of the fuel is comprised of two phases. The bright phase (white) is uranium enriched with a little zirconium (couple of wt.\%). The dark matrix phase is zirconium enriched and contains hydrogen. This microstructure is very standard for this type of fuel and can be considered a "typical" microstructure. Figures G.4 and G.5 highlight the locations of zirconium and uranium, respectively, in the image shown in Figure G.3.

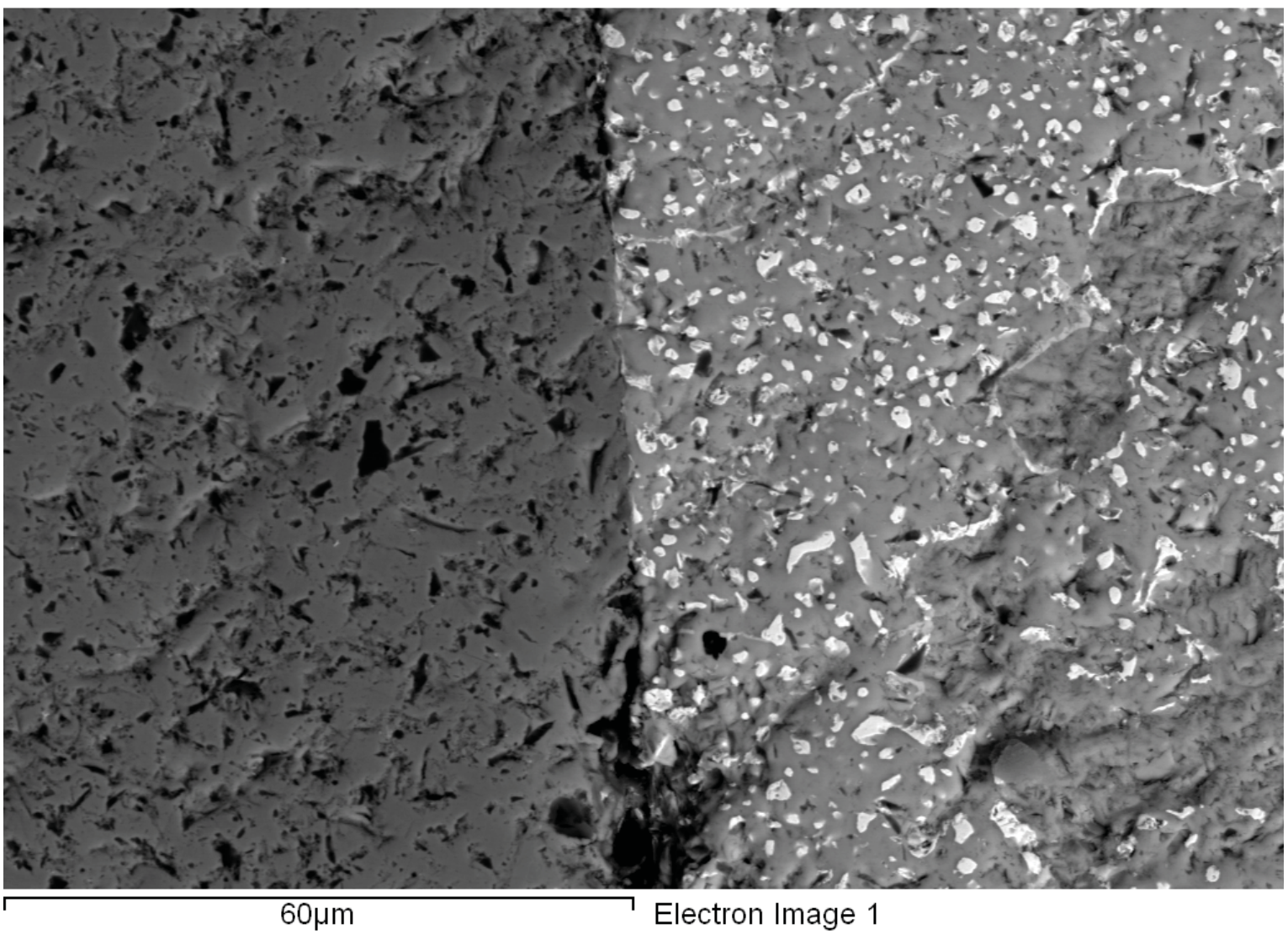

Figure G.1. Micrograph of U-Er-Zr-H Fuel.

\footnotetext{
${ }^{a}$ Personal communication with Dennis D. Keiser at INL (September 7, 2010).
} 
NEA/NSC/DOC(2006)1

Fundamental - FUND

NRAD-FUND-RESR-001

CRIT

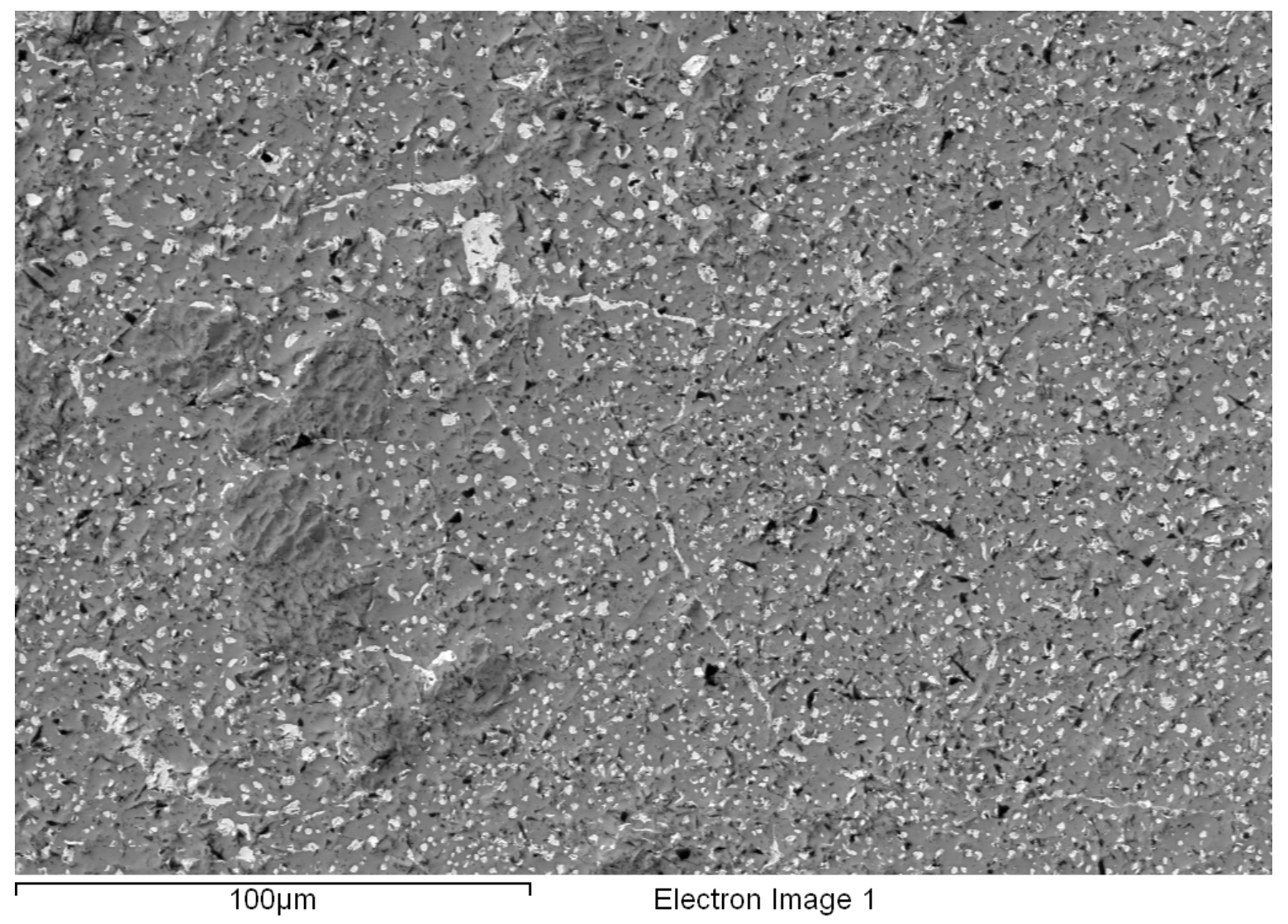

Figure G.2. Micrograph of U-Er-Zr-H Fuel. 
NEA/NSC/DOC(2006)1

Fundamental - FUND

NRAD-FUND-RESR-001

CRIT

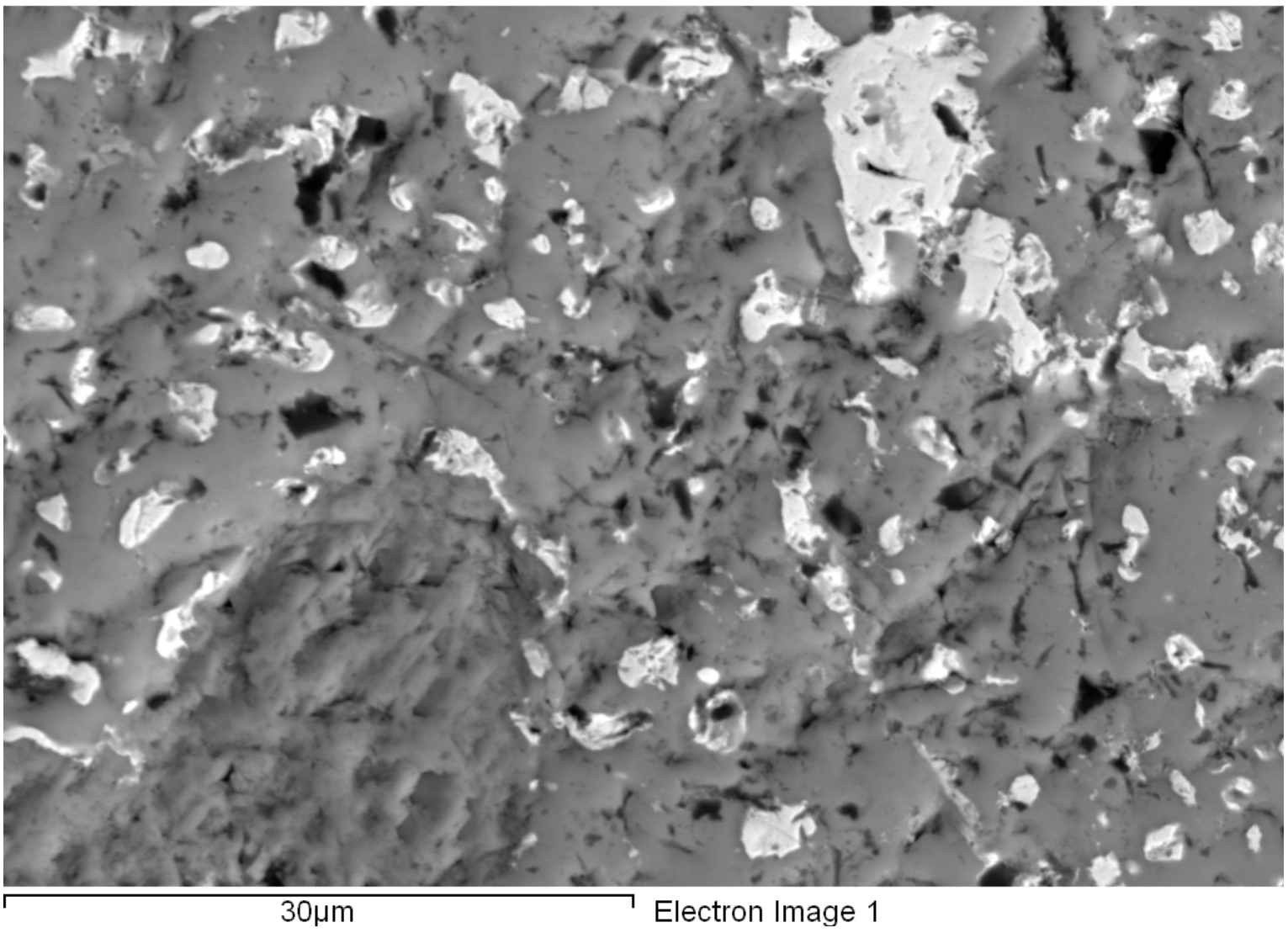

Figure G.3. Micrograph of U-Er-Zr-H Fuel. 
NEA/NSC/DOC(2006)1

Fundamental - FUND

NRAD-FUND-RESR-001

CRIT

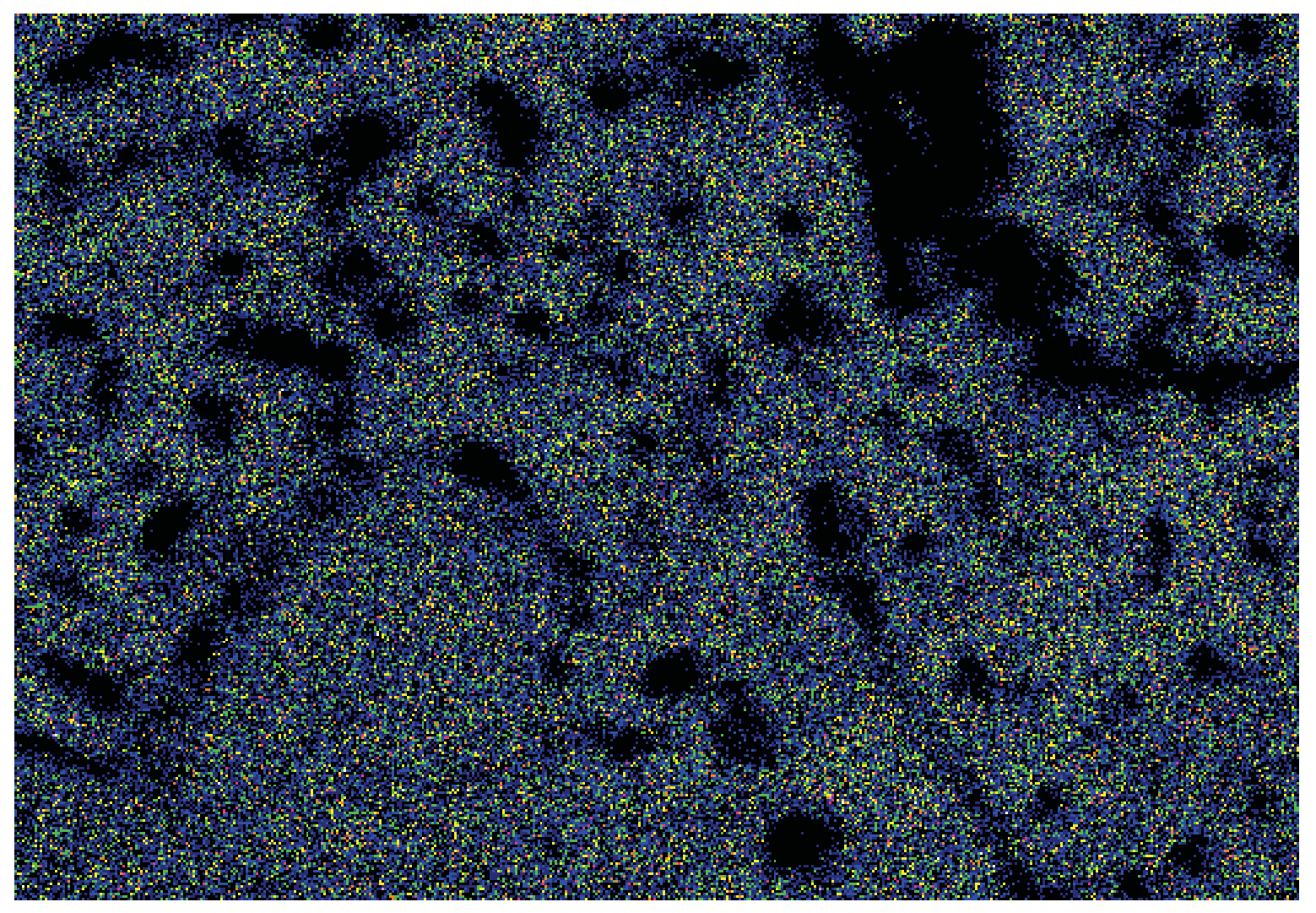

Figure G.4. Micrograph of U-Er-Zr-H Fuel showing Location of Zirconium in Figure G.3. 
NEA/NSC/DOC(2006)1

Fundamental - FUND

NRAD-FUND-RESR-001

CRIT

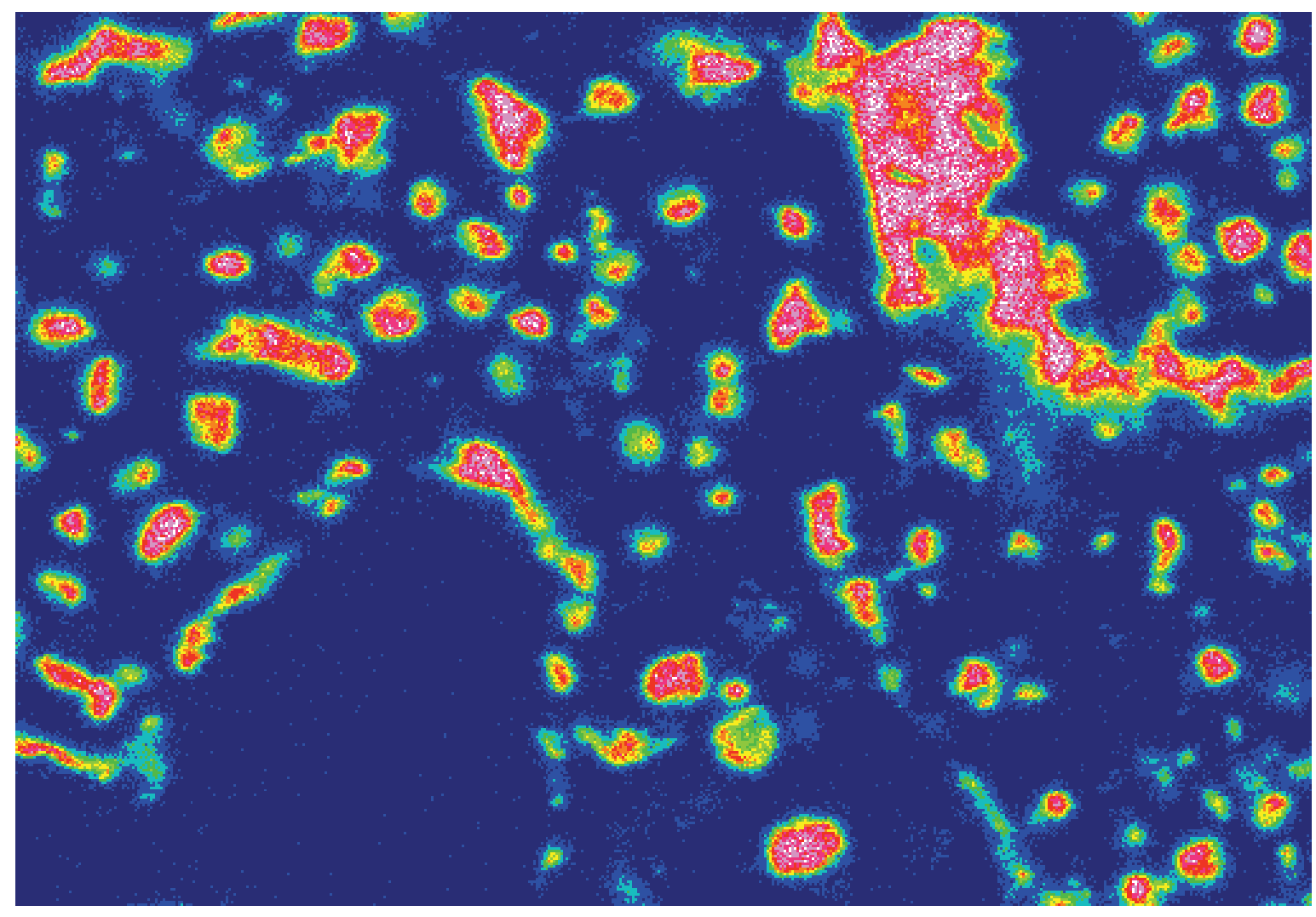

Figure G.5. Micrograph of U-Er-Zr-H Fuel showing Location of Uranium in Figure G.3. 
NEA/NSC/DOC(2006)1

Fundamental - FUND

NRAD-FUND-RESR-001

CRIT

APPENDIX H: INITIAL NRAD LEU CRITICAL WITH 56 FUEL ELEMENTS

\section{H.1 Description of 56-Fuel-Element Core Critical Configuration (NOT BENCHMARKED)}

The initial core critical configuration created during fuel loading, which contains 56 fuel elements, has not been evaluated as a benchmark because it is very similar to the evaluated core configuration. Some basic evaluation was performed to support computational modeling of start-up measurements in the NRAD core.

The 56-fuel-element core is nearly identical to the 60-fuel-element core benchmarked in Section 3 . Besides having four less fuel elements, the graphite block in position A-5 in the 60-fuel-element core is located in position B-5 in the 56-fuel-element core (see Figure H.1).

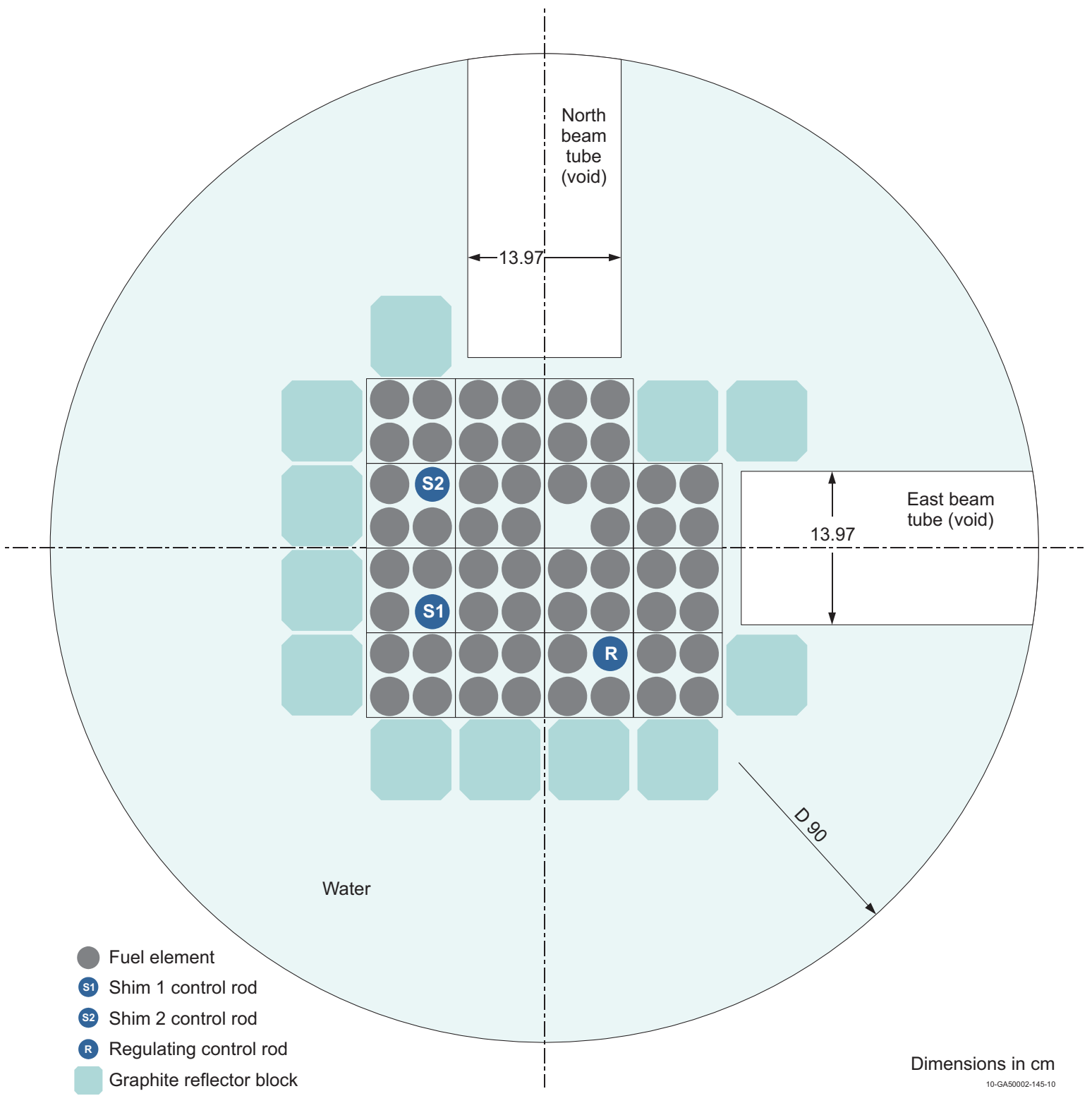

Figure H.1. Midplane Cross Section View of NRAD 56-Fuel-Element Reactor Core. 
NEA/NSC/DOC(2006)1

Fundamental - FUND

NRAD-FUND-RESR-001

CRIT

The shim 1, shim 2, and regulating control rods are withdrawn $38.1,38.1$, and $29.5275 \mathrm{~cm}$, respectively (use Figure 3.8 for placement in the core and Figure 3.11 for reference vertical placement).

An uncertainty analysis was not performed for the initial core critical. Application of the complete list of simplifications, as described in Section 3.1.1.1, produces a bias of 0.00125 (no bias uncertainty evaluated).

\section{H.2 Results of Calculations}

Calculations were performed using MCNP5 and KENO-VI with the ENDF/B-VII.0 cross section library, as discussed in Section 4 and using modified input decks from Appendices A and C. The results are shown in Table H.1. A ENDF/B-VI.8 calculation with MCNP5 is provided for comparison.

Table H.1. Comparison of Eigenvalues for 56-Fuel-Element Core.

\begin{tabular}{|c|c|c|c|c|c|c|c|c|c|}
\hline \multirow{2}{*}{$\begin{array}{c}\text { Analysis } \\
\text { Code }\end{array}$} & \multirow{2}{*}{$\begin{array}{l}\text { Config- } \\
\text { uration }\end{array}$} & \multirow{2}{*}{$\begin{array}{l}\text { Neutron Cross } \\
\text { Section Library }\end{array}$} & \multicolumn{3}{|c|}{ Calculated } & \multicolumn{3}{|c|}{ Expected $^{(a)}$} & \multirow{2}{*}{$\frac{C-E}{E}(\%)$} \\
\hline & & & $\mathbf{k}_{\text {eff }}$ & \pm & $\sigma$ & $\mathbf{k}_{\text {eff }}$ & \pm & $\sigma$ & \\
\hline \multirow{3}{*}{ MCNP5 } & \multirow{3}{*}{$\begin{array}{l}\text { Detailed } \\
\text { Simple }\end{array}$} & ENDF/B-VII.0 & 1.00668 & \pm & 0.00007 & \multirow{3}{*}{$\begin{array}{l}1.0000 \\
1.0013\end{array}$} & \multirow{3}{*}{\multicolumn{2}{|c|}{$\begin{array}{ll} \pm & -- \\
\pm & -- \\
\end{array}$}} & 0.67 \\
\hline & & ENDF/B-VII.0 & 1.00793 & \pm & 0.00007 & & & & 0.67 \\
\hline & & ENDF/B-VI. $8^{(\mathrm{b})}$ & 1.00328 & \pm & 0.00007 & & & & 0.20 \\
\hline \multirow[b]{2}{*}{$\begin{array}{c}\text { KENO- } \\
\text { VI }\end{array}$} & \multirow[b]{2}{*}{ Simple } & $\begin{array}{l}\text { ENDF/B-VII.0 } \\
\text { (238-group) }\end{array}$ & 1.007762 & \pm & 0.000064 & \multirow{2}{*}{\multicolumn{3}{|c|}{$1.0013 \pm$}} & 0.63 \\
\hline & & $\begin{array}{c}\text { ENDF/B-VII.0 } \\
\begin{array}{c}\text { continuous } \\
\text { energy) }\end{array}\end{array}$ & 1.003245 & \pm & 0.000077 & & & & 0.20 \\
\hline
\end{tabular}

(a) A comprehensive analysis of the uncertainties in this configuration and the model bias have not been evaluated; therefore, this is not a benchmarked experiment.

(b) Using ENDF/B-VII.0 cross section data for erbium isotopes.

(c) Continuous energy results for KENO-VI provided by Steve Bowman at Oak Ridge National Laboratory.

\section{H.3 MCNP-Calculated Spectral Data}

A summary of the computed neutron spectral data using MCNP5 for the 56-fuel-element model is provided in Table H.2. 
NEA/NSC/DOC(2006)1

Fundamental - FUND

NRAD-FUND-RESR-001

CRIT

Table H.2. Neutron Spectral Data for 56-Fuel-Element Model (MCNP5).

\begin{tabular}{|c|c|c|c|c|}
\hline \multicolumn{2}{|c|}{ Configuration } & Detailed & Simple & Simple \\
\hline \multicolumn{2}{|c|}{$\begin{array}{l}\text { Neutron Cross } \\
\text { Section Library }\end{array}$} & ENDF/B-VII.0 & ENDF/B-VII.0 & ENDF/B-VI.8 \\
\hline \multicolumn{2}{|c|}{$\mathbf{k}_{\text {eff }}$} & 1.00668 & 1.00793 & 1.00328 \\
\hline \multicolumn{2}{|c|}{$\pm \boldsymbol{\sigma}_{\mathrm{k}}$} & 0.00007 & 0.00007 & 0.00007 \\
\hline \multicolumn{2}{|c|}{ Neutron Leakage (\%) } & 0.03 & 2.11 & 2.11 \\
\hline \multirow{3}{*}{$\begin{array}{c}\text { Fission Fraction, } \\
\text { by Energy (\%) }\end{array}$} & Thermal $(<0.625 \mathrm{eV})$ & 80.57 & 80.73 & 80.68 \\
\hline & Intermediate & 16.43 & 16.29 & 16.28 \\
\hline & Fast $(>100 \mathrm{keV})$ & 3.00 & 2.98 & 3.04 \\
\hline \multirow{4}{*}{$\begin{array}{c}\text { Fission Fraction, } \\
\text { by Isotope }(\%)\end{array}$} & ${ }^{234} \mathbf{U}$ & 0.015 & 0.015 & 0.016 \\
\hline & ${ }^{235} \mathbf{U}$ & 98.738 & 98.742 & 98.711 \\
\hline & ${ }^{236} \mathbf{U}$ & 0.009 & 0.009 & 0.009 \\
\hline & ${ }^{238} \mathbf{U}$ & 1.238 & 1.234 & 1.264 \\
\hline \multicolumn{2}{|c|}{$\begin{array}{l}\text { Average Number of } \\
\text { Neutrons Produced } \\
\text { per Fission }\end{array}$} & 2.444 & 2.444 & 2.443 \\
\hline \multicolumn{2}{|c|}{$\begin{array}{c}\text { Energy of Average } \\
\text { Neutron Lethargy } \\
\text { Causing Fission (eV) }\end{array}$} & 0.26719 & 0.26321 & 0.27396 \\
\hline
\end{tabular}

(a) The neutron leakage is calculated using the neutron balance tables provided in the MCNP output file. The weight fraction of neutrons lost due to escaping the boundaries of the benchmark model are divided by the total weight fraction of neutron loss.

\section{H.4 KENO-Calculated Spectral Data}

A summary of the computed neutron spectral data using KENO-VI for the 56-fuel-element model is provided in Table H.3.

Table H.3. Neutron Spectral Data for 56-Fuel-Element Model (KENO).

\begin{tabular}{|c|c|c||}
\hline Configuration & Simple & Simple \\
\hline $\begin{array}{c}\text { Neutron Cross } \\
\text { Section Library }\end{array}$ & $\begin{array}{c}\text { ENDF/B-VII.0 } \\
(238 \text {-group) }\end{array}$ & $\begin{array}{c}\text { ENDF/B-VII.0 } \\
\text { (continuous energy) }\end{array}$ \\
\hline $\mathbf{k}_{\text {eff }}$ & 1.007563 & 1.003245 \\
$\pm \boldsymbol{\sigma}_{\mathbf{k}}$ & 0.000065 & 0.000077 \\
\hline $\begin{array}{c}\text { Average Number of } \\
\text { Neutrons Produced } \\
\text { per Fission }\end{array}$ & 2.44385 & 2.44390 \\
\hline $\begin{array}{c}\text { Energy of Average } \\
\text { Neutron Lethargy } \\
\text { Causing Fission (eV) }\end{array}$ & 0.254070 & 0.270297 \\
\hline Mean Free Path (cm) & 0.688180 & 0.689187 \\
\hline \hline
\end{tabular}

